NBSIR 88-3788

\title{
Inelastic Behavior of Full-Scale Bridge Columns Subjected to Cyclic Loading
}

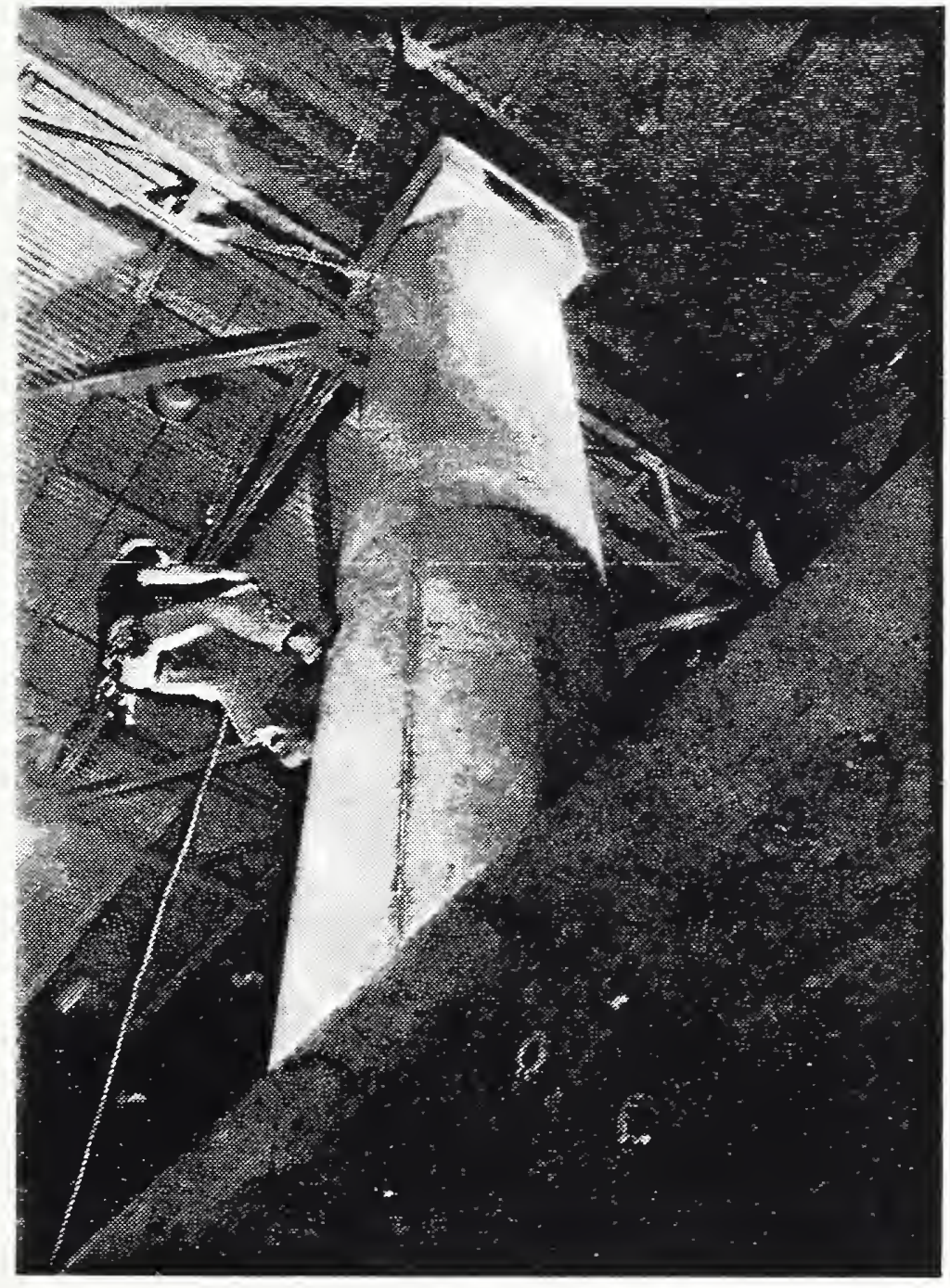

U.S. DEPARTMENT OF COMMERCE National Bureau of Standards National Engineering Laboratory Center for Building Technology $-Q C \longrightarrow, M D 20899$

100

.456

$88-3788$

1988

C. 2

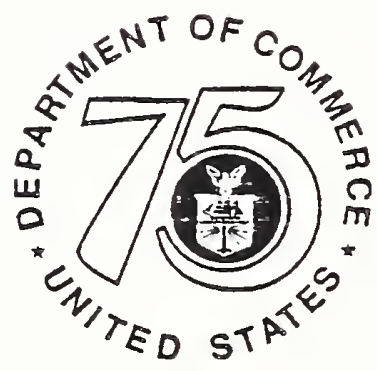

75 Yeans SIlmulating Ameriea's Progress 

INELASTIC BEHAVIOR OF FULL-SCALE BRIDGE COLUMNS SUBJECTED TO CYCLIC LOADING

William C. Stone

Geraldine S. Cheok

U.S. DEPARTMENT OF COMMERCE

National Bureau of Standards

National Engineering Laboratory

Center for Building Technology

Gaithersburg, MD 20899

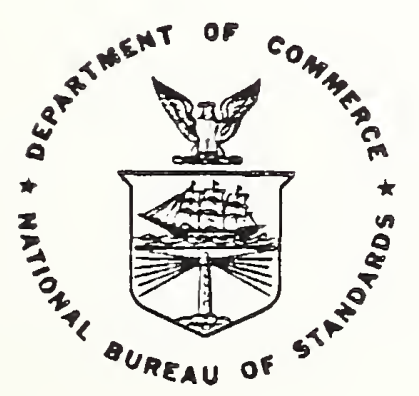




\begin{abstract}
Circular, spirally reinforced concrete bridge columns were subjected to cyclic loading (representing seismic loads) in the laboratory. The test articles were prototype columns designed in accordance with recent [1983] California Department of Transportation (CALTRANS) specifications.

Two full-scale columns, each measuring 5 feet (1.52m) in diameter with aspect ratios (height/width) of 3 and 6 , were subjected to slow reversed cyclic lateral load with constant axial load to simulate the gravity weight of the bridge superstructure. Details are presented concerning the design of the special test apparatus required to conduct the tests as well as recommendations for future improvements in test procedures.

Results from the tests are presented in the form of energy absorption graphs and bar charts, load-displacement hysteresis curves, longitudinal and confining steel strains, and curvature profiles. Comparisons of the ultimate moment capacities, measured displacement ductilities, plastic hinge lengths, cyclic energy absorption capacity and the failure modes of the full-scale specimens are made with those observed from 1/6-scale model tests.
\end{abstract}

Keywords: Axial Load; Inelastic Behavior; Bridges; Columns; Concrete; Confinement; Cyclic Load; Ductility; Energy Absorption; Failure; Full Scale; Lateral Load; Microconcrete; Modeling; Plastic Hinge; Scale Effects . 


\section{ACKNOWLEDGEMENT}

The authors would like to extend their sincere thanks Mr. Jim Little, Mr. Frank Rankin, Mr. Erik Anderson, and Mr. Herb Wechsler of the Center for Building Technology laboratory staff for their help in conducting both the full-scale and model tests. The assistance Mr. Stuart Foltz, Mr. Richard Morales, Dr. John Gross, Dr. Charles Scribner, Mr. Charles Yancey, and Mr. Mark Johnson of the CBT professional staff is also gratefully acknowledged. These individuals often worked long hours and weekends to ensure the successful conduct of the tests described in this report. The authors also wish to extend their thanks to Mr. James H. Gates of the California Department of Transportation, for serving as a continuing advisor on current design practice for bridge columns in seismic regions, to Dr. Nigel Priestley of the University of California, San Diego for his helpful comments on New Zealand seismic design practice and current research projects at the University of Canterbury, New Zealand and to Dr. William Gamble of the University of Illinois, who assisted with the design of the full-scale test specimens and reaction fixtures. 


\section{PREFACE}

The majority of highway and mass transit bridges in the United States with reinforced concrete columns are older structures which were not designed for earthquake loading or were designed with minimum criteria. Many of these columns have failed in previous earthquakes. Dynamic, elastic anaylses of column structures subjected to ground motions recorded during severe earthquakes have shown that the resulting inertial loads are generally significantly greater than the static lateral loads recommended by previous design codes. However, these structures can survive severe earthquakes if they are ductile and can absorb and dissipate seismic energy by inelastic action. This point was clearly demonstrated during both the 1971 San Fernando earthquake as well as the more recent 1985 Mexico City earthquake, where proper detailing often determined whether a structure survived or collapsed.

Energy dissipation provided by the development of ductile plastic hinges in columns is essential to the satisfactory response under seismic loading of many structures. A large portion of modern bridge structures constructed in zones of high seismic activity are supported by piers consisting of one or more columns. Inelastic response of these bridge structures under seismic loads will inevitably involve the development of plastic hinges in the columns, unless mechanical energy dissipators are incorporated in the design. Behavior of bridge columns is thus fundamentally different from that of building frames, where the strength design approach tries to ensure that plastic hinges develop in beams. This is accomplished by specifying column flexural and shear strengths to be higher than the maximum column loads that will occur when hinges form in the beams.

This basic difference in philosophy between building frames and bridge frames means that much of the research on building frames is not applicable to bridge seismic design. To date, only two countries, New Zealand and Japan, have carried out extensive testing of bridge columns to improve highway construction codes. There is still a paucity of 


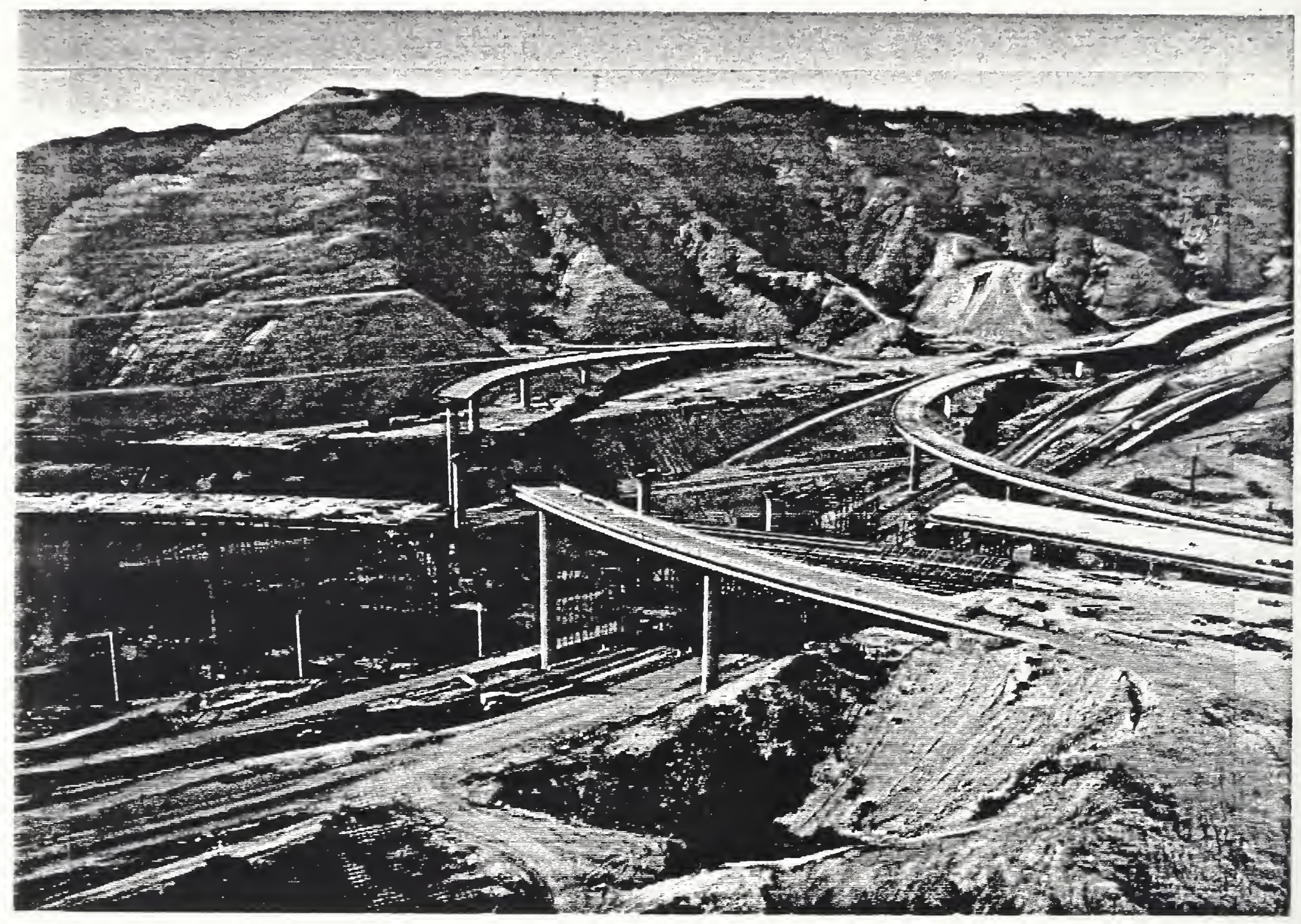

Figure I: Collapsed bridge in the San Fernando earthquake 
such research in the U.S. despite the problems made apparent in the 1971 San Fernando earthquake, where 42 highway bridges received significant damage, and five bridges collapsed [3] (see Figure I). Much of the damage was a consequence of inadequate column detailing resulting in:

a) insufficient ductility to accomodate the imposed displacements;

b) shear failure in shorter columns; and,

c) anchorage failure of longitudinal reinforcement in plastic hinges forming at the column bases.

Damage to bridge piers in the San Fernando earthquake highlighted the need for reassessment of existing seismic design practice for bridges in the U.S. Since 1971, column design requirements have been modified. They now require additional confinement steel to avoid "birdcaging" or compression buckling of the longitudinal steel (see Figure II), and continuous steel at the footings and pier cap to avoid the pull-out problem (see Figure III). Until the initiation of the test program described in this report, the adequacy of these new designs had not been verified.

It is now widely accepted that adequate ductility of column plastic hinges can only be obtained if sufficient transverse reinforcement is provided to confine the concrete core of the column, to prevent lateral buckling of the longitudinal flexural reinforcement, and to provide adequate shear reinforcement. During the San Fernando earthquake, the failure of the columns of several bridges and buildings could be attributed directly to inadequate confinement of the plastic hinge regions. However, the amount and distribution of confining reinforcement necessary to insure adequate ductility without significant strength degradation is still a matter of controversy.

It is important to note that nearly all present design codes for bridge column seismic details (with the previously noted exceptions of New Zealand and Japan) are based on results of extensive research programs for building columns. Building columns are generally much smaller in cross section (12- 15 in) than bridge columns which are typically 48-60 inches or larger in crosssection. Reinforcement ratios are also very different for bridge columns. 
These differences and others, which are discussed in Reference 1, may lead to substantially different performance of a bridge column in a seismic event.

In a workshop on earthquake resistance of highway bridges in 1979, the Applied Technology Council (ATC) stated that,

"There is a pressing need for experimental studies to determine the reserve capacities of various bridge components. Much of the considerable research work on column behavior has been done on relatively small specimens and has been extrapolated for bridges from tests of columns typically used in buildings. Bridge columns are larger and (usually) lower stréssed axially than building columns and this does not permit easy extrapolation from the present wealth of building column data. Therefore work is (urgently) needed to determine whether the behavior of small sections can be extrapolated to larger cross sections [2]."

Furthermore, the ASCE-TCLEE Task Committee on research needs stated in March 1979 that,

"experimental testing of selected reinforced concrete (bridge) columns should be performed to determine the lateral resistance and adequacy of reinforcement. Particular emphasis should be placed on those columns designed using pre-1971 California criteria."

Based on these recommendations the National Bureau of Standards proposed, in the fall of 1980, a test program to be known as the "Large Scale Bridge Column Project." Due to the high costs associated with performing full scale tests, sufficient funding did not become available until mid-1983. At this time, design work began on the specimens $\cdots$ full scale, 60-inch ( $1.52 \mathrm{~m})$ diameter columns -. as well as the necessary laboratory test fixtures. Sponsors for the project included the National Science Foundation (NSF), the National Bureau of Standards (NBS), the Federal Highway Administration (FHWA) and the California Department of Transportation (CALTRANS). The objectives of the project were to address the following topics: 


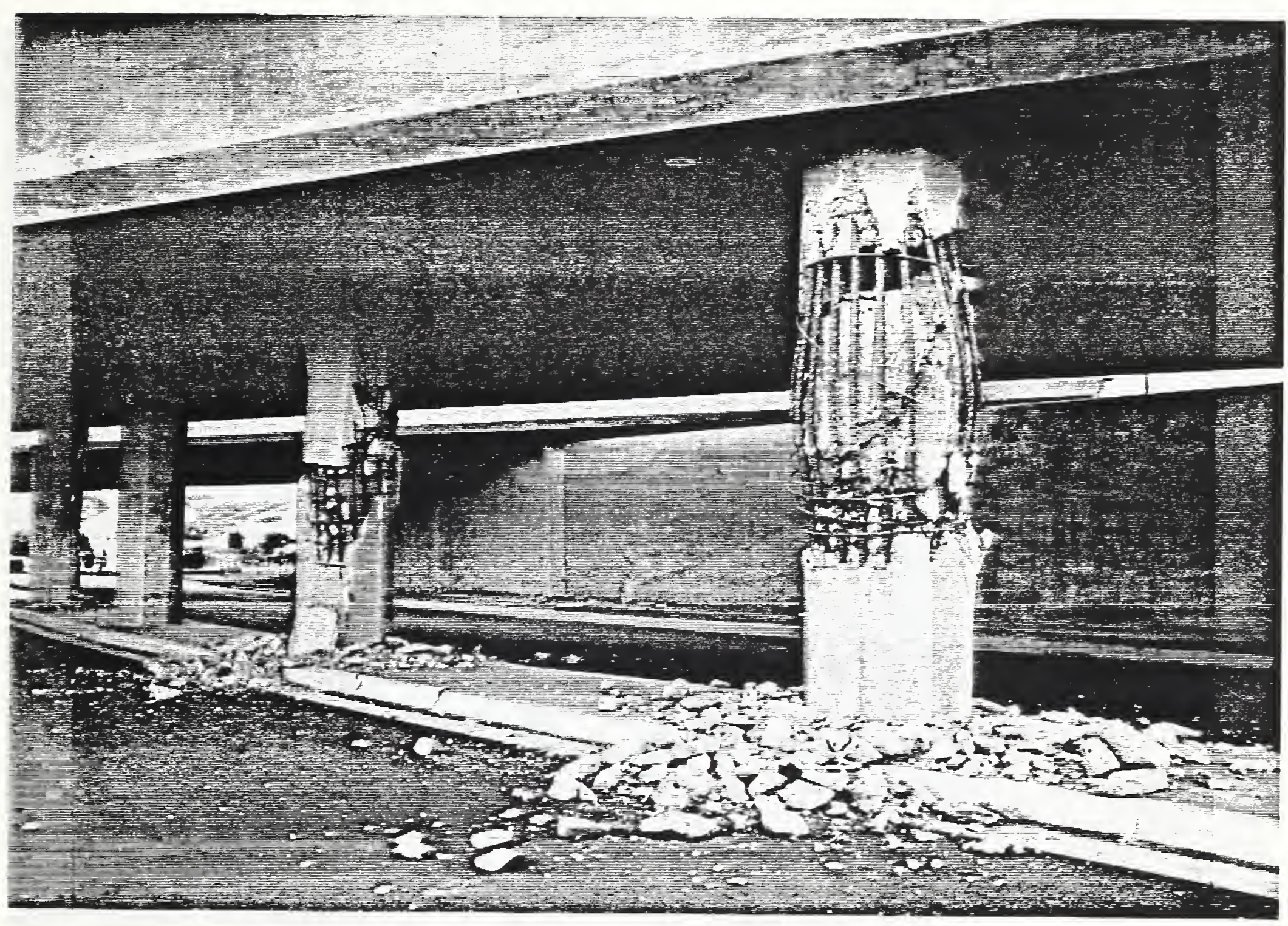

Figure II: Longitudinal bar buckling - "Bird-caging effect" 


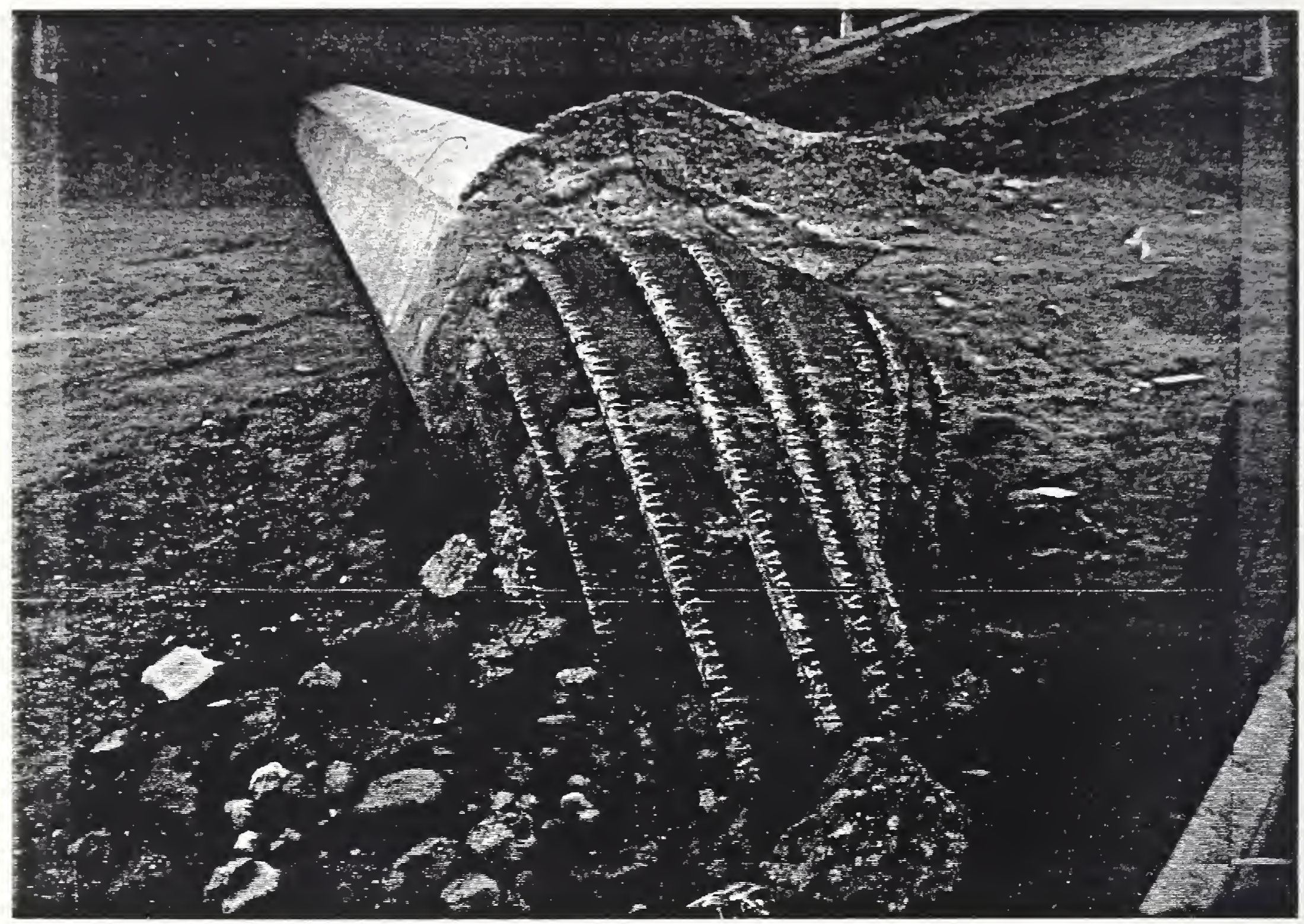

Figure III: Pullout of longitudinal bars from the foundation 
a) The effect of scale factor on bridge column design (i.e. could models be effectively used to predict full-scale behavior)

b) The effectiveness of current design details (i.e. determine ductility capacity of columns).

c) Identification of symptomatic problems in present detailing practices.

The project was initially divided into three phases. The first phase consisted of constructing and testing two full scale, 60-inch ( $1.52 \mathrm{~m})$ diameter, spirally confined bridge columns, designed to recent CALTRANS specifications. These specimens were to serve as benchmark data for subsequent model tests and to verify at full scale the performance of the post-1971 design requirements. The prototype specimens were to replicate, as closely as possible, actual bridge columns and the boundary and loading conditions that would be experienced by a bridge column in the field. A minimum of two prototype tests were to be conducted to investigate two general classes of bridge columns currently in use in seismically active regions of the U.S. These included a short 15 foot $(4.6 \mathrm{~m})$ high column which would be susceptible to shear type failures and a tall 30 foot $(9.2 \mathrm{~m})$ high column which would be used to investigate the performance of a predominately flexure-type column with continuous longitudinal reinforcement through the plastic hinge region. A special computer-controlled testing laboratory, known as the NBS Large Scale Structural Research Facility, was designed and constructed to apply column axial loads of $12,000 \mathrm{kip}(53.4 \mathrm{MN})$ which simulated dead weight of the bridge superstructure and lateral loads of up to $1,200 \mathrm{kip}$ ( $5.34 \mathrm{MN}$ ) which caused column moments of up to 54,000 kip-feet (73.3 $M N-m)$. Specimens weighing up to $4800 \mathrm{kip}(21.36 \mathrm{MN}$ ) with heights of up to 60 feet $(18.5 \mathrm{~m})$ and column diameters of up to 8 feet $(2.44 \mathrm{~m})$ could be accomodated in the facility with access from a casting yard by means of a rail transport system.

Phase II, which was conducted in parallel with Phase $I$, involved the construction and testing of 1/6-scale models of the prototypes under identical load histories and boundary conditions. Data gathering and sensor layout for the model specimens were designed to be identical to those of the prototype so that a direct comparison could be made. A further variable studied in this phase was the effect of using microconcrete, which is the current recommended 
structural modelling practice [23], versus the use of a small nominal maximum size aggegate ready-mix concrete. The chief advantage of the latter was that it was less expensive.

The third and final phase of the project involved making comparisons between the model and prototype specimens. Such comparisons were to be based on ductility factor, energy absorption capacity, ultimate moment capacity, plastic hinge length, and extent of yield penetration in the longitudinal reinforcement.

This report is the second in a series of reports which discusses the results of the NBS Large Scale Bridge Column Project. This report presents the findings of Phase I and III described above. A detailed description of Phase II (model tests) as well as a literature review of previous bridge column research is presented in Reference 1. 
Table of Contents

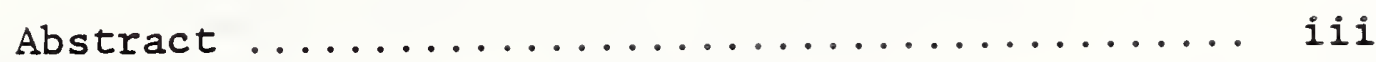

Acknowledgement $\ldots \ldots \ldots \ldots \ldots \ldots \ldots$ iv

Preface $\ldots \ldots \ldots \ldots \ldots \ldots \ldots \ldots \ldots \ldots \ldots \ldots \ldots \ldots \ldots \ldots$

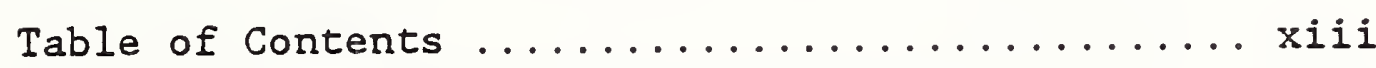

1.0 Introduction $\ldots \ldots \ldots \ldots \ldots \ldots \ldots \ldots \ldots$

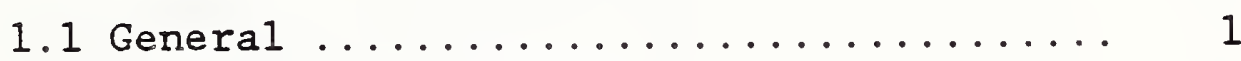

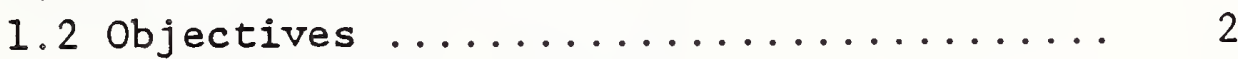

1.3 Test Outline .................. 3

2.0 Design of Test Specimens $\ldots \ldots \ldots \ldots \ldots \ldots$

3.0 Test Results and Observations ........... 15

3.1 Introduction $\ldots \ldots \ldots \ldots \ldots \ldots \ldots \ldots \ldots$

3.2 Flexure specimen ............... 17

3.2.1 Material Properties ........... 17

3.2.2 Ductility Factor $(D F)=1$, Cycle 1.17

3.2.3 Ductility Factor $=2$, Cycles $2 \& 3 \quad 19$

3.2.4 Ductility Factor $=3$, Cycles $4 \& 520$

3.2.5 Ductility Factor $=4$, Cycles 6-15 26

3.2.6 Ductility Factor $=5$, Cycles $16-18 \quad 33$

3.2.7 Ductility Factor $=6$, Cycles 19-21 33

3.2.8 Ductility Factor $=6.6$, Cycle $22 \quad 36$

3.3 Shear specimen $\ldots \ldots \ldots \ldots \ldots \ldots \ldots \ldots 42$

3.3.1 Material Properties ............ 42

3.3.2 Ductility Factor $=1$, Cycle $1 \ldots 42$

3.3.3 Ductility Factor $=2$, Cycles 2-3. 46

3.3.4 Ductility Factor $=4$, Cycles 4-5. 46

3.3.5 Ductility Factor $=6$, Cycles 6-7. 53

3.3.6 Ductility Factor $=8$, Cycles 8-9. 58

3.3.7 Ductility Factor $=10$, Cycles 10-12 58

4.0 Discussion of Results ................67 67

4.1 Flexure Column Moments and Displacements 67

4.2 Shear Column Moments and Displacements .. 84

4.3 Structural Ductility: Comparison of Test Results with New Zealand Design Charts

for structural Ductility ............. 96

4.4 Strain in Longitudinal Reinforcement .... 99

4.5 Strains in Confining Reinforcement ..... 109

4.6 Column Curvatures and Estimation of 
Plastic Hinge Lengths ............ 109

4.7 Inelastic Strain Energy Capacity ....... 125

4.8 Similitude Relationships: Model

versus Prototype ................ 125

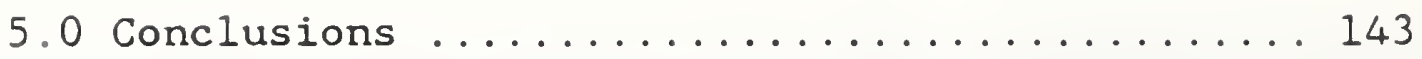

Appendix A ....................... 147

A. 1 Laboratory Related Problems and Logistics 147

A.1.1 Introduction .............. 147

A.1.2 The Moving Specimen Concept ...... 154

A.1.3 Rail Transport System ......... 159

A.1.4 Reaction Wall System ........... 167

A.1.5 Deflection Considerations ....... 172

A.1.6 Tie-Back Frame ............ 175

A.1.7 Ful1-Scale Hinge Boundary Condition 180

A.1.8 Apparatus Connections ......... 183

A.1.9 Loading Systems ............ 188

A. 2 Mechanics of the Test Apparatus ........ 192

A. 3 Access Techniques for Large Scale Tests.. 195

A. 4 Specimen Demolition and Removal ........ 200

A.5 Material and Construction Process ....... 203

A.5.1 Material ................. 203

A.5.2 Construction Process .......... 205

A. 6 Instrumentation ................ 209

A.6.2 Clip Gages ................ 214

A.6.2 Flatcells and the Measurement

of Base Reaction Forces ......... 216

A.6.3 Tie-Back Frame as a Load Cell ..... 226

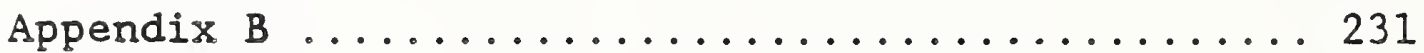

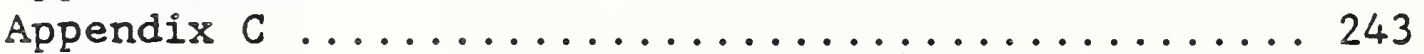

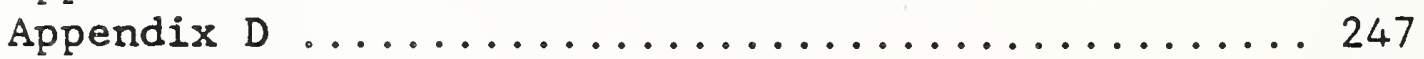

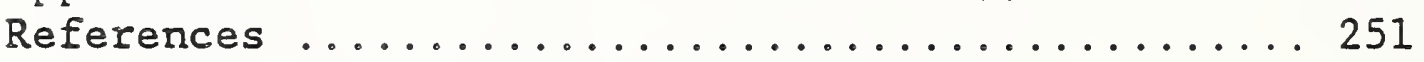




\subsection{INTRODUCTION}

\subsection{General}

Full scale testing of a structure or structural component is generally called for when there is a lack of empirical data validating the procedure of extrapolating full scale behavior from that of model specimens. Testing of full scale prototypes is a costly and time consuming proposition, particularly in terms of instrumentation and construction costs, which may include fabrication of unusual test apparatus for use on only a limited number of tests. With this constraint, design guidelines for bridge columns have primarily relied upon the results obtained from model tests. Furthermore, the design guidelines for bridge columns in the United States have been based largely on tests of model building columns. The design differences between building columns and bridge columns are discussed in Reference 1.

As a result of severe damage sustained by many bridge structures following the 1971 San Fernando earthquake, substantial modifications were made to the seismic design guidelines for the state of California [4,5]. The need for experimental testing of these new procedures, at full-scale, was first proposed at the Applied Technology Council Workshop on Earthquake Resistance of Highway Bridges held in the spring of 1979 [2]. In response to the findings of Reference 2, an experimental test program was initiated by the National Bureau of Standards in the spring of 1983 to investigate the seismic performance of full-scale bridge columns. The test program was sponsored by the National Science Foundation (NSF), the California Department of Transportation (CALTRANS), the Federal Highway Administration (FHWA) and the National Bureau of Standards (NBS). The program involved the testing of full scale and replicate model bridge columns in an effort to determine the effects of scale and the effectiveness of the new reinforcement details adopted by CALTRANS and AASHTO. This constitutes, to the authors knowledge, the first laboratory test of full scale bridge columns subjected to quasi-static cyclic lateral loading with combined axial load. 
This report is the second in a series describing the NBS Bridge Column Test Program. The results of six $1 / 6$ scale model tests (the actual length scale factor, $s_{1}$, was 6.1), a literature survey, and background information on the test program are presented in Reference 1. To perform the tests described in this report many engineering problems had to be solved, particularly in the construction of the testing apparatus for the full-scale specimens and in the measures necessary to ensure similitude between-model and prototype. A discussion of the techniques used and their effectiveness, as well as alternative approaches which were considered during design of test apparatus, is presented in Appendix A.

Two full-scale tests were carried out. Because specimen geometry was different for the two tests, the data presented should be carefully considered with the understanding that each test represents an initial benchnark for comparison and that further full scale testing of replicate specimens is merited in order to establish a statistical basis for the relationships and behavior described. Some of the results presented in Chapters 4 and 5 indicate that alternative specimen construction techniques are possible which may result in a substantial reduction in the cost of testing. This will make future full-scale testing more economical. Recommendations for future fullscale test procedures are presented in Appendix B.

\section{2 objectives}

It was realized at the beginning that only a very limited number of full scale specimens could be tested. Three were originally considered desireable, but budget and manpower limitations eventually caused the number to be reduced to two. Specific objectives were as follows:

1. To determine the ductility capacity of representative bridge columns designed in accordance with recent CALTRANS standards.

2. To determine the effects of scale on column behavior.

3. To determine the effects of aspect ratio (L/D) on column behavior. 
4. To determine the adequacy of transverse reinforcement as presently required by CALTRANS for prevention of longitudinal bar buckling.

The two cantilevered bridge columns described in this report were designed and constructed in accordance with recent CALTRANS specifications [4]. These specifications meet or exceed the "Seismic Design Guidelines for Highway Bridges" [5]. One column had an aspect ratio (Height / Diameter) of 6; the other 3. These aspect ratios were chosen so that both flexure- dominated and shear-dominated failures could be studied. Evaluation of column performance was based on the following criteria:

1. Energy absorption capacity: a measure of a column's ability to dissipate seismic energy through inelastic deformation. This can be either the area bounded by a single load-deflection hysteresis cycle, or the summation of all such cycles up to failure of the column. This presently appears to be the most effective measure of seismic performance.

2. Displacement ductility factor: maximum lateral deflection at column failure divided by the yield deflection. This is a relative measure of energy absorption capacity now used in some code specifications.

3. Ultimate moment capacity: maximum moment occurring prior to column failure. Useful for comparison with analytically predicted capacity.

4. Effectiveness of transverse confinement: qualitative observations concerning the ability of present confining reinforcement requirements to prevent buckling of longitudinal steel and extend ductility.

\subsection{Test Outline}

The dimensions of the two full scale columns are presented in Figs. 1.1, 1.2 and Table 1.1 and are typical of current design practice. The height of the flexure column, which had an aspect ratio of 6 , was $30 \mathrm{ft} .(9.14 \mathrm{~m}$ ) measured from the top of the footing to the hinge at the top of the column. The 


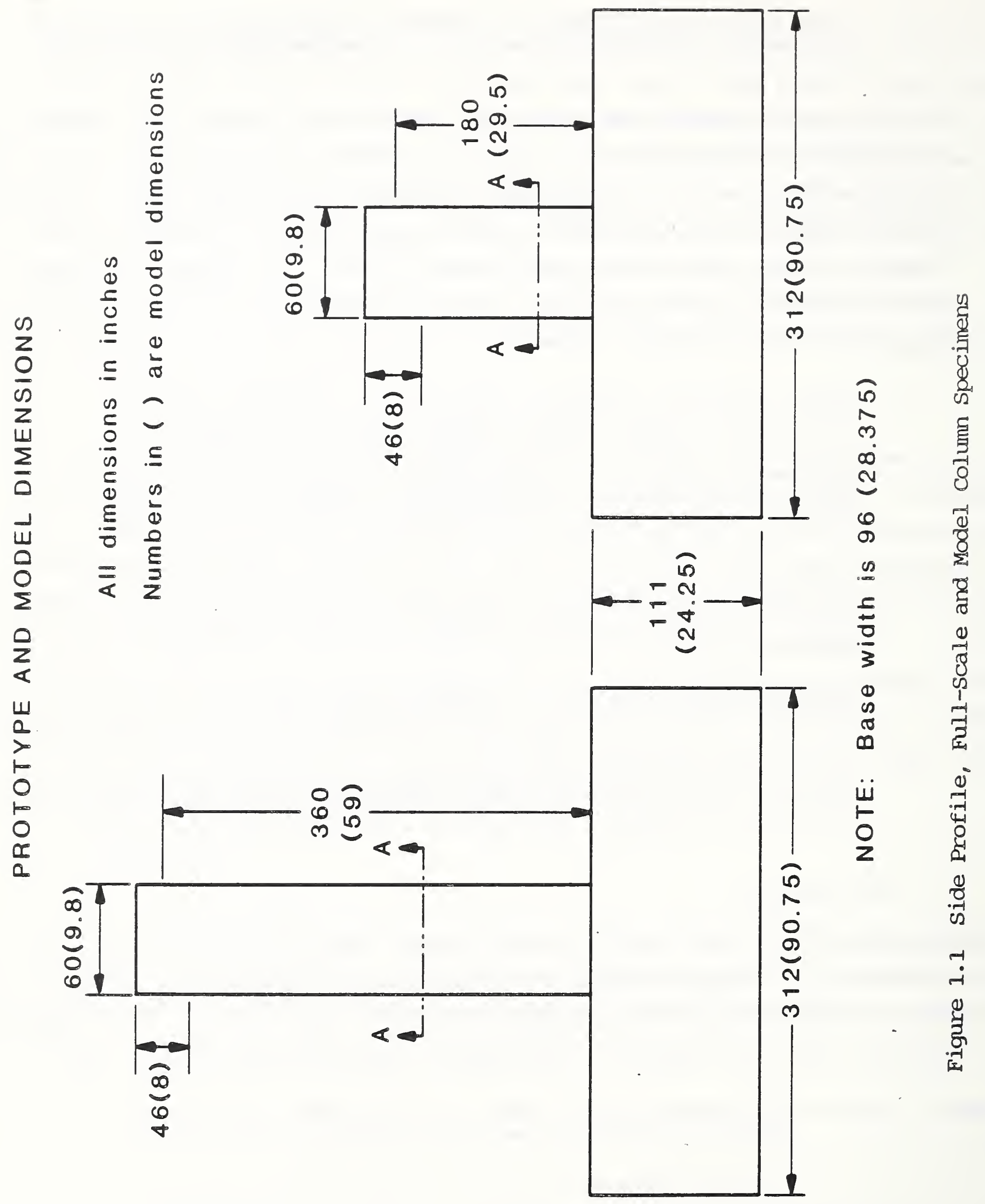




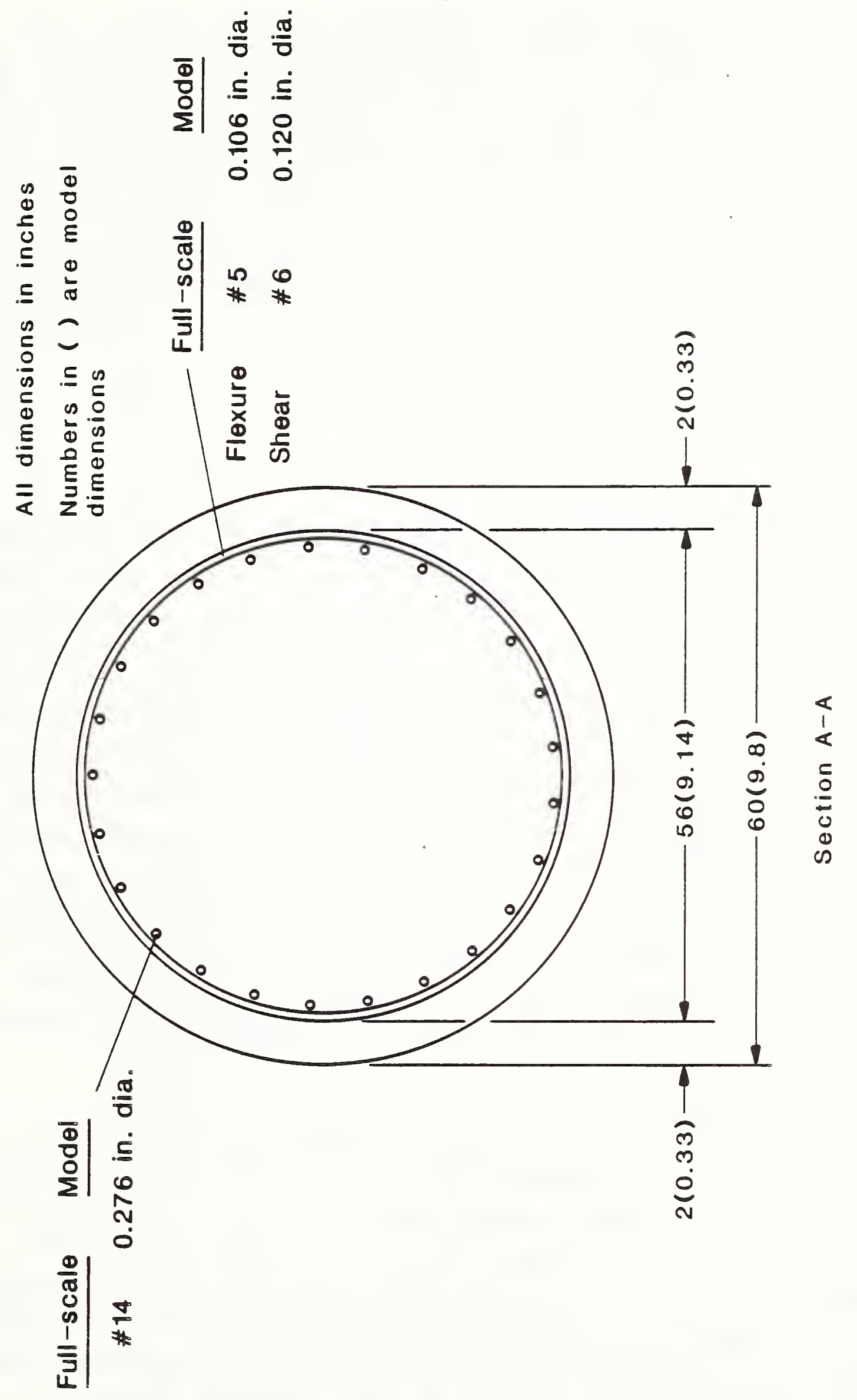

है 
The height of the shear column, which had an aspect ratio of 3 , was $15 \mathrm{ft}$. $(4.57 \mathrm{~m})$. Both columns were circular in cross section with a diameter of 5 ft. $(1.52 \mathrm{~m})$. The longitudinal reinforcement consisted of 25 - \#14 (1.69 in., $43 \mathrm{~mm}$ ) deformed steel reinforcing bars, grade 60 (60 ksi nominal yield), spaced evenly around the perimeter of the column. The transverse reinforcement consisted of \#5 (0.625 in., $16 \mathrm{~mm})$, grade 60 deformed steel spirals with a pitch of $3-1 / 2$ in. $(88.9 \mathrm{~mm})$ for the flexure column and \#6 (0.75 in., $19 \mathrm{~mm}$ ), grade 60 deformed steel spirals with a pitch of 2 - $1 / 8$ in. $(53.97 \mathrm{~mm}$ ) for the shear column. Material specifications are presented in Appendix A, Tables A.1 thru A.3.

The boundary conditions for the columns were, for all test specimens, fixed at the column base and hinged at the top. These were felt to best model the insitu boundary conditions for a broad class of bridge columns used in seismic regions, i.e. those which can be assumed to act as single cantilevered sections with the bridge superstructure supported on elastomeric bearing pads. Furthermore an axial column load which simulated the vertical reaction of the bridge superstructure was to be applied in such a manner as to maintain a vertical reference axis throughout the test. This precluded the use of axial post-tensioning for application of the vertical force, since that method does not produce the $P$-delta effects experienced in the real structure under the influence of lateral loads. The mechanisms by which these boundary conditions were achieved in the laboratory for the model and prototype specimens were quite different and are discussed in detail in Chapter 2.

The columns were first loaded axially to a specified load of 1000 kip (4,448.2 $\mathrm{kN}$ ), a value equal to approximately $0.1 \mathrm{f}^{\prime} \mathrm{c} \mathrm{A}_{\mathrm{g}}$. Axial load was held constant during the test and was the same for both specimens. The columns were then subjected to reversed cyclic lateral loads. The yield deflection (referred to as $\Delta_{y}$ throughout this report) was detemined experimentally as described in Chapter 3. Thereafter, cyclic lateral deflections were increased by multiples of $\Delta_{y}$. The lateral load was applied at the center of gravity of the column footing. Loading histories for the columns are discussed in Chapter 3 . The cycling of the columns was performed under displacement control using a double acting servo-hydraulic jack. Axial loads were applied under load control 
under load control using a specially converted servo-hydraulic universal testing machine. Strains in spirals and along the longitudinal bars were measured using strain gages. External displacement transducers were used to measure column rotation, lateral displacement and column curvature. Al1 passive test apparatus (e.g. supports, lateral restraint systems) were instrumented and calibrated for monitoring reactions because the specimen and test apparatus constituted a statically indeterminant system.

Table 1.1 Column Dimensions

\begin{tabular}{|c|c|c|c|c|}
\hline Specimen & $\begin{array}{c}\text { Type } \\
\text { of } \\
\text { Concrete }\end{array}$ & Height & $\begin{array}{l}\text { Diameter } \\
\text { (inches) }\end{array}$ & $\begin{array}{l}\text { Axial } \\
\text { Load } \\
\text { (kip) }\end{array}$ \\
\hline
\end{tabular}

Model Colums

$\begin{array}{llccc}\text { N1 } & \text { Microconcrete } & 2^{\prime}-5.5^{\prime \prime} & 9.8 & 26.87 \\ \text { N2 } & \begin{array}{l}\text { Microconcrete } \\ \text { N3 }\end{array} & 2^{\prime}-5.5^{\prime \prime} & 9.8 & 53.75 \\ \text { N4 } & 4^{\prime}-11^{\prime \prime} & 9.8 & 26.87 \\ \text { Nicroconcrete } & \begin{array}{l}\text { Ready-Mix } \\ \left(1 / 4^{\prime \prime} \text { Grave1) }\right.\end{array} & 2^{\prime}-5.5^{\prime \prime} & 9.8 & 26.87 \\ \text { N6 } & \begin{array}{l}\text { Ready-Mix } \\ \left(1 / 4^{\prime \prime} \text { Grave1) }\right. \\ \text { Ready-Mix } \\ \left(1 / 4^{\prime \prime} \text { Grave1) }\right.\end{array} & 4^{\prime}-11^{\prime \prime} & 9.8 & 53.75 \\ & & & 9.8 & 26.87\end{array}$

Prototype Columns

$\begin{array}{llccr}\text { Flexure } & \begin{array}{l}\text { Ready-Mix } \\ \left(3 / 4^{\prime \prime} \text { Grave1) }\right.\end{array} & 30^{\circ}=0^{\prime \prime} & 60.0 & 1000.00 \\ \text { Shear } & \begin{array}{l}\text { Ready-Mix } \\ \left(3 / 4^{\prime \prime} \text { Grave1) }\right.\end{array} & 15^{\prime}-0^{n} & 60.0 & 1000.00\end{array}$





\subsection{DESIGN OF TEST SPECIMENS}

Both columns were built to meet CALTRANS specifications effective in 1983 [4]. The final column diameter, aspect ratio, and reinforcing details were selected on the basis of discussions with CALTRANS engineers [18] to reflect standard field practice and representative column sizes. The resulting dimensions were a height of $30 \mathrm{ft} .(9.14 \mathrm{~m})$ for the flexure column and $15 \mathrm{ft} .(4.57 \mathrm{~m})$ for the shear column with a diameter of $5 \mathrm{ft} .(1.52 \mathrm{~m})$ for both columns.

The longitudinal reinforcement for both the flexure and shear columns consisted of 25 continuous lengths of grade 60 \#14 deformed bars ( 1.69 in., 43 $\mathrm{mm})$. This resulted in a longitudinal reinforcement ratio, $\rho_{t}$, of $2 \frac{\gamma}{3}$ The center-to-center spacing of the longitudinal bars was 6.83 in. (173 $\mathrm{mm}$ ). CALTRANS specifies that neither welded nor lapped splices are permitted for longitudinal reinforcement larger than \#11 bars ( 1.41 in., $35.8 \mathrm{~mm}$ ) within a region extending $10 \mathrm{ft} .(3.0 \mathrm{~m})$ above the column footing for a fixed base column.

The transverse reinforcement for the flexure column was a spiral made from \#5 $(0.625$ in., $15.9 \mathrm{~mm})$ grade 60 deformed steel bars with a pitch of 3.5 in. $(88.9 \mathrm{~mm})$ resulting in a volumetric reinforcement ratio, $\rho_{S}$, of 0.00633 . The spiral for the shear column was made from \#6 (0.75 in., $19.1 \mathrm{~mm}$ ) grade 60 deformed steel bars spaced at $2-1 / 8 \mathrm{in.}(54.0 \mathrm{~mm})$ giving a volumetric reinforcement ratio of 0.01479 . The spiral extended from the top of the column into the column footing to the point of tangency of the longitudinal bar hooks as per CALTRANS Design Handbook [6] Section 8.18.2.1.3. The dimensions and steel arrangement for both columns are shown in Figs. 2.1. 2.3 .

CALTRANS specifies a minimum amount of transverse reinforcement in their design code for bridge columns [4]. The amount of transverse steel required in the potential plastic hinge region is calculated from the following equation for columns with diameters equal to or larger than $5 \mathrm{ft}$. (1.52 m): 


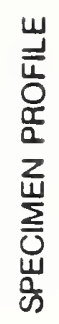

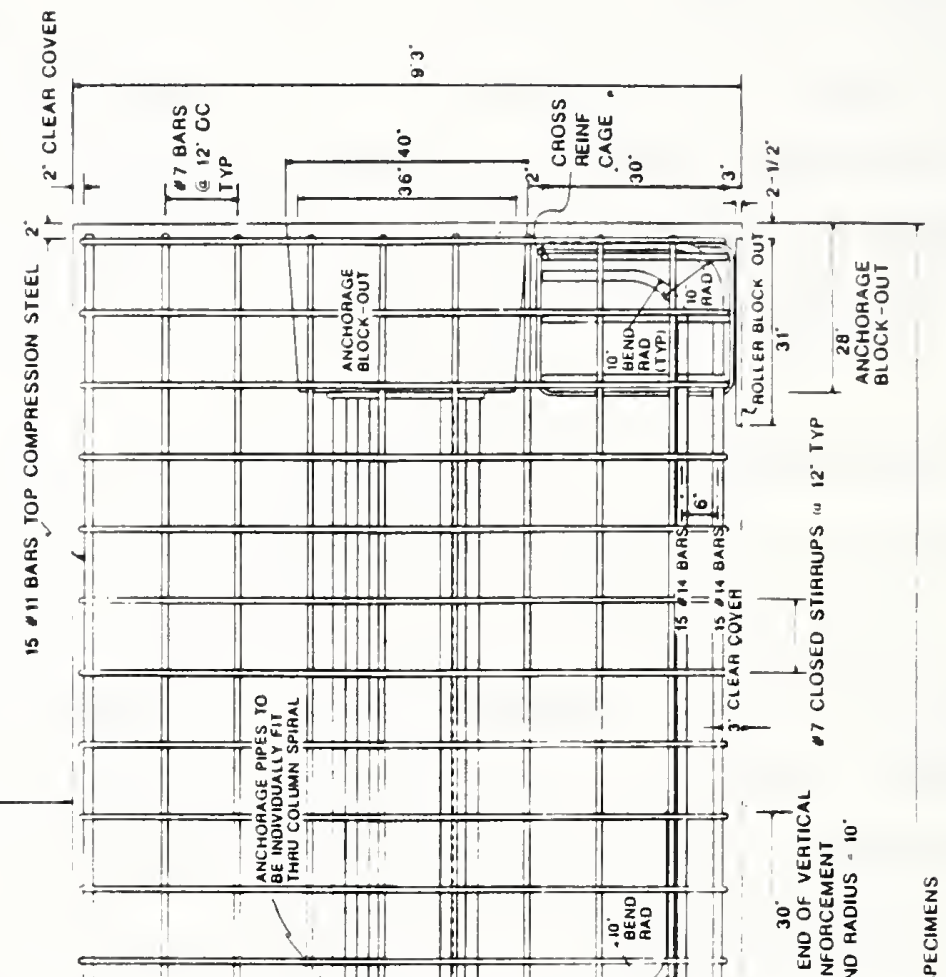

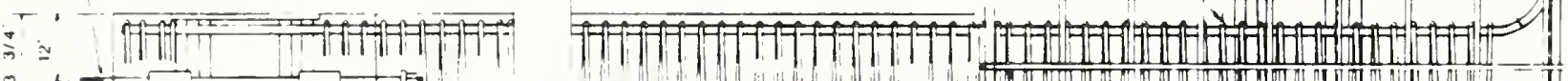

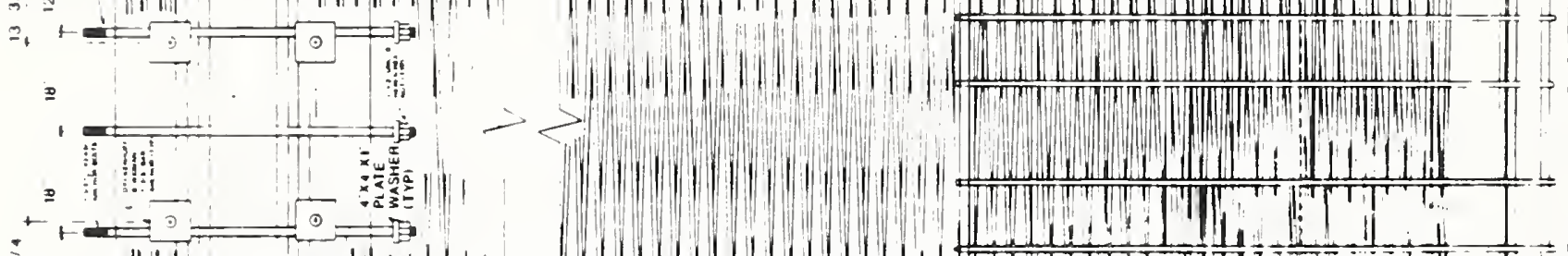

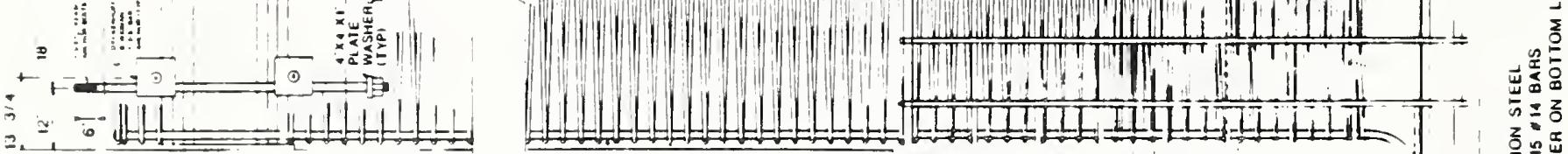
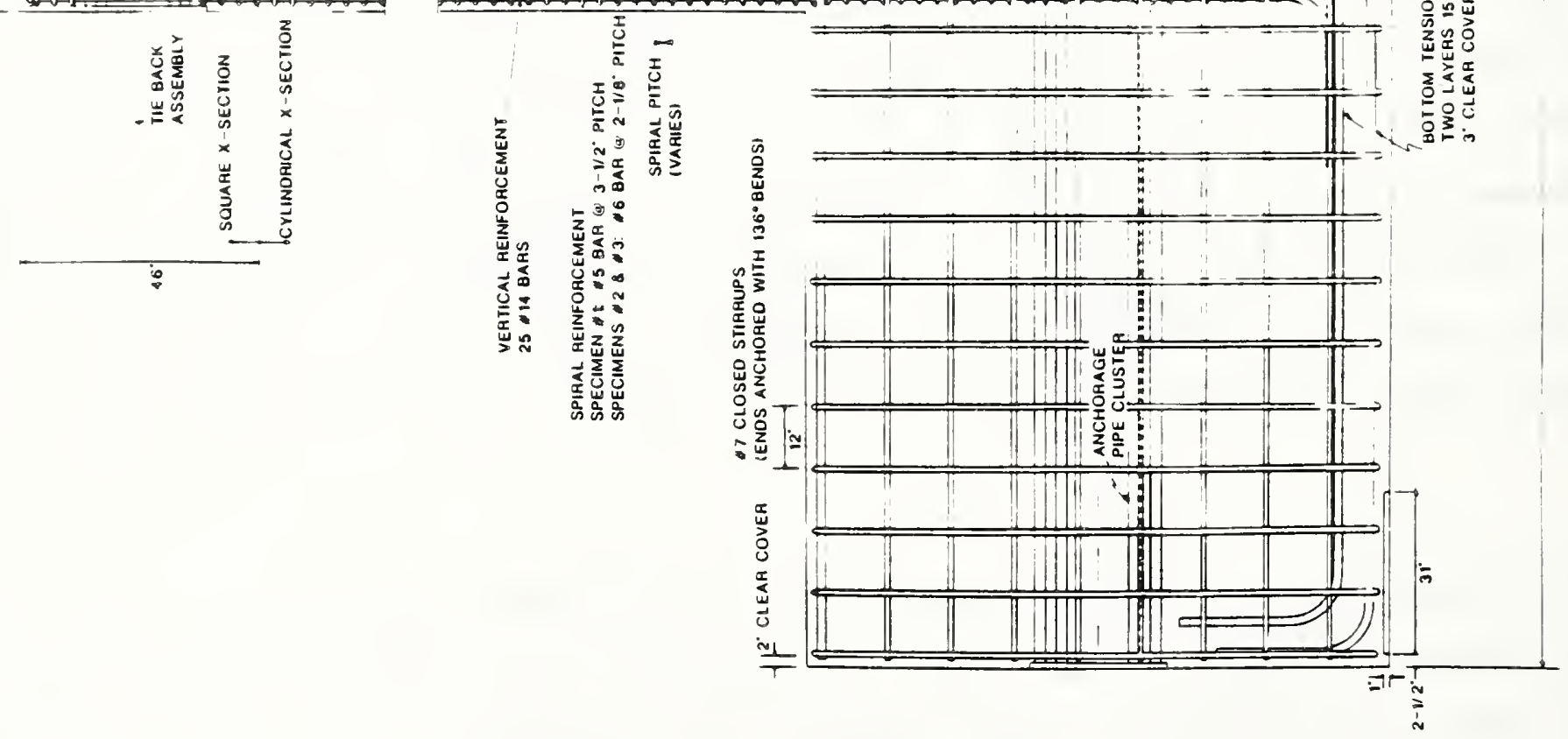

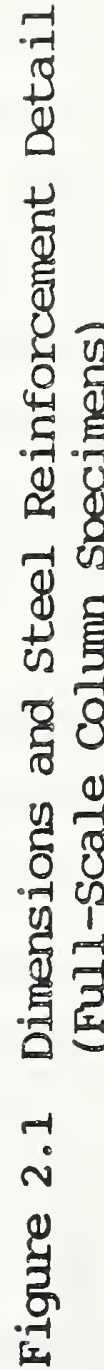




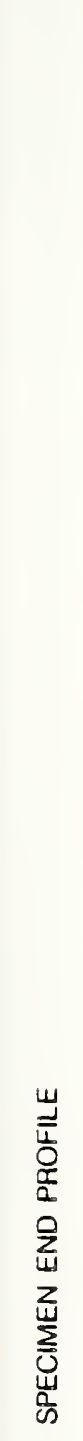

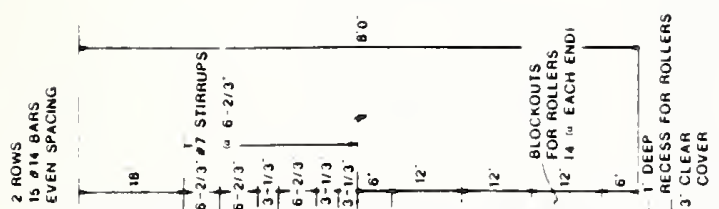
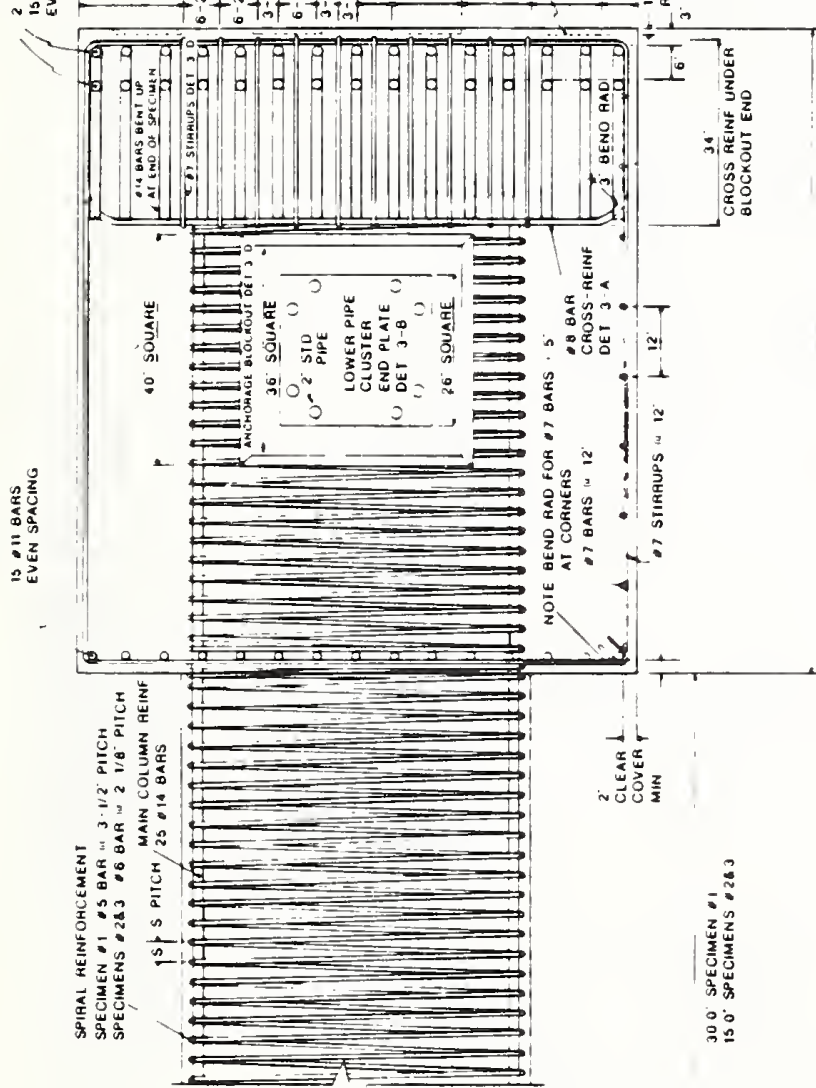

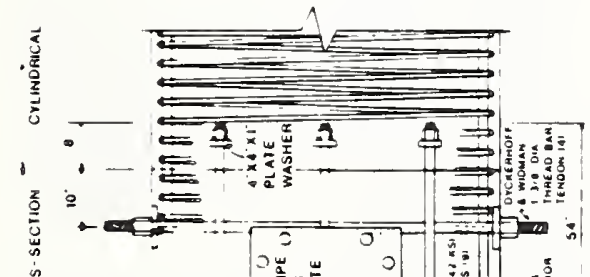
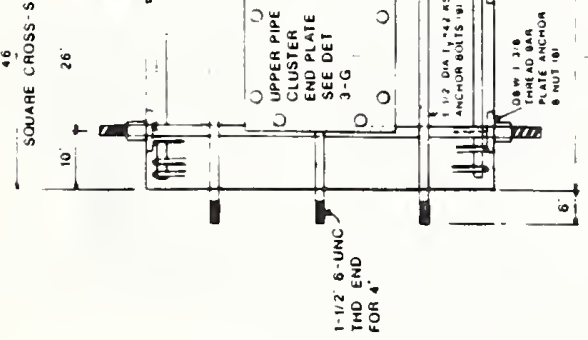

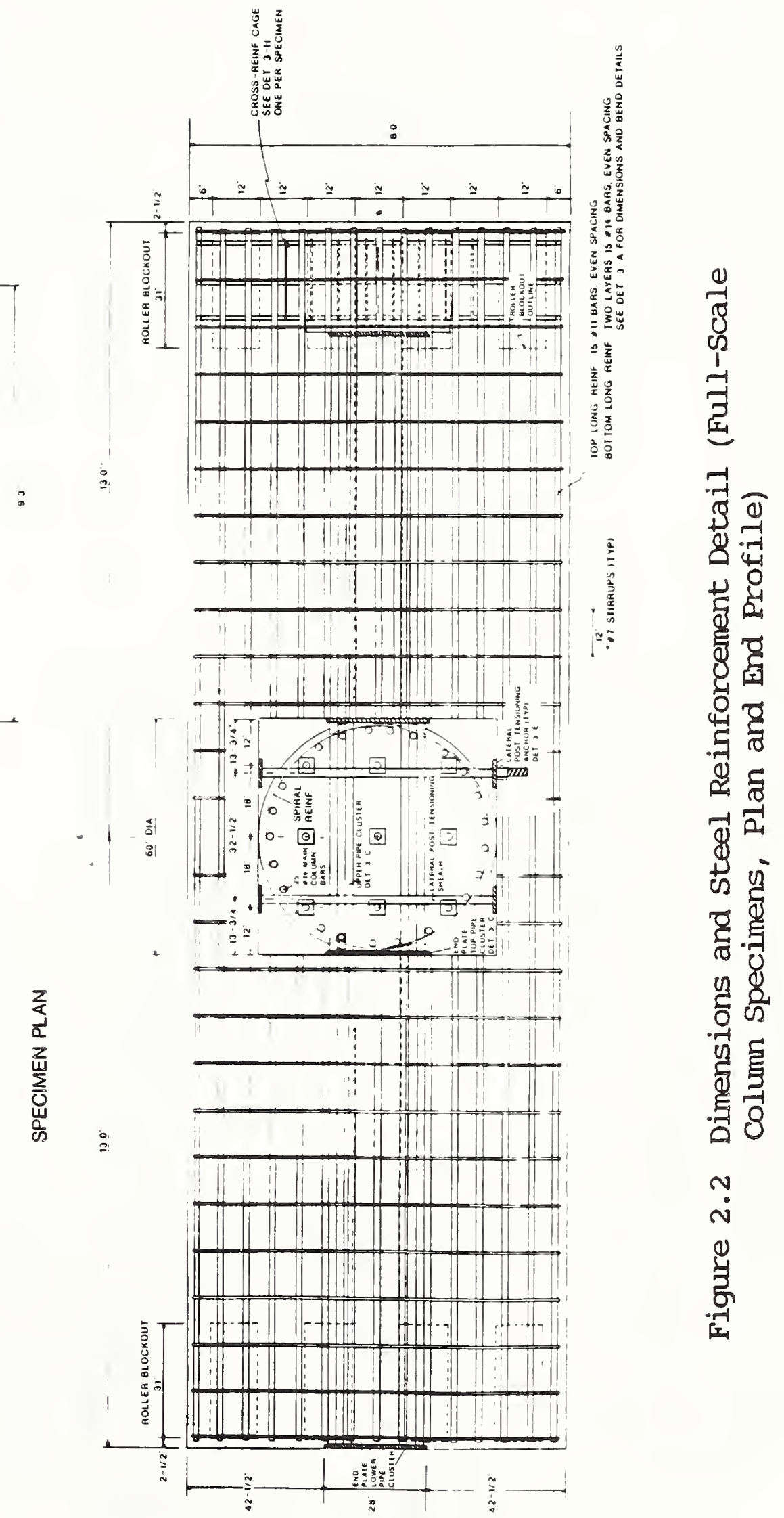




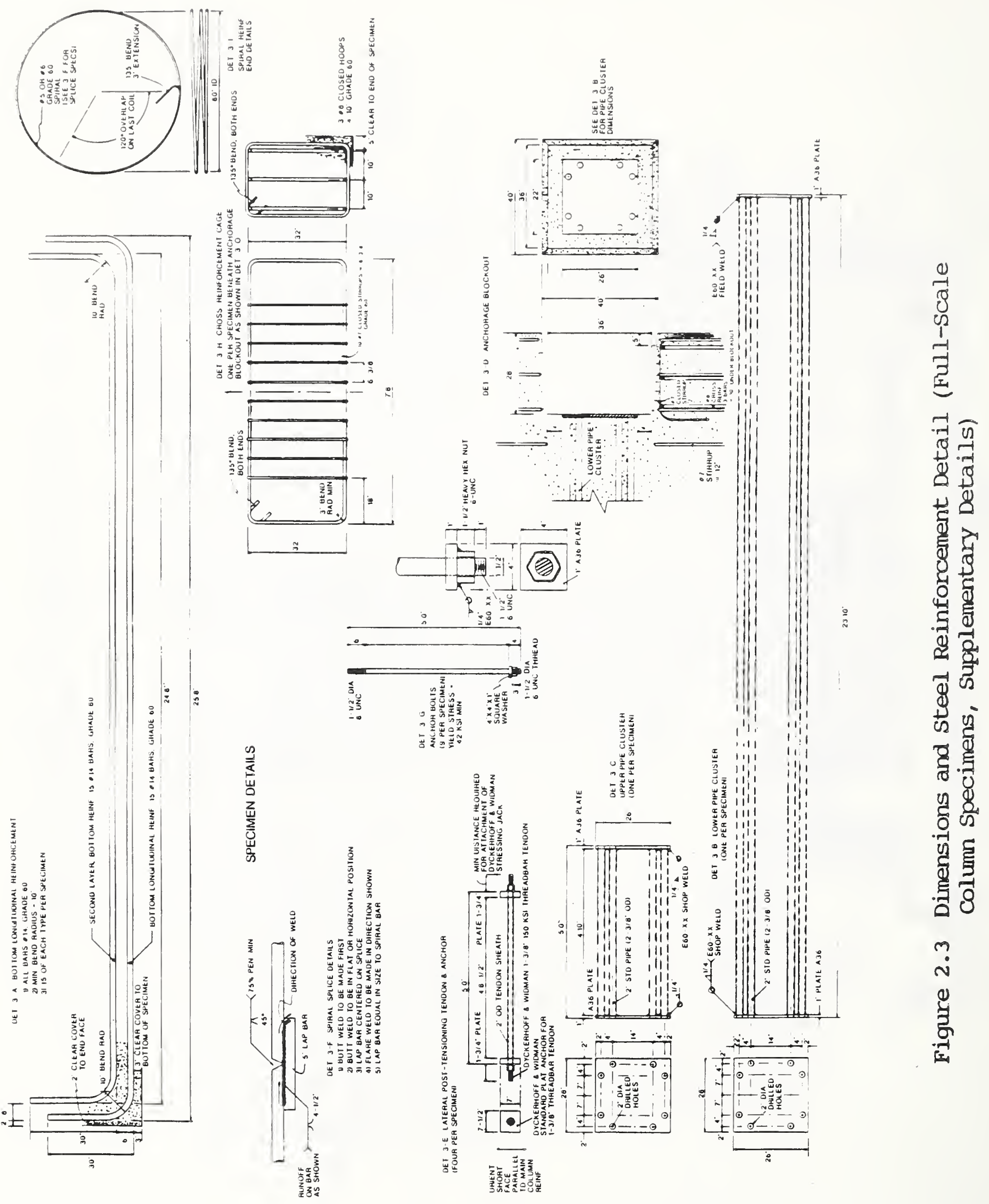




$$
\begin{aligned}
\rho_{\mathrm{s}} & \geq 0.12\left[\frac{f^{\prime}{ }_{c}}{f_{y}}\right]\left[0.5+1.25 \frac{P_{e}}{f^{\prime}{ }_{c}{ }^{A g}}\right] \\
& \geq 0.12 \quad(5.2 / 60)\left[0.5+1.25 *\left(1000 / 5.2 * \Pi * 30^{2}\right)\right] \\
& \geq 0.00608 \quad \begin{array}{l}
\text { (based on the concrete compressive strength of } \\
\text { the prototype flexure column) }
\end{array}
\end{aligned}
$$

However, this reinforcement ratio must not be less than:

$$
\begin{aligned}
\rho_{s} & \geq 0.45\left[\frac{A_{g}}{A_{c}}-1\right]\left[\frac{f_{c}^{\prime}}{f_{y}}\right] \\
& \geq 0.45\left(30^{2} / 28^{2}-1\right) 5.2 / 60 \\
& \geq 0.00577
\end{aligned}
$$

Equation 2.1, therefore, governed the amount of transverse reinforcement for these columns. The potential plastic hinge length as defined by CALTRANS [4] is the greater of:

1. The maximum horizontal dimension $=60 \mathrm{in} .(1.52 \mathrm{~m})$.

2. $1 / 6$ of the column length $=360 / 6$ in. $=60$ in. $(1.52 \mathrm{~m}) \quad$ Flexure

$$
=180 / 6 \text { in. }=30 \mathrm{in} \cdot(0.74 \mathrm{~m}) \quad \text { Shear }
$$

3. 24 in. $(0.61 \mathrm{~m})$.

The potential plastic hinge length for both the flexure and shear columns is therefore equal to $60 \mathrm{in.}(1.52 \mathrm{~m})$.

The $\left(P_{e} / f^{\prime} c A_{g}\right)$ ratio for both columns was

$$
P_{e} / f^{\prime} c A_{g}=0.09
$$

based on a concrete design strength of $4000 \mathrm{psi}$ (27.6 MPa) and an axial load of $1000 \mathrm{kip}(4,448.2 \mathrm{kN})$. Actual concrete strengths obtained from compression 
tests of $12 \times 6$ in. (305 x $122 \mathrm{~mm}$ ) cylinders were 5200 psi (35.9 MPa) for the flexure column and 4980 psi (28.54 MPa) for the shear column. These led to the following axial loading conditions for the two specimens:

$$
\begin{array}{ll}
\mathrm{Pe} / f^{\prime} \mathrm{CAg}=0.068 & \text { [flexure specimen] } \\
\mathrm{Pe} / f^{\prime} \mathrm{CAg}=0.085 & \text { [shear specimen] }
\end{array}
$$

The following chapter describes the results of the prototype tests. The means by which the tests were carried out are described in detail in Appendix A. 


\subsection{TEST RESULTS AND OBSERVATIONS \\ 3.1 Introduction}

The method used to determine the yield displacement was the same as that used for the model tests [1]. In brief, the ultimate moment of the column was determined using ACI column charts [11]. From this moment value, an ultimate lateral load was obtained. The columns were then laterally loaded to $75 \%$ of ultimate lateral load in the forward and then in the reverse direction. Displacements were experimentally measured in both these directions. The average of the two displacements divided by 0.75 was then used as the yield displacement, $\Delta_{y}$. This definition of the yield displacement was used by Priestley et. al. [12] in their test programs at the University of Canterbury and is graphically defined in Fig. 3.1 .

While cyclic load test procedures for steel structures are in the process of standardization [13], no such recommended procedures have yet been agreed upon for testing reinforced concrete structures. The determination of $\Delta y$, and the cyclic load history to which the structure will be subjected, is therefore somewhat arbitrary. Unfortunately, there is evidence that column behavior is dependent upon cyclic load history [14]. For these reasons, and because of the wealth of bridge column test data available for comparison from New Zealand, the procedure described above for the determination of yield deflection, as well as the practice of using only two complete cycles at any given level of displacement ductility, was adopted. Observations concerning the validity of the method for the determination of yield displacement are presented in Chapter 4.

The columns were tested in the NBS Large Scale Test Facility described in Chapter 2. Loading history for each prototype column was identical to its corresponding model column. The loading sequence for the flexure column was one cycle to determine yield displacement, two cycles each at $\mu$ equal to \pm 2 and $\pm 3,10$ cycles at $\mu$ equal to \pm 4 and two cycles each at $\mu$ equal to $\pm 5, \pm 6$, ... where $\mu$, the displacement ductility, is defined as the ratio 


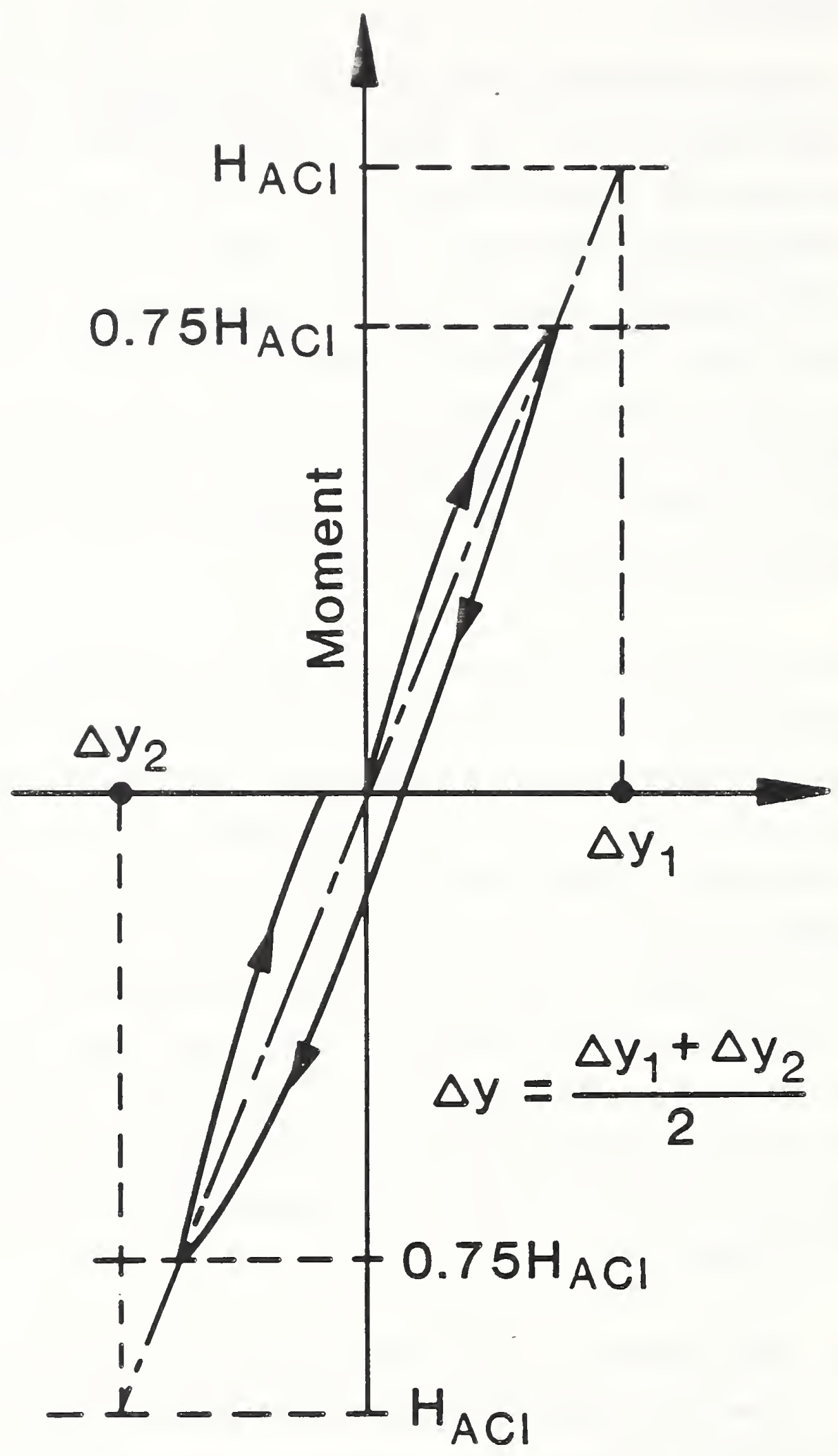

Figure 3.1 Experimental Definition of Yield Deflection as per Reference 12. 
of the displacement at any point to the yield displacement. A third cycle was conducted if at a given ductility level, the moment capacity of the column in the second cycle was significantly lower than that obtained in the first cycle.

The columns were first loaded axially to $1,000 \mathrm{kip}(4,448.2 \mathrm{kN})$. This load was chosen as being representative of the gravity load due to the bridge superstructure. The columns were then laterally loaded in the east-west direction with the first excursion to the east (forward direction) and then to the west (reverse direction). A complete cycle was defined as an excursion to the east followed by a return to the initial position and a subsequent excursion to the west followed by a return to the initial position. The entire test was performed under displacement control.

A detailed discussion of the observations and behavior of the columns during each test is presented in this chapter. The discussion is presented in a cycle-by-cycle format augmented by figures to depict any significant changes in column appearance. A discussion of results is presented in Chapter 4.

\subsection{Flexure Specimen}

\subsubsection{MATERIAL PROPERTIES}

$$
\begin{aligned}
& \mathrm{f}^{\prime} \mathrm{c}=5200 \mathrm{psi}(35.8 \mathrm{MPa}) \\
& \mathrm{P}_{\mathrm{e}}=1000 \mathrm{kip}(4,448.2 \mathrm{kN}) \\
& \mathrm{M}_{\mathrm{u}} \text { (experimental) }=9643 \mathrm{kip}-\mathrm{ft}(13 \mathrm{MN}-\mathrm{m}) \\
& \mathrm{P}_{\mathrm{h}}=200 \mathrm{kip}(889.6 \mathrm{kN}) \\
& \Delta_{\mathrm{y}} \text { (experimental) }=3.53 \mathrm{in} .(89.7 \mathrm{~mm})
\end{aligned}
$$

Where $\mathrm{P}_{\mathrm{e}}$ is the axial load imposed on the column, $\mathrm{P}_{\mathrm{h}}$ is lateral load equal to 758 of the ultimate lateral load, and $M_{u}$ is the maximum moment achieved experimentally. The loading history for the column is shown in Fig. 3.2

\subsubsection{DUCTILITY FACTOR $(D F)=1$, CYCLE 1}

Flexural cracking spaced at approximately $1 \mathrm{ft}$. (305 mm) apart was observed on both the east and west sides of the column. Cracking on the west side was first noted at a lateral load of $36.8 \mathrm{kip}$ and at a height of $4-1 / 2 \mathrm{ft}$. 


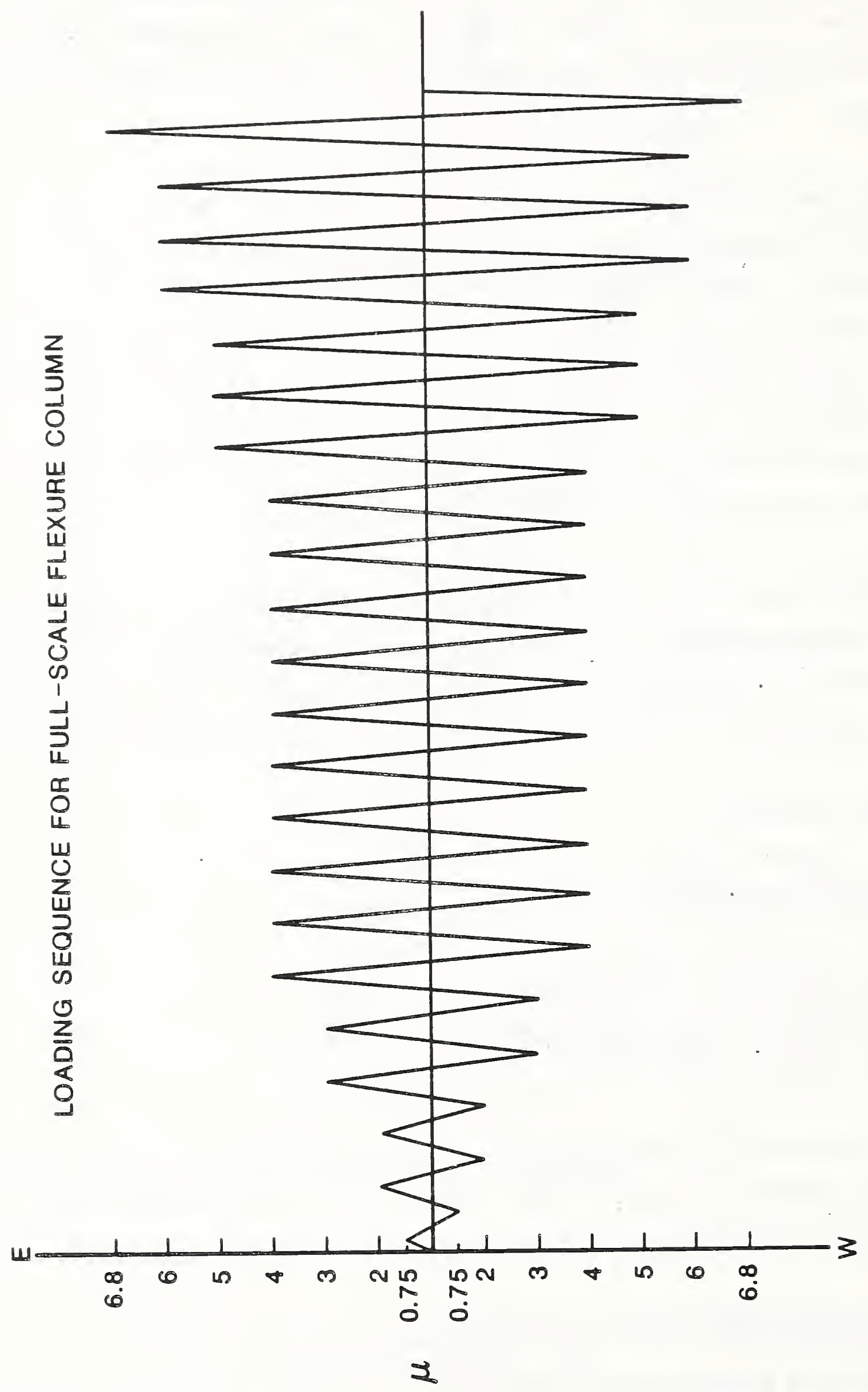


$(1372 \mathrm{~mm})$ above the base of the column. The length of the cracks were approximately $4 \mathrm{ft}$. (1219 mm) long. Upon loading to $200 \mathrm{kip}$ ( $889.6 \mathrm{kN}$ ) laterally to the west, flexural cracks were observed up to approximately 10 ft. (3048 $\mathrm{mm}$ ) and some of the existing cracks had propagated to the middle of the column i.e. the north-south axis. The measured displacement upon loading laterally to $200 \mathrm{kip}$ to the east was $2.500 \mathrm{in} .(63.5 \mathrm{~mm})$ and $2.799 \mathrm{in}$. $(71 \mathrm{~mm})$ to the west. The yield displacement for this column was therefore equal to 3.533 in. $(89.7 \mathrm{~mm})$.

$$
\begin{aligned}
\Delta_{y} & =\frac{.4(2.5+2.799)}{3} \quad \text { in. } \\
& =3.533 \mathrm{in.}
\end{aligned}
$$

See Section 3.1 for an explanation of the method used to calculate yield displacement.

Because of the instrumentation difficulties described in Chapter 2 regarding the direct measurement of friction forces developed in the roller support system, the actual lateral load seen by the column $\left(P_{h}\right)$ was somewhat less than $200 \mathrm{kip}(889.6 \mathrm{kN})$. It will be shown in Chapter 4 that these friction forces resulted in the underestimation of $\Delta_{y}$ by approximataly 28 for the full scale Flexure specimen and 1 for the full scale shear specimen. This factor is taken into account in later comparisons between prototype and model specimens.

\subsubsection{DUCTILITY FACTOR $=2$, CYCLES $2 \& 3$}

Cycle 2: Extensive formation of additional cracks were noted. Vertical cracks were observed forming between the flexural cracks up to a height of approximately $8 \mathrm{ft} .\left(2438 \mathrm{~mm}\right.$ ). Some diagonal cracks (approximately $45^{\circ}$ ) were noted on the north and south side of the column. Propagation of existing flexural cracks to the north-south axis at a height of $10 \mathrm{ft}$. (3048 mm) occurred. Incipient spalling at the base of the column on the west side was noted. No spalling on the east side was observed. Again, cracking of concrete could be heard. Cracks on the top face of the footing on the east side developed. Flexure cracks in the footing on the east and north faces 
occurred. These cracks occurred at the what appeared to the pour line. The crack pattern on the west side of the column is shown in Fig. 3.3.

Cycle 3: Upon reaching $2 \Delta_{y}$ to the east, 2 pieces of concrete cover on the west side spalled off.

\subsubsection{DUCTILITY FACTOR $=3$, CYCLES $4 \& 5$}

Cycle 4: Flaking of concrete on the west side of the column up to a height of $4 \mathrm{ft} .-10 \mathrm{in}$. (1473 mm) was noted on loading to the east. Fig. 3.4 shows this flaking of the west side of the column. The maximum width of the flake area was $3 \mathrm{ft}$. $-10 \mathrm{in.}(1168 \mathrm{~mm})$. Additional flexural and shear cracks, mainly in the bottom third of the column, were observed.

On loading to the west, a piece of concrete cover $1 \mathrm{ft}$. 7 in. (L) $x 2 \mathrm{ft}$.1 in. (W) $[483 \mathrm{~mm} \times 635 \mathrm{~mm}]$ spalled off on the west side of the column as shown in Fig. 3.5. The extent of cracking on the west side of the column can also be clearly seen in Fig. 3.6. The east face began to show signs of flaking. The area of flaking was approximately $2 \mathrm{ft} . \times 3 \mathrm{ft}$. $[610 \mathrm{~mm} \times 914$ $\mathrm{mm}$ ] (Note all dimensions are width $\mathrm{x}$ height). Some additional flexural and shear cracks were noted. Two additional cracks on the top face of the footing on the west side were noted.

Cycle 5: Several pieces of cover concrete spalled off on the east side of the column on the excursion to the east. The spall area was $1 \mathrm{ft}$. $-10 \mathrm{in}$. $\mathrm{x} 2 \mathrm{ft}$. -1 in. (559 mm $\times 635 \mathrm{~mm}$ ) and is shown in Fig. 3.7. The depth of the cover concrete was approximately $4 \mathrm{in.}(102 \mathrm{~mm})$ as compared with a specified cover of $2 \mathrm{in.} \mathrm{(51} \mathrm{mm}$ ) in the plan drawings. Additional spalling of the west side of the column occurred increasing the spall area to approximately $2 \mathrm{ft}$. $\mathrm{x} 3$ ft. - 2 in. $(610 \times 965 \mathrm{~mm})$. The spalling of the concrete cover did not, however, expose any reinforcing steel at this stage of the test. A shear crack on the north face and another on the south face of the footing coinciding with the north-south axis of the column were noted. 


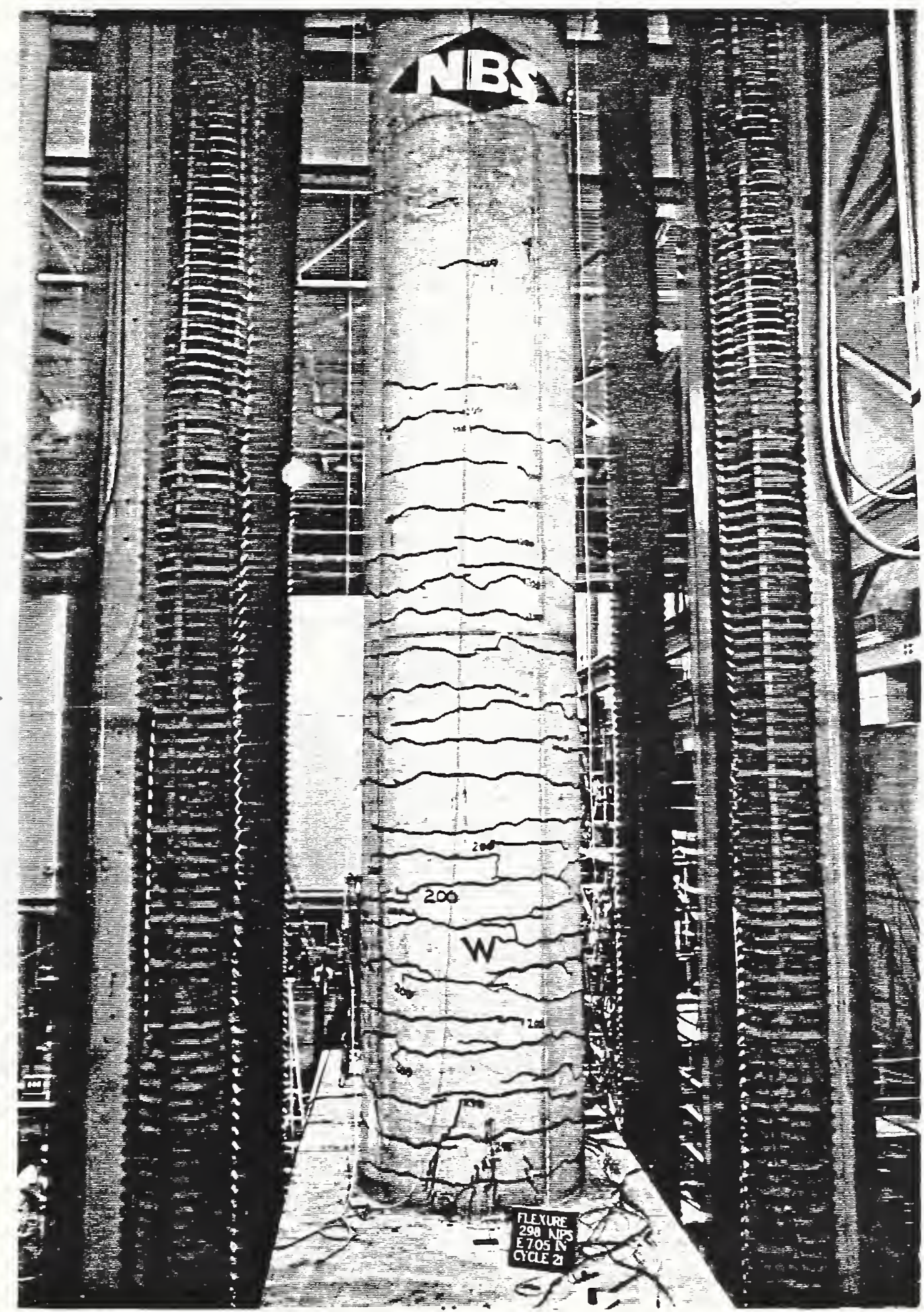

Figure 3.3: Flexure Specimen

Displacement $=2 \Delta y ;$ Cycle 1 East

View of West Side of Column 


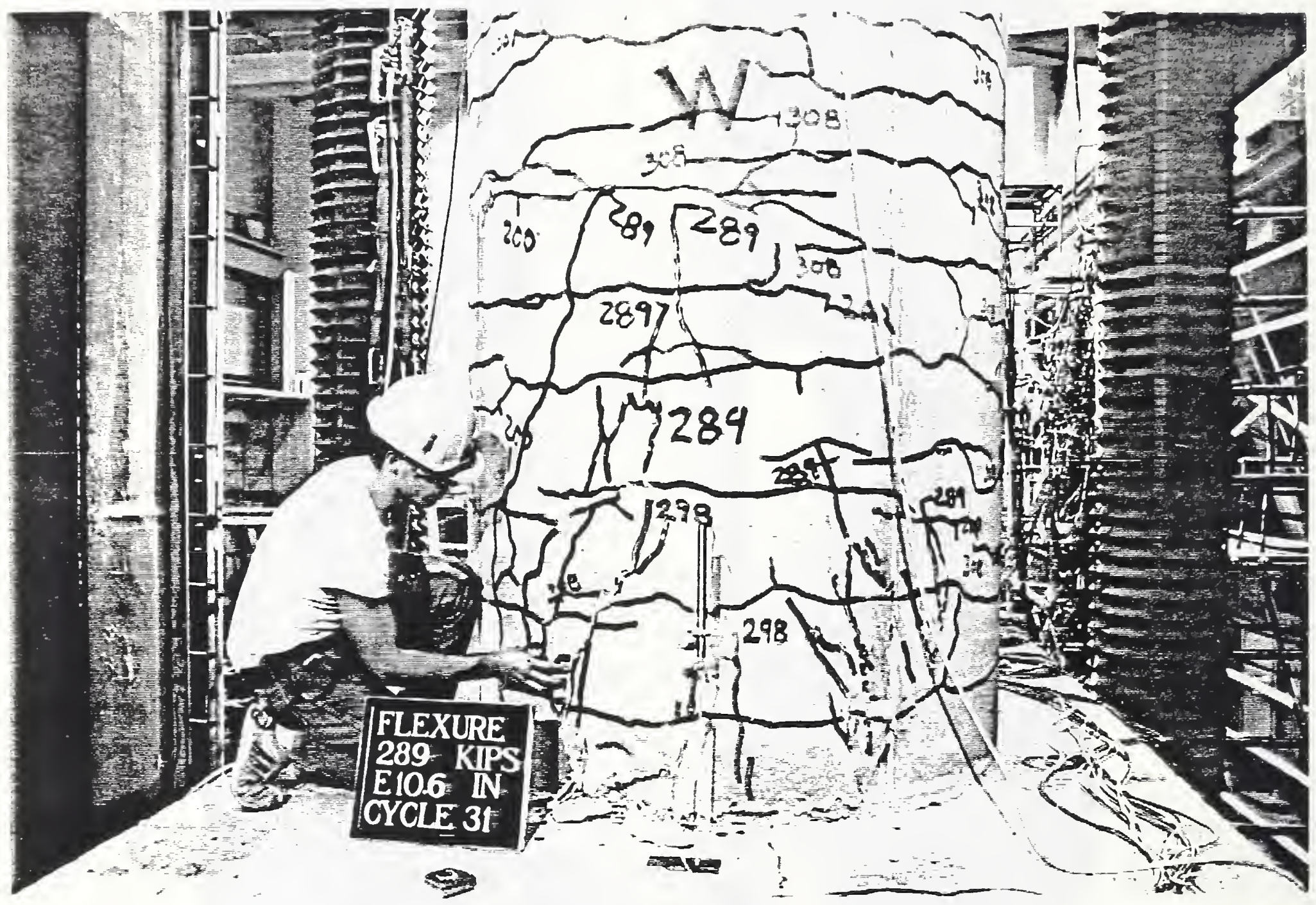

Figure 3.4: Flexure Specimen

Displacement $=3 \Delta y$; Cycle 1 East

View of East Side of Column 


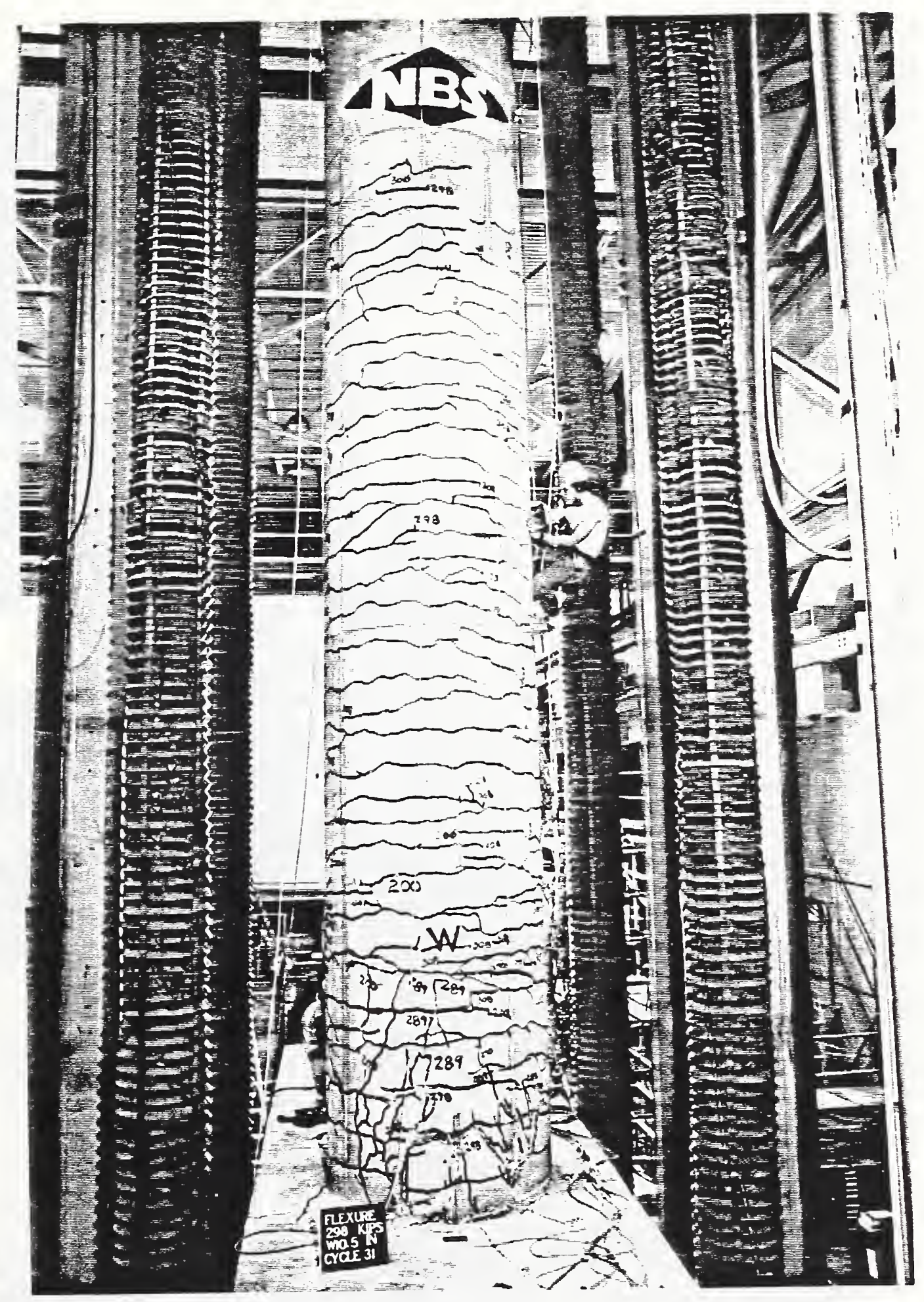

Figure 3.5: Flexure Specimen

Displacement $=3 \Delta y$; Cycle 1 West; View of West Side of Column.

Note Technician Marking Cracks on Right Side of Column. 


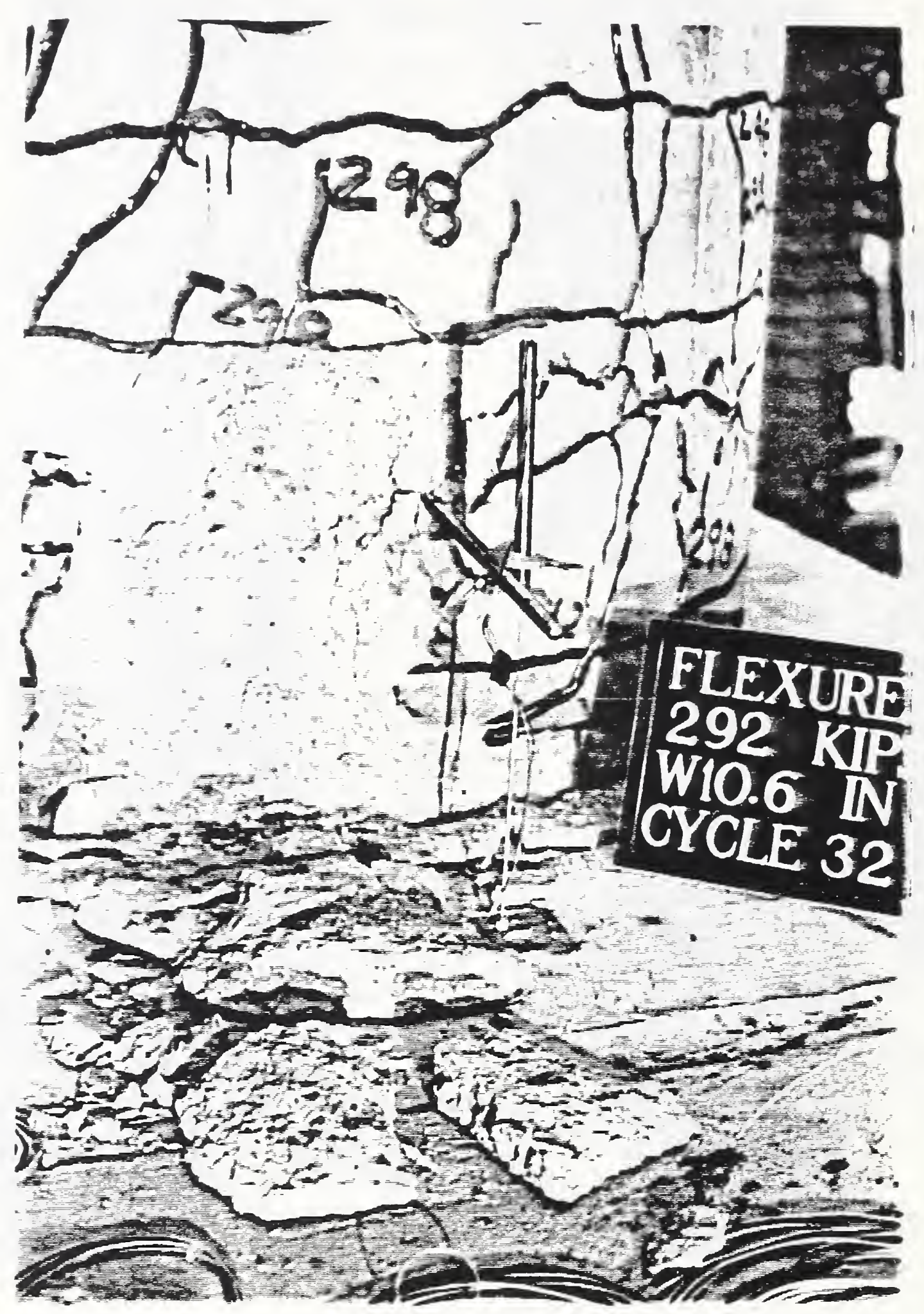

Figure 3.6: Flexure Specimen

Displacement $=3 \Delta y ;$ Cycle 2 West

View of West Side of Column Showing

Commencement of Spalling 


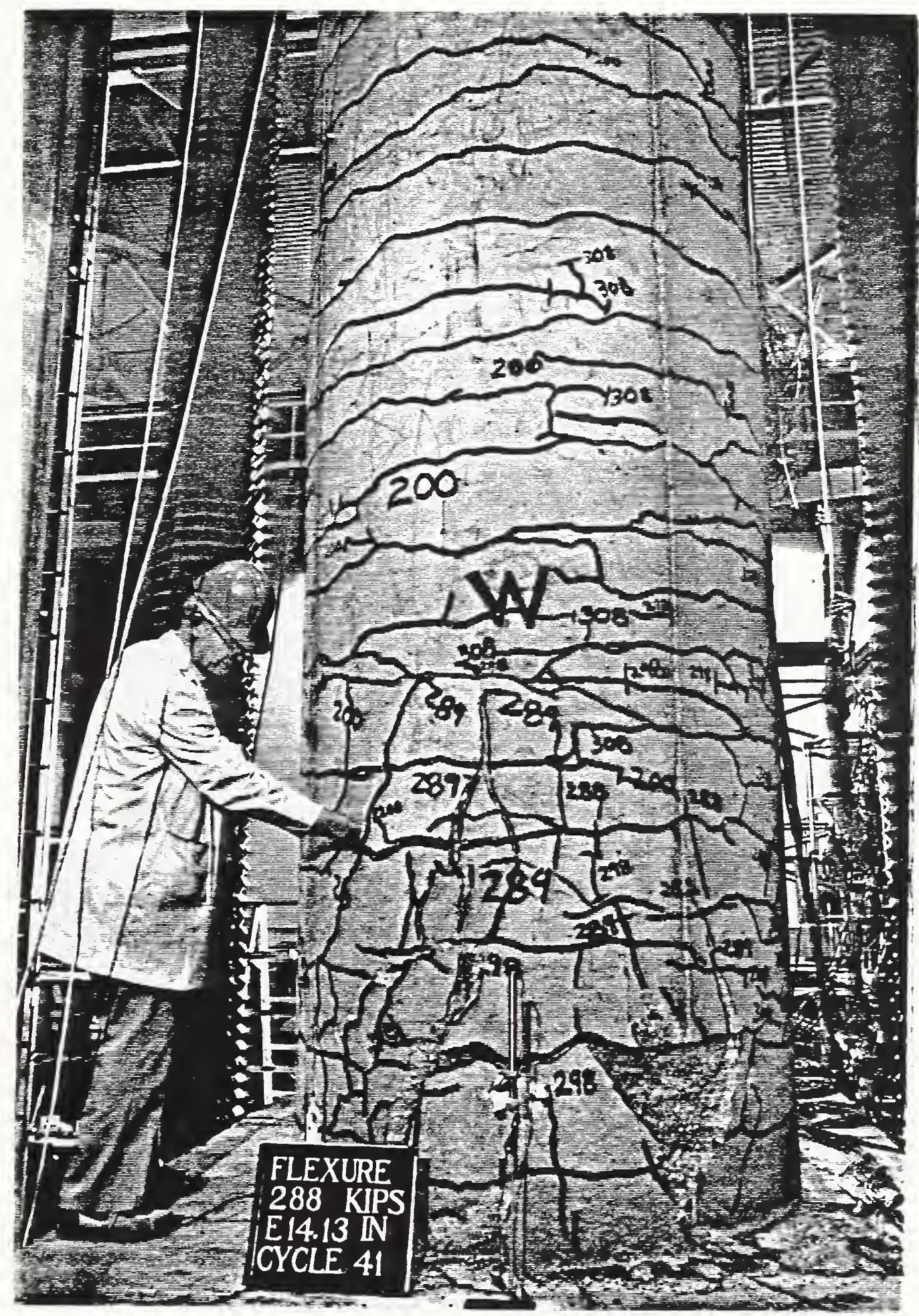

Figure 3.7: Flexure Specimen

Displacement $=4 \Delta y ;$ Cycle 1 East

View of West Side of Column 


\subsubsection{DUCTILITY FACTOR - 4, CYCLES $6-15$}

Cycle 6: Shear cracks were noted on the north and south faces of the footing. Additional spalling of the west side of the column took place exposing the spiral on that side. Views of the west side of the column before spalling and after spalling are shown in Figs. 3.8 and 3.9. The exposed spiral on the west side is indicated on Fig. 3.9. The spall area was approximately $1 \mathrm{ft} .-7$ in. $\mathrm{x} 3 \mathrm{ft} .-6 \mathrm{in.}(48.3 \mathrm{~cm} \times 106.7 \mathrm{~cm})$ on the west side of the column and $3 \mathrm{ft}$. $\mathrm{x} 2 \mathrm{ft} .(91.4 \mathrm{~cm} \times 61 \mathrm{~cm})$ on the east side of the column. The spall area on the east side is shown in Fig. 3.10. The thickness of the cover concrete on the west side was also approximately $4 \mathrm{in.}(10.2 \mathrm{~cm})$. Some additional shear cracks formed on the north side of the column mainly in the bottom third of the column.

Cycle 7: Crackwidths on the east side of the column were approximately 1/4 in. $(6.35 \mathrm{~mm})$ at $a$ height of $3 \mathrm{ft} .-4 \mathrm{in.}(101.6 \mathrm{~cm})$ and at $3 \mathrm{ft}$. $9 \mathrm{in.}$ $(114.3 \mathrm{~cm})$ above the column base. The spiral was still not exposed on the east side of the column at this stage although additional spalling of the cover concrete occurred in this cycle. Fig. 3.11 shows the east face of the column and the extent of the spall area.

Cycles 8 - 15: Additional spalling of the cover concrete took place over these eight cycles with no significant changes to the spall areas or crack pattern occurring. The spiral on the east side of the column was exposed during the $12^{\text {th }}$ cycle. Figs. 3.12 and 3.13 show the spall areas on the east and west sides of the column respectively. The LVDT measuring the rotation on the west side was removed due to the loss of the cover concrete which held it in place. 


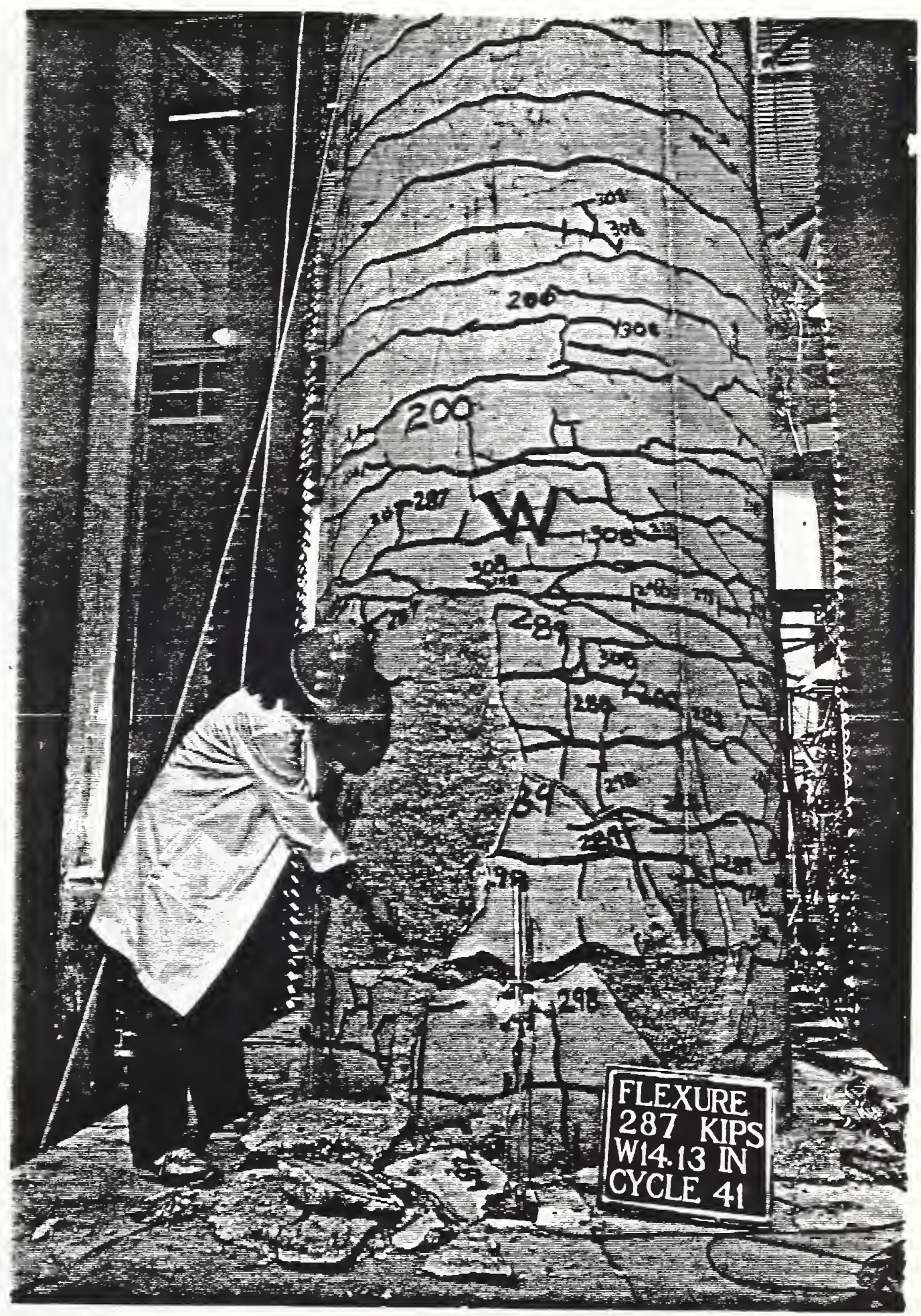

Figure 3.8: Flexure Specimen

Displacement $=4 \Delta y$; Cycle 1 West

View of West Side of Column 


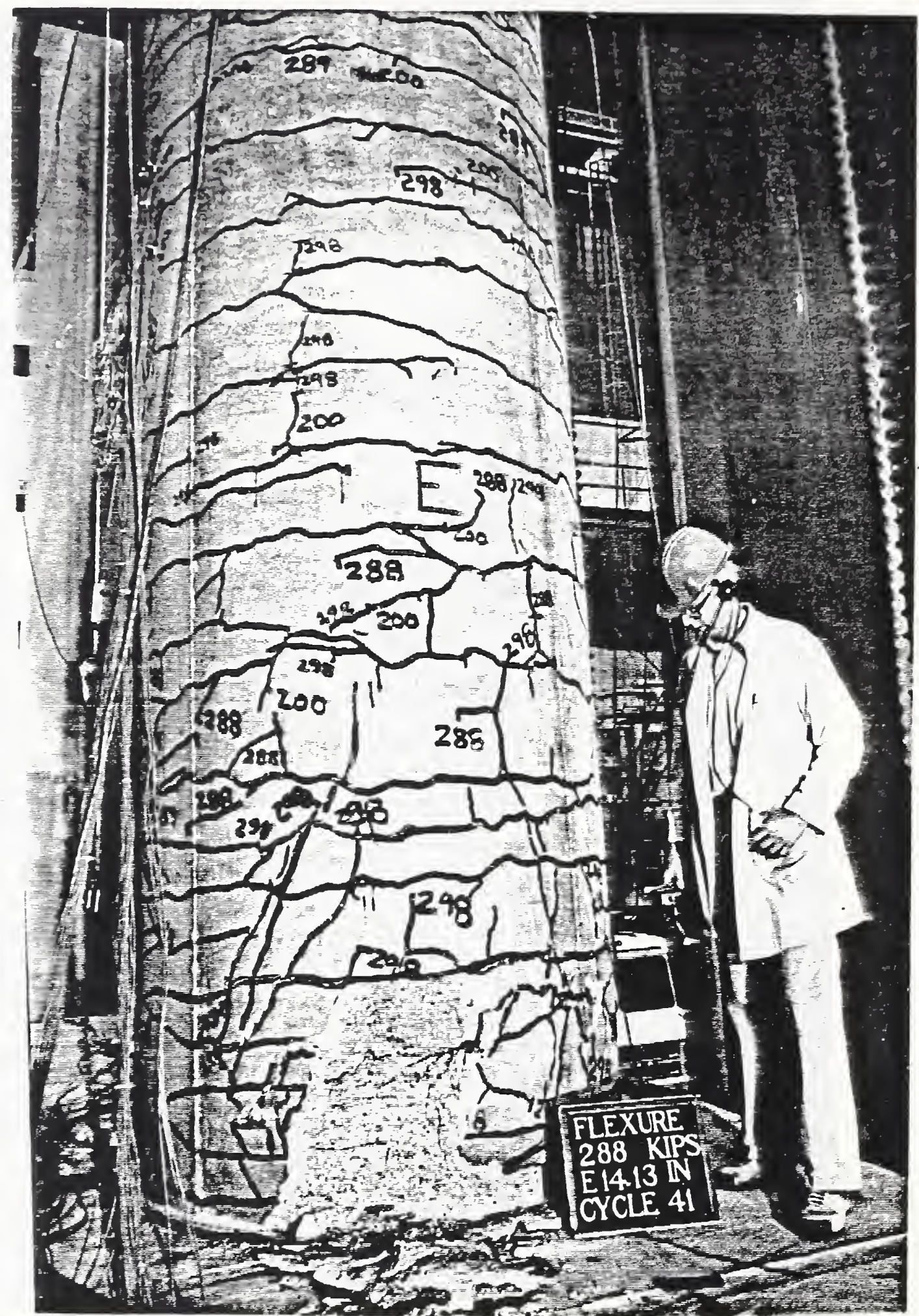

Figure 3.9: Flexure Specimen

Displacement $=4 \Delta y ;$ Cycle 1 East

View of East Side of Column 


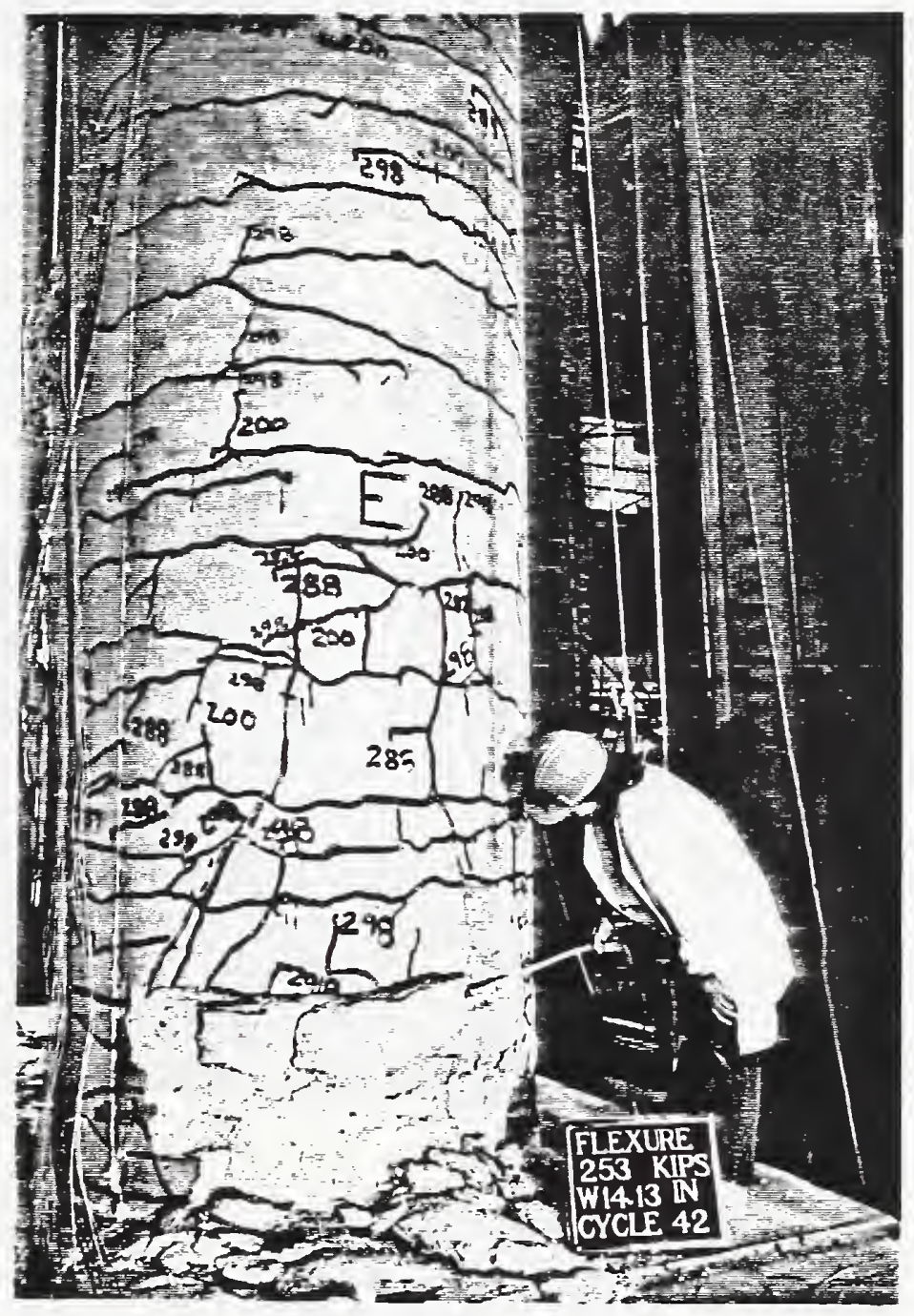

Figure 3.10: Flexure Specimen

Displacement $=4 \Delta y ;$ Cycle 2 West

View of East Side of Column 


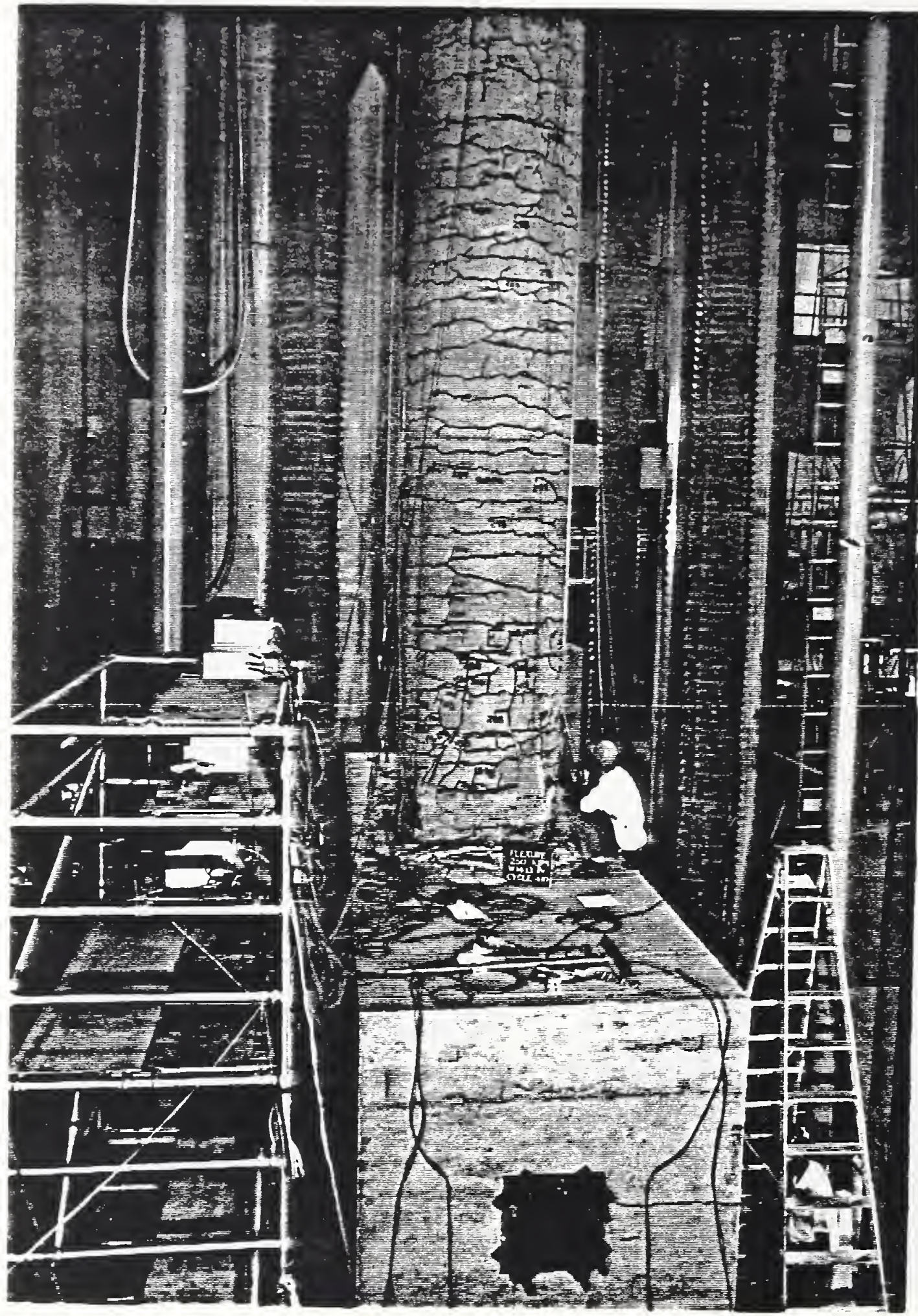

Figure 3.11: Flexure Specimen

Displacement $=4 \Delta y ;$ Cycle 10 West

View of East Side of Column 


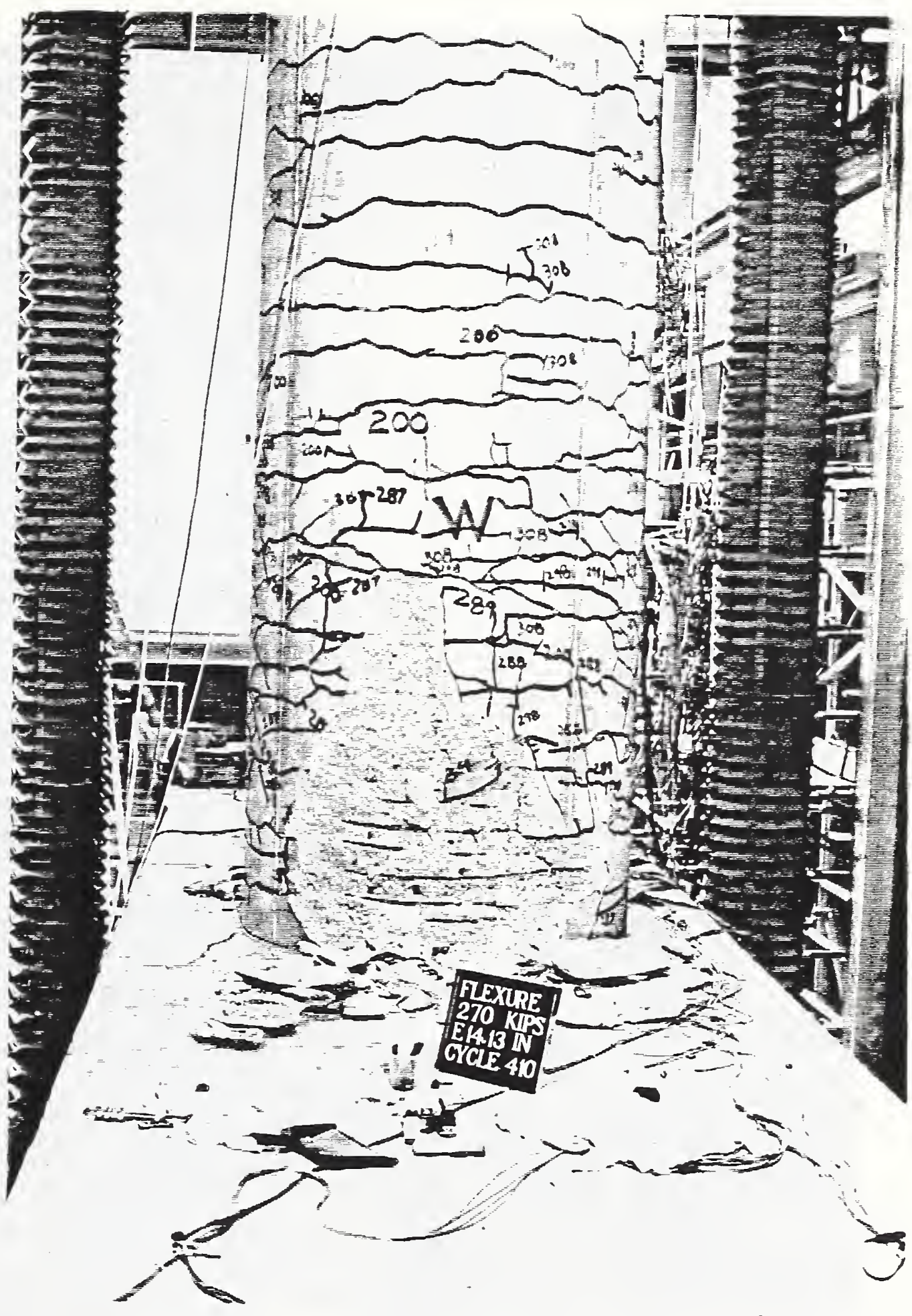

Figure 3.12: Flexure Specimen

Displacement $=4 \Delta y$; Cycle 10 East

View of West Side of Column 


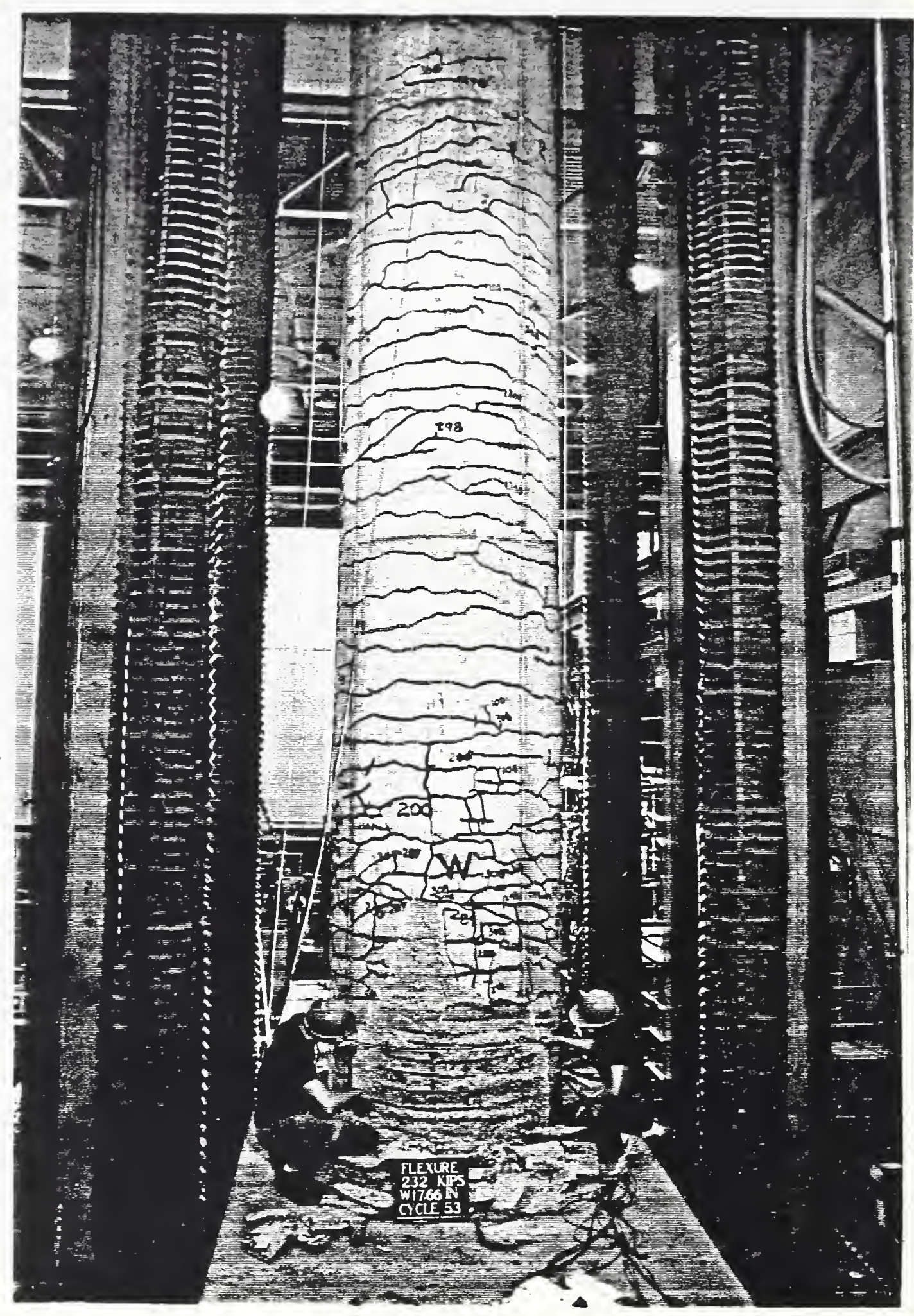

Figure 3.13: Flexure Specimen

Displacement $=5 \Delta y$; Cycle 3 West

View of West Side of Column 


\subsubsection{DUCTILITY FACTOR $=5$, CYCLES $16 \cdot 18$}

Cycles 16 - 18: Approximately 7 shear cracks were noted on the south face of the footing and about 2 were noted on the north face of the footing. Again, only minor spalling occurred with no significant changes in the crack pattern or spall areas during these three cycles. The spall areas on the east side of the column was $4 \mathrm{ft}$. $6 \mathrm{in.} \times 3 \mathrm{ft} .-61 / 2 \mathrm{in.}(1372 \mathrm{~mm} \times 1079 \mathrm{~mm}$ ) and $4 \mathrm{ft}$. - 3 in. $x 4 \mathrm{ft} .-2$ in. (1295 mm x $1270 \mathrm{~mm})$ on the west side. The crackwidth on the west side was approximately $3 / 8 \mathrm{in.}(95 \mathrm{~mm})$ at a height of $3 \mathrm{ft} .-5$ in. (1041 mm) above the top of the footing. Figs. 3.14 and 3.15 show the spall area on the west and east side of the column with the main reinforcing bars exposed, respectively.

A third cycle, cycle 18, was completed at this ductility level not because of a degradation in the load carrying capcity of the column was noted but because the corresponding model, model $\mathrm{N} 6$, was cycled three times at this ductility level.

\subsubsection{DUCTITLITY FACTOR $=6$, CYCLES $19-21$}

Cycle 19: The two longitudinal bars on the center of the west side of the

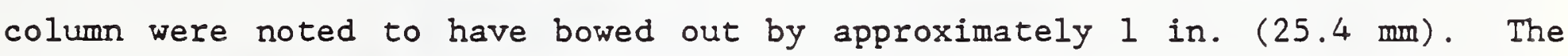
spiral between these two bars showed signs of straightening which indicates yielding.

Cycle 20: A spiral on the west side of the column at a height of $1 \mathrm{ft}$. 5 $1 / 4$ in. (438 $\mathrm{mm}$ ) fractured during the excursion to the east. The fracture occurred where the spiral was spliced. Fig. 3.16 shows the fractured spiral on the left side of the photo and the bowed longitudinal bars on the right. During the excursion to the west, a longitudinal bar fractured on the west side of the column. A drop in lateral load of approximately $13 \%$ corresponded to the fractures of the spiral and the longitudinal bar. 


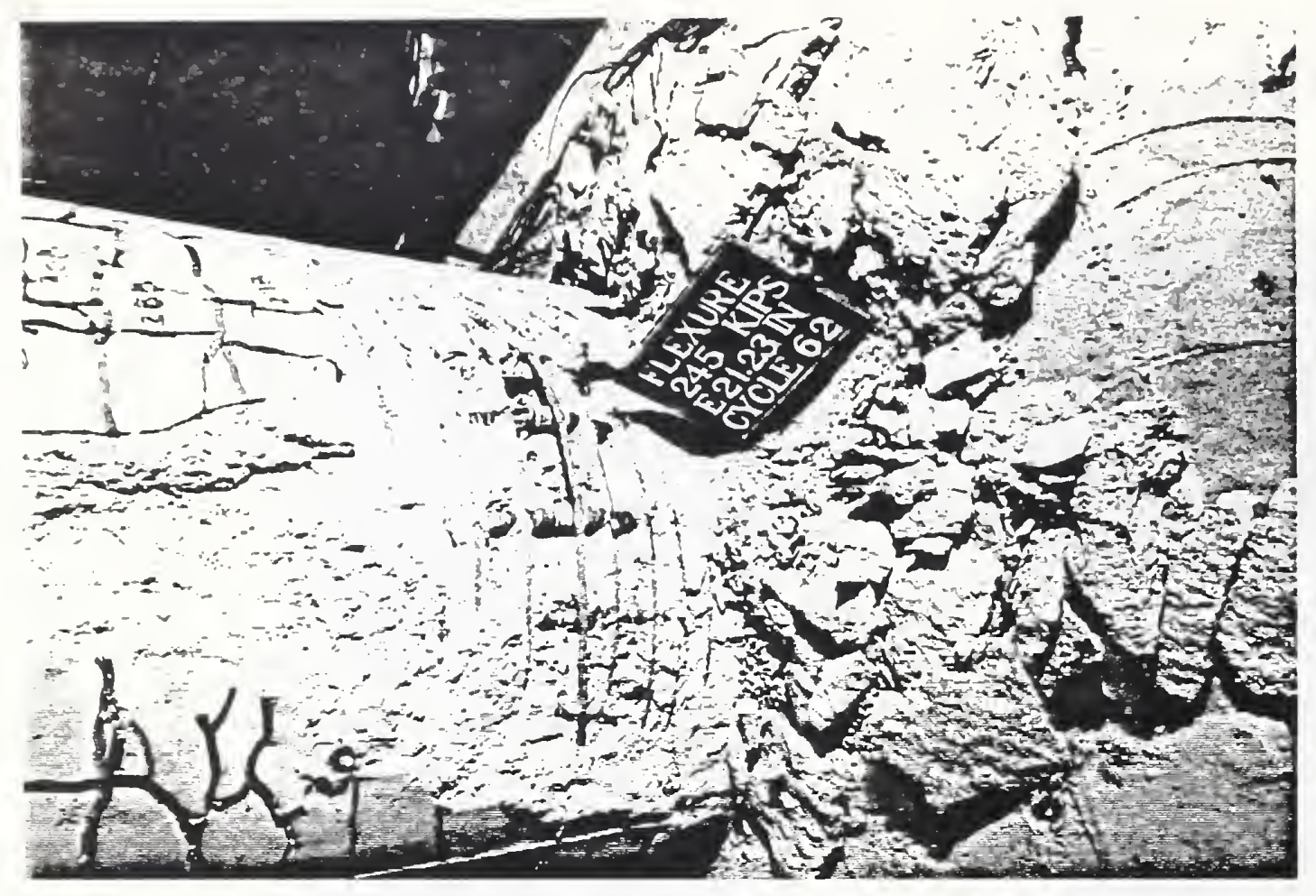

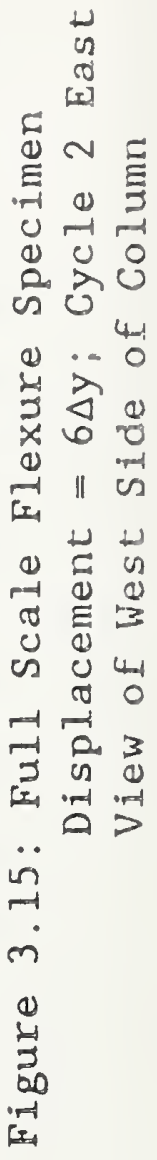

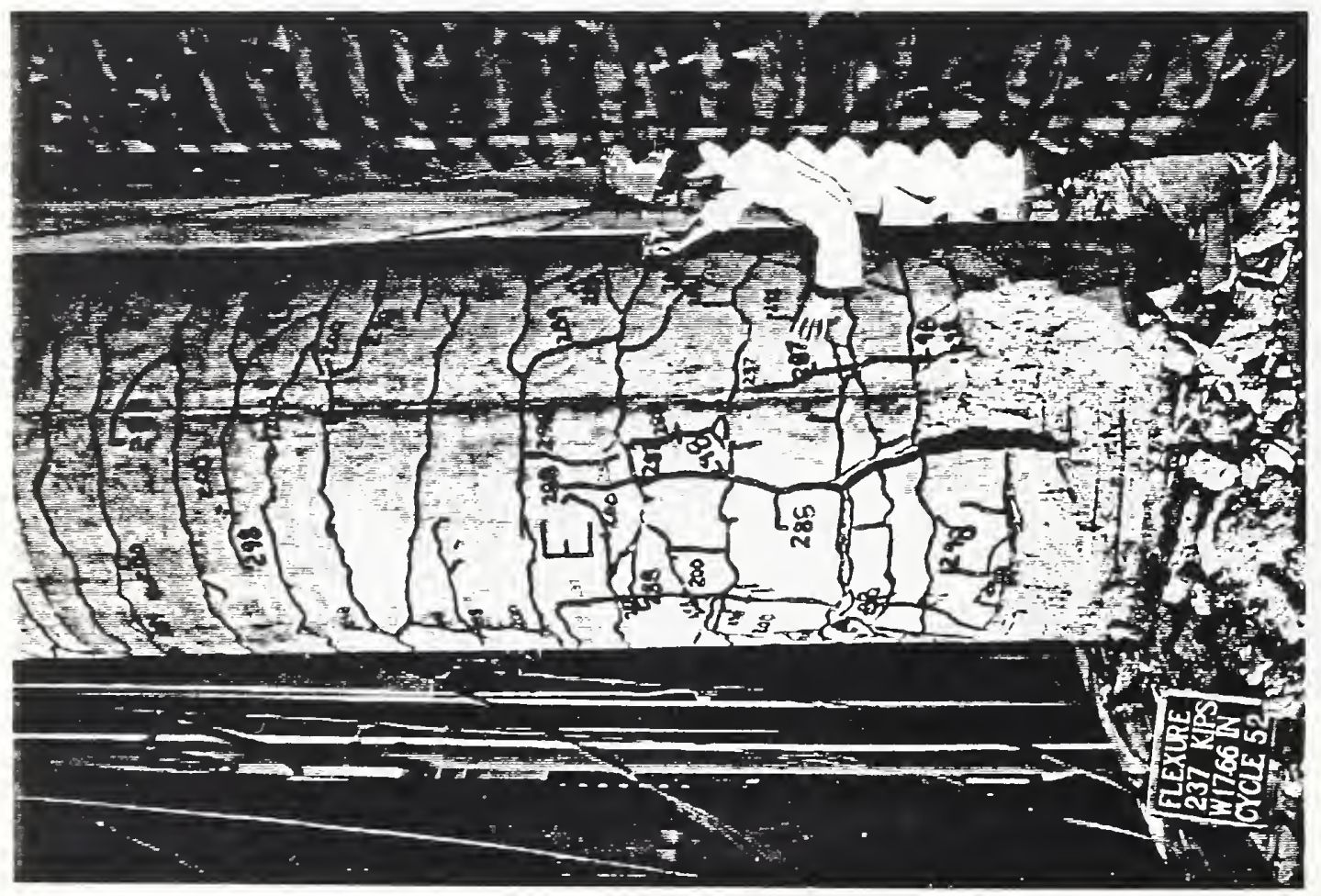




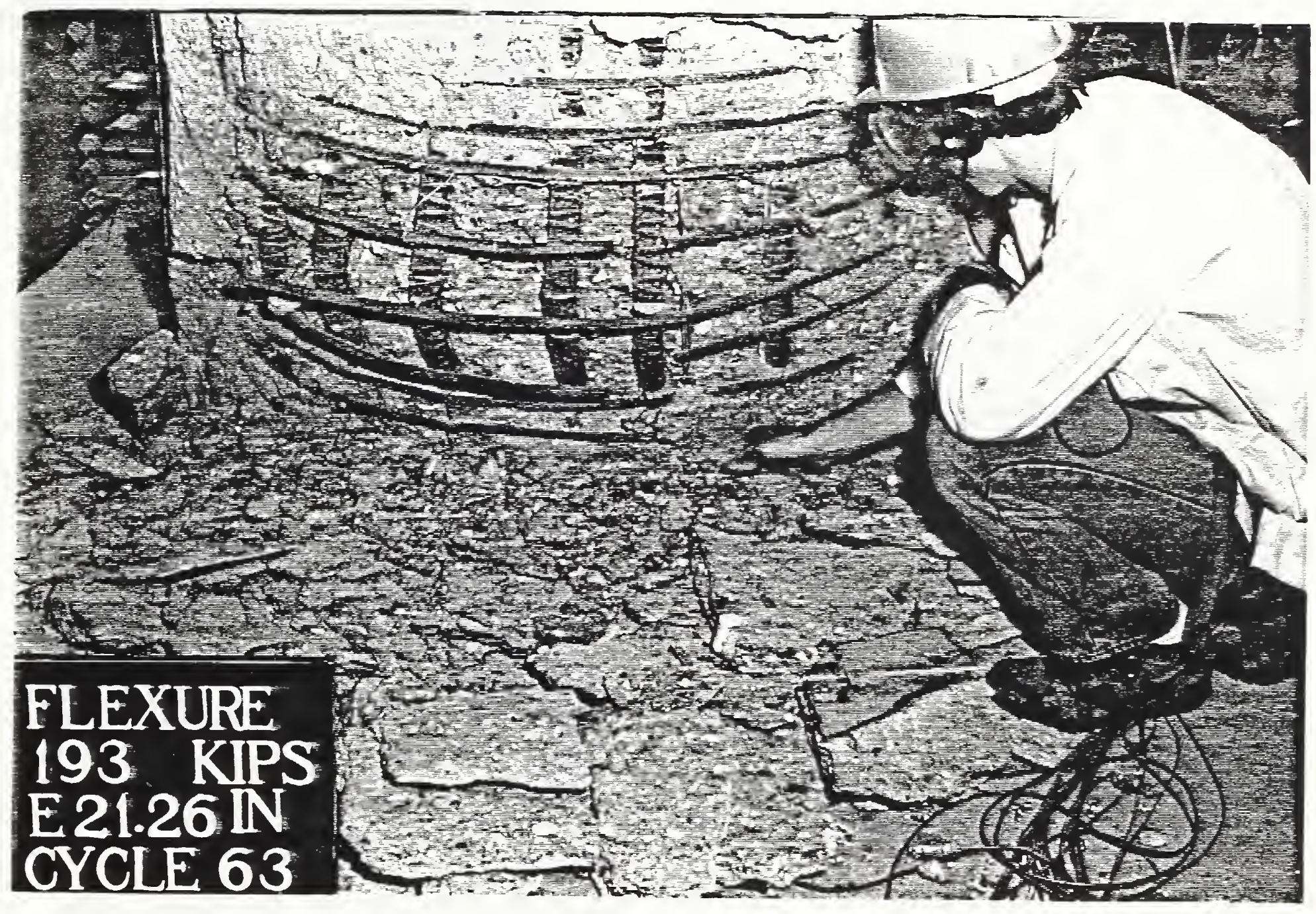

Figure 3.16: Flexure Specimen

Displacement $=6 \Delta y ;$ Cycle 3 East

View of West Side of Column 
Cycle 21: On the excursion east, a second spiral on the west side below the first fractured spiral fractured. A third spiral located right above the first fractured spiral fractured shortly after the fracture of the second spiral. The three fractured spirals in addition to the longitudinal bar which fractured in the last cycle are shown in Fig. 3.17. During the excursion west, three additional longitudinal bars on the west side of the column fractured. On the subsequent excursion back to initial' position, a fourth spiral fractured on the west side. The fractured longitudinal bars are shown in Fig. 3.18.

\subsubsection{DUCTILITY FACTOR $=6.6$, CYCLE 22}

Due to the limitation of $23.4 \mathrm{in.} \mathrm{(594} \mathrm{mm)} \mathrm{set} \mathrm{by} \mathrm{the} \mathrm{maximum} \mathrm{stroke} \mathrm{of} \mathrm{the}$ servo-hydraulic ram, a maximum ductility factor achievable for this test was 6.6. This did not, however, pose a problem as the column had already reached its failure state at the previous ductility level as will be discussed in further detail in Chapter 4.

Two vertical bars on the east side of the column fractured during the excursion to the east as shown in Fig. 3.19. Fig. 3.20 shows the west side of the column during the excursion east. On the excursion west, two additional longitudinal bars on the west side fractured. This made a total of six fractured longitudinal bars on the west side and two on the east side. The six fractured bars on the west is graphically shown in Fig. 3.20. The extent of the lateral displacement to the column is shown in Fig. 3.21. 


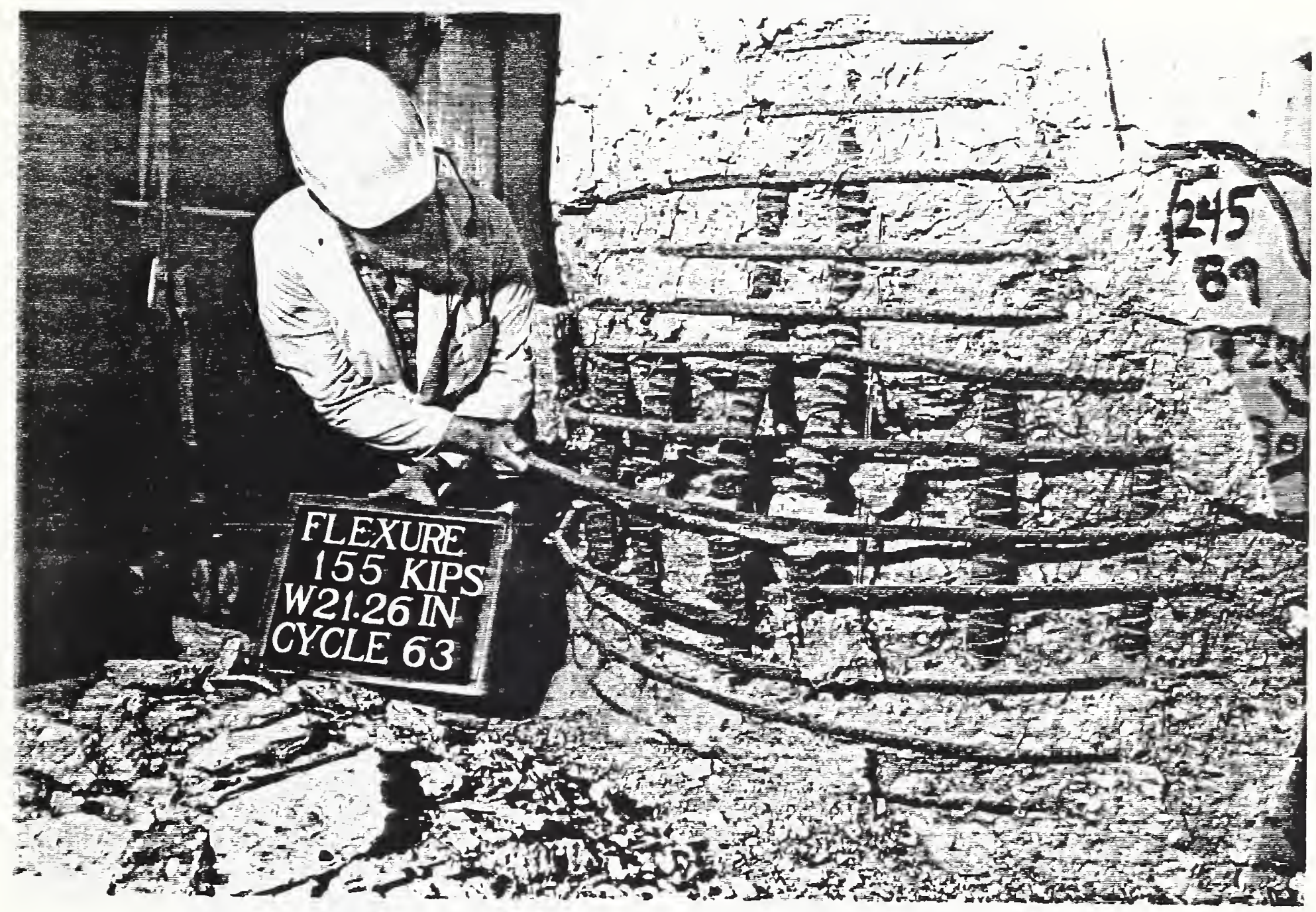

Figure 3.17: Flexure Specimen

Displacement $=6 \Delta y ;$ Cycle 3 West

View of West Side of Column 


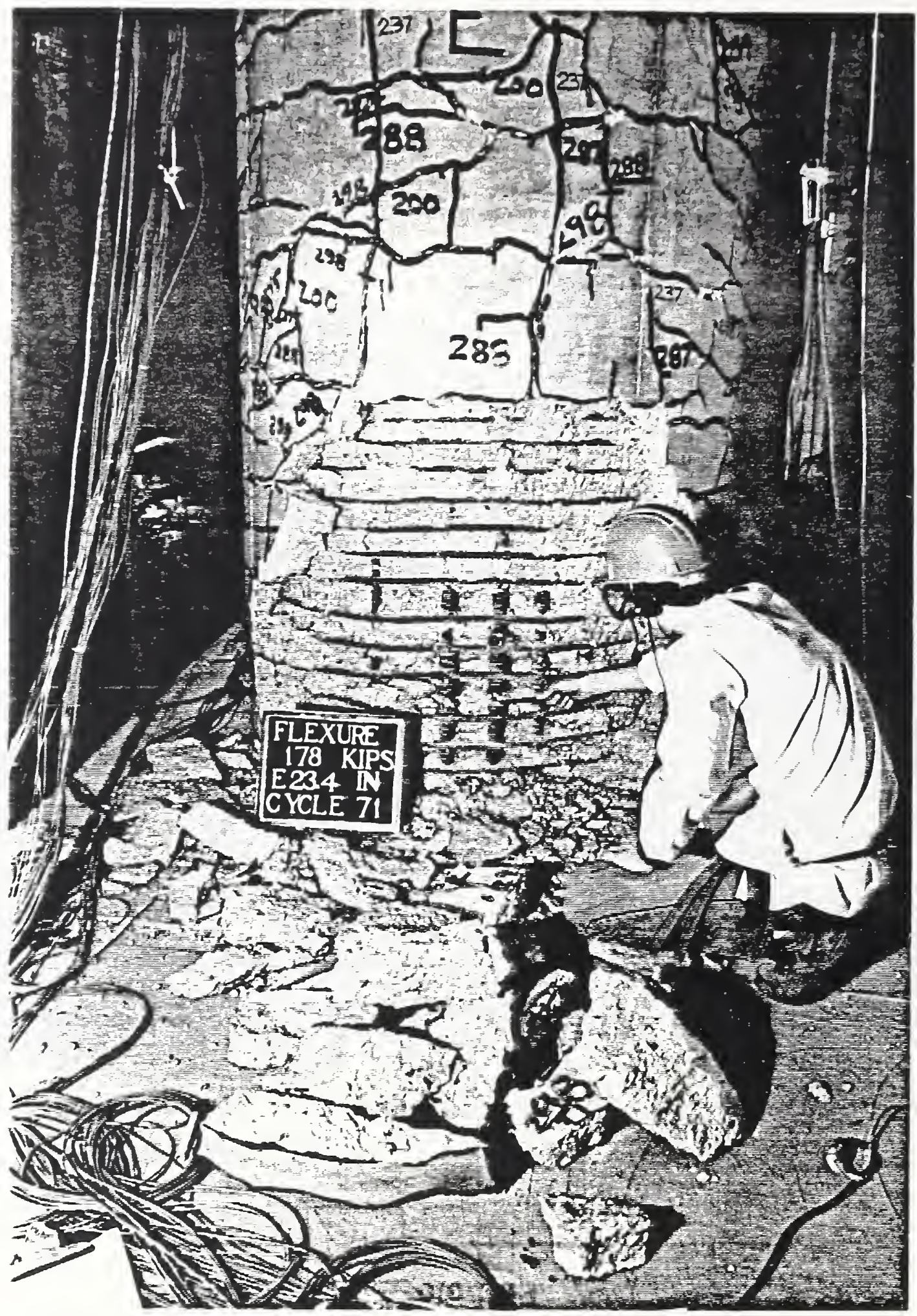

Figure 3.18: Flexure Specimen

Displacement $=7 \Delta y ;$ Cycle 1 East

View of East Side of Column 


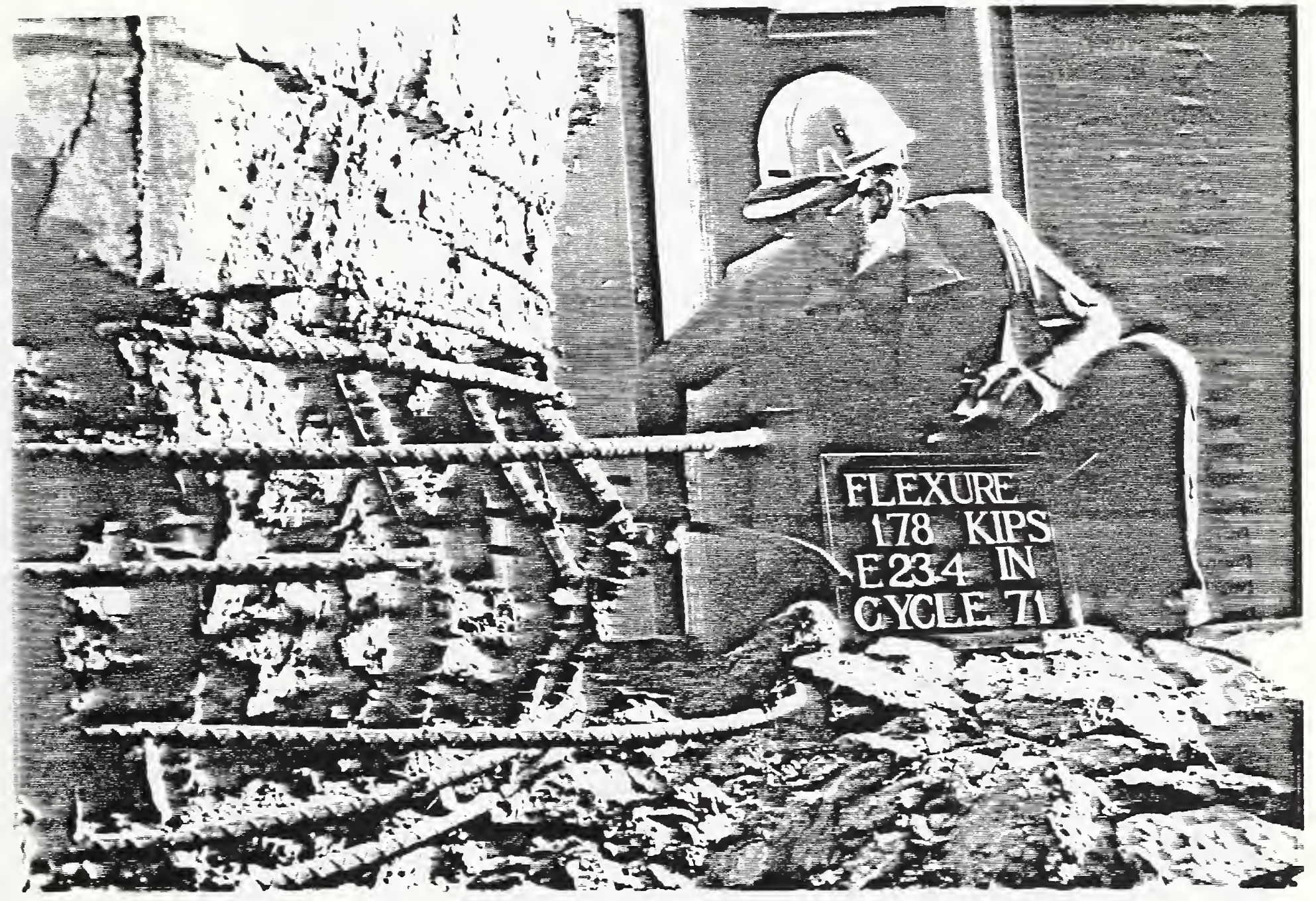

Figure 3.19: Flexure Specimen

Displacement $=7 \Delta y ;$ Cycle 1 East

View of West Side of Column 


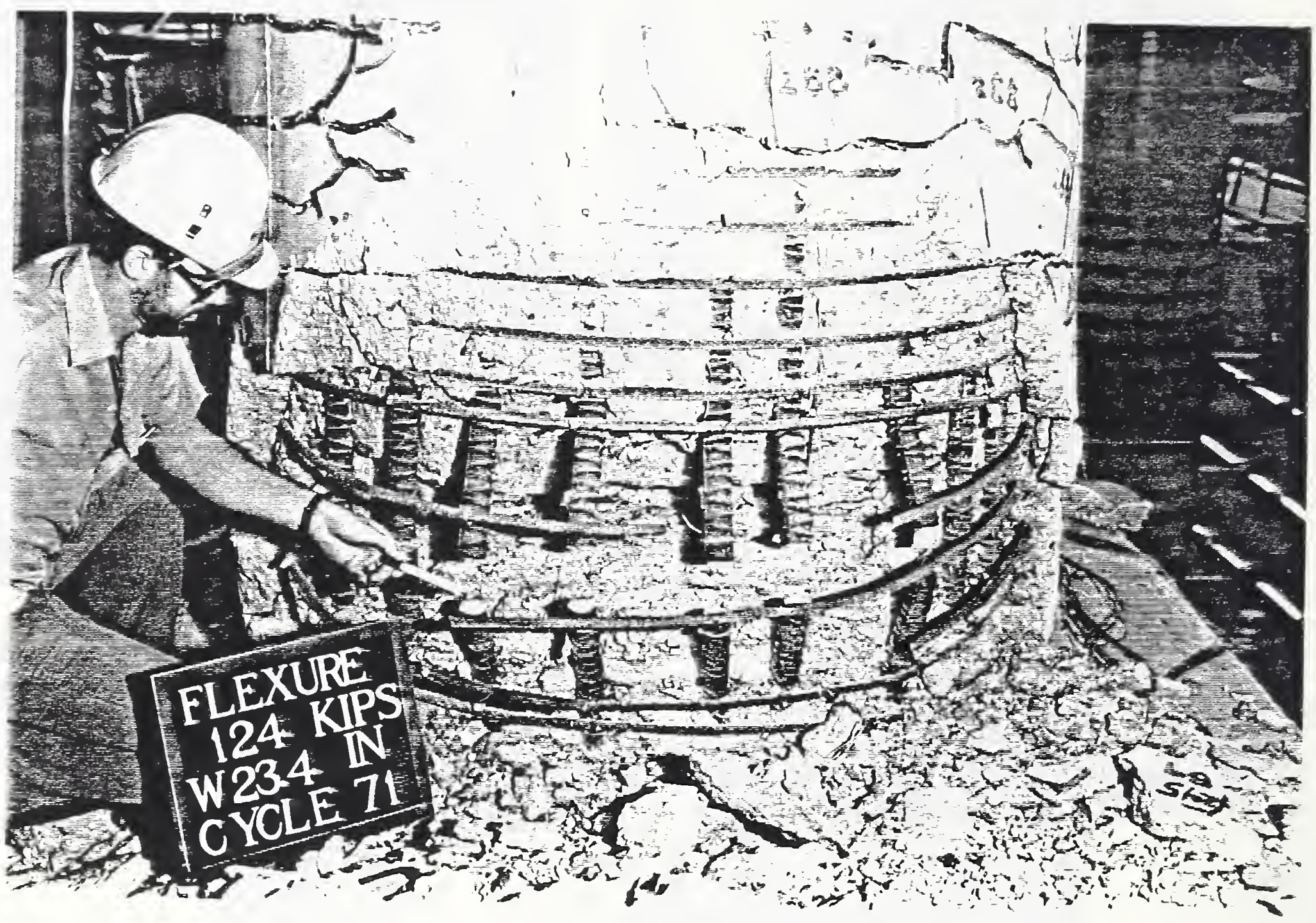

Figure 3.20: Flexure Specimen

Displacement $=7 \Delta y$; Cycle 1 West

View of West Side of Column 


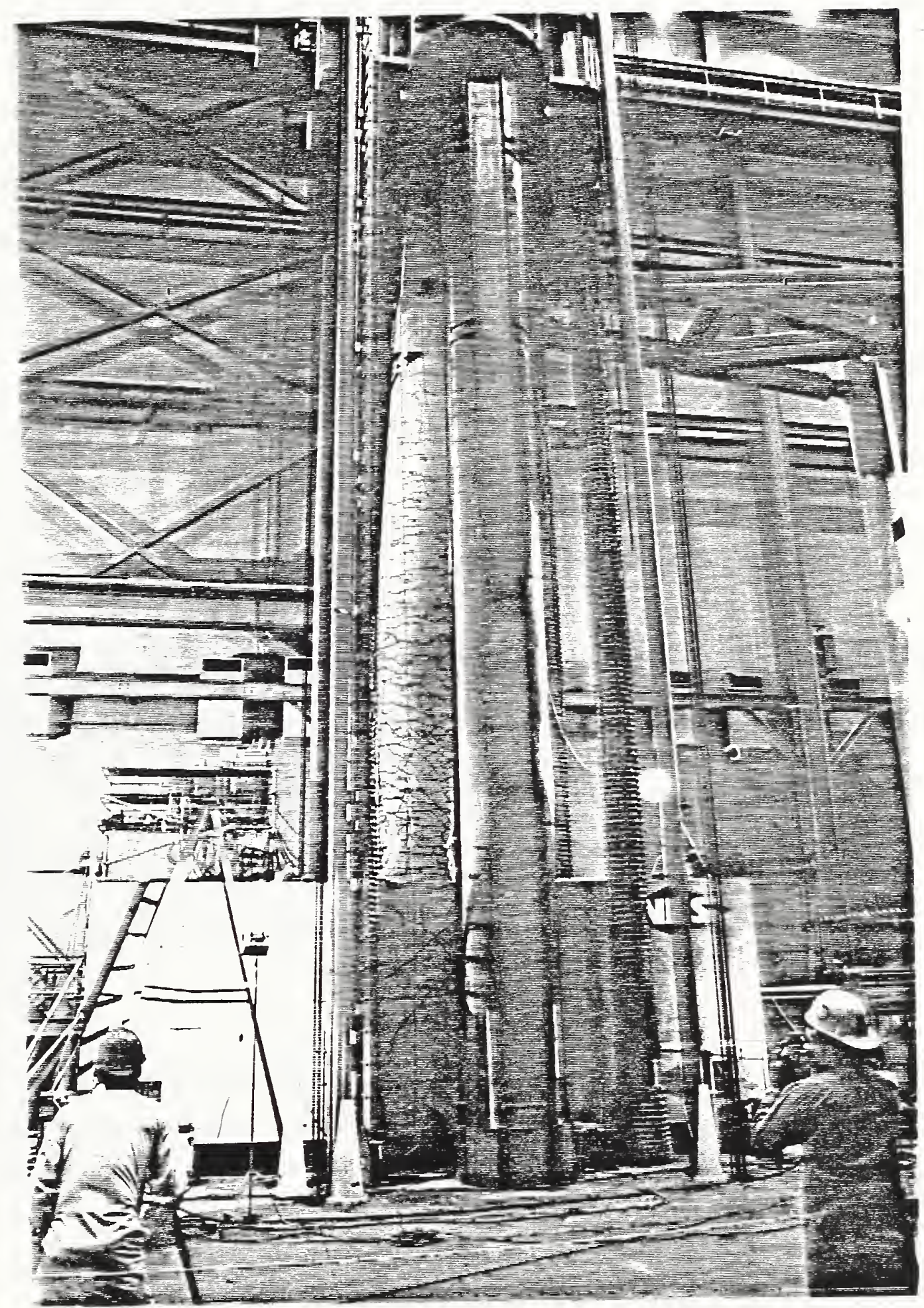

Figure 3.21: Flexure Specimen Displacement $=7 \Delta y$; Cycle 1 East Overall View of Test 


\subsection{Shear specimen}

\subsubsection{MATERIAL PROPERTIES}

$$
\begin{aligned}
& \mathrm{f}^{\prime} \mathrm{c}=4,140 \mathrm{psi}(28.5 \mathrm{MPa}) \\
& \mathrm{P}_{\mathrm{e}}=1000 \mathrm{kip}(4,448.2 \mathrm{kN}) \\
& \mathrm{M}_{\mathrm{u}} \text { (experimental) }=11640(15.8 \mathrm{MN}-\mathrm{m}) \\
& \mathrm{P}_{\mathrm{h}}=400 \mathrm{kip}(1779.3 \mathrm{kN}) \\
& \Delta_{\mathrm{y}} \text { (experimental) }=1.40 \mathrm{in} .(35.6 \mathrm{~mm})
\end{aligned}
$$

The loading history for the shear specimen is shown in Fig. 3.22. Note that the first excursion was to the west instead of to the east as with the flexure column.

\subsubsection{DUCITILITY FACTOR $=1$, CYCLE 1}

The first flexural crack, $2 \mathrm{ft}$. above the base, was noted on the west side at a lateral load of $191.5 \mathrm{kip}$ on the excursion west. Hairline flexural cracks running from north to south were observed on the west side up to a height of 8 ft. 10 in. (2692 mm). A crack at the column/base joint on the west side was noted. Hairline flexural cracks on the north and south faces of the column footing at approximately mid-height of the footing were also noted. Fig. 3.23 shows a view of the west side of the column.

First cracking of the east side of the column occurred at a lateral load of 140 kip on the excursion east. Only flexural cracks were noted on the east side of the column during this excursion up to a height of $9 \mathrm{ft}$. 3 in. (2819 $\mathrm{mm}$ ). The crack pattern is shown in Fig. 3.24.

The measured displacements at lateral load equal to $400 \mathrm{kip}$ were 1.144 in. $(29.1 \mathrm{~mm})$ on the excursion west and $0.951 \mathrm{in.}(24.2 \mathrm{~mm})$ on the excursion east. The yield displacement was therefore equal to $1.40 \mathrm{in}$. (35.6 mm).

$$
\Delta_{y}=\frac{4(1.144+0.951)}{3} \text { in. }
$$




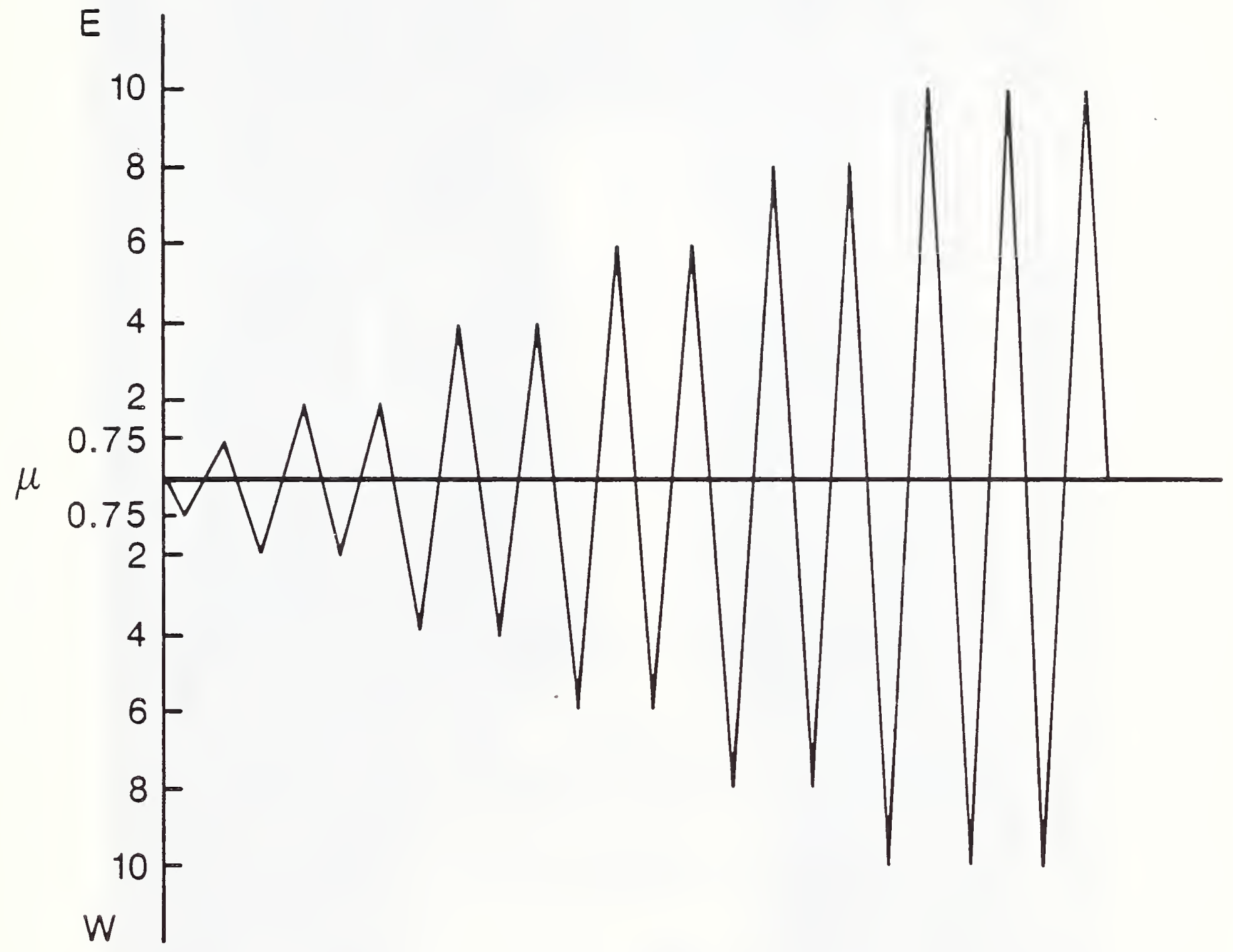

Figure 3.22 Loading History for Shear Column 


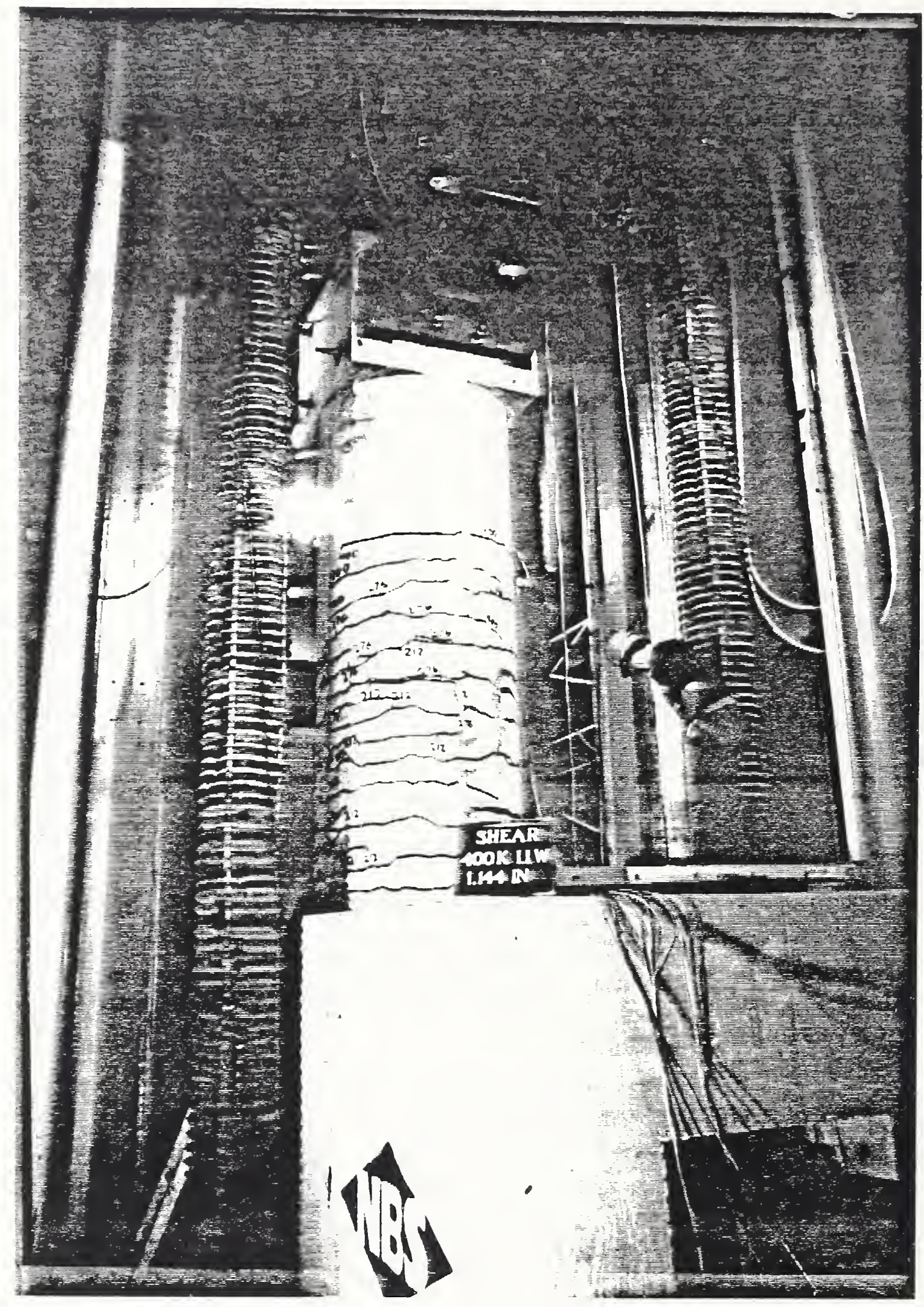

Figure 3.23: Shear Specimen

Displacement $=1 \Delta y ;$ Cycle 1 West

View of West Side of Column 


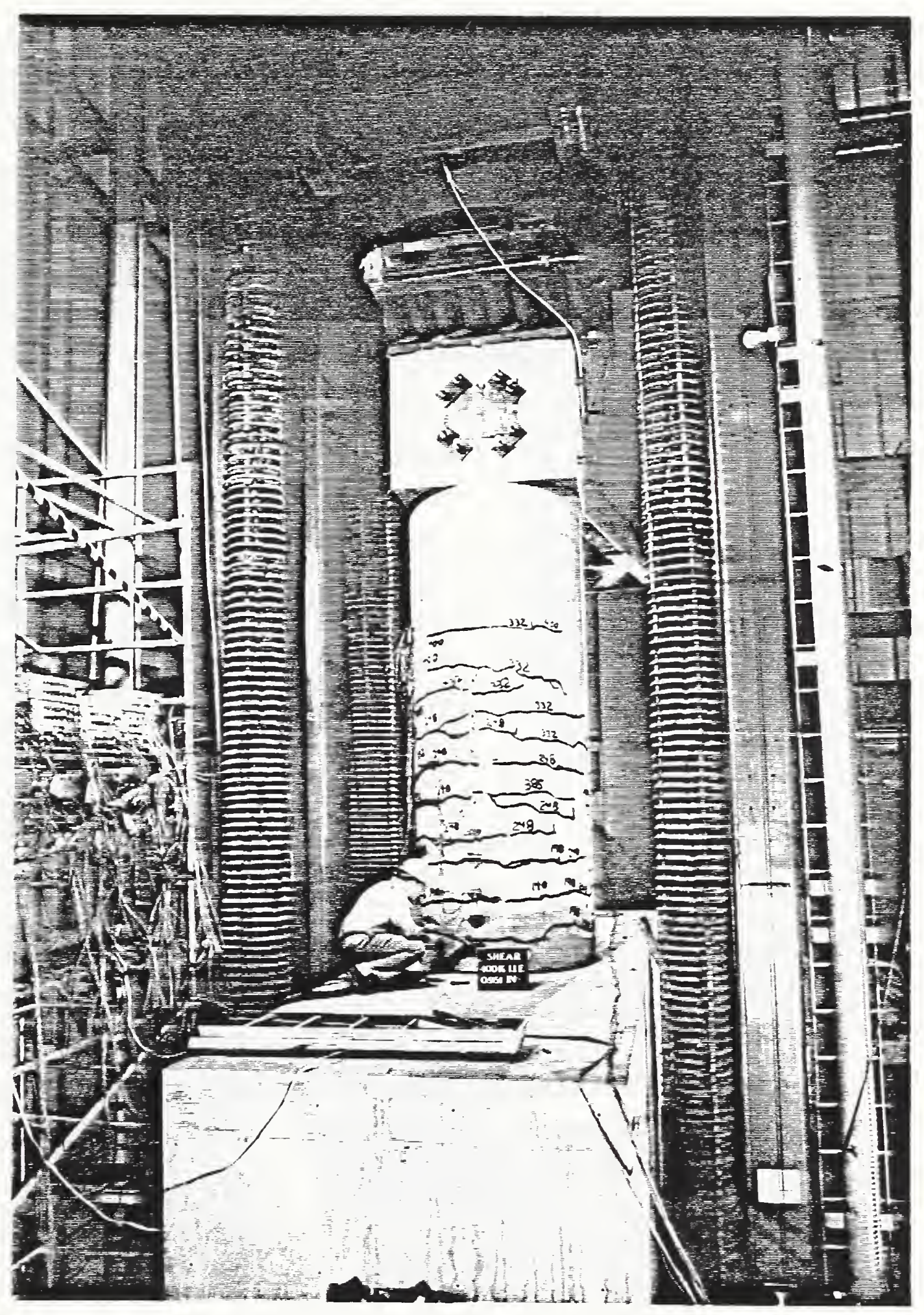

Figure 3.24: Shear Specimen

Displacement $=1 \Delta y$; Cycle 1 East

View of East Side of Column 
Note that the affect of friction bewteen the hilman rollers and the track system was not taken into account in the $400 \mathrm{kip}$ ( $1779.3 \mathrm{kN}$ ) lateral load. This was done so that this test would be consistent with the flexure test.

\subsubsection{DUCTILITY FACTOR $=2$, CYCLES 2 AND 3}

Cycle 2: Extensive cracking was noted during this cycle. Flexural cracking extended to the top of the column on both the east and west faces. Formation of diagonal cracks at approximately $45^{\circ}$ from horizontal on the north and south faces were observed. The extent of the flexural cracks on the west face and shear cracks on the north face are shown in Fig. 3.25.

Cycle 3: Some additional flexural and shear cracks were observed on the north and south faces. However, no significant change in crack pattern was noted. Fig. 3.26 shows a view of the east face of the column. An overall view of the test set-up looking east is shown in Fig. 3.27 .

\section{3 .4 DUCTILITY FACTOR $=4$, CYCLES 4 AND 5}

Cycle 4: Spalling of the east side of the column was noted at a lateral load of approximately $578 \mathrm{kip}$. The spall area located on the southeast face was approximately 10 in. $\times 23$ in. (W $x$ H) at a height of about 24 in. above the column base. Maximum crackwidths on the west face was approximately 0.2 in.

On the excursion east, flexural cracks were noted on the east and west faces in the upper third of the column. More shear cracking was also noted on the north and south faces. Spalling of the west face of the column at approximately 9 in. above the base also occurred during this excursion. The spall area was approximately $4.5 \mathrm{ft}$. in the east-west direction. Some additional spalling occurred on the east face. The spall areas on the east and west faces are shown in Figs. 3.28 and 3.29 respectively. Fig. 3.30 shows an overall view of the test set-up looking west. 


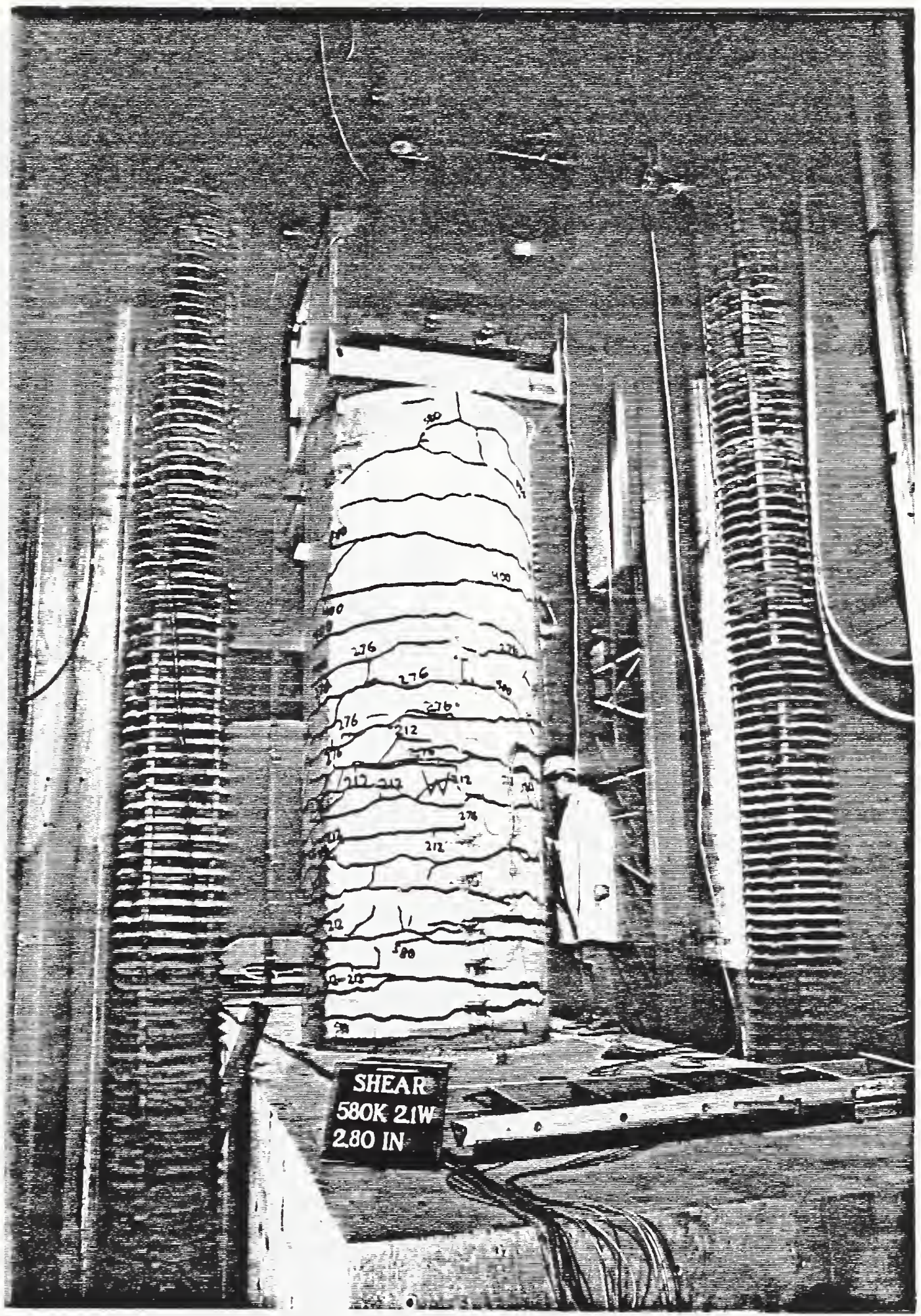

Figure 3.25: Shear Specimen

Displacement $=2 \Delta y$; Cycle 1 West

View of West Side of Column 


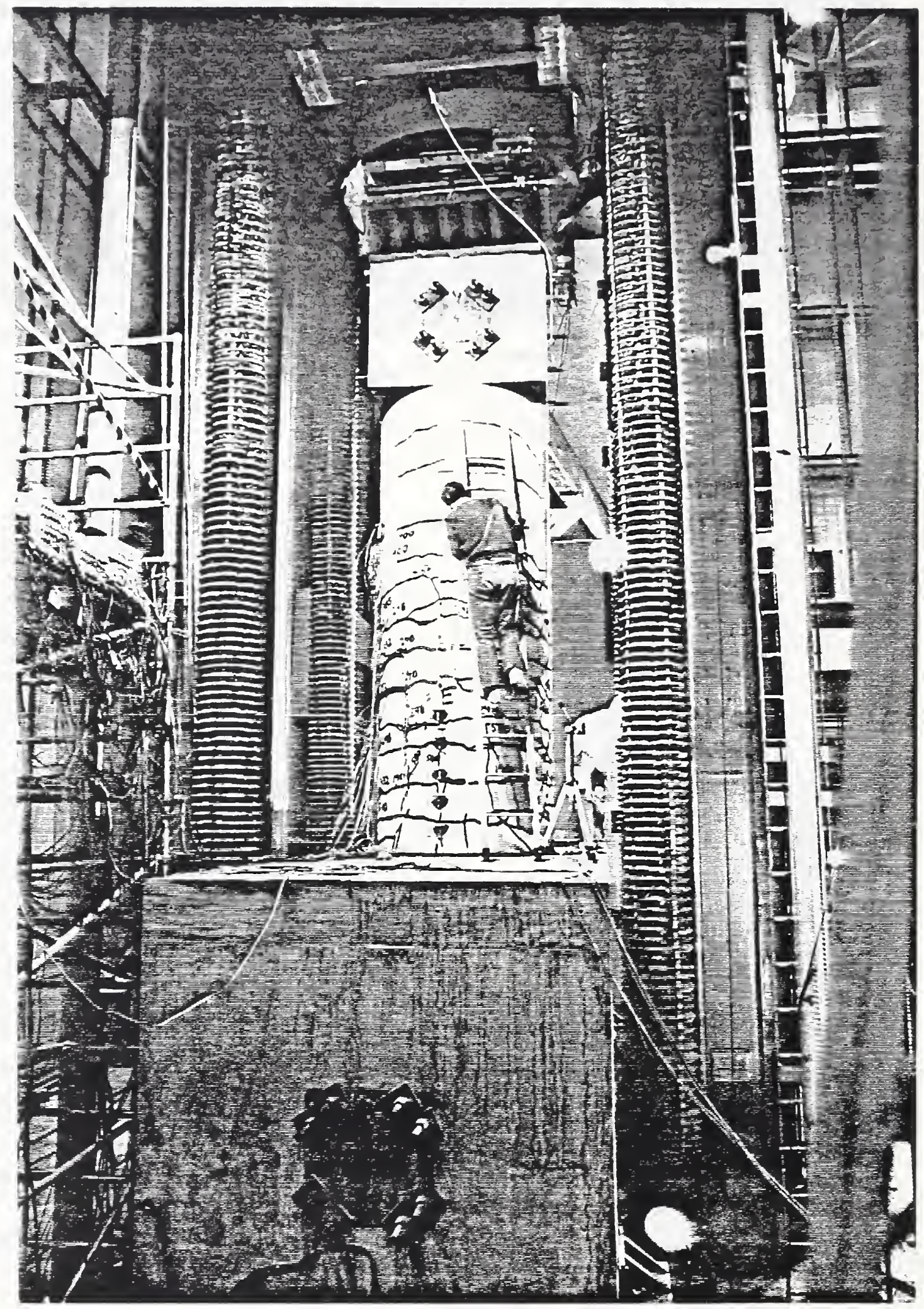

Figure 3.26: Shear Specimen

Displacement $=2 \Delta y ;$ Cycle 2 East

View of East Side of Column 


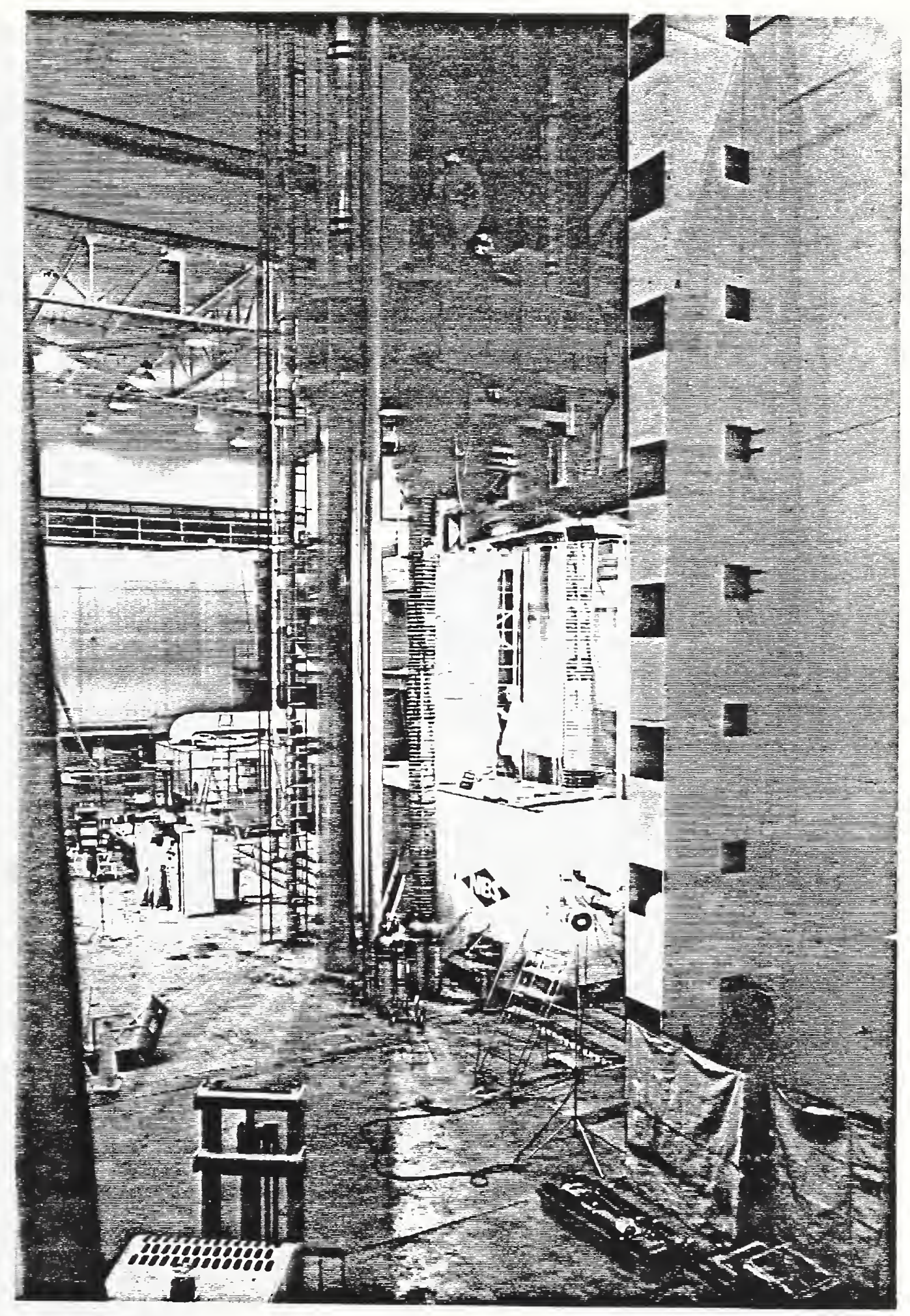

Figure 3.27 Shear Specimen

Displacement $=2 \Delta y$; Cycle 2 East

Overall View of Test and West Side of Column. 


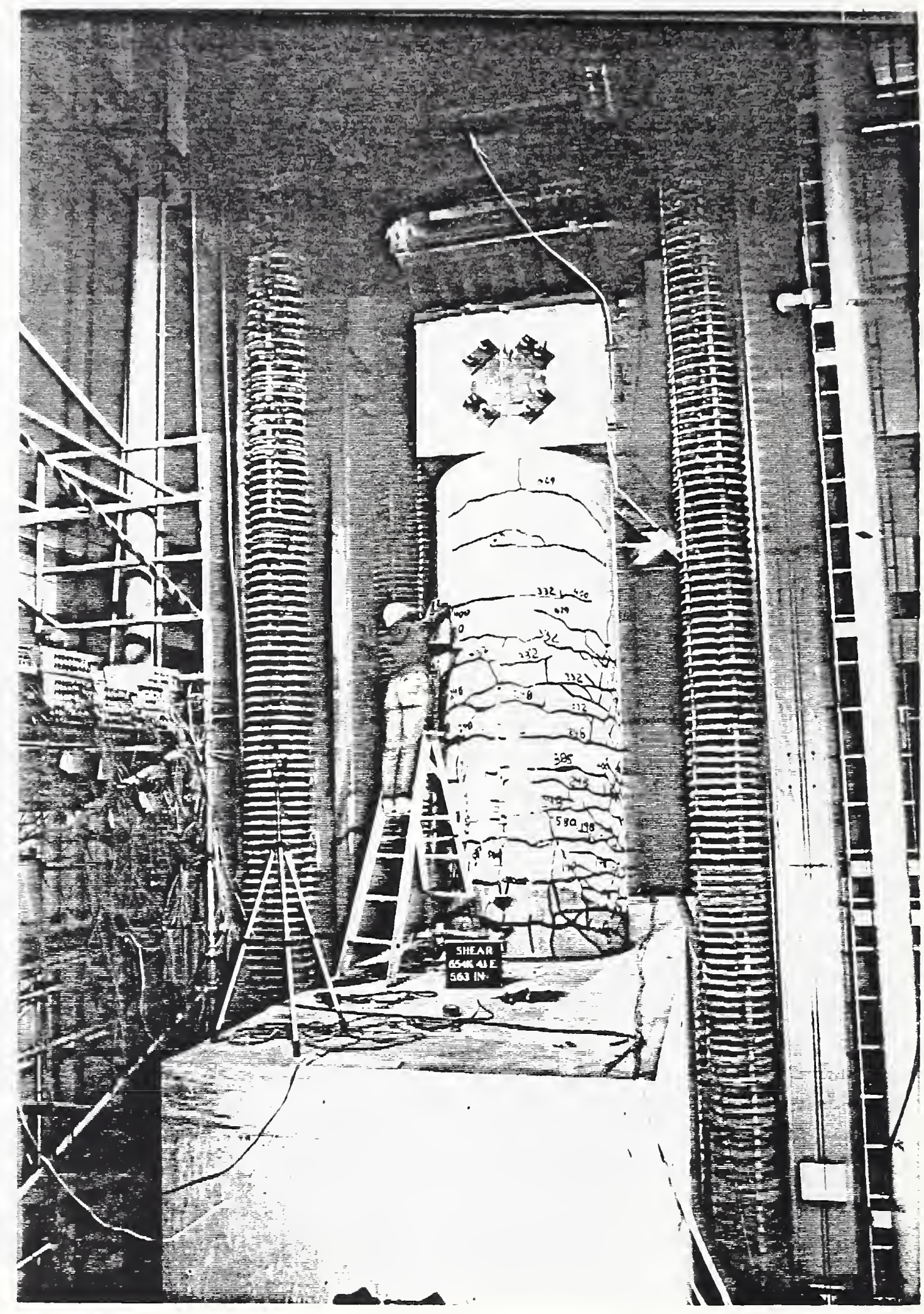

Figure 3.28: Shear Specimen

Displacement $=4 \Delta y$; Cycle 1 East

View of East Side of Column 


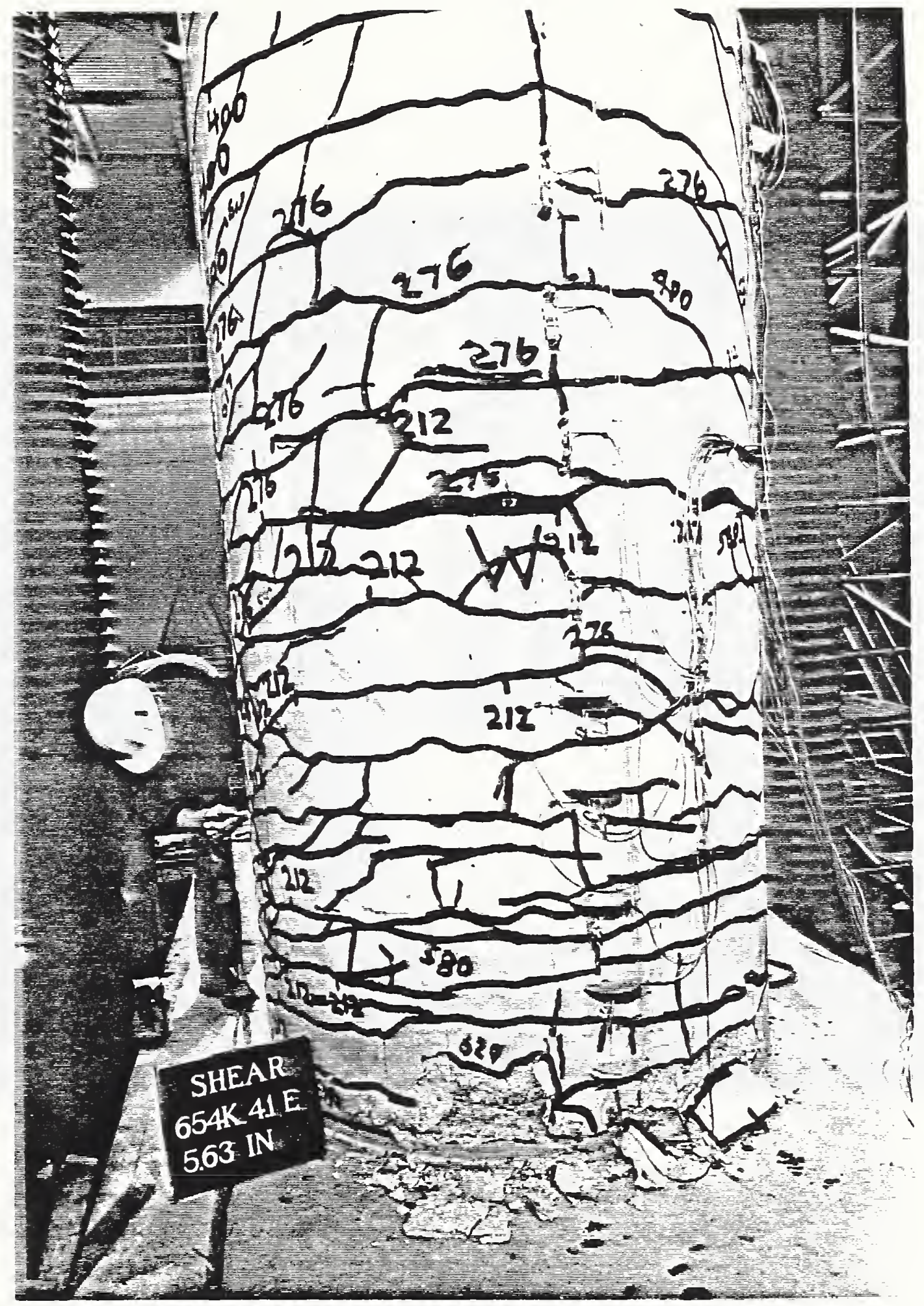

Figure 3.29: Shear Specimen

Displacement $=4 \Delta y ;$ Cycle 1 East

View of West Side of Column 


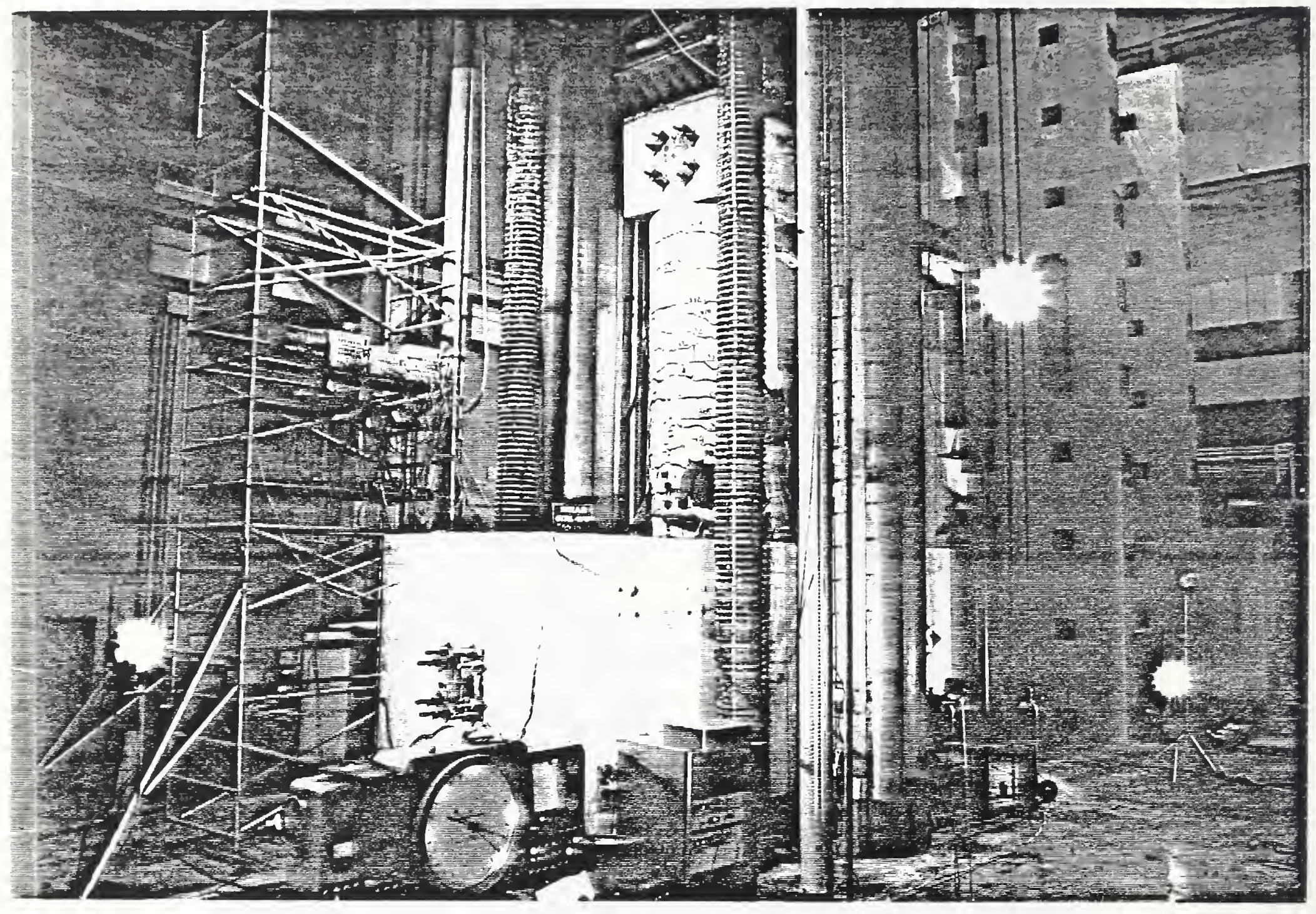

Figure 3.30: Shear Specimen

Displacement $=4 \Delta y$; Cycle 1 West

Overall View of East Side of Column 
Cycle 5: No change in crack pattern was noted.

\section{3 .5 DUCTILITY FACTOR $=6$, CYCLES 6 AND 7}

Cycle 6: Spalling of the east and west faces of the column was noted. Spirals at heights of 15,10 and 7 (59.1, 39.4,27.6 mm) inches above the top of the footing were exposed on the west side due to the spalling. Spirals on the east side were exposed at heights of $22,20,17,14,12,8$, and 6 (86.6, $78.7,66.9,55.1,47.2,31.5$, and $23.6 \mathrm{~mm}$ ) inches above the top of the footing. The spalling disconnected some to the cables to the clip gages on the east side.

The spall area on the west side was approximately 15 in. $x 54$ in. (381 mm $\mathrm{x}$ $1372 \mathrm{~mm})$. The east face had spalled in 4 different locations. Fig. 3.31 shows the spall area on the west face of the column. Some additional shear cracks were noted on the east and west faces of the column.

Extensive flexural cracking of the footing on the north and south faces was noted. The crack patterns on these two faces were almost identical. Some of these cracks were extensions of the radial cracks on the top of the footing. Additional radial cracks on top of the footing on both the east and west sides were also noted.

Cycle 7: Additional cracks of the footing were noted. No additional flexure or shear cracks were noted. A significantly large piece of cover concrete on the southeast side of the column was held in place only by the ties used in construction of the steel cage. Fig. 3.32 shows the spall areas on the east side and Fig. 3.33 shows the piece of concrete ready to spall off. The cracking of the north face of the footing and the north face of the column is shown in Fig. 3.34 


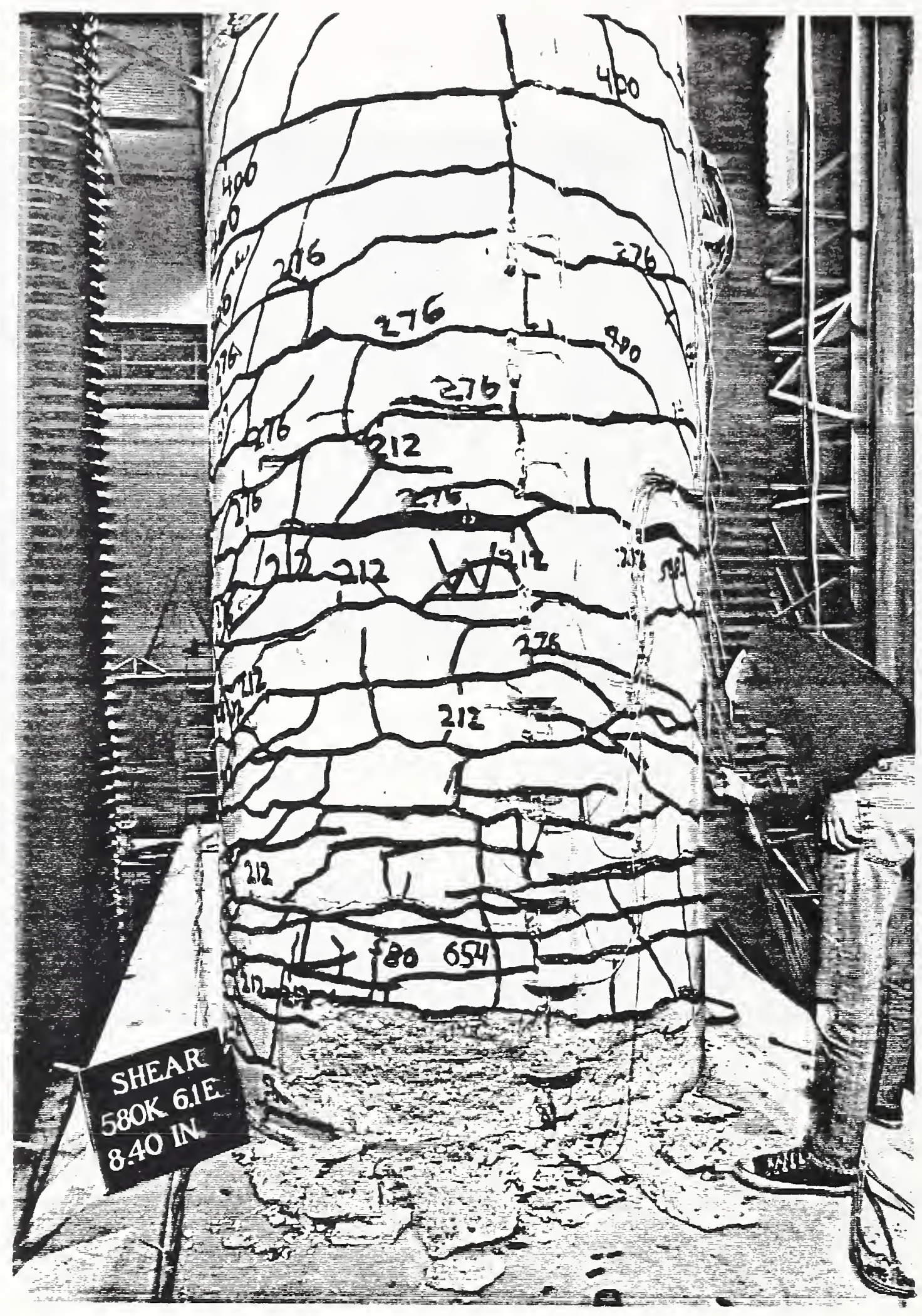

Figure 3.31: Shear Specimen

Displacement $=6 \Delta y ;$ Cycle 1 East

View of West Side of Column 


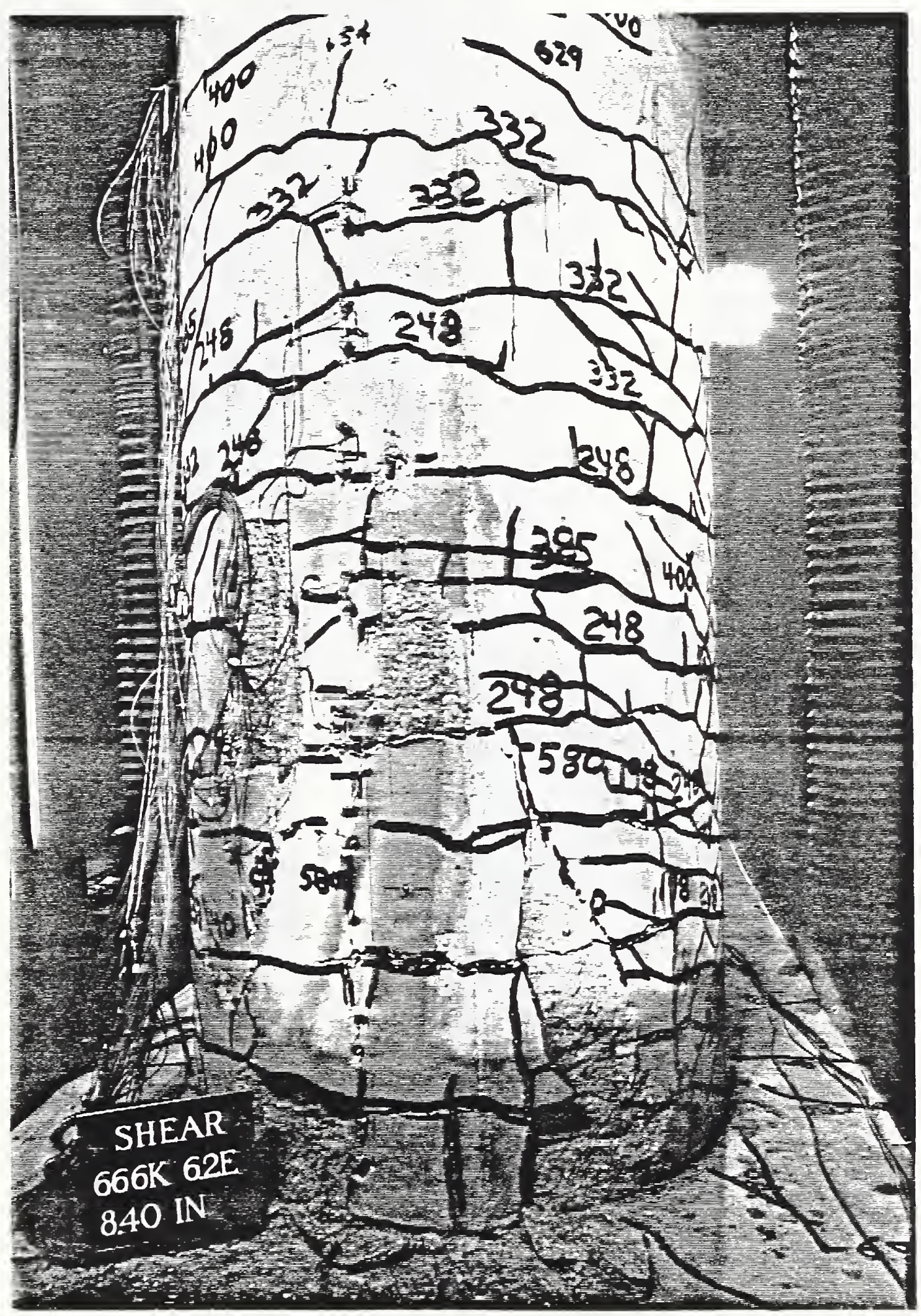

Figure 3.32: Shear Specimen

Displacement $=6 \Delta y ;$ Cycle 2 East

View of East Side of Column 


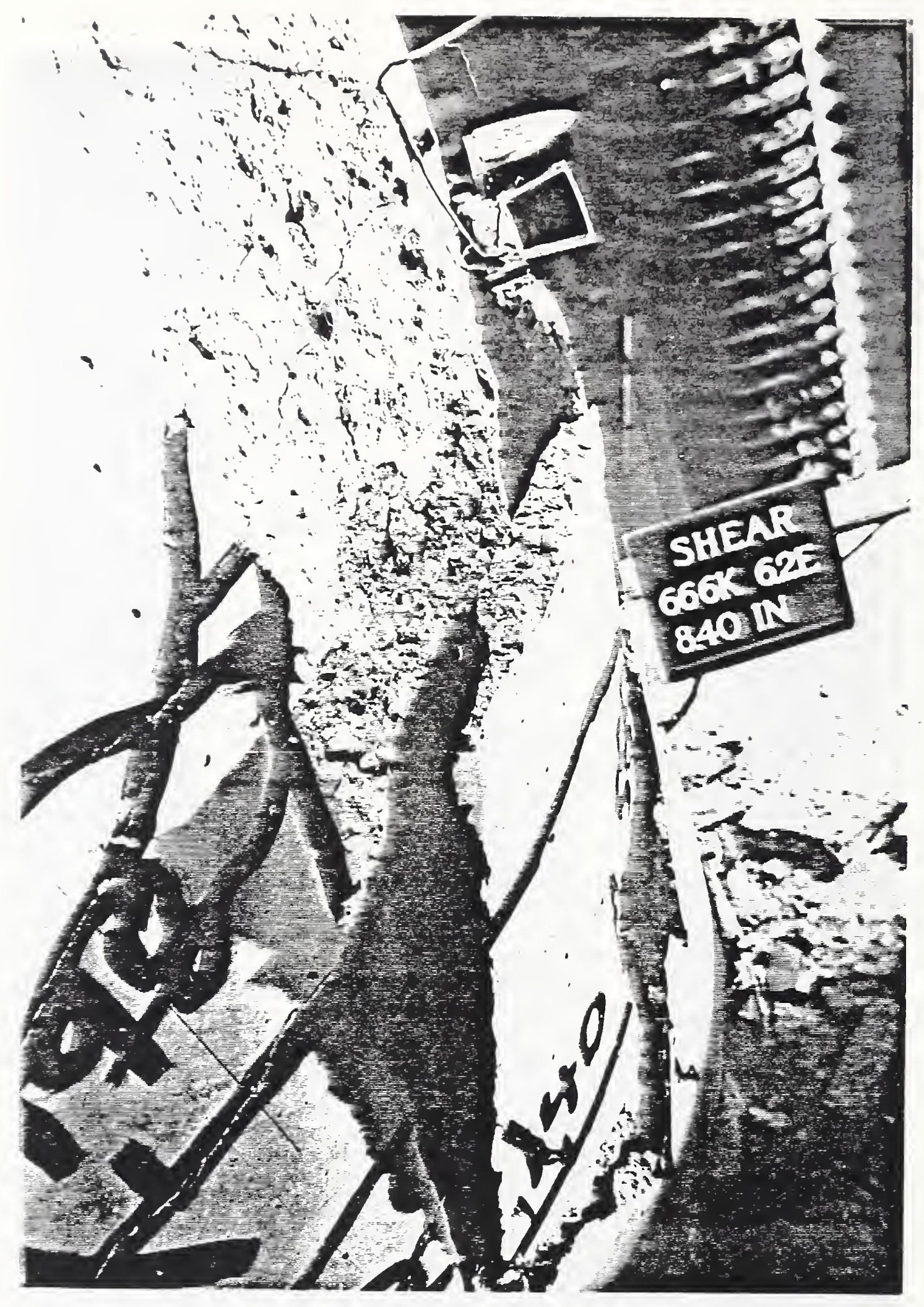

Figure 3.33: Shear Specimen

Displacement $=6 \Delta y ;$ Cycle 2 East

View of West Side of Column

Showing Spalled Concrete Section. 


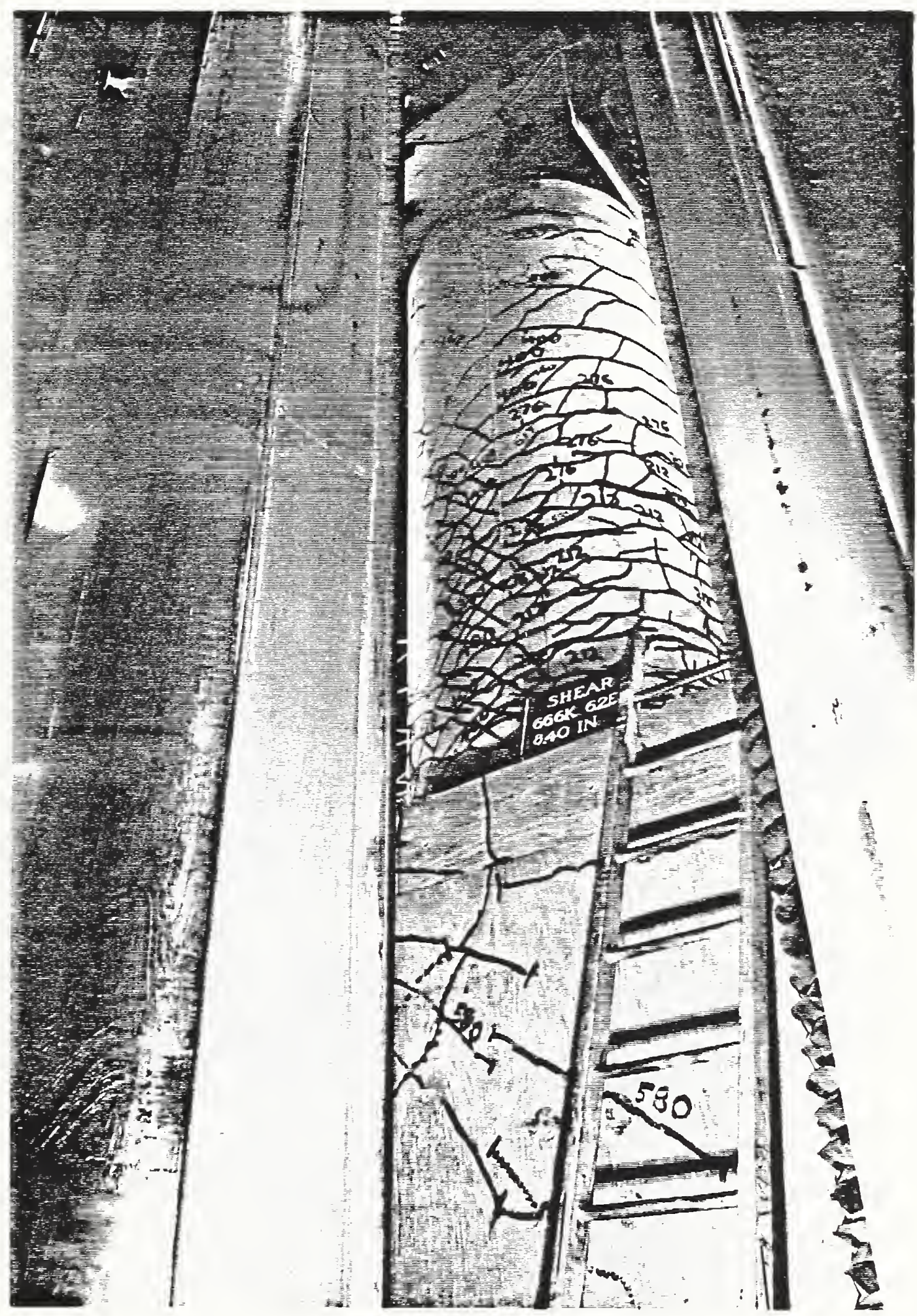

Figure 3.34: Shear Specimen

Displacement $=6 \Delta y ;$ Cycle 2 East

View of North Side of Column

Showing Extent of Diagonal Cracking. 


\subsubsection{DUCTILITY FACTOR $=8$, CYCLES 8 AND 9}

Cycle 8: On the excursion west, a muffled bang was heard. No visible signs of spiral or vertical bar fracture were noted due to the concrete obscuring most of the bars. However, the spirals on the west side of the column appear to have buldged out. More shear cracks were noted on the north and south. faces of the column. Spalling of the east and west sides of the column. continued. Propagation of the radial cracks on the top of the footing and cracks on the north face of the footing occurred. Figs. 3.35 and 3.36 show the spall areas of the east and west side respectively.

Cycle 9: No significant change in crack pattern noted.

\subsubsection{DUCTILITY FACTOR $=10$, CYCLES 10,11 AND 12}

Cycle 10: Some spalling occurred with no significant change in crack pattern on the excursion west. Two loud bangs and a softer bang was heard on the excursion east. These bangs appear to originate from the east side of the column. Again, no visible evidence of whether the bangs were spiral or vertical bars fracturing as the concrete core was still pretty much intact.

On the excursion back to center position from the east excursion, a vertical bar on the west side of the column could to be seen to have fractured at a height of $18 \mathrm{in}$. above the base. The spall area on the east side is approximately $60 \times 53$ in. (1524 x $1346 \mathrm{~mm}$ ) and the spall area on the west side is approximately $32 \times 53$ in. $(813 \times 1346 \mathrm{~mm})$. Some gauging of the footing at the column-base joint was noted on the west side and is shown in Fig. 3.37. The extensive spalling of the east face of the column is shown in Fig. 3.38 .

Cycle 11: No bangs were heard on the excursion west. On the excursion east, several bangs were heard. A spiral on the northeast side at a height of $4 \mathrm{ft}$. 6 in. (1372 $\mathrm{mm}$ ) fractured. The vertical bar directly behind the fractured spiral also fractured. The location of the fracture was $5 \mathrm{ft}$. (1524 mm) 


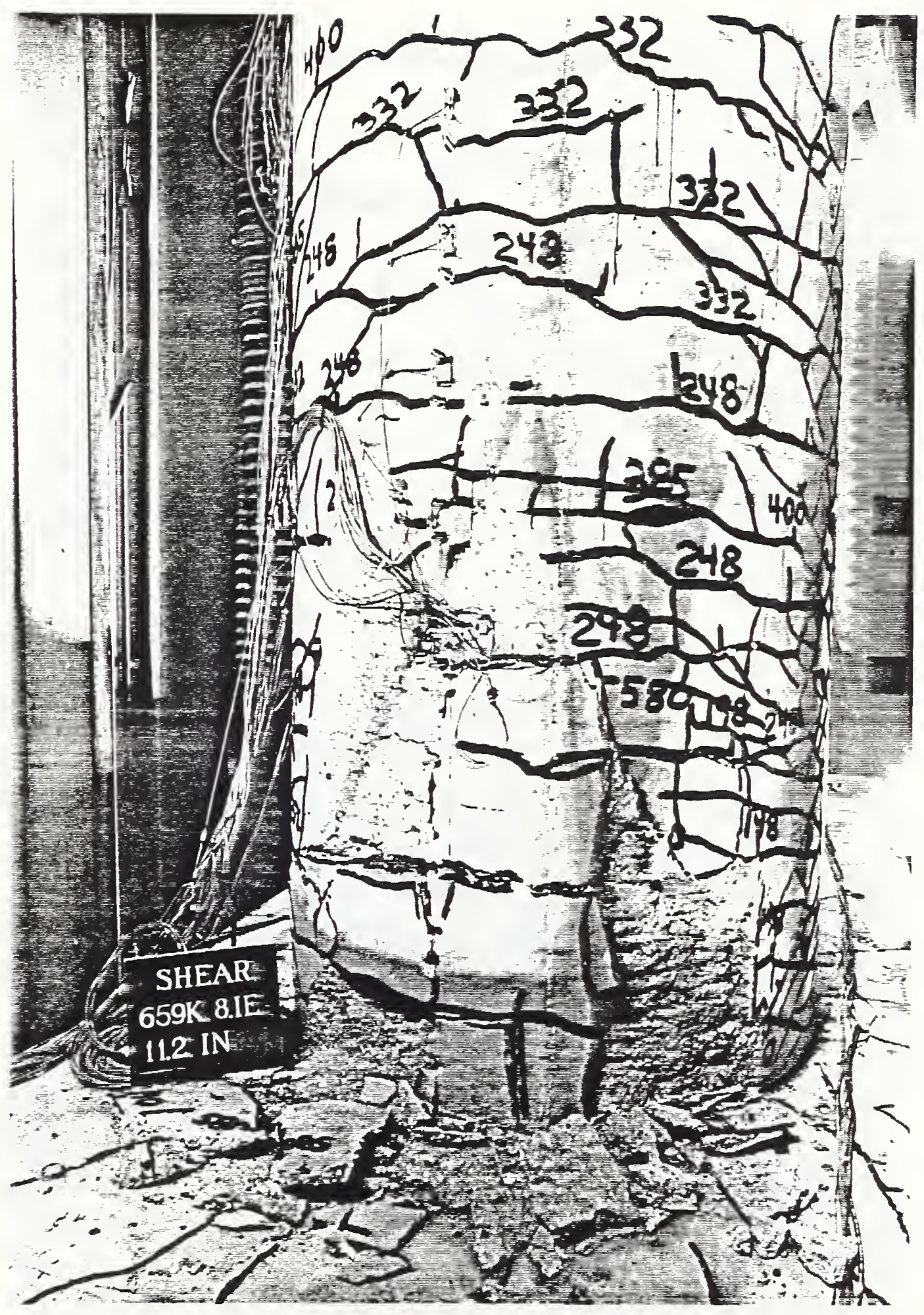

Figure 3.35: Shear Specimen

Displacement $=8 \Delta y ;$ Cycle 1 East

View of East Side of Column 


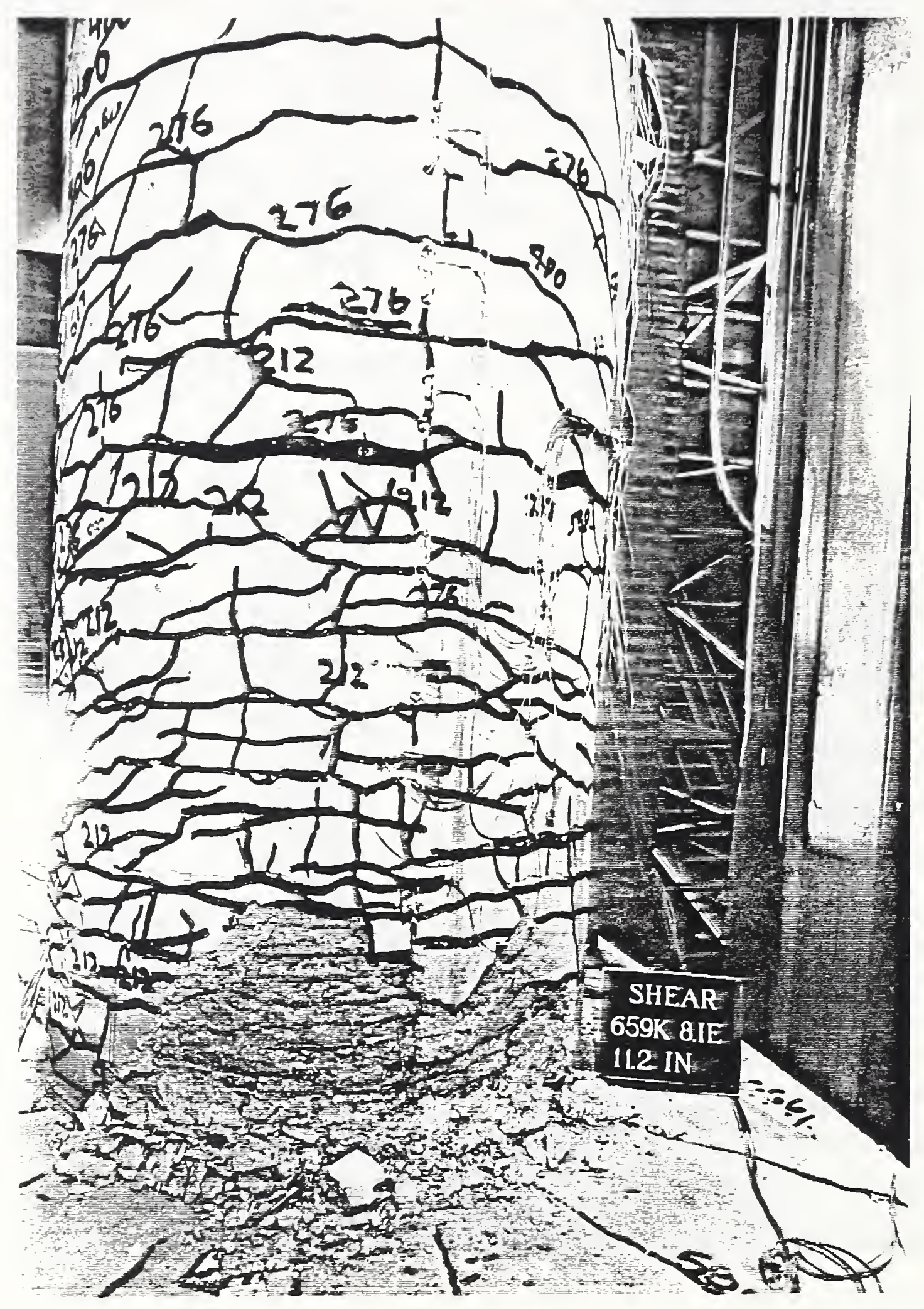

Figure 3.36: Shear Specimen

Displacement $=8 \Delta y$; Cycle 1 East

View of West Side of Column 


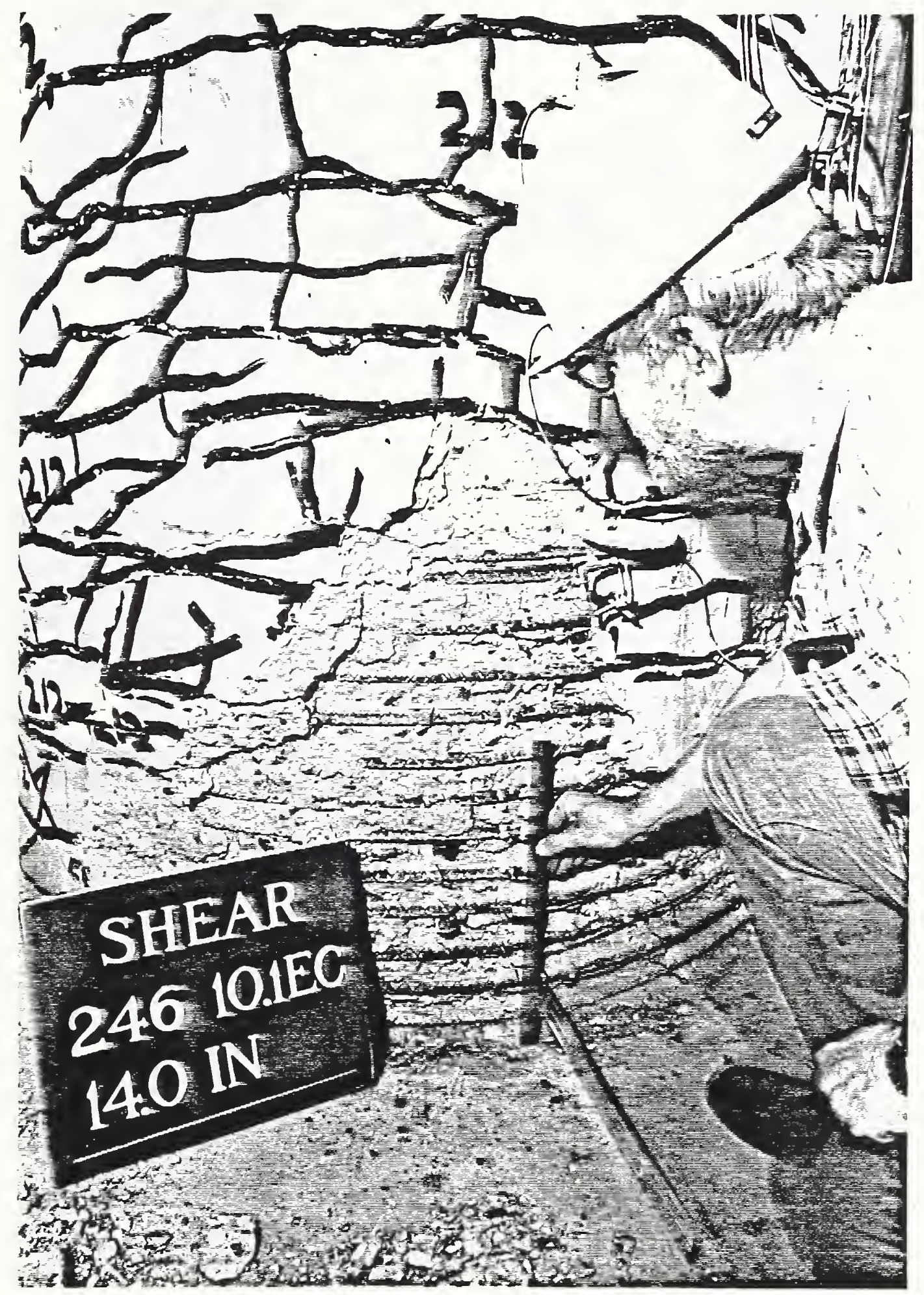

Figure 3.37: Shear Specimen

Displacement $=10 \Delta y$; Cycle 1 East

View of West Side of Column 


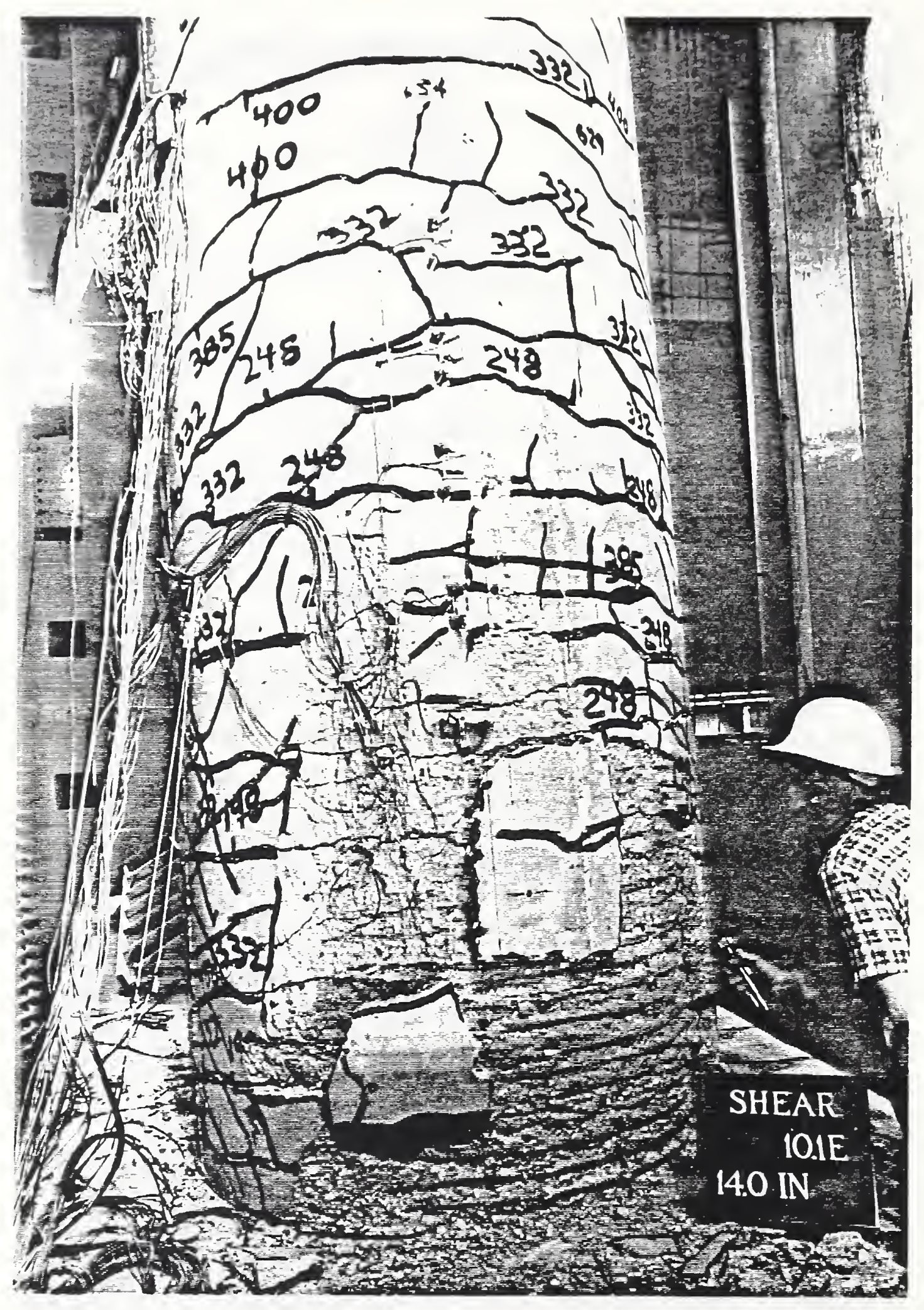

Figure 3.38: Shear Specimen

Displacement $=10 \Delta y ;$ Cycle 1 East

View of East Side of Column 
above the base. A spiral on the west side approximately 8 in. (203 mm) above the base could be seen to have fractured. Extensive buckling of the vertical bars on the west was noted.

On the excursion back to center from the east, several bangs were heard. Two vertical bars north of the east-west axis fractured at approximately 5 in. $(127 \mathrm{~mm}$ ) above the base. A third bar on the west side fractured at a height of $14 \mathrm{in.} \mathrm{(356} \mathrm{mm)} \mathrm{above} \mathrm{the} \mathrm{base.} \mathrm{A} \mathrm{total} \mathrm{of} 4$ vertical bars and a spiral could be seen to have fractured on the west and a total of one vertical bar and a spiral fracture were visible on the east side. The buckled and fractured bars on the west is shown in Fig. 3.39. An overall view of the column is shown in Fig. 3.40 .

Cycle 12: Two bangs which seemed to originate from the west side were heard on the excursion west. However, no additional bar fractures were however visible. The concrete core was observed to be breaking up.

On the excursion east, several loud bangs were heard from the east and west sides. At the end of the eastward excursion, a total of 6 vertical bars and one spiral hoop were observed to have fractured on the west side. A total of 5 vertical bars and a spiral on the east side were also fractured. All but one of the longitudinal fractures occurred approximately 9 in. (229 mm) above the base. The unusual bar failure was at a height of $5 \mathrm{ft}$. ( $1524 \mathrm{~mm}$ ) above the base approximately 20 degrees counterclockwise (second bar) from centerline (maximum fiber distance from neutral axis). This was a clean fracture with no signs of prior yielding. On closer inspection a tack weld was discovered on the inside face of the bar where a temporary support frame had been attached during erection of the column reinforcement cage prior to casting. Because this failure did not occur until after buckling-induced fracture of the 11 longitudinal bars mentioned above it is felt that this had no adverse affect on the test data. However, it does underscore the need to avoid weldments, particularly involving reinforcing bar, in the potential plastic hinge region. 
On the return excursion to center, a soft bang was heard. At center position, the following bars were noted to have fractured:

Bar location

(referenced to the eastmost/ westmost bar)

East:

1 bar south eastmost

1 bar north

2 bars north

3 bars north

4 bars north

Spiral, 4 bars north
Height of fracture, in. (mm) above the base

West:

3 bars south

9 (229)

2 bars south

$10(254)$

1 bar south

$13(330)$

westmost

11 (279)

$6 \quad(152)$

8 (203)

9 (229)

$53(1346)$

52 (1321)

48 (1219)

1 bar north

2 bars north

19 (483)

4 (102)

4 (102)

3 bars north

$4(102)$

Spiral, 2 bars north

4 (102)

Final spall areas were approximately $5 \mathrm{ft}$ x $5 \mathrm{ft}$ (1524 x $1524 \mathrm{~mm}$ ) on the east side and $2 \mathrm{ft} .9$ in. $x 5 \mathrm{ft} .6 \mathrm{in.}(838 \times 1676 \mathrm{~mm})$ on the west side. 


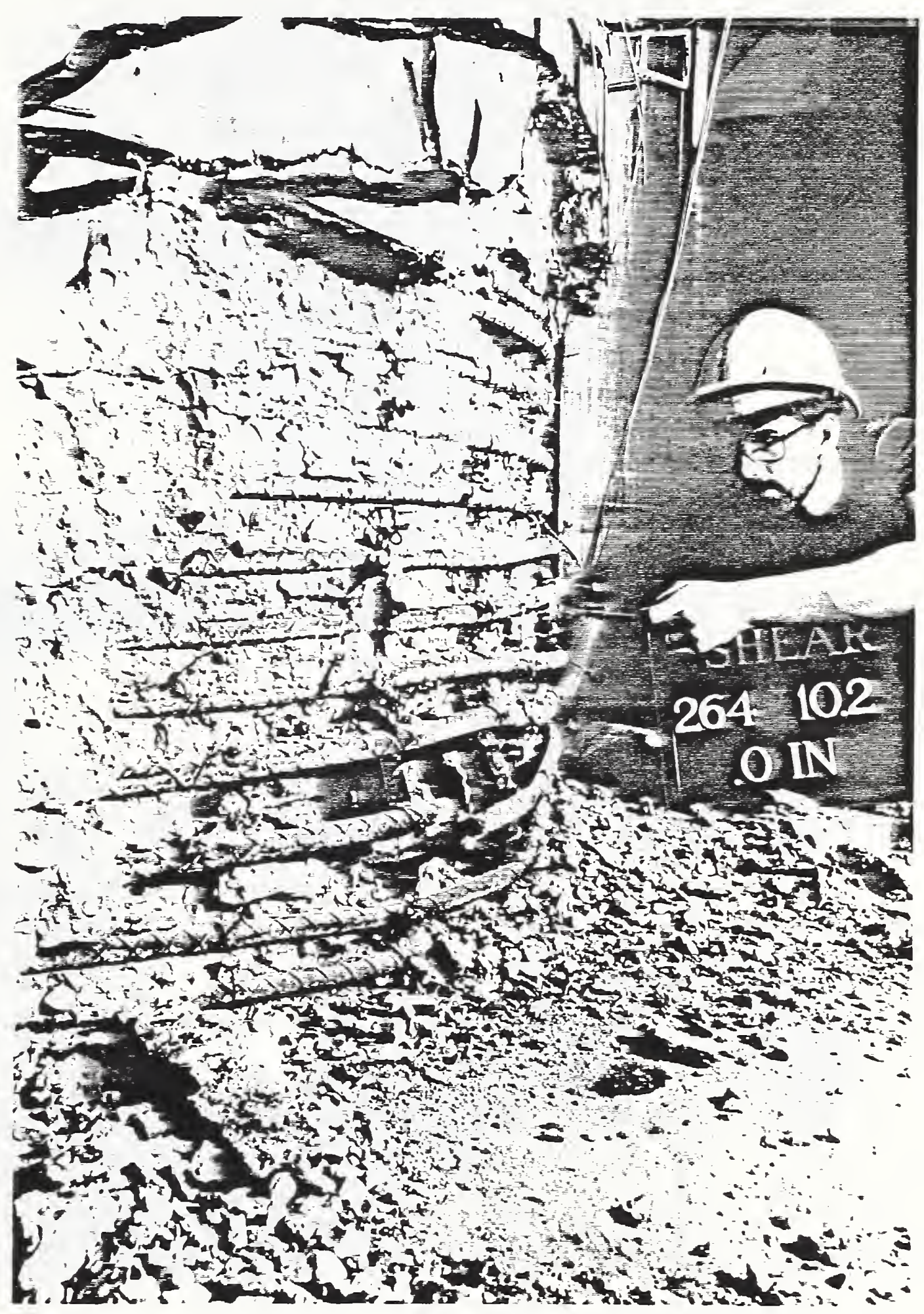

Figure 3.39: Shear Specimen

Displacement $=10 \Delta y ;$ Cycle 2 East

View of West Side of Column 


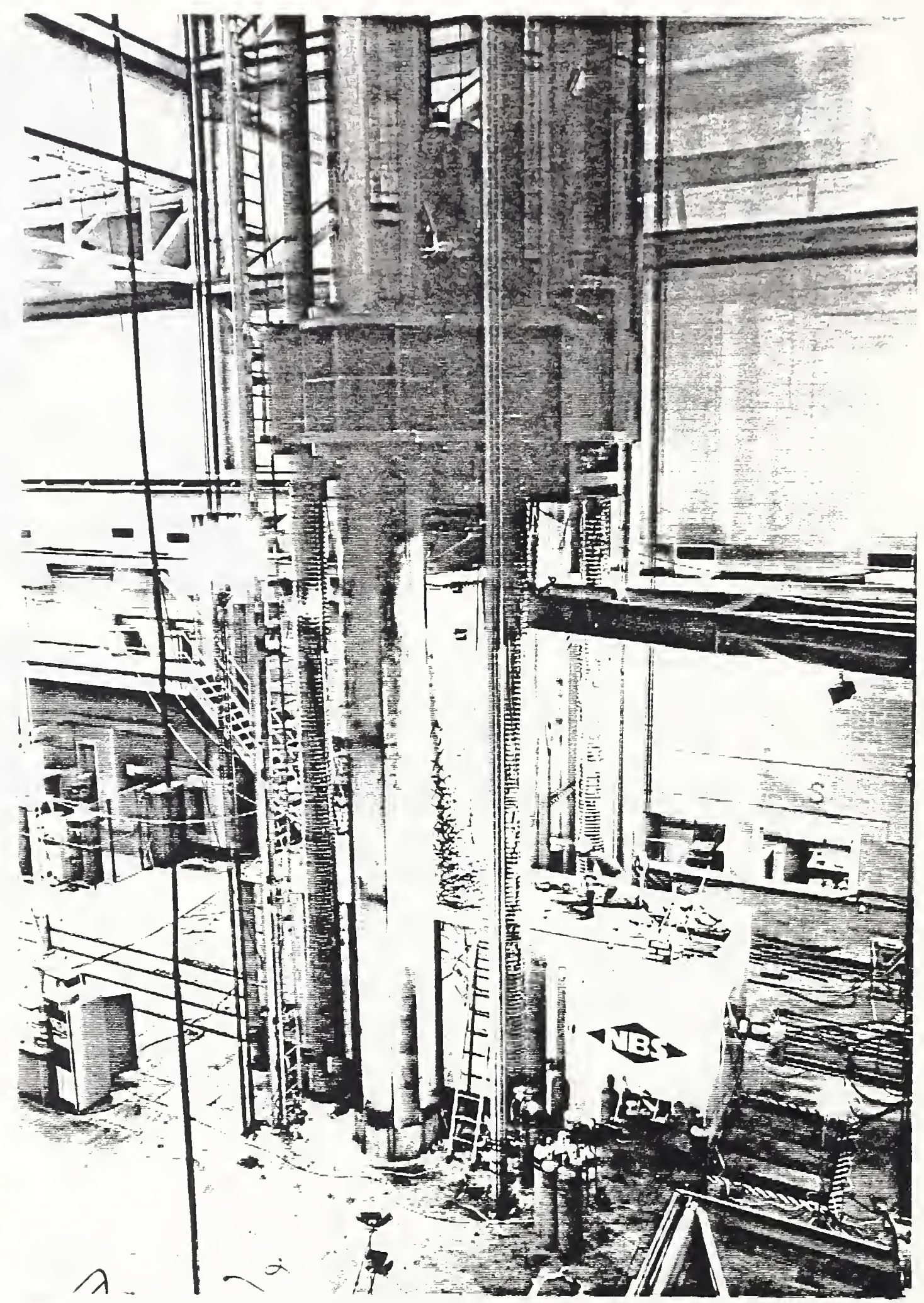

Figure 3.40: Shear Specimen

Displacement $=10 \Delta y$; Cycle 2 West

Overall View of Test; West Side

is to Right of Column. 


\subsection{DISCUSSION OF RESULTS}

There are several traditional methods of analyzing results of cyclic load tests on reinforced concrete structures. These involve presentations of load-deflection histories, longitudinal and confining steel strain profiles, and comparisons of theoretical and experimental determinations of plastic hinge lengths. All of these traditional methods are presented in this chapter. The format that is used is the same as that used in references 7 , 15, 16, and 17 in an effort to be compatible with previous work in the field. The primary emphasis of this chapter, however, will be to address the two principal questions posed at the beginning of the project:

1) How effective are recent CALTRANS bridge column detailing procedures for resisting seismic loads?

2) Can full-scale bridge column behavior be predicted from model specimens?

Special attention is given to the study of cyclic inelastic strain energy dissipation as a means of characterizing overall structural performance under seismic loading. It will be shown later in this chapter that this appears to provide the best measure of similitude between model and prototype behavior.

Tables 4.1 through 4.3 present details of the longitudinal and transverse reinforcement, as well as calculated specimen strengths for both the fullscale and 1/6-scale model tests. Representative stress-strain curves for the various reinforcing steels are presented in Appendix B. Interaction diagrams for both model and prototype specimens are presented in Figures 4.1 and 4.2. The two different diagrams superimposed in Figure 4.1 resulted from differing concrete strengths for the full-scale shear and flexure columns. However, for axial loads significantly below the balance point both curves coincide and thus both full-scale tests are represented by the same point.

\subsection{Flexure Column Moments and Displacements}

As described in Chapter 2 there were two approaches possible for the determination of column base moment and shear. Due to the early failure of the flatcell electronics during the full scale flexure test and a power outage 
Table 4.1 Details of the Transverse Reinforcement and Concrete for Full-Scale and 1/6-Scale Model Specimens.

\begin{tabular}{|c|c|c|c|c|c|c|c|c|c|}
\hline \multirow[b]{2}{*}{ Specimen } & \multicolumn{2}{|c|}{ Plain Conc. } & \multicolumn{4}{|c|}{ Transverse Reinforcing } & \multicolumn{3}{|c|}{ Confined Concrete } \\
\hline & $\begin{array}{c}f^{\prime} c \\
(p s i)\end{array}$ & $\begin{array}{c}E_{C} \\
(k s i)\end{array}$ & $\begin{array}{l}\text { Bar Dia. } \\
\text { (in.) }\end{array}$ & $\begin{array}{c}\text { Spacing } \\
\text { (in.) }\end{array}$ & $\int_{s}$ & $\begin{array}{c}f_{y h} \\
(k s i)\end{array}$ & $\begin{array}{c}\mathrm{f}_{1} \\
(\mathrm{ksi})\end{array}$ & $\begin{array}{l}f^{\prime} c c \\
(p s i)\end{array}$ & $\epsilon_{\max }$ \\
\hline $\mathrm{N} 1$ & 3.49 & 3367 & 0.120 & 0.350 & .0145 & 64.0 & .454 & 5.40 & .023 \\
\hline N2 & 3.35 & 3299 & 0.120 & 0.350 & .0145 & 64.0 & .454 & 5.25 & .023 \\
\hline N4 & 3.54 & 3391 & 0.120 & 0.350 & .0145 & 64.0 & .454 & 5.45 & .023 \\
\hline N5 & 3.53 & 3387 & $0: 120$ & 0.350 & .0145 & 64.0 & .454 & 5.45 & .023 \\
\hline SHEAR & 4.98 & 4022 & 0.750 & 2.125 & .0152 & $* 63.1$ & .457 & 5.93 & .024 \\
\hline N3 & 3.68 & 3458 & 0.106 & 0.570 & .0069 & 69.0 & .228 & 4.66 & .010 \\
\hline N6 & 3.38 & 3352 & 0.106 & 0.570 & .0069 & 69.0 & .228 & 4.35 & .010 \\
\hline FLEX & 5.20 & 4110 & 0.625 & 3.500 & .0065 & 71.5 & .222 & 5.66 & .014 \\
\hline
\end{tabular}

Where

$$
\begin{aligned}
& f^{\prime} c=\text { compressive strength of concrete at time of testing. } \\
& E_{c}=\text { modulus of elasticity of concrete } \\
& \int_{s}=\text { volumetric ratio of spiral reinforcement to the confined core } \\
& f_{y h}=\text { yield strength of spiral reinforcement } \\
& f_{l}=\text { effective lateral confining pressure on concrete } \\
& f^{\prime}{ }_{c c}=\text { maximum strength of confined concrete } \\
& \epsilon_{\max }=\text { maximum allowable concrete strain }
\end{aligned}
$$

Equations used for determining confined concrete properties are presented in Reference 15.

* This value was obtained from Fig. C.5 using a 0.002 offset. 
Table 4.2: Longitudinal Reinforcing Steel Details for Full-Scale and 1/6-Scale Model Bridge Column Specimens.

\begin{tabular}{|c|c|c|c|c|c|c|c|c|c|}
\hline Specimen & $\frac{f_{y}}{(k s i)}$ & $\mathrm{f}_{\text {su }}$ & $\begin{array}{l}\text { Bar Dia. } \\
\text { (in.) }\end{array}$ & $\begin{array}{l}\text { number } \\
\text { of bars }\end{array}$ & $\int$ & $\varepsilon_{s h}$ & $-\varepsilon S u$ & $\begin{array}{c}E_{S} \\
(k S i)\end{array}$ & $\begin{array}{c}E_{s h} \\
(k s i)\end{array}$ \\
\hline Models & 64.7 & 78.2 & 0.276 & 25 & .02 & .0128 & .090 & 29615 & 802 \\
\hline $\begin{array}{l}\text { Full- } \\
\text { Scale }\end{array}$ & 68.9 & 103.6 & 1.693 & 25 & .02 & .0122 & .155 & 27438 & 1454 \\
\hline
\end{tabular}

Where

$\mathrm{f}_{\mathrm{y}}=$ yield strength of longitudinal reinforcing steel

$\mathrm{f}_{\mathrm{su}}^{\mathrm{y}}=\mathrm{ultimate}$ strength of longitudinal reinforcing steel

$\int^{\text {su }}=$ volumetric ratio of spiral reinforcement to the confined core

$\varepsilon_{\text {sh }}=$ steel strain at onset of strain hardening

$\varepsilon_{\text {su }}=$ maximum steel strain

$E_{S}$ = Young's modulus of reinforcing steel

$E_{\text {sh }}=$ strain hardening modulus at $\varepsilon_{\text {sh }}$

Table 4.3: Calculated Ideal Strengths of Full-Scale and 1/6-Scale Model Bridge Column Specimens.

\begin{tabular}{|c|c|c|c|c|c|}
\hline Specimen & $\begin{array}{c}P_{e} \\
(k i p s)\end{array}$ & $\frac{P_{e}}{f^{\prime} c^{A} g}$ & $\begin{array}{c}M_{i} \\
(k i p-f t)\end{array}$ & $\begin{array}{l}\text { Column } \\
\text { Height } \\
\text { (inch) }\end{array}$ & $\begin{array}{c}P_{i} \\
(k i p s)\end{array}$ \\
\hline $\begin{array}{l}\text { N1 } \\
\text { N2 } \\
\text { N4 } \\
\text { N5 } \\
\text { SHEAR }\end{array}$ & $\begin{array}{r}26.87 \\
53.75 \\
26.87 \\
53.75 \\
1000.00\end{array}$ & $\begin{array}{l}.100 \\
.210 \\
.100 \\
.200 \\
.071\end{array}$ & $\begin{array}{r}32.37 \\
35.37 \\
32.37 \\
35.37 \\
7988.3\end{array}$ & $\begin{array}{r}29.5 \\
29.5 \\
29.5 \\
29.5 \\
180.0\end{array}$ & $\begin{array}{r}13.17 \\
14.39 \\
13.17 \\
14.39 \\
532.55\end{array}$ \\
\hline $\begin{array}{l}\text { N3 } \\
\text { N6 } \\
\text { ELEX }\end{array}$ & $\begin{array}{r}26.87 \\
26.87 \\
1000.00\end{array}$ & $\begin{array}{l}.100 \\
.110 \\
.068\end{array}$ & $\begin{array}{r}32.37 \\
32.37 \\
8041.1\end{array}$ & $\begin{array}{r}59.0 \\
59.0 \\
360.0\end{array}$ & $\begin{array}{r}6.58 \\
6.58 \\
268.04\end{array}$ \\
\hline
\end{tabular}

Where

$\mathrm{P}_{\mathrm{e}}=$ applied axial column load

$M_{i}=$ ideal moment capacity calculated using ACI approach where an ultimate concrete strain of .003 together with a rectangular concrete stress block are assumed.

$P_{i}=$ ideal lateral load capacity $=\left(M_{i}-P_{e} \Delta\right) / h_{1}$ in general; evaluated here at $\Delta=0$, where $h_{1}=$ effective height of test column from fixed support to point of contraflexure. 


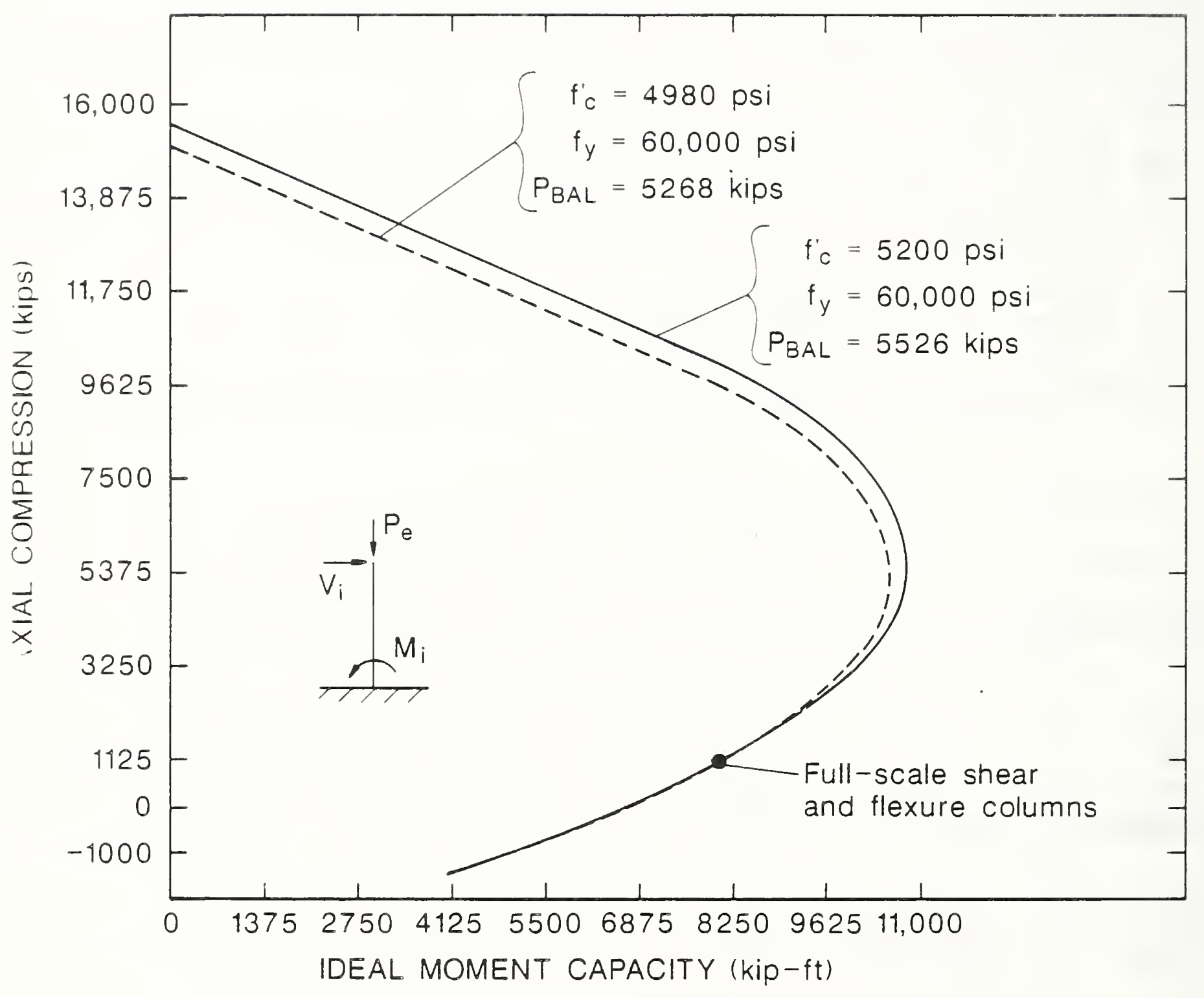

Figure 4.1: Interaction Diagram for Full-Scale Columns 


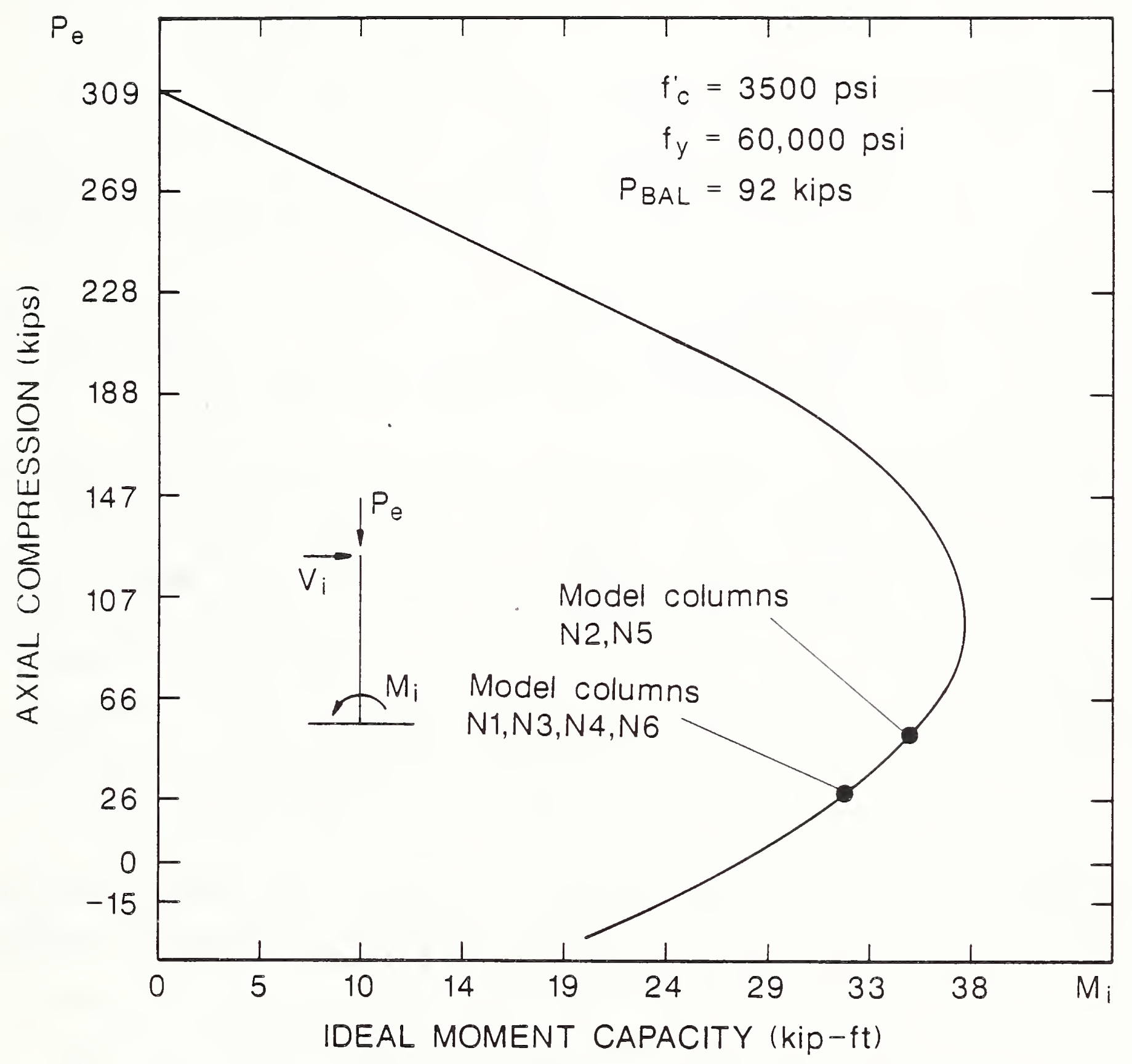

Figure 4.2: Interaction Diagram for Model Columns 
after cycling at $2 \Delta_{y}$ for the shear column, it was not possible to construct moment and shear histories from the bottom up. The top-of-column reaction force approach was therefore adopted. The equilibrium equations are described in Appendix A (reproduced here as equations 4.1 and 4.2).

$$
\begin{aligned}
& \mathrm{M}=\mathrm{P}_{\mathrm{af}}\left(\mathrm{h}_{\mathrm{l}}\right)-\mathrm{P}_{\mathrm{m}}\left(\mathrm{h}_{2}\right)+\mathrm{P}_{\mathrm{a}}\left(\Delta_{\mathrm{t}}\right)+\mathrm{W}_{\mathrm{i}} \mathrm{h}\left(\Delta_{\mathrm{r}} / 2\right) \\
& \mathrm{V}=\mathrm{P}_{\mathrm{af}}-\mathrm{P}_{\mathrm{m}}
\end{aligned}
$$

Load histories for $\mathrm{P}_{\text {af }}$ ( A-Frame 1oad), $\mathrm{P}_{\mathrm{m}}$ (1ateral load absorbed by the vertical test machine), and Pram (applied lateral load) for the flexure column are shown in Figure 4.3. Note that the measured A-Frame load is actually greater than the applied ram load due to the small offset lever from the A-Frame attachment hinge to the test machine loading head. Load dissipated into the vertical test machine (c) is used in conjunction with $A$ Frame load for final determination of column base moment (d).

The $\mathrm{x}$-axis for all of these plots is the data acquisition scan number which serves only to separate the cyclic data for easier interpretation. $P_{a}$ (applied axial load) and $W_{i}$ h (weight of the column) were constant, as were $h_{1}$ (height of test column from base to point of counterflexure) and $h_{2}$ (height from base of column to centerline of top-of-column hinge). The effective total displacement, $\Delta_{t}$, for computation of $P-\Delta$ moment can be derived from $\Delta_{r}$, the lateral displacement of column base, by consideration of the test apparatus geometry, as shown in Appendix A, Figure A.33.

It is interesting to note that it is possible to recover the cyclic variation in average roller friction as follows by permutation of equations A.1 through A.6, presented in Appendix A.

$$
\mu_{\text {avg }} \approx \frac{P_{a f}-P_{m}-P_{\text {ram }}}{\sum_{\substack{i=1 \\ i=1}} N_{i}} \approx \frac{P_{a f}-P_{m}-P_{\text {ram }}}{\left(W+P_{e}\right)}
$$

This variation of average coefficient of friction is plotted versus scan number in Figure 4.4. From this it can be seen that the coefficient of 
friction is constantly changing during lateral displacement, as would be expected given the friction force-displacement calibration history presented in Figure A.13 (Appendix A). The sharp peaks for each cycle represent the transition from rolling to static friction as the lateral actuator reaches the end of a lateral excursion, prior to displacement reversal. Also note the general trend for increased coefficient of friction as the displacement is increased. This occurs because of the greater transfer of load to the rollers at either end of the base block (one side unloads, one side loads) at successively greater displacements until the maximum column moment begins to degrade. The short horizontal steps on the coefficient of friction plot, approximately halfway from zero to the peaks, represent the coefficient of rolling friction which averaged approximately 18 during the test. The static coefficient of friction averaged between $2-2.5 \%$.

Table 4.4 summarizes the column moments due to both lateral load and P- $\Delta$ effects. The moments are calculated end points (maximum displacement) for each cycle until failure using equation 4.1. Plots of load and moment versus column lateral. displacement (base of column displacement relative to point of contraflexure) are presented in Figures 4.5 and 4.6. Significant drops in lateral load during an outward excursion signify points where either spiral or longitudinal reinforcing steel within the plastic hinge region fractured.

Figures 4.7 and 4.8 compare performance of the full-scale flexure column with its 1/6-scale models. Lateral load has been normalized by the calculated ACI lateral load $V_{i}$ which would cause a moment of $M_{i}$ at the column base: thus $M / M_{i}$ would have been equally applicable for the $y$-axis label. This convention will be used throughout the remainder of this report. The $x$-axis in Figures 4.7 and 4.8 has likewise been normalized by dividing by the yield deflection, $\Delta_{y}$, and thus represents displacement ductility, $\mu$. This permits direct comparison between model and prototype without regard to scaling of results. The maximum moments for both full scale column and model columns constructed from microconcrete and ready mix concrete (N3, N6) respectively were determined to be $1.20,1.23$, and 1.14 times the calculated ultimate moment using ACI procedures. Ultimate 
Table 4.4 Moments for Full Scale Flexure Column

\begin{tabular}{|c|c|c|c|c|c|c|}
\hline Cycle 1 & $\begin{array}{l}\text { Lateral } \\
\text { Load } \\
\text { (kips) }\end{array}$ & $\begin{array}{l}\text { Delta } \\
\text { (in.) }\end{array}$ & $\begin{array}{l}\text { Axial } \\
\text { Load } \\
\text { (kips) }\end{array}$ & $\begin{array}{l}\text { Moment } \\
\text { due to } \\
\text { P-Delta } \\
(k-f t)\end{array}$ & $\begin{array}{l}\text { Moment } \\
\text { due to } \\
\text { Lateral } \\
\text { Load } \\
(k-f t)\end{array}$ & $\begin{array}{l}\text { Total } \\
\text { Moment } \\
(k-f t)\end{array}$ \\
\hline $11 \mathrm{E}$ & 176.30 & 2.743 & 1000.00 & 228.58 & 5289.00 & 5517.58 \\
\hline $11 \mathrm{~W}$ & 194.60 & 3.071 & 1000.00 & 255.92 & 5838.00 & 6093.92 \\
\hline $21 E$ & 268.40 & 7.745 & 1000.00 & 645.42 & 8052.00 & 8697.42 \\
\hline $21 \mathrm{~W}$ & 282.00 & 7.717 & 1000.00 & 643.08 & 8460.00 & 9103.08 \\
\hline $22 E$ & 268.20 & 7.772 & 1000.00 & 647.67 & 8046.00 & 8693.67 \\
\hline $22 \mathrm{~W}$ & 276.60 & 7.706 & 1000.00 & 642.17 & 8298.00 & 8940.17 \\
\hline $31 E$ & 282.10 & 11.330 & 1000.00 & 944.17 & 8463.00 & 9407.17 \\
\hline $31 \mathrm{~W}$ & 270.00 & 11.570 & 1000.00 & 964.17 & 8100.00 & 9064.17 \\
\hline $32 \mathrm{E}$ & 271.70 & 11.630 & 1000.00 & 969.17 & 8151.00 & 9120.17 \\
\hline $32 \mathrm{~W}$ & 259.90 & 11.570 & 1000.00 & 964.17 & 7797.00 & 8761.17 \\
\hline $41 \mathrm{E}$ & 269.60 & 15.520 & 1000.00 & 1293.33 & 8088.00 & 9381.33 \\
\hline $41 W$ & 255.70 & 15.410 & 1000.00 & 1284.17 & 7671.00 & 8955.17 \\
\hline $42 \mathrm{E}$ & 260.50 & 15.480 & 1000.00 & 1290.00 & 7815.00 & 9105.00 \\
\hline $42 \mathrm{~W}$ & 248.80 & 15.460 & 1000.00 & 1288.33 & 7464.00 & 8752.33 \\
\hline $43 E$ & 256.90 & 15.480 & 1000.00 & 1290.00 & 7707.00 & 8997.00 \\
\hline $43 \mathrm{~W}$ & 247.70 & 15.450 & 1000.00 & 1287.50 & 7431.00 & 8718.50 \\
\hline $44 E$ & 254.30 & 15.470 & 1000.00 & 1289.17 & 7629.00 & 8918.17 \\
\hline $44 \mathrm{~W}$ & 247.50 & 15.440 & 1000.00 & 1286.67 & 7425.00 & 8711.67 \\
\hline $4 j E$ & 253.00 & 15.470 & 1000.00 & 1289.17 & 7590.00 & 8879.17 \\
\hline $45 \mathrm{~W}$ & 244.80 & 15.440 & 1000.00 & 1286.67 & 7344.00 & 8630.67 \\
\hline $46 E$ & 250.80 & 15.470 & 1000.00 & 1289.17 & 7524.00 & 8813.17 \\
\hline $46 W$ & 244.20 & 15.440 & 1000.00 & 1286.67 & 7326.00 & 8612.67 \\
\hline $47 E$ & 249.50 & 15.470 & 1000.00 & 1289.17 & 7485.00 & 8774.17 \\
\hline $47 \mathrm{~W}$ & 243.50 & 15.450 & 1000.00 & 1287.50 & 7305.00 & 8592.50 \\
\hline $48 E$ & 248.00 & 15.470 & 1000.00 & 1289.17 & 7440.00 & 8729.17 \\
\hline $48 \mathrm{~W}$ & 242.50 & 15.440 & 1000.00 & 1286.67 & 7275.00 & 8561.67 \\
\hline
\end{tabular}


Table 4.4 (continued)

\begin{tabular}{|lcccccc|}
\hline Cycle & $\begin{array}{c}\text { Lateral } \\
\text { Load }\end{array}$ & Delta & $\begin{array}{c}\text { Axial } \\
\text { Load }\end{array}$ & $\begin{array}{c}\text { Moment } \\
\text { due to } \\
\text { P-Delta }\end{array}$ & $\begin{array}{c}\text { Moment } \\
\text { due to } \\
\text { Lateral } \\
\text { Load } \\
\text { (k-ft) }\end{array}$ & $\begin{array}{c}\text { Total } \\
\text { Moment }\end{array}$ \\
\hline & (kips) & (in.) & (kips) & (k-ft) & \\
$49 \mathrm{E}$ & 247.70 & 15.470 & 1000.00 & 1289.17 & 7431.00 & 8720.17 \\
$49 \mathrm{~W}$ & 240.00 & 15.450 & 1000.00 & 1287.50 & 7200.00 & 8487.50 \\
$410 \mathrm{E}$ & 247.30 & 15.470 & 1000.00 & 1289.17 & 7419.00 & 8708.17 \\
$410 \mathrm{~W}$ & 238.40 & 15.450 & 1000.00 & 1287.50 & 7152.00 & 8439.50 \\
$51 \mathrm{E}$ & 267.60 & 19.380 & 1000.00 & 1615.00 & 8028.00 & 9643.00 \\
$51 \mathrm{~W}$ & 246.00 & 19.380 & 1000.00 & 1615.00 & 7380.00 & 8995.00 \\
$52 \mathrm{E}$ & 262.30 & 19.390 & 1000.00 & 1615.83 & 7869.00 & 9484.83 \\
$52 \mathrm{~W}$ & 237.90 & 19.370 & 1000.00 & 1614.17 & 7137.00 & 8751.17 \\
$53 \mathrm{E}$ & 261.90 & 19.440 & 1000.00 & 1620.00 & 7857.00 & 9477.00 \\
$53 \mathrm{~W}$ & 226.60 & 19.410 & 1000.00 & 1617.50 & 6798.00 & 8415.50 \\
$61 \mathrm{E}$ & 242.10 & 23.370 & 1000.00 & 1947.50 & 7263.00 & 9210.50 \\
$61 \mathrm{~W}$ & 223.00 & 23.250 & 1000.00 & 1937.50 & 6690.00 & 8627.50 \\
$62 \mathrm{E}$ & 242.10 & 23.370 & 1000.00 & 1947.50 & 7263.00 & 9210.50 \\
$62 \mathrm{~W}$ & 197.30 & 23.330 & 1000.00 & 1944.17 & 5919.00 & 7863.17 \\
$63 \mathrm{E}$ & 186.60 & 23.380 & 1000.00 & 1948.33 & 5598.00 & 7546.33 \\
$63 \mathrm{~W}$ & 120.00 & 23.280 & 1000.00 & 1940.00 & 3600.00 & 5540.00 \\
$6.6 \mathrm{E}$ & 108.10 & 25.630 & 1000.00 & 2135.83 & 3243.00 & 5378.83 \\
$6.6 \mathrm{~W}$ & 20.27 & 25.390 & 1000.00 & 2115.83 & 608.10 & 2723.93 \\
\hline
\end{tabular}

$111 \mathrm{E}=1 \Delta_{\mathrm{y}}$, Cycle 1 east excursion, $102 \mathrm{~W}=10 \Delta \mathrm{y}$, Cycle 2 , West excursion, etc.

2 This is the displacement of the centerline of the top-of-column hinge (see Figure 2.36) at maximum extension for a given cycle. This is used in the determination of the $P-\Delta$ portion of the total moment. The actual column lateral deflection, from the base to the point of contraflexure, may be obtained by multiplying the above deflections by 0.9114 . 

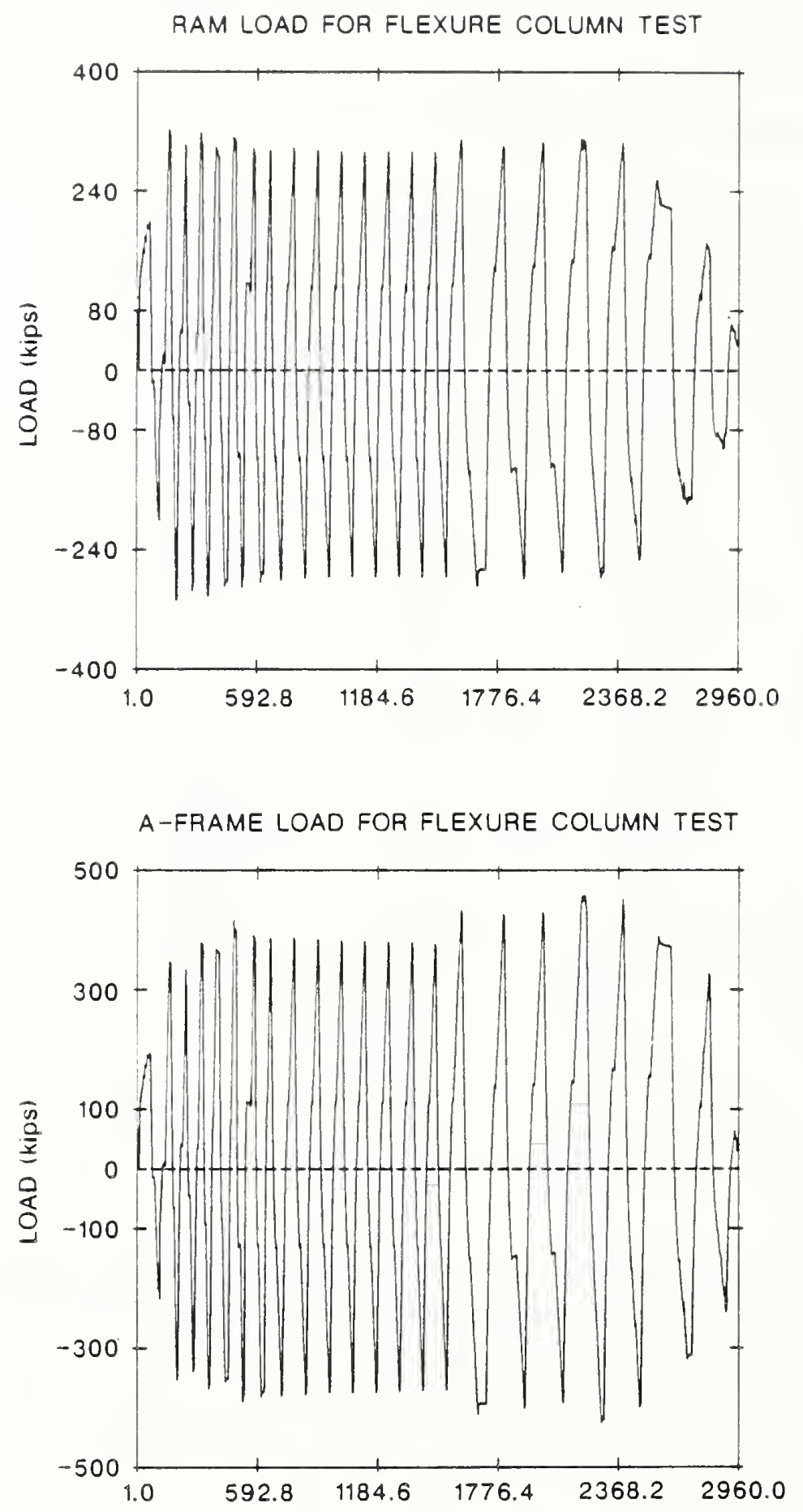

Figure 4.3: Reaction Forces at work During the Testing of the FullScale Flexure Column Specimen. 

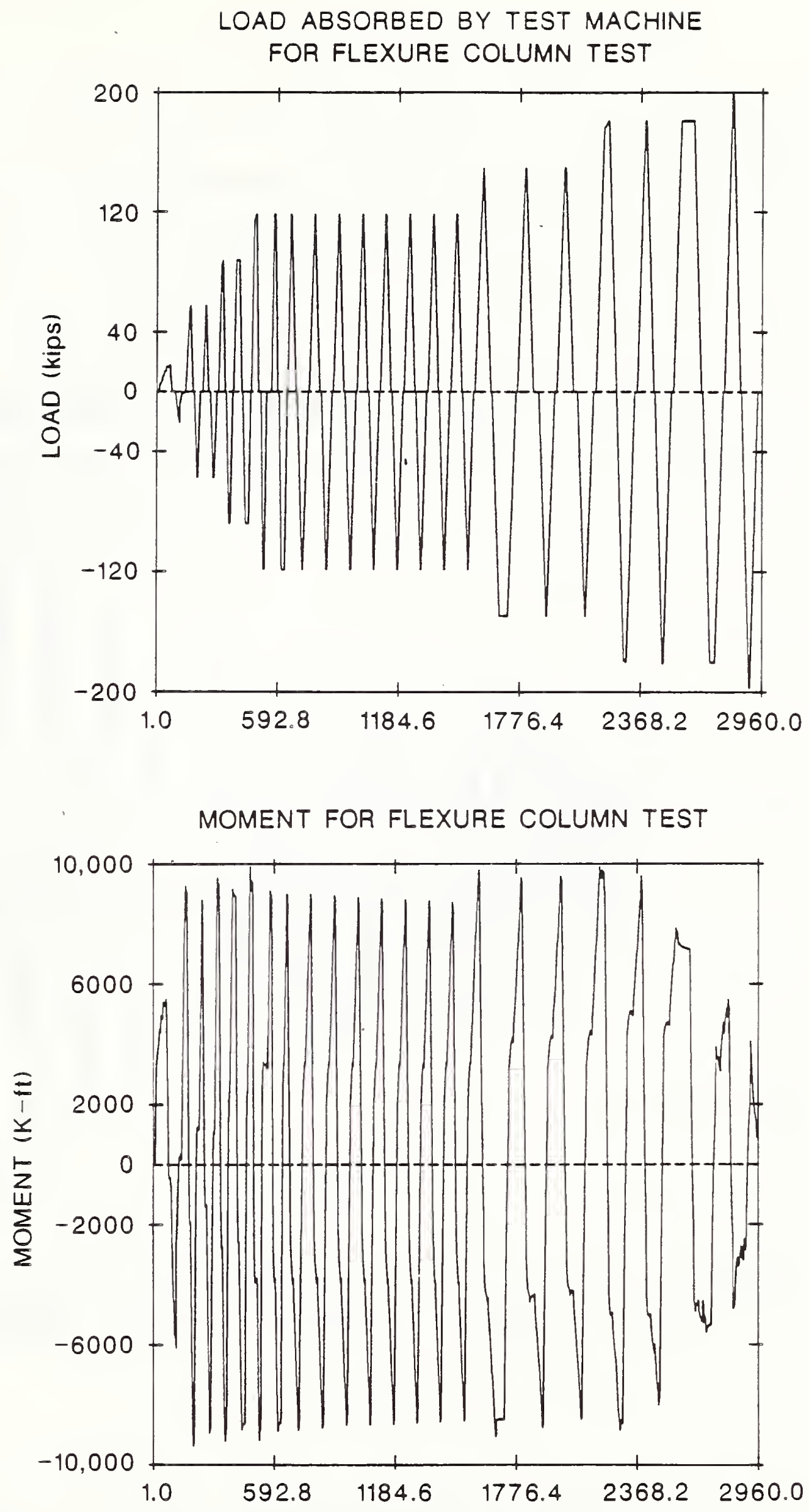

Figure 4.3: Reaction Forces at work During the Testing of the FullScale Flexure Column Specimen (continued). 
FRICTION COEFFICIENT FOR FLEXURE COLUMN TEST

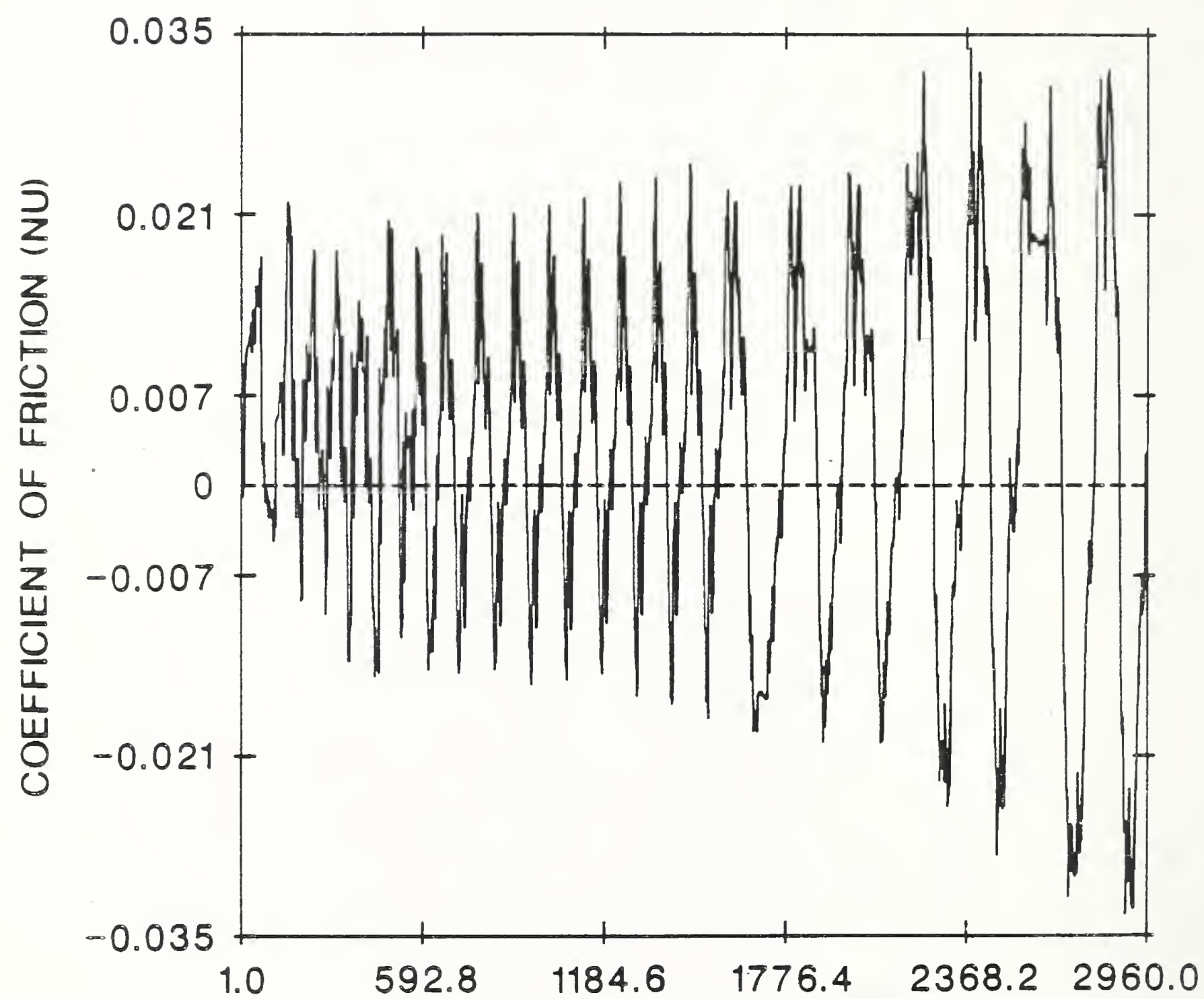

Figure 4.4: Variation of Coefficient of Friction for Supporting Roller System, Full Scale Flexure Column Test. X-Axis Represents Data Acquisition System Scan Number. Generally there were approximately equal number of scans per cycle so that individual complete cycles are represented by two sign reversals on the $y$-axis. 
displacement ductilities of $6.6,5$, and 4 were recorded for the full-scale column, and models $\mathrm{N} 3$ and $\mathrm{N} 6$ respectively. Note that maximum normalized displacements were approximately 5 and 7 for models N3 and N6 (Figure 4.8.). However, these latter values were recorded after moment resistance had dropped below $0.8 \mathrm{M}$, the criteria used in this report as the gage for determining when a column was "failed". Although currently there are no requirements in the United States for column ductility (only confining reinforcement ratios are required), at least one country (New Zealand) has adopted design spectra based on ductility with a ductility factor of 6 generally being considered the minimum value. The full-scale flexure column therefore exceeded this criterion but the models did not. 


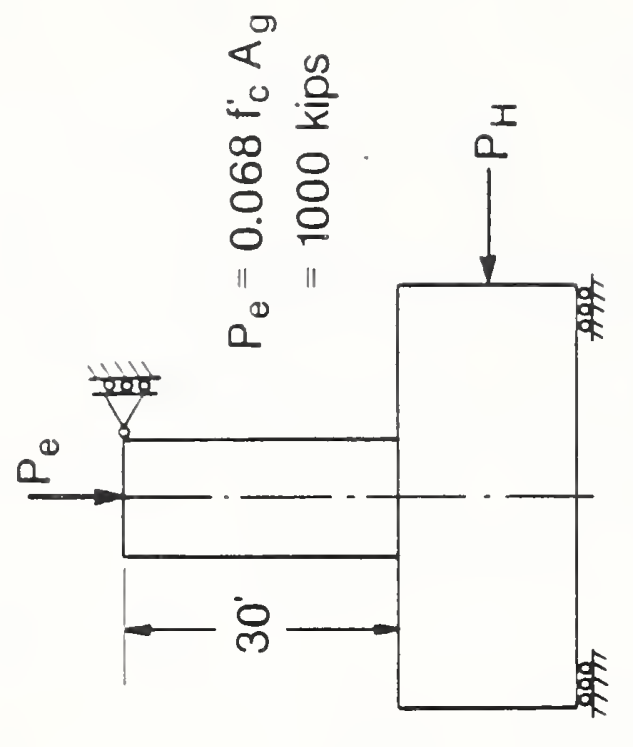

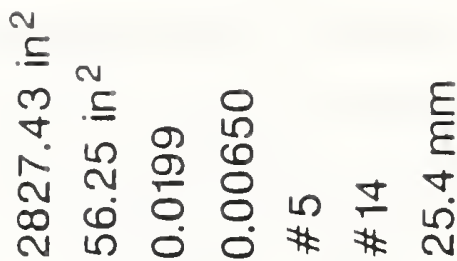
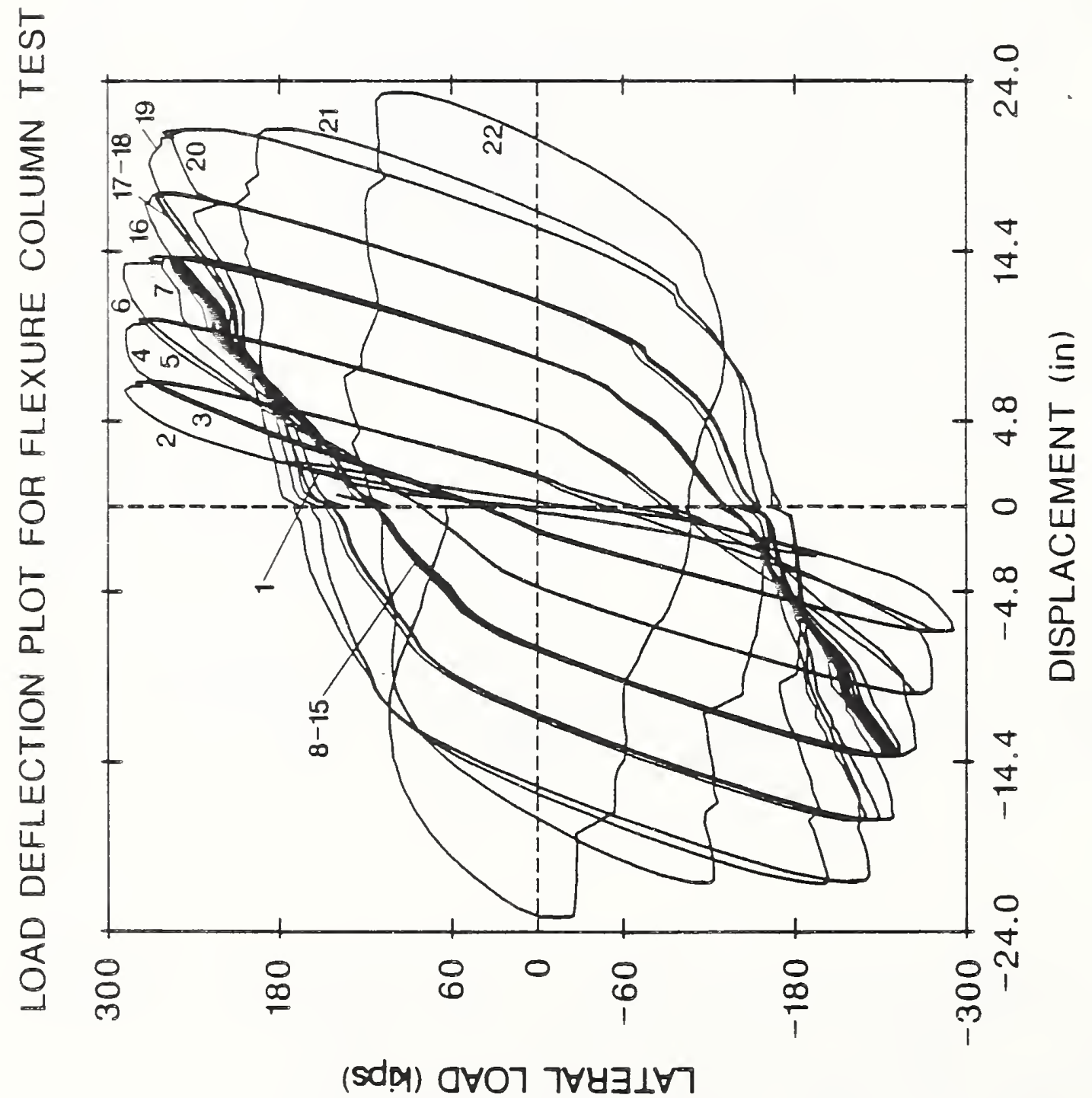

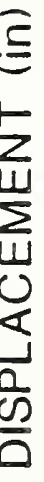
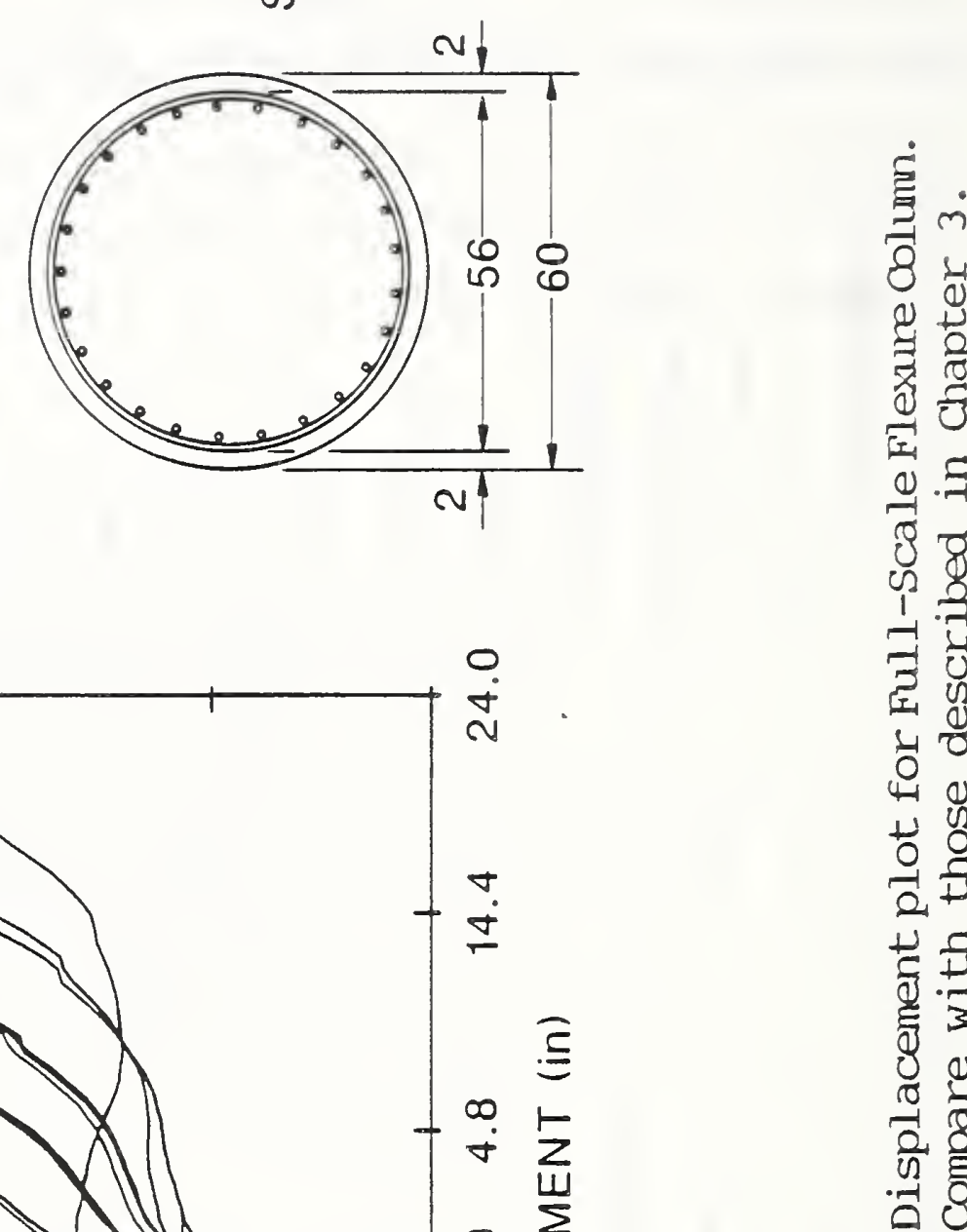

is

苟

?

?

总

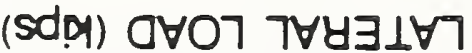




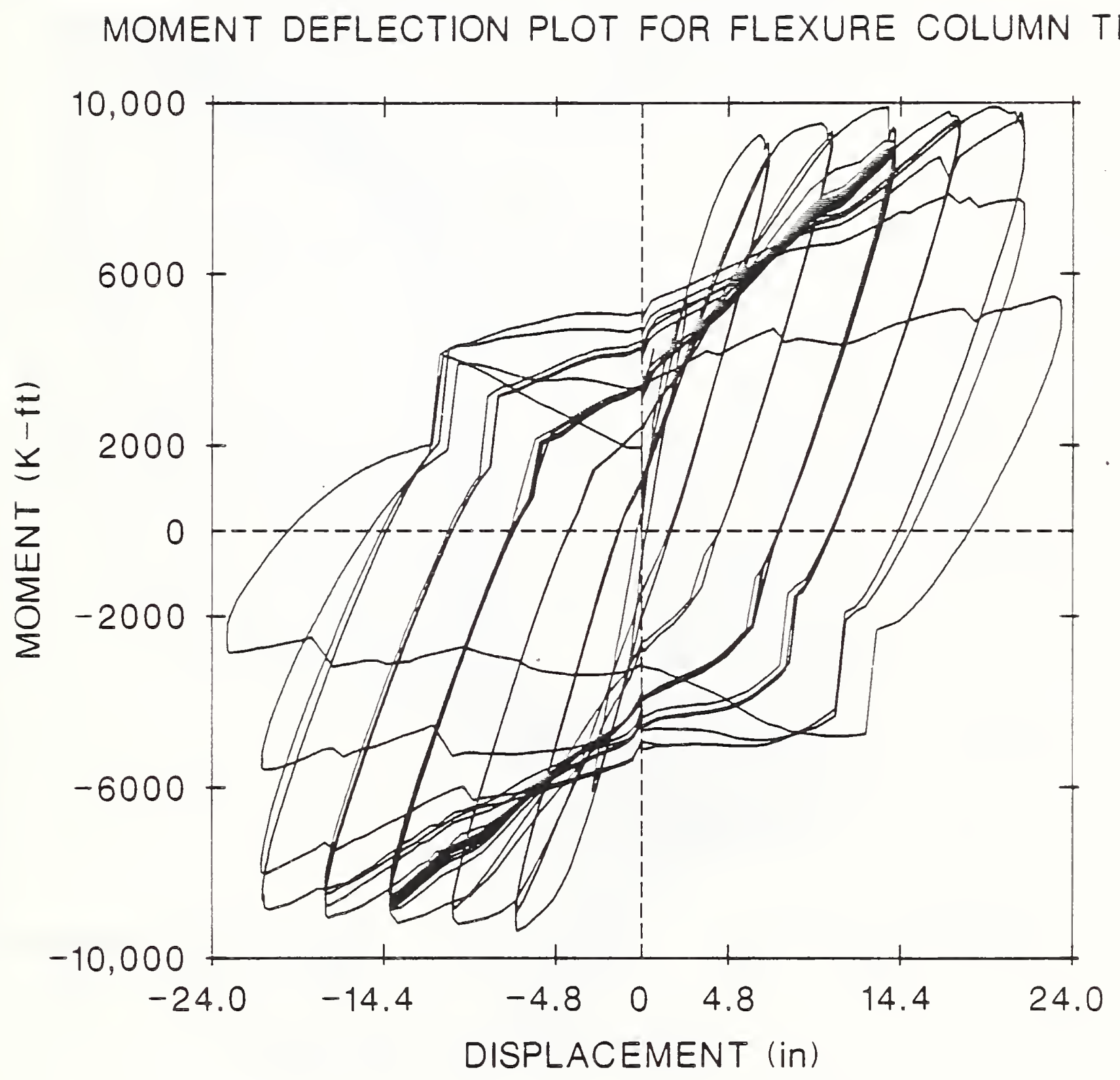

Figure 4.6: Moment versus Lateral Displacement plot for Full-Scale Flexure Column Test. 


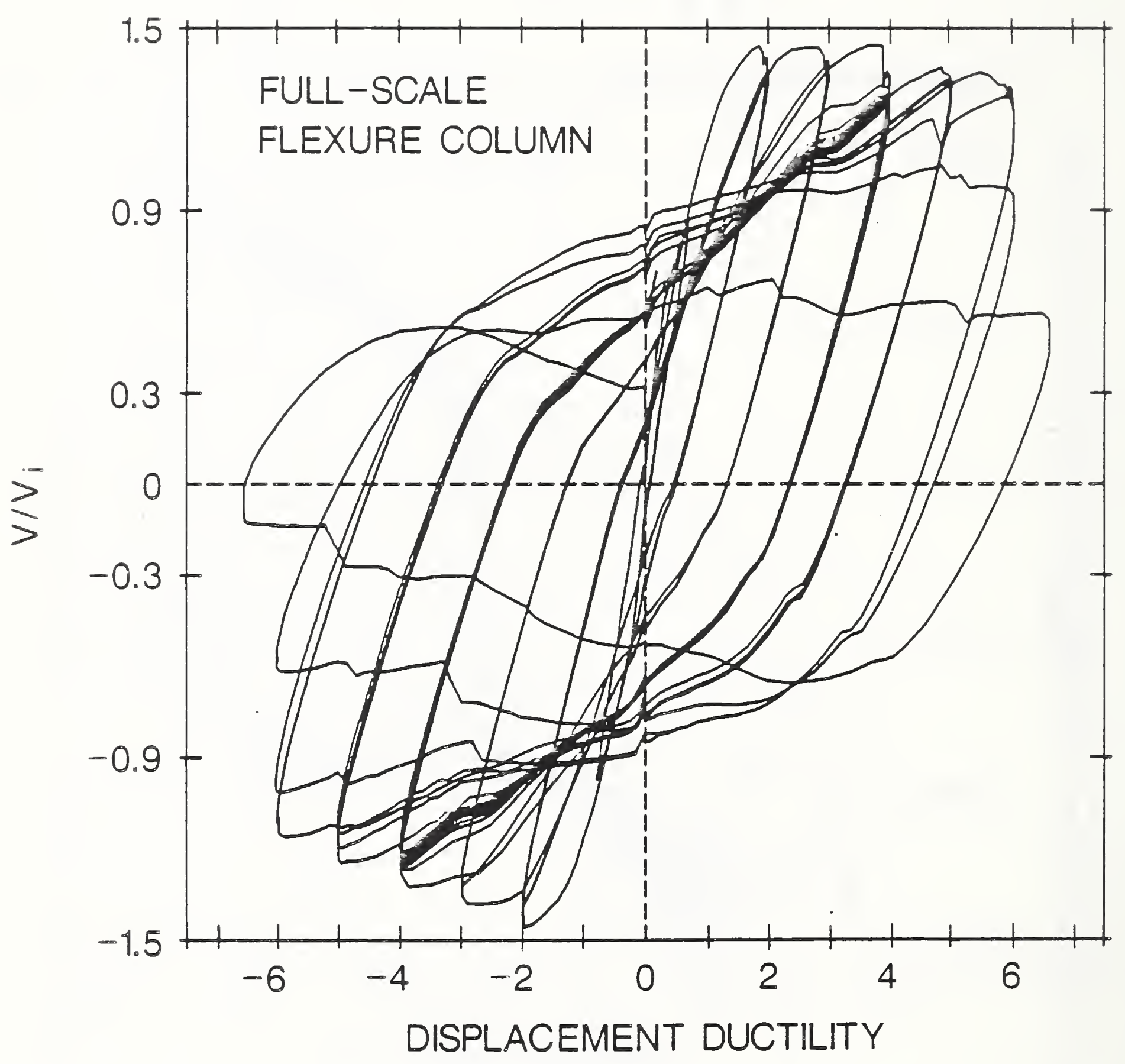

Figure 4.7: Normalized Lateral Load $\left(V / V_{i}\right)$ versus Displacement Ductility $\left(\Delta / \Delta_{y}\right)$ for Full-Scale Flexure Column. 

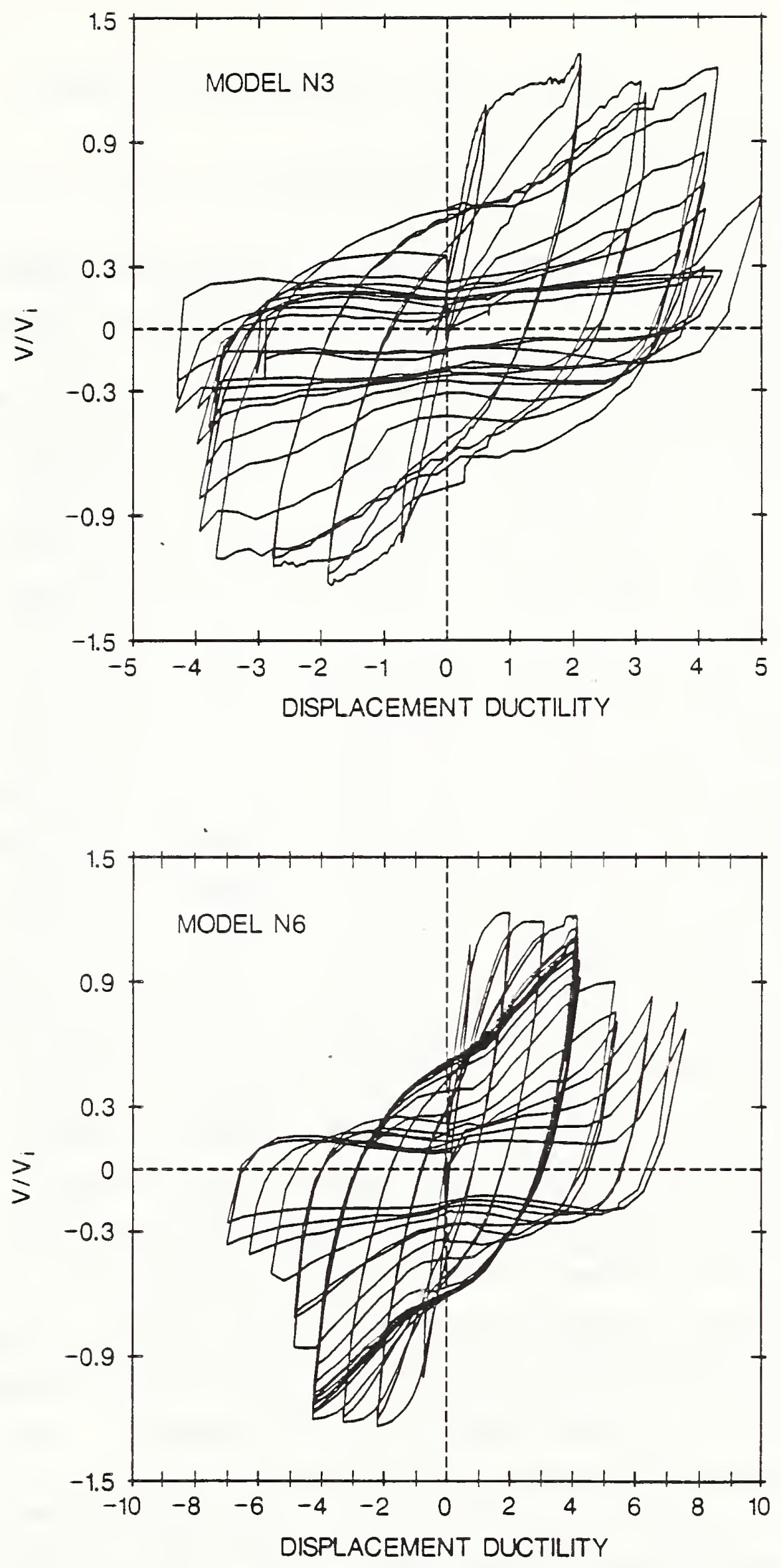

Figure 4.8: Normalized Lateral Load $\left(V / V_{j}\right)$ versus Displacement Ductility $\left(\Delta / \Delta_{y}\right)$ for Model Columns N3 and N6. 


\subsection{Shear Column Moments and Displacements}

Similar to the approach uesd in Section 4.1, the information for determining moment and shear for the full-scale shear column are shown in Figure 4.9.

The variation of average coefficient of friction is plotted versus scan number in Figure 4.10. Both Figures 4.9 and 4.10 are similar to those presented for the flexure column with the exception that the load transferred to the vertical testing machine was substantially less (Figure 4.9c) than that for the flexure column and the lateral load is slightly more than double due to the 50 \% reduction in column height. The reason for the difference in the load transferred to the test machine is twofold: yield displacement ( $3.53 \mathrm{in}$. for the flexure column versus 1.40 in. for the shear column [89 mm, $35 \mathrm{~mm}]$ ) was substantially lower (and hence hinge displacement and therefore test machine loading head displacement) was less; and, special measures were taken to eliminate friction between the hinge and test machine crosshead. Knowing that the test machine would be stiffer at lower elevations, a layer of $600-1.5$ in (38 mm) ball bearings were placed between two hardened steel, machined plates in molybdenum disulphide grease atop the column. The effect is readily apparent in Figure $4.9 \mathrm{c}$ where it is seen that the load absorbed by the test machine is reduced to zero over the majority of the cycles. The spikes represent the transition from rolling to static friction at maximum lateral displacement for each cycle. This decrease in load absorbed by the testing machine also permits a better picture of friction forces in the supporting rollex system (Figure 4.10) where the rolling friction portion of a cycle is now clearly evident as a mid-height plateau at approximately $+/$ - 18 friction. The maximum average static coefficient of friction was approximately 28 .

Table 4.5 summarizes the column moments, due to both lateral load and P- $\Delta$ effects at the maximum displacement end points of each cycle until failure for the full-scale shear column. Moments are calculated using equation 4.1. 
Table 4.5 Moment for Full Scale Shear Column

\begin{tabular}{|c|c|c|c|c|c|c|}
\hline Cycle 1 & $\begin{array}{l}\text { Lateral } \\
\text { Load } \\
\text { (kip) }\end{array}$ & $\begin{array}{l}\text { Delta } \\
\text { (in.) }\end{array}$ & $\begin{array}{l}\text { Axial } \\
\text { Load } \\
\text { (kip) }\end{array}$ & $\begin{array}{l}\text { Moment } \\
\text { due to } \\
\text { P-Delta } \\
(\mathrm{k} \text {-ft })\end{array}$ & $\begin{array}{l}\text { Moment } \\
\text { due to } \\
\text { Lateral } \\
\text { Load } \\
(\mathrm{k}-\mathrm{ft})\end{array}$ & $\begin{array}{l}\text { Total } \\
\text { Moment } \\
(k-f t)\end{array}$ \\
\hline $11 \mathrm{~W}$ & 407.80 & 1.367 & 1000.00 & 113.92 & 6117.00 & 6230.92 \\
\hline $11 E$ & 381.40 & 1.136 & 1000.00 & 94.67 & 5721.00 & 5815.67 \\
\hline $21 \mathrm{~W}$ & 595.80 & 3.342 & 1000.00 & 278.50 & 8937.00 & 9215.50 \\
\hline $21 E$ & 634.50 & 3.345 & 1000.00 & 278.75 & 9517.50 & 9796.25 \\
\hline $22 \mathrm{~W}$ & 563.10 & 3.358 & 1000.00 & 279.83 & 8446.50 & 8726.33 \\
\hline $22 E$ & 622.10 & 3.359 & 1000.00 & 279.92 & 9331.50 & 9611.42 \\
\hline $41 \mathrm{~W}$ & 618.80 & 6.777 & 1000.00 & 564.75 & 9282.00 & 9846.75 \\
\hline $41 \mathrm{E}$ & 738.00 & 6.824 & 1000.00 & 568.67 & 11070.00 & 11638.67 \\
\hline $42 W$ & 611.40 & 6.785 & 1000.00 & 565.42 & 9171.00 & 9736.42 \\
\hline $42 E$ & 700.50 & 6.715 & 1000.00 & 559.58 & 10507.50 & 11067.08 \\
\hline $61 \mathrm{~W}$ & 654.10 & 10.220 & 1000.00 & 851.67 & 9811.50 & 10663.17 \\
\hline $61 \mathrm{E}$ & 703.40 & 10.030 & 1000.00 & 835.83 & 10551.00 & 11386.83 \\
\hline $62 \mathrm{~W}$ & 566.70 & 10.050 & 1000.00 & 837.50 & 8500.50 & 9338.00 \\
\hline $62 \mathrm{E}$ & 662.60 & 10.040 & 1000.00 & 836.67 & 9939.00 & 10775.67 \\
\hline $81 \mathrm{~W}$ & 607.30 & 13.370 & 1000.00 & 1114.17 & 9109.50 & 10223.67 \\
\hline $81 E$ & 674.50 & 13.380 & 1000.00 & 1115.00 & 10117.50 & 11232.50 \\
\hline $82 \mathrm{~W}$ & 565.60 & 13.390 & 1000.00 & 1115.83 & 8484.00 & 9599.83 \\
\hline $82 E$ & 653.70 & 13.380 & 1000.00 & 1115.00 & 9805.50 & 10920.50 \\
\hline $101 \mathrm{~W}$ & 574.90 & 16.720 & 1000.00 & 1393.33 & 8623.50 & 10016.83 \\
\hline $101 \mathrm{E}$ & 623.30 & 16.730 & 1000.00 & 1394.17 & 9349.50 & 10743.67 \\
\hline $102 \mathrm{~W}$ & 544.60 & 16.700 & 1000.00 & 1391.67 & 8169.00 & 9560.67 \\
\hline $102 E$ & 498.90 & 16.740 & 1000.00 & 1395.00 & 7483.50 & 8878.50 \\
\hline $103 \mathrm{~W}$ & 359.60 & 16.680 & 1000.00 & 1390.00 & 5394.00 & 6784.00 \\
\hline $103 \mathrm{E}$ & 259.00 & 16.740 & 1000.00 & 1395.00 & 3885.00 & 5280.00 \\
\hline
\end{tabular}

$111 E=1 \Delta_{y}$, Cycle 1 east excursion, $103 \mathrm{~W}=10 \Delta_{y}$, Cycle 3 west excursion, etc.

2 This is the displacement of the centerline of the top-of-column hinge (see Figure 2.36) at maximum extension for a given cycle. This is used in the determination of the P-A portion of the total moment. The actual column lateral deflection, from the base to the point of contraflexure, may be obtained by multiplying the above deflections by 0.9114 . 

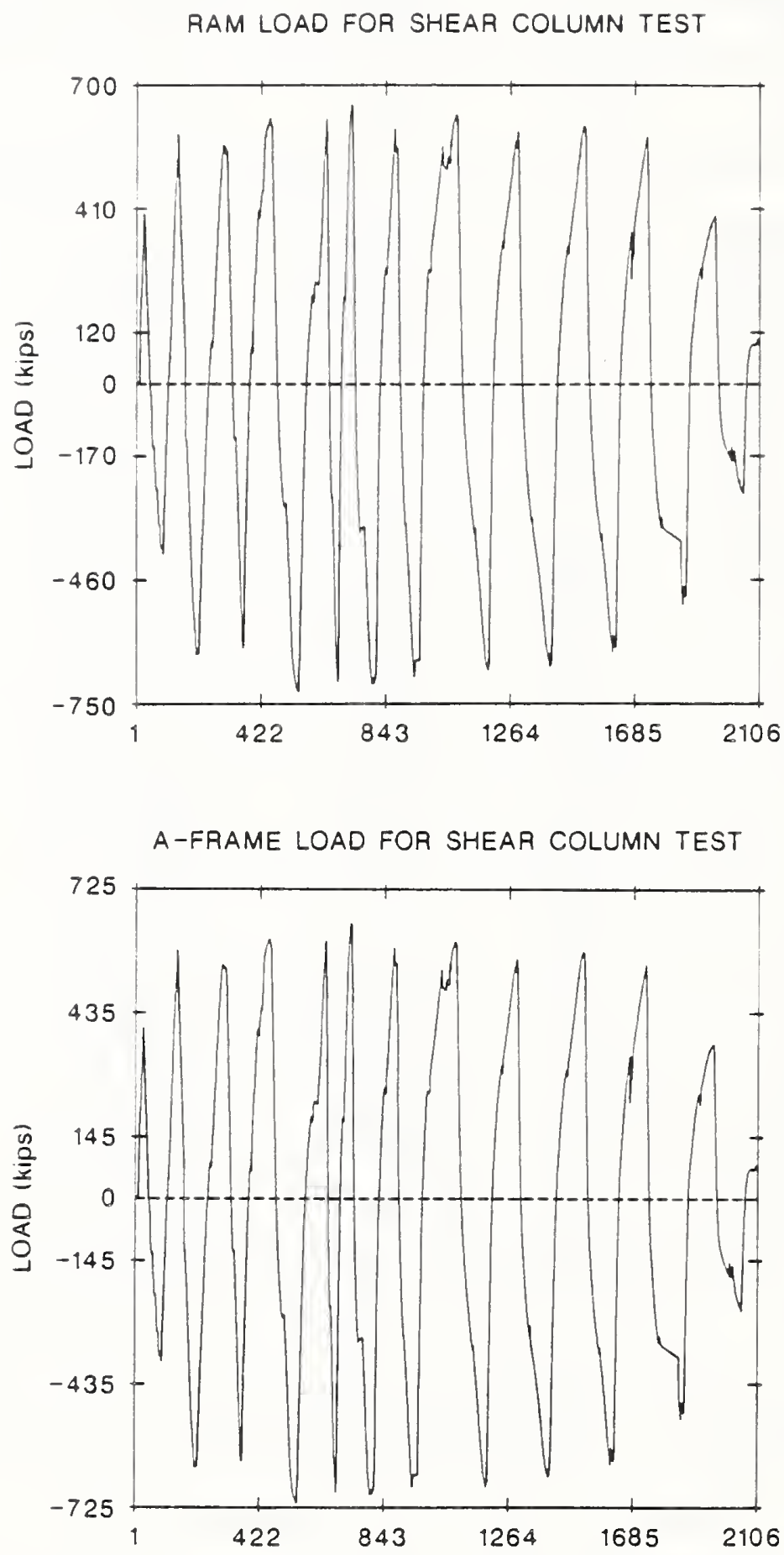

Figure 4.9: Reaction Forces at work During the Testing of the FullScale Shear Column. 

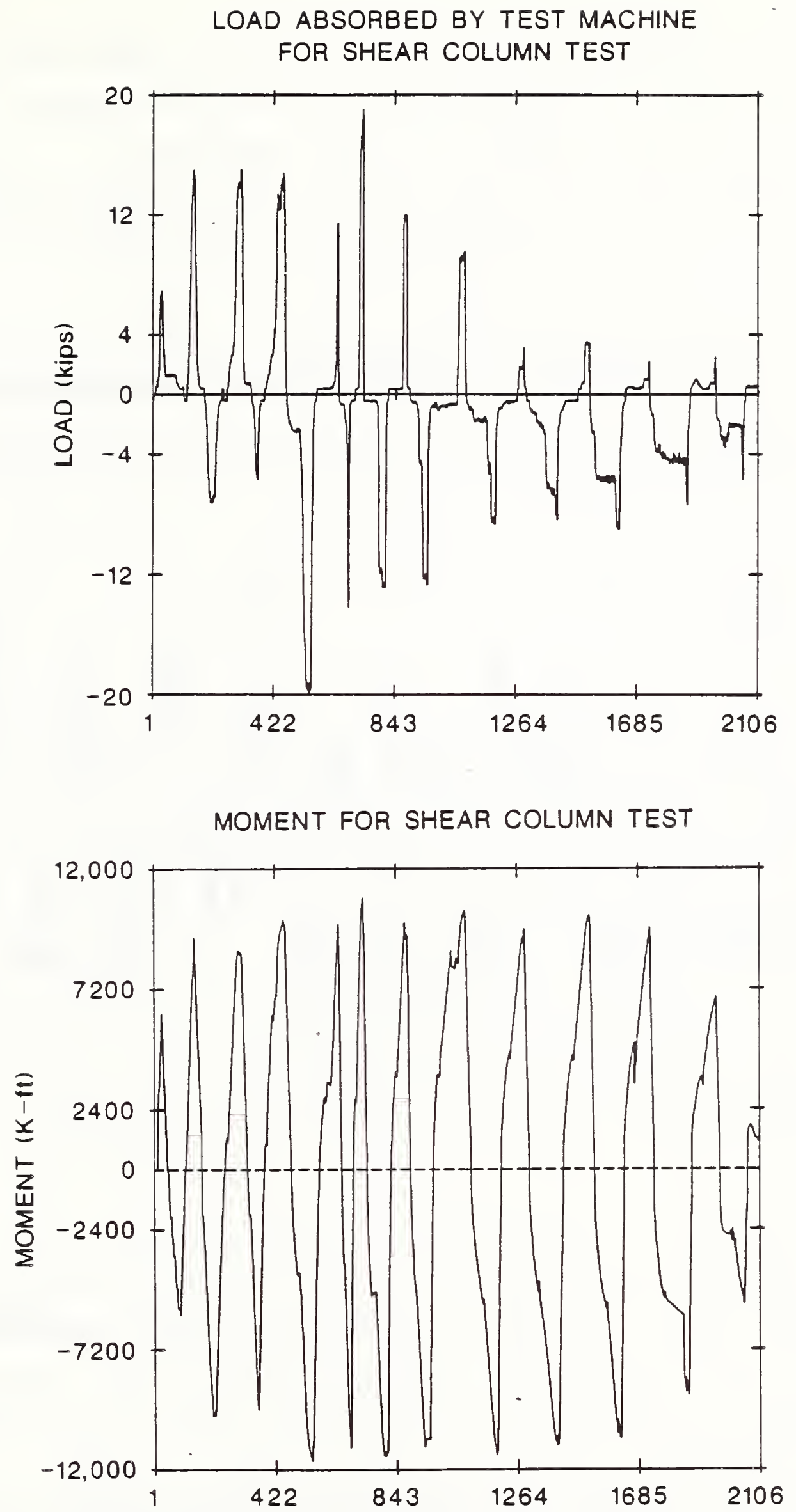

Figure 4.9: Reaction Forces at work During the Testing of the FullScale Shear Column Specimen (continued). 
COEFFICIENT OF FRICTION FOR SHEAR COLUMN TEST

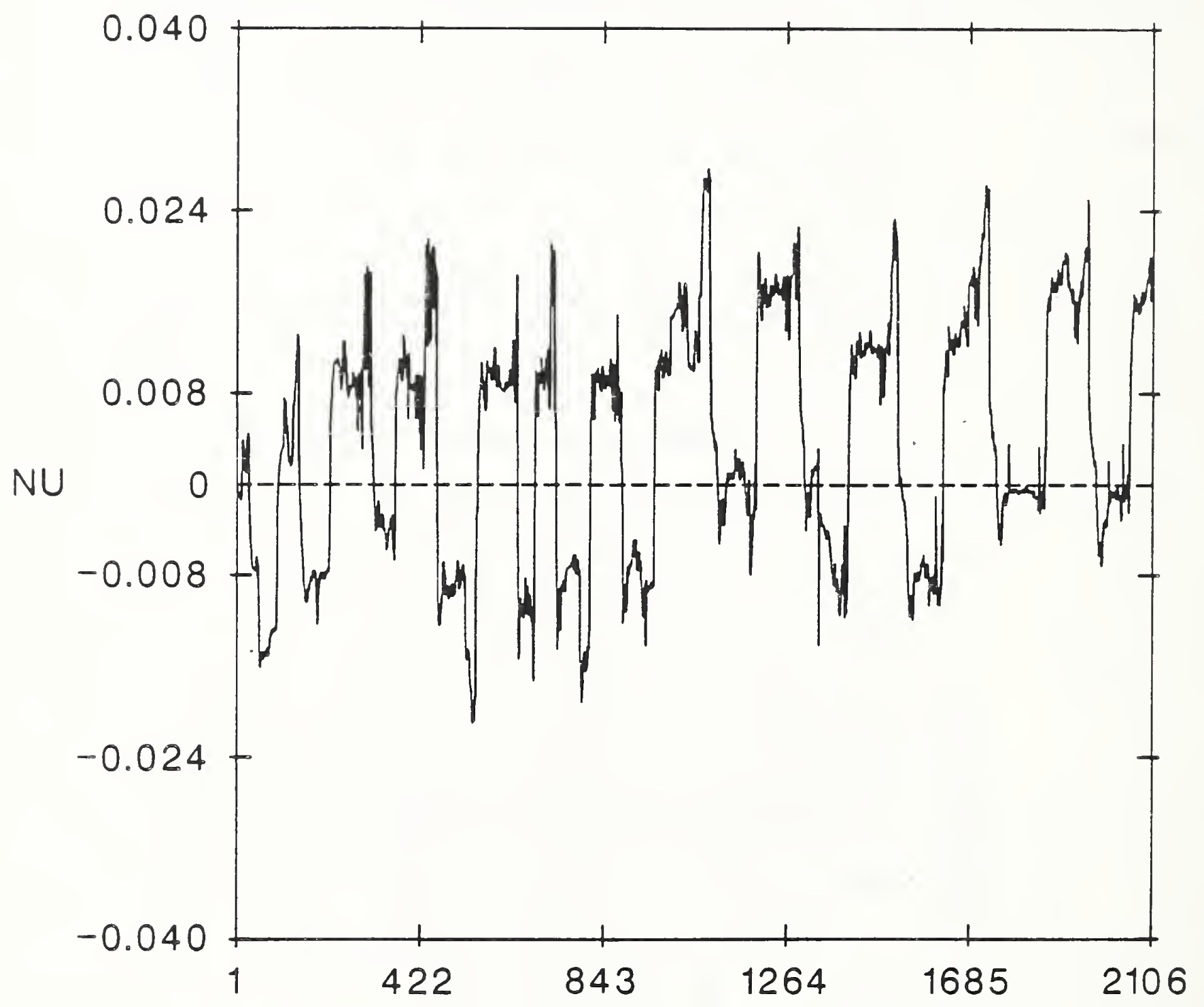

Figure 4.10: Variation of Coefficient of Friction for Supporting Roller System, Full Scale Flexure Column Test. X-Axis Represents Data Acquisition System Scan Number. Generally there were approximately equal number of scans per cycle so that individual complete cycles are represented by two sign reversals on the $y$-axis. 
Plots of load and moment versus column lateral displacement (base of column displacement relative to point of contraflexure) are presented in Figures 4.11 and 4.12. Significant drops in lateral load during an outward excursion signify points where either spiral or longitudinal reinforcing steel within the plastic hinge region fractured.

Figures $4.13,4.14$ and 4.15 compare performance of the full-scale shear column with its 1/6-scale models, including those for which higher axial loads were applied $\left(0.2 f^{\prime} c^{A} g\right.$ versus $\left.0.1 f^{\prime} c^{A}\right)$. Lateral load has been normalized by the calculated ACI lateral load $V_{i}$ which would cause a moment of $M_{i}$ at the column base, thus $M / M_{i}$ would have been equally applicable for the $\mathrm{y}$-axis label. The $\mathrm{x}$-axes in Figures 4.13 through 4.15 have likewise been normalized by dividing by yield deflection, $\Delta_{y}$, and thus represents displacement ductility $\mu$. The maximum moments for both full scale column and the model columns (N1, N4) which were constructed from microconcrete and ready mix concrete, respectively, were determined to be $1.18,1.16$, and 1.20 times the calculated ultimate moment using ACI procedures. Models N2 and N5 (identical to $\mathrm{Nl}$ and $\mathrm{N} 4$, respectively, but with the higher axial load ratio), showed peak $M / M_{i}$ ratios of 1.32 each, substantially higher than for the lower stressed columns. The moment enhancement for those columns with $\mathrm{P}_{e} / f^{\prime} c^{A}=0.1$ approximately agrees with the value of 1.13 predicted in Reference 17 for columns with $P_{e} / f^{\prime} c^{A} g \leq 0.1$. The 1.32 values for specimens $\mathrm{N} 2$ and $\mathrm{N} 5$ are on the high side of the $15 \%$ error band predicted in Reference 17 as follows:

$$
M / M_{i}=1.13+2.35\left(P_{e} / f^{\prime} c^{A} g-0.1\right)^{2}=1.15
$$

Ultimate displacement ductilities of 10,8 , and 10 were recorded for the full-scale column, and models $\mathrm{N} 1$ and $\mathrm{N} 4$ respectively. Note that maximum normalized displacements were approximately 10 and 12 for models N1 and N4 (Figure 4.8). However, these latter values were recorded after moment resistance had dropped below $0.8 \mathrm{M}$; thus they were not considered in the evaluation. All of the shear column specimens, both model and prototype, had ultimate displacement ductilities in excess of 6 , and thus would appear 

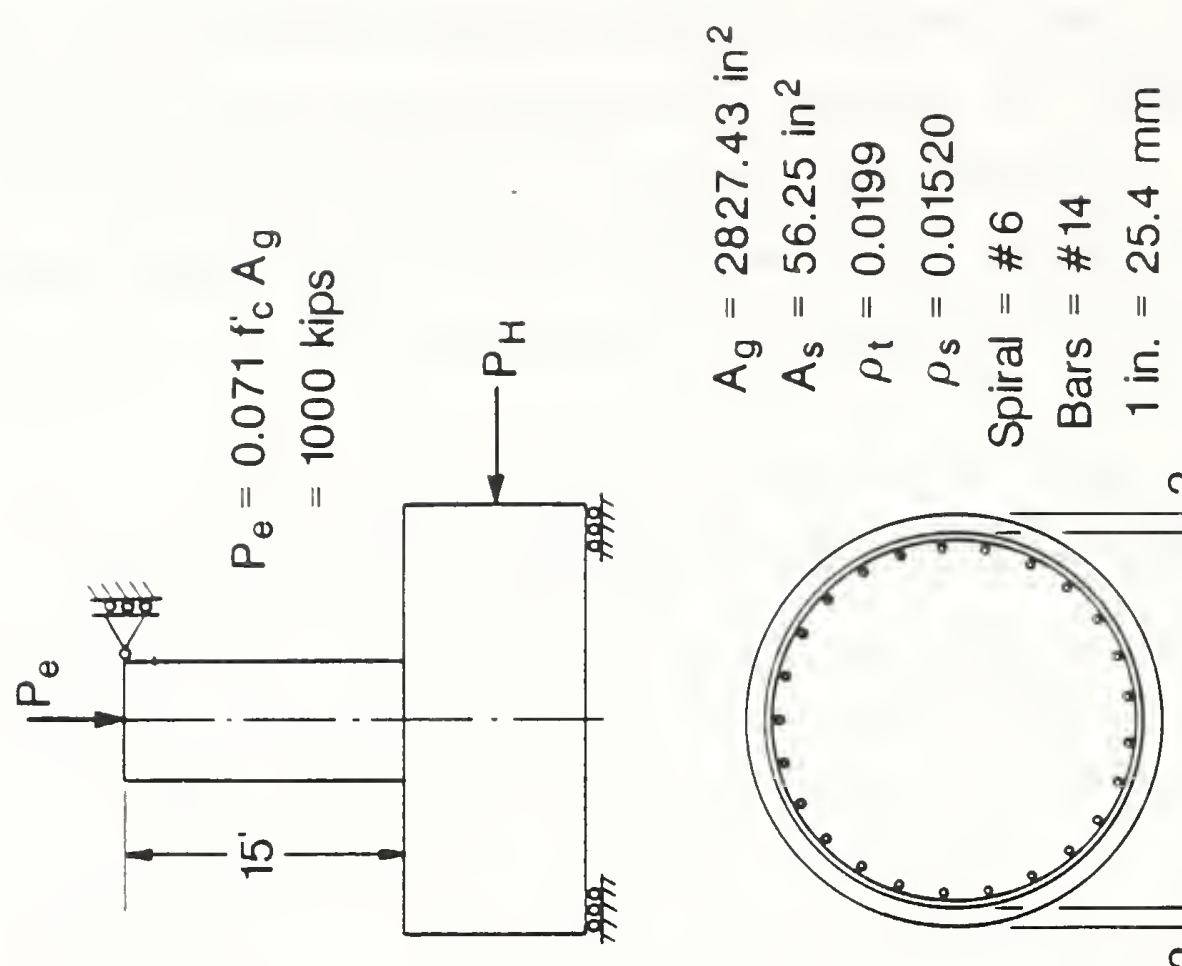

«

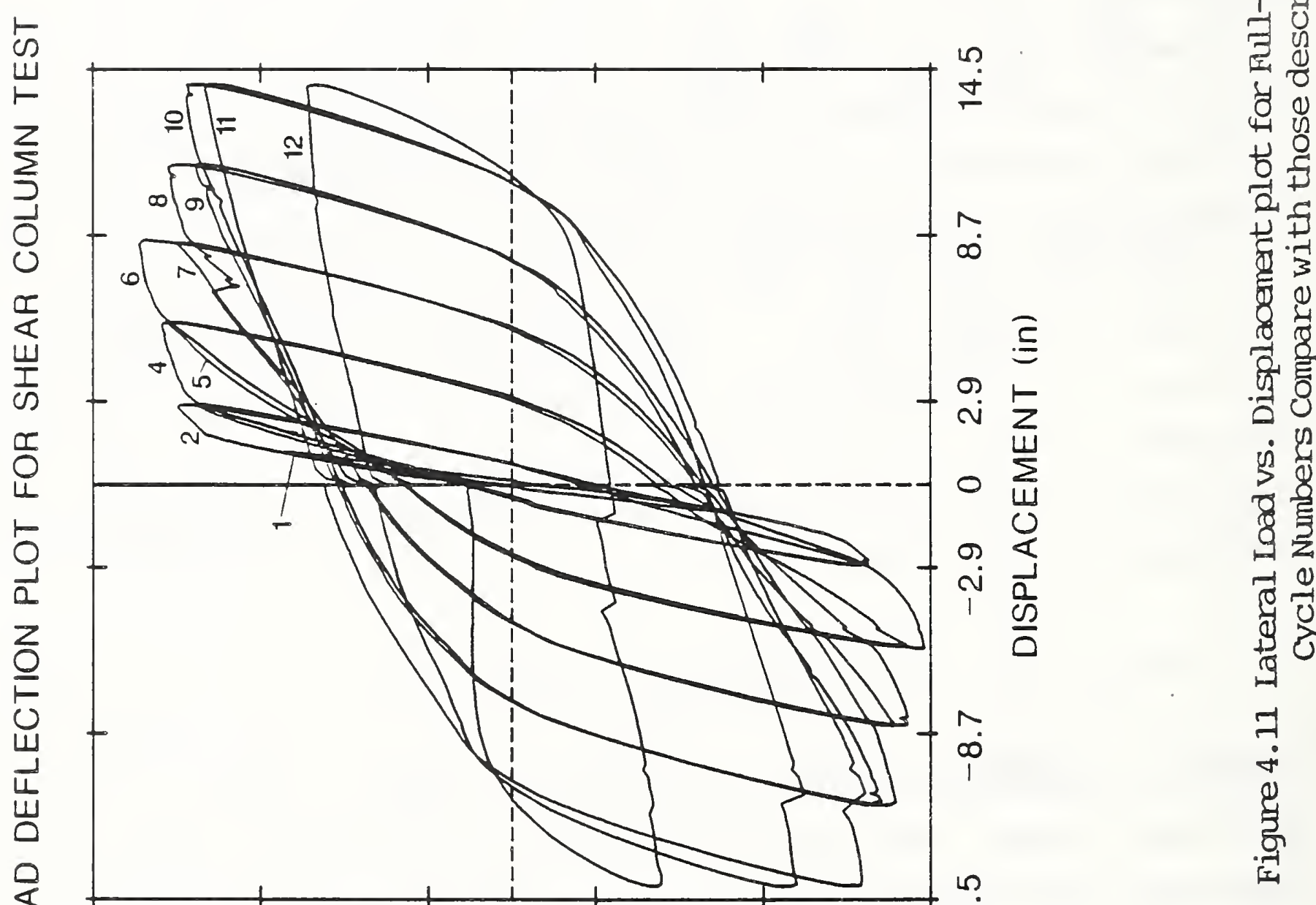




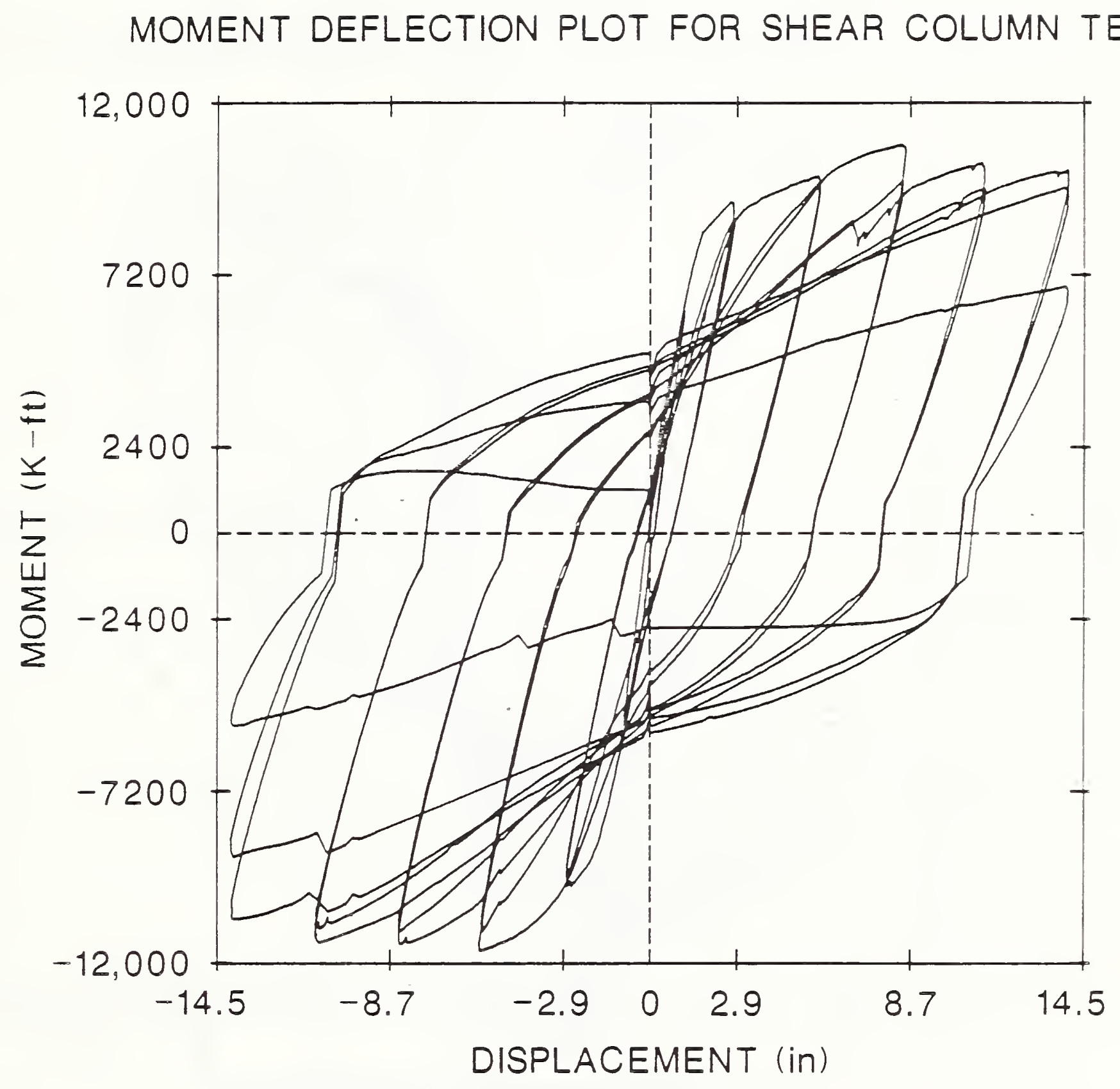

Figure 4.12: Moment versus Lateral Displacement plot for Full-Scale Shear Column Test. 


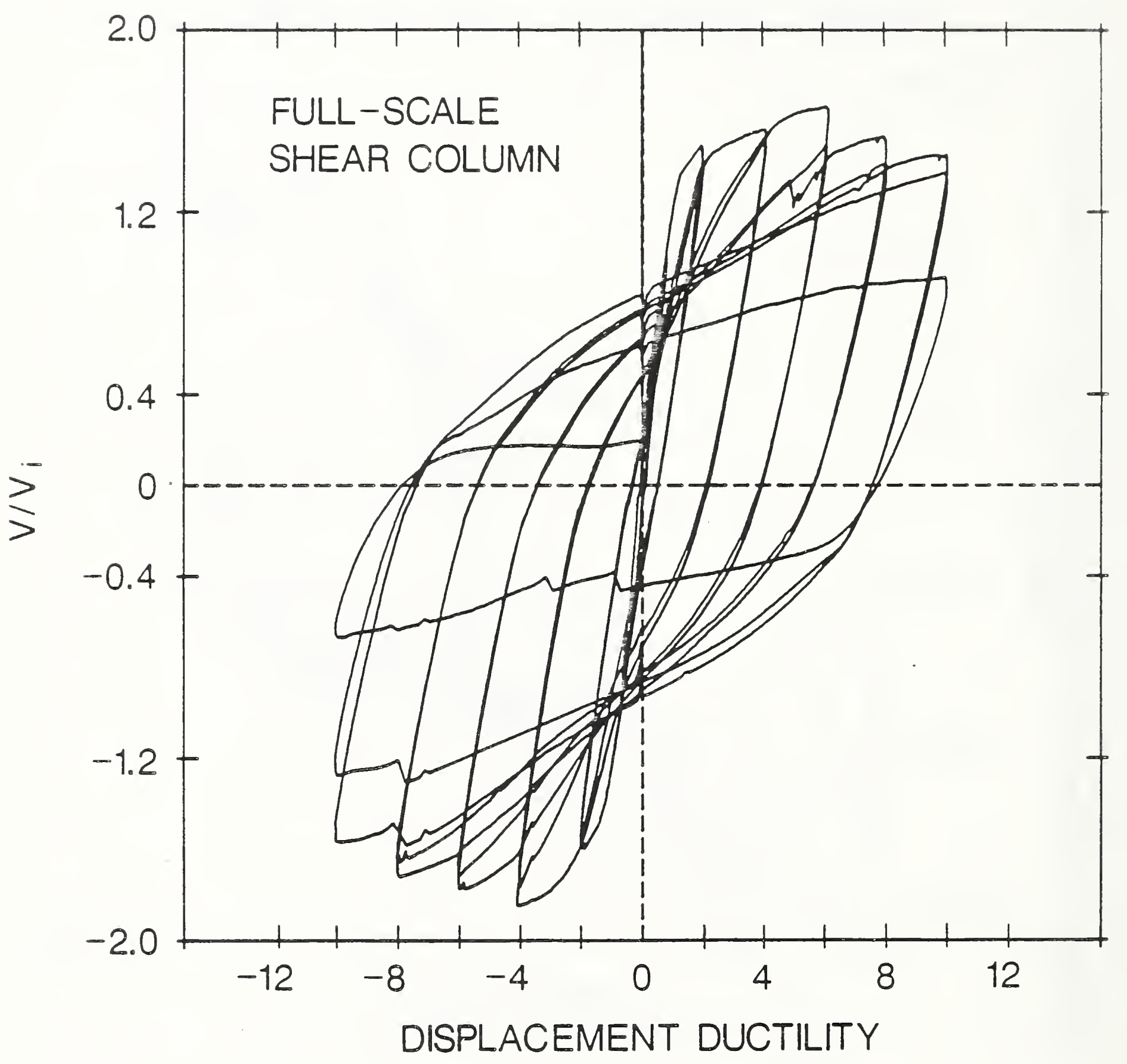

Figure 4.13: Normalized Lateral Load $\left(V / V_{i}\right)$ versus Displacement Ductility $\left(\Delta / \Delta_{y}\right)$ for Full-Scale Shear Column. 

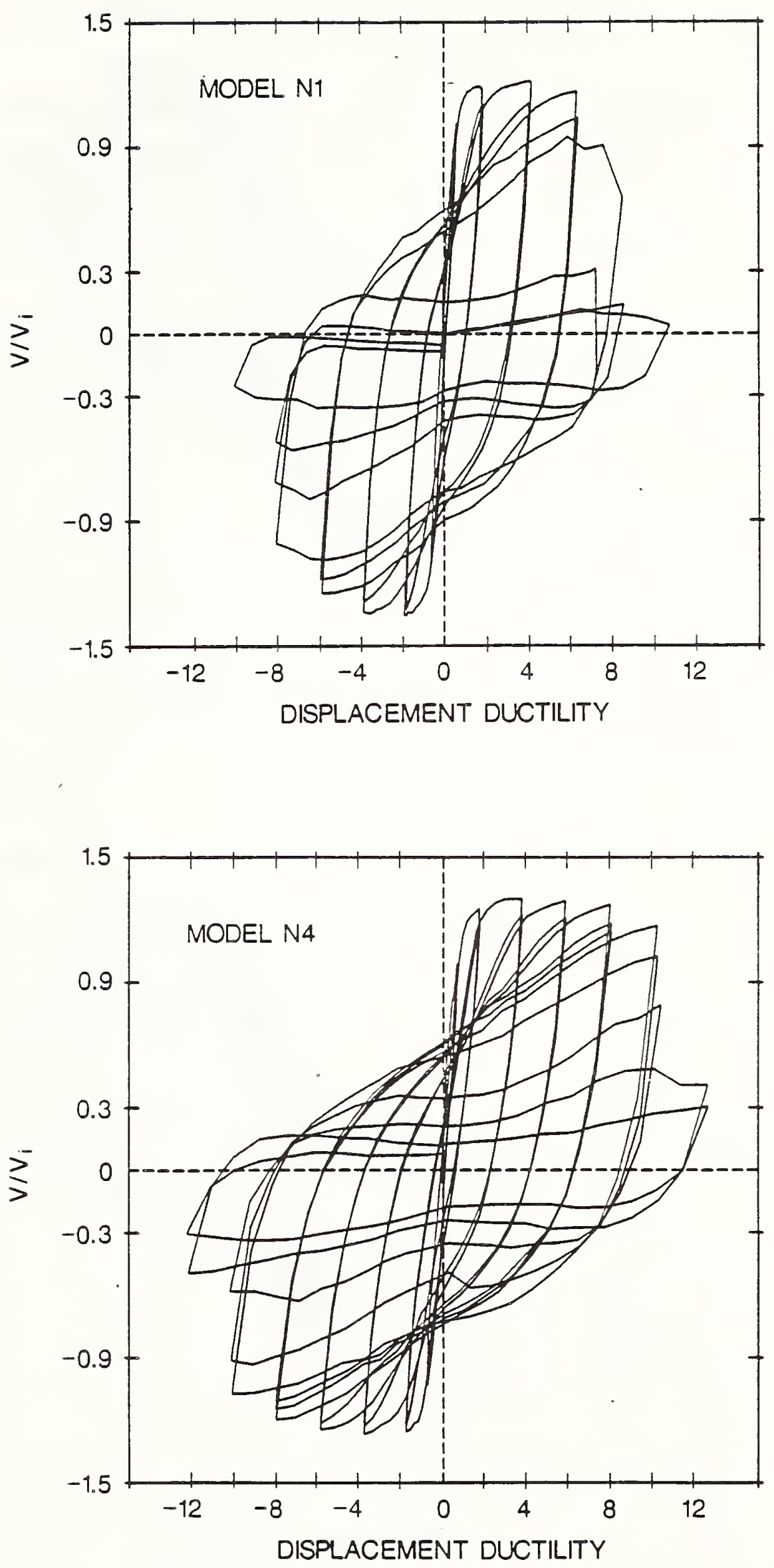

Figure 4.14: Normalized Lateral Load $\left(V / V_{i}\right)$ versus Displacement Ductility $\left(\Delta / \Delta_{y}\right)$ for $1 / 6$ Scale Model Shear Columns. $\mathrm{P}_{\mathrm{e}} /\left(\mathrm{f}^{\prime}{ }_{c^{\mathrm{A}} \mathrm{A}}\right) \approx 0.1$ 

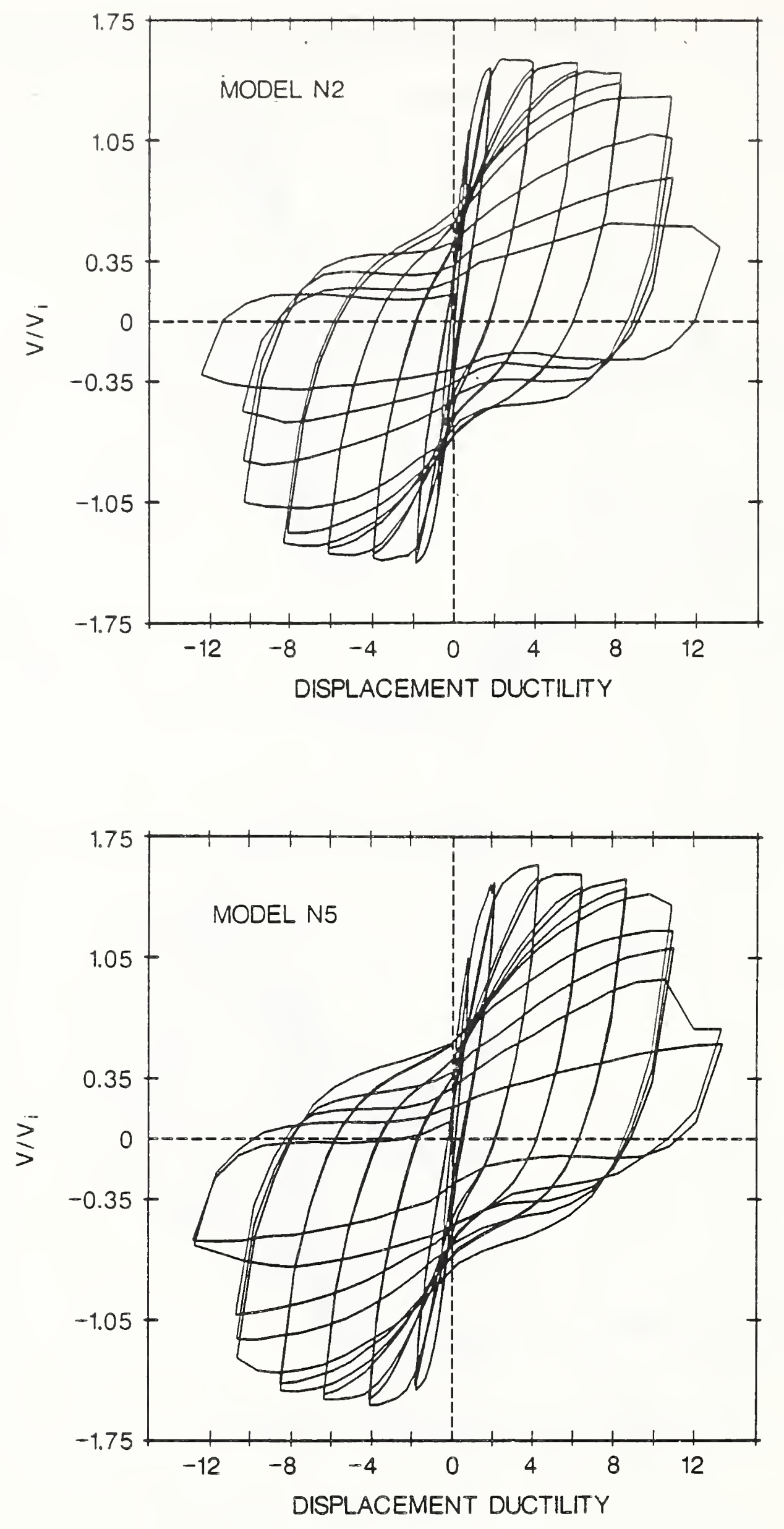

Figure 4.15: Normalized Lateral Load $\left(V / V_{i}\right)$ versus Displacement Ductility $\left(\Delta / \Delta_{y}\right)$ for $1 / 6$ Scale Model Shear Columns. $\mathrm{P}_{\mathrm{e}} /\left(\mathrm{f}^{\prime} \mathrm{c}^{\mathrm{A}} \mathrm{g}\right) \approx 0.2$ 
to be sufficiently reinforced. The amount of spiral reinforcement ( $\left.\rho_{\mathrm{S}}\right)$ provided for these columns, however, was substantially in excess of that required by Reference 6 with the final choice for $\rho_{s}$ for the shear column specimens being based on recommendations from CALTRANS [4].

Model specimens $\mathrm{N} 2$ and $\mathrm{N} 5$ (which had a $\mathrm{P}_{\mathrm{e}} / \mathrm{f}^{\prime} \mathrm{c}^{\mathrm{A}} \mathrm{g}$ value of 0.2 ) had ultimate displacement ductilities of 10 and 12 , respectively, which can be compared with values of 8 and 10 for specimens $N 1$ and $N 4 \quad\left(P / f^{\prime} c^{A} g=0.1\right)$. This indicates that, within the bounds studied in this test program, increased axial load appears to be beneficial. This hypothesis is further supported by comparing the load-displacement histories in Figures 4.14 and 4.15 which show consistently wider hysteresis loops for a given displacement ductility, indicating that more strain energy per cycle is dissipated inelastically. The ultimate moment capacities and displacement ductilities described above are summarized in Table 4.6 .

Table 4.6 Experimental Maximum Moment and Ductility Capacity

\begin{tabular}{|c|c|c|c|c|c|c|c|c|}
\hline \multirow[t]{2}{*}{ Specimen } & \multirow{2}{*}{$\frac{\mathrm{P}_{\mathrm{e}}}{\mathrm{f}^{\prime} \mathrm{c}^{\mathrm{A}} \mathrm{g}}$} & \multirow{2}{*}{$\begin{array}{l}\text { Aspect } \\
\text { Ratio } \\
\left(h_{1} / D\right)\end{array}$} & \multicolumn{3}{|c|}{ Ultimate Moment Capacity } & \multicolumn{3}{|c|}{ Ductility Capacity } \\
\hline & & & $\frac{M_{i}}{(k-f t .)}$ & $\begin{array}{c}M_{\exp } \\
\left(k-f t_{0}\right)\end{array}$ & $M_{i} / M_{\exp }$ & $\left(\begin{array}{c}\Delta y \\
\text { in.) }\end{array}\right.$ & $\begin{array}{l}\Delta u \\
\text { (in.) }\end{array}$ & $\mu=\Delta_{u} / \Delta_{y}$ \\
\hline N1 & 0.100 & 3 & 32.37 & 38.35 & 1.18 & 0.38 & 3.04 & 8.0 \\
\hline N2 & 0.210 & 3 & 35.37 & 46.52 & 1.32 & 0.22 & 2.20 & 10.0 \\
\hline N3 & 0.100 & 6 & 32.37 & 39.76 & 1.23 & 1.01 & 4.04 & 4.0 \\
\hline N4 & 0.100 & 3 & 32.37 & 37.48 & 1.16 & 0.21 & 2.10 & 10.0 \\
\hline N5 & 0.200 & 3 & 35.37 & 46.61 & 1.32 & 0.19 & 2.28 & 12.0 \\
\hline N6 & 0.110 & 6 & 32.37 & 36.87 & 1.14 & 0.66 & 3.30 & 5.0 \\
\hline Shear & 0.071 & 3 & 7988.30 & 11640.00 & 1.46 & 1.40 & 14.02 & 10.0 \\
\hline Flexure & 0.068 & 6 & 8041.10 & 9643.00 & 1.20 & 3.53 & 23.30 & 6.6 \\
\hline
\end{tabular}


4.3 Comparison of Test Results with New Zealand Design Charts for Structural Ductility.

It is useful at this point to make a comparison between the column ductilities measured in this study and their predicted ductility. Predicted ductilities are determined graphically from a design diagram presented in Reference 17, which is based on the New Zealand code, reproduced here as Figure 4.16. The $\mathrm{x}$-axis is the ratio of the volumetric ratio of confining reinforcement provided over that specified in NZ-3101 [20]. This ratio is represented by the letter $\alpha$. The $\alpha$ values for the tests reported in this paper are shown in Table 4.7. Also shown in the table are the observed experimental ultimate displacement ductility and the ductility predicted using Figure 4.16. The dark circles in Figure 4.16 represent the actual ultimate displacement ductilities observed during tests. The lines in Figure 4.16 show how the predicted values were obtained for the same specimens. The upper line is for columns with aspect ratios of 3 (the shear columns) the lower line for an aspect ratio of 6 (flexure columns). It is interesting to note that the ductility of the full-scale flexure specimen, which had approximately the amount of confining reinforcement required by NZ3101, agrees well with the predicted ductility value. The predicted ductilities for the flexure model specimens were, however, substantially greater than those observed experimentally. The same was true for both the prototype and model shear specimens. One possible cause for the discrepancy, in the more heavily confined shear specimens could be that large increases in the amount of confining steel become increasingly ineffective and asymptotically approach some maximum ductility. Experimental evidence to support this theory is contained in Reference 19 which shows that vastly increased amounts of spiral confinement in post-tensioned anchorage zones do not proportionally improve their ultimate load capacity. 


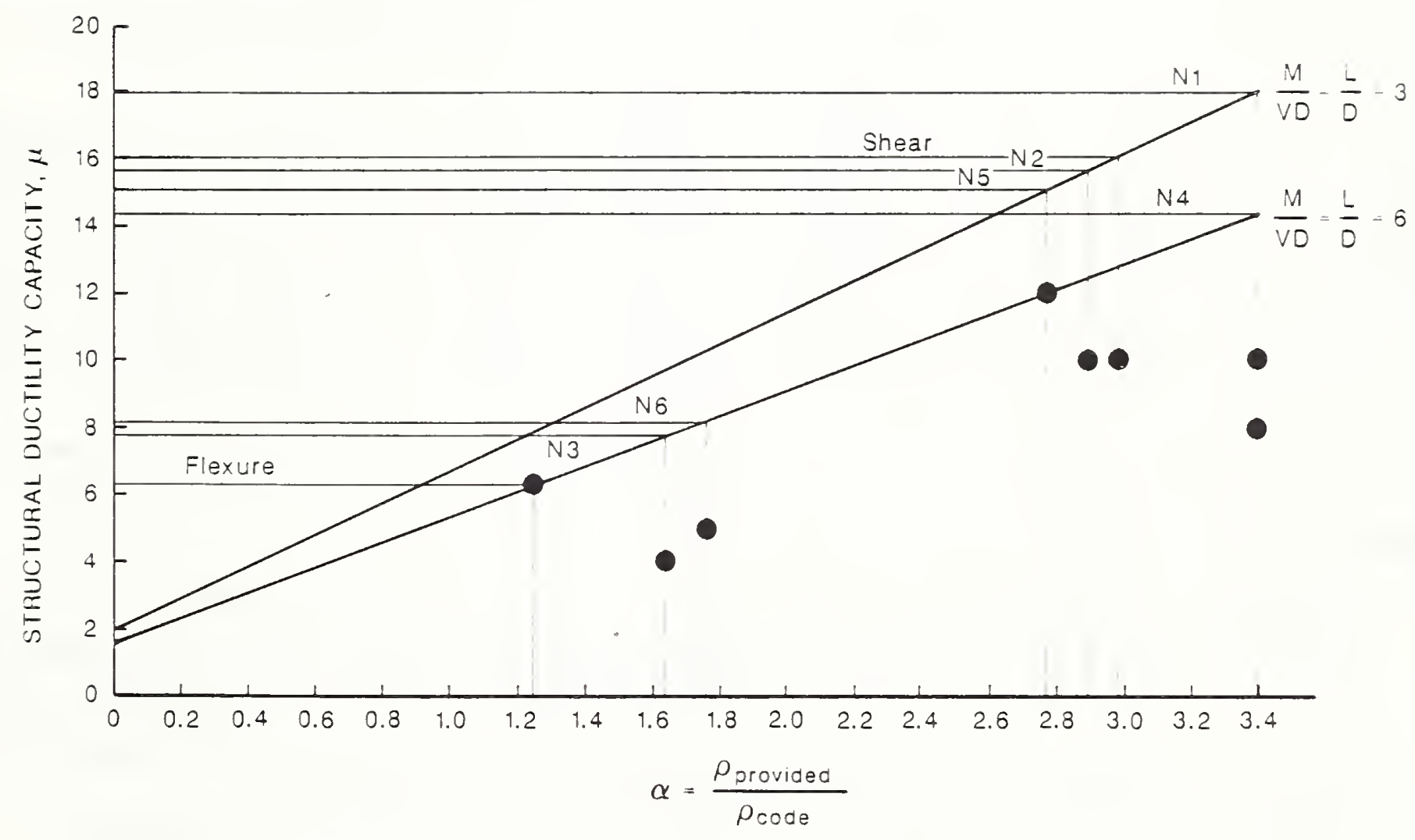

Figure 4.16 Structure Ductility Capacity Related to Confinement Ratio 
Table 4.7 Effectiveness of Confining Reinforcement: A Comparison of CALTRANS and NZ3101 Required Spiral Reinforcement and Experimental Ductility Factors.

\begin{tabular}{|c|c|c|c|c|c|c|c|c|}
\hline Specimen & $\frac{P_{e}}{f^{\prime} c^{A} g}$ & $\begin{array}{l}\text { Ratio } \\
\left(\mathrm{h}_{1} / \mathrm{D}\right)\end{array}$ & $\int_{p r v}$ & $\int$ code & $\begin{array}{c}\alpha= \\
\int_{\text {prv }} / \int_{\text {code }}\end{array}$ & $\mu_{\exp }$ & $\mu_{\mathrm{n} z}$ & $\mu_{\exp } / \mu_{\mathrm{nz}}$ \\
\hline $\mathrm{NI}$ & 0.100 & 3 & .0145 & .0042 & 3.40 & 8.0 & 17.5 & 0.46 \\
\hline $\mathrm{N} 2$ & 0.210 & 3 & .0145 & .0050 & 2.86 & 10.0 & 15.5 & 0.65 \\
\hline N3 & 0.100 & 6 & .0069 & .0041 & 1.63 & 4.0 & 7.5 & 0.53 \\
\hline N4 & 0.100 & 3 & .0145 & .0042 & 3.40 & 10.0 & 14.1 & 0.71 \\
\hline N5 & 0.200 & 3 & .0145 & .0052 & 2.75 & 12.0 & 15.0 & 0.80 \\
\hline N6 & 0.110 & 6 & .0069 & .0038 & 1.76 & 5.0 & 8.0 & 0.63 \\
\hline Shear & 0.071 & 3 & .0152 & .0050 & 2.96 & 10.0 & 16.0 & 0.63 \\
\hline Flexure & 0.068 & 6 & .0065 & .0052 & 1.22 & 6.6 & 6.1 & 1.08 \\
\hline
\end{tabular}

Where

$\left(h_{1} / \mathrm{D}\right)=$ column height (to point of contraflexure) divided by diameter lprv = spiral volumetric reinforcement specified by CALTRANS [18] for the present test series. Note that for specimens N1, N2, N4, N5, and the full scale shear column, fprv was substantially greater than that called for in Reference 6.

Coode = spiral volumetric reinforcement required by $\mathrm{NZ}-3101$ [20]

= the greater of:

$=0.45\left(A_{g} / A_{c}-1\right)\left(f^{\prime}{ }_{c} / f_{y h}\right)\left(0.5+1.25 P_{e} /\left(\phi f^{\prime}{ }_{c} A_{g}\right)\right)$

or

$=0.12\left(f^{\prime} c / f_{y h}\right)\left(0.5+1.25 P_{e} /\left(\phi f^{\prime} c^{A} g\right)\right)$

$\mu_{\exp } \quad=$ experimental ultimate ductility

$\mu_{\mathrm{nz}} \quad=$ predicted ultimate ductility from Figure 4. 16

$\phi \quad=$ strength reduction factor for confined members $=0.9$ 


\subsection{Strain in Longitudinal Reinforcement}

Figures 4.17 through 4.24 show longitudinal reinforcing strains superimposed on an outline of the test specimen. The vertical axis represents the elevation of a specific strain gage above or below (negative units) the column base. For reference, the axial and lateral load directions are shown on each figure. Model specimens were oriented such that they were displaced along a north-south direction while the full scale specimens were displaced along an east-west direction. These directions are noted only because they were used in Chapter 3 , as well as Reference 1 , in the cycle-by-cycle descriptions of the column tests; specimen behavior obviously is not dependent on magnetic bearing.

Each specimen contained strain gages on the four longitudinal reinforcing bars which were furthest from the neutral axis, thus providing redundant measurements for both sides. Following the specimen orientation convention described above, the full scale specimens contained east and west longitudinal bar gages; models contained north and south longitudinal bar gages.

The longitudinal bar yield strain for the models and prototypes were 2184 and 2511 microstrain, respectively. Tables 4.8 and 4.9 list the depth to which the longitudinal reinforcement yielded in the column foundation and the height above the column base to which yielding progressed prior to column failure.

Two trends are observed in the data in Table 4.8. First, increased aspect ratio $\left(h_{1} / D\right)$ leads to nominally decreased yield length of longitudinal reinforcement in the foundation. Increasing column axial load, on the contrary, tends to increase the depth of yielding. The maximum depth of yielding for all cases is approximately half of the column diameter. The experimental yield lengths varied between 19-38\% of the ACI specified development lengths. 
Table 4.8: Extent of Yielding of Longitudinal Reinforcement in Column Foundation

\begin{tabular}{|c|c|c|c|c|c|}
\hline Specimen & $\begin{array}{l}\text { Yield Dis. } \\
\quad \text { (in.) } * *\end{array}$ & $\begin{array}{c}D \\
\text { (in.) }\end{array}$ & $\mathrm{YD} / \mathrm{D}$ & $\left(\begin{array}{l}1_{d} \\
\text { in })\end{array}\right.$ & $\mathrm{YD} / 1_{\mathrm{d}}$ \\
\hline N1 & 3.3 & 9.8 & .34 & $15.3^{*}$ & .21 \\
\hline $\mathrm{N} 2$ & 4.7 & 9.8 & .48 & $15.6 *$ & .30 \\
\hline N3 & 2.8 & 9.8 & .29 & $14.9 \%$ & .19 \\
\hline $\mathrm{N} 4$ & 4.8 & 9.8 & .49 & $15.2^{*}$ & .32 \\
\hline N5 & 5.4 & 9.8 & .55 & $15.2^{*}$ & .36 \\
\hline N6 & 3.8 & 9.8 & .39 & $15.5^{*}$ & .24 \\
\hline SHEAR & 31.7 & 60.0 & .53 & 83.0 & .38 \\
\hline FLEXURE & 25.6 & 60.0 & .42 & 81.2 & .31 \\
\hline
\end{tabular}

* Scaled from prototype development length using $1_{\mathrm{d}}=0.085 \mathrm{f} /{ }_{\mathrm{f}}{ }^{\prime} \mathrm{c}$ and a scale factor of 6.1 .

** Average of four values representing the peaks for the east and west (north and south, models) instrumented bars at their displacement maxima to either side of center position.

Where:

$Y D=$ length of longitudinal reinforcement embedded in foundation over which yielding has occurred (inches)

$I_{D}=A C I$ development length (inches) for longitudinal reinforcement $D^{D}=$ column diameter (inches) 

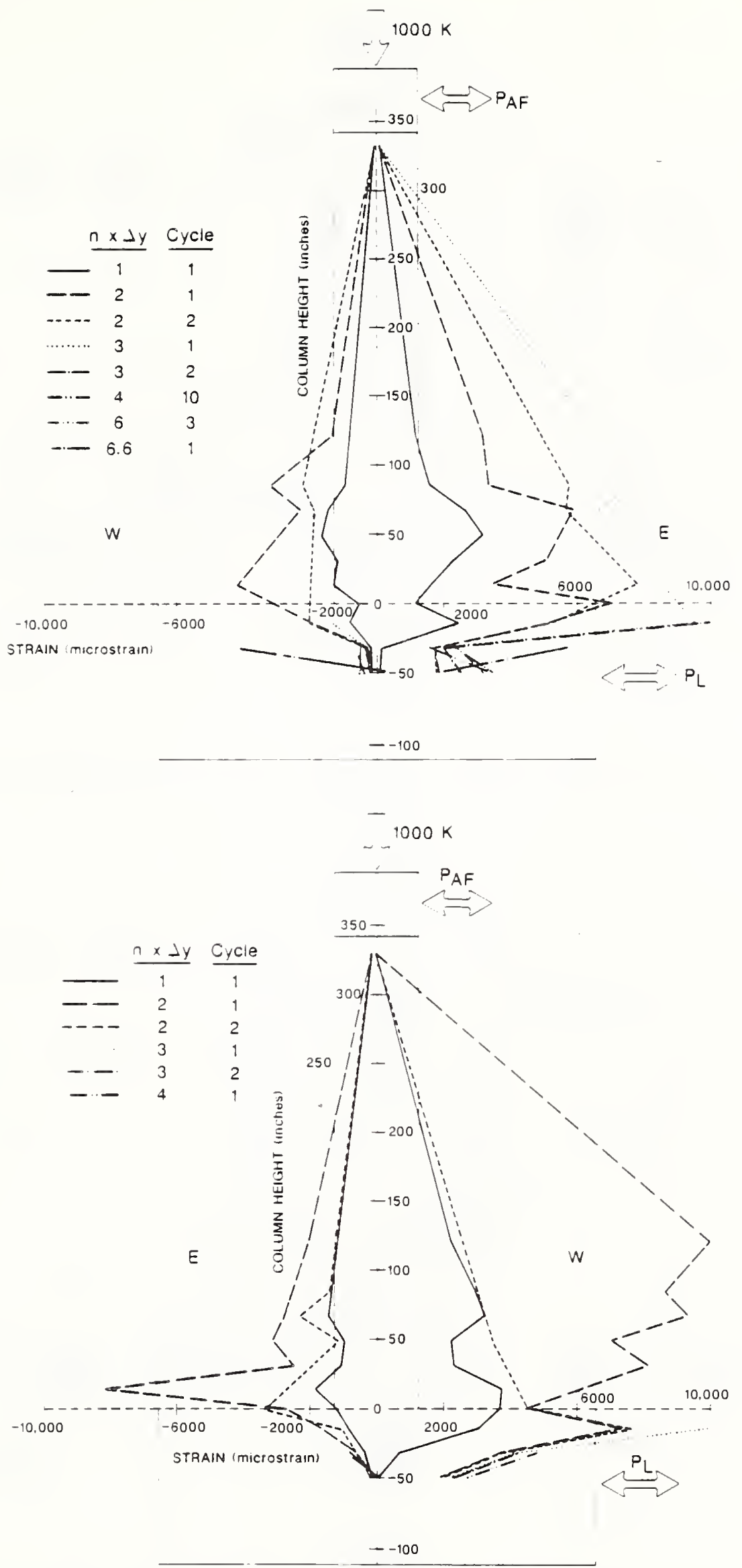

Figure 4.17: Longitudinal Reinforcement Strains for Full-Scale Flexure Column. Top Figure

= East Gage Set; Bottom = West Gage Set 

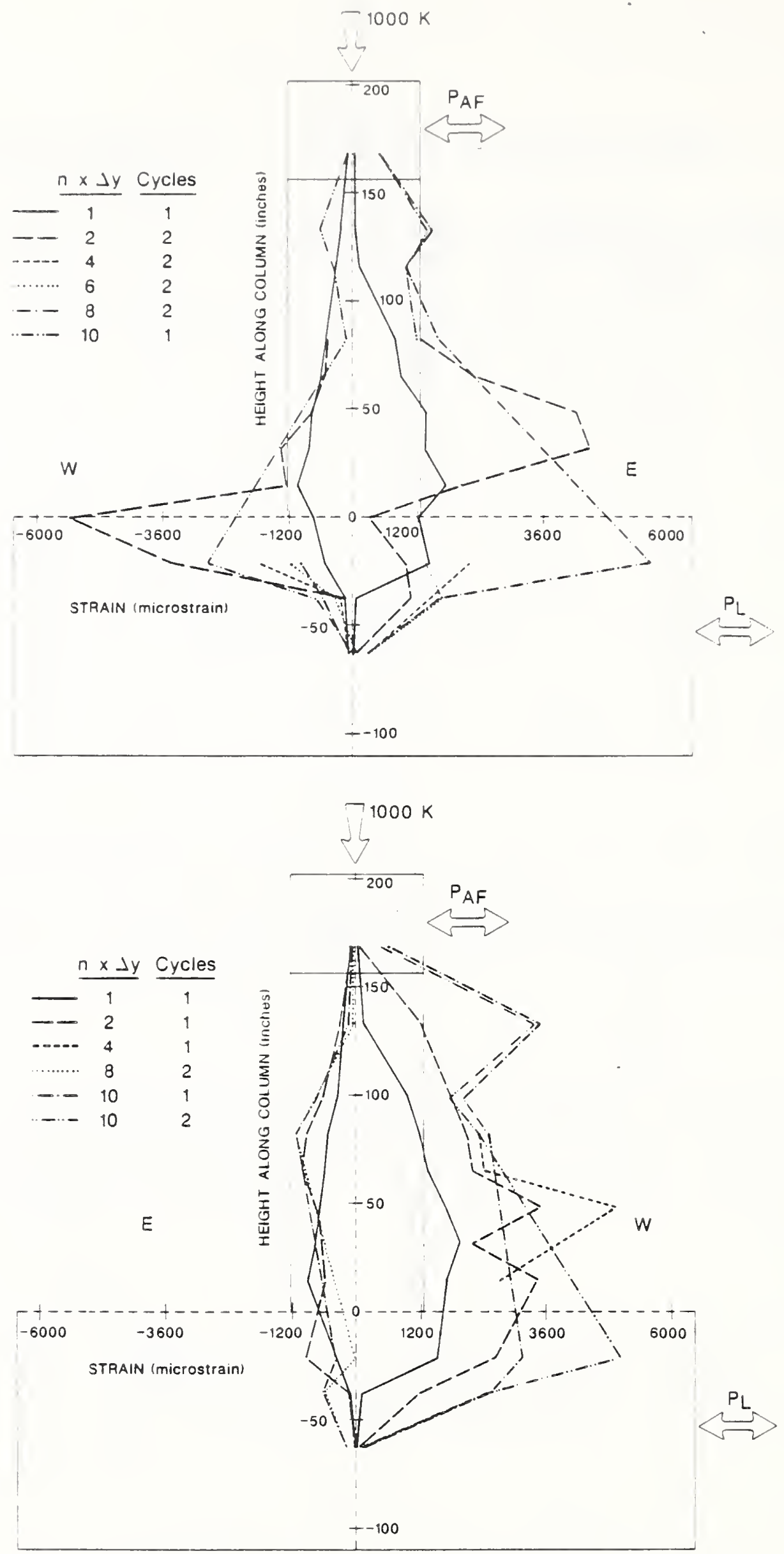

Figure 4.18: Longitudinal Reinforcement Strains for Full-Scale Shear Column. Top Figure

= East Gage Set; Bottom = West Gage Set 

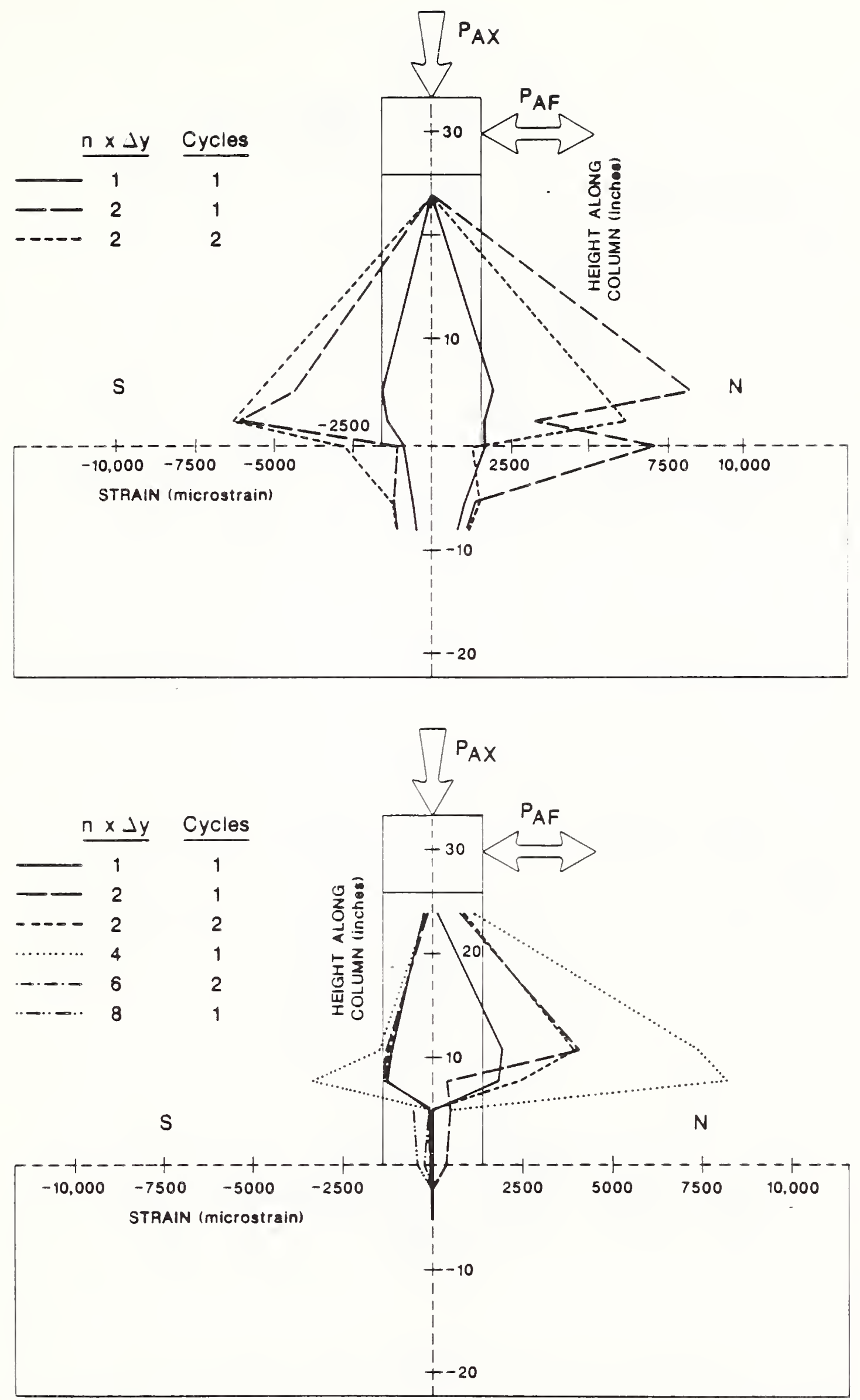

Figure 4.19: Longitudinal Reinforcement Strains for Model N1 Top Figure = North Gage Set; Bottom $=$ South Gage Set 

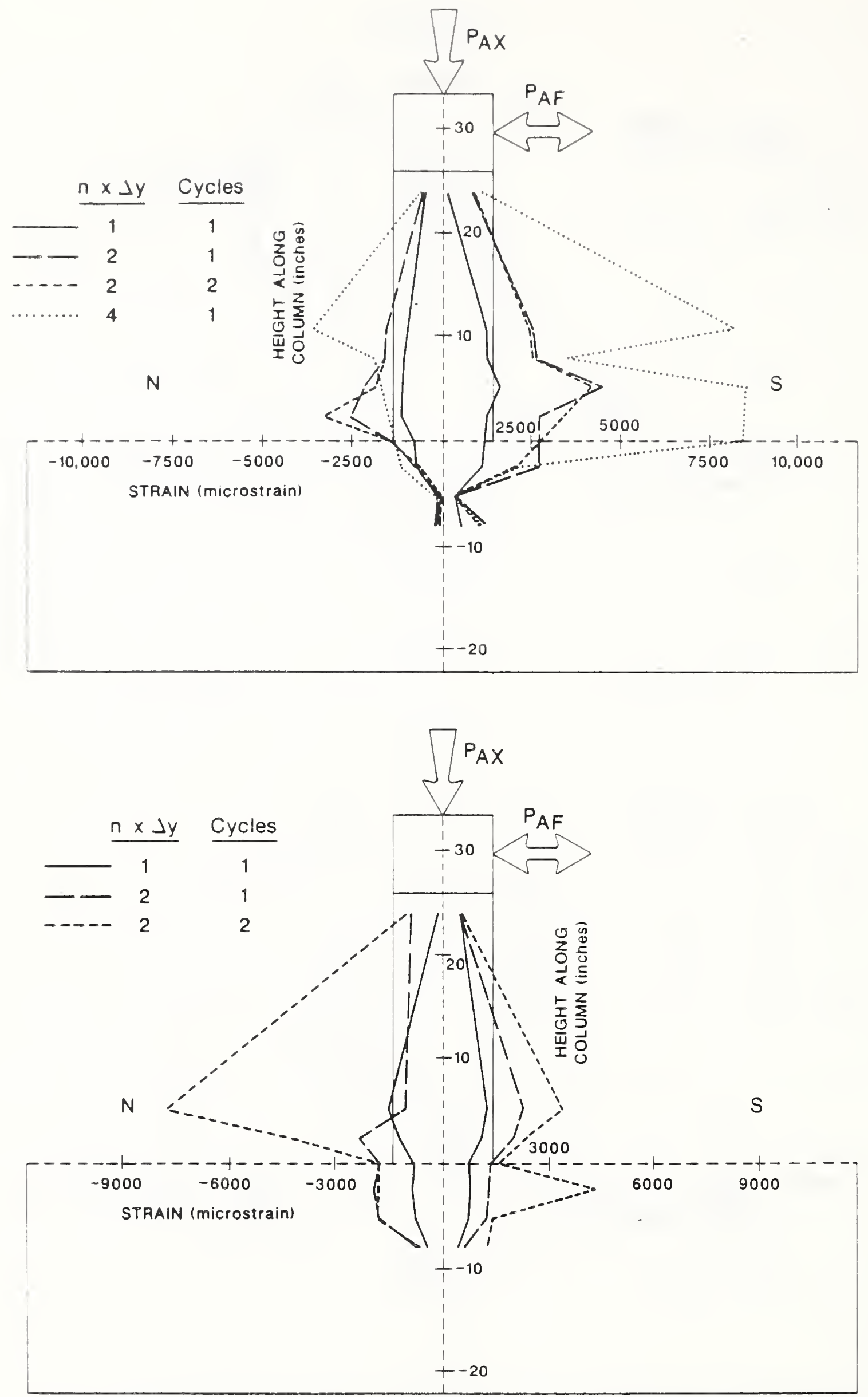

Figure 4.20: Longitudinal Reinforcement Strains for Model N2 Top Figure = North Gage Set; Bottom = South Gage Set 

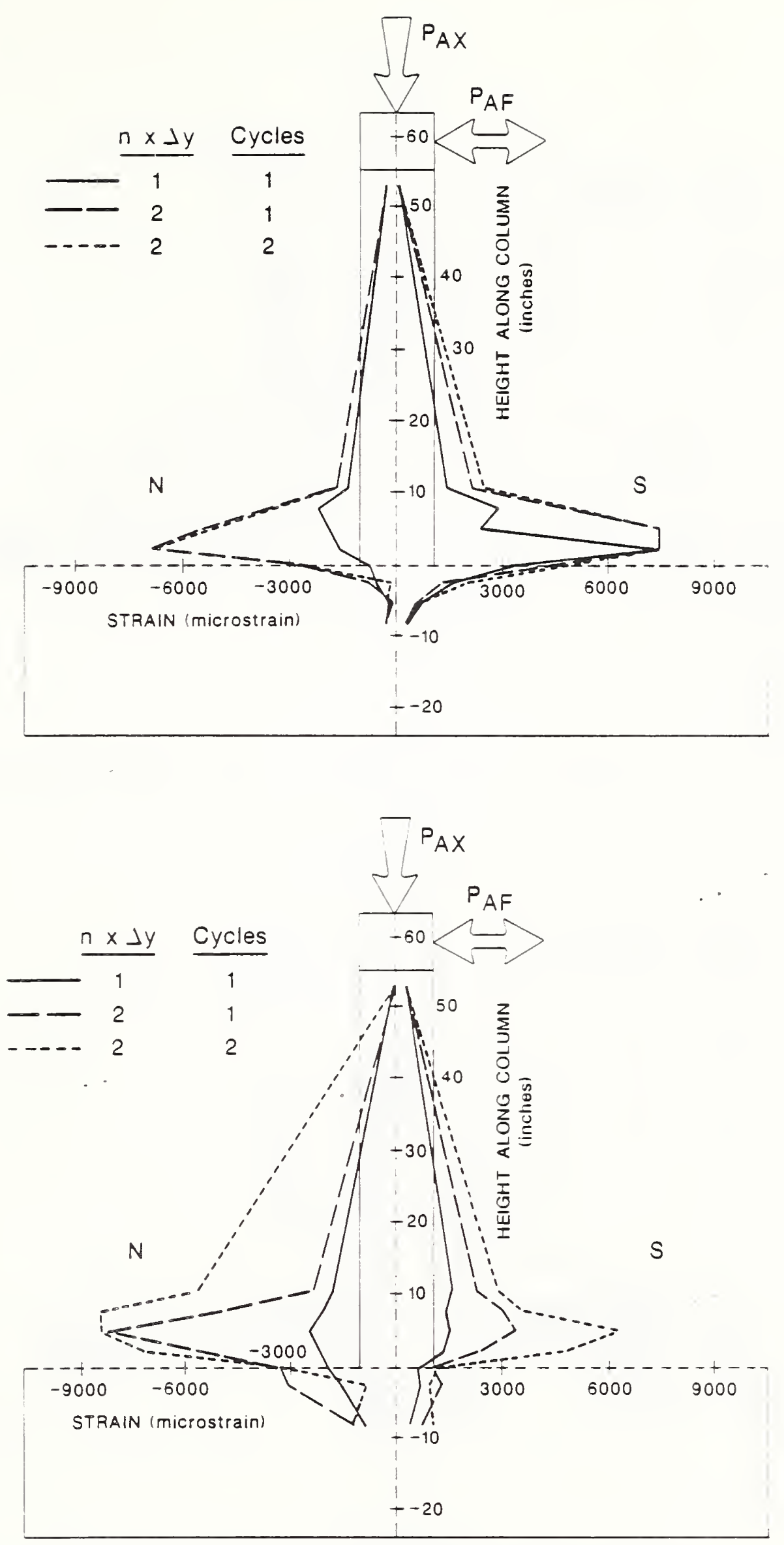

Figure 4.21: Longitudinal Reinforcement Strains for Model N3 Top Figure = North Gage Set; Bottom = South Gage Set 

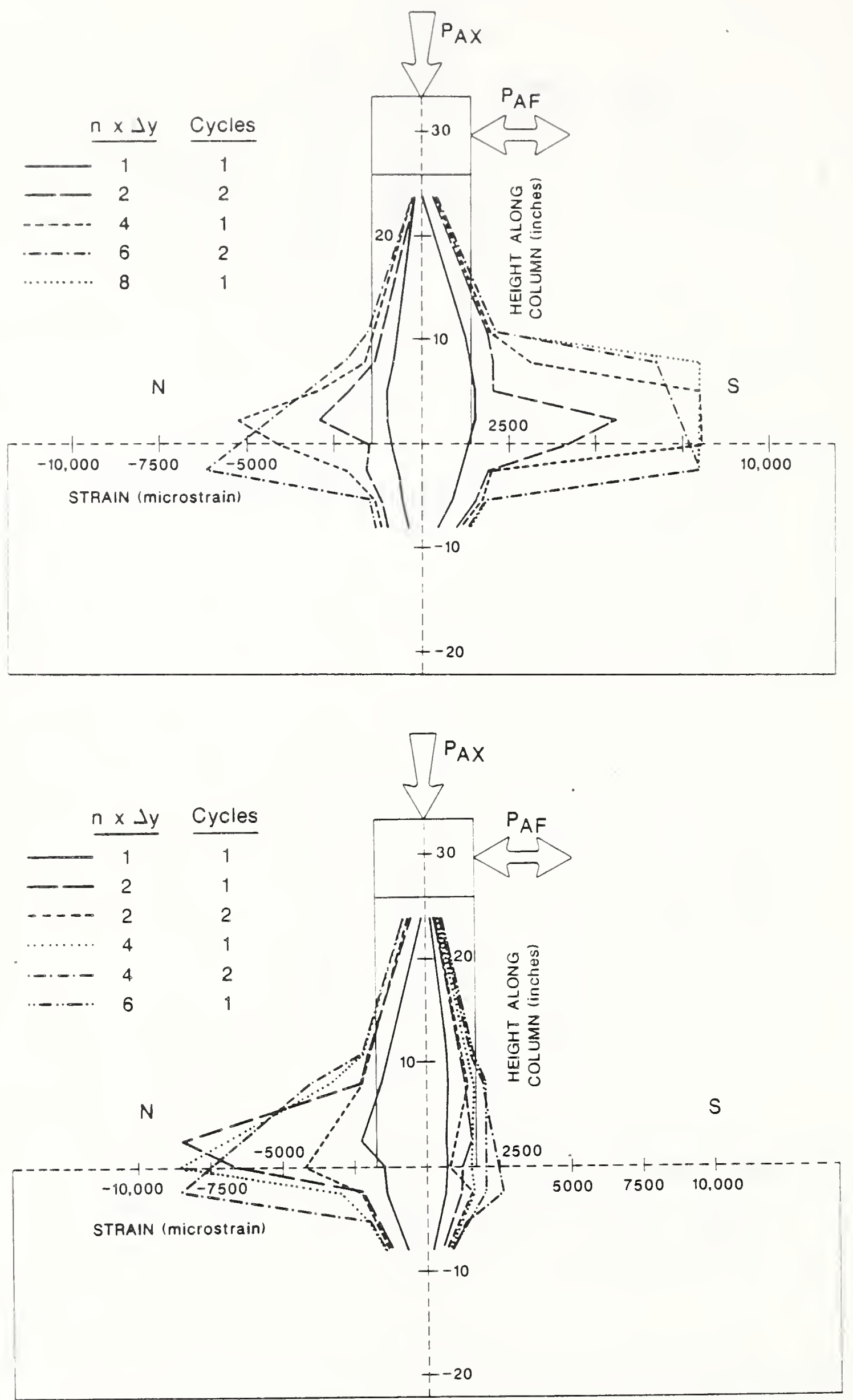

Figure 4.22: Longitudinal Reinforcement Strains for Model N4 Top Figure = North Gage Set; Bottom = South Gage Set 

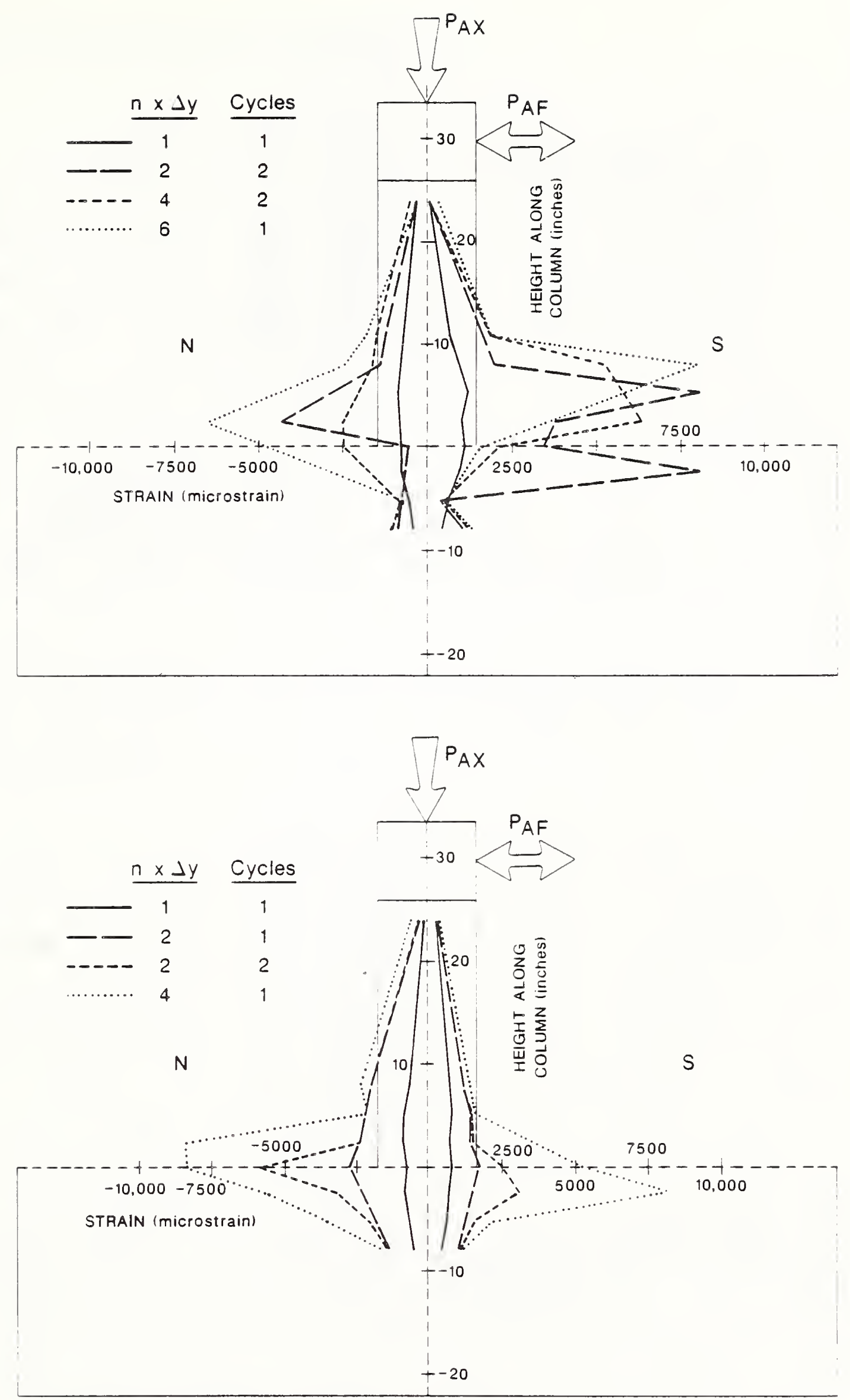

Figure 4.23: Longitudinal Reinforcement Strains for Model N5 Top Figure = North Gage Set; Bottom = South Gage Set 

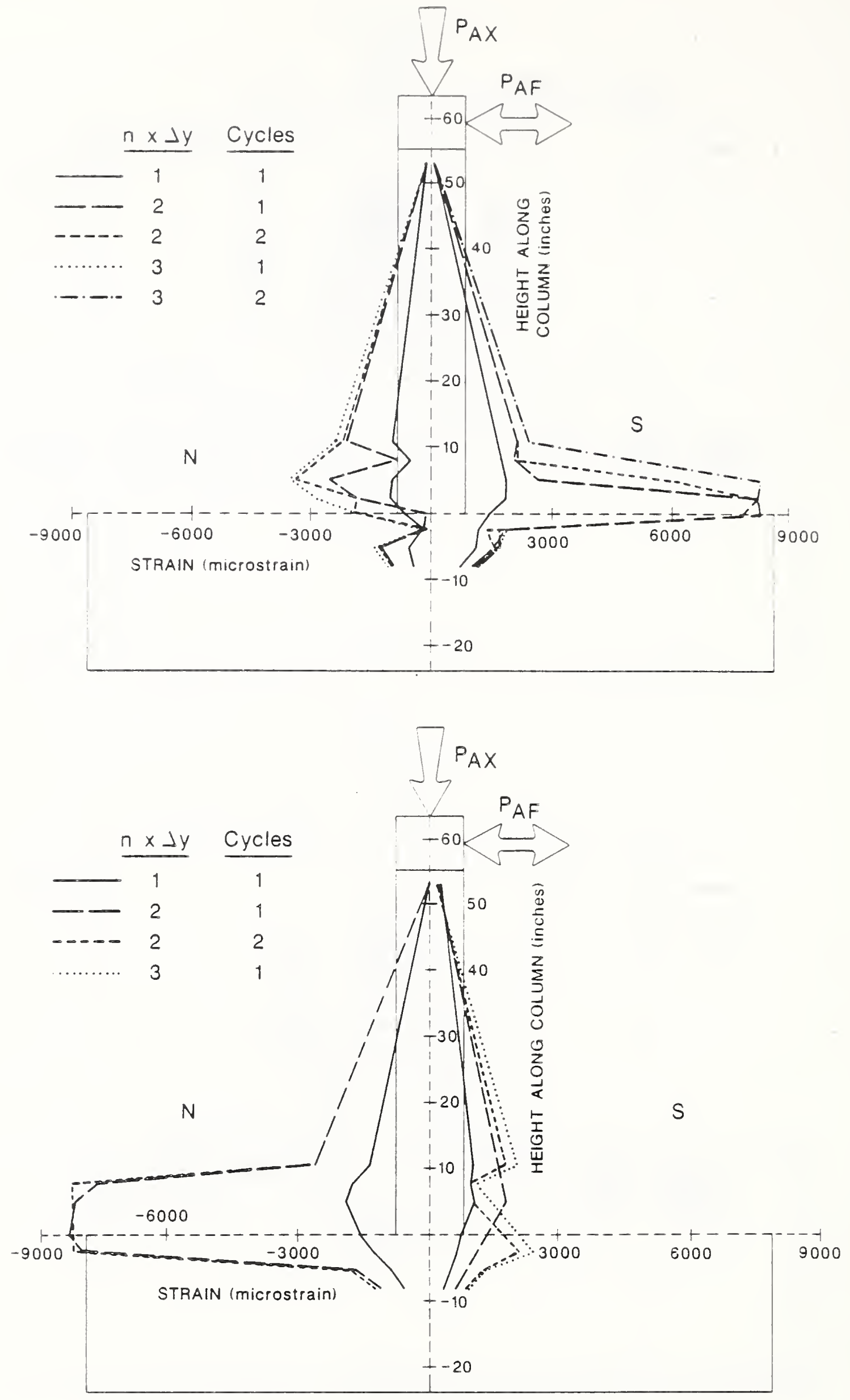

Figure 4.24: Longitudinal Reinforcement Strains for Model N6 Top Figure = North Gage Set; Bottom = South Gage Set 


\subsection{Strains in Confining Reinforcement}

Figures 4.25 through 4.32 present strain profiles for the confining reinforcement in a manner analogous to that for the longitudinal reinforcement. These generally indicate, that there is minimal yielding of the spiral inside the foundation block and that most of the confining stresses are concentrated between the base of the column and a height approximately one column diameter above the base. Above this elevation there is a rapid decrease in confining steel strain to well below yield levels even at the highest displacement ductilities. No clear differences existed between specimens with different column aspect ratios and differing axial loads.

\subsection{Column Curvatures and Estimation of Plastic Hinge Lengths}

If the axial strains are known at two locations on opposing sides of the neutral axis at the same elevation above the column base, then the column curvature at that point is given by:

$$
I / R=\left(\epsilon_{1}-\epsilon_{2}\right) / X
$$

Where $\epsilon_{1}$ and $\epsilon_{2}$ are the two measured strains and $X$ is the separation distance between the two instrumented locations. Generally, $X$ is taken to be the column diameter, $D$, and the strains can be measured either by means of strain gages on longitudinal reinforcement or by means of external potentiometers. The latter technique is useful provided a stiff mounting mechanism is available that is unaffected by concrete spalling. This technique is more resilient and can be used to observe variations in curvature to lateral displacements near failure. The strain gage approach was used initially and generally produced reliable information for only a few cycles beyond a displacement of $2 \Delta_{y}$, at which point the gages typically debonded at their limiting strain. The external clip gage technique was implemented for the second full scale test and produced reliable results up to a displacement of $6 \Delta_{y}$. At that point the lower gages were removed so as to prevent damage from spalling concrete.

Plots of column curvature are presented in Figures 4.33 through 4.37. 


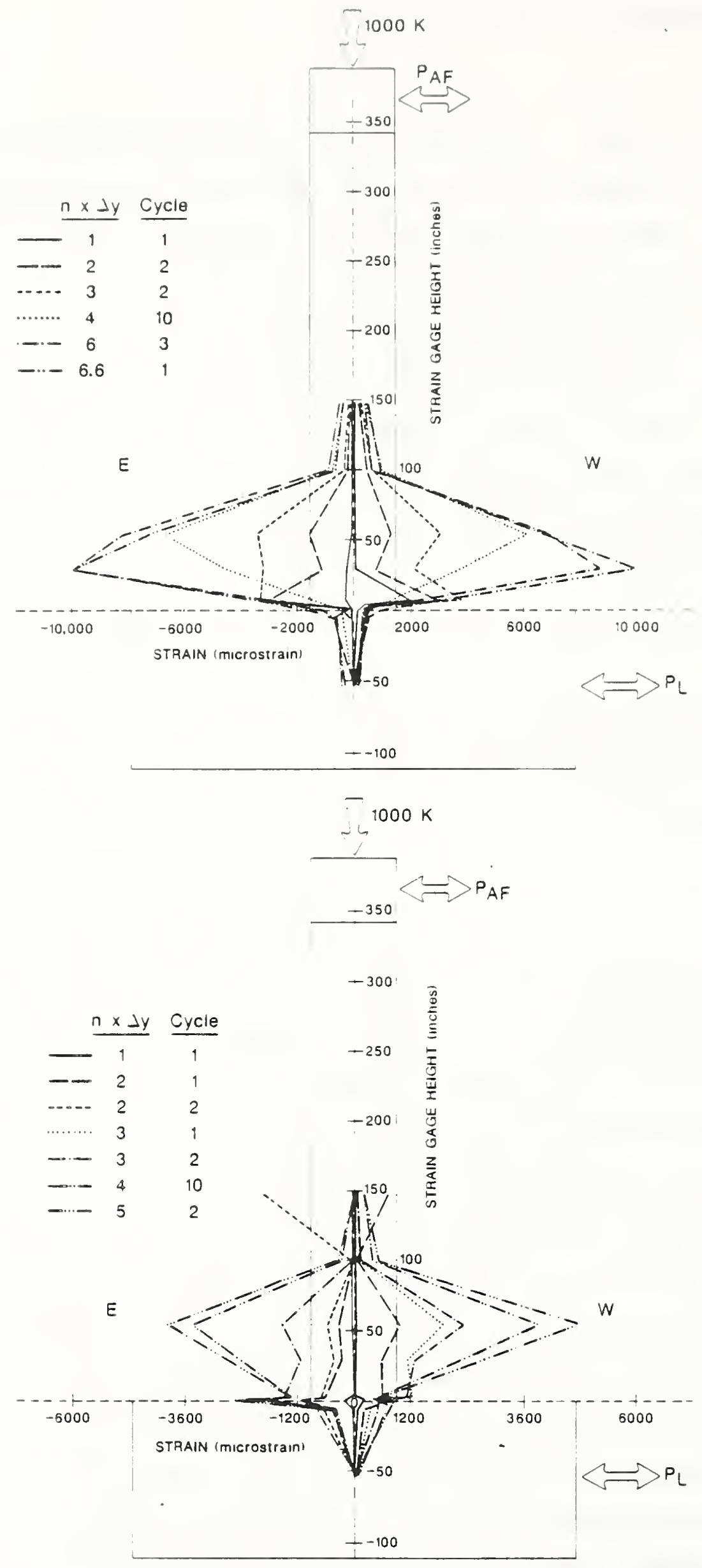

Figure 4.25: Confining Steel Strain for Full-Scale Flexure Column. Top Figure = North Gages; Bottom Figure = South Gages . 


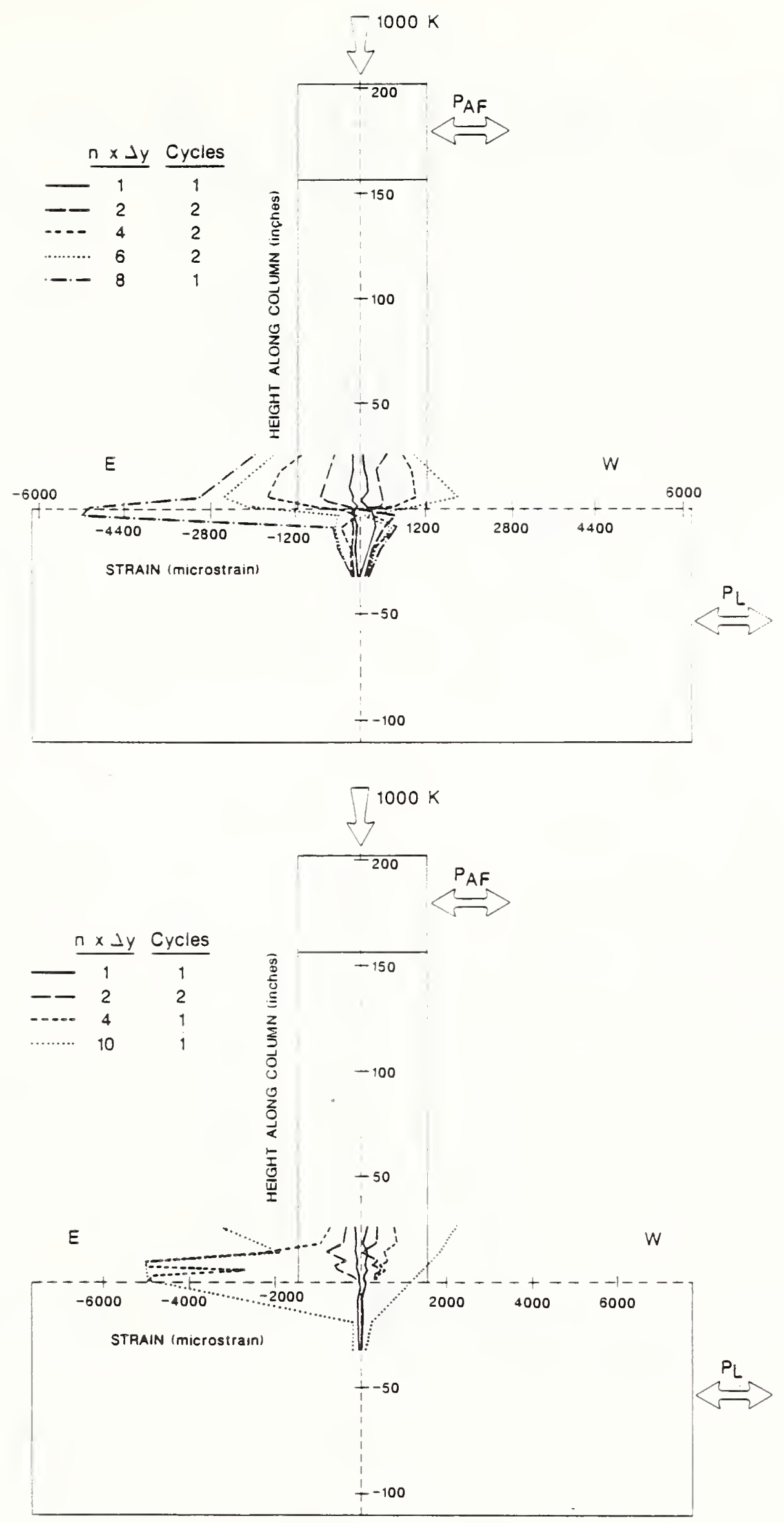

Figure 4.26: Confining Steel Strain for Full-Scale Shear Column. Top Figure = North Cages; Bottom Figure = South Cages .

111 

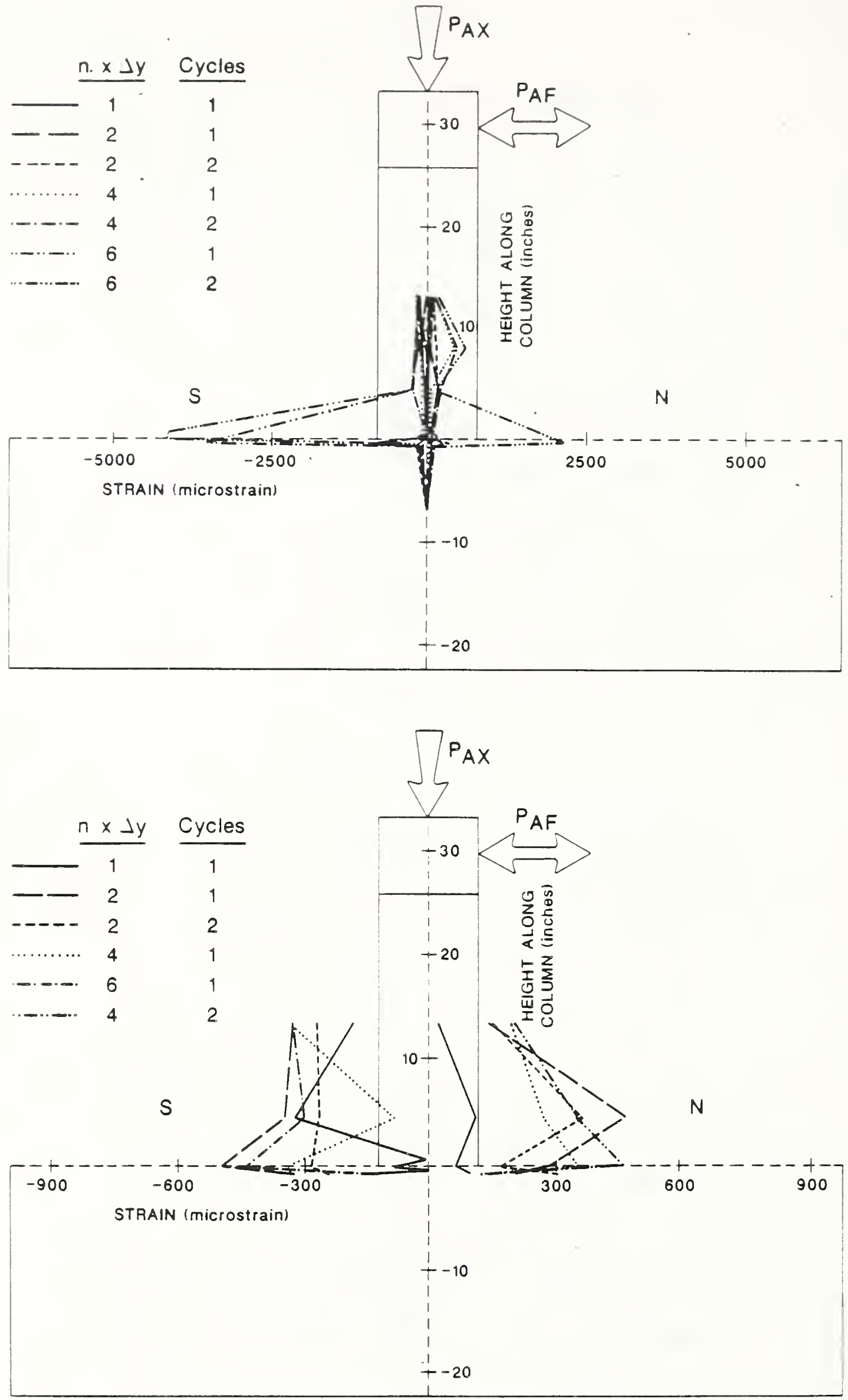

Figure 4.27: Confining Steel Strain for Model Column N1. Top Figure = East Gages;

Bottom Figure $=$ West Gages . 


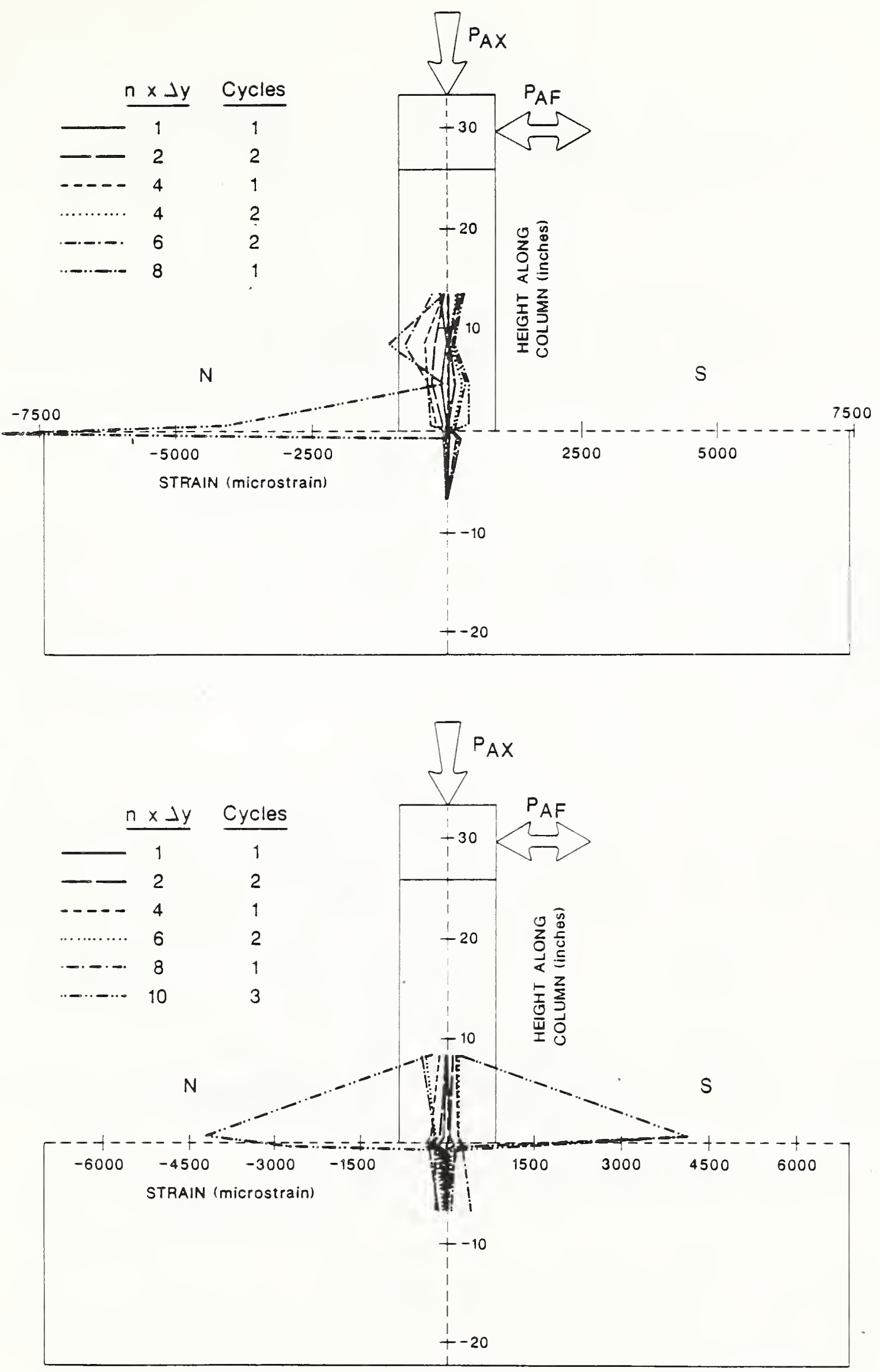

Figure 4.28: Confining Steel Strain for Model Column N2. Top Figure = East Gages; Bottom Figure = West Gages. 


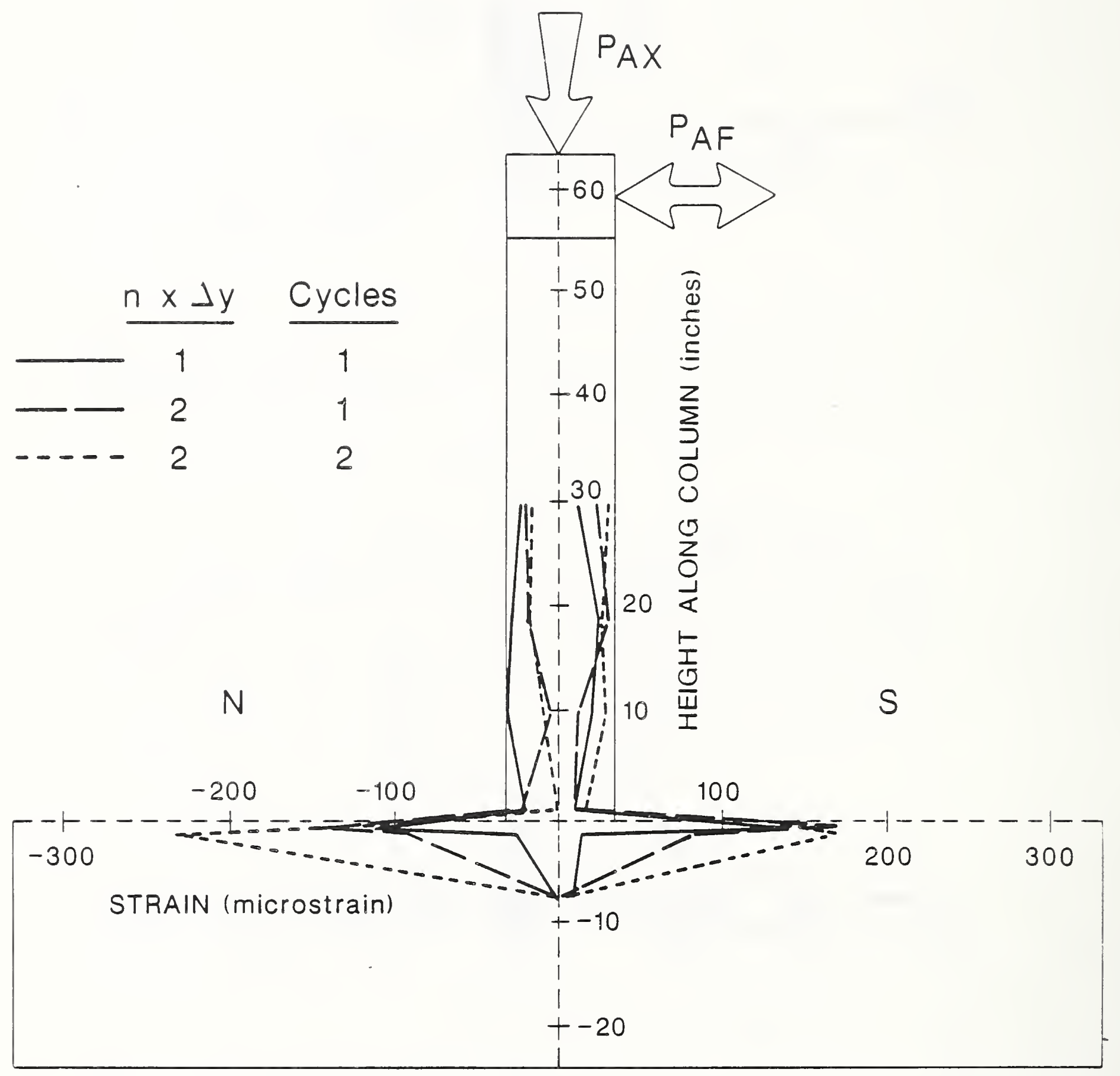

Figure 4.29: Confining Steel Strain for Model Column N3. 

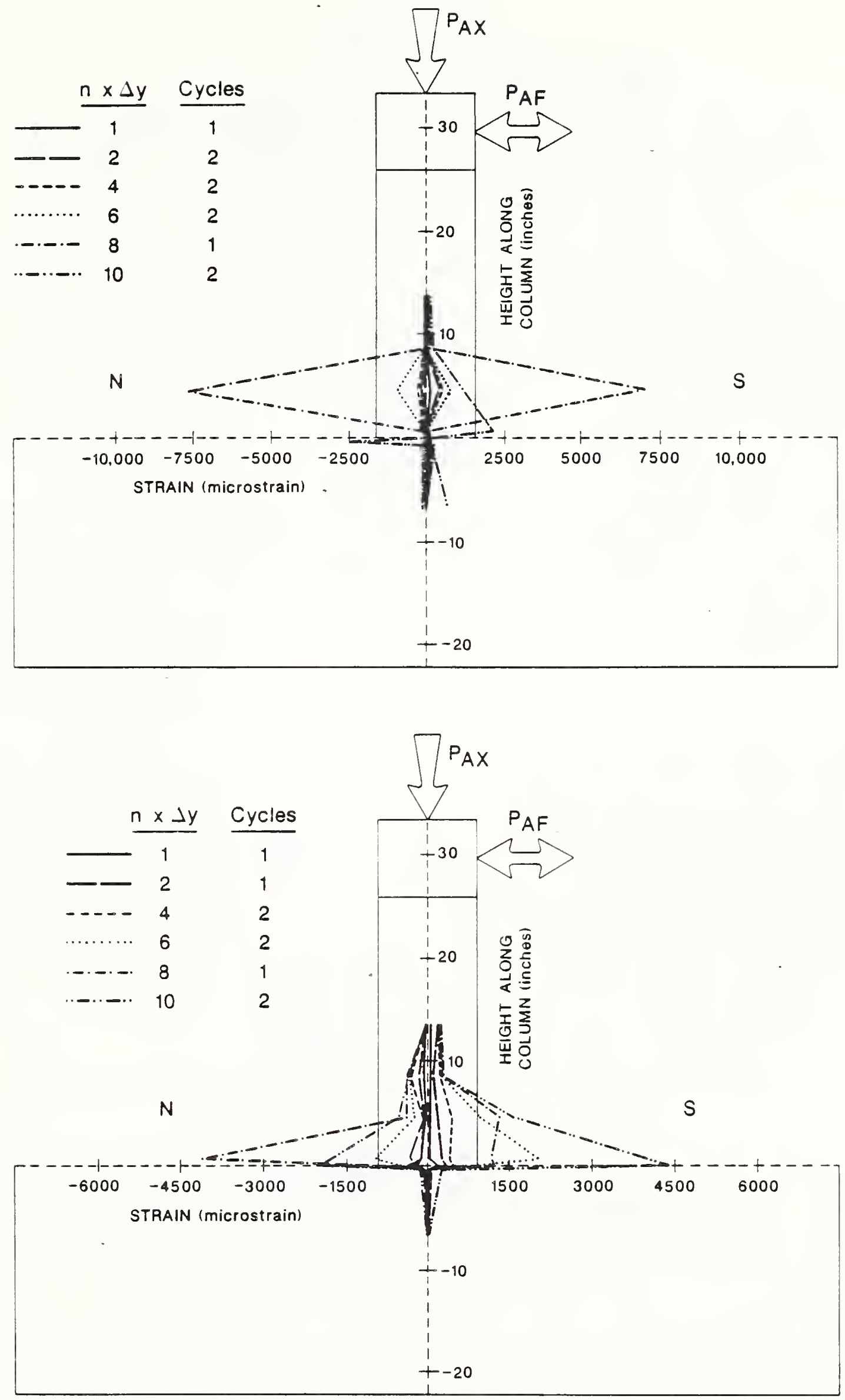

Figure 4.30: Confining Steel Strain for Model Column N4. Top Figure = East Gages;

Bottom Figure = West Gages. 

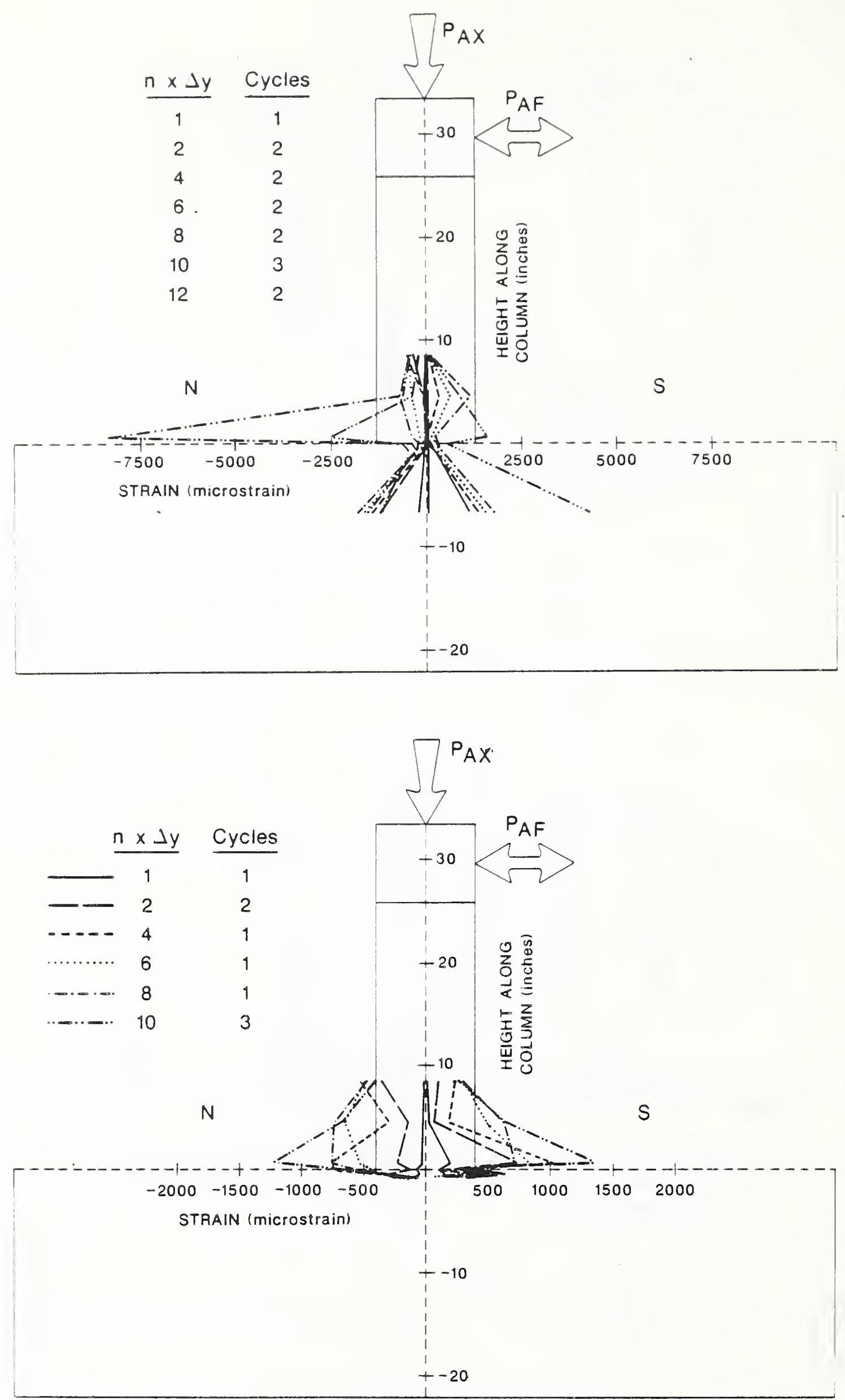

Figure 4.31: Confining Steel Strain for Model Column N5. Top Figure = East Gages;

Bottom Figure = West Gages. 

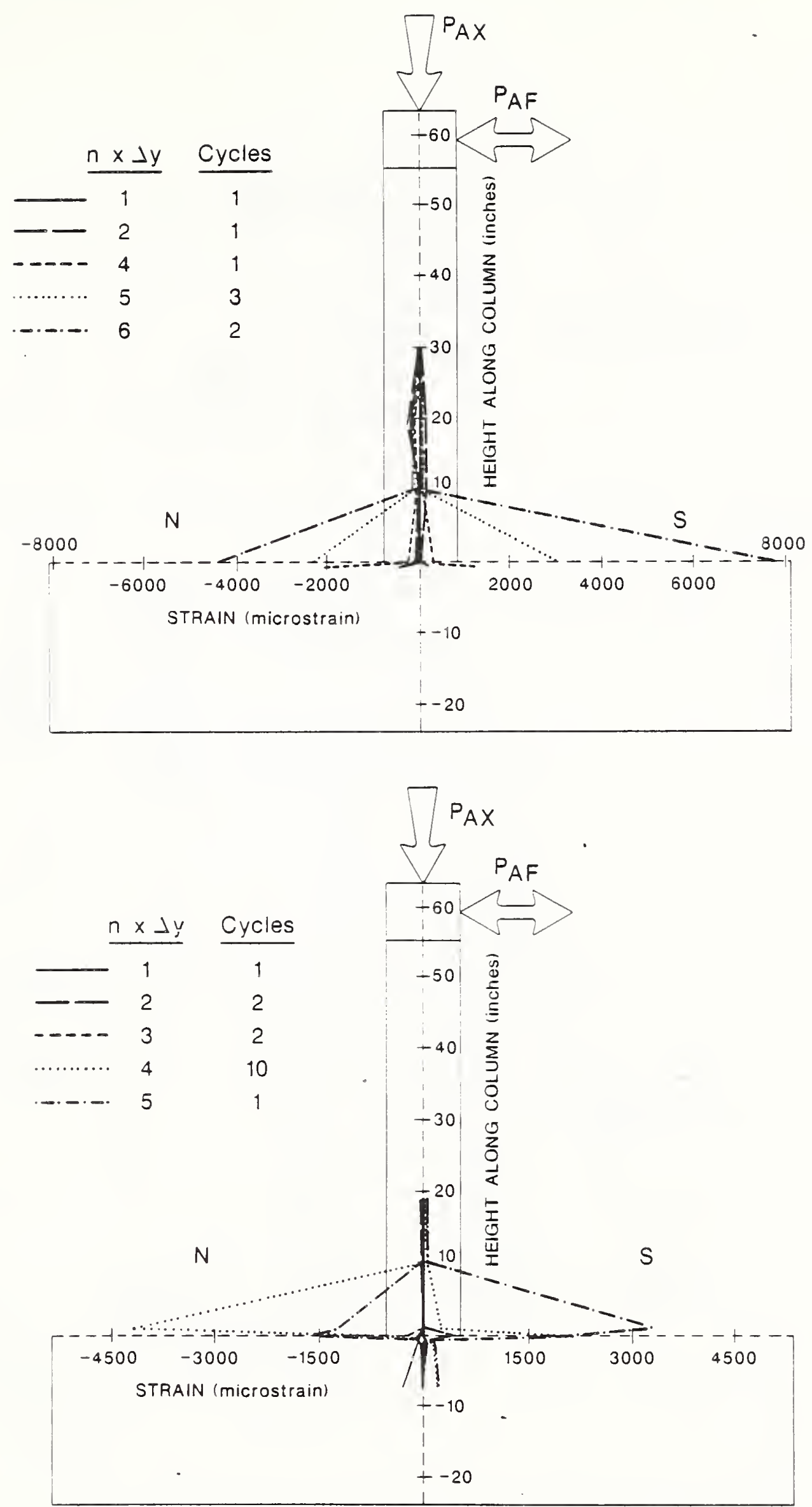

Figure 4.32: Confining Steel Strain for Model Column N6. Top Figure = East Gages; Bottom Figure = West Gages. 


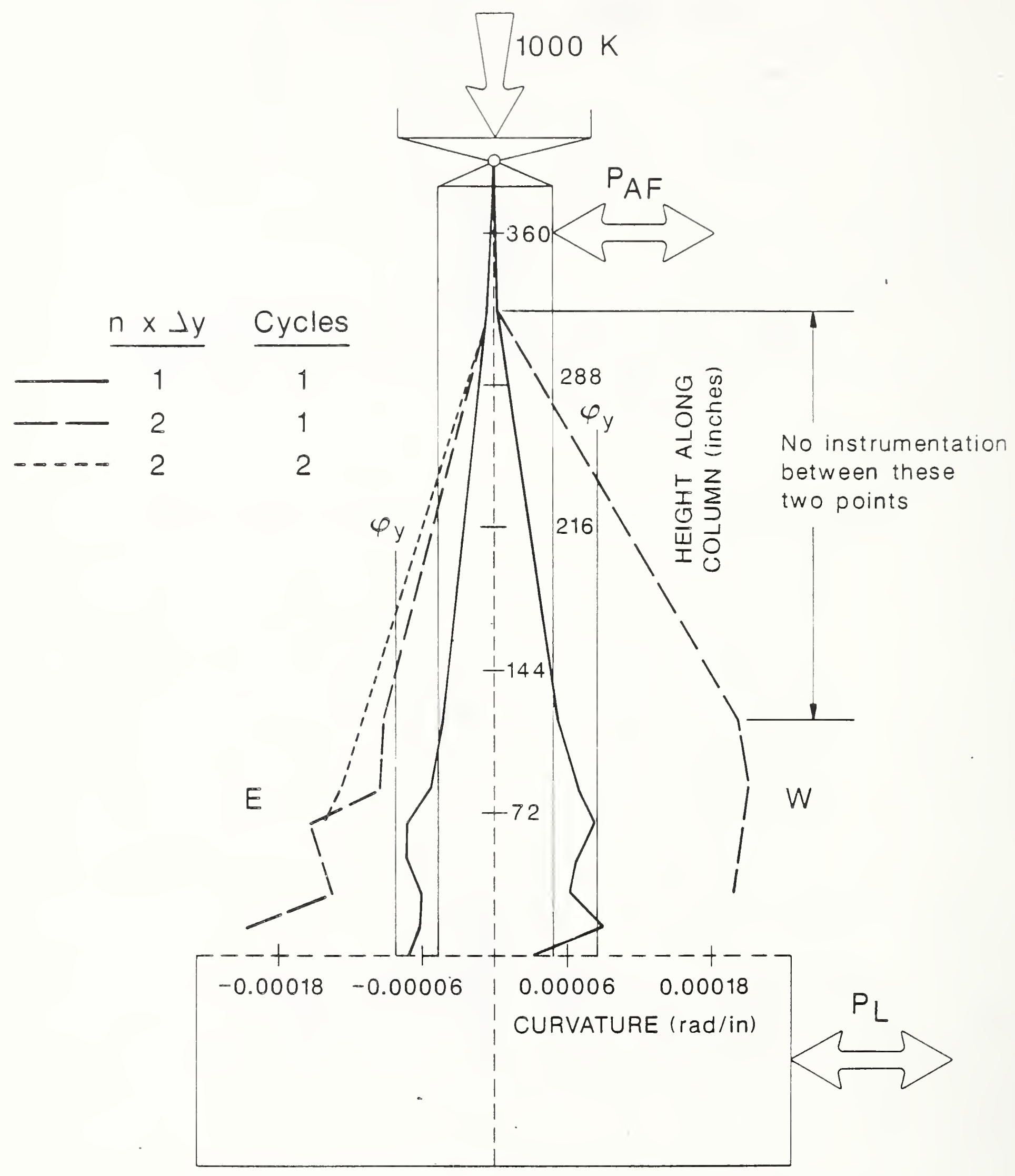

Figure 4.33: Column Curvature (radians/inch) for Full-Scale Flexure Column 

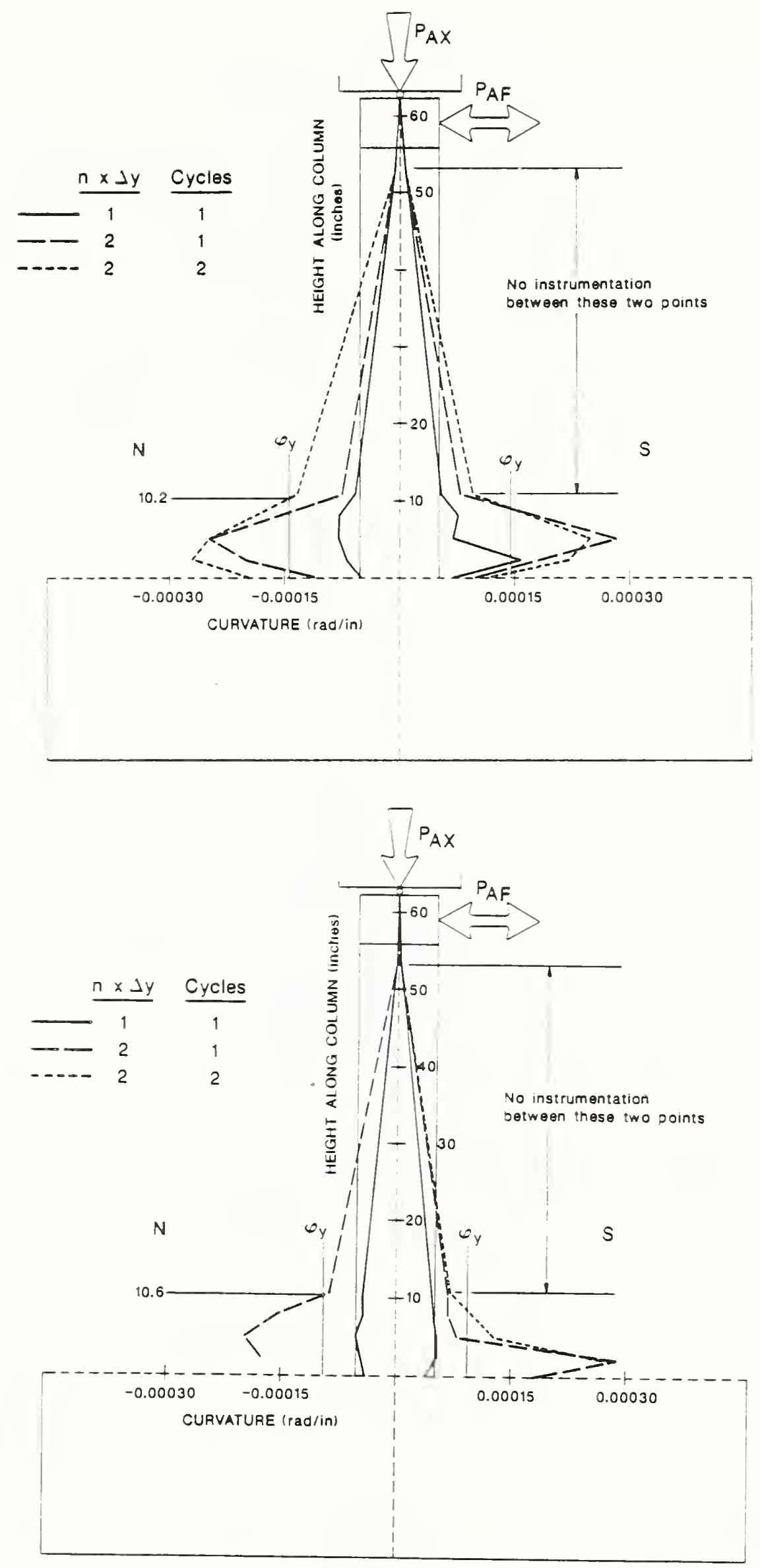

Figure 4.34: Column Curvature (radians/inch) for Model Specimens N3 and N6, Companion Specimens for Full-Scale Flexure Column 


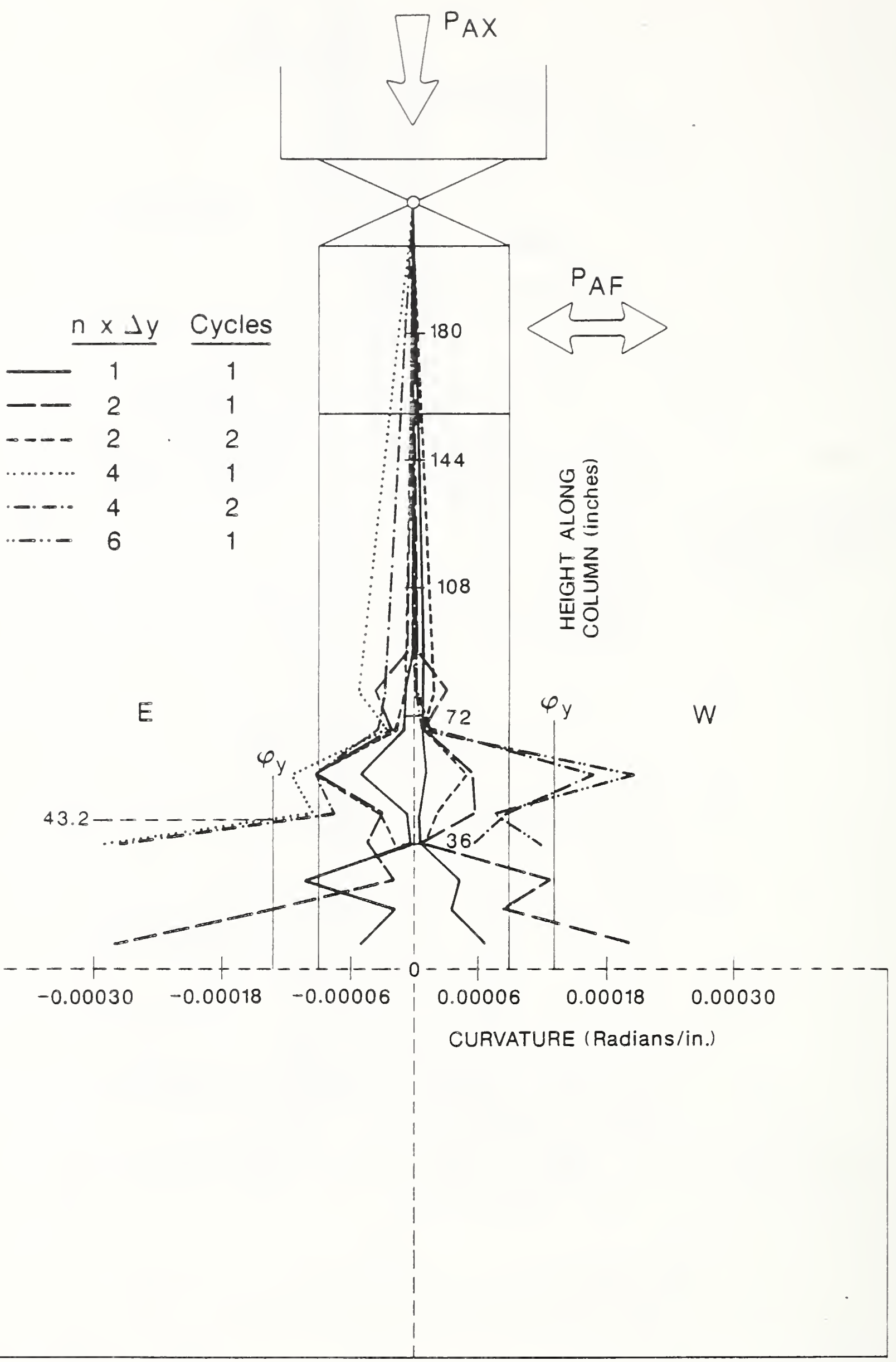

Figure 4.35: Column Curvature (radians/inch) for Full-Scale Shear Column 


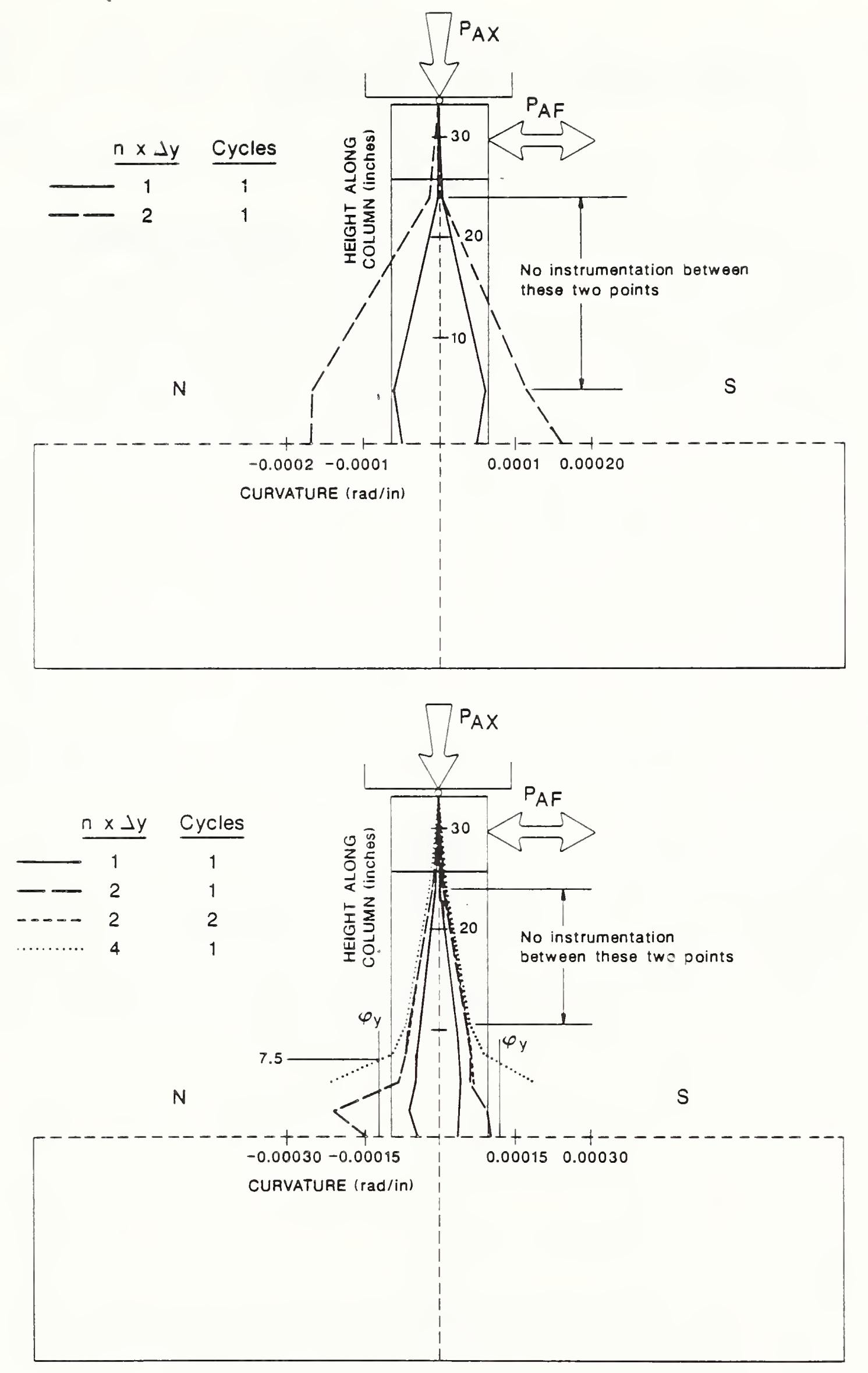

Figure 4.36: Column Curvature (radians/inch) for Model Specimens $\mathrm{N} 1$ and $\mathrm{N} 4$, Companion Specimens for Full-Scale Shear Column 

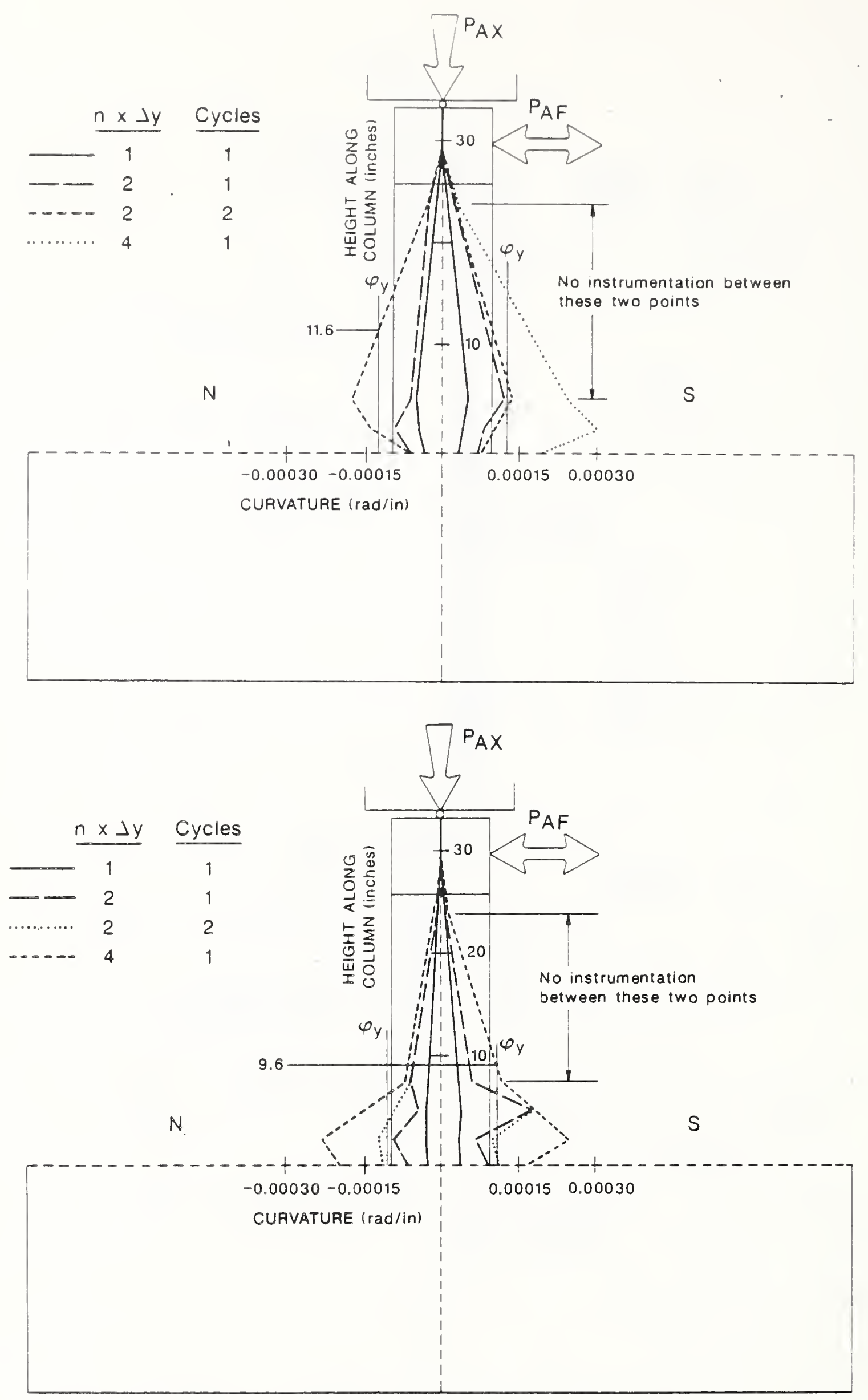

Figure 4.37: Column Curvature (radians/inch) for Model Specimens N2 and N5, Companion Specimens for Models N1 and N4 with $\mathrm{P}_{\mathrm{e}} / \mathrm{f}^{\prime} \mathrm{c}^{\mathrm{A}} \mathrm{g}=0.2$. 
If a linear strain distribution is assumed up to first yielding of the longitudinal reinforcing, then the yield curvature is calculated by moment area principles as:

$$
\phi_{\mathrm{y}}=\left(3 \Delta_{\mathrm{y}} / \mathrm{L}^{2}\right)
$$

Where $\Delta_{y}$ is the experimentally determined yield deflection, and $L$ is the height of the column from the base to the point of contraflexure. These values are tabulated in Table 4.9 along with other information concerning plastic hinge lengths. The experimental values of plastic hinge length for the tests discussed in this report were determined as that length of column over which the curvature exceeded $\phi_{y}$ (see delimiting lines on Figures 4.33 through 4.37). With the exception of the full-scale flexure column the plastic hinge length $I_{p}$ was generally between $0.7 \mathrm{D}$ to $1.2 \mathrm{D}$. These values were substantially larger than the recommended theoretical value of $0.5 \mathrm{D}$ given in references 15,16 , and 17 . The experimentally determined value of $L_{p}$ for the full scale flexure specimen $\left(\mathrm{L}_{\mathrm{p}} / \mathrm{D}=1.98\right)$ seems well outside that predicted using equations presented in references 15,21 , and 22. The test data for this column was closely scrutinized and appears valid, despite the discrepancy.

Note that in Table 4.9 the yield curvatures $\left(\phi_{y}\right)$ for the model specimens have been divided by the scale factor $\left(S_{1}\right)$ of 6.1 , since curvature has dimensions of $1 / S_{1}$. This was done for comparison purposes only. The delimiting lines used to determine the bounds of the plastic hinge for the model specimens utilized the unscaled, experimentally determined value of $\phi_{y}$. 
Table 4.9: Experimental Plastic Hinge Lengths $\left(\mathrm{L}_{\mathrm{p}}\right)$

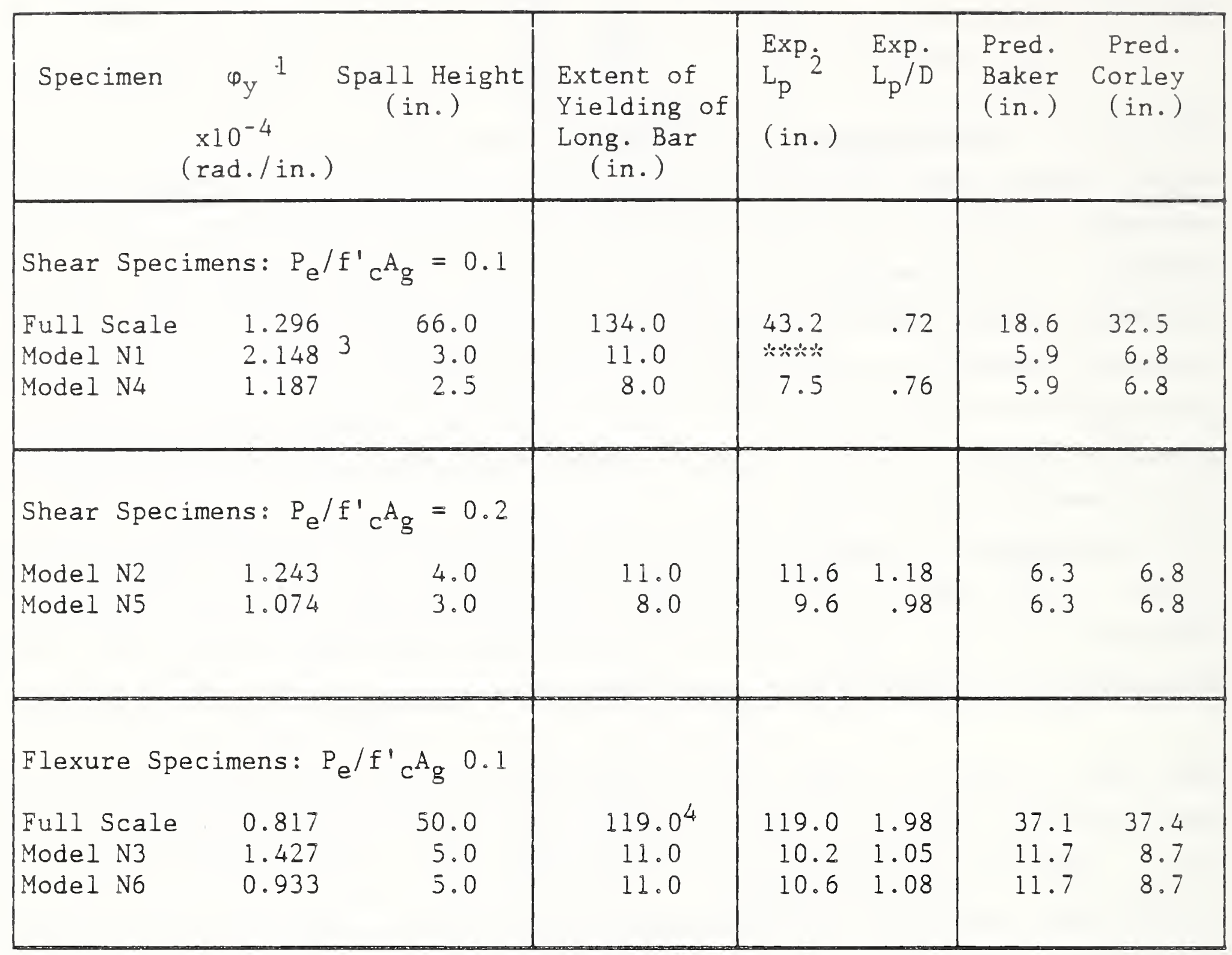

Notes:

1. $\varphi_{y}=\left(3 \Delta_{y} / L^{2}\right)$. The curvature values for the models were divided by $s_{1}$ (scale factor) to account for scale.

2. Plastic hinge length was obtained from Figures 4.33 through 4.37 and was determined as that length over which the curvature (as measured experimentally) was greater than $\varphi_{y}$.

3. Excessive flexibility for this column ( $\Delta_{y}$ was approximately twice the predicted value), as well as premature failure of the instrumentation used to determine curvature, precluded an experimental determination of $L_{p}$.

4. No instrumentation was available above this height and it is possible that longitudinal bar yielding could have extended further. 


\subsection{Inelastic Strain Energy Capacity}

An effective method for measuring overall column performance subjected to cyclic load is to calculate the amount of strain energy dissipated through inelastic action. The two cyclic load test data analysis computer programs described in, Reference 1 (TURBO-LOOP and GRAPH) were used to determine the amount of strain energy dissipated during each load-displacement cycle for the full scale tests. This was done using computer graphics by filling the area bounded by the loaddeflection hysteresis loops with pixels of a specified color, counting the number of pixels of that color, and converting this to engineering units by means of a scale factor. Figure 4.38 shows two bar-graphs generated using this technique for the prototype flexure and shear column tests. Several things are apparent from these plots. First, each increase in displacement ductility (until failure of the column) results in a substantially higher amount of energy being inelastically dissipated. The second cycle at a given displacement ductility generally results in the dissipation of slightly less energy. It is interesting to note, however, that the results for the flexure specimen, which sustained 10 cycles at $4 \Delta_{y}$, indicate that after the third cycle at $4 \Delta y$ that the energy dissipation appears to stabalize so that the 10 th cycle dissipates nearly $90 \%$ that of the first. This is important because it indicates that there apparently exists a threshold displacement below which a substantial number of inelastic cycles may take place during which energy is dissipated without marked degradation of the column. Above this threshold, additional cyclic load quickly causes failure. This behavior is evident in both the flexure and shear columns by the rapid decrease in energy per cycle during the final few cycles before the column failed.

\subsection{Similitude Relationships: Model versus Prototype}

Before discussing specific findings regarding similitude it will be useful to briefly review the fundamental concepts of scale factors for reinforced concrete structures. A "true model" is one which maintains complete similarity with

the prototype. Stress and strain characteristics for the materials used in a true model are scaled by the factors $s_{\sigma}$ and $s_{\epsilon}$, respectively, and lengths are modified by the previously mentioned length scale factor, $\mathbf{s}_{1}$. For reinforced 
concrete, it is not practical to achieve this due to the difficulty of scaling the modulus of elasticity of the reinforcing bars. Steel is the only practical reinforcing material. This leads to the concept of a "practical true model", in which $s_{\sigma}=s_{\epsilon}=1$ and the consequent requirement that model reinforcing steel be capable of reproducing the stress-strain curve for the prototype reinforcement. Ideally, the concrete stress-strain curve should also replicate that for the prototype. But because of different curing conditions this is generally not possible and a "distorted model" results. However, a practical true model can still be achieved by scaling the resultant forces and moments by $s_{\sigma}$. $A$ practical experimental value of $s_{\sigma}$ is the ratio of the compressive strengths of prototype and model concretes, $f^{\prime} \mathrm{cp} / f^{\prime} \mathrm{cm}$. What remains, theoretically, is the relationship between model and prototype based solely on the length scale factor $s_{1}$. In this report, estimates of $s_{1}$ are determined experimentally from consideration of deflections, moments, and strain energy. The following symbols and definitions will be used throughout the remainder of the report:

$\mathrm{s}_{\mathrm{d}}=$ experimental scale factor for yield deflection

$$
=\Delta_{y p} / \Delta_{y m}
$$

$s_{1 m}=$ experimental scale factor for ultimate moment

$=\left(M_{u p} / M_{u m}\right)^{1 / 3}$

$s_{1 e}=$ experimental scale factor for absorbed strain energy

$$
\begin{aligned}
& =\left(E_{p c} / E_{m c}\right)^{1 / 3} \\
& =\left(E_{p t} / E_{m t}\right)^{1 / 3}
\end{aligned}
$$

where

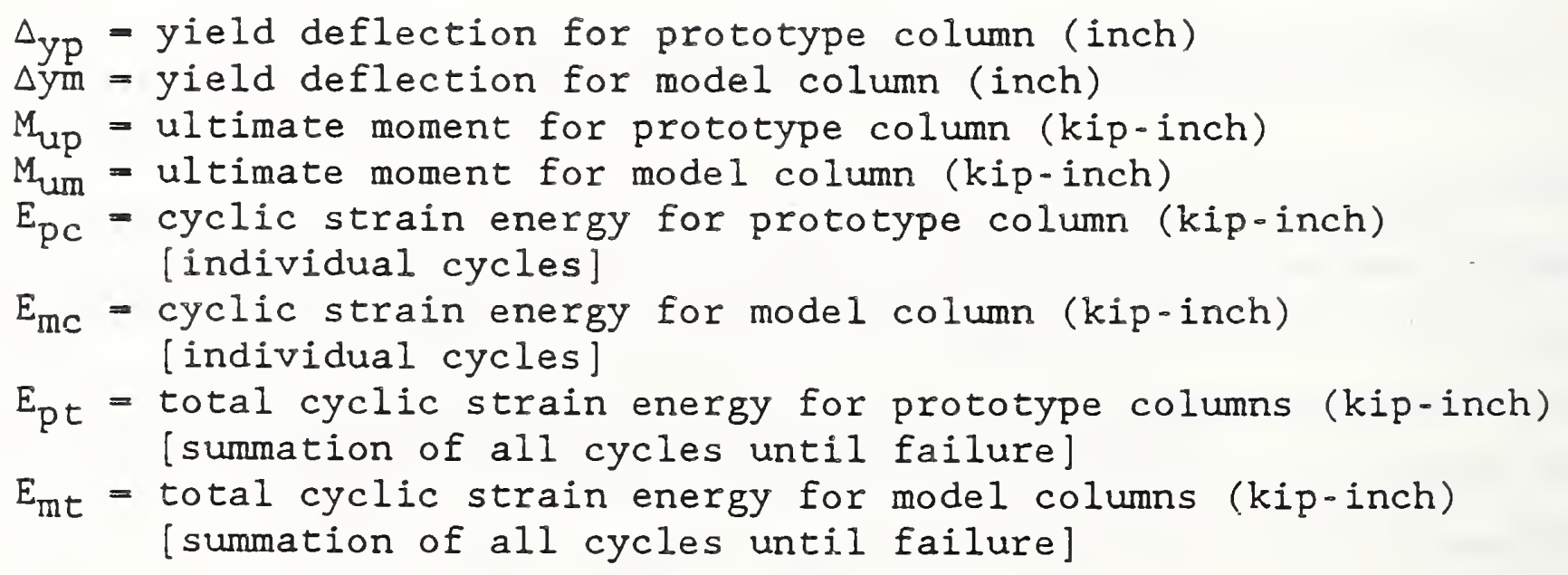



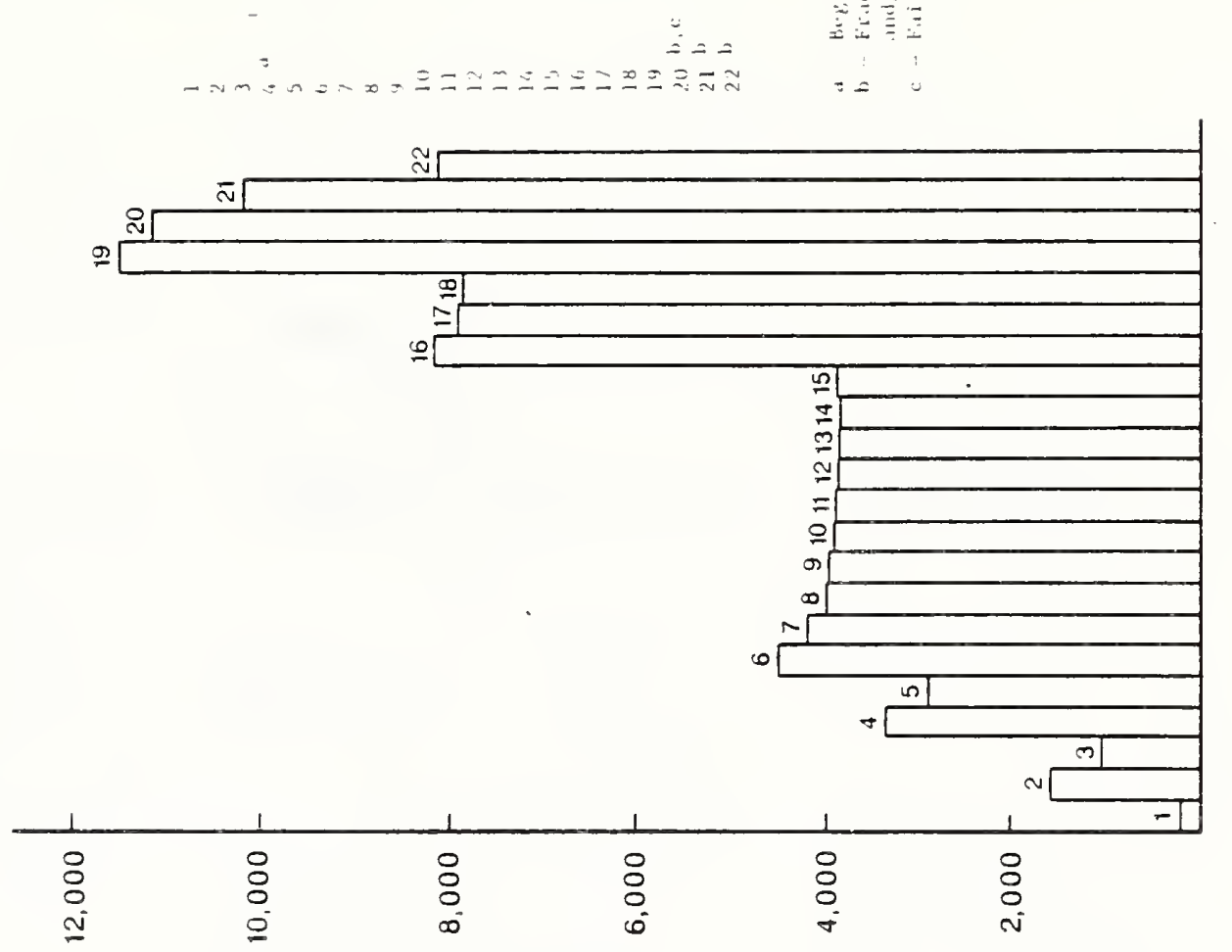

(แ!- У) ᄉอษ

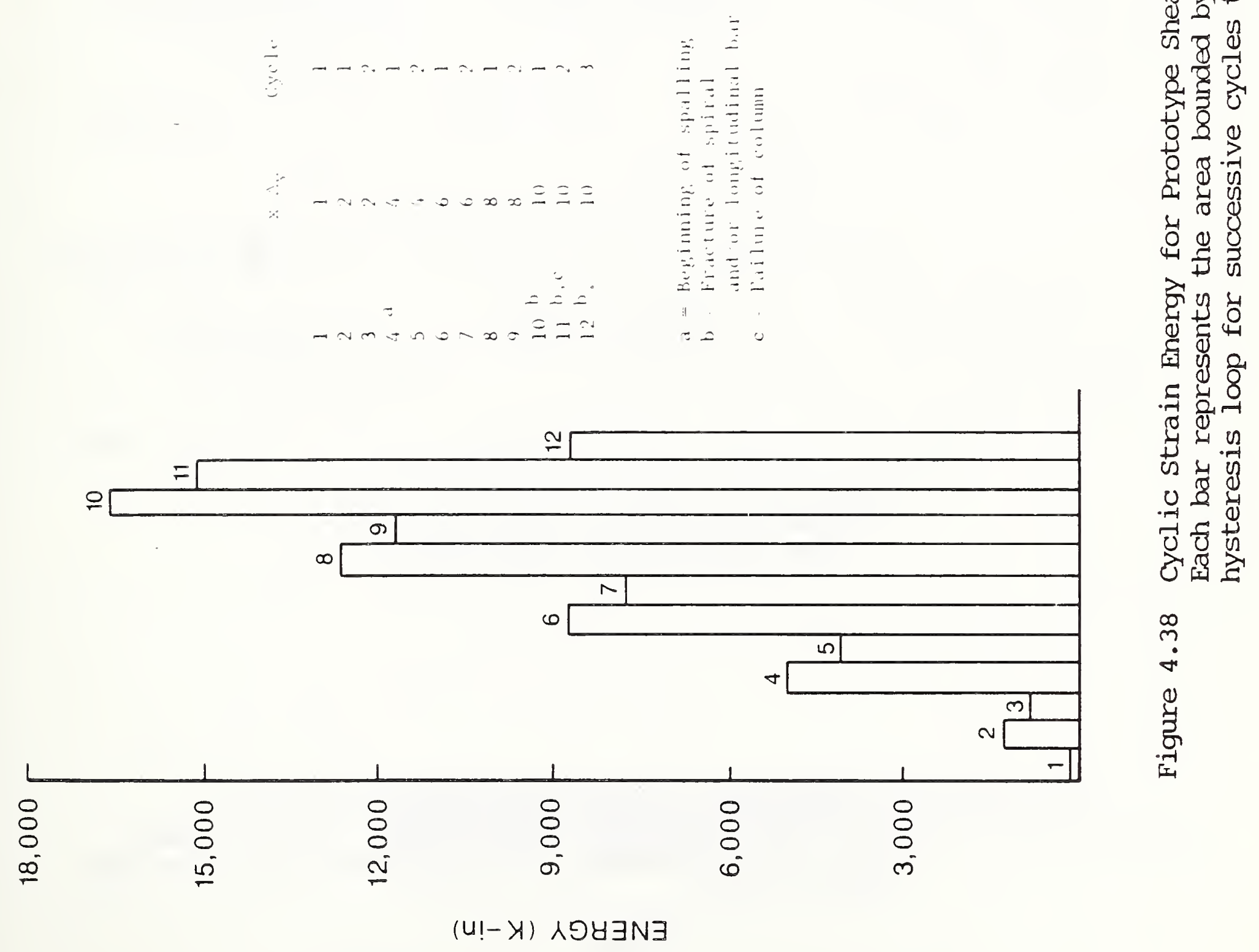



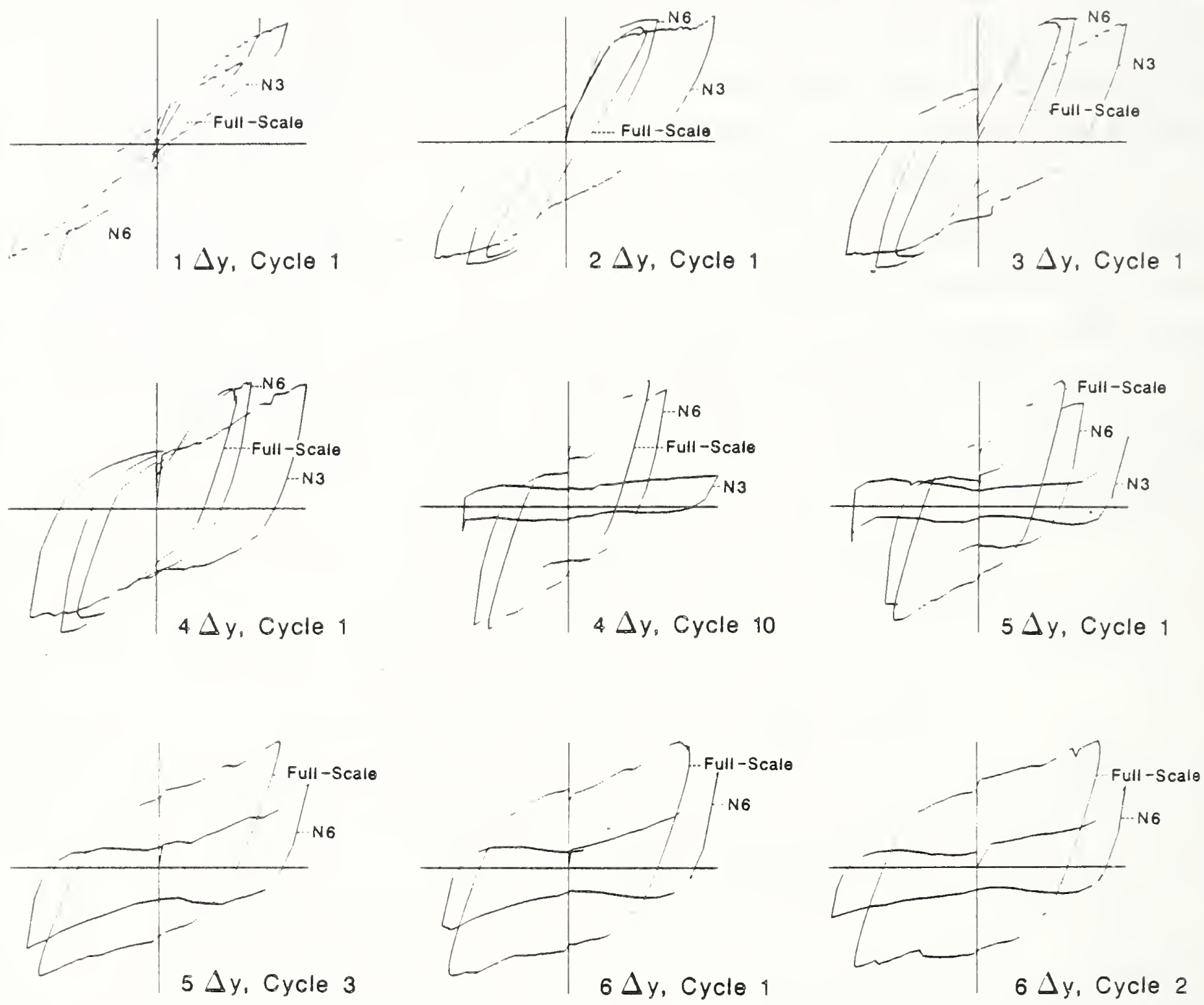

COMPARISONS OF HYSTERESIS CURVES

FOR THE FLEXURE SPECIMENS

Figure 4.39: A Comparison of Model and Prototype LoadDeformation Behavior Under Reversed Cyclic Loading for Flexure Specimens. Note that Model Data has been scaled by $\mathrm{s}_{1}{ }^{3}$. 

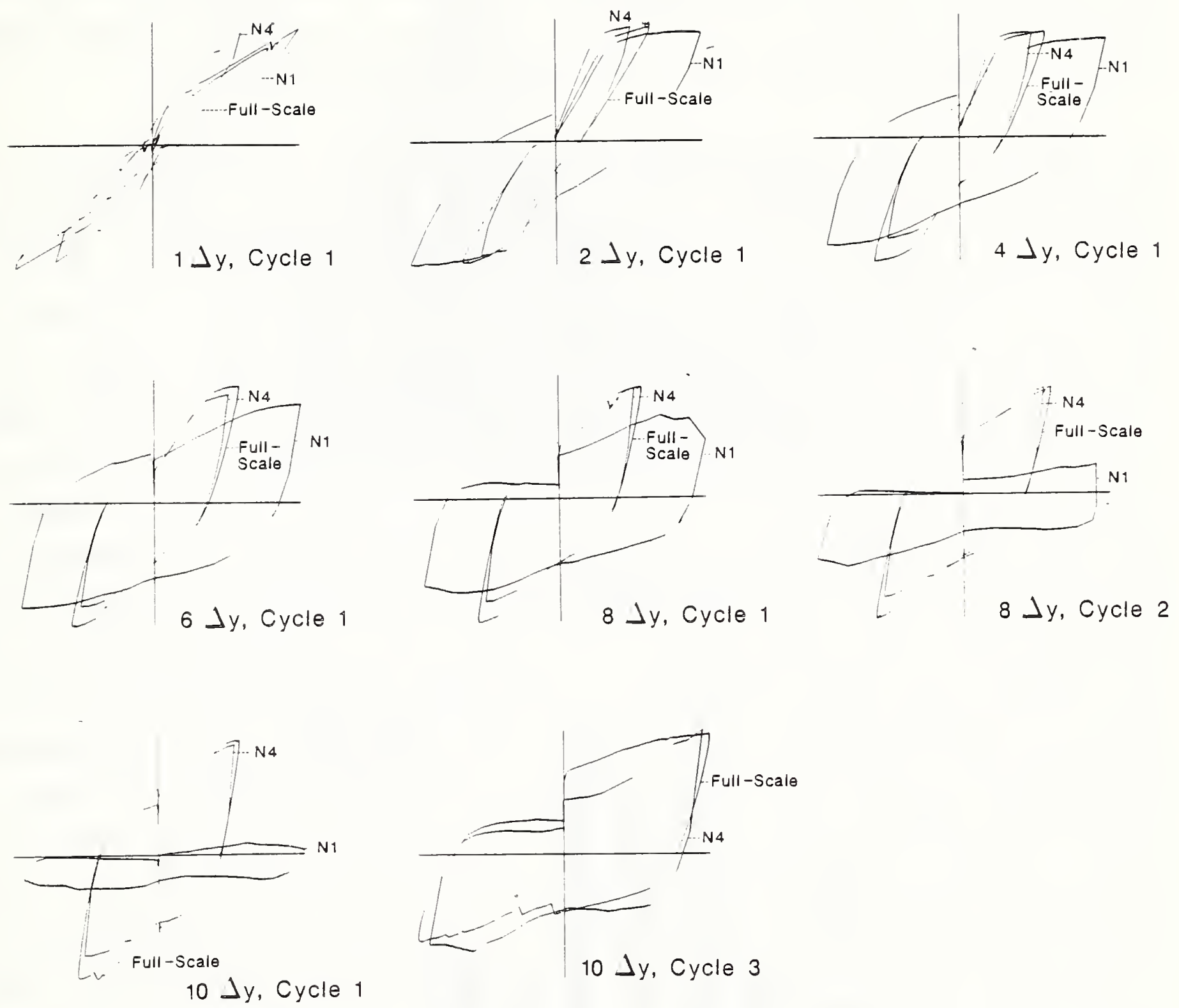

\section{COMPARISONS OF HYSTERESIS CURVES FOR THE SHEAR SPECIMENS}

Figure 4.40: A Comparison of Model and Prototype LoadDeformation Behavior Under Reversed Cyclic Loading for Shear Specimens. Note that Model Data has been scaled by $\mathrm{s}_{1}{ }^{3}$. 
The proximity of these experimentally determined scale factors to that for the practical true model $\left(s_{1}=6.1\right)$ will serve as a measure of the ability to predict prototype bridge column performance from model tests.

The units of strain energy (both cyclic and total, as defined above) are force multiplied by displacement. To achieve similitude force must be multiplied by the square of sl (37.21) and displacement must be multiplied by sl (6.1). Thus, energy is scaled by $\mathrm{s}_{1}{ }^{3}$ for the practical true model. To account for differences in concrete compressive strength the model energy was also multiplied by $s_{\sigma}$, as defined above. Figures 4.39 and 4.40 show comparisons between load-deflection behavior for model and prototype columns for each cycle. When viewing these figures keep in mind that model columns N1 and N3 were constructed from microconcrete in accordance with accepted experimental practice [23]. Models N4 and N6 were constructed from commercially available ready-mix concrete which used "pea gravel" (1/4 inch [6 $\mathrm{mm}]$ nominal maximum size washed river gravel) as coarse aggregate. The trends shown in Figures 4.39 and 4.40 indicate that the models constructed from ready-mix concrete reproduced the performance of the prototype quite well on a cycle by cycle basis. The microconcrete models were generally shown to be more flexible. Thus they had larger initial displacements when $\Delta_{y}$ was determined. This increased displacement under similar applied lateral load explains the differences between the shape of each hysteresis loop for the microconcrete models versus those for the prototype and ready-mix model. In general, more energy was dissipated per cycle in the microconcrete models, and was more pronounced in the shear column tests.

The scaled areas bounded by the hysteresis loops of Figures 4.39 and 4.40 can be used to determine energy dissipation per cycle, using the procedures defined in section 4.6. These values are shown on the bar charts in Figure 4.41. These charts clearly show that the microconcrete models overpredict the energy dissipation per cycle in the prototype, and exhibit premature column failure, as evidenced by the rapid degradation in energy dissipation beginning at $4 \Delta y$ for the flexure columns and $8 \Delta y$ for the shear columns. The rapid failure of the microconcrete flexure column was caused by fracture of the confining spiral reinforcement in the plastic hinge region during the second 
COMPARISON OF ENERGY ABSORBED ON A PER CYCLE BASIS . FOR THE FLEXURE COLUMN
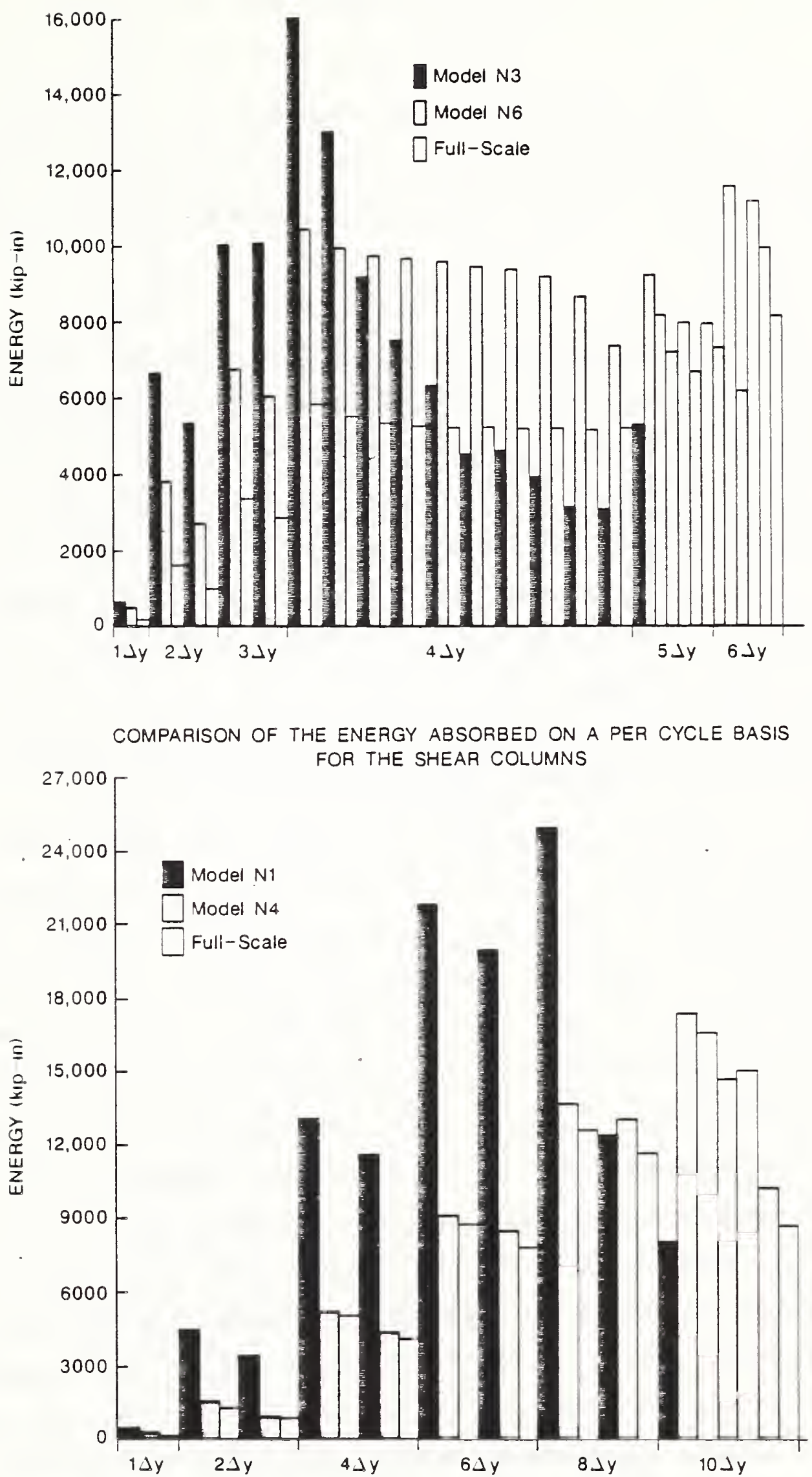

Figure 4.41: A Comparison of Cyclic Energy Dissipation between Model and Prototype Specimens. Top Chart is for Flexure Specimens $\left(h_{1} / D=6\right)$ Bottom Chart is for Shear Specimens $\left(h_{1} / D=3\right)$. 
cycle at $4 \Delta_{y}$. The ready-mix model columns, on the other hand, appear to track the cycle-by-cycle performance of the prototypes quite well, although the ready-mix model flexure column shows some overprediction of energy dissipation per cycle.

An important factor not accounted for in these graphs is the effect which losses in applied lateral load (due to friction in the roller transport system, and loads transferred to the vertical test machine) had in the determination of $\Delta_{y}$ for the prototype columns. Following completion of the prototype tests a comparison was made between the effective lateral load applied to the prototype column (actual column base moment divided by column height after friction losses had been accounted) versus the applied lateral load. The variation of $f_{1 e}=$ $F_{\text {eff }} / F_{\text {ram }}$ (where $F_{\text {eff }}=$ the actual lateral load applied to the column, $F_{\text {ram }}=$ the lateral load applied to the column base block by the hydraulic actuator, and $\mathrm{f}_{\mathrm{le}}$ is the load effectiveness ratio) is plotted in Figure 4.42 for a typical cycle of lateral load. The spikes represent locations where the ram load underwent a sign reversal while a finite value of effective lateral load remained on the column. Such load reversal spikes occurred twice per cycle. Between the spikes a relative steady state exists over which the ratio of effective lateral load to ram load is constant. For the prototype flexure column this value was 0.913; for the shear column it was 0.973 . If it is assumed that both effective lateral load, and therefore the initial estimate of $\Delta_{y}$, were affected by these loss ratios, then the effective energy per cycle that would have been obtained if losses were not present can be obtained by dividing prototype cyclic energy by $\left(f_{1 e}\right)^{3}$. This term is defined as the energy modification factor ( $f_{e m}$ ) and is used to compensate for the fact that no losses existed in the model tests. For the flexure column the energy modification factor was 0.761 ; for the shear column it was 0.922 . Revised bar graphs which incorporate the above adjustment factor are shown in Figure 4.43. These indicate further improvement in the relation between ready-mix models and the prototypes. However, the microconcrete models still differ substantially from the prototypes. One possible explanation for the difference is the importance of aggregate interlock in cyclic energy dissipation. It is likely that less interaction of this nature takes place in microconcrete. 
LATERAL TO RAM LOAD RATIO FOR THE FLEXURE COLUMN

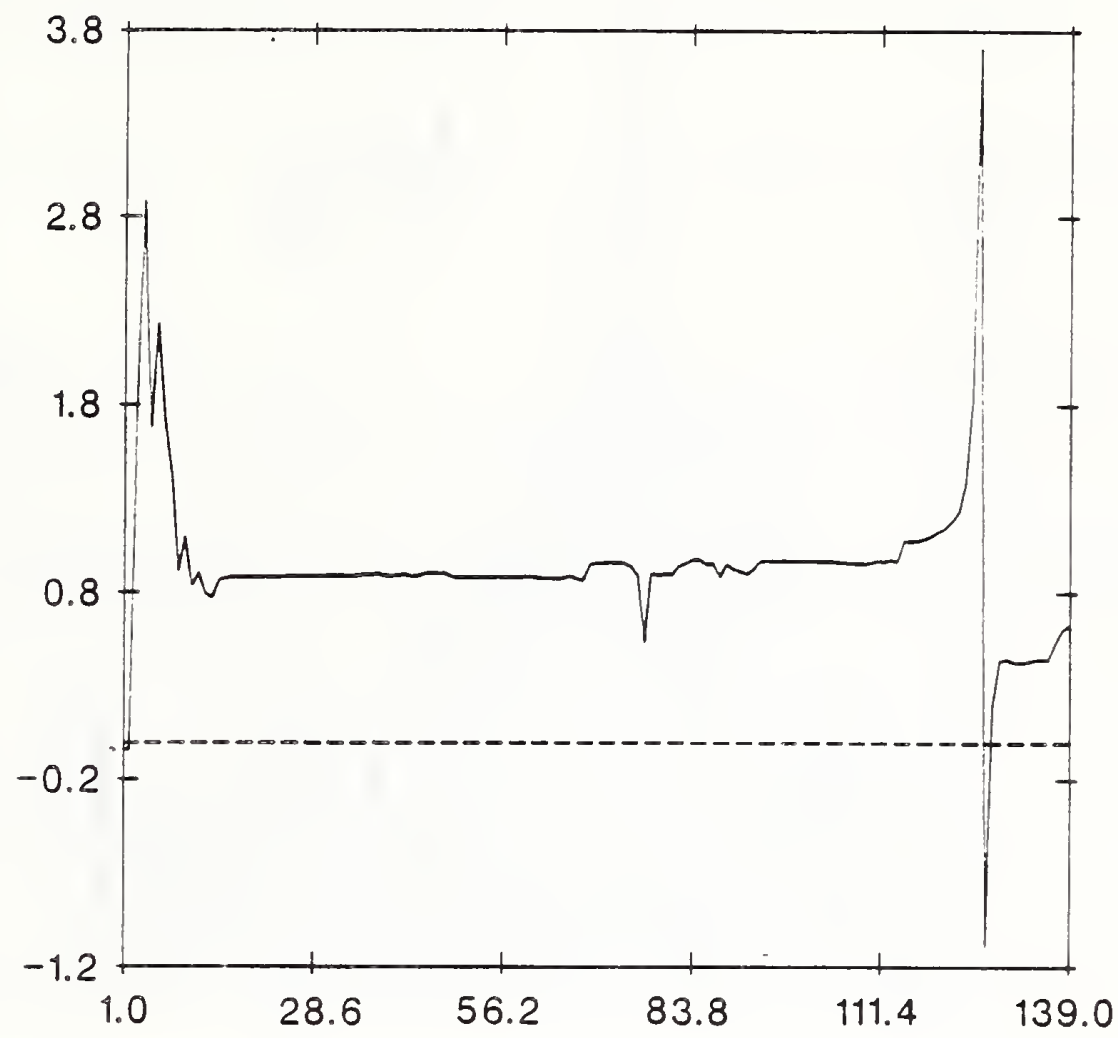

LATERAL TO RAM LOAD RATIO FOR SHEAR COLUMN, CYCLE 11

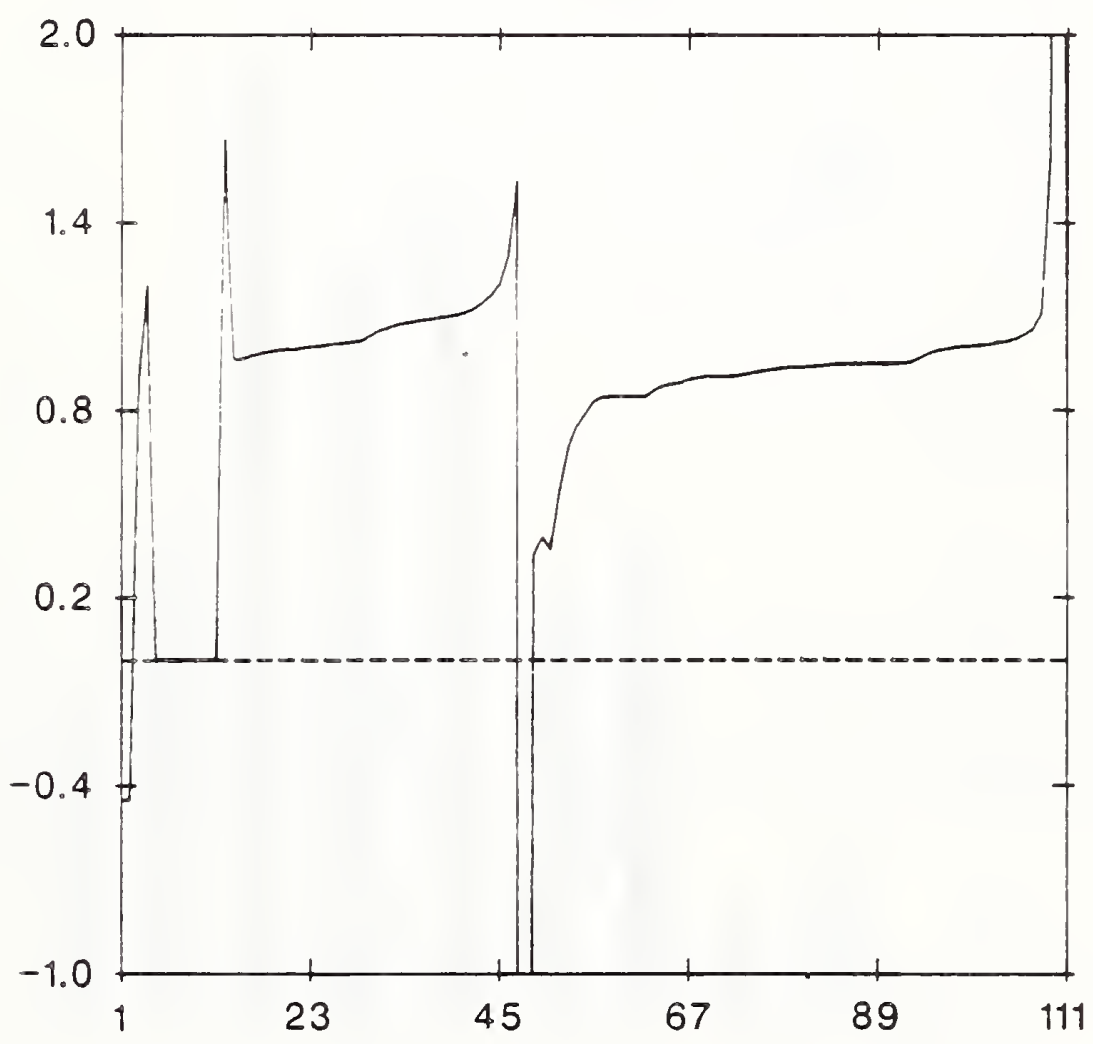

Figure 4.42: Ratio of Effective Lateral Load to Applied Ram Load for prototype Flexure and Shear Columns. 


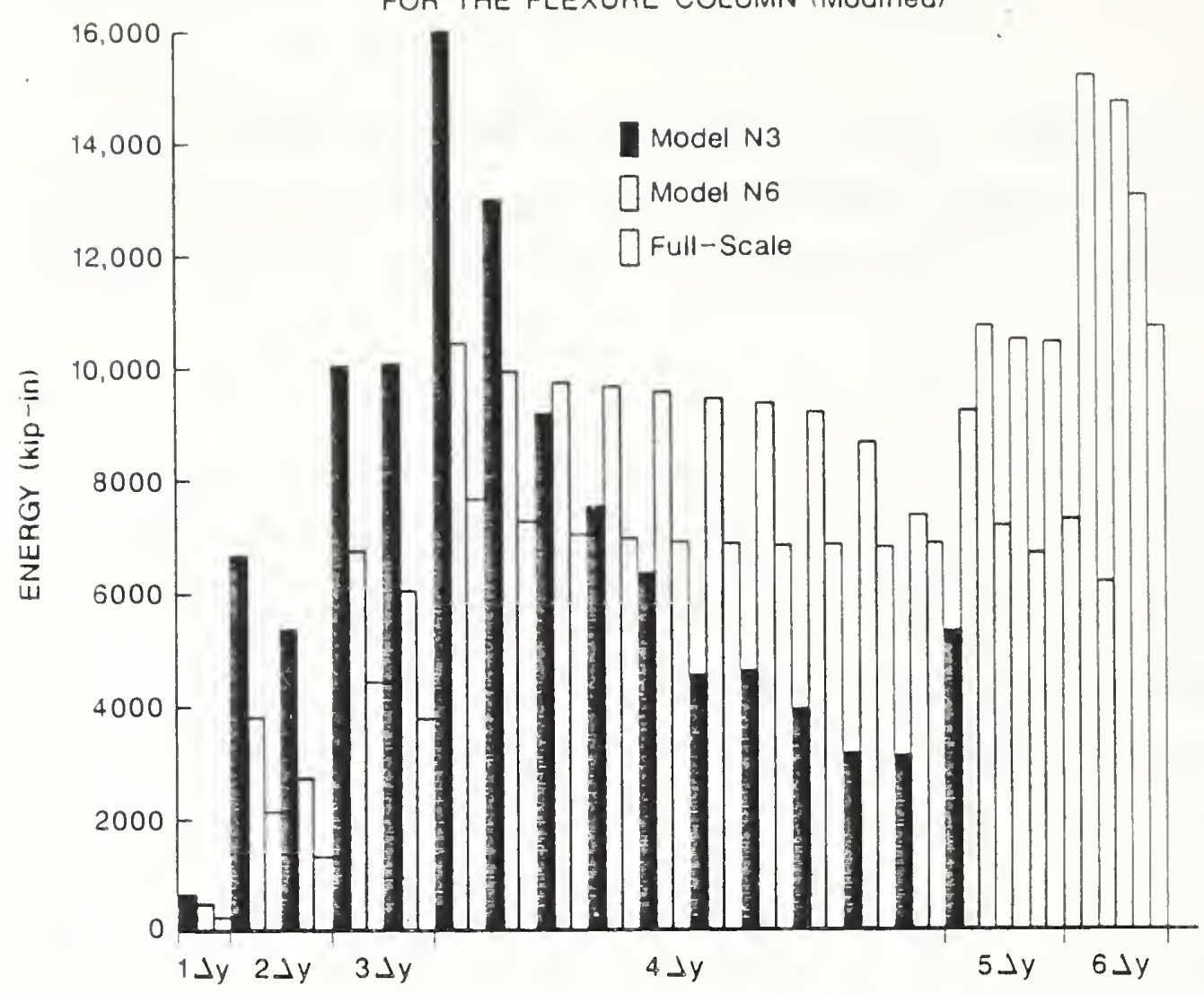

COMPARISON OF THE ENERGY ABSORBED ON A PER CYCLE BASIS FOR THE SHEAP COLUMNS (Modified)

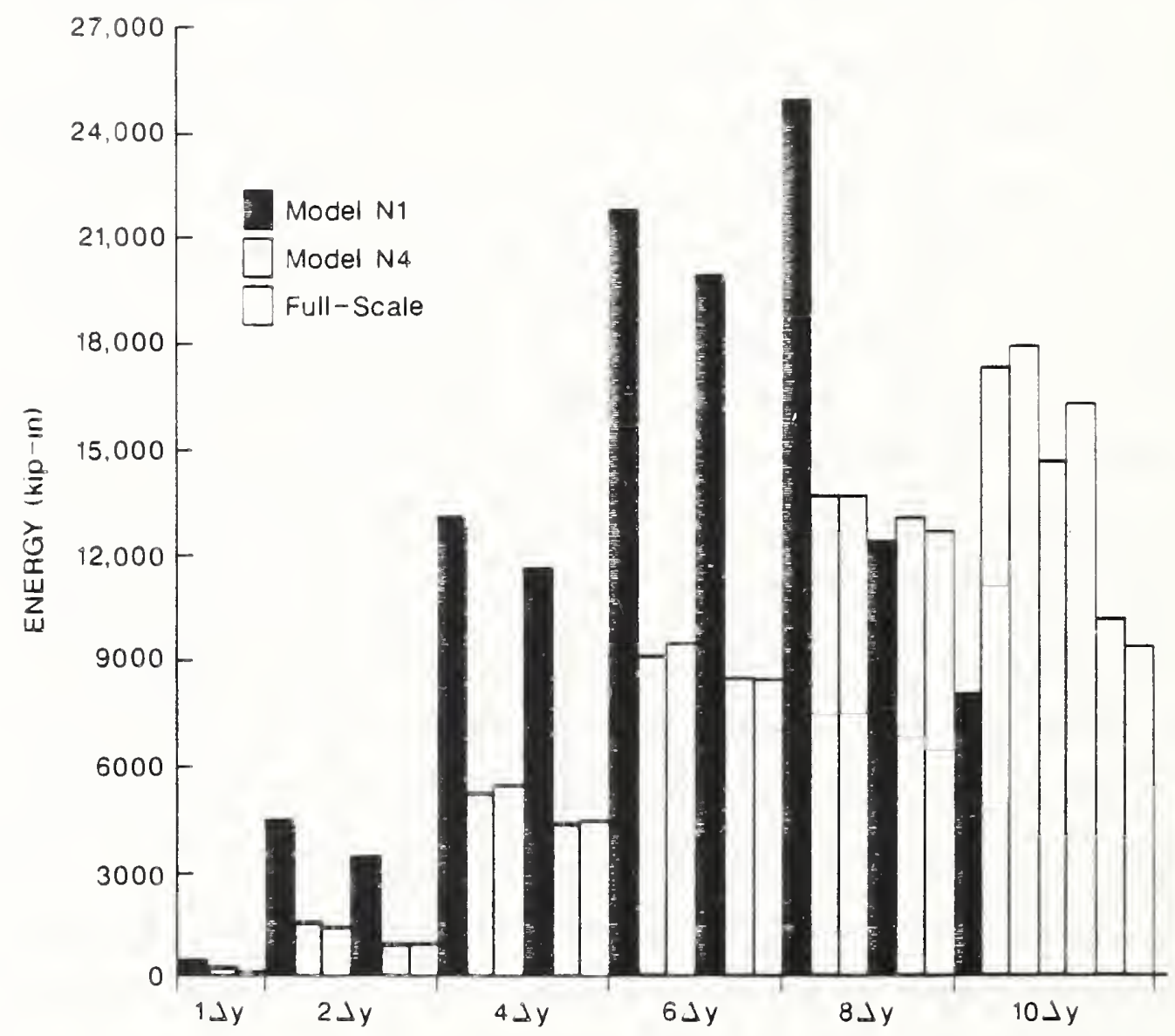

Figure 4.43: A Comparison of Cyclic Energy Dissipation between Model and Prototype Specimens with modifications to account for differences in compressive strength between models and prototypes, and for friction losses in the prototype tests. Top Chart is for Flexure Specimens $(\mathrm{h} 1 / \mathrm{D}=6)$; Bottom Chart is for Shear Specimens (h1/D $=3$ ). 
Table 4.10 Experimental Scale Factor for Absorbed Energy*** [on a cycle-by-cycle basis]

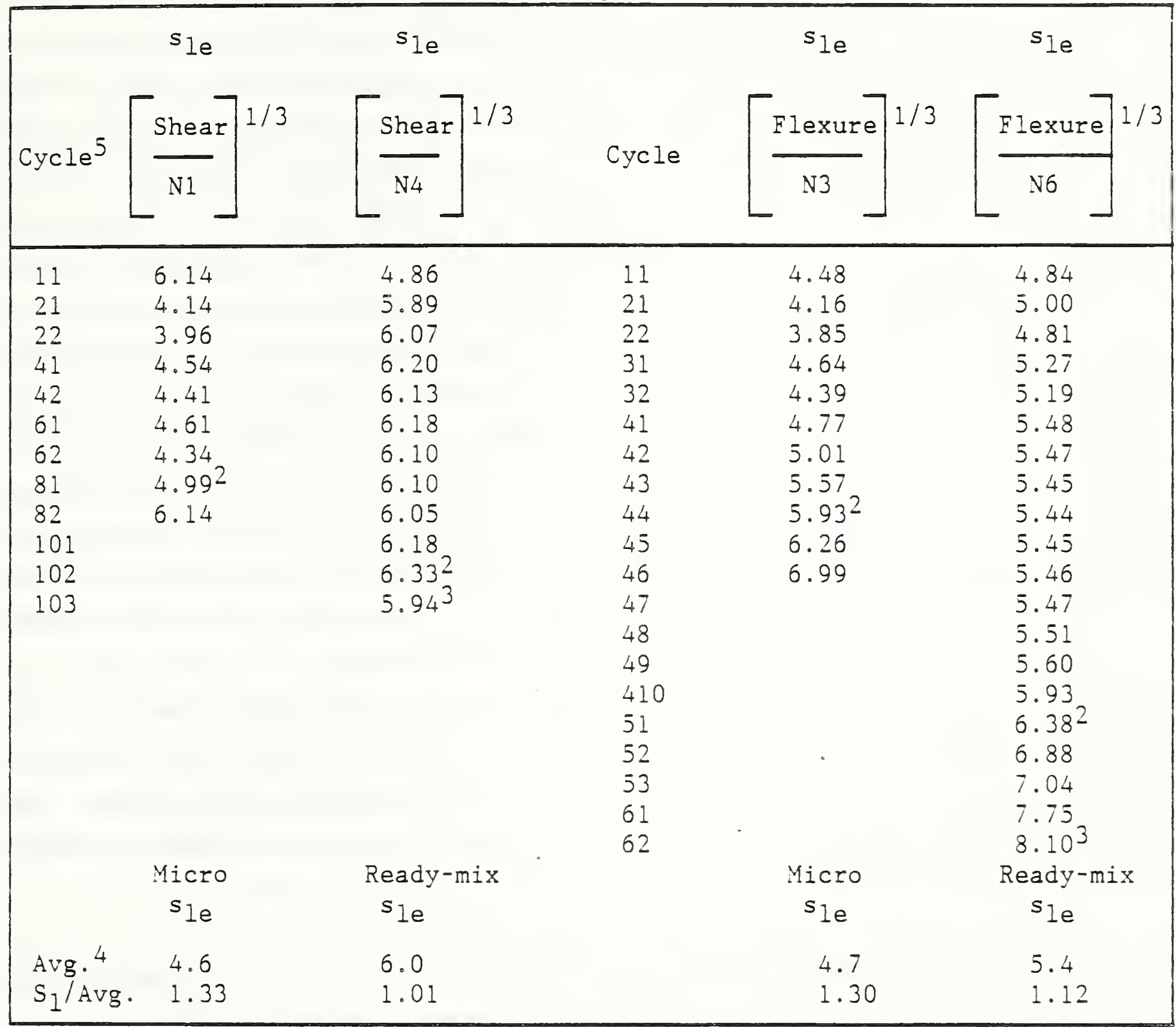

1: Shear $=$ Full scale shear column, Flexure $=$ Full scale flexure column $\mathrm{Nl}=$ Microconcrete shear model, $\mathrm{N} 4$ = Ready-mix shear model

N3 = Microconcrete flexure model, N6 = Ready-mix flexure model

2: Failure of model.

3: Failure of full scale column.

4: Averaged up to failure of the model.

5: Cycle 4l, e.g., is Cycle number 1, displacement ductility of $4 \Delta y$ etc.

** Energy calculated by graphically integrating area bounded by lateral load vs column deflection hysteresis loops for each complete lateral excursion at a given displacement ductility using procedures outlined in Reference 1. Cyclic energy for the model specimens was multiplied by $s_{\sigma}$ as described in Section 4.7. Prototype cyclic energy was scaled by $f_{e m}$, as described in Section 4.7 . 
Values listed represent the Cyclic Experimental Scale Factor for Absorbed Energy $\left(s_{1 e}\right)$.

At the beginning of this section it was stated that the model energy was scaled by $\mathrm{s}_{1}{ }^{3}$ for comparison in the bar charts just presented. The proximity between model and prototype individual cycle energy values in the bar charts therefore represents a measure of the accuracy with which prototype behavior is predicted by model tests. For example, the high values of cyclic strain energy dissipation for the microconcrete models, when compared with the prototype, indicate that the scale factor for energy absorption, based on these tests, is less than 6.1. The values listed in Table 4.10 examine this aspect of similitude by presenting the experimental scale factor for energy absorption, sle, calculated on a cycle-by-cycle basis. This calculation is possible because identical load histories were used for both models and prototypes. Averages for $s_{l e}$ up to the failure of the model specimens are presented at the bottom of the table. An experimental scale factor less than $s_{1}$ (which for this set of tests was 6.1) indicates that the models overestimate the prototype absorbed cyclic strain energy. In this sense, the microconcrete models are seen to perform poorly, with approximately a $30 \%$ difference between experimental and practical true model scale factors. Therefore, use of microconcrete test results (based on the limited data available) would likely result in unconservative expectations for prototype energy absorption capacity.

The ready-mix shear model agrees well with the prototype on a cycle-by-cycle basis and exhibits only a $1 \frac{8}{8}$ difference between experimental and practical true scale factors. The ready-mix flexure model, while generally tracking prototype behavior (see Figure 4.39), is shown to have a 128 difference between experimental and practical true scale factors, based on consideration of cyclic absorbed strain energy.

In Table 4.10 comparisons were made between cyclic energy dissipation for model and prototype columns on a cycle-by-cycle basis. An alternative comparison may be made between the total energy (summation of cycle energies) dissipated by model and prototype columns up to their respective failure points. Failure was determined when the maximum moment decreased to less than 
808 of the peak moment at $2 \Delta y$, first cycle. Column (a) in Table 4.11 represents unmodified test data, with no corrections made for differences in concrete strength between specimens, nor accounting for friction losses and test machine interaction in the prototype tests. Columns (b) and (c) in Table 4.11 successively add these corrections. The final values [column (c)] indicate reasonable correlation between the total energy dissipation capacity of the ready-mix model columns and their prototype companions. The experimental scale factor for total energy for the ready-mix shear model column is shown to exceed the practical true model scale factor by $8 \%$ (unconservative) while that the ready-mix flexure model column leads to a $4 \%$ lower (conservative) value. Both of these values are encouraging, given the variance generally associated with testing of reinforced concrete structures, and indicate that total energy absorption capacity can likely be predicted through the use of appropriate model tests. No comparisons are made in Table 4.11 between microconcrete model columns and their respective prototypes due to the inability of these models to reproduce the cyclic load-deformation behavior of the prototypes.

Table 4.12 summarizes two other important specimen parameters relating model to prototype performance. The experimental scale factor for yield deflection, sld, has been determined using equation (4.7) and is shown in column (a). Column (b) modifies sld to account for losses due friction and test machine interaction for the prototype columns. The ratio of $\mathrm{s}_{1} / \mathrm{s}_{1 \mathrm{~d}}$ is a measure of the effectiveness with which the model data can be used to predict prototype yield displacements. Values of this ratio greater than 1.0 indicate conservatism (displacements predicted by model tests would be greater than actually achieved in the prototype), whereas values less than 1.0 are unconservative (prototype displacements would be greater than predicted on the basis of model tests). Both of the above statements assume that model results would be extrapolated to prototype using the practical true length scale factor, $s_{1}$, and stress scale factor $s_{\sigma}$. Use of microconcrete model columns would therefore lead to overestimation of prototype yield deflection .. by an average of 608. The ready-mix shear model specimen was shown to underpredict prototype yield displacement by $11 \%$, while the ready-mix flexure model over-predicts yield displacement by 48 . 
The second part of Table 4.12 presents information concerning the experimental scale factor for ultimate moment, s $1 \mathrm{~m}$, determined in accordance with equation 4.8. Similar to the calculations for strain energy, two levels. of modifications are made to the original column moment data presented in column (c). Differences in concrete compressive strength are accounted for in column (d) while losses due to friction and test machine interaction in the prototype tests are accounted for in column (e). The ratio of $\mathrm{s}_{1} / \mathrm{s}_{1 \mathrm{~m}}{ }^{\prime}$, , shown in the far right column, indicates that all of the models (both microconcrete and readymix) were able to accurately predict prototype ultimate moment using only the considerations for the practical true model (moment scales by $s_{1}^{3}$ ), and the stress scale factor, $s_{\sigma}$.

The ability of the microconcrete model columns to accurately predict prototype ultimate moment, yet not be able to model deflections nor cyclic energy dissipation, is difficult to explain. Ultimate moment is determined chiefly from the compressive strength of the concrete and the ultimate tensile strength of the reinforcing steel. Because both the ready-mix and microconcrete models had similar concrete strengths, as well as identical longitudinal reinforcement, it should be expected that they would exhibit similar ultimate moments. Adjustment of the predicted prototype moments by the scale factor for stress, $s_{\sigma}$, also appears valid given the uniform agreement between the resulting experimental and length scale factors for the practical true model.

Since the reinforcement and reinforcing pattern was the same for all model columns, the only likely explanation for a large reduction in section stiffness (leading to increased displacement under lateral load) would be a difference in concrete stiffness between the ready-mix concrete and microconcrete. The mix proportions for these two concretes, presented in Table 4.13, show that the microconcrete has a lower volume fraction of aggregate than the ready-mix concrete. Because the modulus of the aggregate is approximately 5 times greater than that for cement paste, the ready-mix is inherently a stiffer concrete. Additionally, the cement paste in microconcrete contains greater air content because the smaller size aggregates entrap more air in mixing. These factors can be shown through simulation to produce a decrease of approximately $20 \%$ in modulus of elasticity for microconcrete when compared to ready-mix concrete. 
Table 4.11 Scale Factors Relating Prototype and 1/6-Scale Model Column Behavior: Total Strain Energy to Failure*

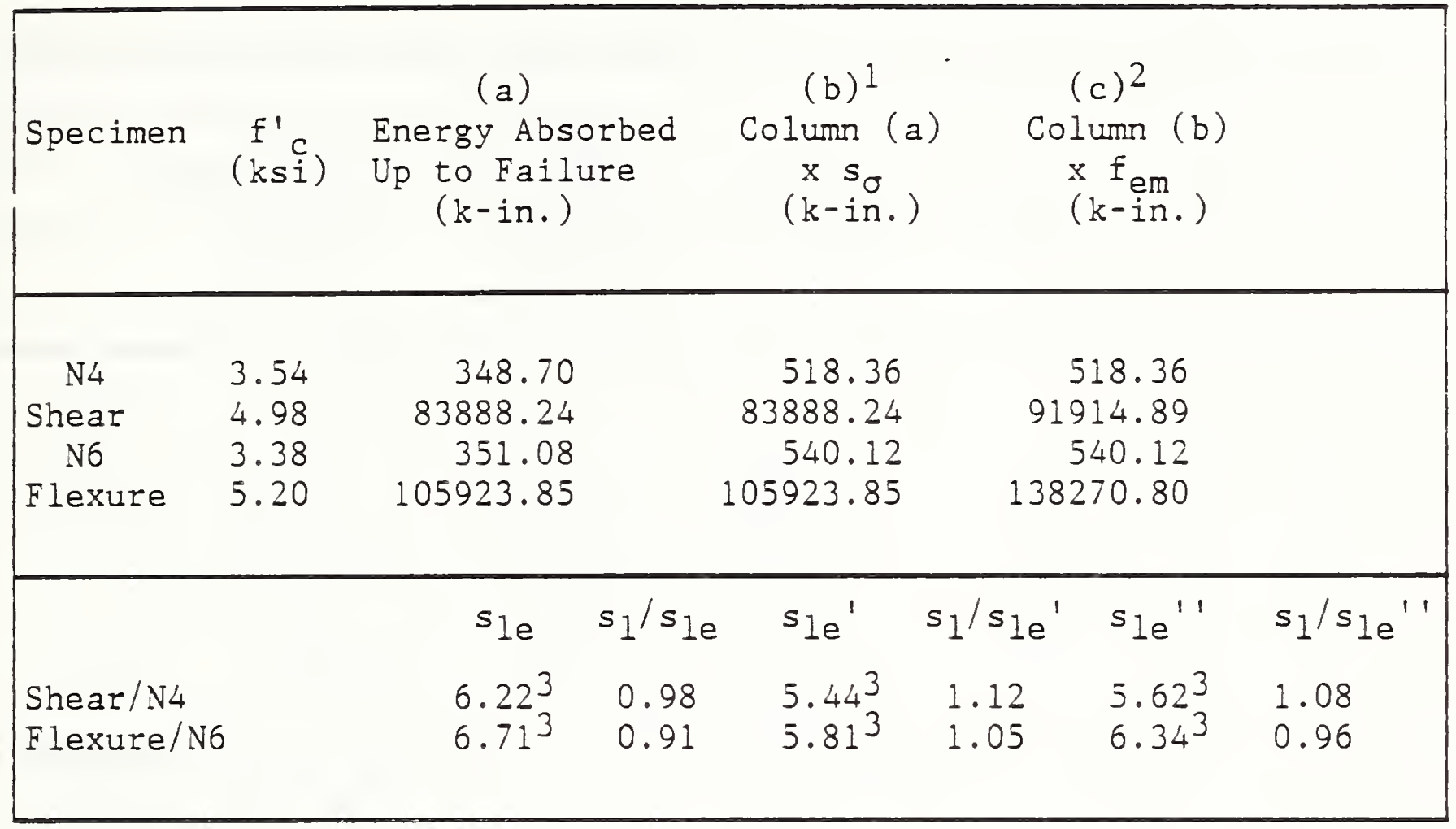

1: The energy absorbed by the model columns has been modified to account for differences in concrete compressive strength between model and prototype.

2: The energy absorbed by the prototype column has been modified to account for losses in lateral load due to friction and test machine interaction when determining $\Delta_{\mathrm{y}}$ for the prototype columns. Note that $\mathrm{f}_{\mathrm{em}}=1.096$ for the shear column; 1.3054 for flexure column.

3: This value represents the cube root of the ratio of the sum of all prototype cyclic strain energy to the sum of all model cyclic strain energy up to failure of the respective columns (e.g. Shear/N1). Recall that N1 and N3 were constructed with microconcrete; $\mathrm{N} 4$ and $\mathrm{N} 6$ were constructed using fine aggregate ready-mix. Otherwise these specimens, respectively, were identical.

$*$ No comparison is made for microconcrete models, since these were not effective in reproducing prototype behavior on a cycle-by-cycie basis. 
Table 4.12 Scale Factors Relating Full-Scale and 1/6-Scale Model Column Behavior: Displacements and Moments

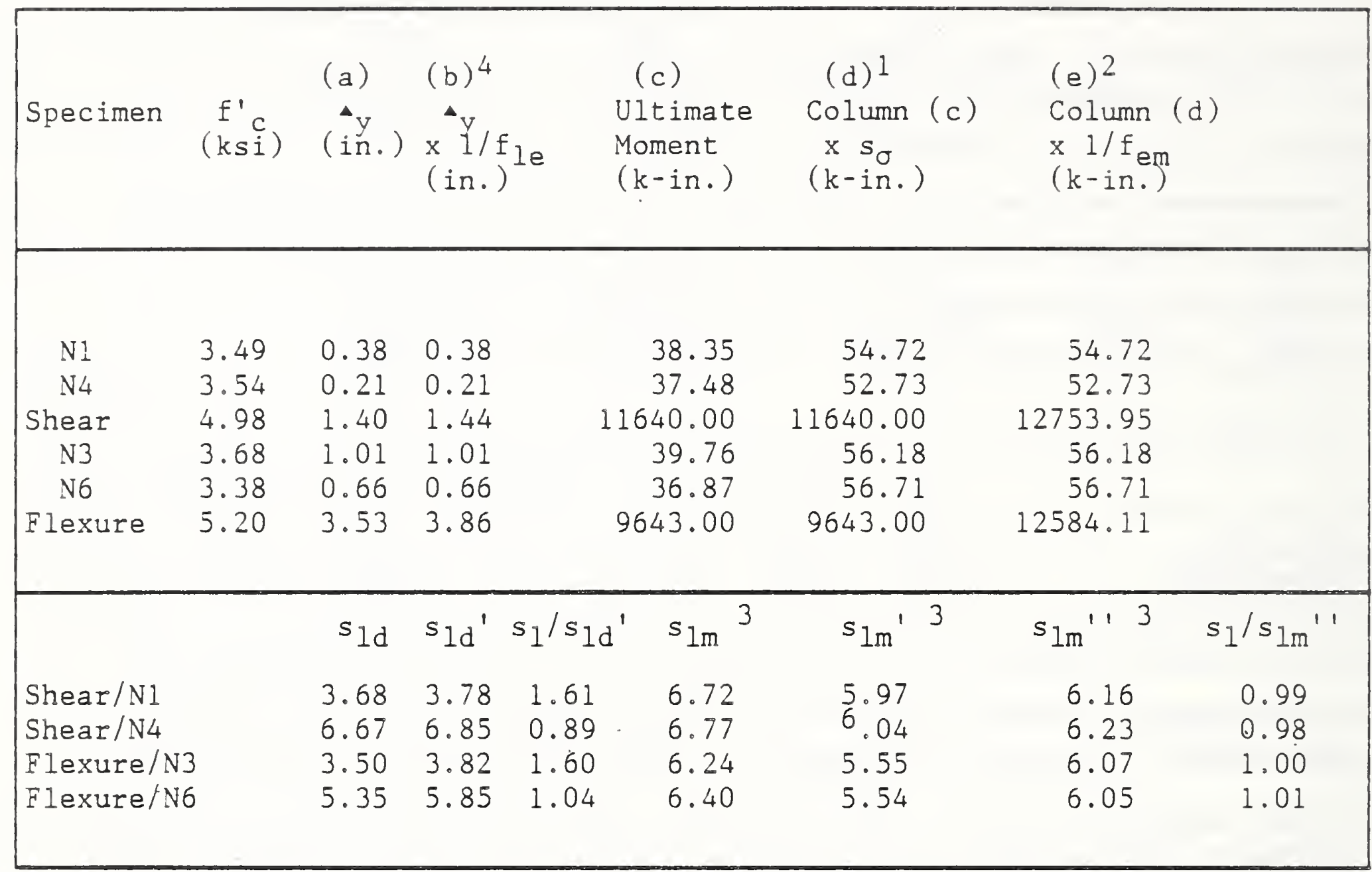

1: Ultimate moment for model columns has been modified to account for differences in concrete compressive strength between model and prototype.

2: Ultimate moment for prototype column has been modified to account for losses in lateral load due to friction and test machine interaction. Note that $\mathrm{f}_{\mathrm{em}}=1.096$ for the shear column; 1.3054 for flexure column.

3: This value represents the cube root of the ratio of the prototype moment

to the moment in its corresponding model (e.g. Shear/N1). Recall that N1 and N3 were constructed with microconcrete; N4 and N6 were constructed using fine aggregate ready-mix. Otherwise these specimens, respectively, were identical.

4: Yield displacement for prototype columns has been modified to account for losses in lateral load during determination of $y$ (see note 2 above) 
This would explain the $22 \%$ greater yield displacement observed for microconcrete model column $\mathrm{N} 2$ when compared with its ready-mix counterpart, N5. But it does not account for the $53 \%$ and $80 \%$ increase in yield deflection as indicated by the ratios of $\Delta_{y}(\mathrm{~N} 3 / \mathrm{N} 6)$ and $\Delta_{y}(\mathrm{~N} 1 / \mathrm{N} 4)$, respectively.

One possible source for the remaining, and highly variable, difference in stiffness is because microconcrete mixes are typically somewhat sticky, are considerably less workable, and exhibit much smaller slump than for ready-mix concrete of equal compressive strength. It is thus difficult to place, even with vibration. Visual inspection of the microconcrete specimens following test indicated the presence of numerous small voids varying in size from $1 / 8-1 / 4$ in. (3-6 mm) in diameter. Unfortunately, the column specimens were sufficienty cracked following test that useable cores - - which would have allowed for the determination of in-situ concrete modulus - - were not obtainable.

Even if the differences in stiffness described above could be quantitatively accounted for, the rapid failure of the microconcrete columns, as evidenced in Figure 4.43, precludes their ability to track the prototype test columns to failure. It is the author's opinion that this shortcoming results from the inability of microconcrete to develop significant shear force across the cement matrix under load reversal following initial cracking - loads carried in readymix concrete by means of aggregate interlock.

Table 4.13: Mix Design for Model Columns

\begin{tabular}{|l|cc|cc|}
\hline Material & \multicolumn{2}{|c|}{$\begin{array}{l}\text { Microconcrete Volume } \\
\text { (1b/cu.yard) }\end{array}$} & $\begin{array}{l}\text { Ready-Mix } \\
\text { (cu.ft. }\end{array}$ & $\begin{array}{c}\text { Volume } \\
\text { (cu.ft.) }\end{array}$ \\
\hline Cement (Type I) & 699.3 & 3.57 & 605.7 & 3.09 \\
Fine Aggregate & 2724.3 & 15.88 & 1460.0 & 8.52 \\
Coarse Aggregate & 0.0 & 0.00 & 1575.0 & 9.19 \\
Water & 461.0 & 6.96 & 370.4 & 5.45 \\
slump & 0.5 in. & & 4.0 in. & \\
& & &. & \\
\hline
\end{tabular}




\subsection{CONCLUSIONS}

1. The requirements for longitudinal and confining (spiral) reinforcing steel, as defined in Reference 6 [CALTRANS] are sufficient to achieve a displacement ductility factor of 6 for full-scale bridge columns with an aspect ratio (height/diameter) of 6 and a displacement ductility factor of 10 for full scale bridge columns with an aspect ratio of 3 . These values were based on tests of single prototype specimens.

2. Similitude studies were conducted to determine if prototype behavior could be predicted from tests of 1/6-scale model replicates. Structural modeling theory calls for the scaling of not only the reinforcing steel, but also the concrete, leading to the use of "microconcrete." The use of microconcrete for specimens subjected to cyclic load, particularly those in which shear effects might be expected to dominate cyclic behavior, was questioned due to the possible differences in the details of the aggregate-interlock mechanism of microconcrete compared with prototype concrete. Two sets of model specimens were thus constructed for the present study, one using microconcrete and one using ready-mix concrete with small size (0.25 in.; $6 \mathrm{~mm}$ ) river gravel. The results of these similitude tests are as follows:

a) Model specimens constructed from ready-mix concrete were able to consistently reproduce prototype behavior, on a cycle by cycle basis, with scale factors for absorbed strain energy, ultimate moment, and yield displacement falling close to those for the practical true model, $\mathrm{s}_{1}$.

b) Model specimens constructed from microconcrete were substantially more flexible than both the ready-mix models and prototypes, and hence exhibited substantially greater yield deflections. Failure was generally more rapid than for ready-mix specimens and ultimate displacement ductility was 208 less. Because of this, model cyclic absorbed strain energy, when modified to account for scale factor and differences in concrete strength, is shown to be overpredict (unconservative) the observed results from prototype tests. 
c) Both microconcrete and ready-mix models were able to accurately reproduce prototype ultimate moment capacity. Moment comparisons were made by scaling model ultimate moments by $s_{1}{ }^{3}$ and multiplying this result by the scale factor for stress, $s_{\sigma}$, to account for differences in concrete strength.

d) The ability of the ready-mix model columns to predict with reasonable accuracy the strain energy dissipated during each cycle (the scaled hysteresis loopes essentially overlapped) as well as the total energy dissipated up to column failure shows that correct selection of materials is important for accurate behavior of concrete models subjected to high level cyclic loads.

3. Failure in both model and prototype column specimens was initiated by fracture of the confining reinforcement followed by buckling of the longitudinal reinforcement. Low cycle fatigue generally resulted in fracture of the longitudinal reinforcement during the next level of displacement ductility above that during which the spiral first fractured.

4. Yielding of the longitudinal reinforcement in the column foundation was limited to a depth of less than $50 \%$ of the column diameter. This represents a distance approximately $40 \%$ of the specified (ACI) development length for the longitudinal reinforcement.

5. Experimentally determined ultimate column moments were substantially greater than the nominal (ACI) calculated moment capacity (with $\phi=1.0$ ). The prototype columns (aspect ratios of 6 and 3 ) exhibited experimental ultimate moment to ACI nominal moment ratios (moment enhancement ratio) of 1.20 and 1.46 respectively. Similar ratios were observed for the model specimens. These results are for columns with axial loads of $\mathrm{P}_{e} / f^{\prime}{ }_{c} A_{g}=0.1$.

6. An increase in column axial load from $\mathrm{P}_{\mathrm{e}} / \mathrm{f}^{\prime} \mathrm{c}_{\mathrm{A}} \mathrm{g}=0.1$ to 0.2 resulted in a $20 \%$ increase in ultimate displacement ductility and a $12 \%$ increase in moment enhancement ratio. These were based on comparisons between four model bridge columns and support the findings of other researchers [17]. 
7. The second cycle at a given displacement ductility generally resulted in the dissipation of slightly less energy. It is interesting to note, however, that the results for the flexure specimen, which sustained 10 cycles at $4 \Delta_{y}$, indicated that after the third cycle at $4 \Delta y$ that the energy dissipation appeared to stabalize so that the 10th cycle dissipated nearly $90 \%$ that of the first. This is important because it indicates that there apparently exists a threshold displacement below which a substantial number of inelastic cycles may take place during which energy is dissipated without marked degradation of the column. Above this threshold, additional cyclic load quickly caused failure.

8. Important lessons were learned in carrying out the prototype tests, especially with regard to the design and implementation of instrumentation for monitoring reactions in statically indeterminate test apparatus. The most reliable load measurement systems consisted of single load resisting elements with redundant strain gage instrumentation for verification. Where appropriate, the test fixtures themselves (including the vertical test machine and tie-back frame) were instrumented, calibrated, and successfully used during the full-scale tests. Additional instrumentation was used to provide two independent means of determining column moments and shear. This avoided the possible loss of test data should one set of instrumentation become inoperable during testing. A suggested improved loading apparatus which makes use of single load path instrumentation is presented in Appendix $B$. 



\section{Appendix A: Full Scale Testing Techniques}

\section{A.1 Laboratory Related Problems and Logistics}

\section{A.1.1 Introduction}

During the planning of the project it was decided, following discussions with CAITRANS engineers, that the effect of axial loads of approximately $0.09 f^{\prime} \mathrm{c}^{\mathrm{Ag}}$ and $0.18 f^{\prime} \mathrm{c}^{\mathrm{Ag}}$ would be investigated in the first test series. For a 5 ft. $(1.52 \mathrm{~m})$ diameter column with $4000 \mathrm{psi}(27.6 \mathrm{MPa})$ design concrete strength,

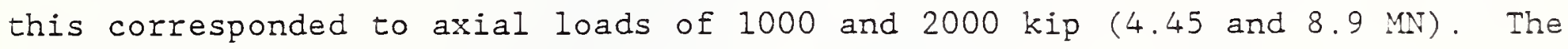
National Bureau of Standards had at its disposal a 12,000 kip (53 MN), manually controlled universal testing machine (Figure A.I) which could meet these loading conditions. The machine was equipped with a tie-down floor system (see Figure A.2) which extended 42 feet $(13 \mathrm{~m}$ ) either side of centerline. The floor system contained 126 bolt emplacements, each capable of handling $150 \mathrm{kip}(668 \mathrm{KN}$ ) loads in tension. The slab was designed to withstand a maximum applied moment of $8400 \mathrm{kip}-\mathrm{ft} .(11.4 \mathrm{MN}-\mathrm{m})$.

Ideally, laboratory tests should be conducted to reproduce loading conditions anticipated in the as-built structure. Earlier it was mentioned that loading of single-bent cantilevered bridge columns during seismic events is predominately due to inertial loads from the bridge superstructure (both lateral and vertical) and the gravity weight (static reactions) of the superstructure. Because most of these bridges use elastomeric bearing pads at the column/superstructure joint, the connection can be modelled as a hinge. For the case of the $1 / 6$ scale model tests, as shown in Figures A.3 and A.4, it was possible to achieve these boundary conditions through use of the NBS Tri-Directional Testing Facility (TTF), a computer controlled loading system 


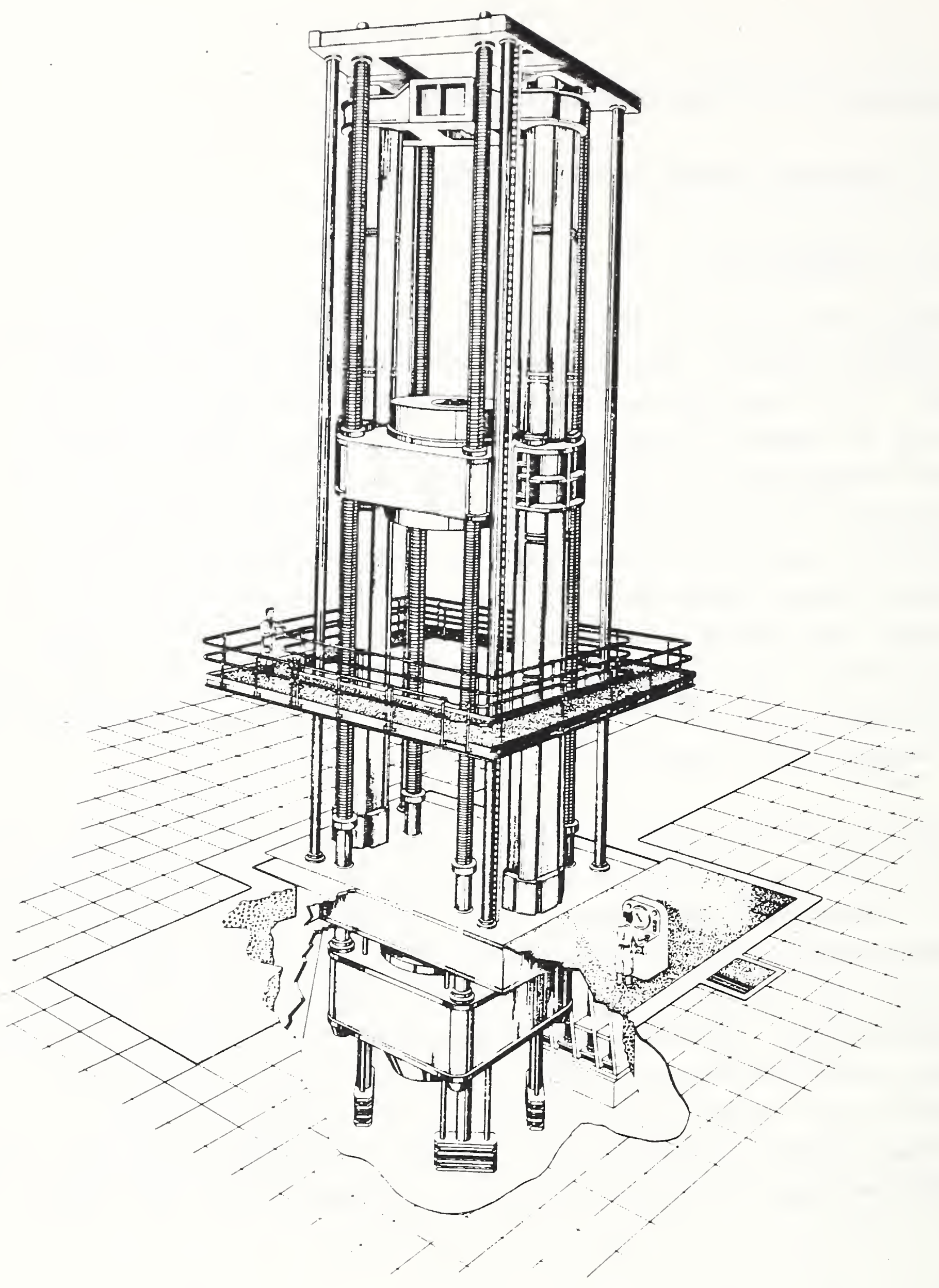

A.1: Artist's Rendering of $12000 \mathrm{kip}$ Test Machine. 


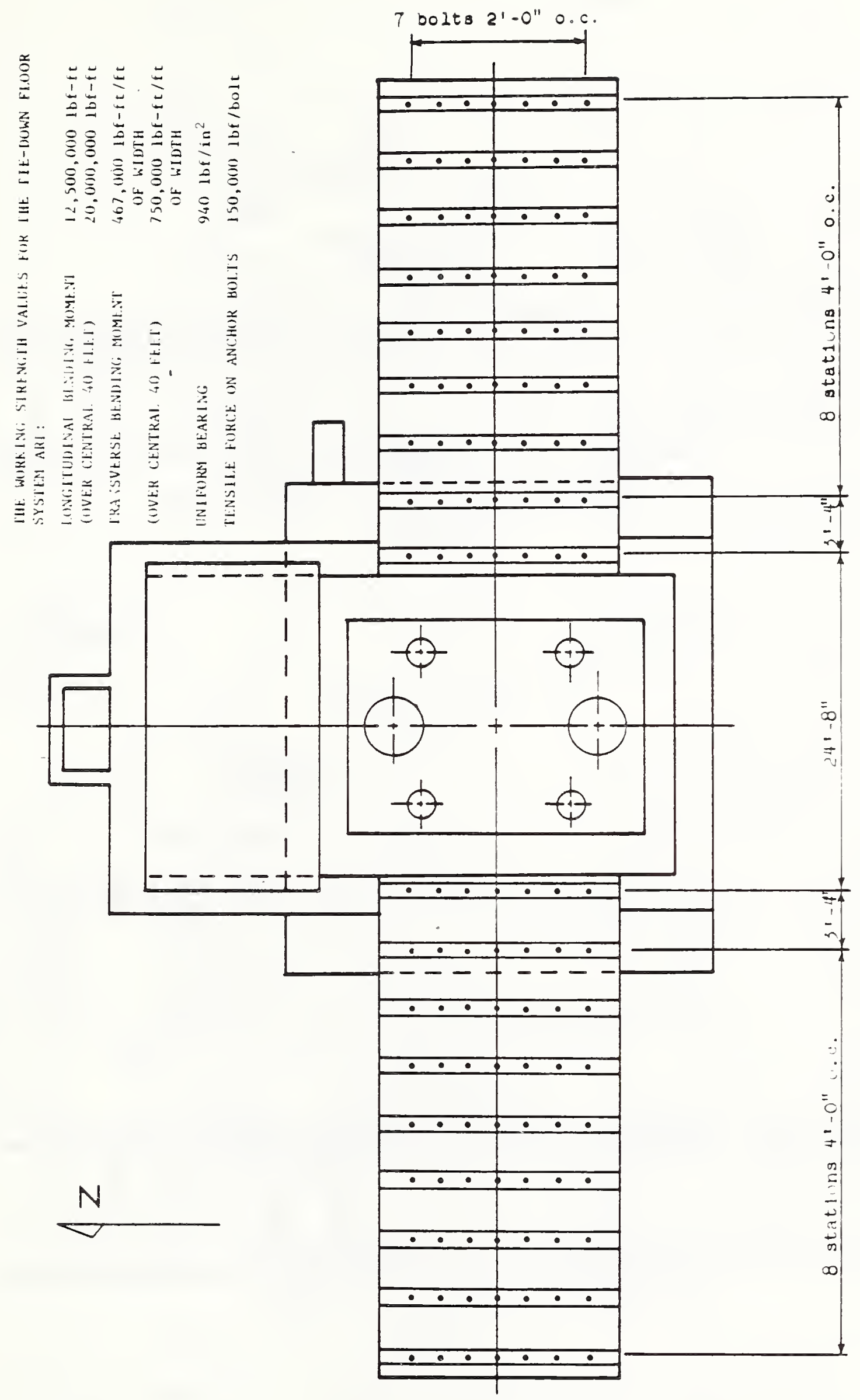

Oี 
TTF TEST SET-UP

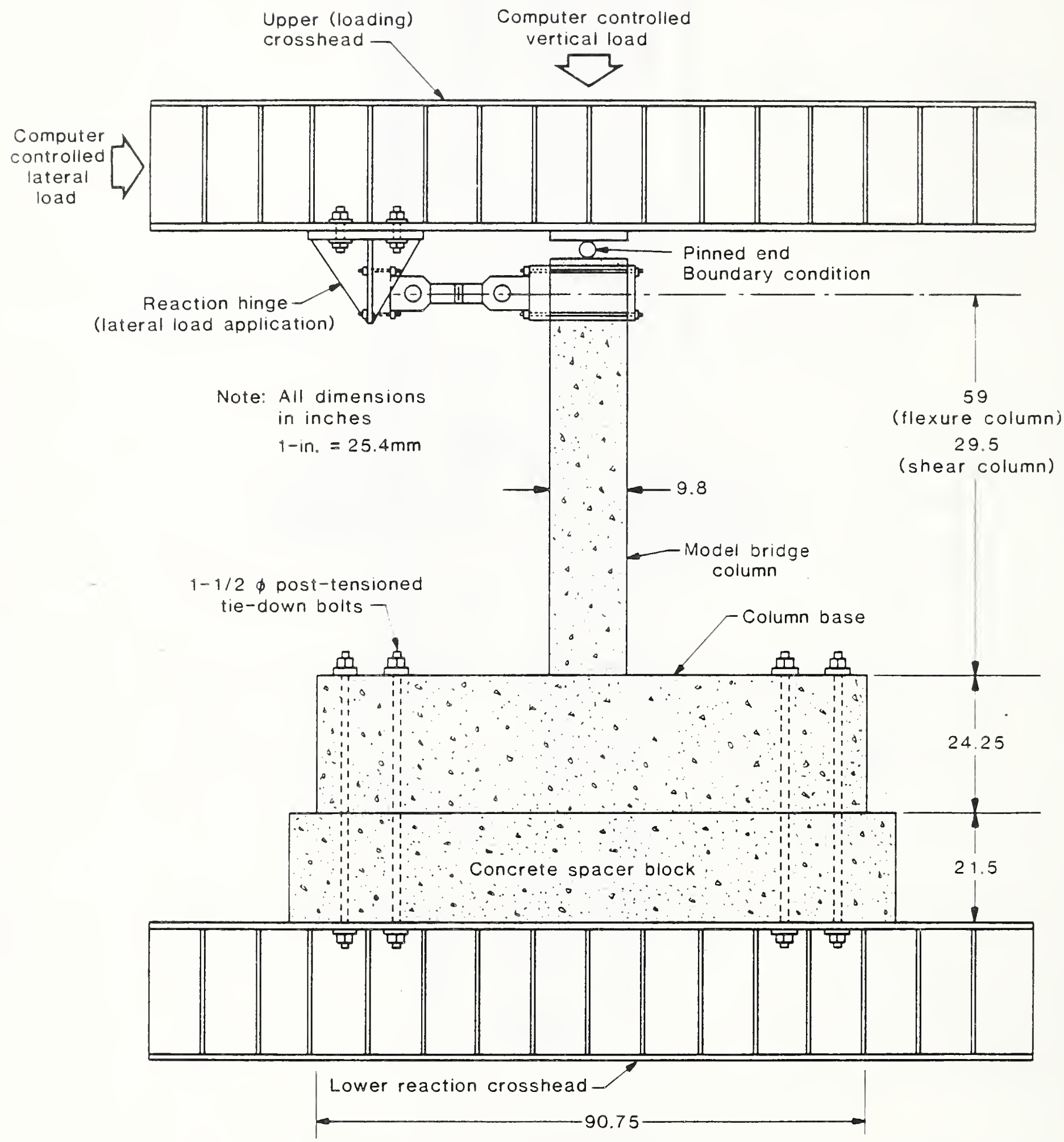

Figure A.3: Lateral View of Model Specimen Mounted in Triaxial Test Facility 


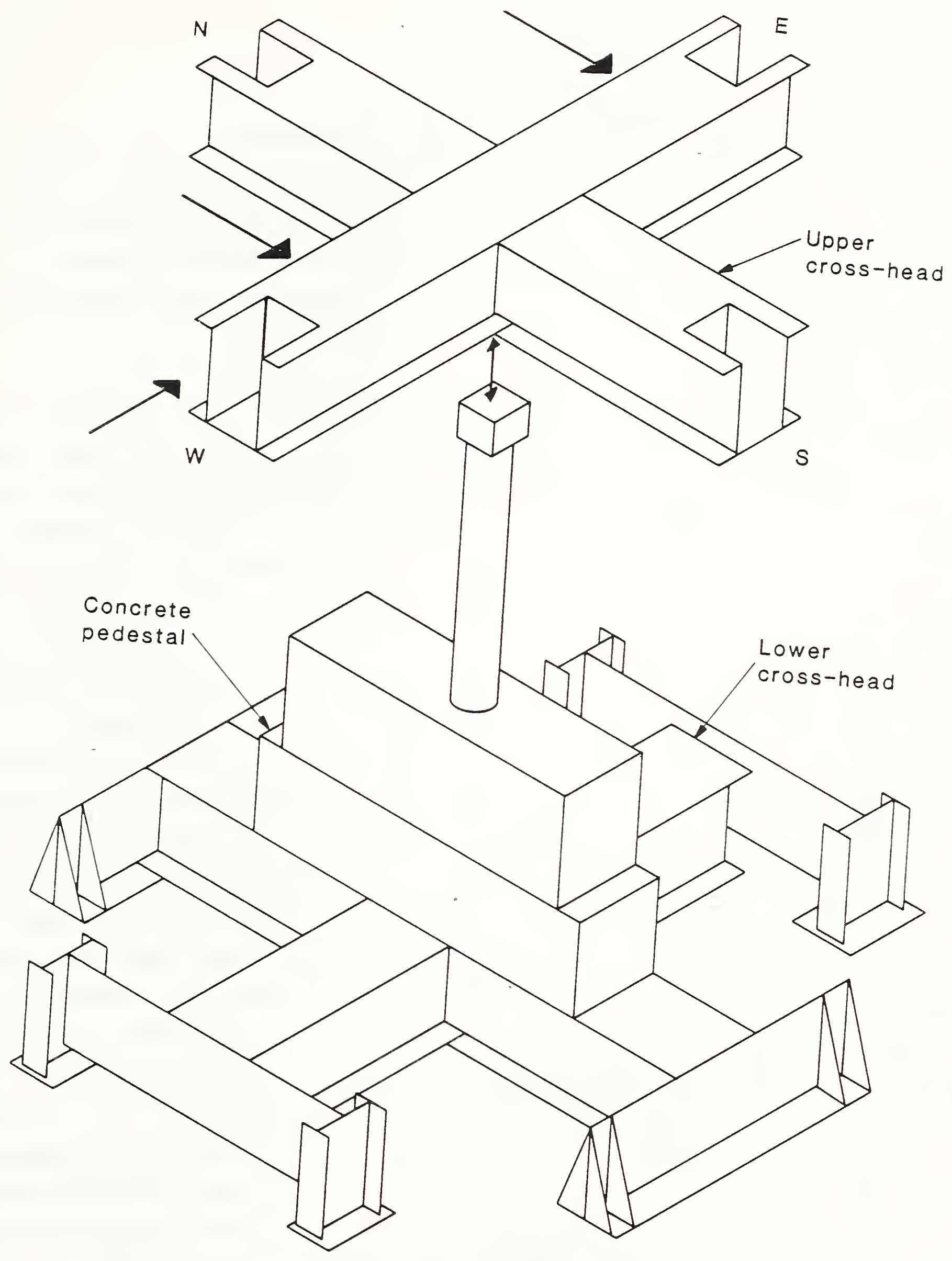

Figure A.4: Isometric View of Model Specimen and Control Loads Applied by Triaxial Test Facility. East West Actuator was used only for Maintainance of Lateral Stability. 
in which both axial and lateral loads could be applied to the top of a test column by means of a moving loading head. Vertical alignment of the axial load was thus assured and appropriate $P-\Delta$ effects were generated during lateral deflections. The column "foundation", as shown in Figure A.3, was rigidly attached to the test floor, thus assuring a fixed-end condition at the column base.

The Tri-Directional Test Facility was limited in use to relatively small specimens. The $12000 \mathrm{kip}$ ( $53 \mathrm{MN}$ ) testing machine, on the other hand, had one primary drawback: the loading head could not sustain any significant lateral displacements due to the likelyhood of rupturing its sensitive membrane load cell. This problem is generally endemic to large capacity vertical testing machines. Because of this several alternative loading methods were investigated, all of which relied upon the technique of moving the column base, while the column top - - which had a hinged boundary condition similar to the model specimens - - was restricted from lateral displacements. One approach used in bridge column tests in New Zealand [7] was to construct a symmetrical specimen as shown in Figure A.5. Lateral loads were applied to the central block while the two ends were pinned [i.e. restrained from lateral motion]. This had the potential benefit of obtaining two tests (the top and bottom specimens were identical, for the price of one, assuming that interaction effects between the two specimens were minimal, and that failure was nominally symmetric. A pronounced asymmetric failure (formation of a hinge on either side of the central load block, but not the other) would have resulted in minimal or no useful data in the inelastic regime from half of the specimen. This was considered an unacceptable risk given the cost of a fullscale specimen. Regardless of the above considerations, use of a specimen such as shown in Figure A.5 would have resulted in full-scale specimens taller than the 60 foot ( $18.3 \mathrm{~m}$ ) vertical access space available inside the testing machine. It would also have demanded the use of a substantially stiffer, taller reaction system for resistance of lateral motion at the upper column hinge. Consideration of these factors eventually led to the moving specimen concept described in the next section. 


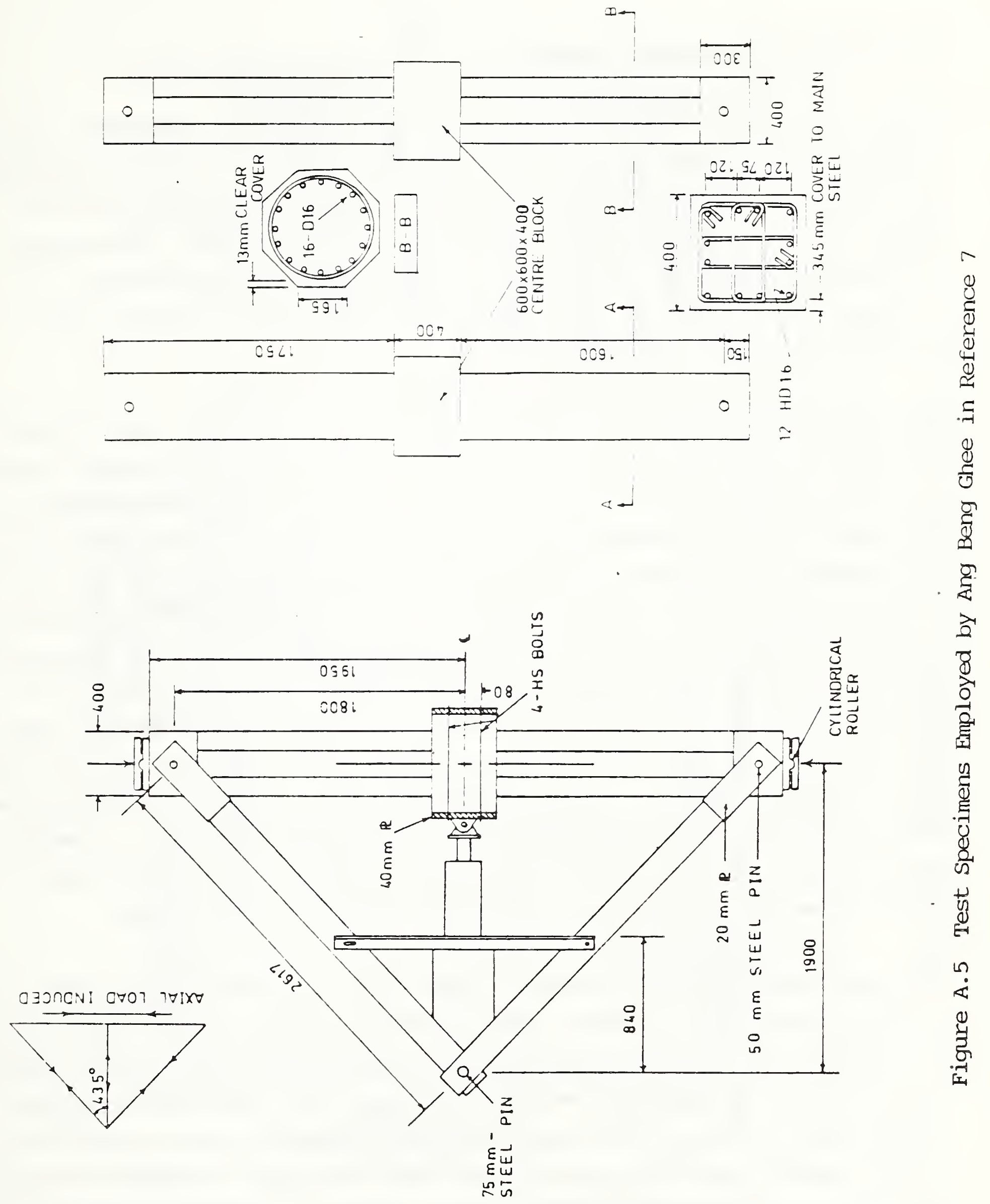




\section{A.1.2 The Moving-Specimen Concept}

Figure A.6 and A.7 show schematics of the test setup, specimen, and data collection system employed for the full-scale tests. In this configuration the column is rigidly cast into a massive, mobile foundation structure. The depth of the base section was designed to accomodate longitudinal bar development lengths as called for in present CALTRANS specifications. For the columns tested in this program, the embedment depth was 8.5 feet $(2.6 \mathrm{~m})$ to the point of tangency of the bar hooks.

The base was reinforced with $15-\# 11$ ( $1.56 \mathrm{sq}$.in; $1006 \mathrm{~mm}^{2}$ ) grade 60 deformed bars for compression and $30-\# 14$ bars (2.25 sq.in.; $1452 \mathrm{~mm}^{2}$ ) grade 60 deformed bars for tension, as shown in Figures 2.1 and 2.2. This reinforcing pattern was sufficient to withstand the moment and shear forces developed at maximum anticipated column plastic moment under a maximum axial load of 2000 kip with a load factor of 1.5. Moment capacity of the base section was analyzed using classical theory for doubly reinforced beams; shear capacity was determined by means of a deep beam analysis using procedures proposed by Zutty [8]. The worst case design criteria for moment in the base block occurred along the vertical section flush with the column face on the side carrying the highest roller support reaction. This corresponded, for a column sustaining an axial load of $2000 \mathrm{kip}(8.9 \mathrm{MN})$ and a lateral deflection sufficient to develop the plastic moment of the column (approximately $8000 \mathrm{ft} .-\mathrm{kip} ; 10.9 \mathrm{MN}-\mathrm{m}$ ), to a design moment for the reaction wall of 21,000 kip-ft. (28.5 MN-m).

The final dimensions of the footing were $26 \mathrm{ft}(7.92 \mathrm{~m})$ long $x 9 \mathrm{ft} .3 \mathrm{in}$. $(2.82 \mathrm{~m})$ high $\times 8 \mathrm{ft} .(2.43 \mathrm{~m})$ wide. This base blcck and its monolithically cast column test section were supported by continuous track roller systems at either end of the footing, as shown in Figure A.6. The spacing between the rollers and the mass of the base block were designed so that no uplifting at either support would occur during the tests, and also to ensure that failure would occur in the column rather than the footing. During the course of any particular cycle the rollers on one side of the specimen were unloading 


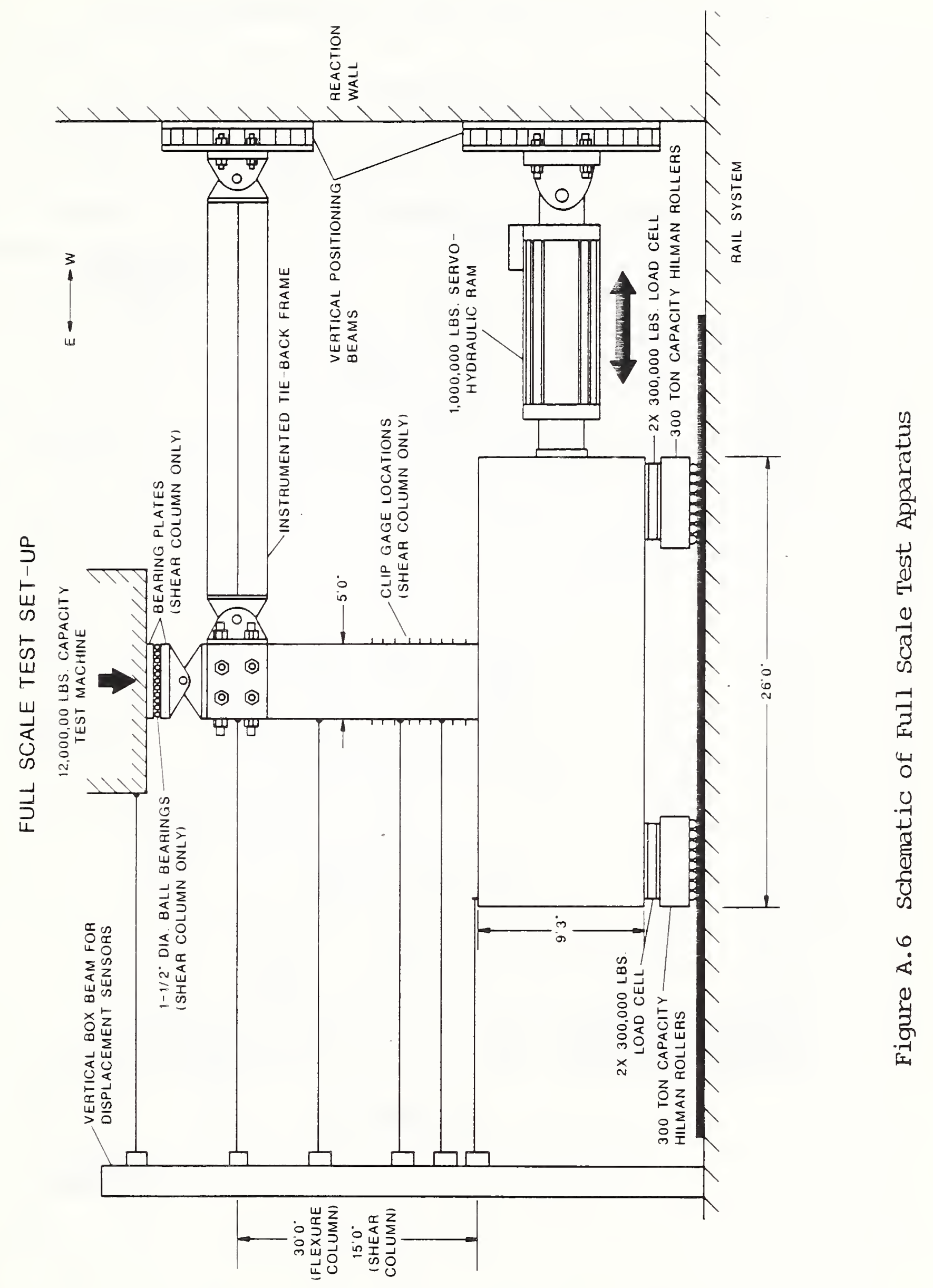




\section{LARGE SCALE STRUCTURAL RESEARCH FACILITY}
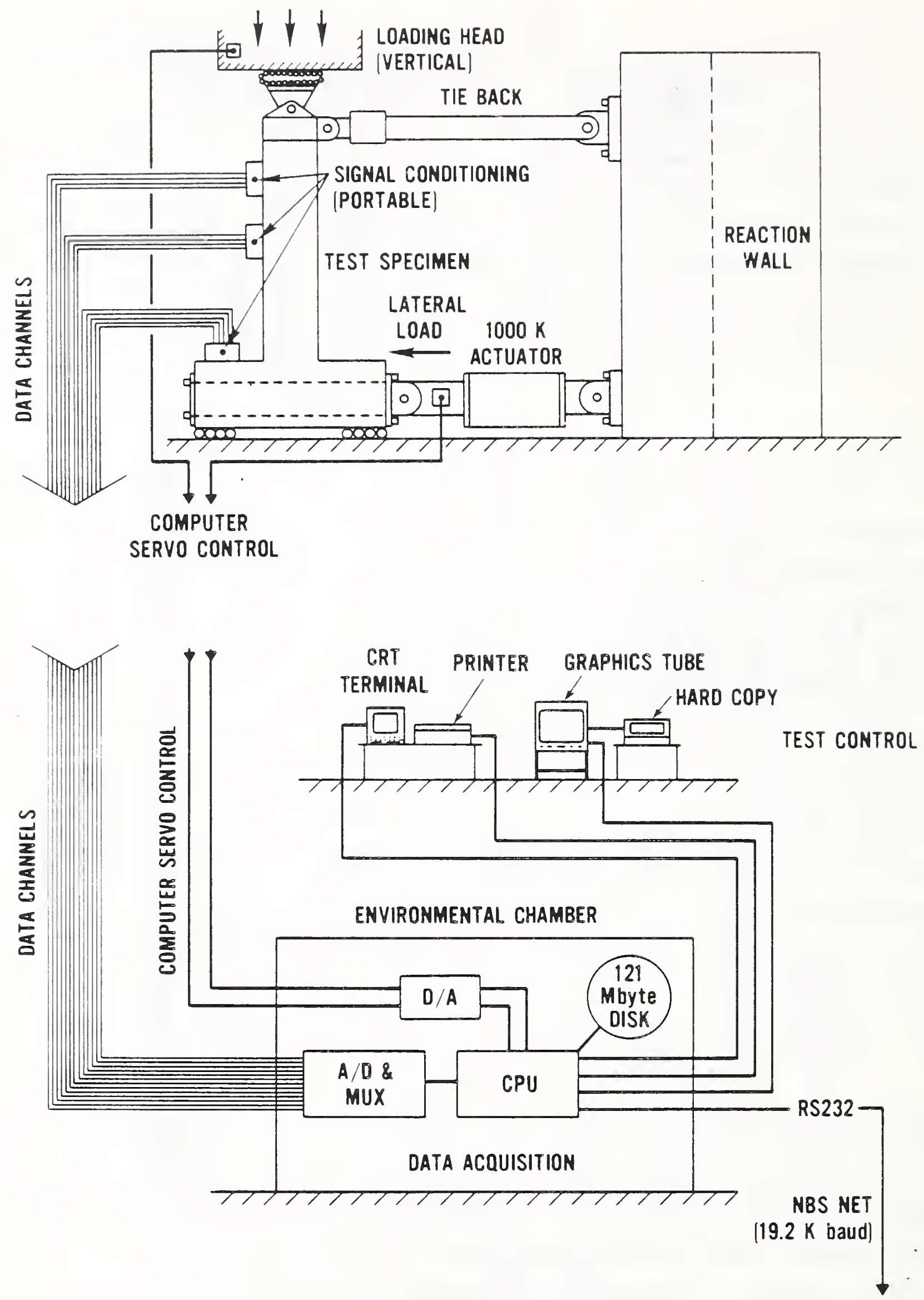

Figure A.7: Data Acquisition System and Test Control for Full Scale Bridge Column Tests. 
while those on the opposite side were picking up more of the vertical reaction. The roller system, therefore, had to be designed such that any side could handle the entire weight of the specimen plus the applied axial load. Figure A.8 shows two charts used to determine the required spacing of the roller transport system. The first of these shows the minimum roller spacing to prevent uplift on the unloading side of the base block as it is displaced laterally from center position. A conservatively low axial load of 800 kip ( $3.6 \mathrm{MN}$ ) was chosen for consideration of the uplift problem. The second chart shows the maximum roller reaction as a function of spacing on the loading side of the base block. The combined allowable load for the four roller units at each end of the specimen was $2400 \mathrm{kip} \mathrm{(10.7} \mathrm{MN).} \mathrm{The} \mathrm{design} \mathrm{moment} \mathrm{was} 9240$ kip-ft. (12.5 MN-m), although moments as high as 12,000 kip-ft. (16.2 MN-m) were anticipated if the cured concrete strength proved substantially higher than the 4000 psi (27 MPa) design strength. The final spacing ( $L$ ) chosen was $23.4 \mathrm{ft} .(7.1 \mathrm{~m})$ which provided a factor of safety of 1.5 for uplift and 1.16 for crushing. 

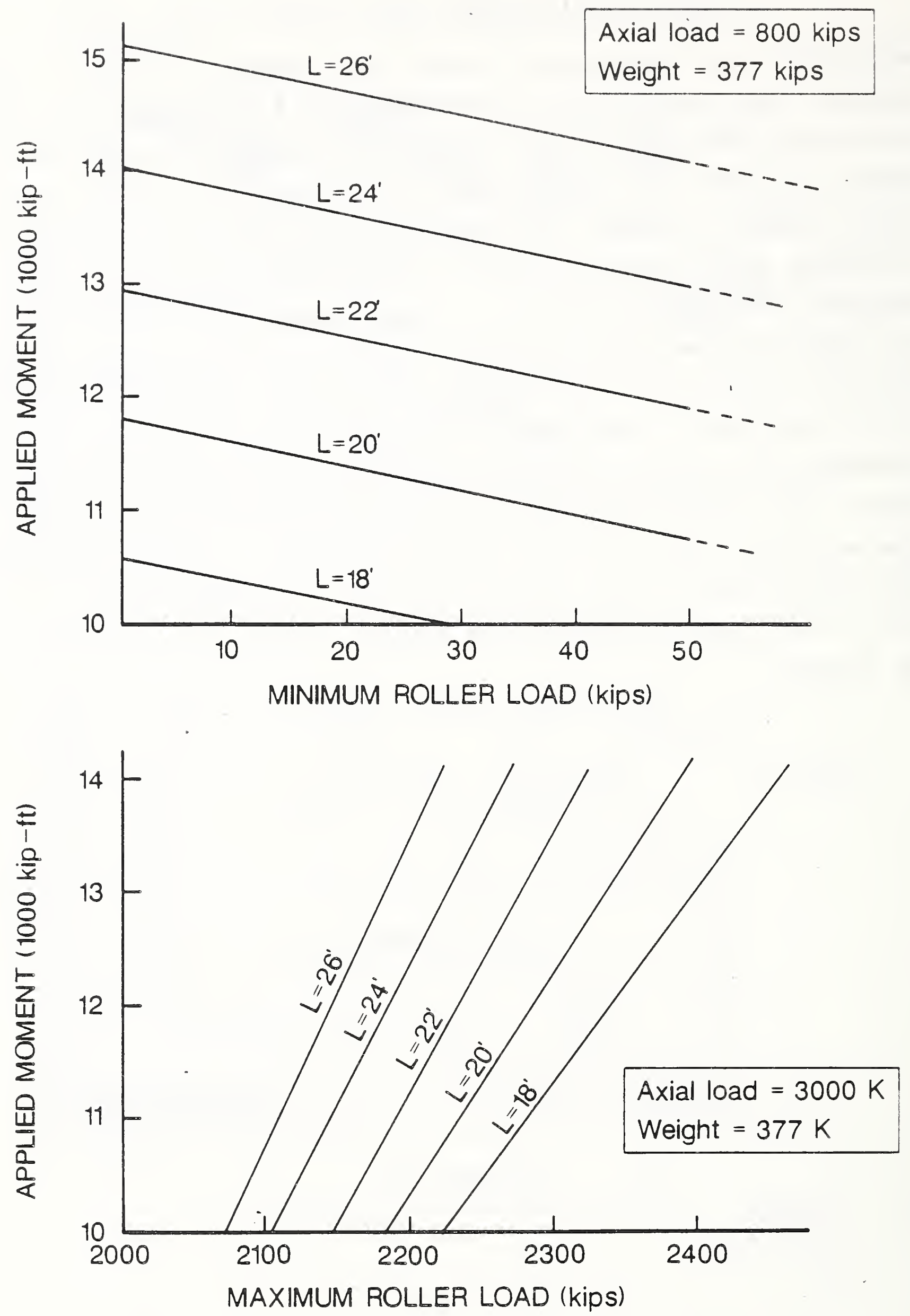

Figure A.8 Design Chart for Roller Reaction Forces as a function of base length. 


\section{A.1.3 Rail Transport System}

The key to the mobile specimen concept was a roller subsystem. This consisted of eight 300 ton ( $2.7 \mathrm{MN}$ ) capacity, specially modified Hillman Rollers as shown in Figure A.9. These were constructed from a continuous chain of 20 hardened rollers, each measuring 2 in. ( $51 \mathrm{~mm}$ ) diameter by 5 in. (130 mm) long held in alignment by means of external connector links fastened at each end of the rollers. The surrounding frame provides the reaction system which carries the loads from the specimen to the individual rollers. Four smaller roller bearings, oriented vertically, were affixed to the corners of each roller system to keep them centered on the rails described below. Four of these roller systems were positioned at each end of the specimen base block, so that a total of eight, with a vertical load capacity of 2400 tons (21.4 MN) were available for specimen handling purposes. Half of this, or 1200 tons (10.7 MN) could be counted on for resisting the 1100 ton ( $9.8 \mathrm{MN}$ ), worst case vertical reaction resulting from the loading and unloading associated with cyclic loading described above.

It is important to recognize the difficulties of handling a specimen weighing 190 tons ( $1.7 \mathrm{MN}$ ) in a laboratory environment. This was well beyond the capacity of both laboratory overhead cranes (combined capacity 55 tons, $0.49 \mathrm{MN}$ ) and therefore once constructed alternative mechanisms of transporting the specimen into the test apparatus were necessary. This led to the concept of a laboratory rail system (Figure A.10). The system consisted of four separate tracks, each 120 feet $(37 \mathrm{~m})$ in length, spaced on two foot $(610 \mathrm{~mm})$ centers, upon which the 300-ton roller units would ride. These were fabricated from 8 in. wide by 2 in. high (203 x $51 \mathrm{~mm}$ ) sections of high strength $\mathrm{T}-1$ steel (100 ksi, $690 \mathrm{MPa}$ yield stress). Construction tolerances allowed for a maximum deviation from level of $0.050 \mathrm{in.} \mathrm{(1.3} \mathrm{mm)} \mathrm{averaged}$ over the length of the track. This required the use of machined shim plates. In addition to providing a means for cyclic loading of the specimen, the rail system permitted easy access and removal of the specimen from the test apparatus and allowed for construction - - and later demolition .. of the specimen at a site some distance away from the test apparatus. Figure A.11 shows a sketch of the transport system and test facility. 


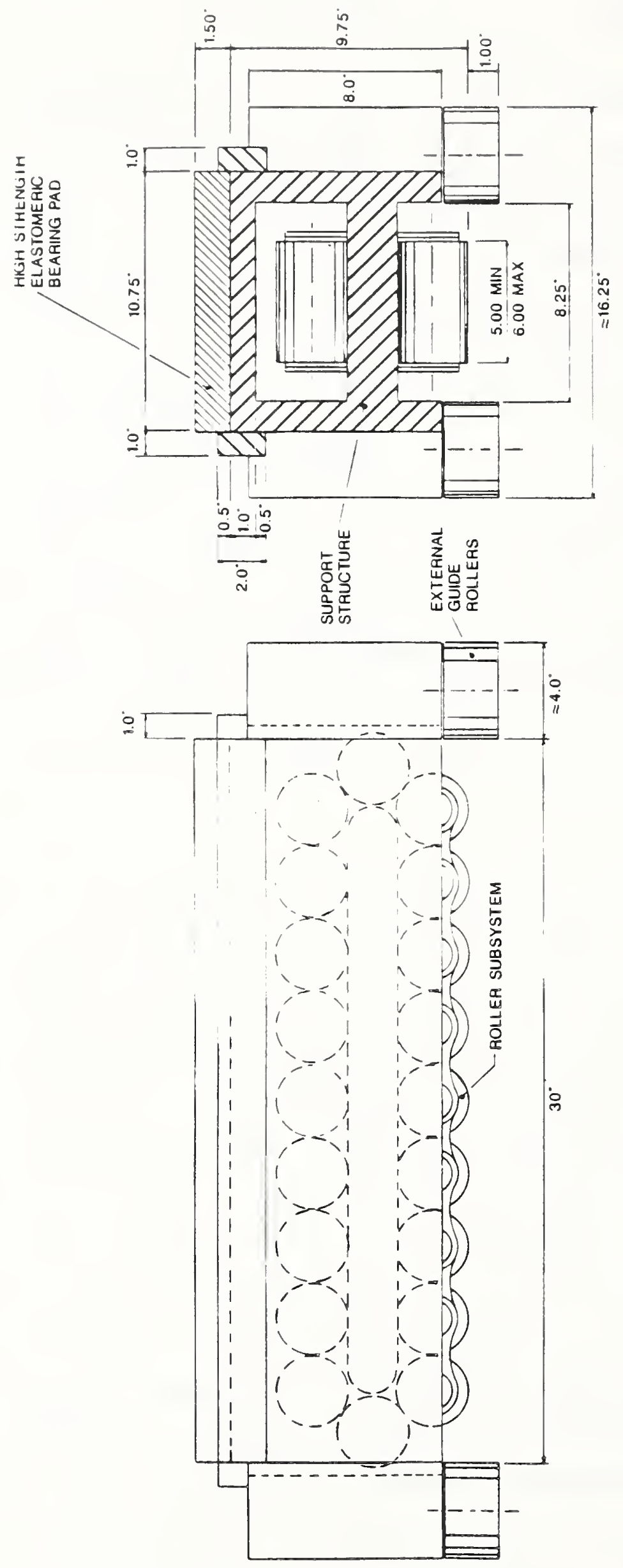

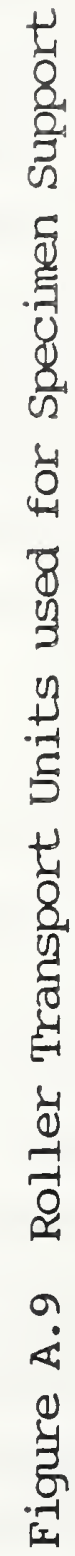




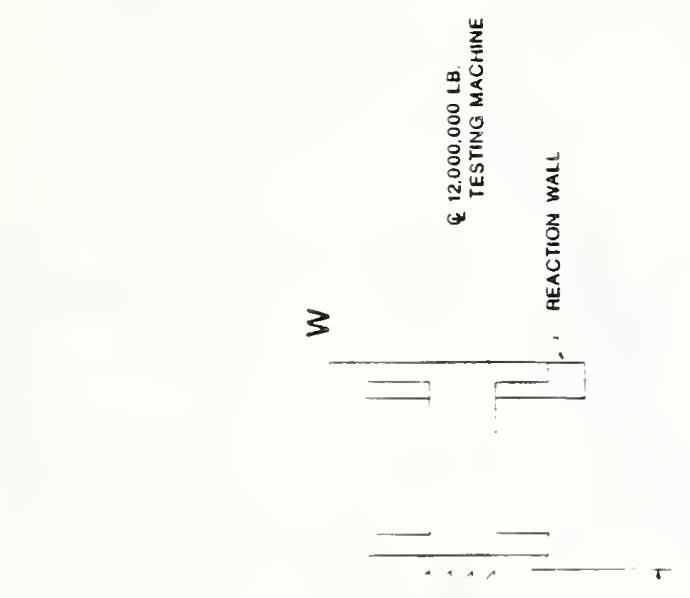

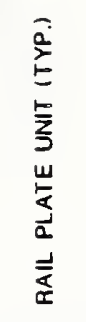

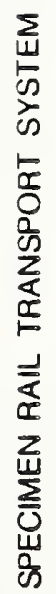
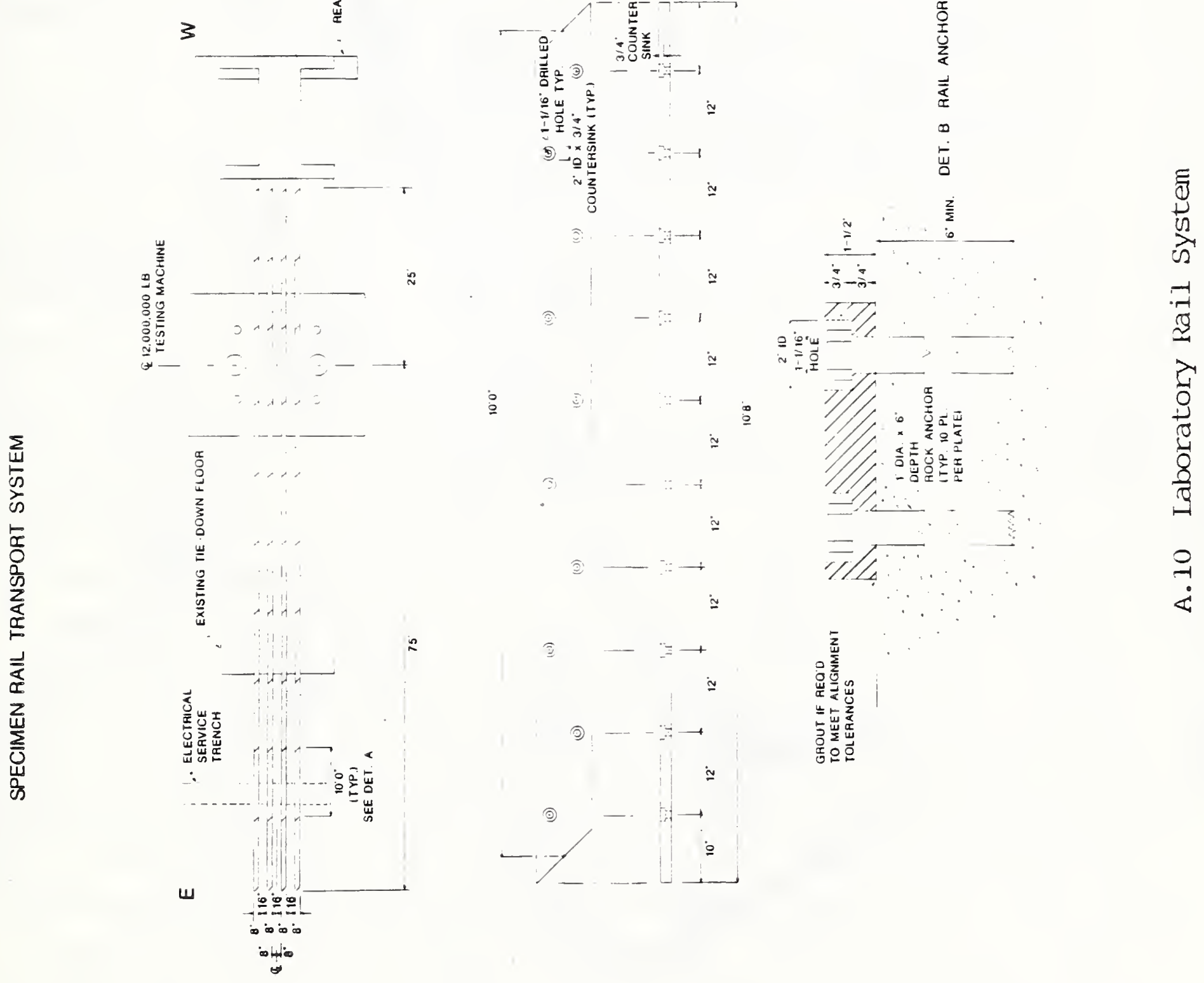


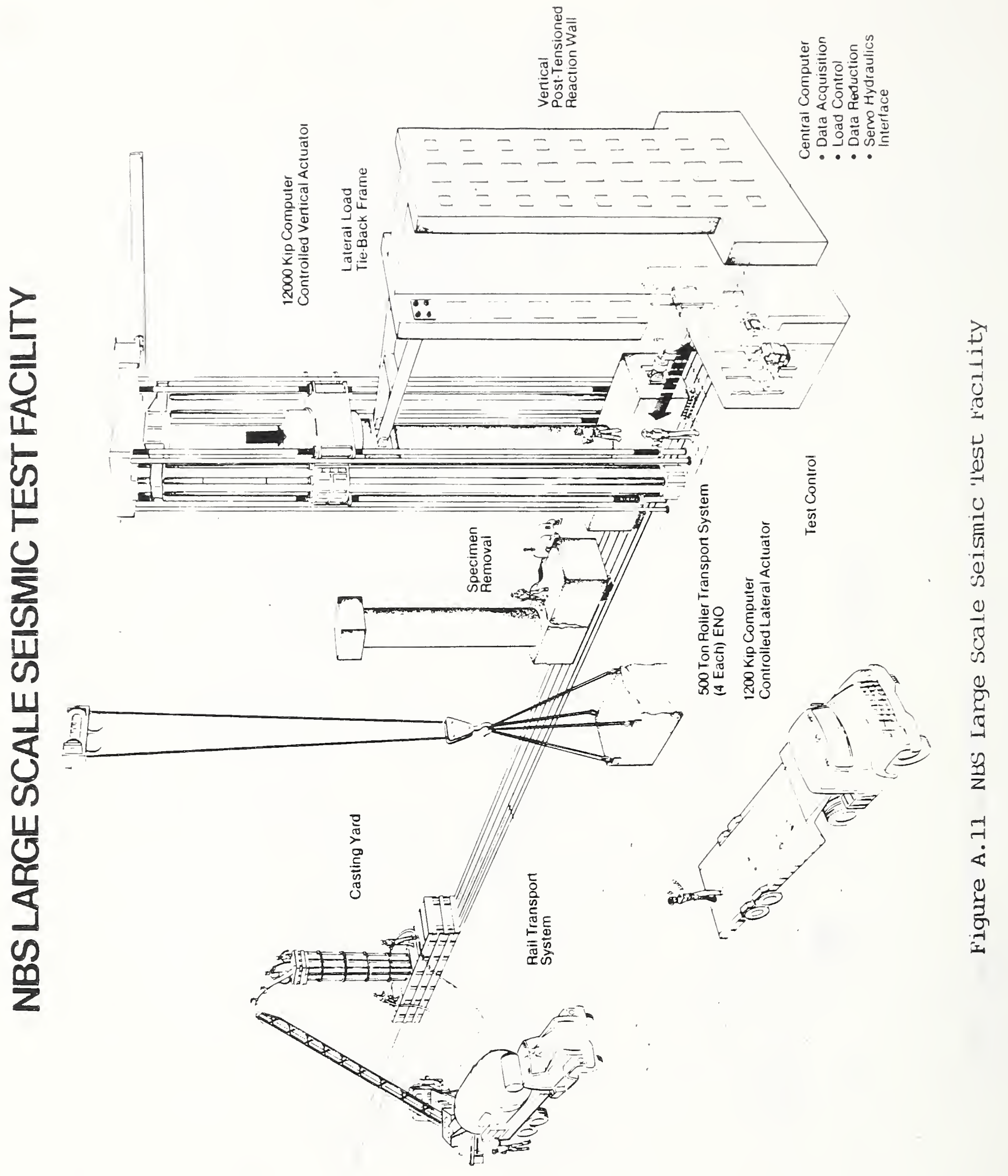


Inherent with the use of the moving specimen concept is the understanding that the roller transport system is not frictionless, and lateral load losses due to friction between the rollers and the rail must be accounted for in order to arrive at the actual applied column moments. The initial estimate of the coefficient of friction for the rollers was $5 \%$ of the applied axial load, which could, in turn, have led to a substantial difference in the actual lateral load perceived by the test column.

To accurately account for any losses that might arise from friction, a series of cyclic load calibration tests were conducted on the rollers as shown in Figure A.12. Two of the roller systems were mounted in the 12000 kip (53 MN) test machine such that a length of the $\mathrm{T}-1$ track used in the actual rail system could be sandwiched between them. The track, in turn, was connected to a servo-hydraulic actuator capable of moving the track back and forth following a sinusoidal control pattern. A series of increasing axial loads (perpendicular to the motion of the track) were applied to this assembly up to a maximum load of 300 tons $(2.7 \mathrm{MN})$, the service capacity of the roller systems. At each increment in axial load two cycles of lateral displacement were carried out and the resulting lateral loads, displacements and axial loads were recorded. A sample of the experimental load-displacement data is presented in Figure A.13. The horizontal sections, which remain essentially stable throughout the majority of the lateral displacement cycle, represent the kinetic rolling friction resistance. The spikes near each end represent the transition between kinetic and static rolling friction resistance. Since a smooth, continuous motion was to be provided during actual testing of the column specimens (by means of a servo-hydraulically controlled actuator), and since the static transition represented only a small percentage of the total displacement cycle, a friction coefficient calibration curve was established as a function of axial load using the constant kinetic friction data. The resulting friction calibration curve is shown in Figure A.14. This indicated a linear variation of the rolling friction coefficient as a function of applied axial load, with a peak valve of 0.0015 at the maximum individualroller service load of 300 tons ( $2.7 \mathrm{MN}$ ). This was substantially less (more than an order of magnitude) than the original $5 \%$ worst-case estimates provided 

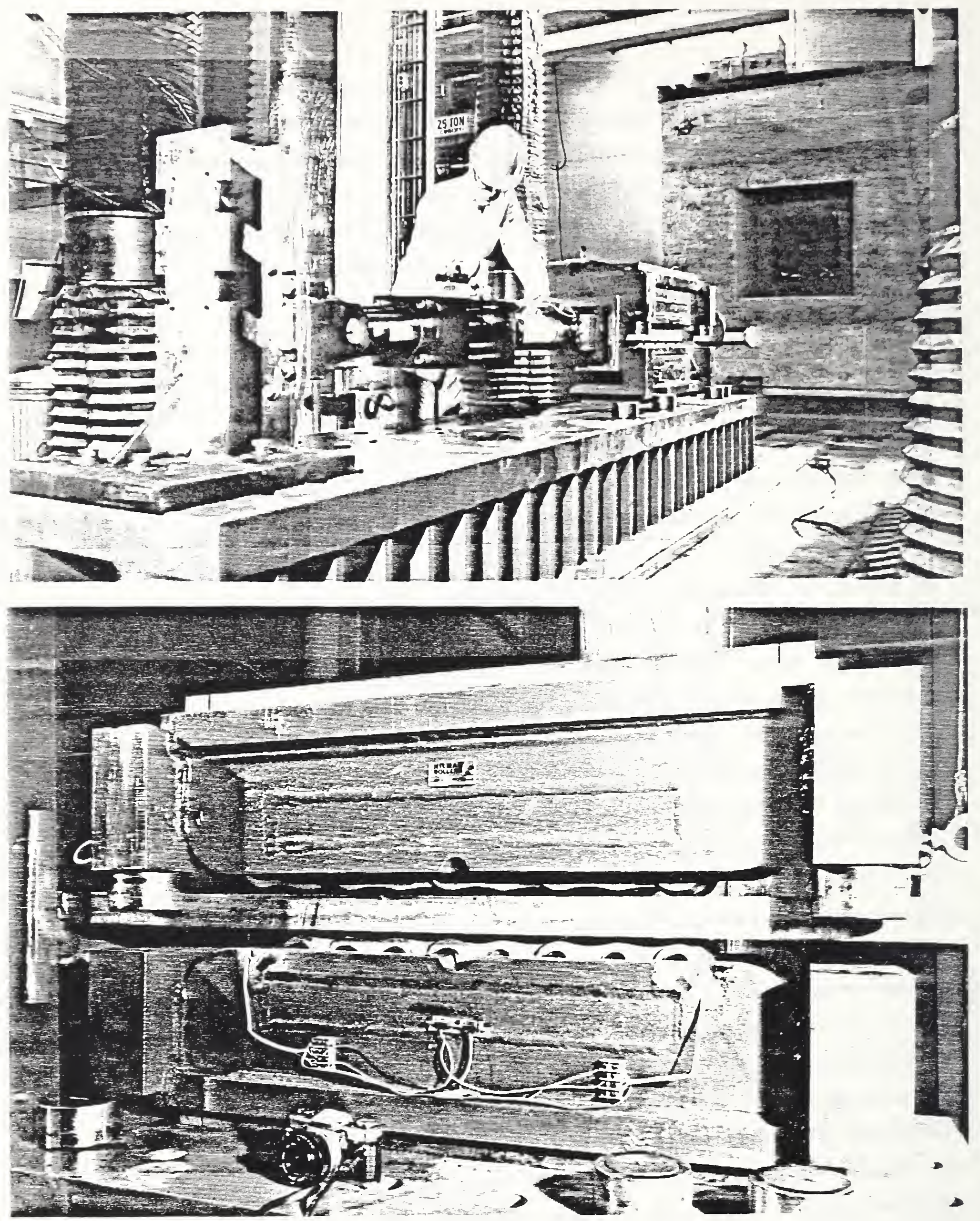

Figure A.12 Roller Friction Calibration Test Apparatus 
FRICTION CALIBRATION FOR HILMAN ROLLERS
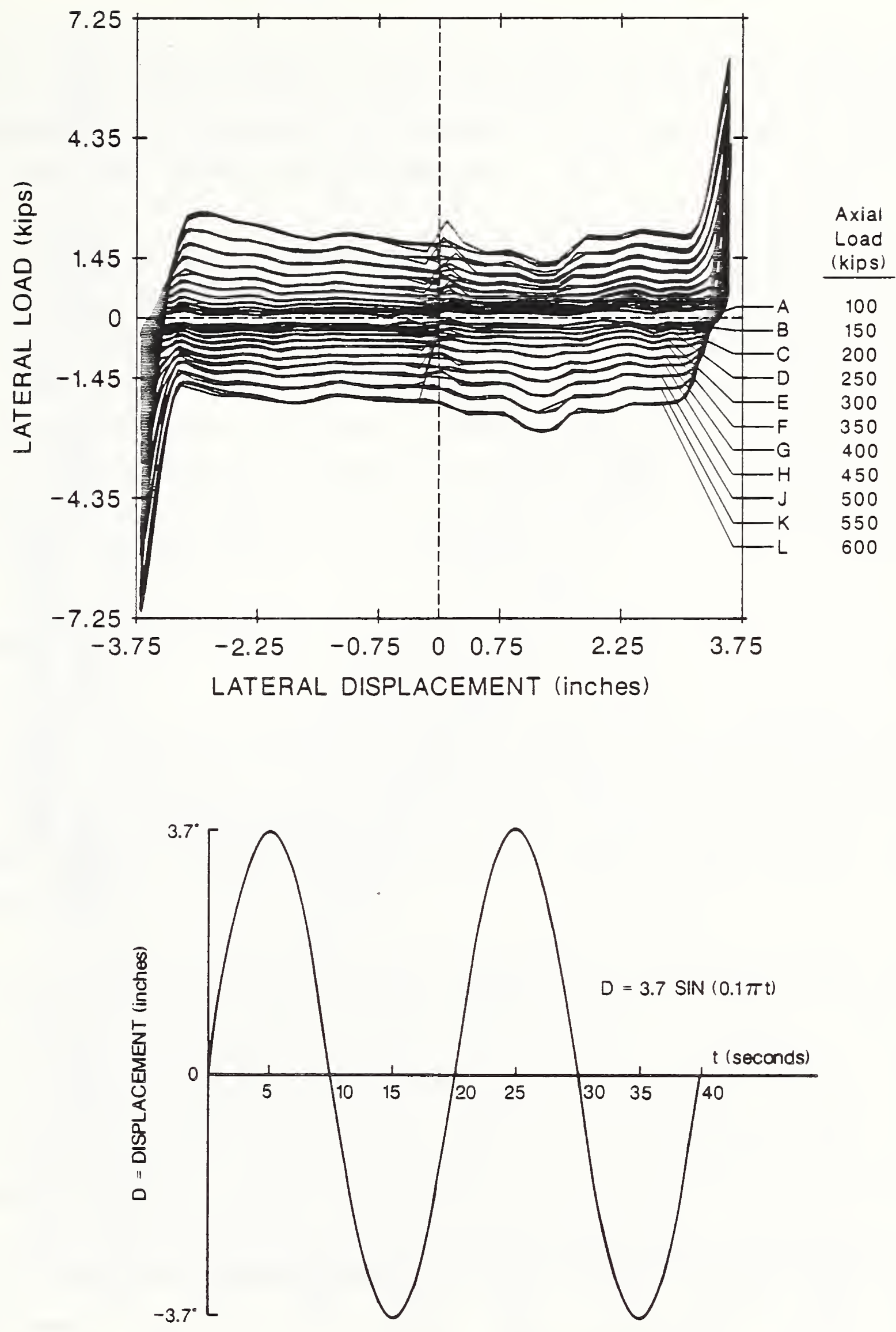

Figure A.13 Roller Friction sample Calibration Data for varying Axial Load 


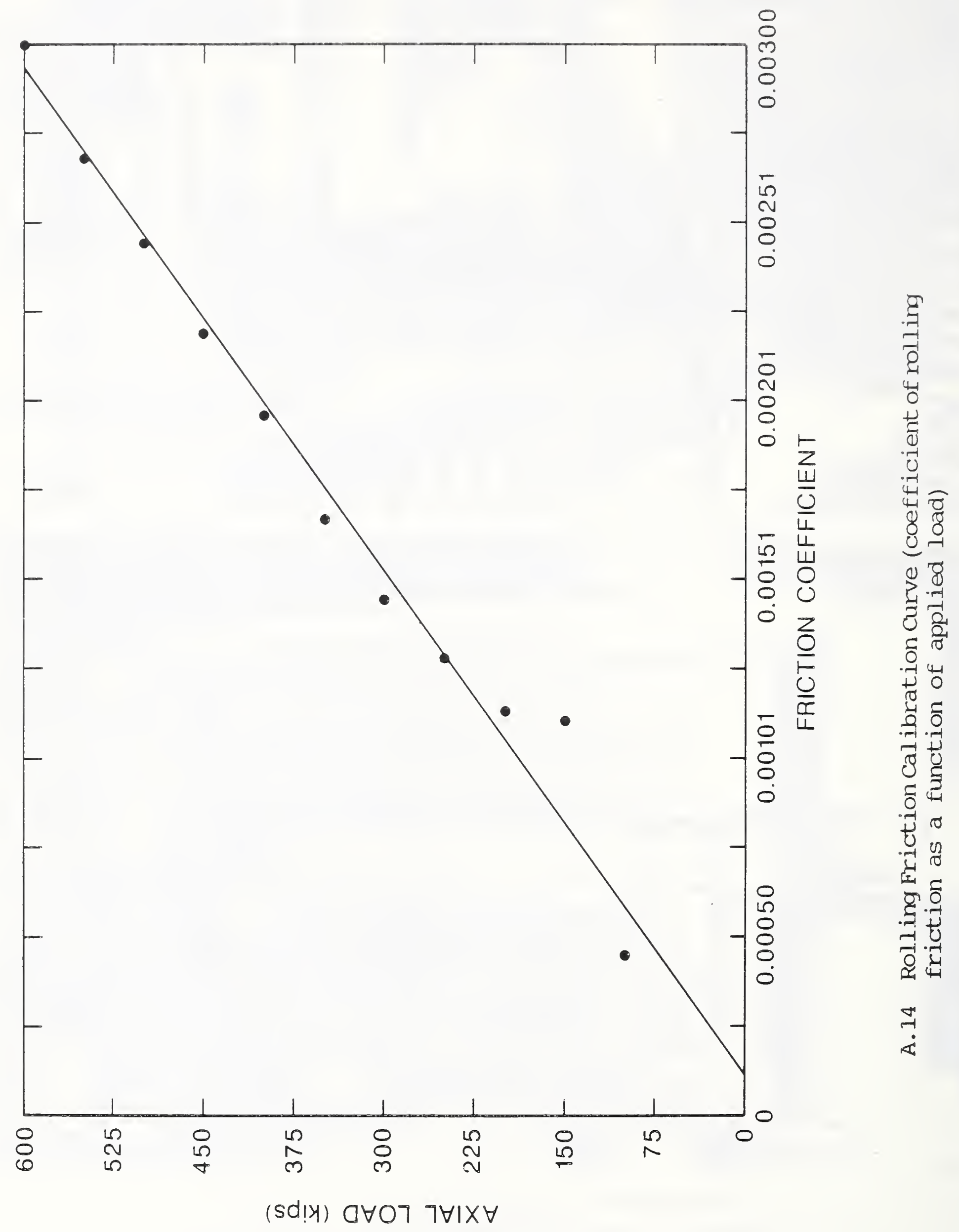


by the manufacturer. For an axial load of $1000 \mathrm{kip}$ ( $4.5 \mathrm{MN}$ ), the value used for both full scale tests, and with the specimen at maximum lateral displacement from centerline this amounted to less than $0.25 \%$ of the applied lateral load being dissipated in friction.

Despite the relatively low friction losses, the decision to monitor friction forces was made upon initial acquisition of the roller system, owing to the 5\% friction estimates provided by the manufacturer. Given a calibration curve it was possible to directly. determine friction forces provided the axial loads being carried by each roller system ( eight of them) were known. A series of custom designed load cells were developed as shown in Figures A.15, A.16, and A.17 to accomplish this purpose. These are described in greater detail in section 2.4.2 under instrumentation.

\section{A.1.4 Reaction Wall System}

At the outset of the project the existing apparatus in the NBS Large Scale Test Facility consisted of the $12000 \mathrm{kip}$ vertical actuator and its tie down floor, as shown in Figures A.1 and A.2 The mechanism developed for resisting the large lateral loads necessary for testing of the bridge columns is described below.

Figure A. 18 shows the lateral reaction forces to be resisted during testing of the full-scale 30-foot, and 15 foot $(9.1$ and $4.6 \mathrm{~m})$ columns. For design purposes it was decided that column axial loads as high as $3000 \mathrm{kip}$ ( $13.4 \mathrm{MN}$ ) would be considered, as would columns only $10 \mathrm{ft}(3 \mathrm{~m})$ in height. Both of these criteria imposed harsher requirements for the reaction wall than would be required for any of the columns described in this report in order to provide capacity for future expansion of test parameters. For nominal material properties (grade 60 reinforcement, $f^{\prime}{ }_{c}=4000$ psi) this resulted in an ultimate moment capacity for the $5 \mathrm{ft}(1.52 \mathrm{~m})$ diameter column previously described of approximately $9240 \mathrm{kip}-\mathrm{ft}$ (12.5 MN-m). The resulting maximum overturning moment to be resisted by the lateral reaction system was therefore 


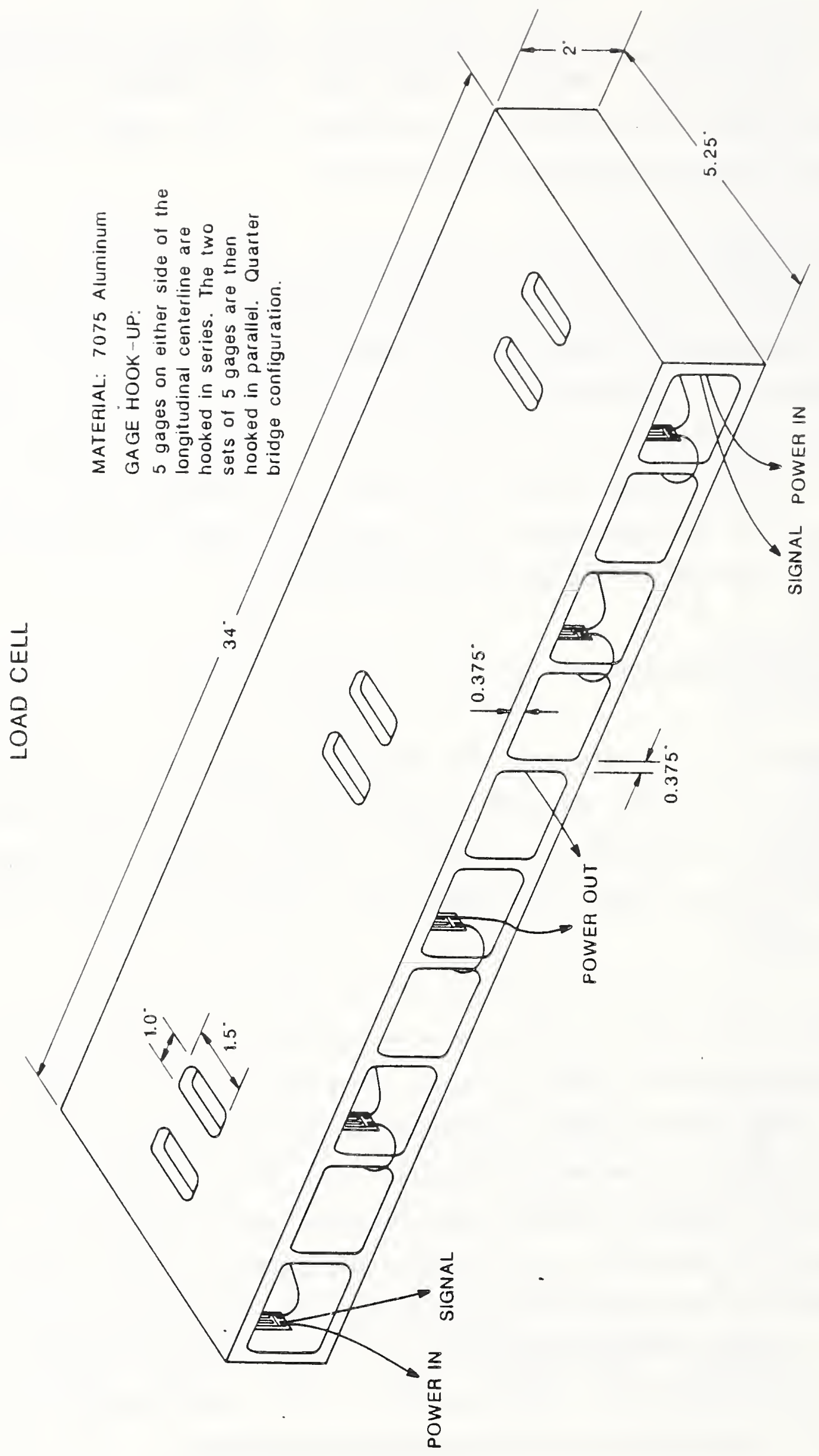

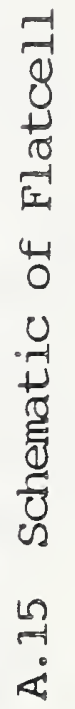




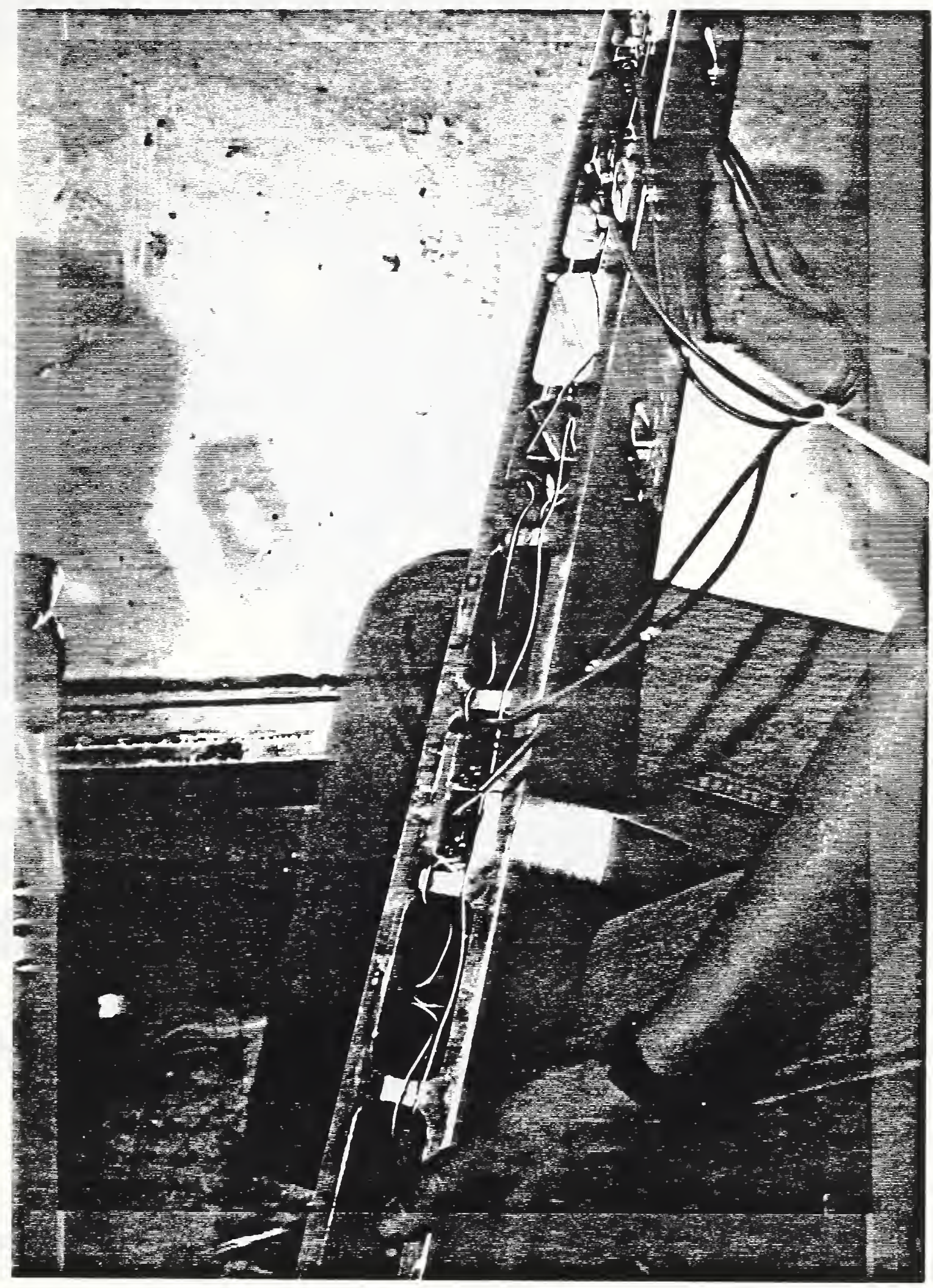

Figure A.16 Close-up of instrumented Flatcell prior to placement under specimen base. 


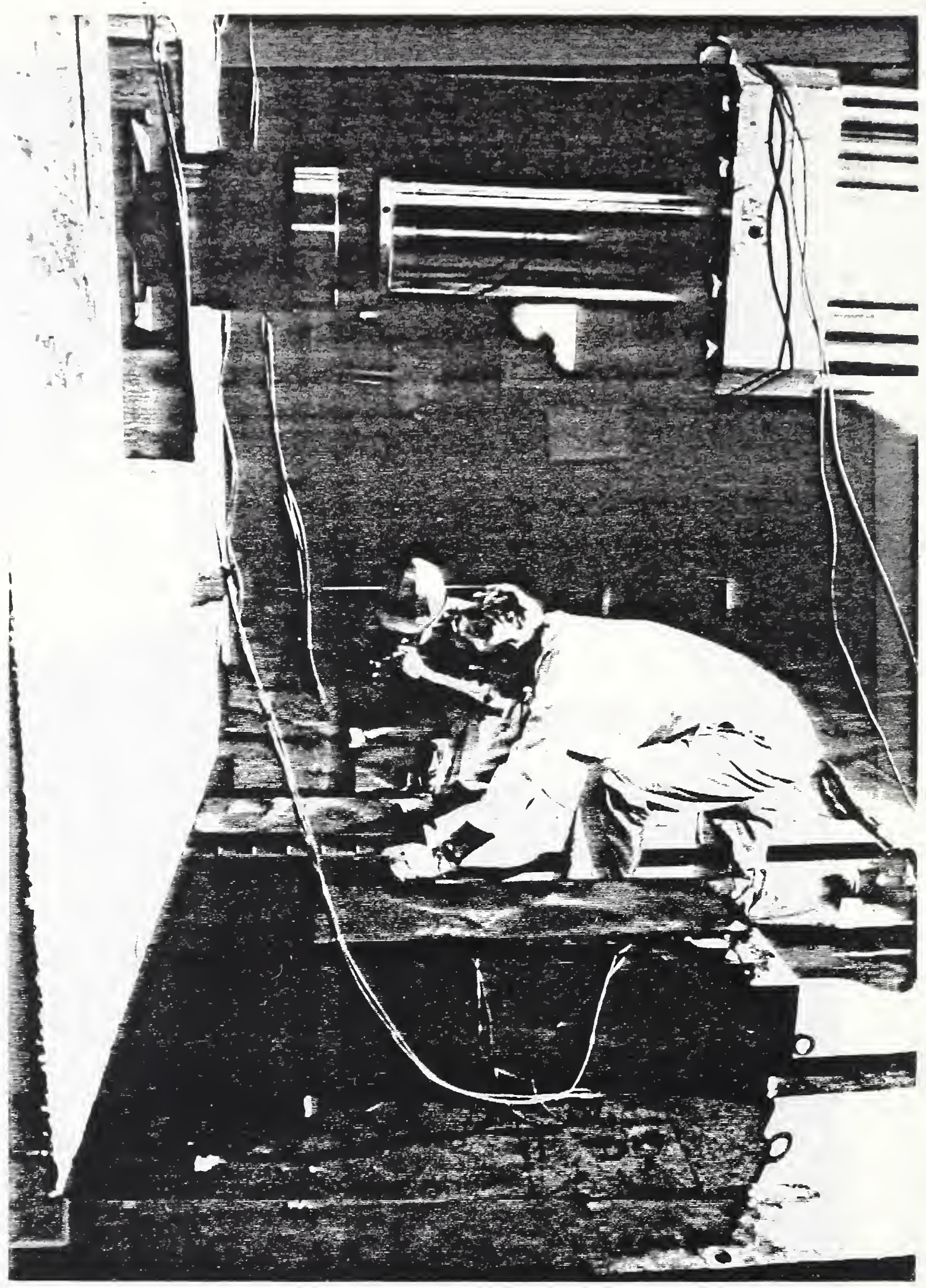

Figure A.17 Placement of Roller/Flatcell stacks underneathe Full Scale Specimen. 

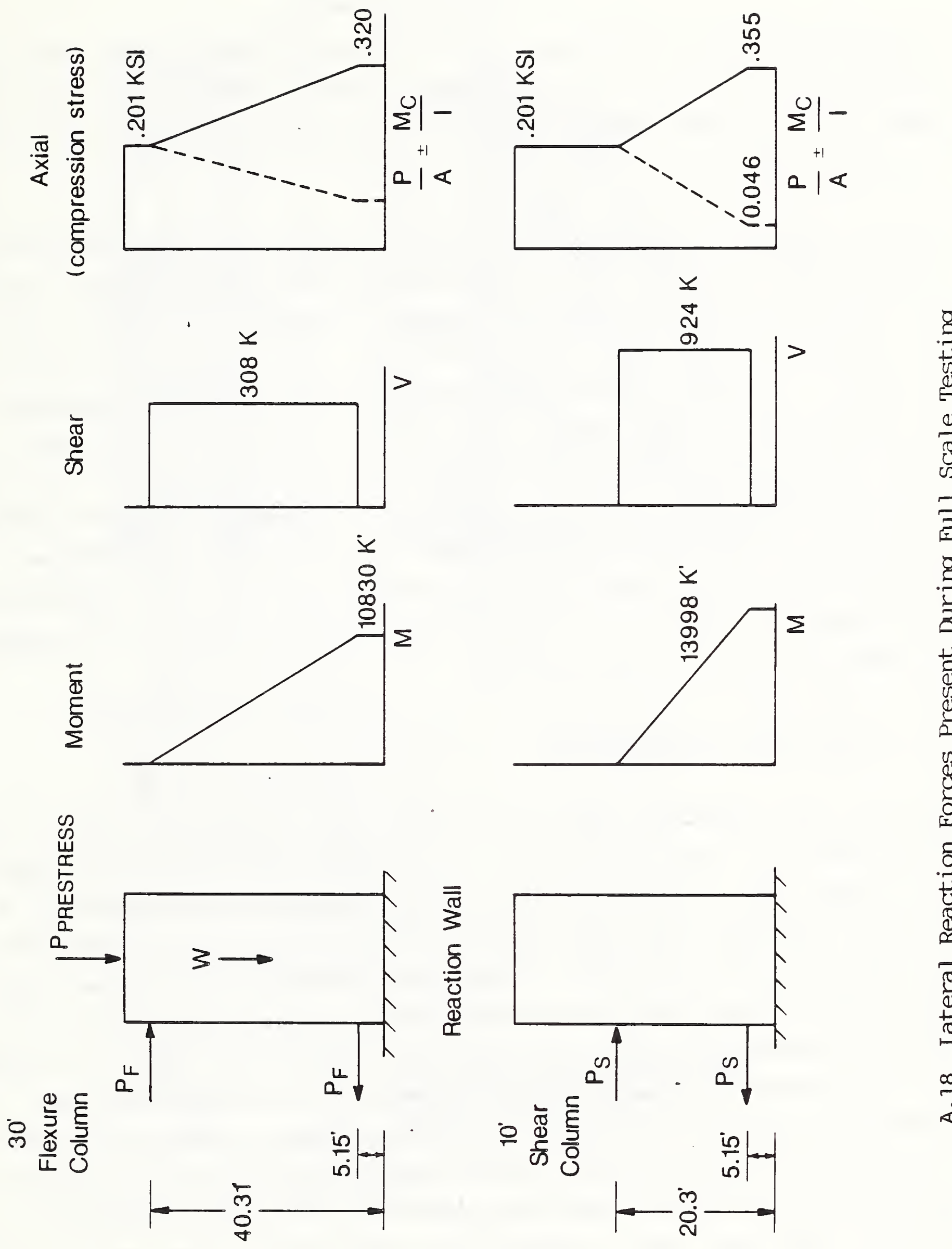

$\overline{\bar{\pi}}$
3
$\frac{0}{0}$
$\frac{0}{0}$
$\frac{0}{10}$
$\frac{1}{10}$

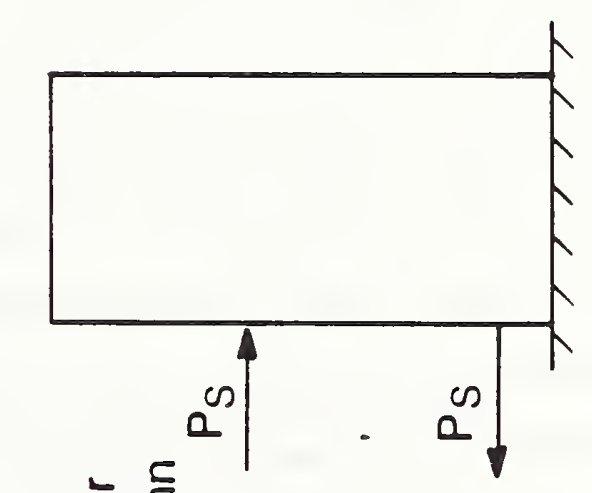

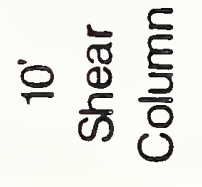

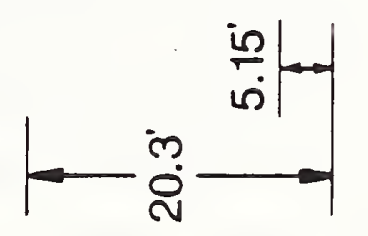


$10,830 \mathrm{kip}-\mathrm{ft}(14.7 \mathrm{MN}-\mathrm{m})$ for a $30 \mathrm{ft}(9 . \mathrm{m})$ tall column and $13998 \mathrm{kip}-\mathrm{ft}$. (19 MN-m) for a $10 \mathrm{ft.} \mathrm{(3m)} \mathrm{tall} \mathrm{column} \mathrm{as} \mathrm{shown} \mathrm{in} \mathrm{Figure} \mathrm{A.18.} \mathrm{The} \mathrm{maximum}$ shear force occurred during loading of the shortest column ( $10 \mathrm{ft} ., 3 \mathrm{~m}$ ) and was equal to $924 \mathrm{kip}(4.1 \mathrm{MN})$.

Several competing designs for the reaction system were conducted in parallel and are shown in Figure A.19. These were a monolithically cast, vertically post-tensioned reinforced concrete "H Beam"; a segmentally precast, vertically post-tensioned reinforced concrete "H Beam"; and a braced double-bent steel "V-Frame". The steel option was eliminated on the grounds of excessive cost, and flexibility: while strength criteria was easily met, deflections at the upper tie-back location for the $30 \mathrm{ft} .(9.1 \mathrm{~m})$ column were $0.32 \mathrm{in}$. (8 $\mathrm{mm}$ ) which was considered unacceptable due to the previously described problem of permitting lateral loads to be carried by the vertical test machine. The monolithically cast $\mathrm{H}$-Beam was more cost-effective than the segmental route and deflections were within tolerance, provided the reaction floor system was presumed to act as a rigid foundation.

\section{A.1.5 Deflection Considerations}

Besides the sensitivity of the vertical test machine to local lateral deflections (i.e. the reaction wall displacement under load with respect to the column top), a further design consideration was the proximity of the National Deadweight Measurement facility located $80 \mathrm{ft}(24 \mathrm{~m})$ from the site of the Large Scale Test Facility. Since both laboratories were housed under the same roof, and built on the same foundation, concern was raised as to the possible detrimental effects of large deflections that might be introduced into the building foundation during the course of a bridge column test. This question was addressed as follows: borings were made at three locations in the vicinity of the testing machine and the proposed reaction wall to bedrock at a depth of $90 \mathrm{ft}$. $(28 \mathrm{~m})$. Material properties were then calculated for each distinct soil layer and a detailed two dimensional linear elastic finite element analysis (Figure A.20) of the test facility was carried out which included the underlying soil stratifications. This analysis showed excessive 


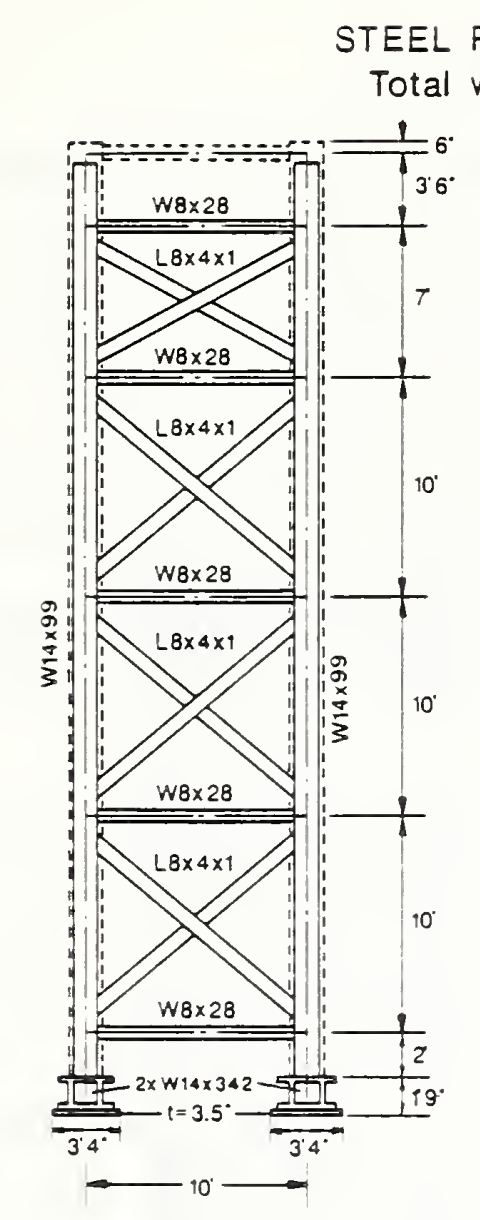

TEEL REACTION FRAME

Total weight $=82$ tons
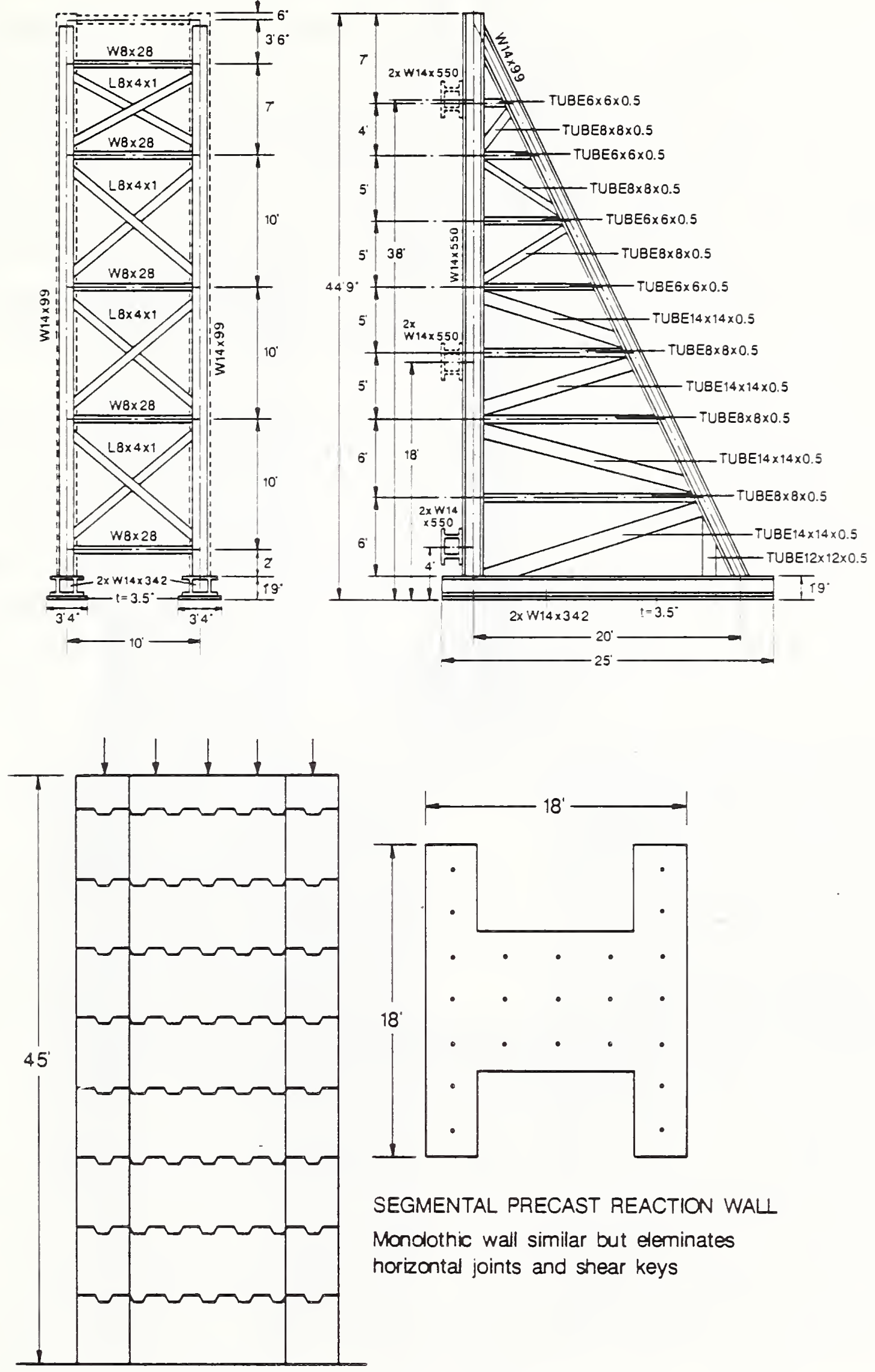

SEGMENTAL PRECAST REACTION WALL

Mondothic wall similar but eleminates horizontal joints and shear keys

Figure A.19 Competing Reaction Wall Designs 


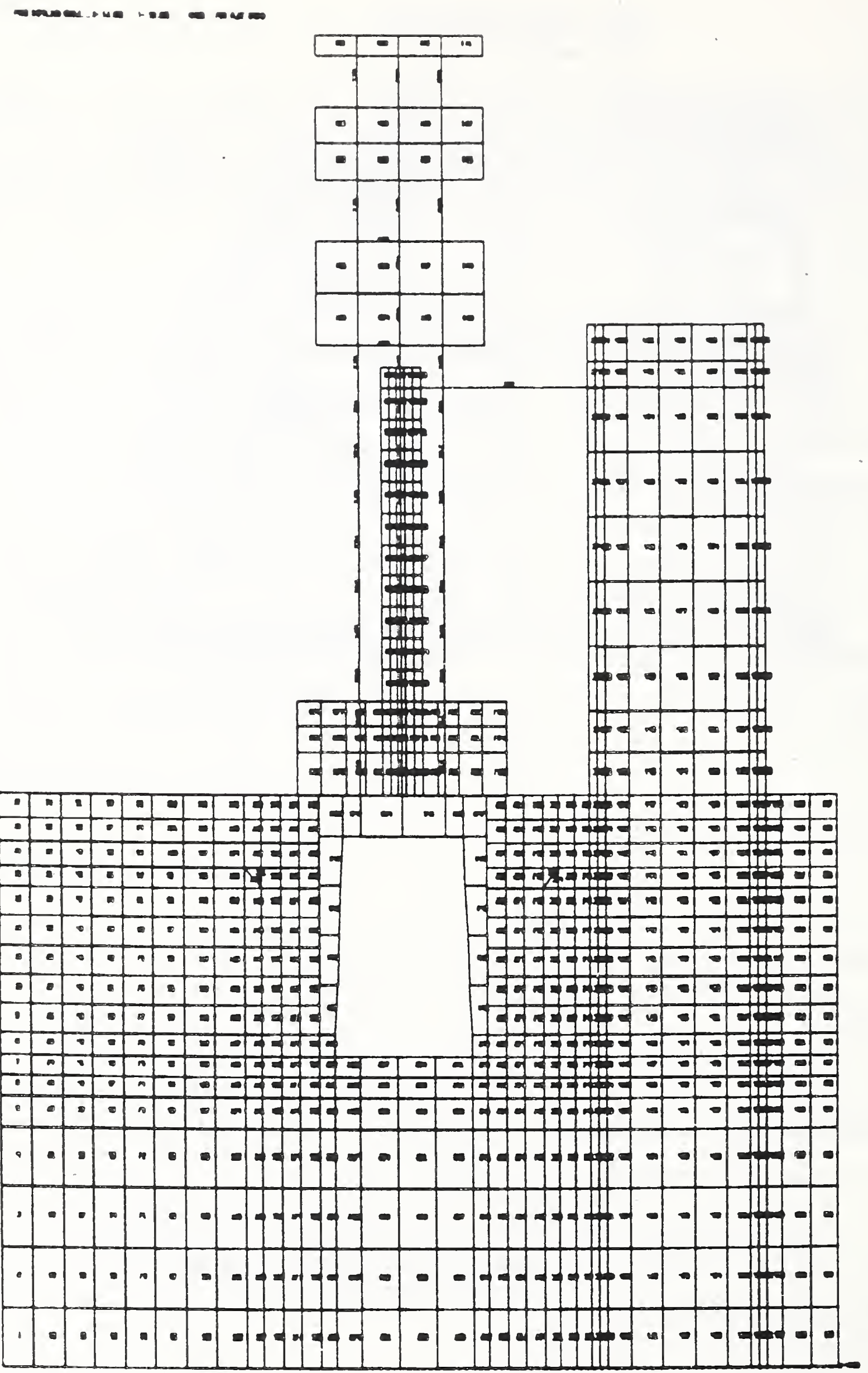

Figure A.20 Finite Element Model of Reaction Wall and Tie-down Floor System 
rigid-body rotation of the tie-down floor system due to compression of the underlying soft clay sediments. The model was verified by a subsequent dead load check (stacking of approximately $100 \mathrm{kip}$ [450 $\mathrm{KN}$ ] of mass at the location of the reaction wall) during which floor displacements and rotations were monitored. The final reaction wall design (Figure A.21) therefore made use of two 42 in. $(1.1 \mathrm{~m})$ drilled caissons which anchored the wall to bedrock. This approach limited lateral deflections at the top of the reaction wall to less than 0.1 in. $(2.5 \mathrm{~mm})$ under test load conditions.

Connection of the reaction wall to the existing tie-down floor was achieved by means of 23 post-tensioning tendons (see Figure A.22), each carrying a preload of $150 \mathrm{kip}(668 \mathrm{KN})$. These, combined with the dead load of the wall produced an axial precompression stress of $0.206 \mathrm{ksi}(1.42 \mathrm{MPa})$, with a resultant decompression moment of $18660 \mathrm{kip}-\mathrm{ft} .(25.3 \mathrm{MN}-\mathrm{m})$ and a shear capacity of $1595 \mathrm{kip}(7.1 \mathrm{MN})$. These produced load factors of 1.7 for both moment and shear for the design loads described earlier.

\section{A.1.6 Tie-Back Frame}

Figure A.23 shows the tie-back "A-Frame" used to carry lateral reaction loads from the column top to the reaction wall. The Irame was designed to be hinged at both ends so as to follow changes in the top-of-column elevation during cyclic lateral loading. It was furthermore designed to resist any torque generated about the column axis due to eccentric failure (spalling etc.) of the column during testing. Service loads for the A-Frame were 1200 kip (5.3 MN) in tension and compression with applied in-plane moments due to torque of $400 \mathrm{kip}-\mathrm{ft}(0.54 \mathrm{MN}-\mathrm{m})$. This was connected to the reaction wall by means of three positioning beams (Figure A.24) which were in turn posttensioned to the reaction wall. The positioning beams permitted the attachment of the A-Frame to the wall at any height; without them attachment points were possible only at fixed heights at $5 \mathrm{ft} .(1.52 \mathrm{~m})$ intervals.

Strain gage instrumentation was applied to the A-Frame at the two locations shown in Figure A.23 so as to provide two full-bridge loadcells at each 


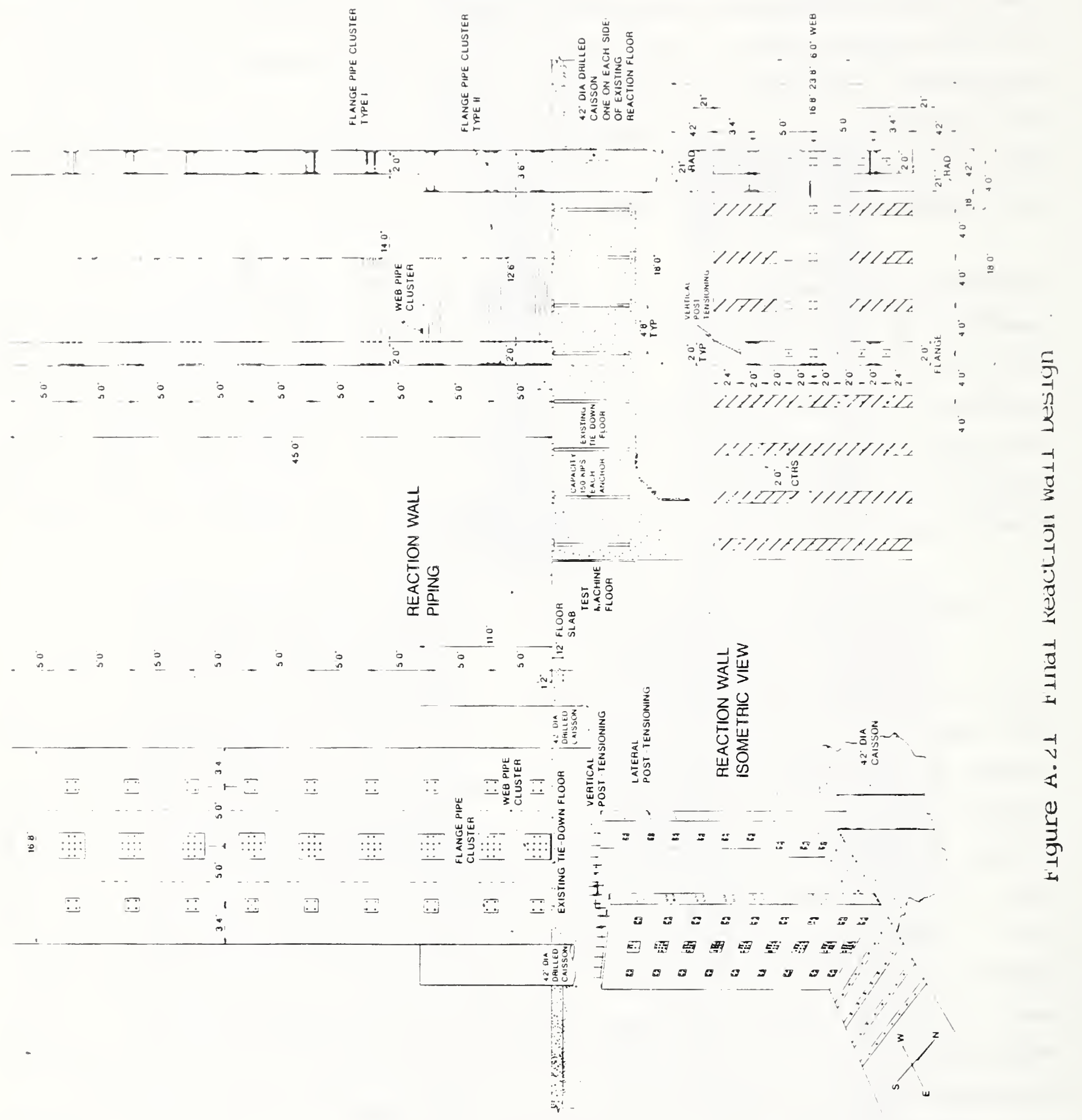




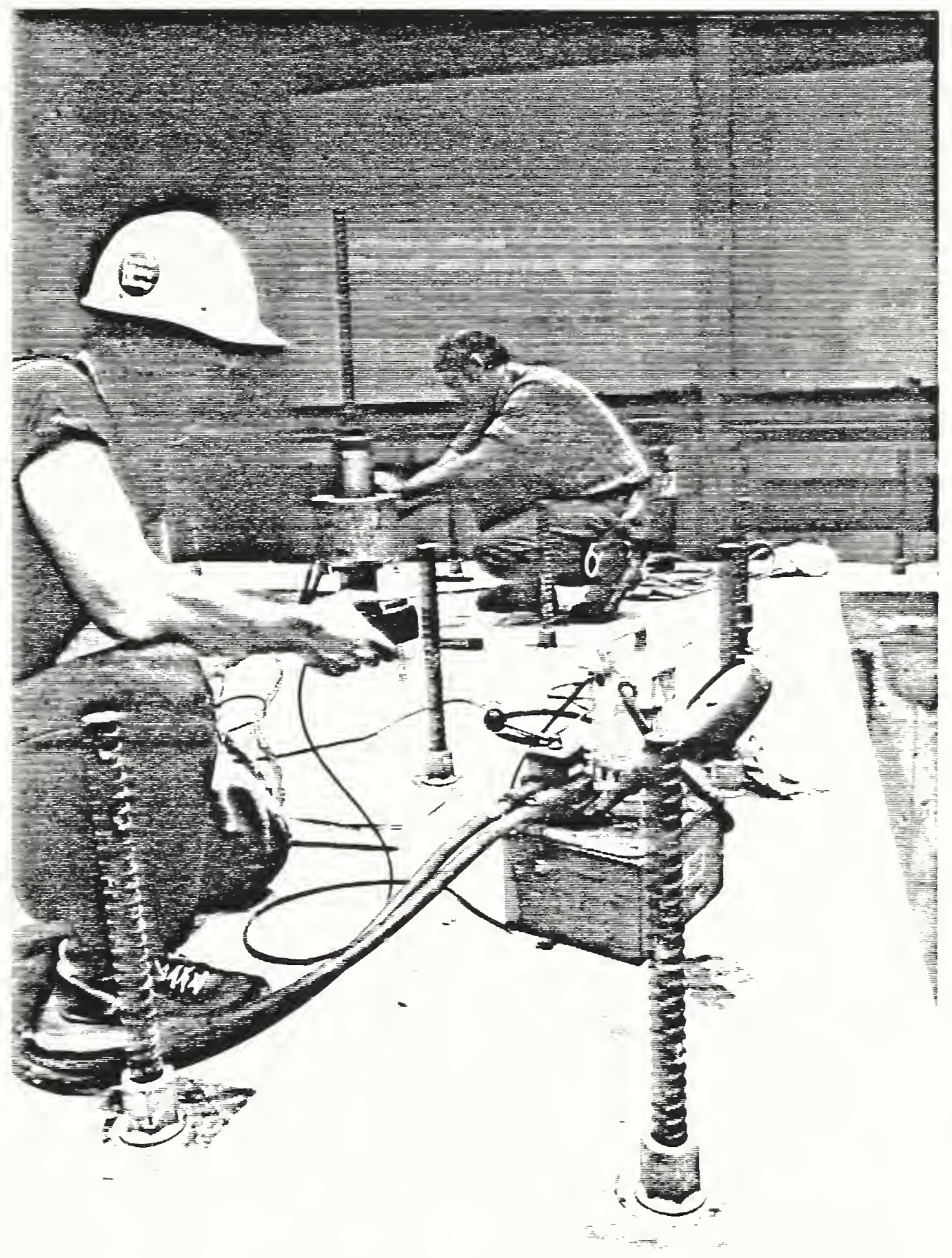

Figure A.22 Vertical Post-tensioning of Reaction Wall to Tie-down Floor 


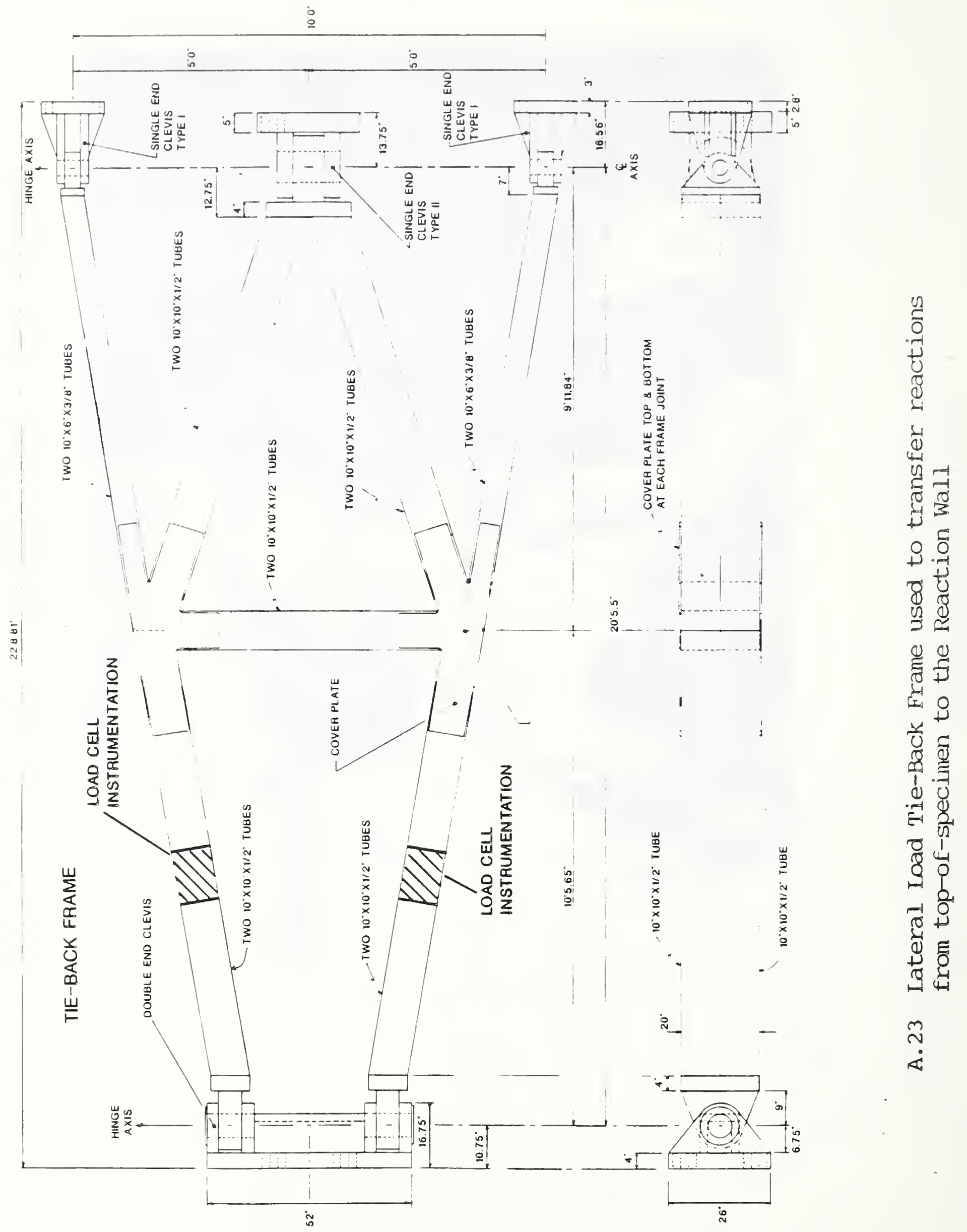




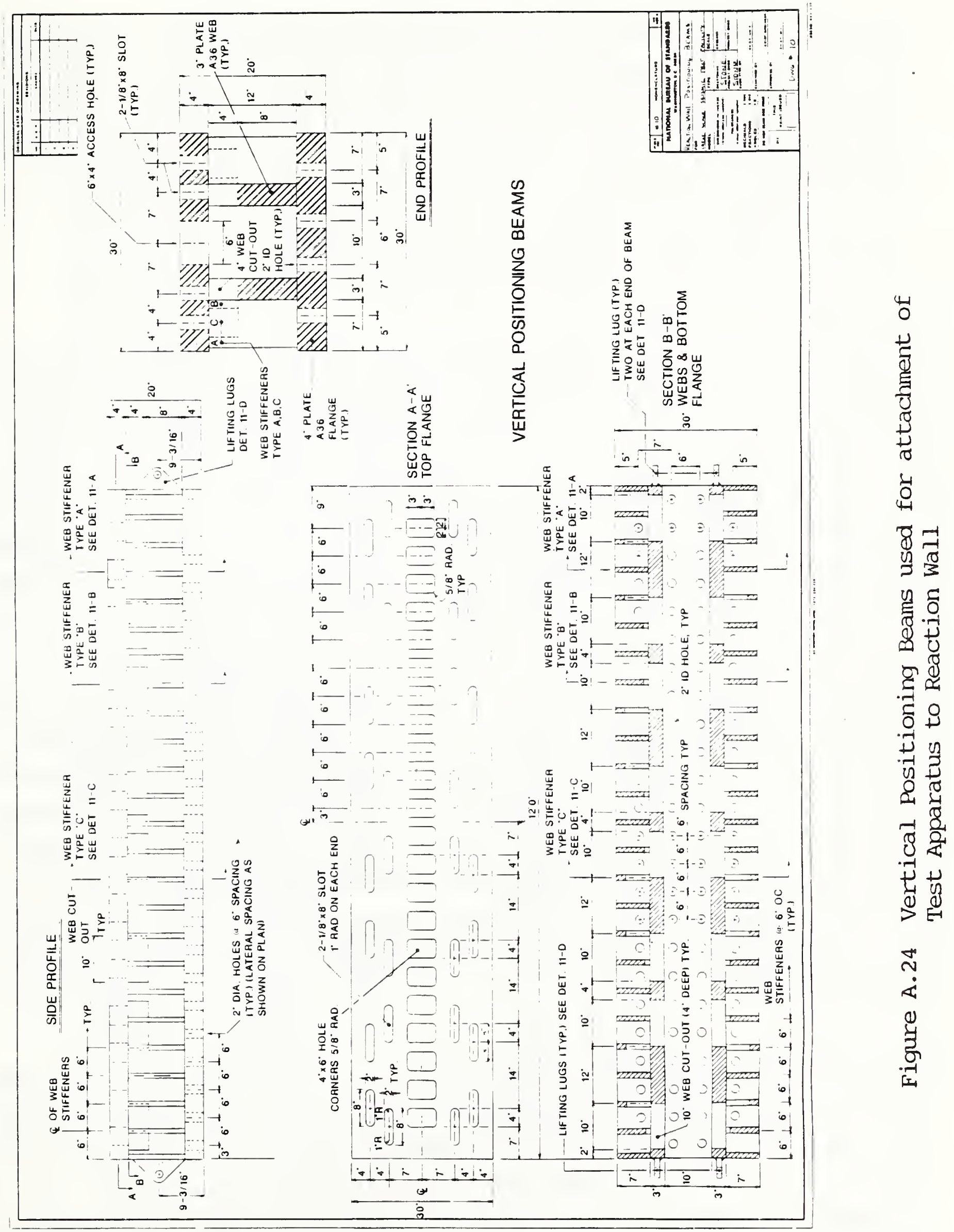


location. The A-Frame was calibrated to $1000 \mathrm{kip}$ (4.5 MN) using the $12000 \mathrm{kip}$ (53.4 MN) testing machine prior to each full-scale test. This provided a direct measurement of losses in the applied lateral load due to friction in the test system, and also a measure of any torque caused by eccentric failure of a specimen.

\section{A.1.7 Full-Scale Hinge Boundary Condition}

For similitude to exist between model and prototype, the top of the full-scale column required a hinged boundary condition. For the model columns it was possible to achieve this by using a hardened cylindrical rod bearing on two hardened plates. This option could not be used for the full-scale columns due to safety considerations surrounding the possibility of a falling rod weighing several tons. An integral, one piece hinge was designed and constructed as shown in Figure A.25. The top surface of the hinge (that which would be in contact with the vertical loading machine head) was faced with a 1 in. (25 mm) plate of hardened 4340 steel. During the second test (aspect ratio $=3$ ) some $600-1.5$ in. (38 mm) ball bearings, placed in molybdenum disulphide grease in a hexagonal closed packed pattern and capped with a second 1 in. (25 mm) 4340 steel plate, were added to the top of the hinge. This served to reduce transmittal of lateral force to the vertical test machine, which was substantially stiffer for the shorter column height of the second test. Figure A.26 shows this hinge being attached atop the second full-scale test specimen. Mortar was used to seat and level the hinge on top of the column prior to vertical load application. The hinge assembly weighed $12 \operatorname{kip}(53 \mathrm{MN})$.

The use of the hinge and tie-back frame as described, while satisfying the required top-of-column hinged boundary condition for the full-scale tests, did not precisely reproduce the model loading situation. The reason for this is as follows: in the model tests, the lateral load was transferred to the column by means of a hinged rod bolted to the column cap block, in a manner similar to that for the prototype specimens. As with the prototype specimens, the top-of-column hinge for the model specimens was not coincident with the lateral tie-back point. However, because both the vertical and lateral loads 


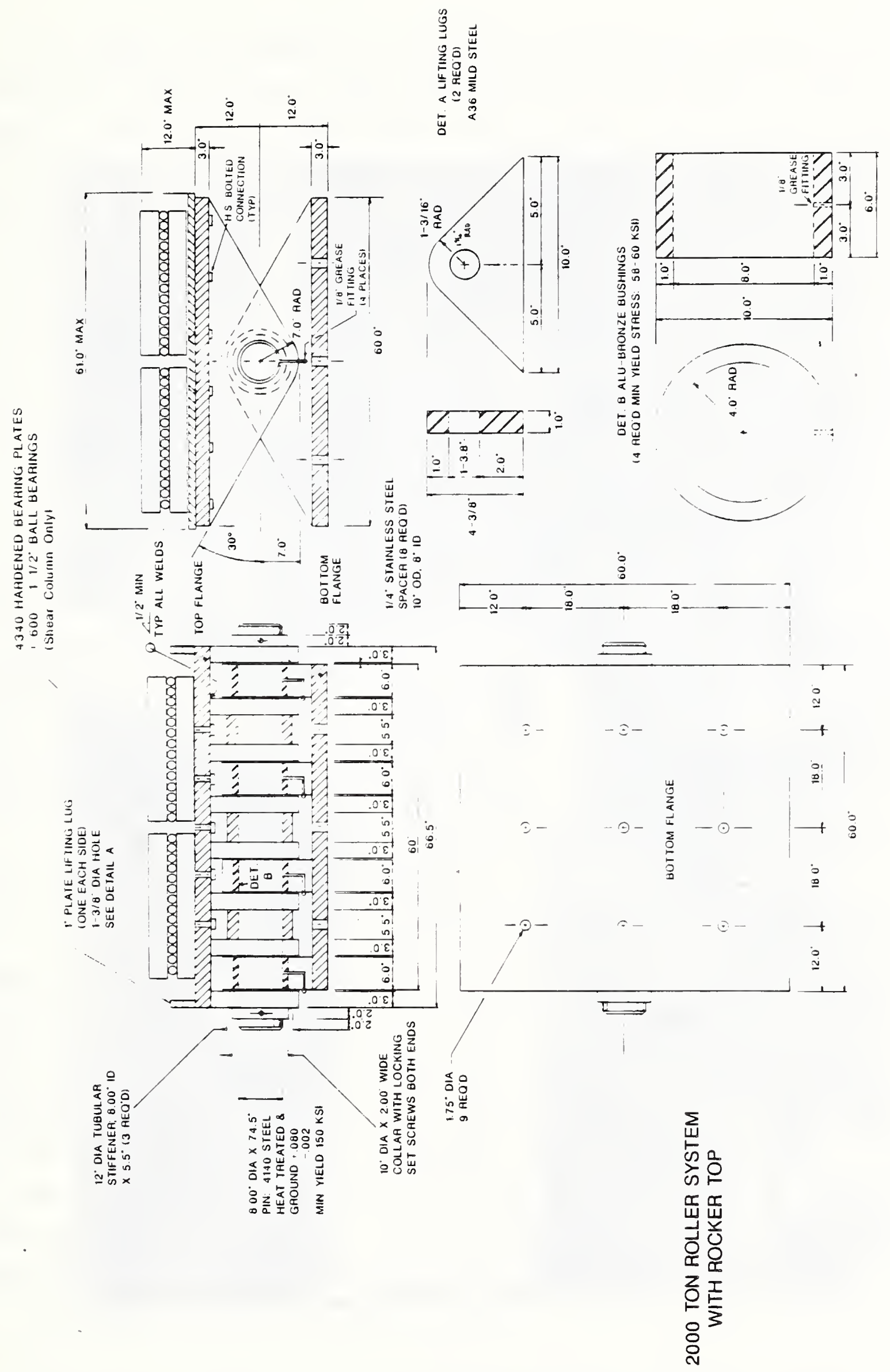

ن

동

E

$\frac{1}{8}$

곡

$\stackrel{n}{\stackrel{n}{4}}$ 


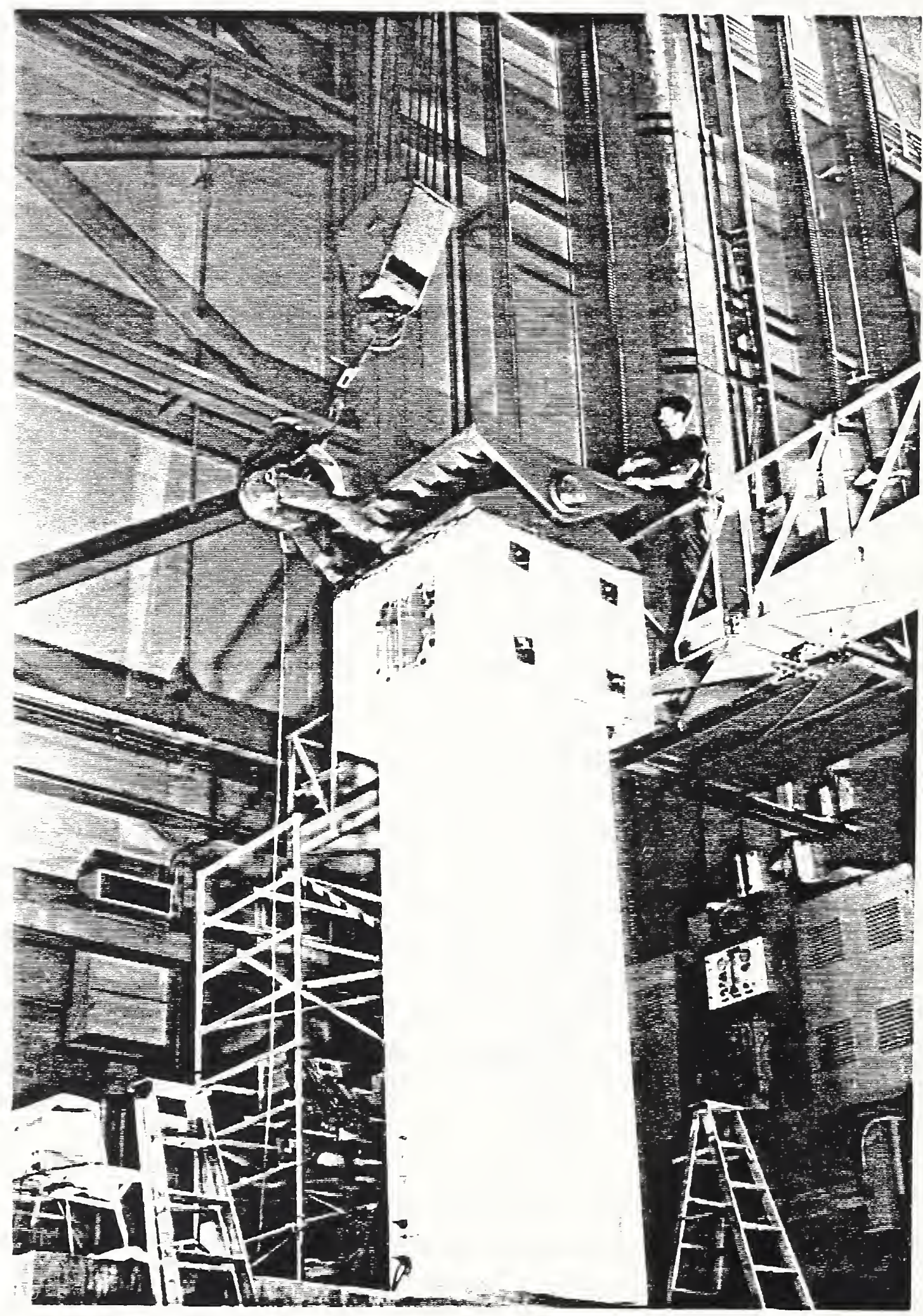

Figure A.26 Full Scale Hinge being positioned on top of Shear Column Specimen 
for the model were applied using a crosshead which moved with the column top, negligible lateral force was transmitted to the column at the level of the top hinge. This was not the case with the full scale tests, since it was the bottom of the column that was moving. The top hinge, therefore, moved laterally in proportion to the cyclic lateral displacements imposed at the bottom of the column and generated potentially significant lateral forces at the top hinge level due to the bending stiffness of the test machine. This lateral machine reaction acted counter to the direction of the tie-back reaction force (see Figure A.34) and explains the need, as described in section A.6.2 to measure the force dissipated into the test machine in order to accurately determine column moment.

An alternative hinge design (Figure A.27), in which the axes of both the tieback frame connection and the top-of-column hinge coincided, was considered in the early design phase of the project. While this would have effectively eliminated the need for instrumentation of top-of-column hinge displacement the fabrication costs were considered prohibitive at the time. Further discussion of this detail is presented in Appendix B. The mechanics of the as-built test apparatus are discussed in Section A.2.

\section{A.1.8 Apparatus Connections}

Figure A.28 shows the A-Frame attachment to the specimen. All such connections, including those between the specimen base and the lateral load actuator, were accomplished with the use of eight Dywidag $1-3 / 8$ in. (35 mm) threaded post-tensioning bars (Figure A.29), each of which carried a preload of $110 \mathrm{kip}(490 \mathrm{KN})$. This, together with similar post-tensioned connections to the reaction wall insured that there would be no slack in the system at load reversal during cyclic lateral loading. Figure A.30 shows a view of the completed lateral reaction system prior to testing. 


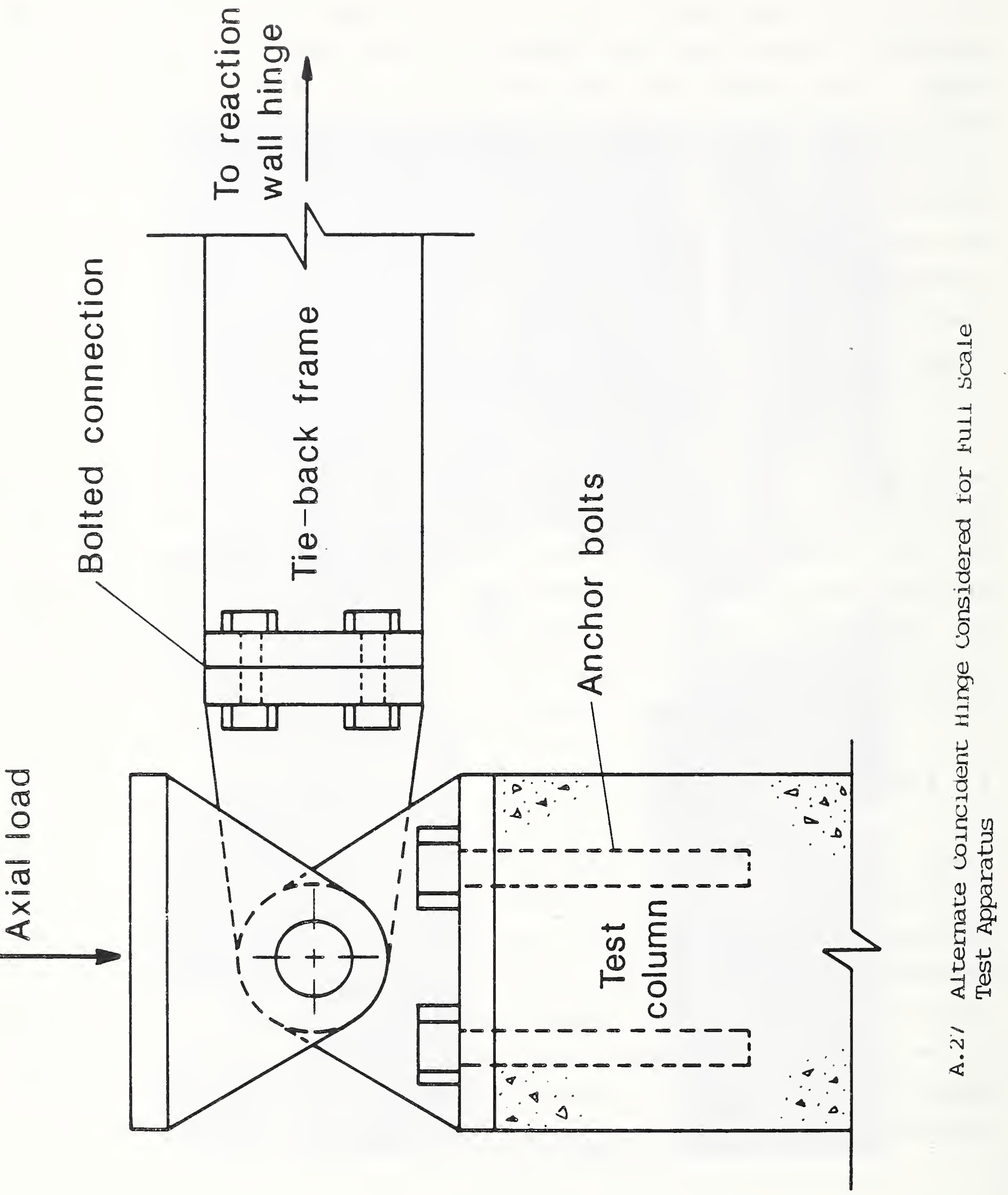




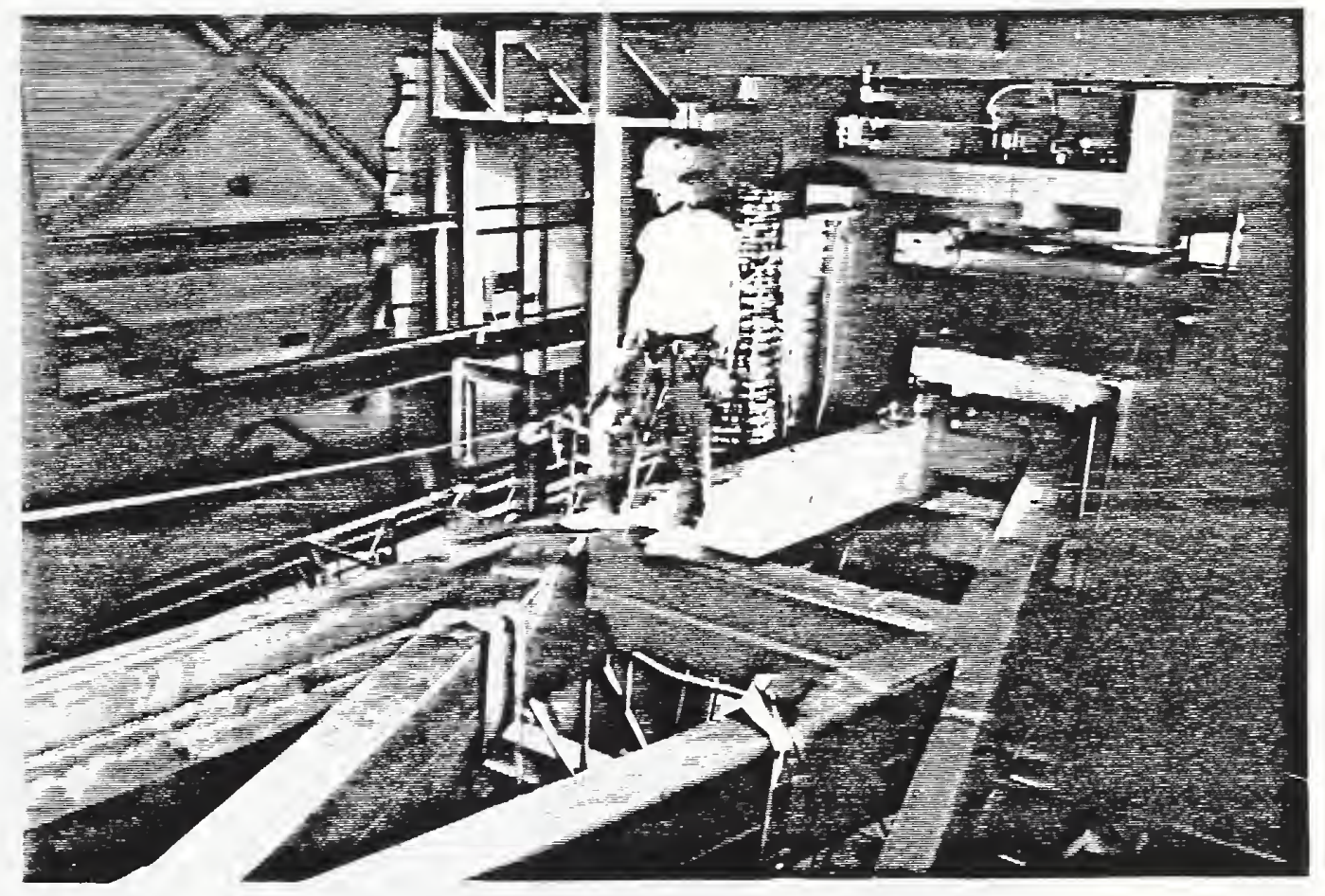

Figure A.28 A-Frame attachment to Column Specimen 


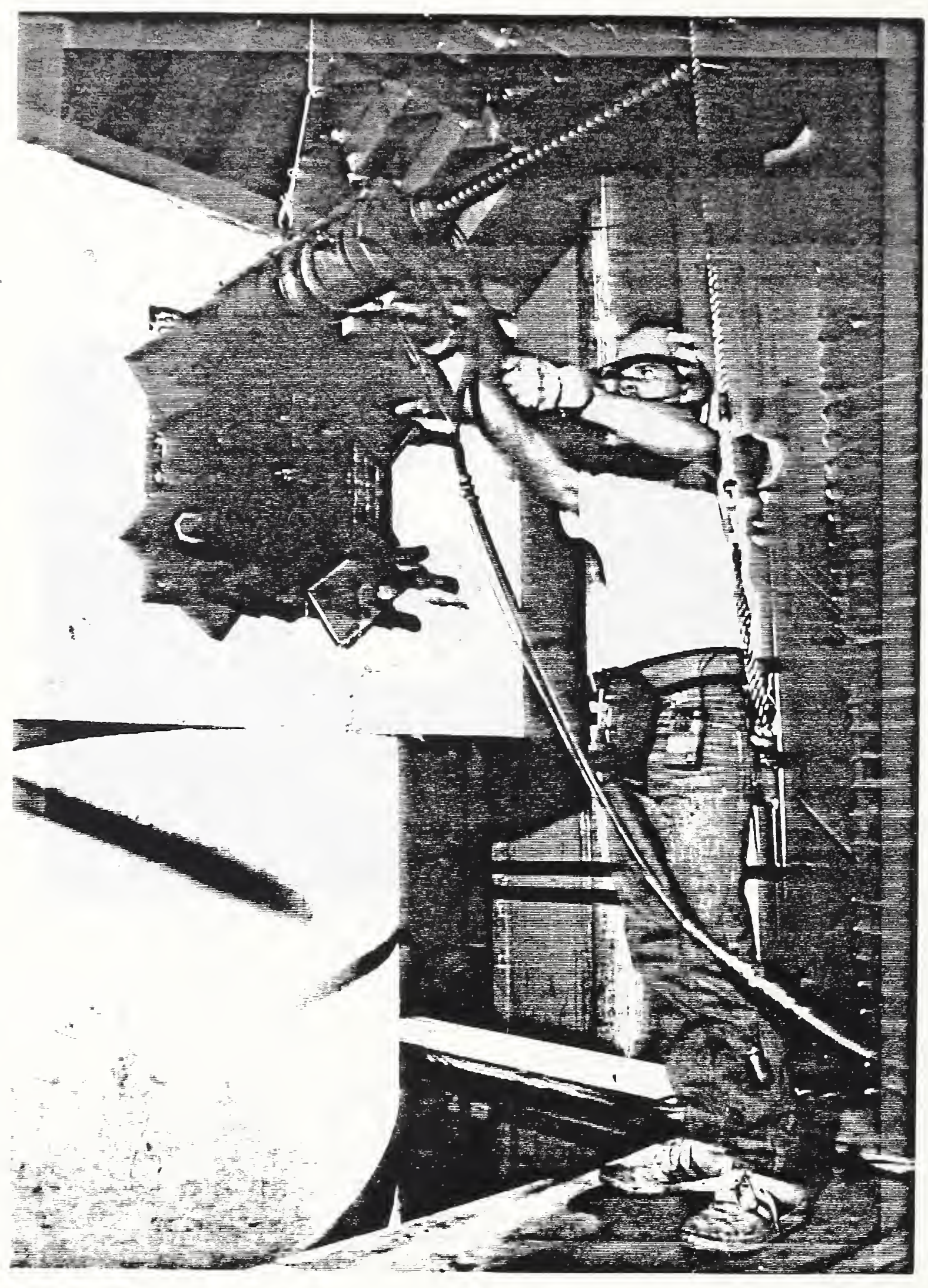

Figure A.29: Lateral Post-Tensioning of A-Frame assembly to column top. 


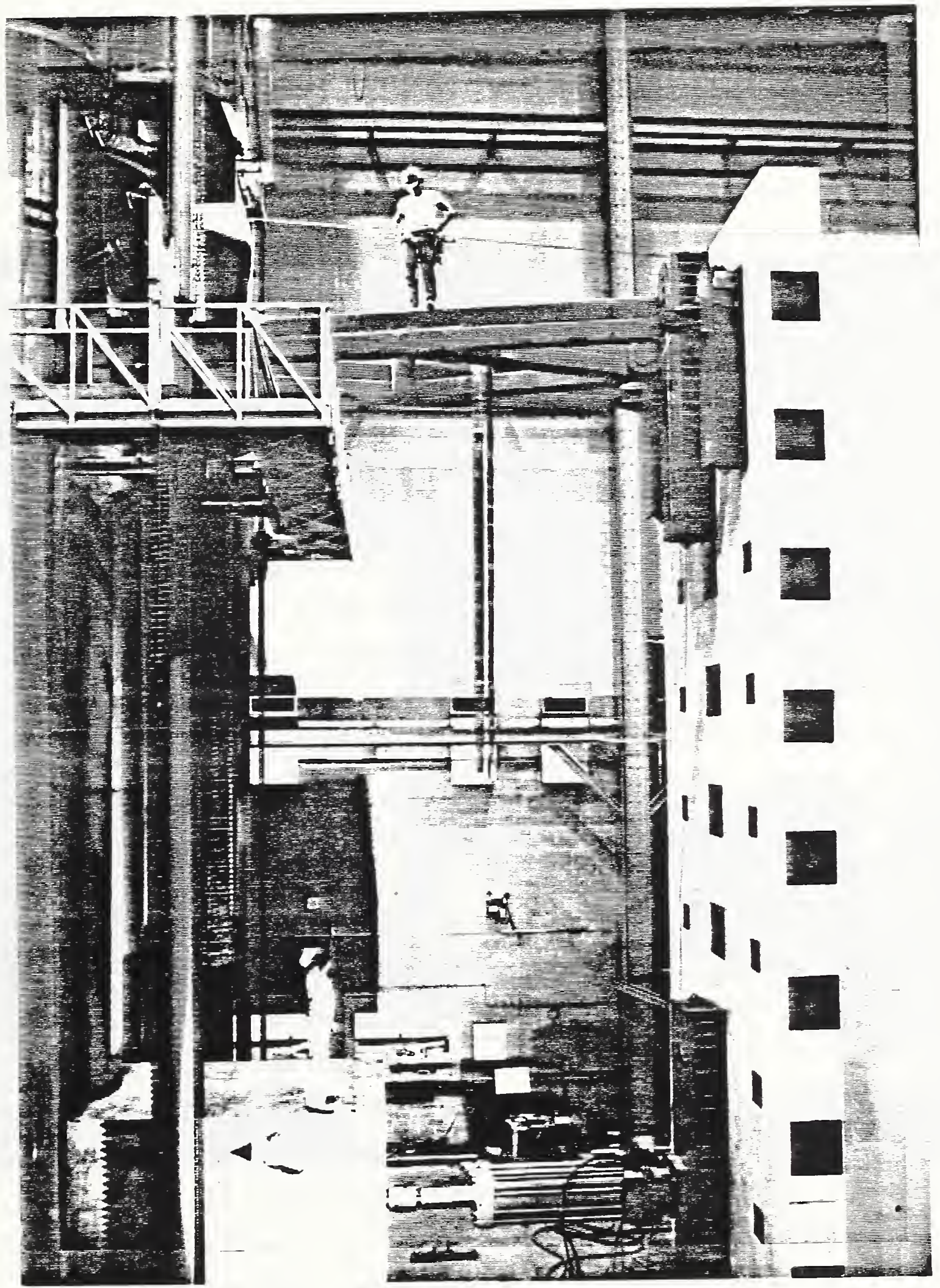

Figure A.30 The completed Lateral Reaction System Prior to Testing showing upper and lower Vertical Positioning beams, Tie-back Frame, Lateral Actuator, and Reaction Wall. 


\section{A.1.9 Loading Systems}

Vertical load was applied using a $12000 \mathrm{kip}$ (53 MN) universal testing machine, as shown in Figure A.11. Because this was to be used to simulate the gravity load of the bridge superstructure, it was necessary to maintain constant load throughout the test. The testing machine was originally designed with manual operation in mind, similar to most other universal testing machines. Accurate load control, therefore, would have been a difficult task during cyclic lateral loading of the test specimen, due to the change in elevation at the top of the column as rotation took place at the column base. A programmable servo-valve was installed within the hydraulic power supply system to the loading cylinder and was found to have stable response and good tracking ability when driven by a programmed control signal. For both full scale tests the vertical test machine was run under load control with a constant applied axial force of $1000 \mathrm{kip}(4.5 \mathrm{MN})$. Maximum local vertical displacement range [ ram stroke] was $24 \mathrm{in.}(0.61 \mathrm{~m})$ prior to the point where the load crosshead would have to be relocated using the exterior screws.

Lateral load was applied using a $1000 \mathrm{kip}(4.5 \mathrm{MN})$ servo-controlled, programmable double acting hydraulic jack as shown in Figure A.31. This had a maximum stroke of $48 \mathrm{in.} \mathrm{(} 1.2 \mathrm{~m}$ ) for monotonic loading. For cyclic loading the maximum stroke either side of null was 24 inches $(0.6 \mathrm{~m})$. Design calculations indicated that this displacement would be sufficient to reach a minimum of $7 \Delta y$ for the $30-\mathrm{ft} .(9.1 \mathrm{~m})$ column and $14 \Delta \mathrm{y}$ for the $15-\mathrm{ft} .(4.6 \mathrm{~m})$ column, thereby ensuring the ability to completely fail both columns. During a full-scale test a "ramp and hold" load-time response was programmed into the servo-controller so that the specimen moved from its central null point to a specified multiple of yield displacement in a continuous, smooth motion. The exception to this procedure, as will was described section 3.1 , was the determination of yield displacement. For that particular case, load control was used to reach a specified lateral force.

A plan view of the completed Large Scale Seismic Test Facility is shown in Figure A.32. 


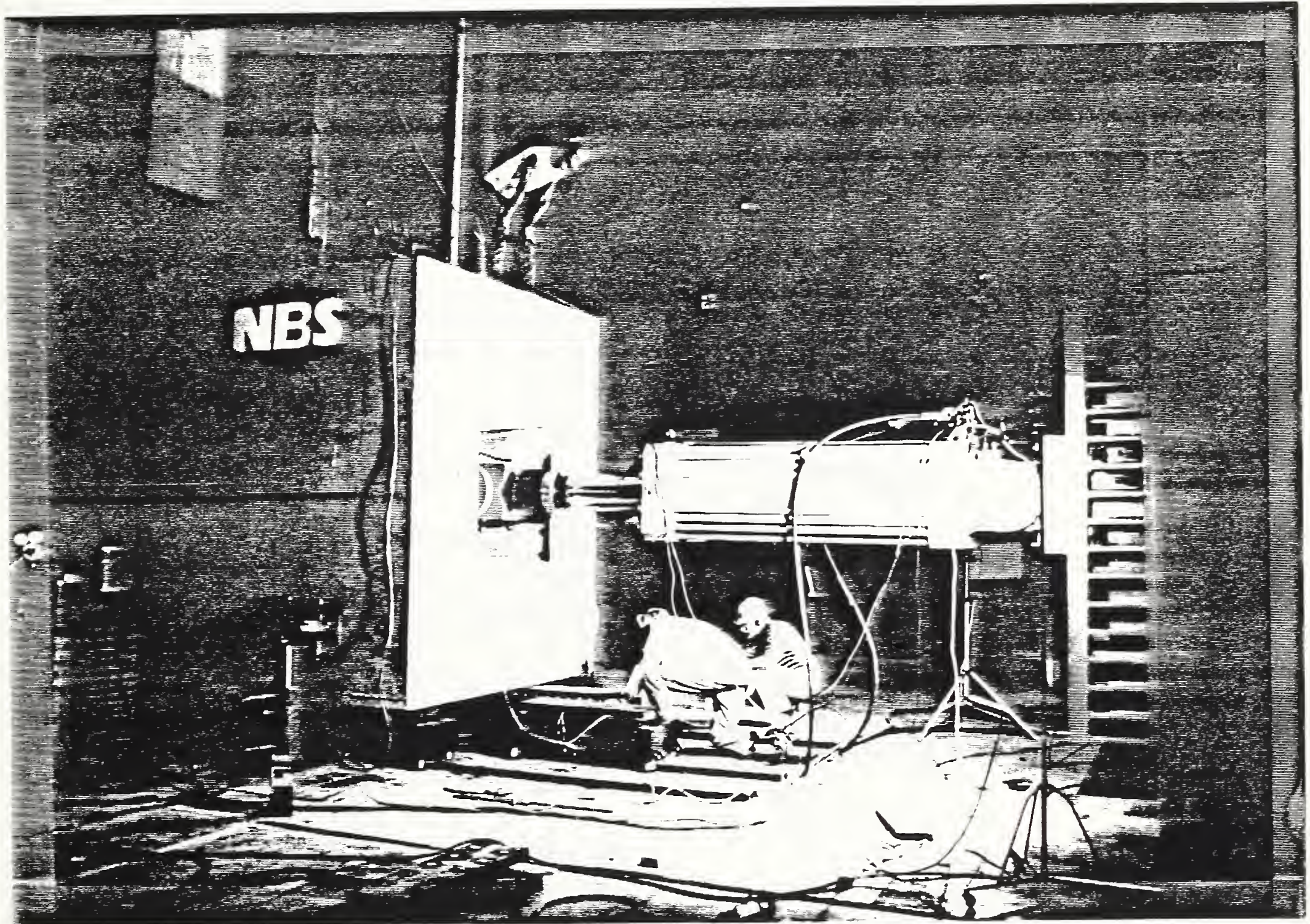

Figure A.31 Servo-controlled 1000 kip hydraulic ram used for Lateral Load. Also note Lifting Bracket and Corner Jack at Lower Right Hand Corner of Base Block for Raising and Lowering Specimen. 


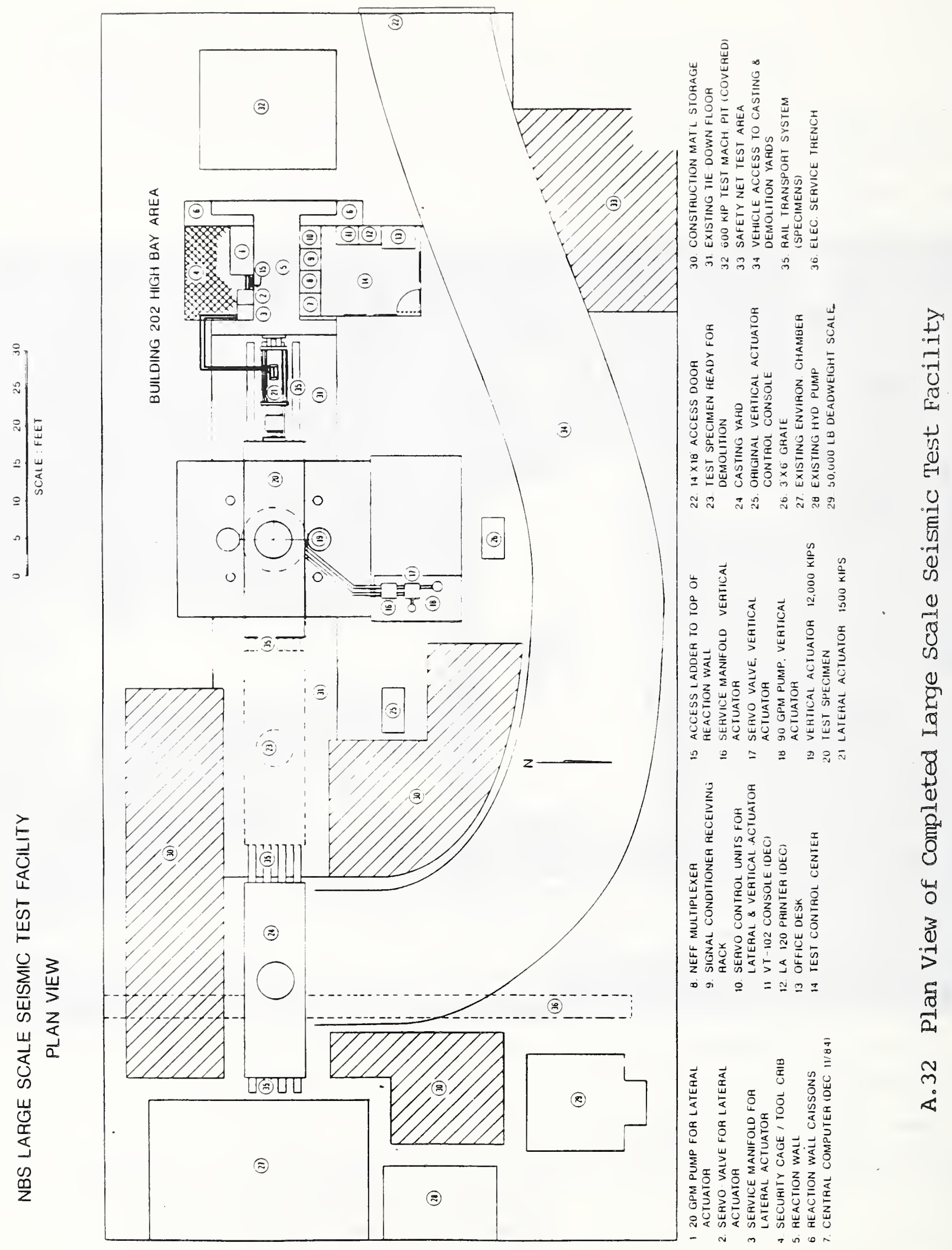



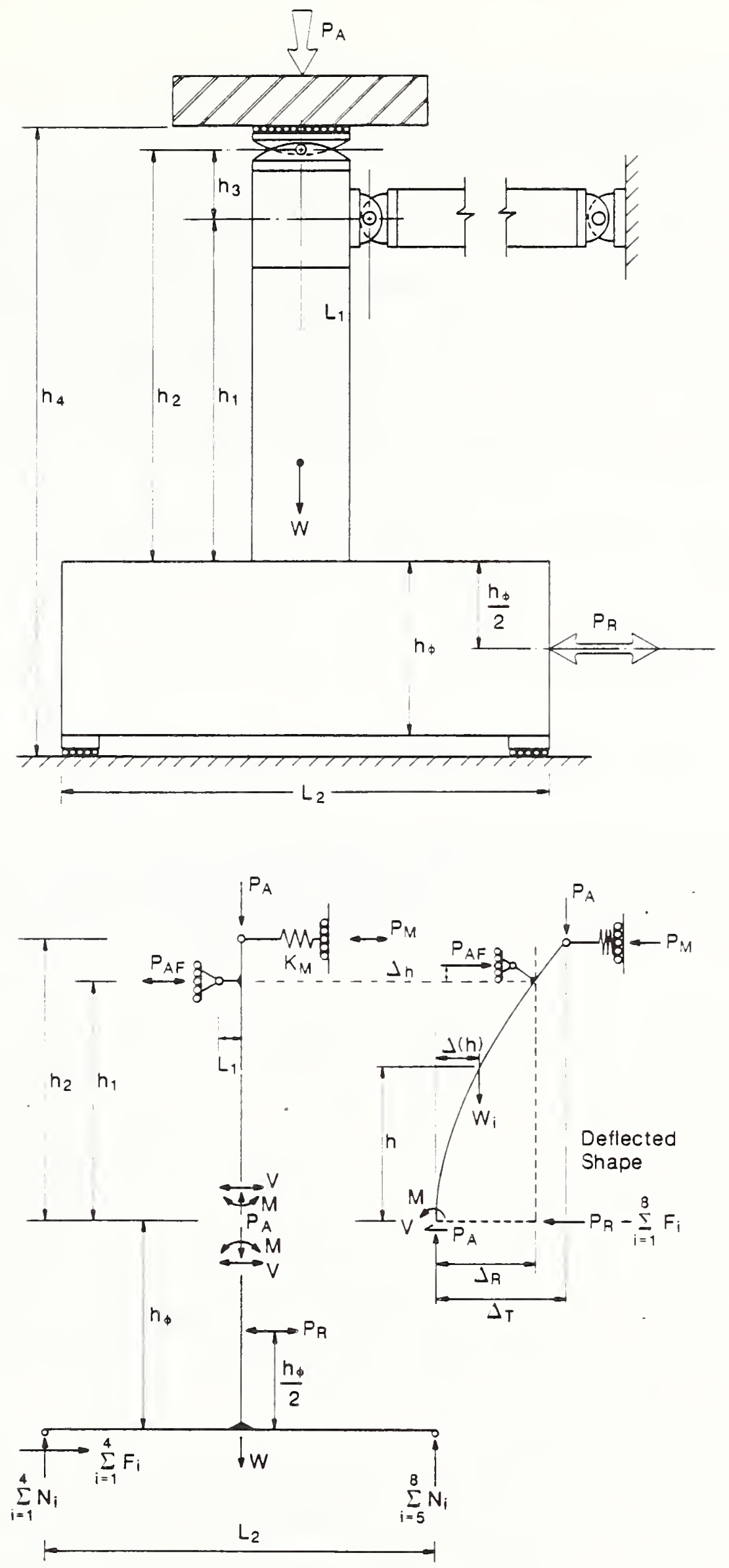

Figure A.33 Mechanics of the Test Apparatus 


\section{A.2 Mechanics of the Test Apparatus}

The complete test apparatus, as shown in Figure A.11 constitutes a statically indeterminate system, as described in Figure A.33. Without special procedures the system consists of 18 unknown reactions and three equations of equilibrium. The known quantities are the applied lateral load and the applied vertical load, which are measured by means of calibrated load cells.

The base column moment and shear can be determined independently by two different means:

Using top-of-column reactions:

$M_{1}=P_{a f}\left(h_{1}+\Delta_{h}\right)-P_{m}\left(h_{2}\right)+P_{a}\left(\Delta_{t}\right)+W_{i} \Delta(h) d h$

but since $\Delta h$ is very small and the moment caused by the displaced weight of the column can be approximated by the column weight times the lateral displacement of the column centroid, Eq. (A.1) can be re-written as:

$M_{1}=P_{a f}\left(h_{1}\right)-P_{m}\left(h_{2}\right)+P_{a}\left(\Delta_{t}\right)+W_{i} h\left(\Delta_{r} / 2\right)$

$\mathrm{VI}=\mathrm{P}_{\mathrm{af}}-\mathrm{P}_{\mathrm{m}}$

Using foundation reactions:

$M_{2}=\sum_{i=1}^{4} N_{i}\left(L_{2}\right) / 2-\sum_{i=5}^{8} N_{i}\left(L_{2}\right) / 2-\sum_{i=1}^{8} F_{i} h_{0}+P_{r} h_{0} / 2$

but, since $F_{i}=\mu_{i} N_{i}$

$M_{2}=\sum_{i=1}^{4} N_{i}\left(L_{2}\right) / 2-\sum_{i=5}^{8} N_{i}\left(L_{2}\right) / 2-\sum_{i=1}^{8} \mu_{i} N_{i} h_{0}+P_{r} h_{0} / 2$

8

$V_{2}=P_{r}-\sum_{i=1} \mu_{i} N_{i}$

Note that: $M_{1}=M_{2}=M$ and $V_{1}=V_{2}=V$ 
In the above equations (as well as Figure A.33) the following definitions apply:

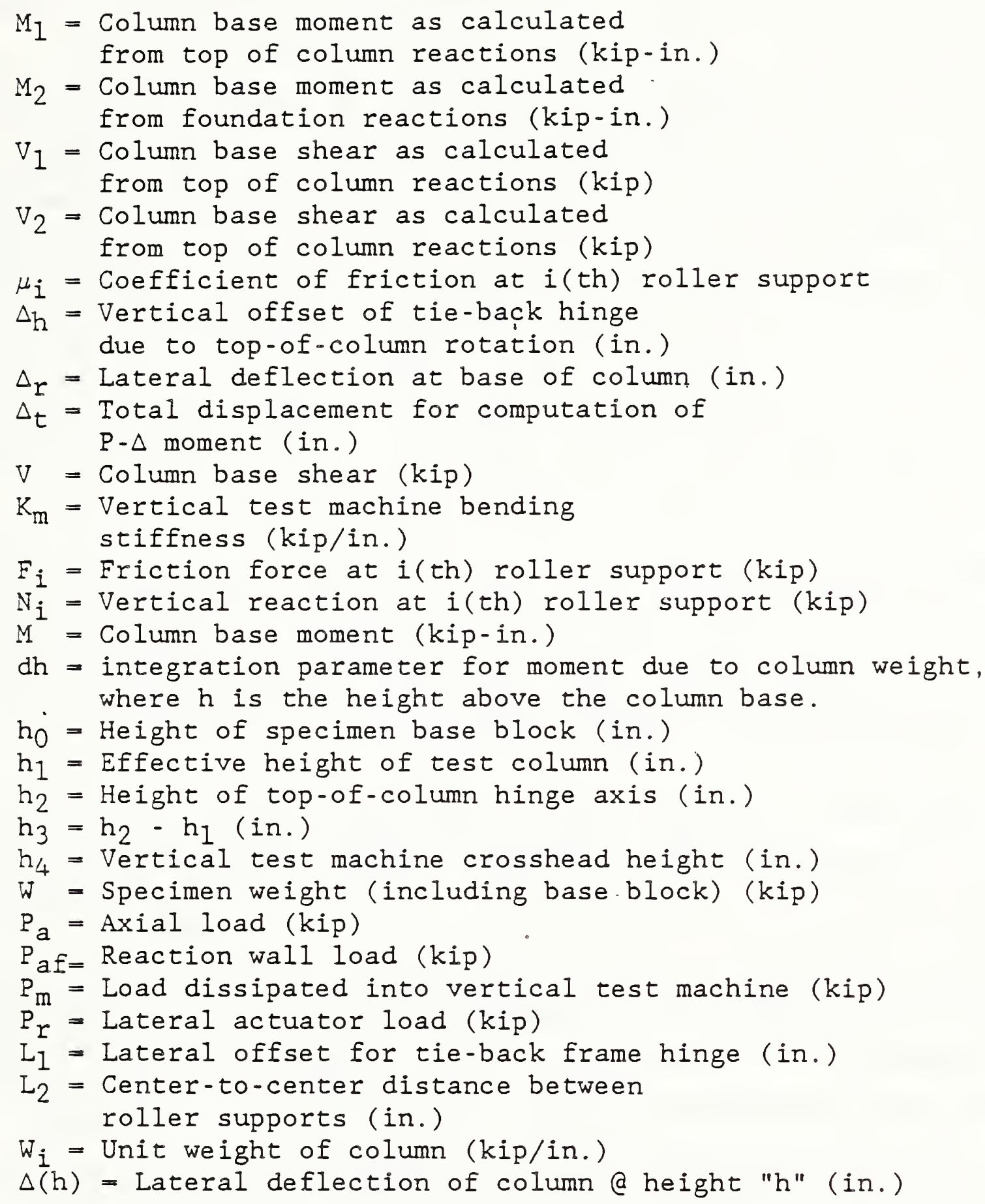

The unknowns are the vertical reaction forces at each of the eight roller supports, the friction forces developed at each of the 8 roller supports, the lateral load resisted by the tie-back frame, and horizontal forces dissipated into the vertical testing machine through the hinge assembly. Procedures were taken to experimentally measure all of these unknowns. 
The vertical reactions at the eight roller units, as well as friction forces developed at each roller, were to be monitored by calibrated, specially fabricated "flat cells" - low aspect ratio machined veerendeel trusses instrumented with strain gages and calibrated to measure both axial and shearing forces. These are described in section A.6.2 (instrumentation) in greater detail. The previously described tie-back frame was instrumented to form four full-bridge strain gage loadcells (see section A.6.3) so that both lateral load and column torque could be monitored. This was calibrated prior to each test by means of axial loading with the $12000 \mathrm{kip}$ (53 MN) vertical test machine. Lateral deflections at the test macine loading head were monitored using a rotary potentiometer mounted to a stable reference structure $30 \mathrm{ft} .(9.1 \mathrm{~m})$ distant from the test apparatus and connected by means of light gage stainless piano wire. Provided an accurate lateral stiffness could be determined for the test machine at each test elevation, crosshead displacement could then be used to directly determine the lateral reaction transmitted to hinge at the top of the column. Such stiffness calibrations were performed for each full-scale specimen as shown in Figures A.34 and A.35.

It should be noted that the actual moment in the test column at any given load stage could be determined within specified bounds of error by completely knowing either the reaction forces at the top of the column, or those at acting on the base structure. The instrumentation of the tie-back frame and the determination of machine lateral bending stiffness therefore provided a redundant mechanism for determination of losses in applied lateral load due to friction in the continuous track roller support system. Furthermore, the eight unknown friction forces could also be determined by knowing the vertical reactions at each roller system and making use of the calibration curves relating coefficient of friction to axial load. The effectiveness of the various techniques used to monitor reaction forces is discussed in Chapter 6 as well as Section A.6. 


\section{A. 3 Access Techniques for Large Scale Tests}

When designing the Large Scale Test Facility, as well as the prototype column specimens, there was an early appreciation of the need for rapid access to significant elevations - - in excess of $50 \mathrm{ft}$. ( $15 \mathrm{~m}$ ) above the test floor in some cases. This generally precluded the use of ladders and off-the-shelf scaffolding. Furthermore, specially constructed permanent stair systems and catwalks would inhibit viewing of the specimens under test, given the space restrictions of the facility, as well as impede placement and removal of test apparatus, since speed of assembly and dissassembly was directly related to ease of overhead crane access to the heavy test setup components.

A somewhat novel approach was adopted as a solution to the access problem. This involved the use of "single rope techniques" [References 8 and 9] in which a researcher could ascend or descend fixed nylon ropes suspended either from the reaction wall, the test machine, or laboratory roof trusses (Figure A.36). This had the distinct advantages of spontaneity - - in minutes a lightweight line could be rigged wherever needed - - and lack of clutter that would be associated with scaffolds, ladders and other more traditional methods.

The method employed a relatively stiff $7 / 16^{\prime \prime}$ (11 mm) kernmantle nylon rope with a braided external sheath (which served to resist abrasion) and a straight-lay, multifiber core. Breaking strength of the line was $77001 \mathrm{~b}$. $(34 \mathrm{KN}$ ) and at any given time during the conduct of a full scale test, some $400 \mathrm{ft}$. (122 m) were rigged at various key locations throughout the laboratory. Researchers and technicians wore alpine style seat harnesses and were able to ascend these lines using mechanical ascenders attached to the harness by means of 1 in. ( $25 \mathrm{~mm}$ ) tubular nylon sling which had a breaking strength of $44001 \mathrm{~b}$. $(20 \mathrm{KN})$. Descent was accomplished by means of a variable friction "rappel rack", as shown clipped to the harness of the researcher (Figure A.37) marking cracks on the full-scale flexure column. A total of four members of the laboratory staff ( none of whom had any prior experience in the use of such hardware) received professional instruction. All learned quickly and 


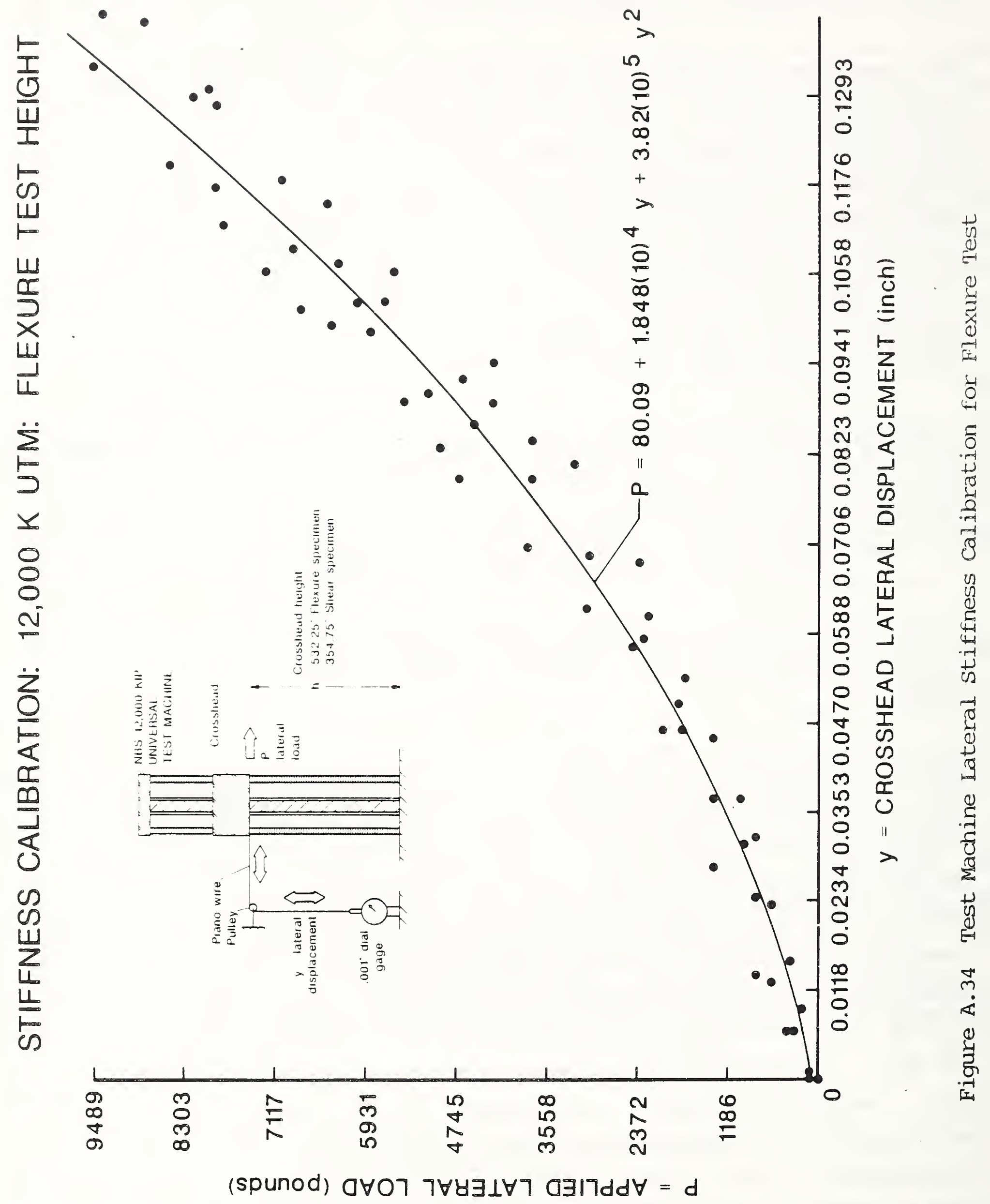




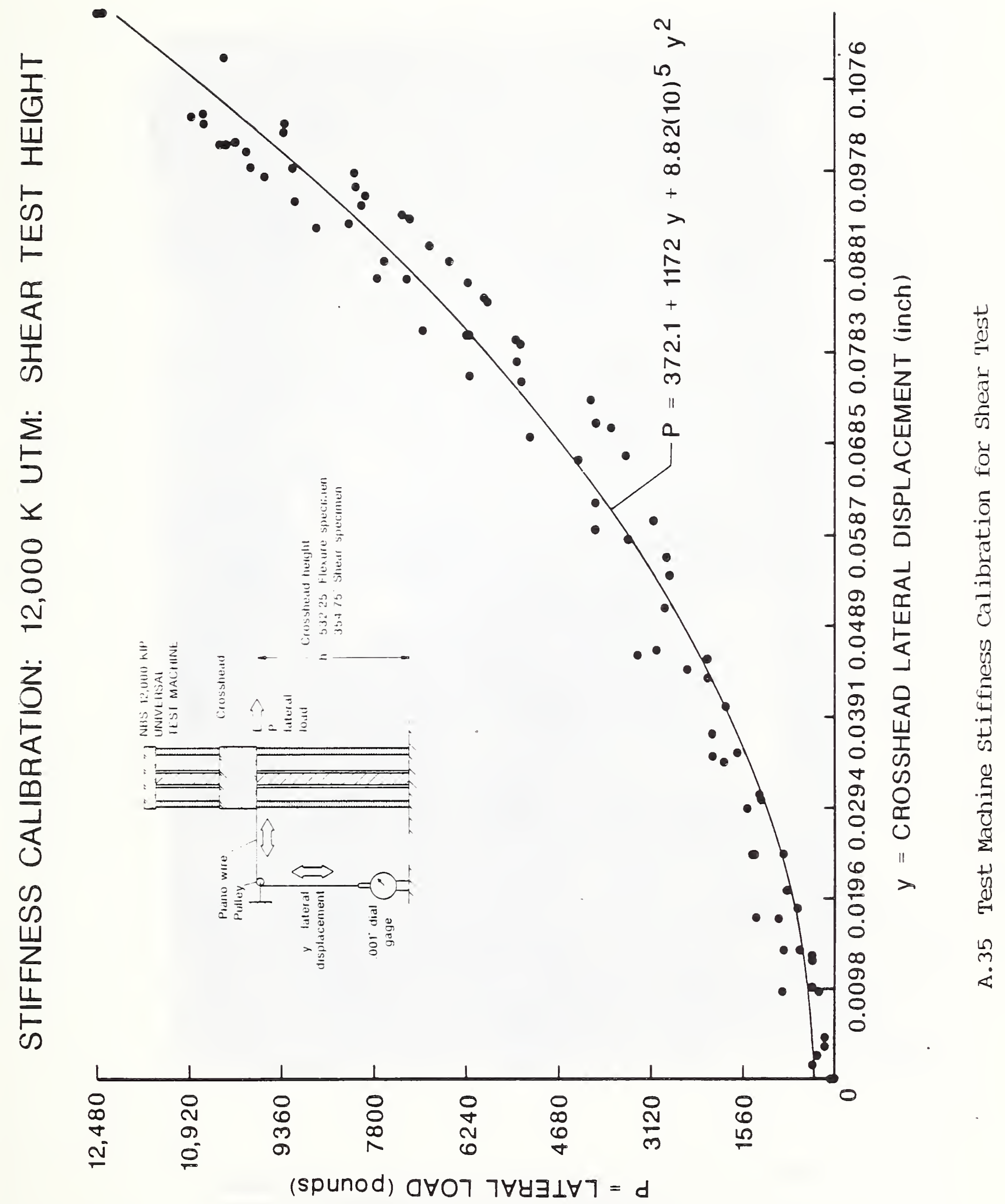




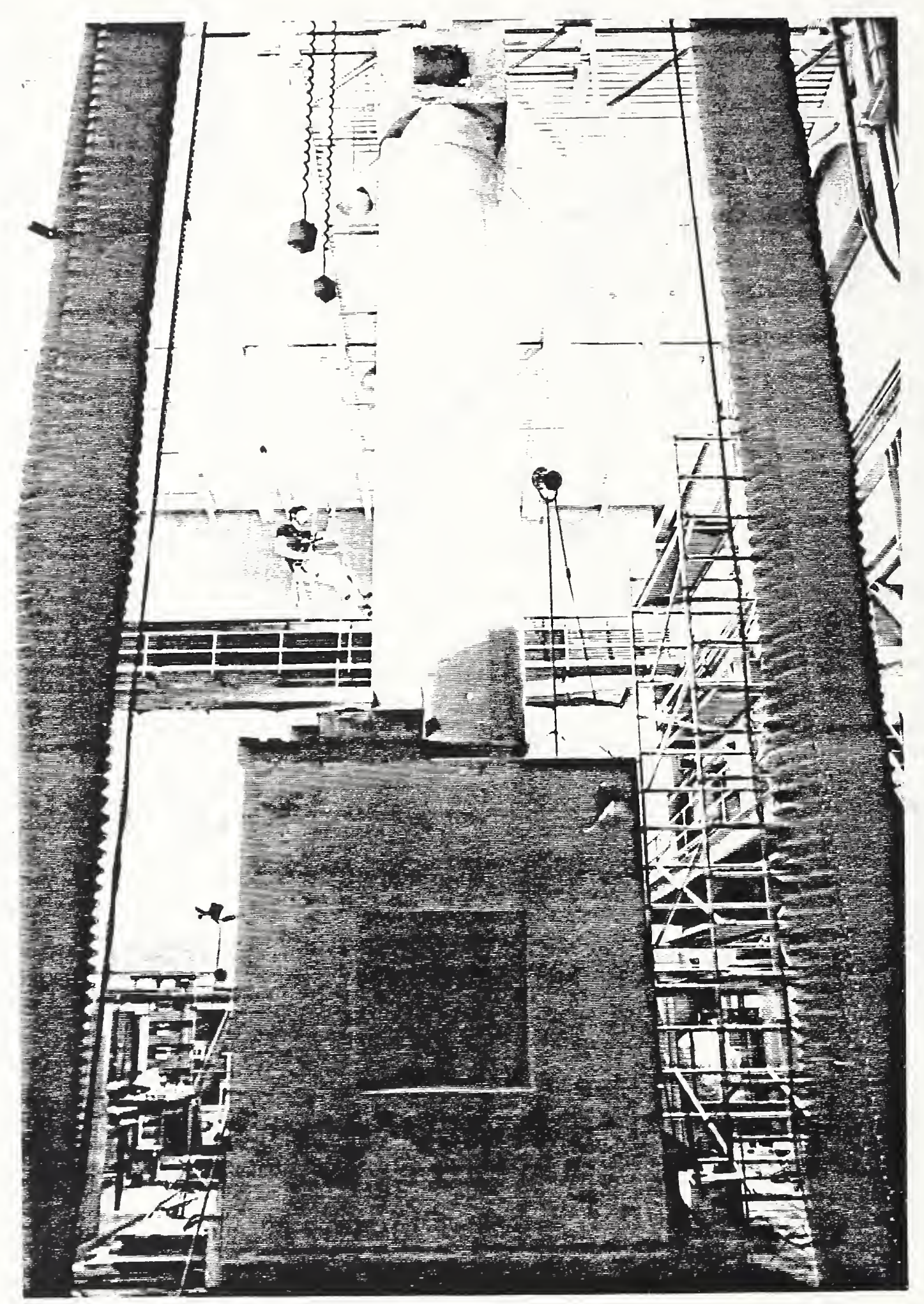

Figure A.36: Vertical Access to Difficult Places was Achieved Using Technical Ropework Methods. 


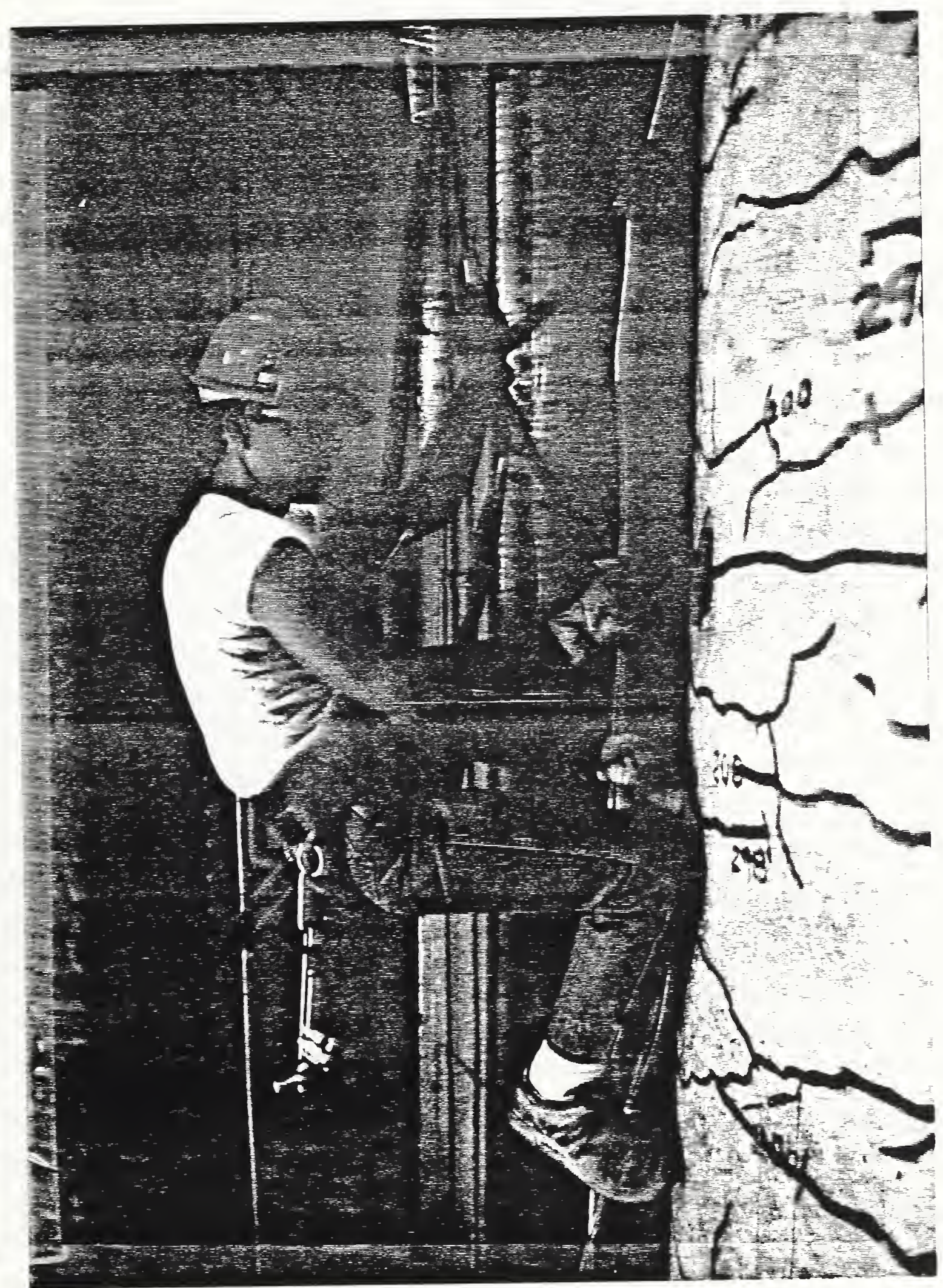

Figure A.37: Crack Marking on Full Scale Flexure Column Test Specimen. 
were able to safely apply the new skills without incident. Ropes were replaced regularly on a 6 -month basis and all slings were inspected prior to each use and replaced without hesitation at the first signs of wear.

One particularly useful application of the above described access techniques was that of crack-marking (Figure A.37). Here several lines were suspended. from the vertical loading head thus permitting rapid access to the entire surface area of the column while not interferring, with photographic documentation. Felt pens typically used for marking cracks in model specimens were not effective for full scale tests since they were too thin for reasonable resolution when viewed at the distances necessary to photograph the entire column (approximately 30 feet, $9.1 \mathrm{~m}$ ). Instead, $0.5 \mathrm{in.}$ ( $12 \mathrm{~mm}$ ) foam tipped glue applicators filled with drawing ink were used as shown in Figure A.37. Another alternative which was considered, but in the end not used because the first approach - - the ink applicators - worked so well, was that of using variously colored spray paints equipped with extension tubes for applying a narrow band. This would have permitted the use of separate colors for identification of the various lateral displacement levels.

While the benefits of single rope techniques for full scale testing (both in the laboratory and in the field) are clear, so is the need for expert instruction for those researchers contemplating the use of such techniques. The authors recommend reading Reference 10 and then contacting a respected alpine or speleological society for sources of training.

\section{A. 4 Specimen Demolition and Removal}

Following testing of a full-scale column there was the significant task of disposing of the now-useless specimen. The use of explosives was considered the most effective method but could not be used indoors owing to the proximity of sensitive test equipment. The method eventually employed was as follows:

1) Prior to casting of the base, insert three horizontally oriented, 2 in. $(50 \mathrm{~mm})$ diameter thin walled steel conduits equally spaced across the height of the base block at each of the third-points along the length of 
the base block. Ensure that these are not plugged during concreting operations.

2) Prior to casting of the base, install 0.625 in. ( $15 \mathrm{~mm}$ ) diameter thin walled aluminum conduits oriented perpendicular to the side (long) face of the base block and lying flush with each layer of longitudinal deformed reinforcing. There were three such layers: a top layer consisting of 15 \#11 bars and two bottom layers consisting of $15 \# 14$ bars. Three such conduits were placed at each of the third points along the length of the base, flush with the vertical tubes described in 1) above.

3) Prior to casting of the base, install concrete lifting anchors (see Figure A.38) such that, once demolition operations have been completed, the base can be hoisted in three separate, approximately equal segments. Each segment must have sufficient embedment anchors to permit stable hoisting and be relatively insensitive to minor errors in the location of the fracture planes generated during the demolition process.

4) Following completion of the test, burn through all longitudinal column reinforcement at the column base using a torch. This is generally a rapid procedure since most reinforcement is either buckled or fractured at this stage already. Severing of the final reinforcement should not be attempted until the column has been rigged to an overhead crane. With the crane in place and the final bars removed, the column can be laid down horizontally on the base block at which point a second crane can be attached at the opposite end for loading to a transport vehicle. If a large capacity overhead crane is available (50 ton) this operation can be done in one motion. Figure A.39 shows a typical full-scale column ready for transport from the testing lab. 


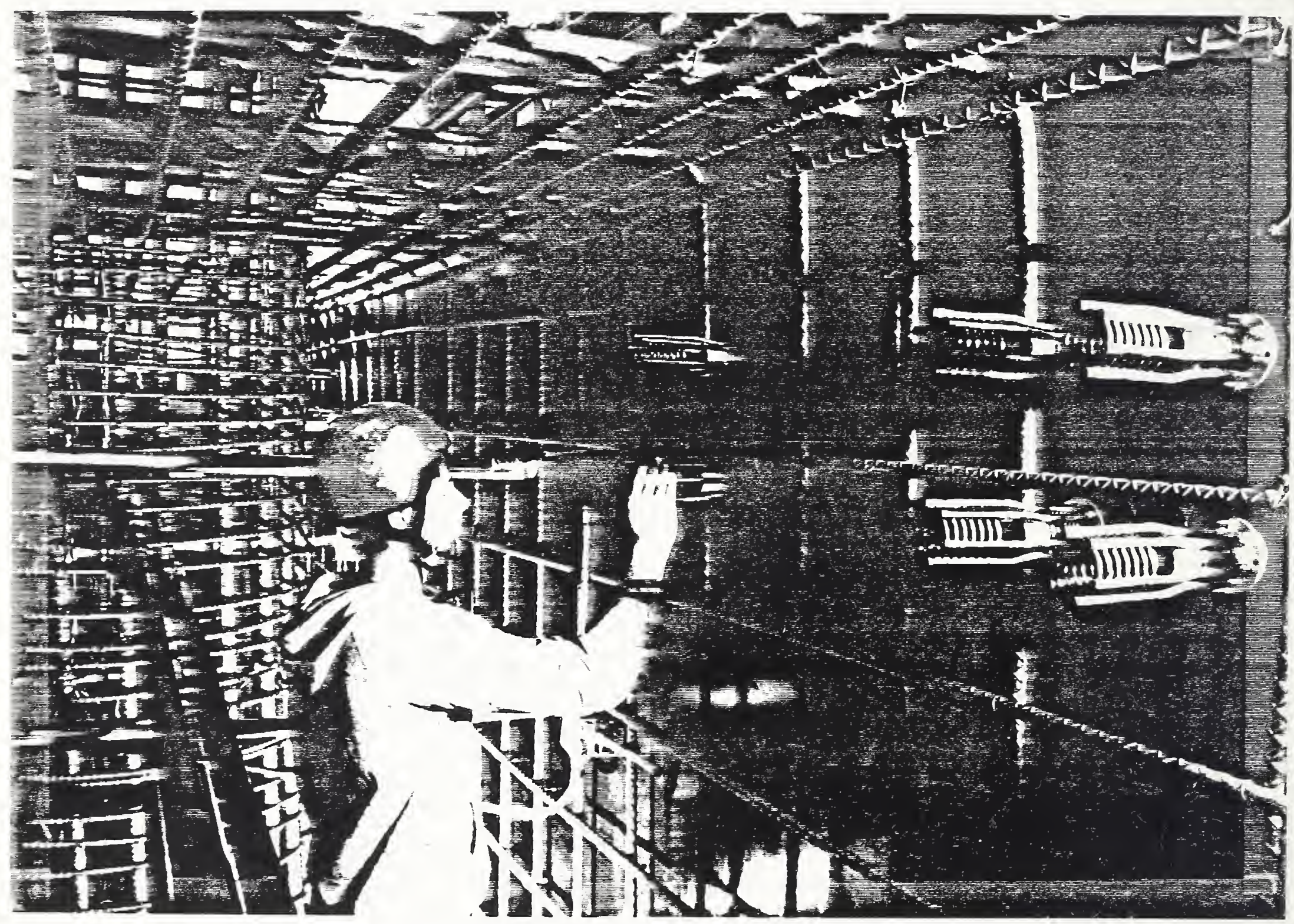

Figure A.38: Installation of Cast-in-place lift Anchors to be used for subsequent Demolition of Specimen. 
5) With the column removed, fill the horizontal conduits with expansive cement. A commercial grade known as "Bristar" was used with excellant results. This cured within 24 hours and initiated a planar vertical crack across the base block at each of the third points.

6) Using an oxygen lance, burn through the horizontal conduits. This is a sufficiently vigorous process that the longitudinal deformed bars are also consumed along the line of the conduit. Short oxygen lance burns are also made along the side faces of the base at each of the fracture lines to cut through the temperature and shrinkage steel.

7) Using jackhammers, cut a blockout in the top face of the base which spans the fracture plane. Three of these are used across the width of the block at each of the third point fractures and they must be sufficiently deep to permit placement of large capacity hydraulic jacks - at least 100 ton ( $890 \mathrm{KN}$ ) capacity each. These are then driven in parallel to their maximum extension, resulting in the splitting-away of the various segments. An oxy-acetylene torch is used to clear away any residual steel and the segments are hoisted onto a waiting transport.

This was a time consuming, labor intensive solution but it was safely carried out within the confines of a laboratory where several other test projects were being conducted at the same time. Two alternative, and likely much less costly, procedures for specimen removal are the above mentioned use of explosives - - if the specimen can be initially transported to an outside location following completion of a test - - and an approach involving different specimen construction procedures which will be described in Appendix $B$.

\section{A. 5 Material and Construction Process}

\section{A. 5.1 MATERIAL}

The nominal size of the coarse aggregate used for the full-scale columns was $3 / 4$ in. $(1.9 \mathrm{~cm})$. The specific gravity of the coarse aggregate in the saturated surface dry condition (SSD) was 2.59. The fine aggregate had a 


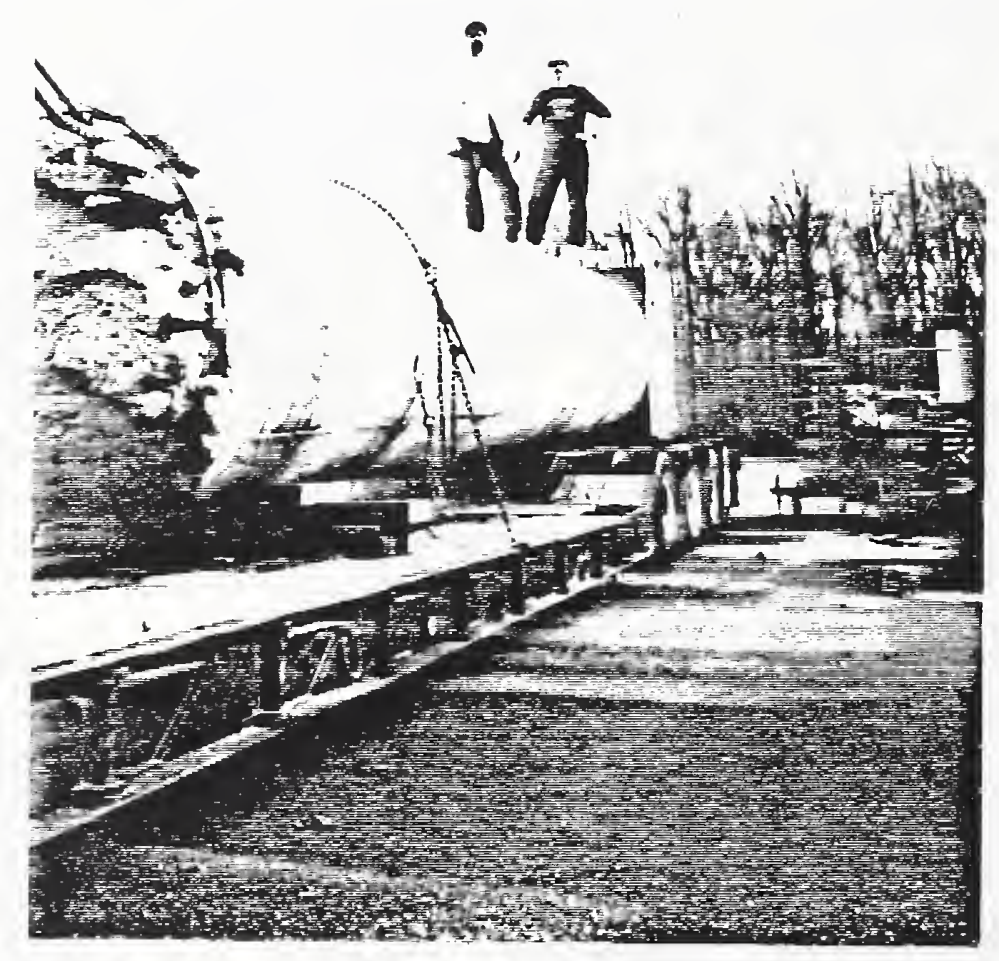

Figure A.39: Flexure Column Ready for Transport from the Laboratory after Testing. Maximum segment weight was limited to 60 tons ( $530 \mathrm{KN})$. 
specific gravity SSD of 2.62, a specific gravity dry of 2.59 and a fineness modulus equal to 2.57. The gradations of the coarse aggregate and the fine aggregate are presented in Tables A.1 and A.2. The mix design for a concrete compressive strength of 4000 psi (27.6 MPa), for 1 cubic yard - dry weights SSD, are given in Table A.3.

\section{A. 5.2 Construction Process}

Commercial contracts were let for the tying of the steel cages and the casting of the columns. Fig. A.40a shows the steel for the shear column and some of the formwork around the base. The formwork for the footing and the column was made of steel for the flexure specimen. Wooden formwork was used for the footing and steel formwork was used for the column of the shear specimen.

The inside of the base in shown in Fig. A.40b. The wooden block-out on the left foreground of the figure is the attachment point for the servo-hydraulic ram applying the lateral load. This inset allowed the ram to be at its midstroke in the neutral or zero position and to have a maximum stroke of 24 in. $(610 \mathrm{~mm})$ in the east and west direction. The pipes originating from the block-out to the opposite end of the footing were used as conduits for the post-tensioning bars attaching the ram to the focting. A closeup of the confining reinforcement for the shear specimen prior to casting of the column section is shown in Figure A.41. Sprial reinforcement is \#6 deformed grade 60 bar at $2-1 / 8$ in $(54 \mathrm{~mm})$ spacing.

Due to the size of the column, application of strain gage instrumentation was not easy. This was particularly true for the flexure column as climbing gear was necessary to scale the outside of the column and to descend inside the column to enable gaging of the longitudinal bars (Figure A.42). Figure A.43 shows part of the waterproofing process required for the gages on the longitudinal bars. A description of strain gage locations and application procedures is used is presented in Section A. 6. 
Table A.I COARSE AGGREGATE

\section{SIZE}

1 in. mesh size

$3 / 4$ in. mesh size

$3 / 8$ in. mesh size

\#4 mesh size

\#8 mesh size
8 PASSING

100.0

96.7

49.5

6.4

3.2

Table A.2 FINE AGGREGATE

\section{SIZE}

$3 / 8$ in. mesh size

\#4 mesh size

\# 8 mesh size

\# 16 mesh size

\# 30 mesh size

\# 50 mesh size

\# 100 mesh size $\frac{8}{8}$ PASSING

100.0

98.1

87.5

74.9

55.4

24.7

1.5
Table A.3 MATERIALS

Cement, Portland ( $6-1 / 4$ sacks), Type I

Sand

Grave 1

Water (31 gal.)

Air Entrained

Water/Cement Ratio

Slump

\section{WT. L LB \\ 588.0 \\ 1100.0 \\ 1936.0 \\ 258.23}




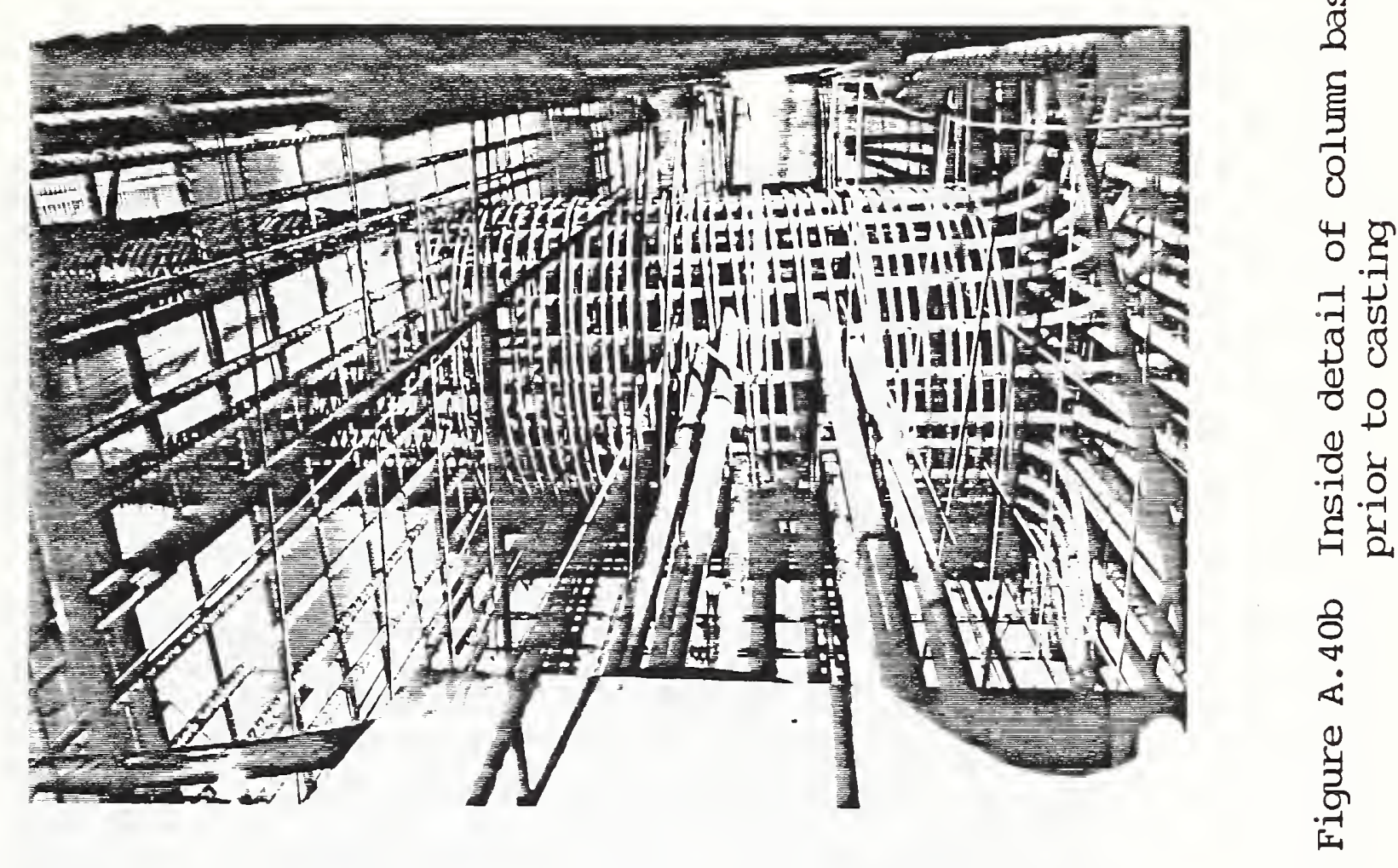

을

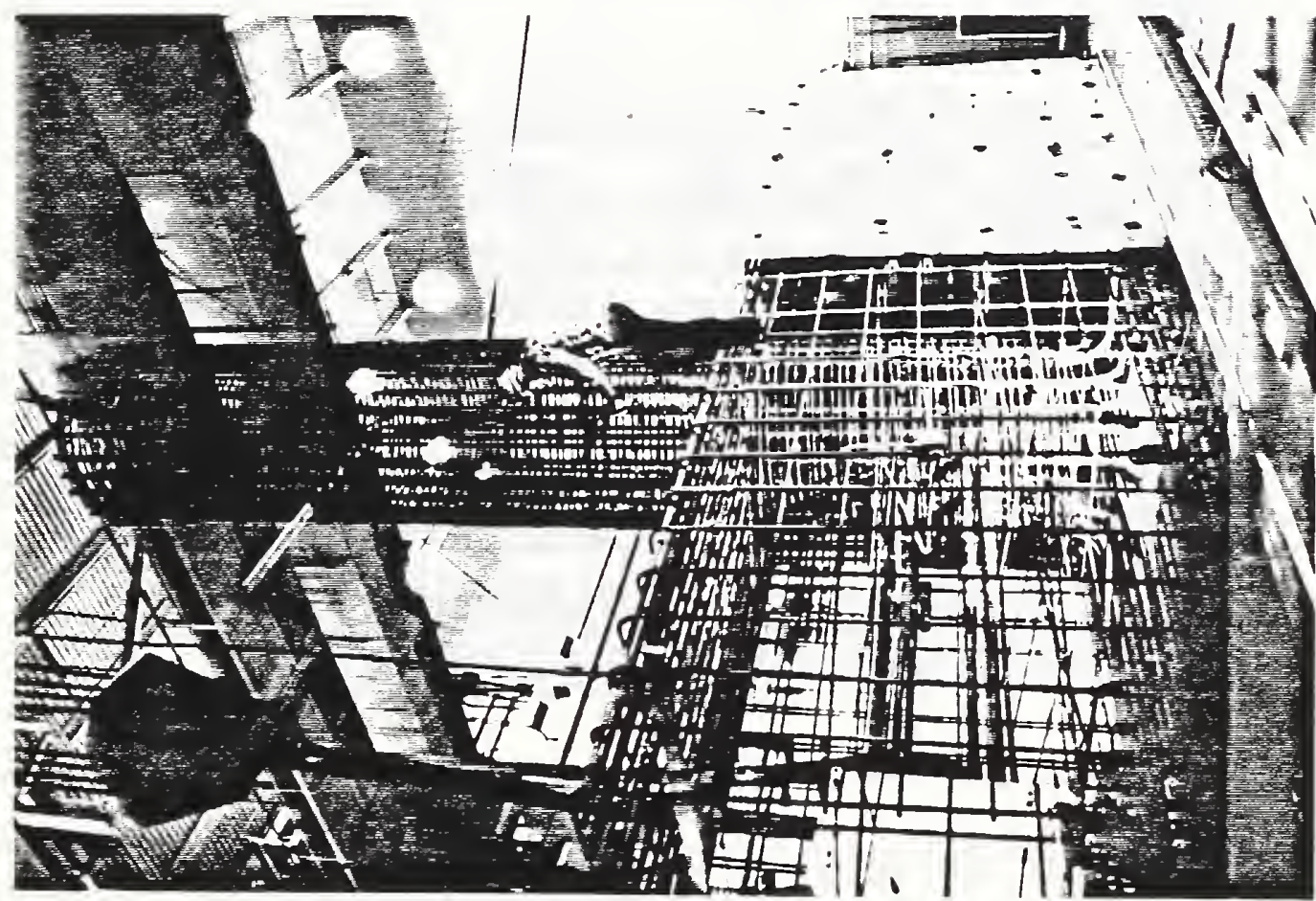

宩告

\begin{tabular}{ll}
4 & 0 \\
3 & 0 \\
\hline
\end{tabular}

$\stackrel{0}{1} 4$

द 0

ब)

क्ष

- 8

곤

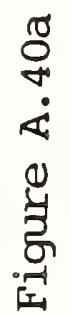




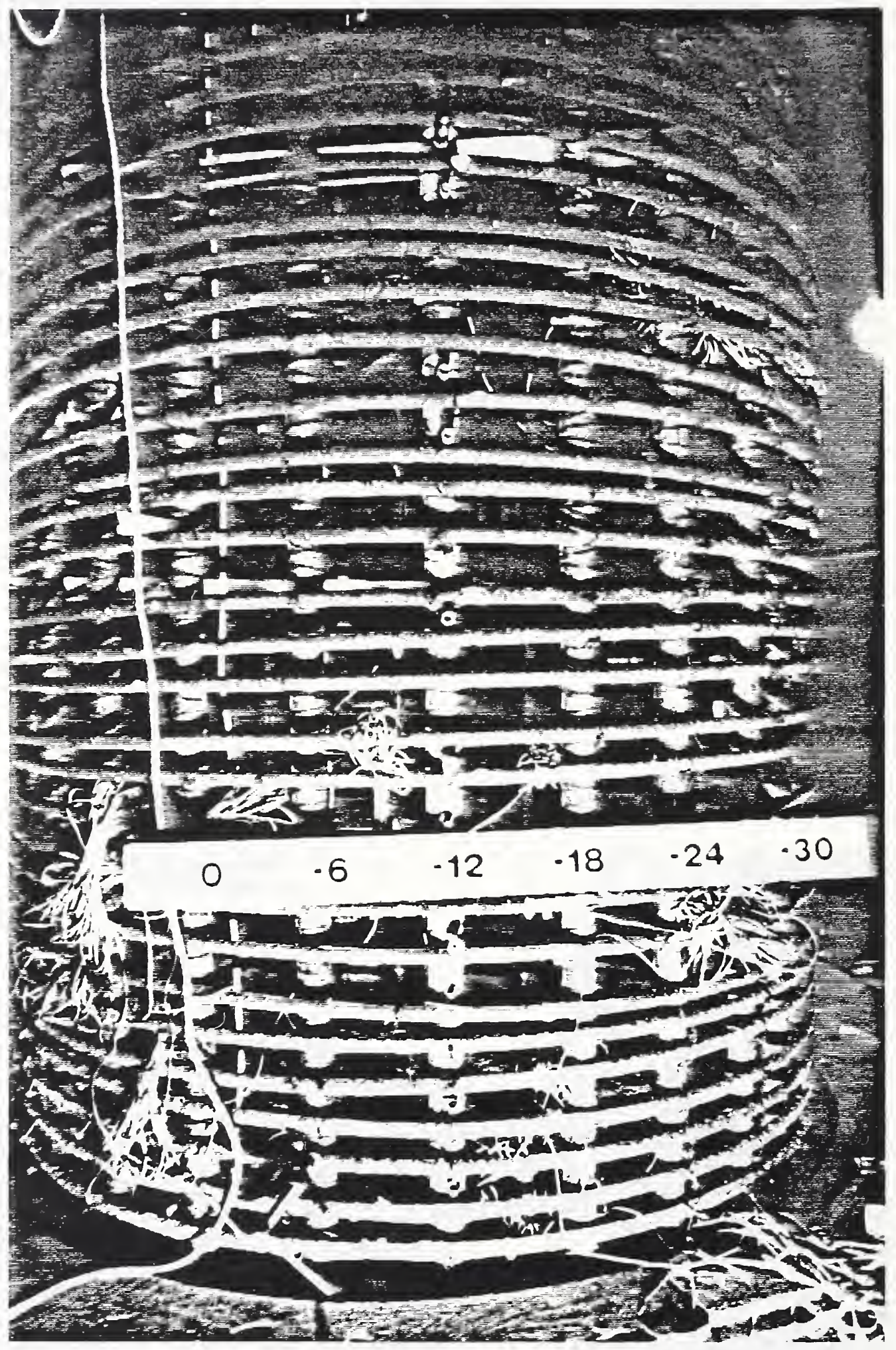

Figure A.41: \#6 Deformed Grade 60 Spiral Reinforcement at $2-1 / 8$ in. ( $54 \mathrm{~mm}$ ) pitch prior to Casting of Full-Scale Shear Column Section. Scale in inches. 
The columns were cast in two phases. The footing was poured in the first phase and the column itself was poured in the second. This created a cold joint at the interface of the column and footing which is standard construction practice. Casting of the flexure column footing is shown in Fig. A.44 where the concrete is being pumped into the footing from a concrete truck. Instead of pumping the concrete for the shear specimen, the concrete was poured into hoppers and by using the overhead cranes, the hoppers were lifted over the specimen where they were emptied as shown in Fig. A.45. This change in procedure was an effort to economize.

After removal of the forms lifting brackets (visible near the bottom right corner of the base block in Figure A.31) were attached at each of the four corners of the specimen. Four 100 ton ( $890 \mathrm{KN}$ ) hydraulic jacks operated in parallel were then inserted at the bracket locations and the entire specimen was lifted approximately $12 \mathrm{in.}(30 \mathrm{~cm})$ whereupon the bottom formwork was removed, the railroad tracks cleaned, and one of the continuous track rollers was placed under the specimen at each corner. The specimen was then moved towards the test apparatus until access from the high-bay crane was possible where the upper hinge assembly was grouted in place. Once in the test assembly the lateral ram was connected to the base block and post-tensioning operations were carried out. With the vertical loading head moved well above the top of the column, the tie-back frame - - which was already attached to the reaction wall - - was swung down in preparation for connection with the load block at the top of the column. The specimen was positioned during this operation with the use of the lateral ram under servo-control. The tie-back frame was then post-tensioned to the top of the column and the vertical loading head brought down into contact with the hinge assembly.

\section{A. 6 Instrumentation}

All columns were instrumented extensively in the potential plastic hinge region. A total of 121 channels were used to acquire data for each test. Of these, two were dedicated to record the lateral load and two channels to 


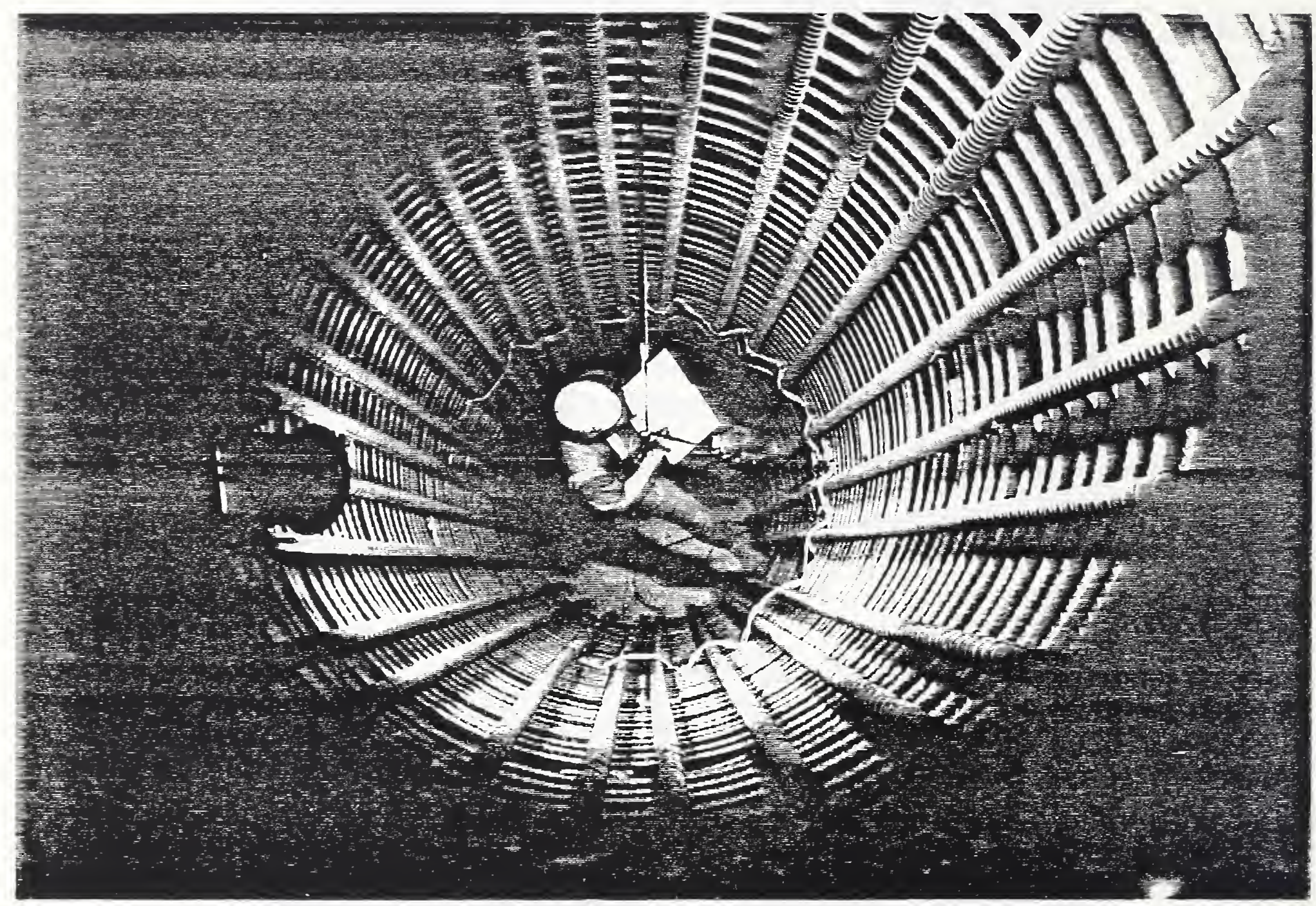

Figure A.42 Vertical Access to Inside of Full-Scale Column Reinforcing Cage Using Technical Ropework Methods. Lines Circling the Researcher Comprise the Wiring Harness for first 50 Spiral and Longitidunal Reinforcing Strain Gages. 


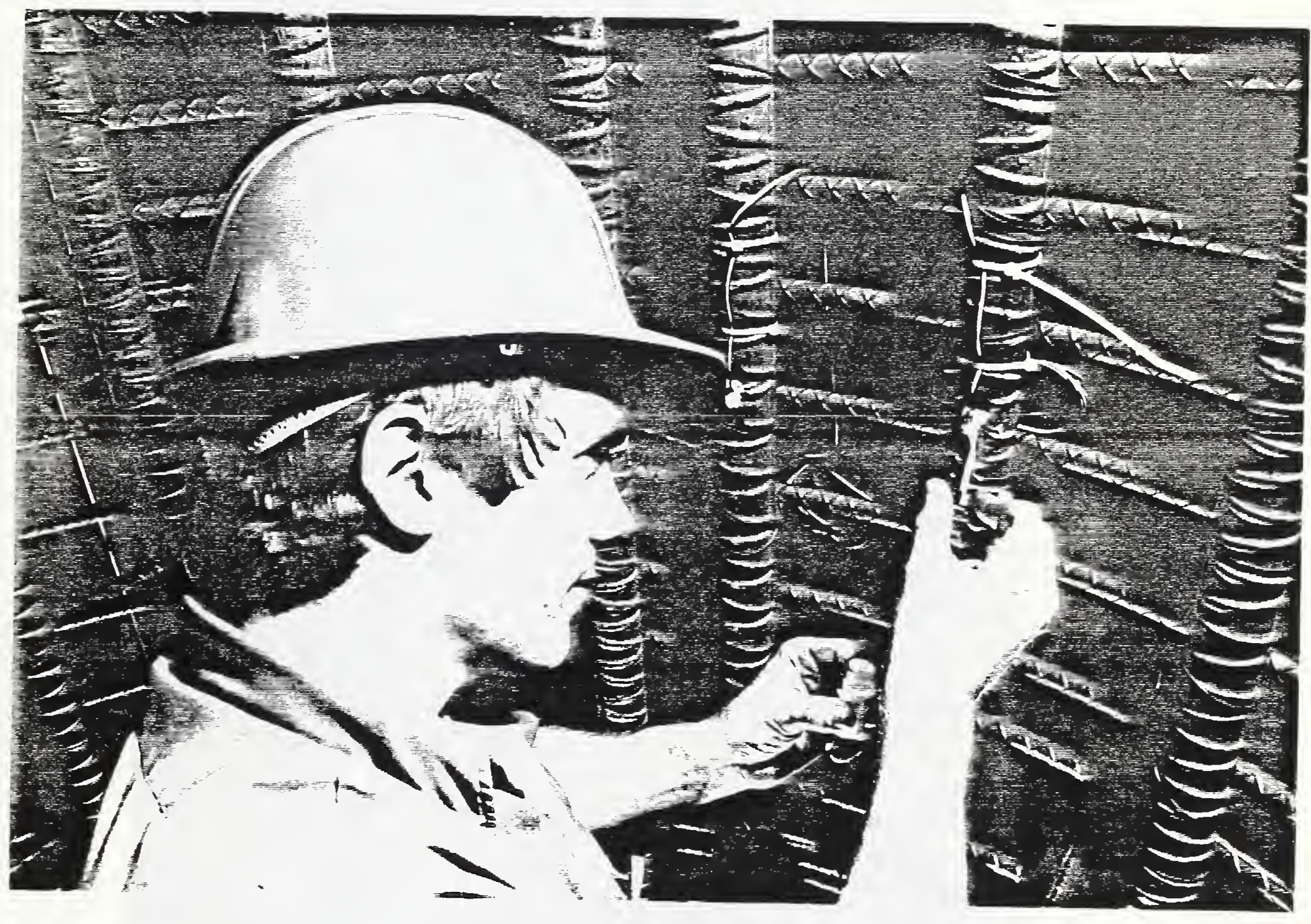

Figure A.43: Application of Strain Gage Waterproofing to Longitudinal Reinforcing Steel

Instrumentation. Surface was Prepped with a Carborundum Grinder, Followed by Filing, and Sanding with Emory Cloth Prior to Cleaning for Strain Gage Installation. 


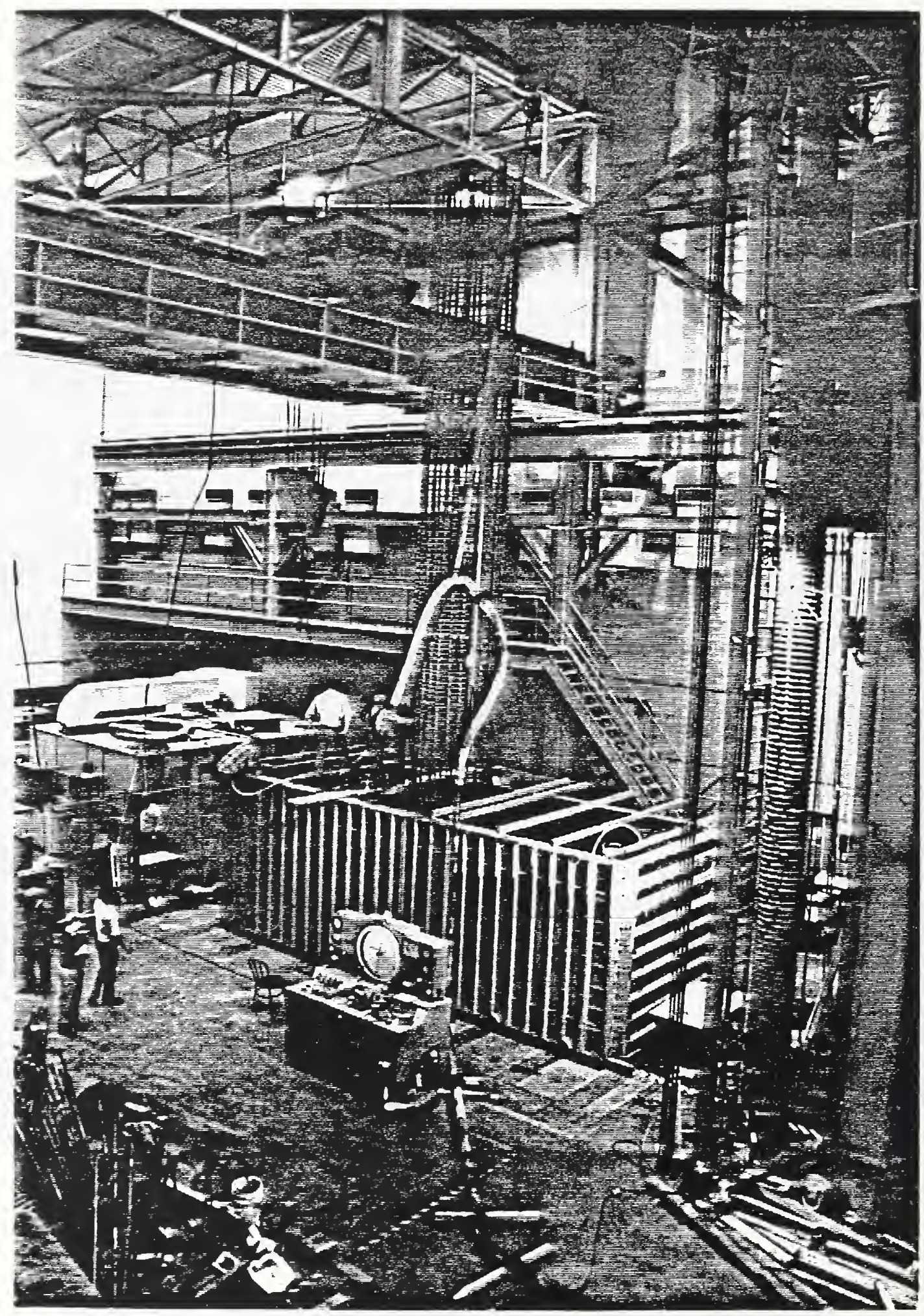

Figure A.44: Casting Full-Scale Flexure Column Base. 


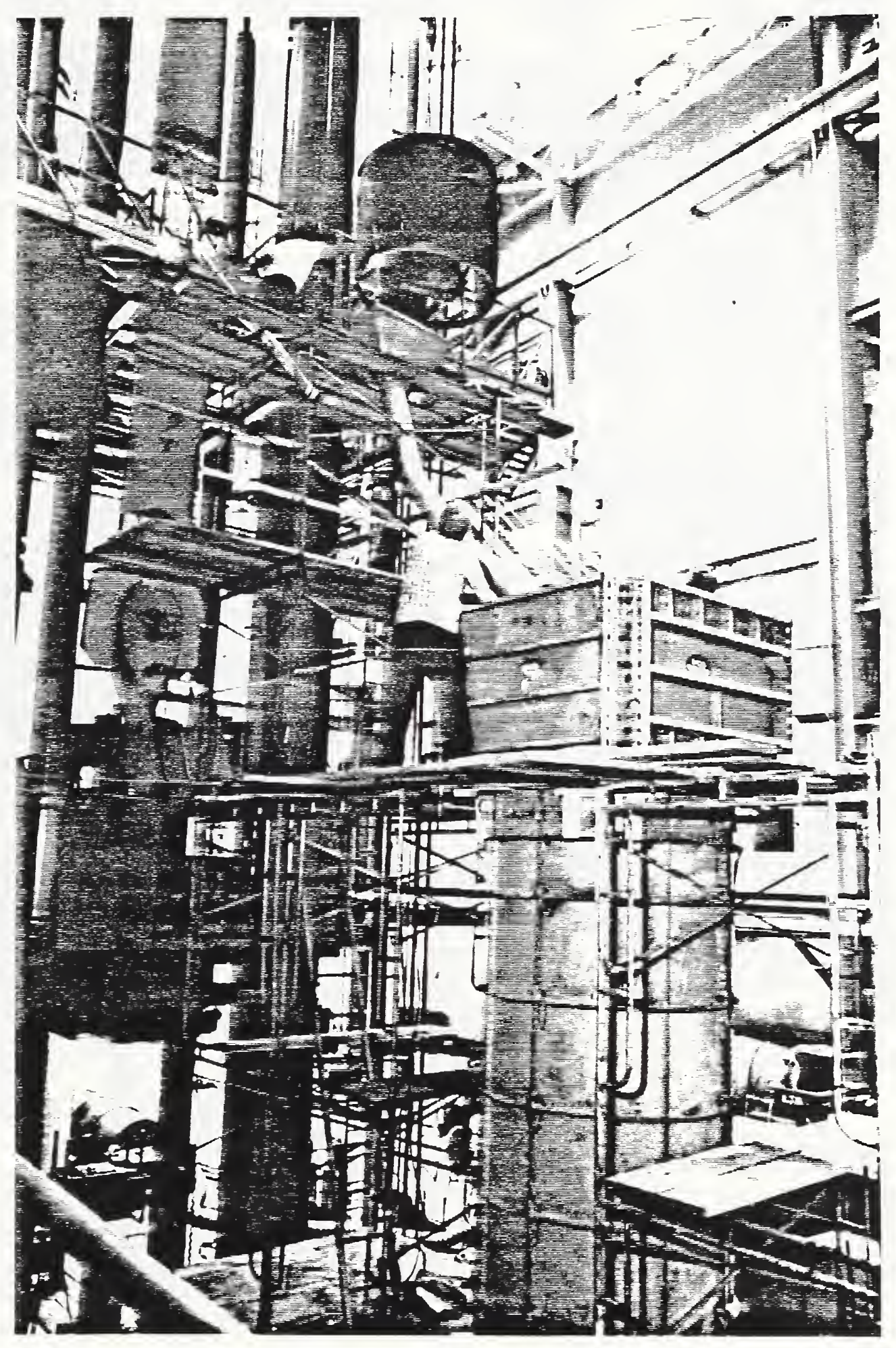

Figure A.45: Casting Full-Scale Shear Column 
record the axial load. Seven channels were used to measure the column displacement at various locations along the height of the columns using highresolution rotary potentiometers connected to a stable tower (Figure A.46) by means of $0.012 \mathrm{in.}(0.3 \mathrm{~mm})$ stainless wire. The rigging tower was located 30 ft. $(9.1 \mathrm{~m})$ distant from the test stand to eliminate the effects of local displacements that would arise if the reference tower was mounted on the specimen (due to flexural deformation of the base block). During the first (flexure) full-scale test two additional channels were used to measure the rotation at the base of the column using linear variable differential transformers (LVDTs). The remaining channels were used to measure the strains along the longitudinal and spiral reinforcement using resistance type foil strain gages.

Redundant strain gaging was used in all critical locations, since repeat tests would not be possible. Figures A.47 and A.48 show the locations of the strain gages for the flexure column. From the results of the model tests and the first full scale test, the strain gage and LVDT locations were modified to better capture column behavior in the shear column. One such modification was to place the spiral gages along the vertical lines of maximum flexural fiber strain, the same as for the longitudinal bar gages. Previously, spiral gages were located along vertical lines rotated 90 degrees from the longitudinal bar gages to eliminate confusion when wiring instrumentation. It was felt that this new orientation would allow for a better capture the first yielding of the spiral.

\section{A.6.1 Clip Gages}

The two LVDTs used to measure column base rotation for the flexure specimen were not used for the shear column test. In the interim between the first and second full-scale test a new, and extremely sensitive "clip gage" was developed to measure local strain (and hence curvature) throughout and beyond the height of the potential plastic hinge region. The original concept for this gage came from a similar device which had been developed at the National Bureau of Standards for cryogenic fracture mechanics studies. The clip gages 


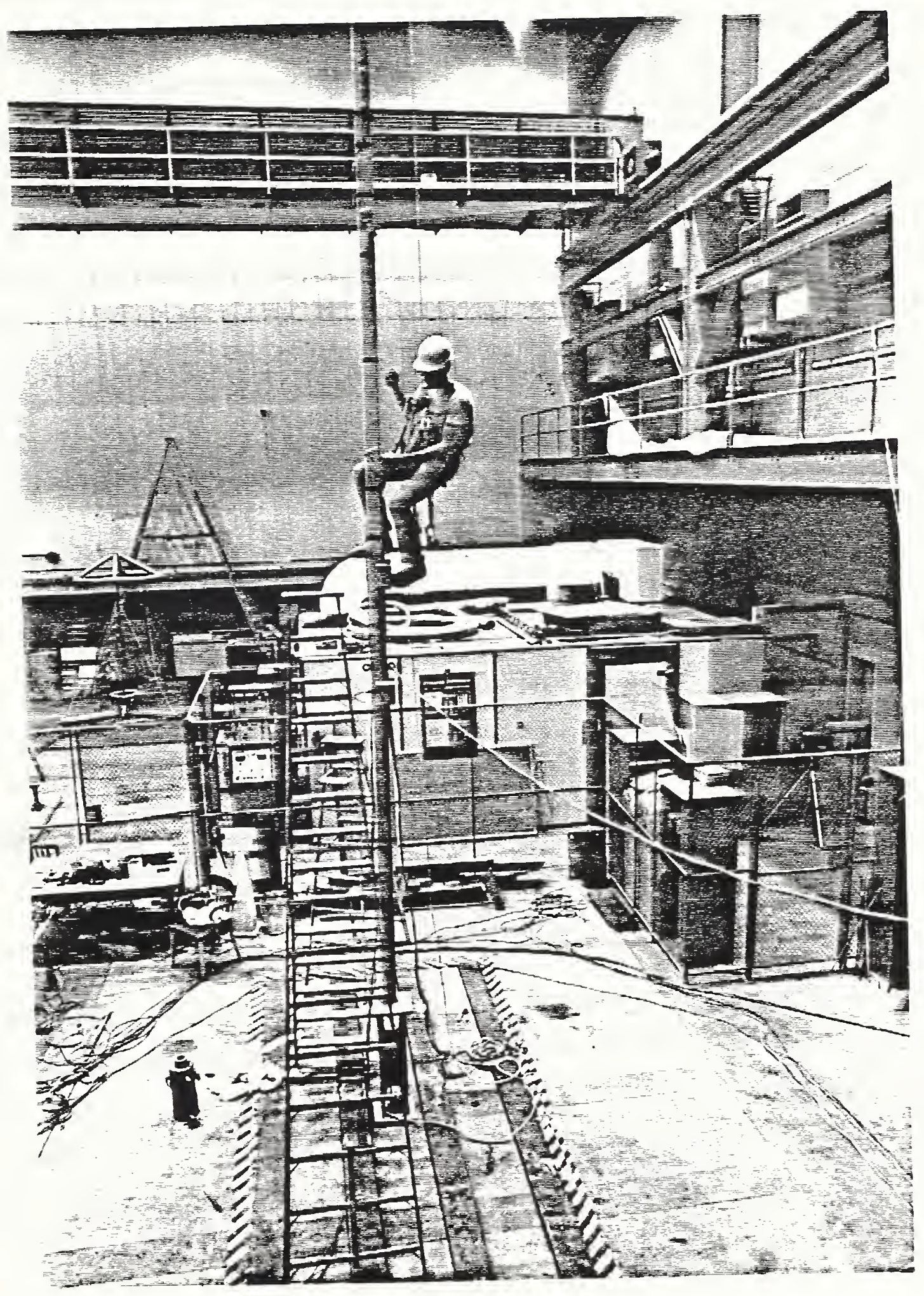

Figure A.46: Stable Tower used for Column Displacement Reference Plane. 
were machined on a numerically controlled mill from 7075-T6 aluminum alloy and had a gage length of $3 \mathrm{in.} \mathrm{(76} \mathrm{mm).} \mathrm{An} \mathrm{isometric} \mathrm{drawing} \mathrm{of} \mathrm{the} \mathrm{clip} \mathrm{gage} \mathrm{is}$ shown in Figure A.49. A total of nine clip gages were mounted on each opposing column face along the line of maximum bending fiber strain. Anchors for mounting the clip gages were tack-welded to the longitudinal reinforcement as shown in Figure A.50 at 15 in. (381 mm) spacing along the lower half of the column. While this technique worked and did not appear to influence the behavior of the longitudinal reinforcement, it was decided following the test that a better procedure would have been to mount threaded connectors for the clip gages on the ends of a continuous rod which extended through the width of the column, thus providing solid support for each pair despite concrete spalling etc. This procedure was used in the New Zealand tests [15]. Taken together, the clip gages provided an accurate external measure of column curvature along the height of the column. Experimental curvature at any discrete height containing a clip gage pair was calculated as:

$$
\begin{aligned}
\mathrm{R}= & \left(\epsilon_{1 i}-\epsilon_{2 i}\right) / \mathrm{D} \quad \text { radians/in. } \\
\text { where } \epsilon_{1 i}= & \begin{array}{c}
\text { tension clip gage displacement/gage length }= \\
\text { tension strain at elevation " } \mathrm{l} "
\end{array} \\
\epsilon_{2 i}= & \begin{array}{c}
\text { compression clip gage displacement/gage length }= \\
\text { compressive strain at elevation "i" }
\end{array} \\
\mathrm{D}_{\mathrm{C}}= & \text { out-to-out of spiral }=56 \text { inches }(1.52 \mathrm{~m})
\end{aligned}
$$

A typical experimental calibration curve and best fit equation for clip gage displacement versus output voltage is presented in Figure A.51 which shows excellent linearity over a 0.9 in. (23 mm) extension range. During actual testing the clip gages were pre-compressed by $1 / 2 \mathrm{in.}$ ( $12 \mathrm{~mm}$ ) to accomodate both positive and negative curvatures. Gage locations are shown in Figure A. 52 .

\section{A.6.2 Flatcells and the Measurement of Base Reaction Forces}

The need to monitor friction and vertical reaction forces generated at the roller supports was recognized early in the test program and a study was 


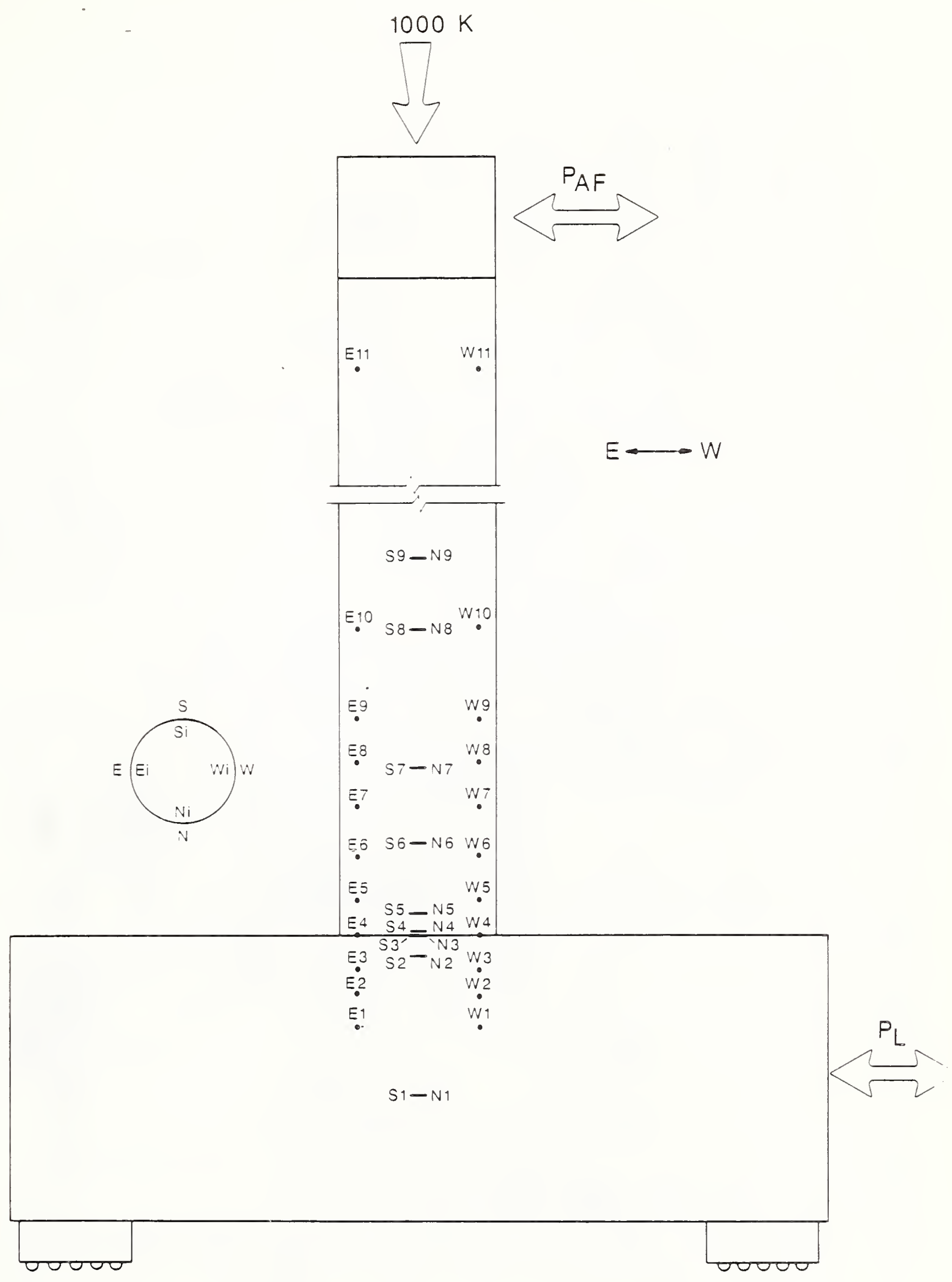

Figure A.47: Location of Strain Gage Instrumentation for Full-Scale Flexure Column. 


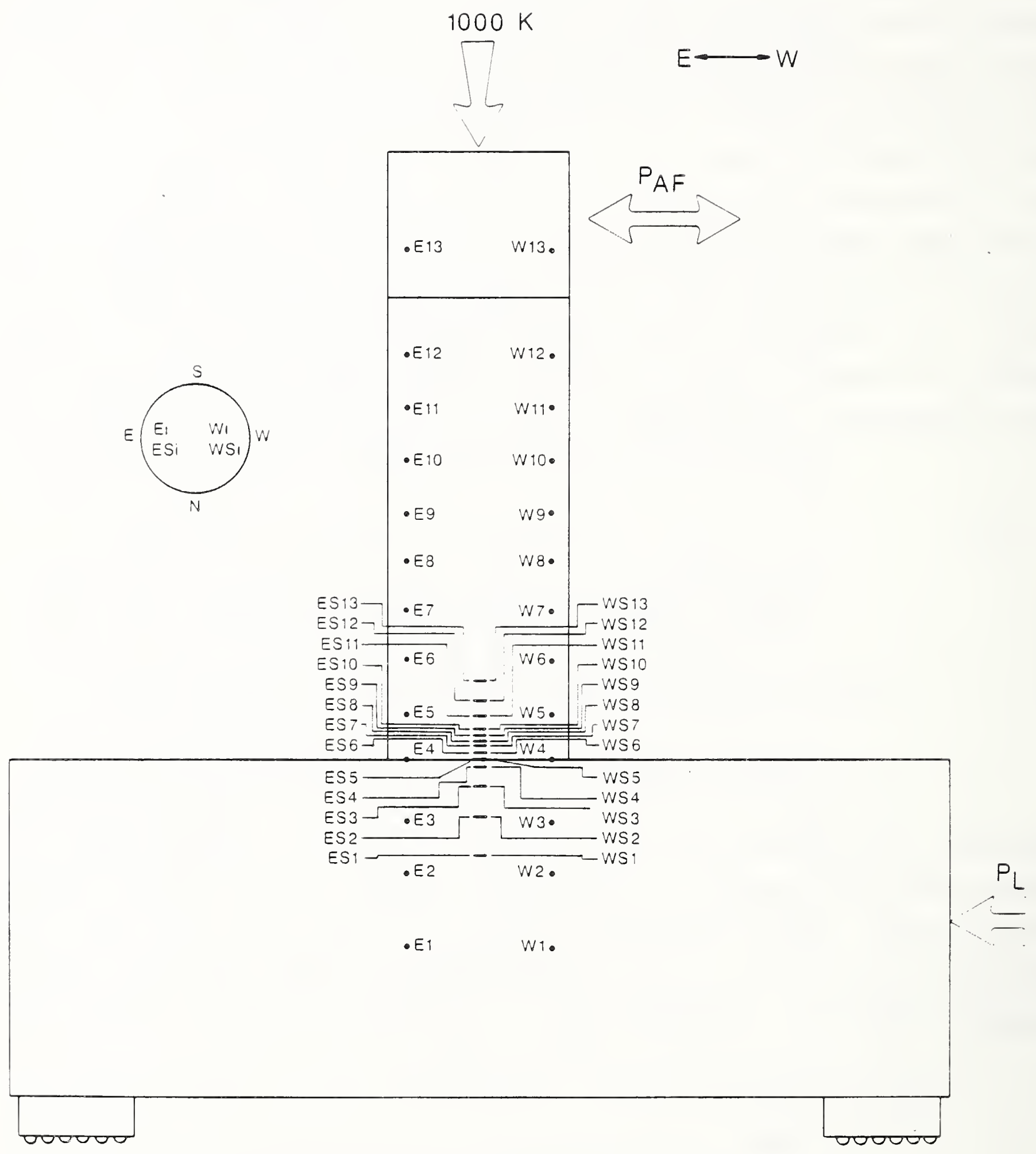

Figure A.48: Location of Strain Gage Instrumentation for Full-Scale Shear Column. 


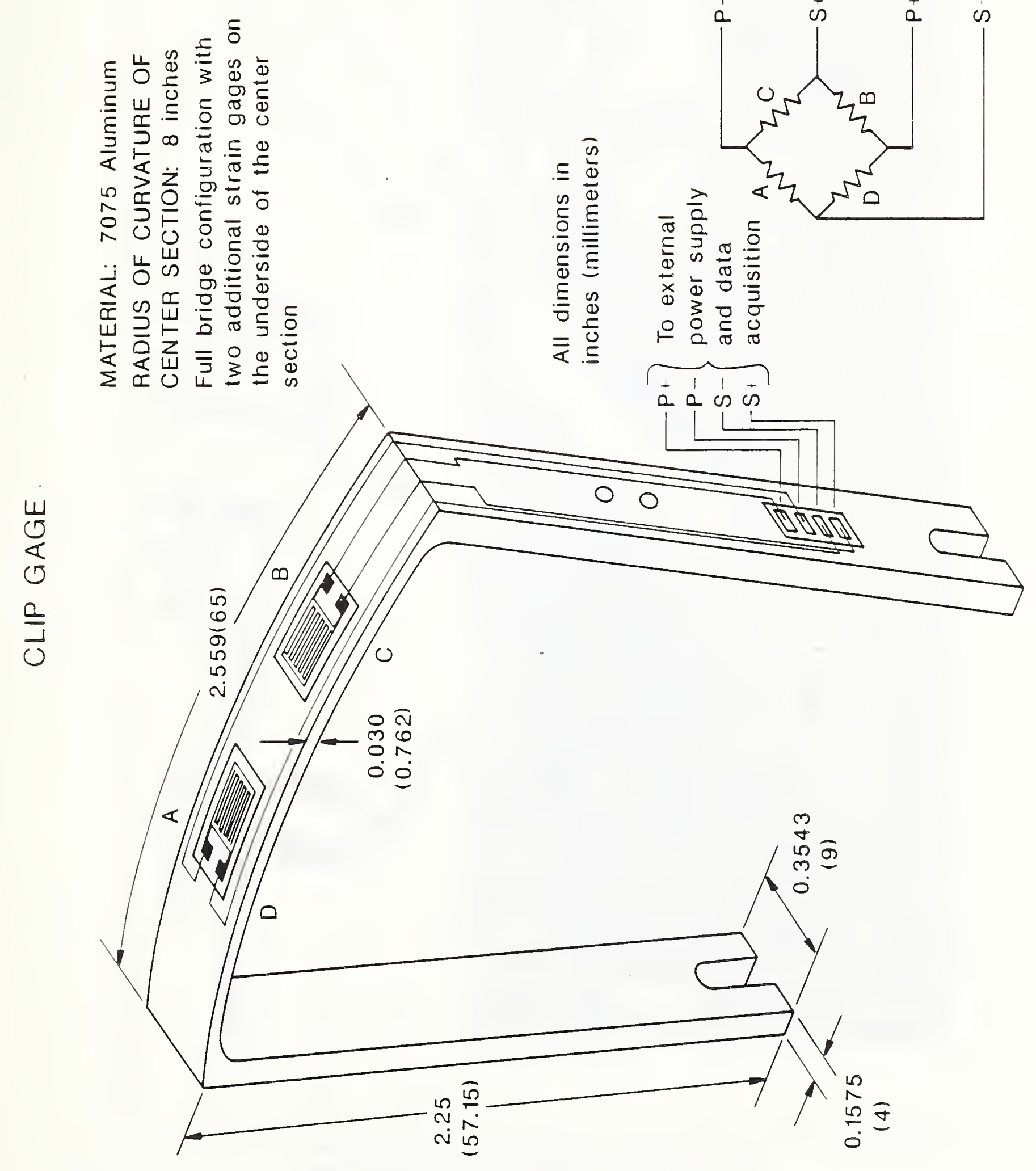

岂 


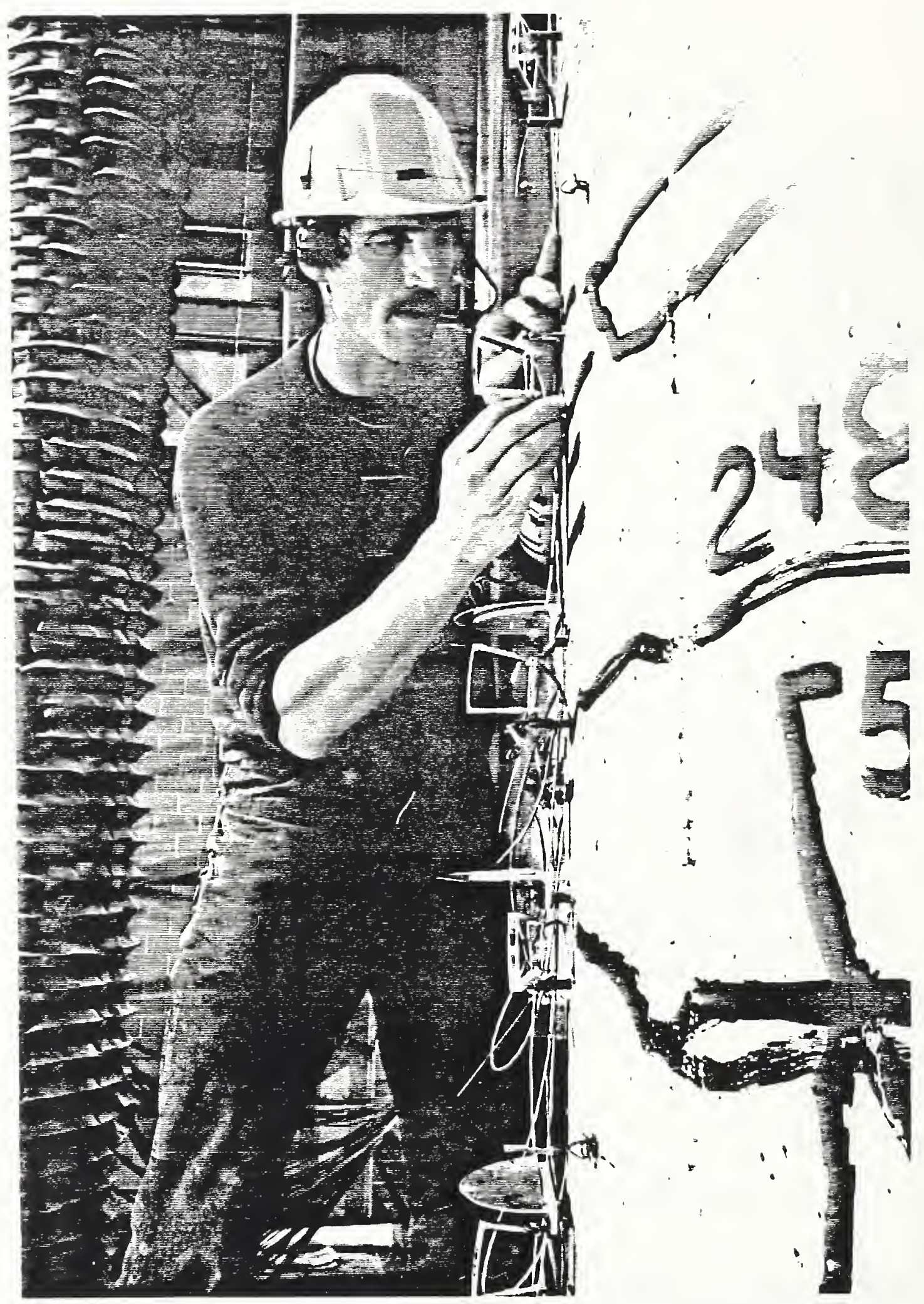

Figure A.50: Clip Gages being Mounted on East Face of Full-Scale Shear Column Specimen. 


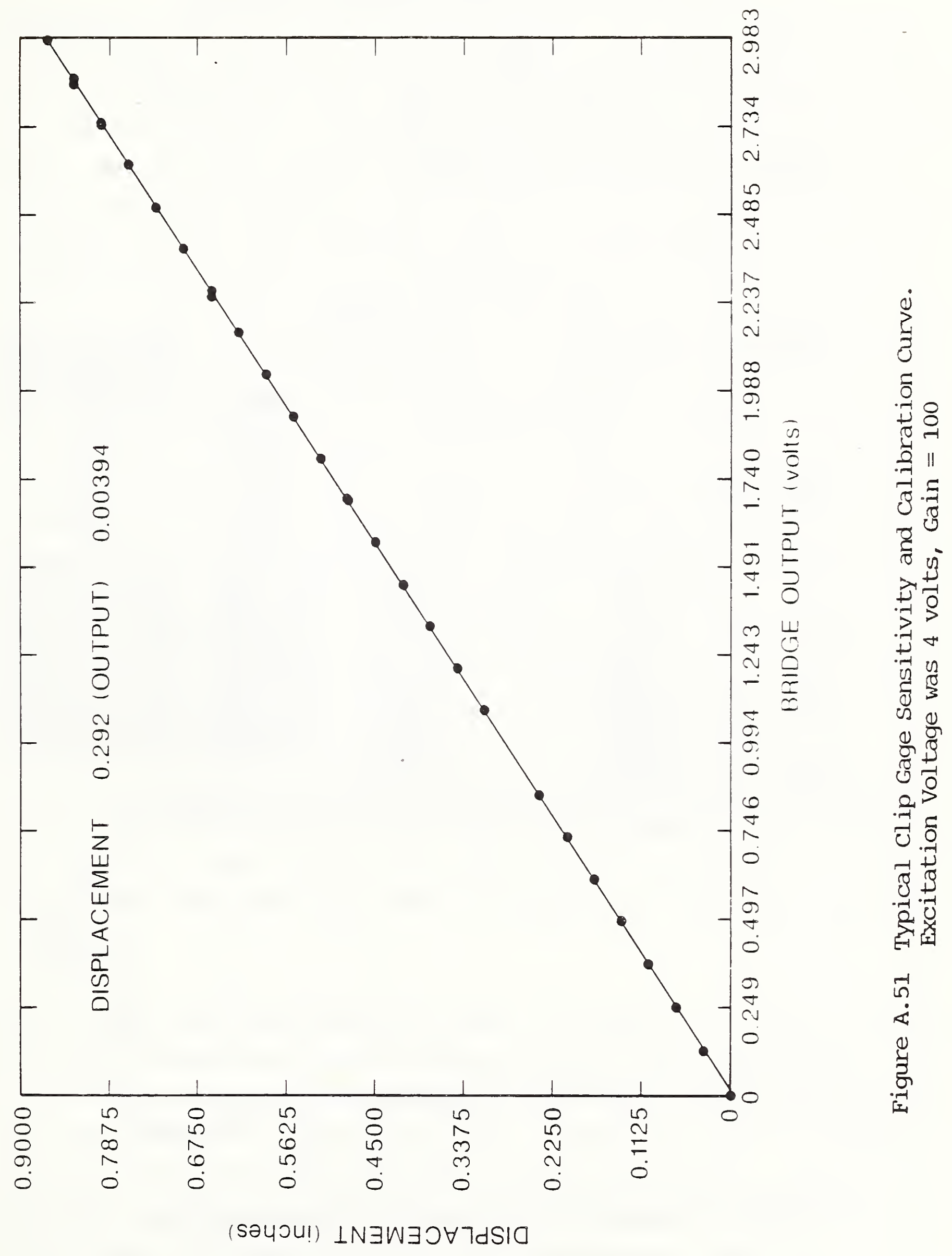


Locations of Clip Gages and Rotary Potentiometers for the Full-Scale Shear Column

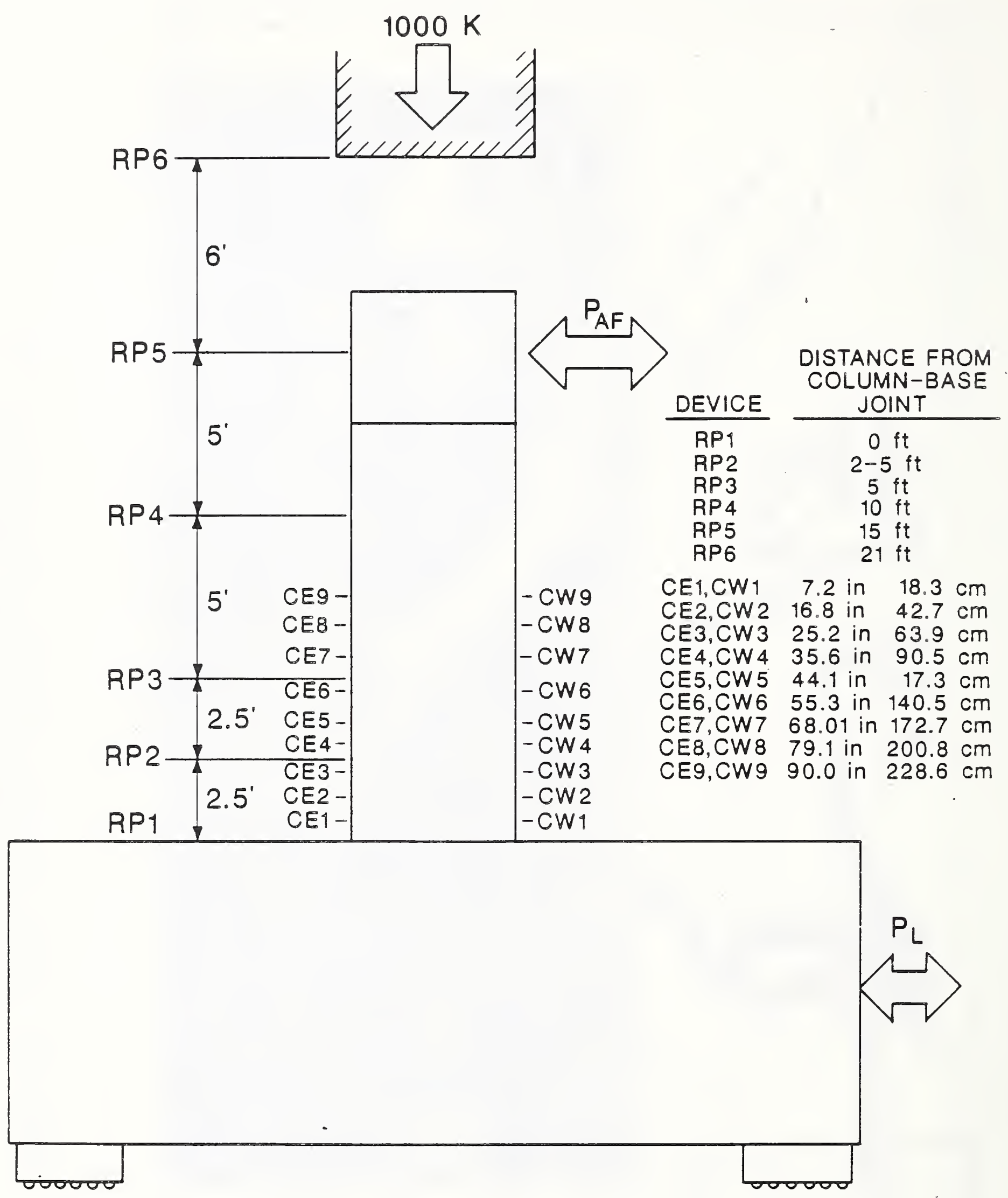

Figure A.52: Clip Gage Locations for Shear Column Test 
conducted to determine the methods available for such measurements. The initial design conditions were that each of the eight roller systems would need to be instrumented since final load distribution to each roller during the course of a test was not predictable; that the friction forces could be as high as 5z, and that service axial loads for each loadcell would be the 300 ton ( $2.7 \mathrm{MN}$ ) rated capacity of the rollers. As a result of the $5 \%$ friction assumption (which was the only number available at the time, since the coefficient of friction tests described in Section A.1.3 had not yet been conducted) each loadcell would have to handle maximum shearing loads of $30 \mathrm{kip}$ (133 KN), perpendicular to the primary instrumentation axis. A survey was made of existing commercial loadcells, including standard industrial axial cells, and low aspect "doughnut" cells, and it was concluded that such classical designs were not tolerant of high lateral load conditions. Furthermore, none could serve as shearing force transducers. The decision was thus made to pursue development of an in-house transducer which had high axial load capacity, high shear force capacity, low aspect ratio, and high sensitivity. The result is shown in Figures A.15 and A.16. This "flatcell" was designed as a monolithically milled vereendeel truss. Strain sensitivity was optimized through the use of a three dimensional finite element model and the resulting dimensions were $31 \times 12$ × 2 in. (770 x $300 \times 50 \mathrm{~mm}$ ). Machining limitations controlled the final design and the maximum achievable width was 6 in. (150 mm) width; hence two such units were needed for each roller system, with each cell rated at $300 \mathrm{kip}$ ( $1.3 \mathrm{MN}$ ) service capacity. Sixteen such devices were fabricated from 6061 T6 aluminum. Each unit weighed 17 Ib. $(7.7 \mathrm{~kg})$.

Each flatcell was instrumented as shown in Figure A.53. Two configurations were used. During the first full-scale (flexure) test web sections 2,6, and 10 (see Figure A.53) were instrumented at mid-height with flexure compensating strain gage pairs to monitor axial load. These six gages were connected in series to average the load along the length of the cell. Three additional independent strain gage pairs were mounted (see Figure A.53b) on the same web sections near the flange to pick up friction forces. This gave a total of 4 instrumentation channels per load cell. It was planned to average the three friction readings during an actual column test. By the time the first two 


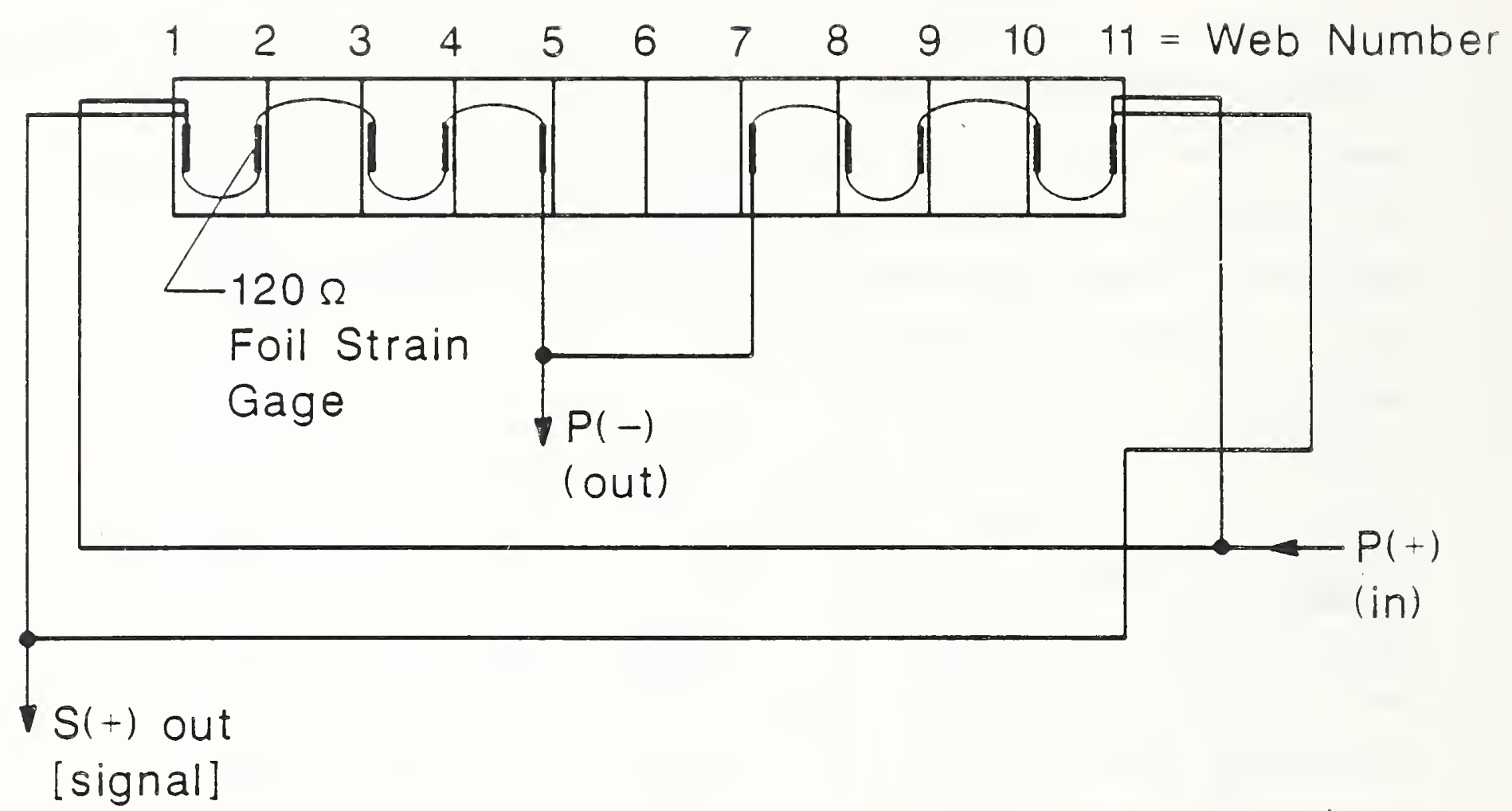

a) WIRING DIAGRAM, SECOND FULL-SCALE TEST

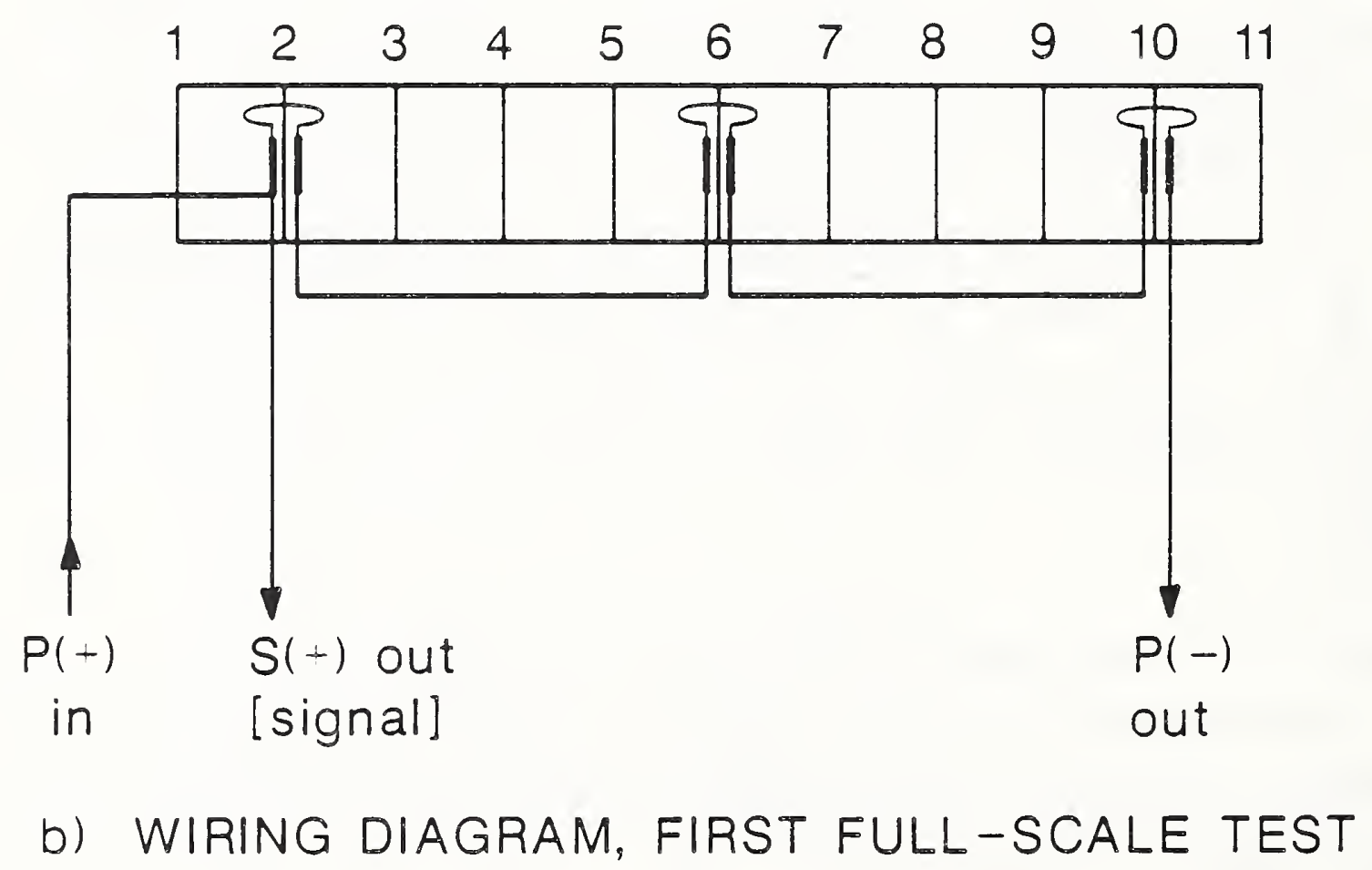

Figure A.53: Wiring Schematic (two versions) for Flatcells. 
prototype cells had been fabricated a friction test apparatus had been assembled (Figure A.12). Output response for the axial channels was linear with applied axial load, and insensitive to lateral displacement. But the measured friction-induced shearing strain did not correlate with the applied lateral load. In view of the accurate calibration curves which were obtained relating coefficient of friction with applied axial load a decision was made to proceed with the first (flexure) full-scale test with only the use of the axial load channels.

Once calibrated, a roller-loadcell stack was constructed as shown in Figure A.17, in which the loadcell was sandwiched between two ground (planar) 0.5 in. $(12 \mathrm{~mm}$ ) plates and placed on top of a $1 \mathrm{in.} \mathrm{(25} \mathrm{mm)} \mathrm{elastomeric} \mathrm{bridge} \mathrm{bearing}$ pad which was seated on top of the roller system. Each of the eight rollerloadcell stacks were covered with a sheet of plastic. Hydrostone grout was placed on top of the plastic and all eight rollers were positioned beneath the test specimen using preset stops. The specimen, which was being held aloft by means of hydraulic jacks at each corner, was then lowered until sufficient contact was made to extrude the grout completely over each top plate. The specimen was then locked at this position until the grout set, under the assumption that any surface irregularities would be eliminated and that each loadcell would see approximately equal load once the hydraulic supports were removed. This assumption proved to be substantially in error.

During the first full-scale test electronic problems developed with two of the axial load monitoring channels, one at each end of the specimen. This, unfortunately, meant no empirical determination of the vertical reaction forces nor the friction forces, since the reactions at all roller contacts were required. Column moment was therefore determined from top-of-column reactions.

It was felt, following examination of loadcell data from the first full-scale test prior to loss of the two chanels described above, that the use of a series gaging system was too prone to failure, since local yielding of one web section (perhaps due to surface irregularities not compensated for with the grout) might lead to failure of a gage, or might not be picked up at all. A 
revised, semi-redundant gaging technique was used for the second full scale test, as shown in Figure A.53a. All loadcells were re-instrumented and calibrated both with and without simulated surface roughness in the loading head of the calibration test machine. The new cells exhibited linear output (see Figure A.54) and were relatively insensitive to surface irregularities. Performance of these cells during the second full-scale test was substantially improved and statics (sum of vertical forces) was met with generally acceptable tolerances. Unfortunately, no data was available beyond $2 \Delta y$ owing to failure of a circuit breaker supplying power to some 32 channels, most of which were associated with the vertical load flatcells. Column moment, as for the first test, was therefore determined on the basis of topof-column reactions. It was possible, however, using the available good flatcell data to make some interesting observations regarding friction force, since average friction force could also be calculated by knowing the reaction frame force, the lateral ram force, and the load resisted by bending of the test machine. A discussion of this topic is presented in Chapter 4.

Too often discussion of ideas which do not work is avoided in scientific reports. The above difficulties are described with openess for the benefit of those researchers who may need to monitor reactions where commercially available hardware is not suitable. Suggestions for improved methods of determining reactions are discussed in Appendix $B$.

\section{A.6.3 Tie-Back Frame}

As a backup to the flatcells, the tie-back "A-Frame" shown in Figure A.23 was instrumented with four full-bridge load cells. A typical calibration curve for one of the four cells is shown in Figure A.55. From statics, the moment at the base of the column could be determined by knowing the A-Frame load, the lateral displacement and applied axial load (for determination of p-delta moment), and the lateral load dissipated into the test machine. During both full scale tests, lateral displacement of the vertical loading head was monitored. This displacement, in conjunction with specific bending stiffness calibrations conducted for the vertical test machine in the test configuration for each specimen, allowed for calculation of lateral load resisted by the 


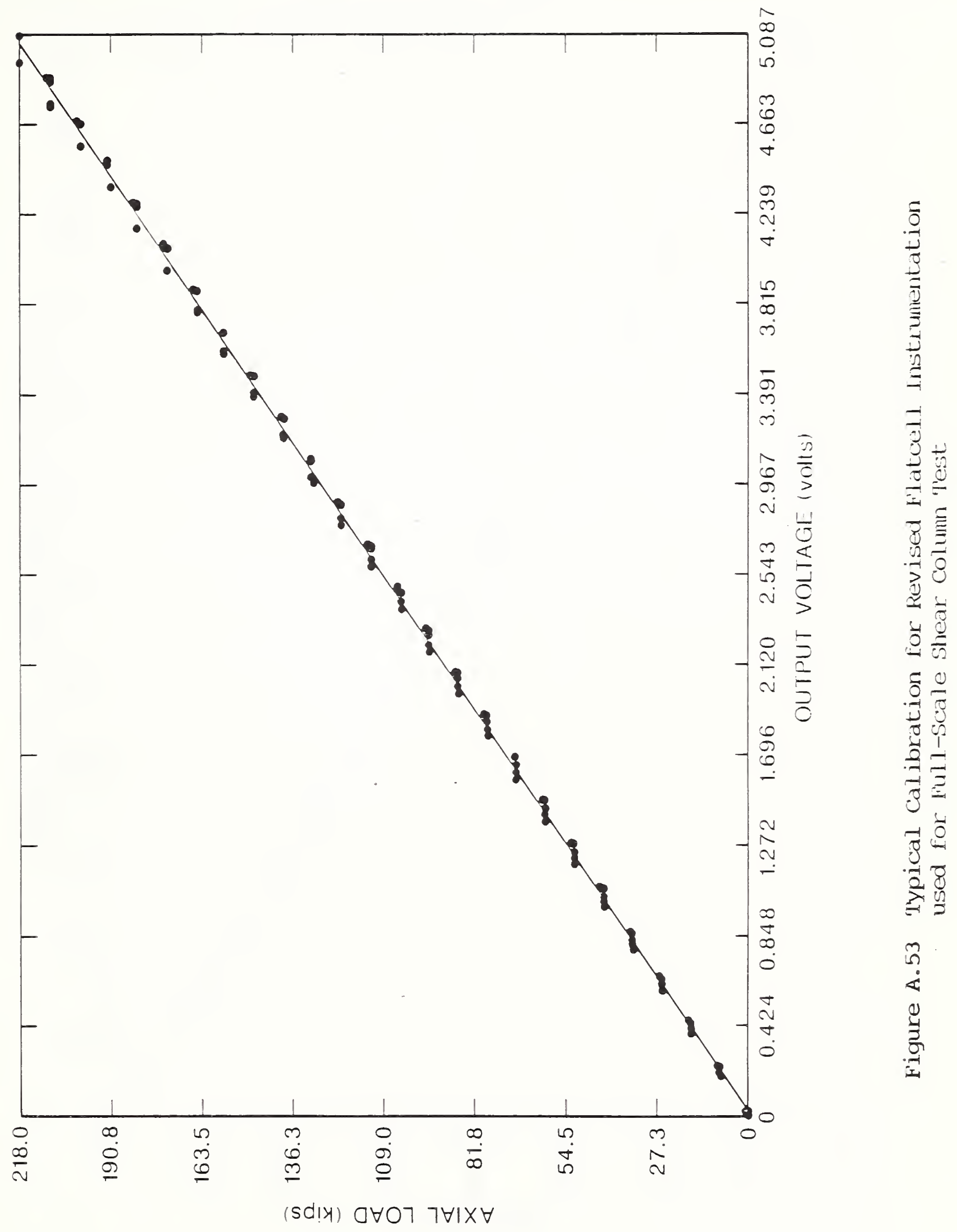




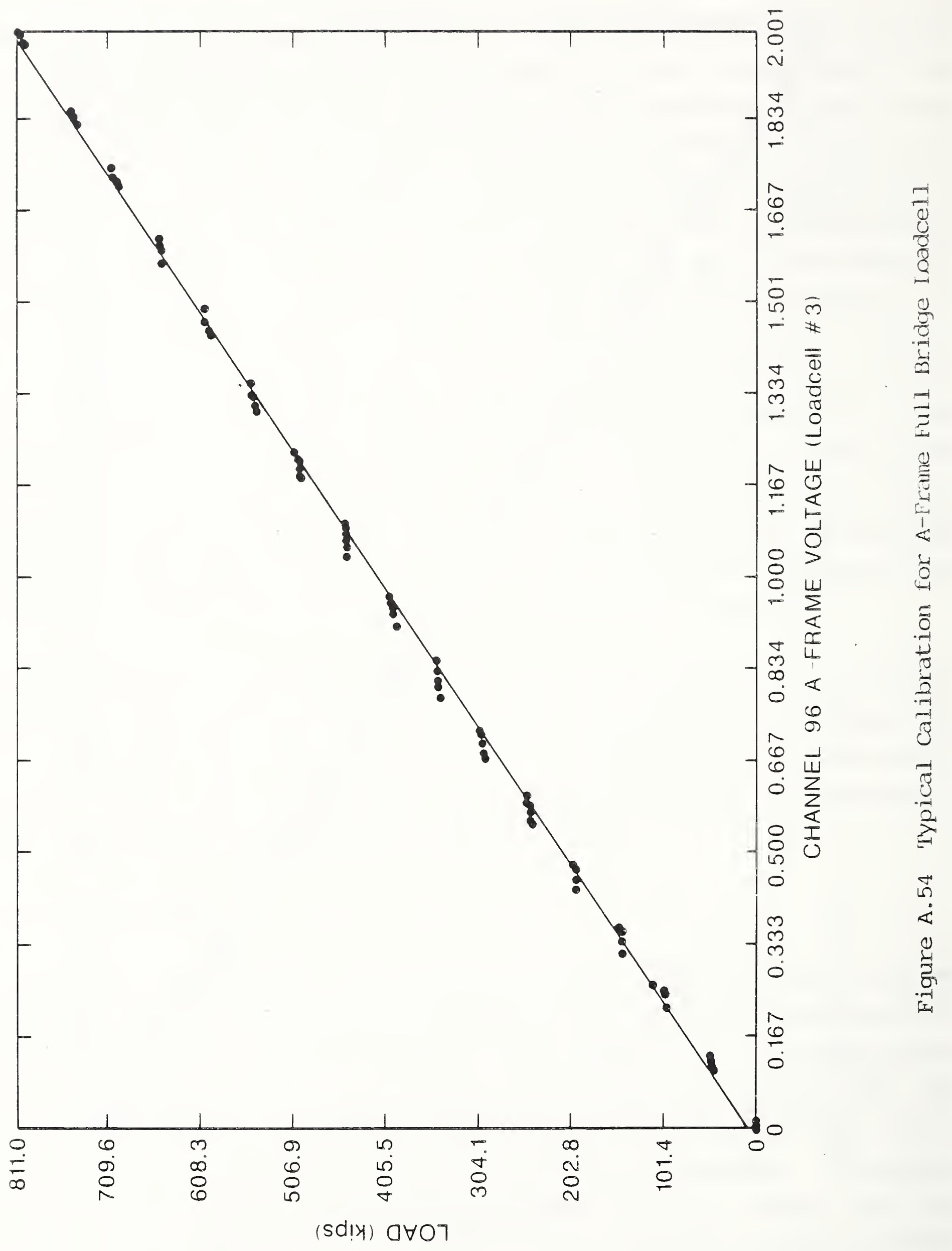


test machine. The above approach was ultimately used to determine column moment in lieu of direct friction measurements. 


\section{APPENDIX B}

\section{Recommendations for Future Full-Scale Test Apparatus and Procedures}

As stated at the beginning of this report, conclusions were drawn from comparisons between single prototpye specimens and models. Accurate determination of the behavior of reinforced concrete elements from experimental data requires a sufficient number of tests to establish statistical bounds on the conclusions. For lifeline structures, such as bridge columns, it would seem prudent to conduct further tests for verification of the conclusions regarding similitude. The eventual payoff will be the ability to use cost-effective models for prediction of prototype behavior within specified limits of confidence. This would eliminate the need for expensive verification (prototype) tests. The need for statistical verification of the results presented in this report is particularly important with regards to the conclusions concerning model construction materials (i.e. that models constructed from small aggregate ready-mix concrete apparently out-performed the microconcrete models).

When amortized over the entire cost of the program, including both labor and hardware expenses, each prototype test cost approximately $\$ 500,000$ in 1986 dollars. From the experience gained from these tests, it is believed that production testing of prototypes could take place at substantially lower costs.

Early in the test program it was recognized that substantial labor and materials costs were tied up in the fabrication of the massive mobile foundation structure for each specimen. During testing this base block usually developed only minor cracking and failure was localized in the column itself and to a depth of a few inches into the base block. Strain gage data indicated that the depth of longitudinal column reinforcement yielding was limited to within $0.8 \mathrm{D}$ into the foundation. Thus, pullout of longitudinal reinforcing bars was not a factor, given the embedment depths presently required by CALTRANS specifications. The implication is that the state of stress in the foundation can be neglected in the assessent of column 
performance, provided full development of longitudinal reinforcement is insured. This permits a reassessment of construction techniques for the full scale specimen.

Given the foundation block does not effect to the performance of the column, that it constitutes $85 \%$ of the total weight of each specimen, and that the block must be demolished and disposed of at great cost at the conclusion of each test, it would seem advantageous to either eliminate it through the use of alternative reaction fixtures or reuse portions of it for subsequent tests. Figure B.I and B.2 show one possible method of making active use of the majority of the specimen weight. Here, only the column itself and a thin slice of the base block corresponding to the width of the column, is cast for each full scale specimen. The remainder of the foundation block is comprised of two precast blocks with shear keys on the interior faces to which the column will be match cast. In fact, since the geometry of this joint does not change from specimen to specimen, actual match casting is not required. Lightweight metal forms can be made to serve the same purpose, allowing fast tracking of casting and testing operations.

If it is assumed that the moving specimen concept is to be retained, the match cast base blocks and central column specimen may then be made to perform as a monolithic unit by means of lateral post-tensioning of the base block, as shown in Figure B.1. Consider the state of stress in such a situation. First, the post-tensioning force in the base block must be sufficient to prevent tension at maximum fiber distance along the two match-cast joints. Figure B.2 shows the forces at work. $M$ is the maximum moment developed by the test column prior to failure and $P$ is the applied axial load. The base block is "b" units wide by "h" units high. The governing equation then becomes:
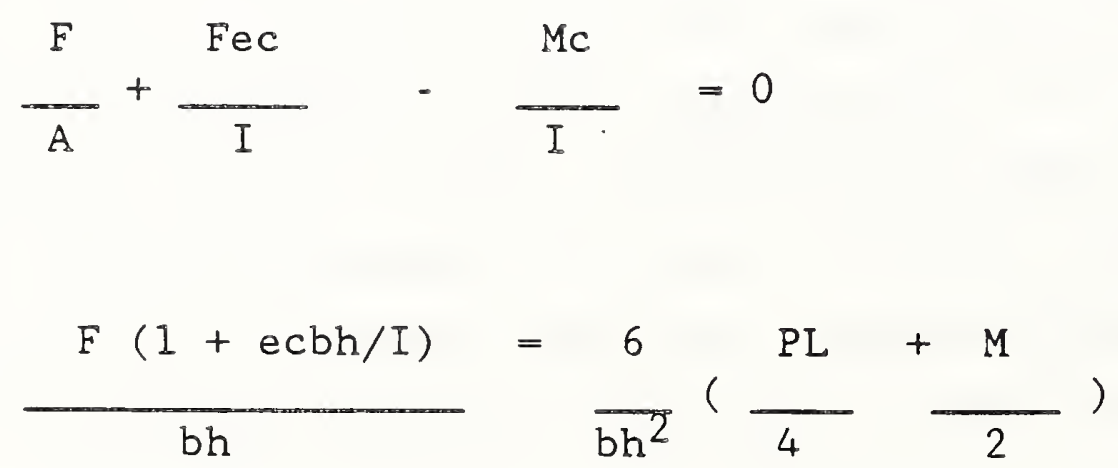


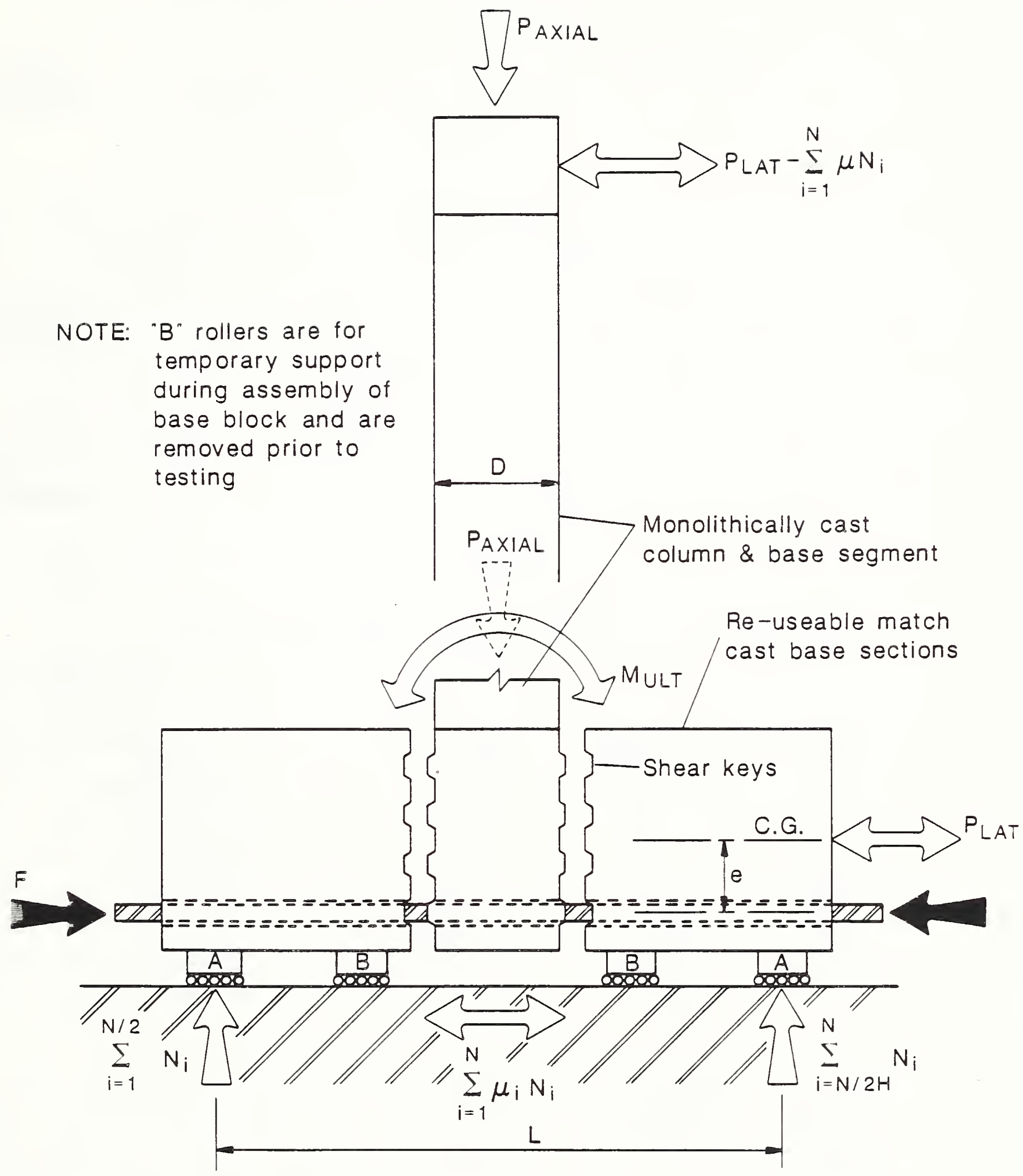

Figure B.1 Match-cast Specimen Concept 


\section{MOMENTS ACTING ON FOUNDATION BLOCK}

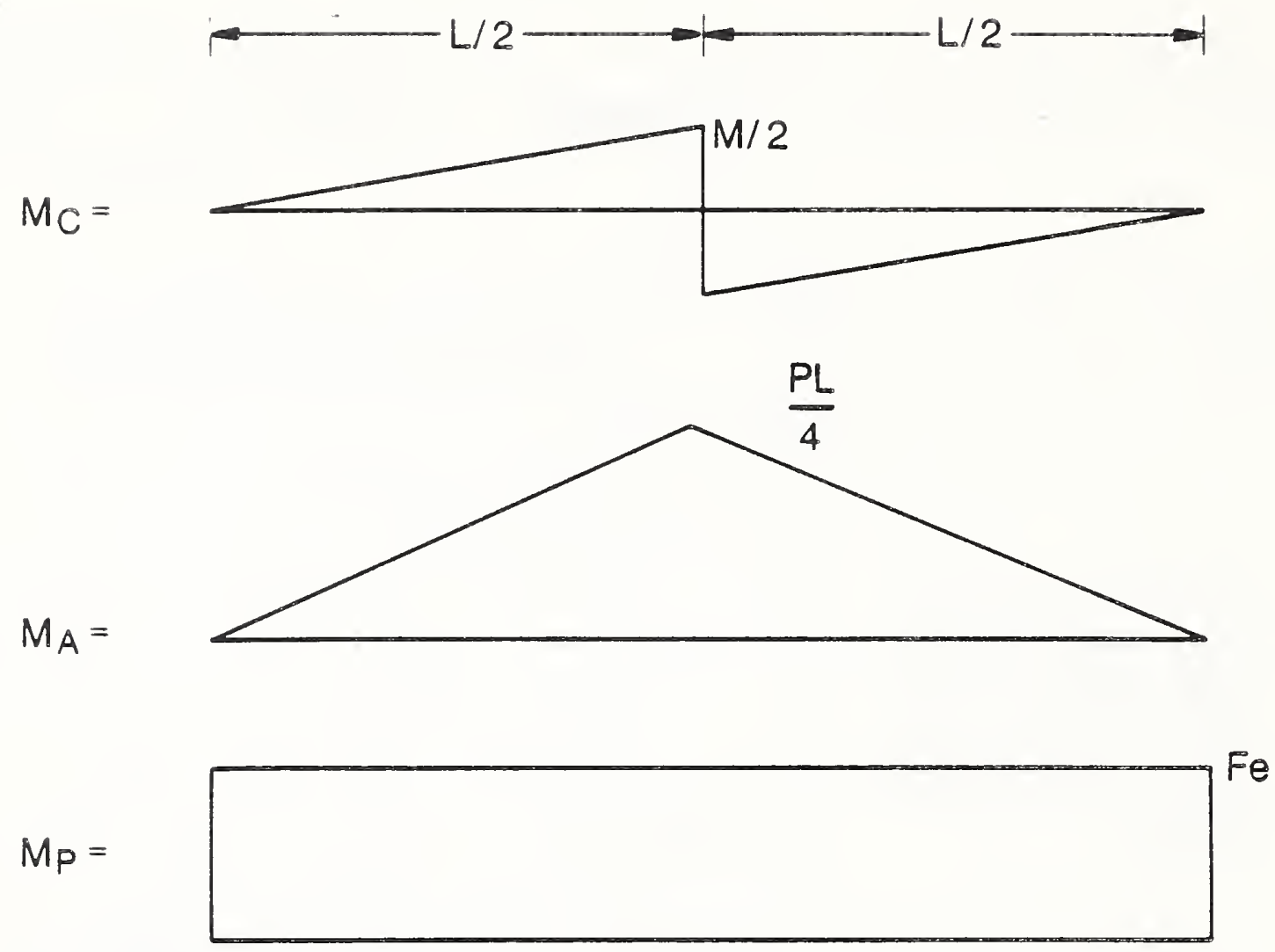

Column

Moment

Axial Load

Moment

Prestress

Moment

FOUNDATION BLOCK: BENDING \& AXIAL INDUCED STRESSES

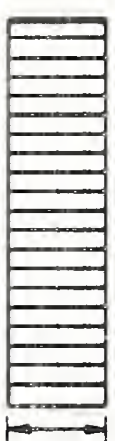

F/A

Due to prestress direct load effect

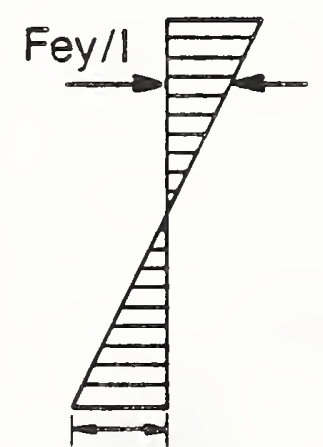

$\frac{\mathrm{FeC}}{\mathrm{I}}$

Due to prestress eccentricity

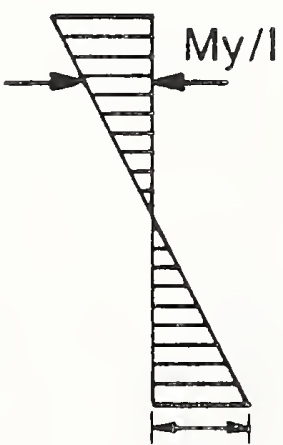

$\frac{M_{C}}{1}$

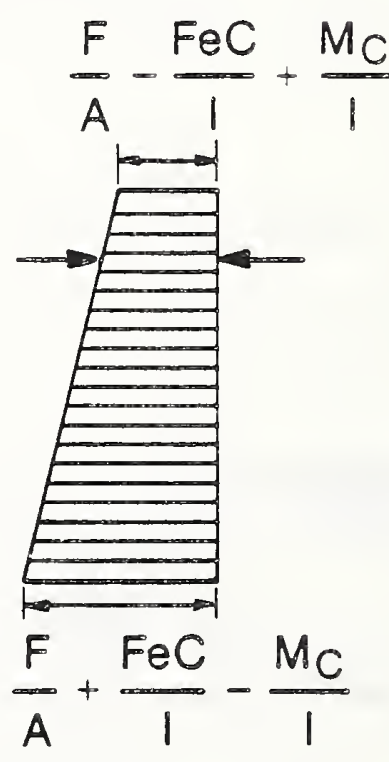

Due to extemal moment $M_{A}+M_{C}$

Figure B.2 Moments Acting on Foundation Block for Match-Cast Specimen Using Roller Supports 


$$
F=\frac{\frac{6}{h}\left(\frac{P L}{4}+\frac{M}{2}\right)}{[1+6 e / h]}
$$

For axial loads of $3000 \mathrm{kip}(13.4 \mathrm{MN})$, the corresponding maximum column moment

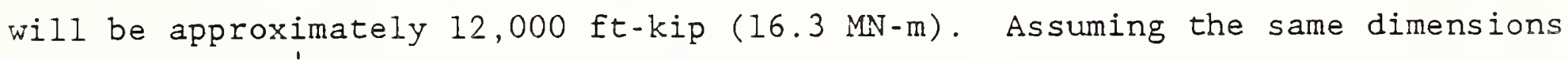
of the prototype specimens for $\mathrm{L}, \mathrm{b}, \mathrm{e}$, and $\mathrm{h}(23.4,8.0,4.625$, and 9.25 ft. $[7.1,2.4,1.41$, and $2.28 \mathrm{~m}]$ respectively), the required lateral posttensioning force is $4125 \mathrm{kip}(18.4 \mathrm{MN})$. In terms of actual hardware, this level of force could be applied by using 27 of the $1-3 / 8$ inch (35 mm) Dywidag threadbars similar to those used for hardware connections in the present test program. Post-tensioning of the precast segments together would likely require 3 days of labor, a small price to pay considering the vast reduction in effort compared to the present method.

Recall that the moving specimen concept was largely developed as a means of utilizing an existing test apparatus (namely the NBS 12000 kip vertical test machine) to the fullest possible extend in order to reduce program costs. The above calculations indicate, clearly, that the moving specimen concept does not lend itself easily to the notion of mass production testing. If one started with a clean slate and could completely dissregard the particular attributes of existing structural test facilities, what would be needed to permit rapid, cost effective testing of bridge columns similar to those described in this report?

First, consider the mechanics of the three part foundation block again. The majority of the lateral post-tensioning requirement, as defined in the above calculations, results from the need to resist the large moments and shear forces set up between the roller supports caused by the column axial load. If the specimen rested against a reaction surface (as the 1/6-scale model specimens did in the present study) then lateral post-tensioning would only need to counteract bending stresses set up by the column base moment 
$\grave{c}$

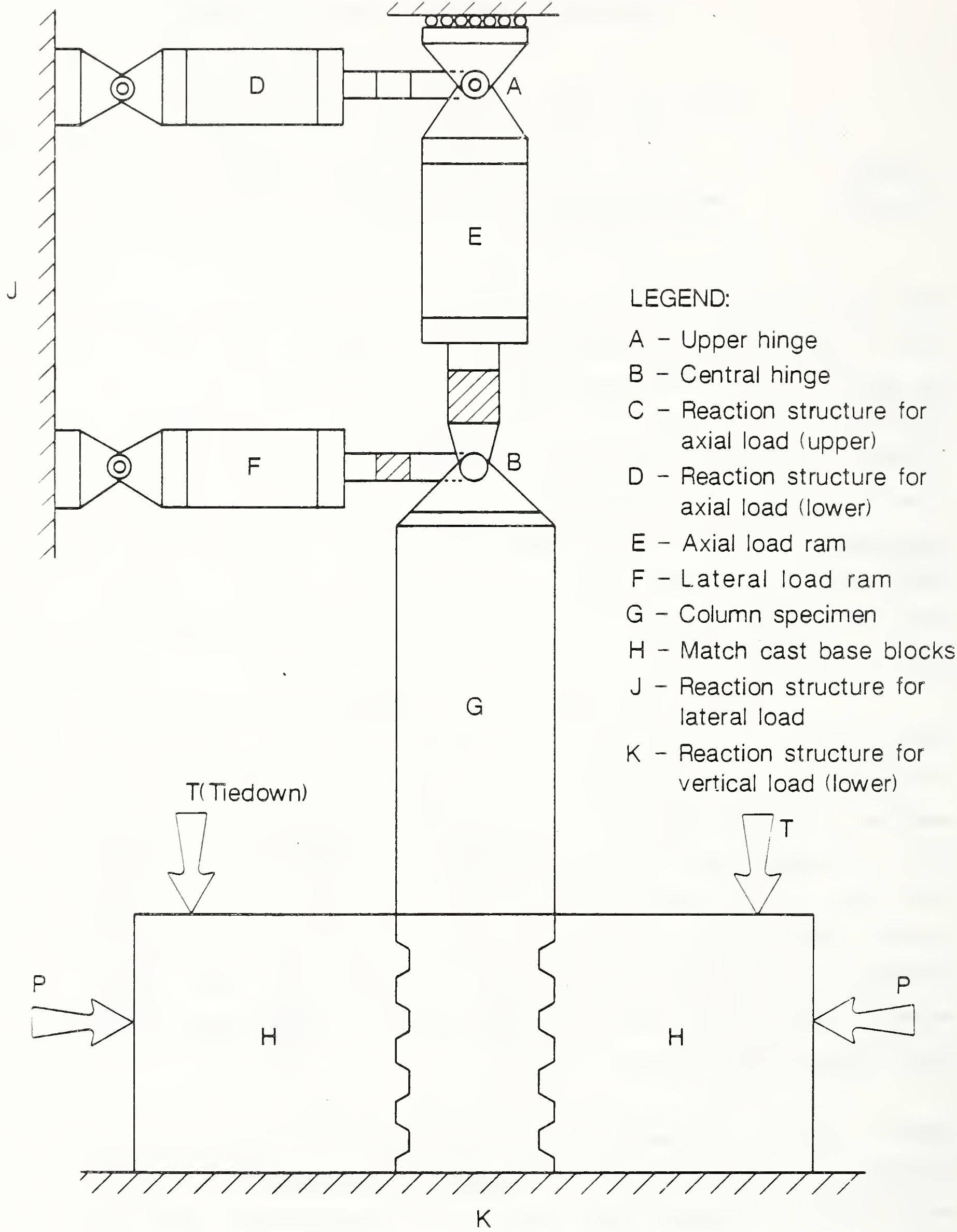

Figure B.3 Alternative Servo-Mechanical Method for Maintaining Axial Load in Vertical Plane 
during testing. Surprisingly, this situation does not greatly reduce the number of post-tensioning rod required. The reason is that without the large flexural compression of the upper half of the block (previously provided by the axial load) eccentric prestressing techniques cannot be used. The Fec/I term in equation Bl vanishes, as does the PL/4 term, and M must be considered for both clockwise and counterclockwise directions. This requirement calls for stressing of 23 bars, a minor improvement over the previously derived 27 bars. Note that in this case the base block would also have to be transversely post-tensioned to the reaction surface (see Figure B.3) to prevent sliding of the specimen under the influence of lateral test loads. Transverse posttensioning would also be needed to prevent foundation uplift in the event that the specimen is not tested in the upright position. Further discussion on this latter option is presented below.

As described earlier in this report, the idea of applying all column forces to the top of the column has substantial merit, and was the method of load application for the model tests in which a computer-controlled loading head was employed. If all column loads can be applied through a coincident hinge at the top of the column, many sources for error are eliminated and direct readings may be made of lateral and vertical loads by means of in-line axial load cells. Friction effects are also eliminated. Certain important considerations still exist, however.

Recall that for realistic simulation of column axial (gravity) load during an earthquake it is necessary to constantly maintain the load vector parallel to the vertical plane. A "follower" load, such as might be achieved through the use of a central axial post-tensioning tendon extending through the middle of the column, does not accurately reproduce this loading state. Nor would the use of a simple hinged actuator operating under load control without a special geometric feedback feature in the control 100p. These three cases are shown graphically in Figure B.4. The above distinctions are drawn because in-situ axial load for a bridge column is due to the dead weight of the superstructure. The load path is always vertical and can give rise to significant $P-\Delta$ effects which serve to accelerate failure under seismic load. 


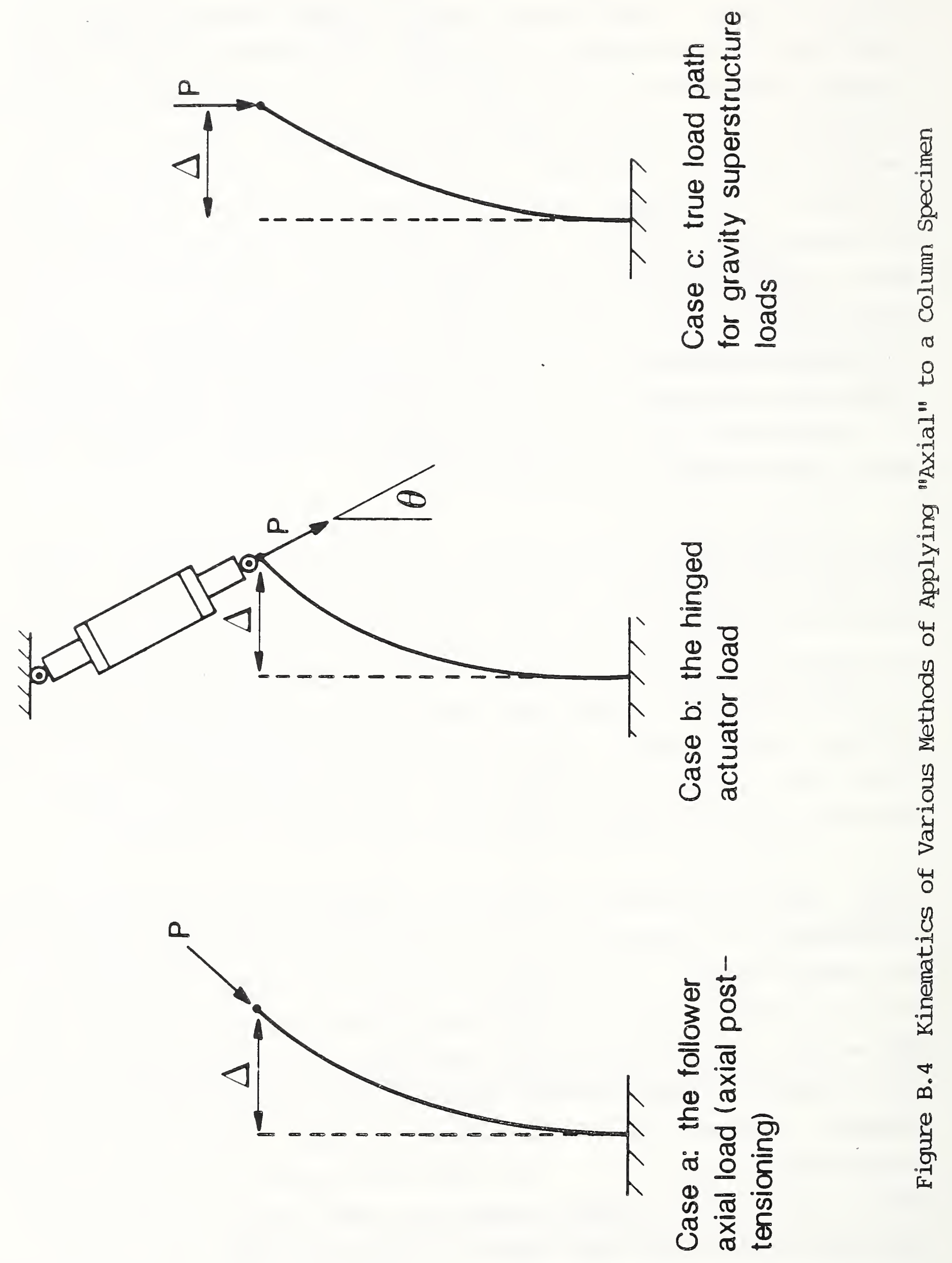


To ignore this fact during experimental testing would lead to Iiberal estimations of energy absorption capacity.

For full-scale tests, two variations of a simple arrangement, such as shown in Figures B. 3 and B.5 offer methods for constructing a traveling load head. In the first case, three servo-hydraulic actuators are used along with two special hinges which permit coincident application of lateral and axial loads to the column head. The two lateral actuators are driven by the same displacement control signal, i.e. they both extend and retract the same distance in concert during the course of a test. The bottom actuator (E) must provide the lateral force necessary to fail the column; the top actuator (D) need only overcome the friction force set up by the roller support at the top hinge (A). The axial load actuator (which could, in fact, be a simple single acting compression jack operated under variable drive pressure control [load control requires a double acting jack]) is connected to both the top-ofcolumn hinge as well as to the top hinge (A) which bears against a reaction surface with a roller support system (which can in all respects be similar to the roller transport systems described in this report). The upper lateral actuator moves the top of the axial load actuator the same amount as the lateral load ram (E) such that axial load actuator always remains in the vertical plane.

This method requires the use of some sophisticated joints which would have to be custom fabricated (and therefore costly) as well as three expensive actuators. Furthermore, the upper reaction surface represents a substantial engineering problem since a stiff overhead frame would have to be constructed. On the positive side, no sophisticated control system is necessary to conduct these tests: a simple, commonly available servocontroller can be used to maintain load control on the axial load ram while identical displacement control signals can be sent to the two lateral actuators. No geometry corrections are necessary in the interpretation of the results and the loadcell readouts represent true values for axial and lateral load, as well as direct computation of column moment. 
A physically simpler system is presented in Figure B.5. Here only two servocontrolled double-acting actuators are employed, each permanently attached to a reaction surface and hinged at both ends. This is precisely the situation mentioned above in which special consideration of the load system geometry must be accounted for before sending a control signal to an actuator. The situation is shown in Figure B.4, case b, where it can be seen that as the top of the column is displaced laterally, the finite angle $\theta$ between the vertical axis and the instantaneous line of action of the axial load actuator gives rise to both vertical and horizontal loads. However, this can be compensated by providing the following control signals to each actuator:

$$
\begin{gathered}
P_{1}(i)=\frac{P}{\cos (\theta)}=\frac{P}{\cos \left[\sin ^{-1}\left(\frac{\Delta_{2}}{L_{1}+\Delta_{1}}\right)\right]} \\
\Delta_{2}(i)=\text { Iateral ram displacement at load stage "i" (inch) }
\end{gathered}
$$

where

$$
\begin{aligned}
P_{I}(i)= & \text { axial ram force (kip) command signal at load stage "i" under load } \\
& \text { control. While shown here as a force, it would actually have to } \\
& \text { be a digitally synthesized voltage sent to the servo } \\
& \text { controller via a DAC unit on the computer. } \\
\Delta_{1}= & \text { piston extension in axial ram at load stage "i" (inch). Again, } \\
& \text { this would be sent to the servo controller as a digitally } \\
& \text { synthesized voltage. } \\
P= & \text { desired constant (load control) axial column load (kip) } \\
L_{1}= & \text { hinge-to-hinge lenth of axial load actuator prior to commencement } \\
& \text { of testing (inch) }
\end{aligned}
$$

Actual implementation of the above algorithm would involve breaking each desired lateral displacement move into many smaller moves (say 50) and iteratively converging at each step to determine the required command signal for the axial load ram so that constant vertical load is maintained. A computerized data acquisition system is required to monitor load and displacement feedback for both rams, as well as two channels of digital-to 


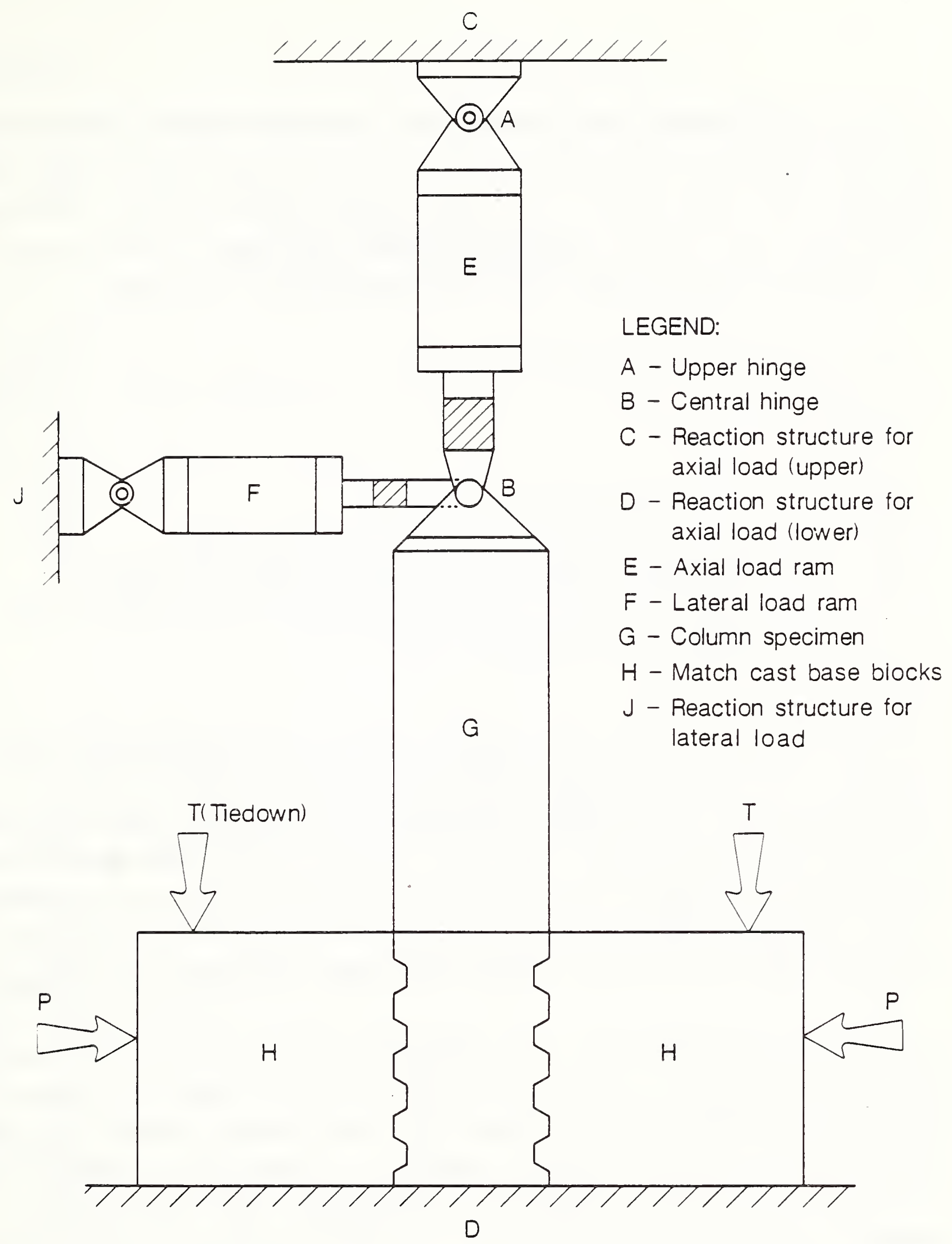

Figure B.5 Simplified Test Apparatus Employing Computer-controlled Actuators 
-analog output to the servo-controllers. Note that the the lateral actuator must be capable of resisting potentially the large lateral load component generated by the axial load ram during large lateral displacements, particularly as column resistance begins to drop. Note that in the calculation of column moment there are three terms, as follows:

$M_{\text {total }}=P_{2} h_{c}+P_{1} \sin (\theta)+P \Delta_{2}$

Where:

$\mathrm{M}_{\text {total }}=$ Maximum Column Moment (kip-ft)

$\mathrm{P}_{2} \quad=$ Load Cell Reading from Lateral Actuator (kip)

$\mathrm{P}_{1} \quad$ Load Cell Reading from Vertical Actuator (kip)

$h_{c}=$ Column Height from Base to Top-of-column Hinge (feet)

$\theta$ = Rotation Angle of Vertical Actuator from the vertical plane (degrees, from equation [4])

$\Delta_{2} \quad=$ Lateral Actuator Displacement (feet)

Considering the low cost of personal computer (PC) based data acquisition systems, for which analog-to-digital converters (ADC), digital-to-analog converters (DAC), and signal conditioning electronics are all presently available as plug-in cards, the cost savings of the above approach will be principally determined by the difference between the cost of programming the control software and the funds saved by the elimination of expensive servohydraulic apparatus and test fixtures and their associated maintenance costs.

It should be noted that the test apparatus shown in Figure B.5 could equally well be constructed in plan view rather than vertically as implied above. This would eliminate access problems and would permit the use of a facility with extensive tie-down floor capacity. Overturning moments would be minimized in reaction fixtures. Furthermore, the requirement for large overhead spaces would be obviated. Since individual specimen components would be substantially lighter, a more versatile transport system, based on air bearings, would be possible in lieu of a rail system. 


\section{APPENDIX C}

Stress Strain Plots for Model and Prototype Reinforcing Steel

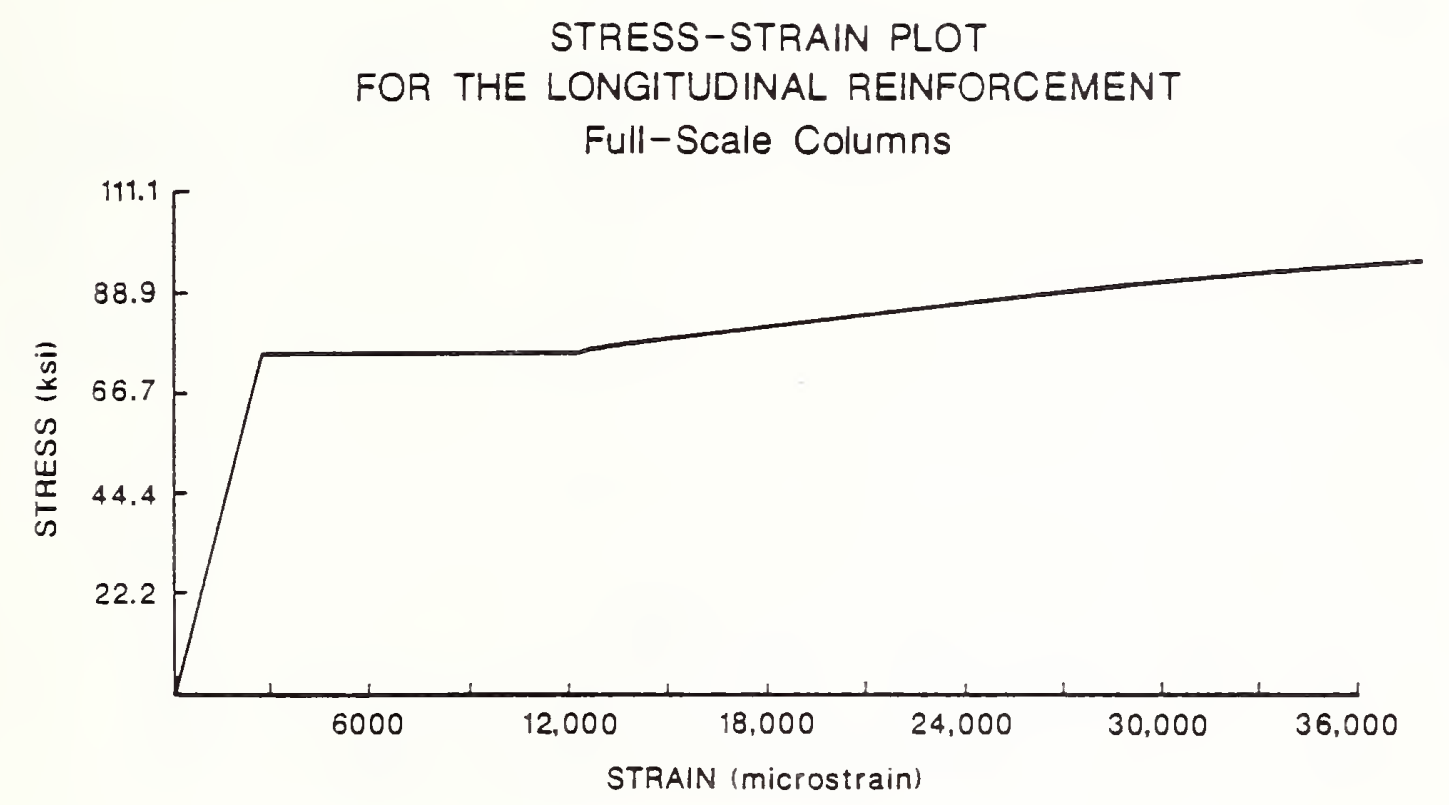

Figure C.1: Longitudinal Reinforcement, Ful1-6rale Col.mns

LONGITUDINAL STEEL FOR MODEL COLUMNS

(from straight bar specimens)

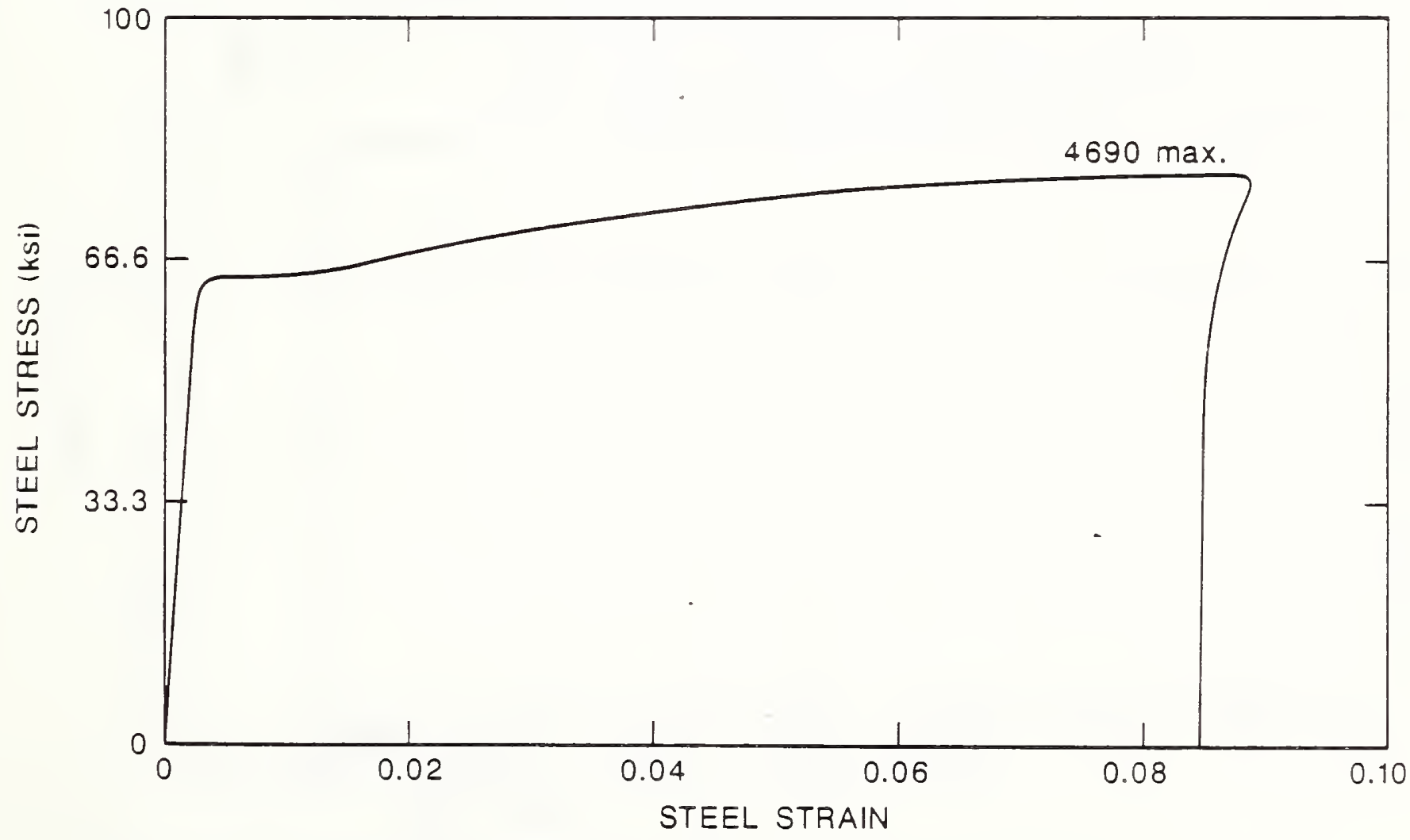

Figure C.2: Longitudinal Reinforcement, Model Columns 
SPIRAL REINFORCEMENT FOR FULL-SCALE FLEXURE COLUMN

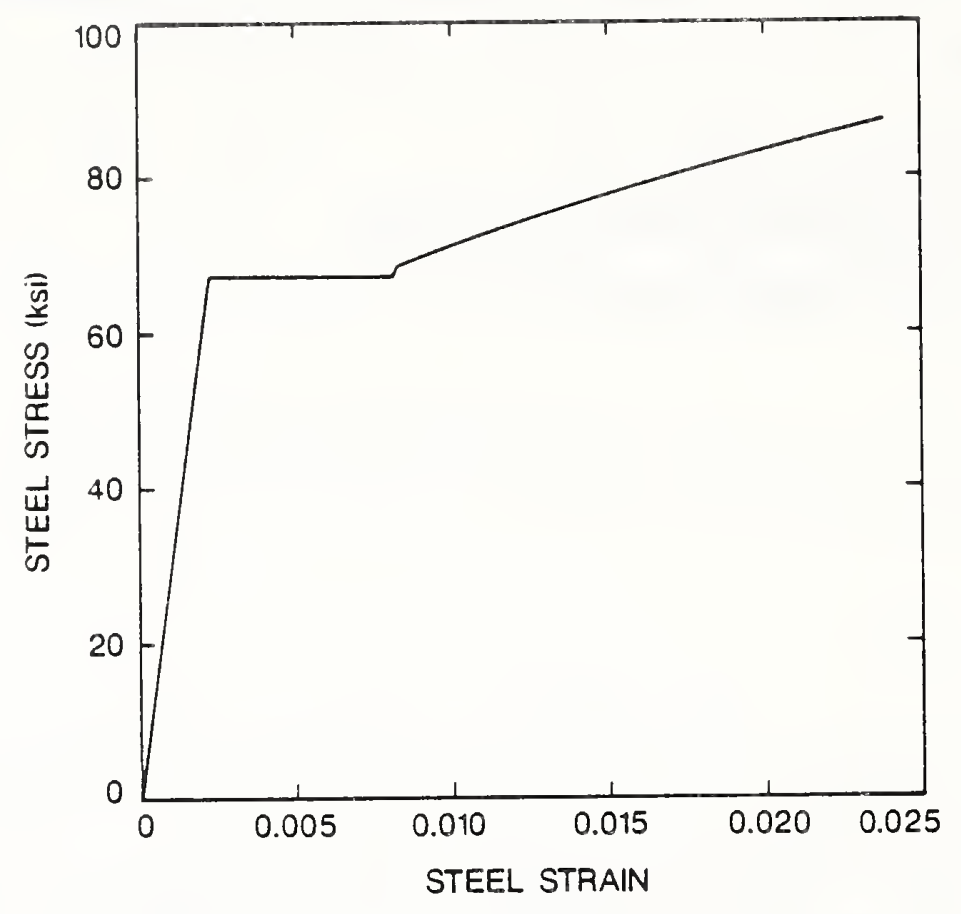

Figure C.3: Spiral Reinforcement, Full-Scale Flexure Columns

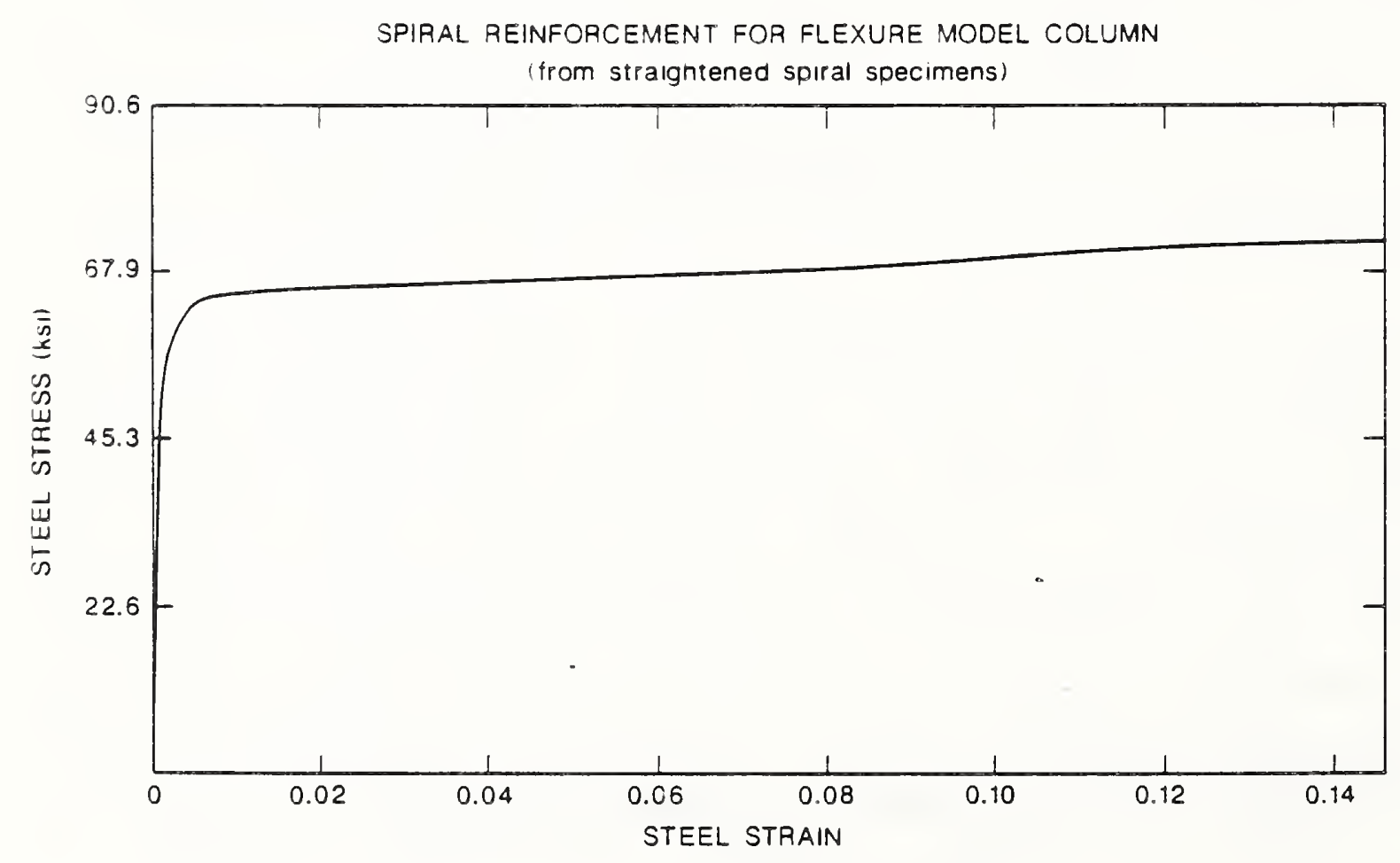

Figure C.4: Spiral Reinforcement, Model Flexure Columns 
SPIRAL REINFORCEMENT FOR FULL-SCALE SHEAR COLUMNS (from straightened spiral specimens)

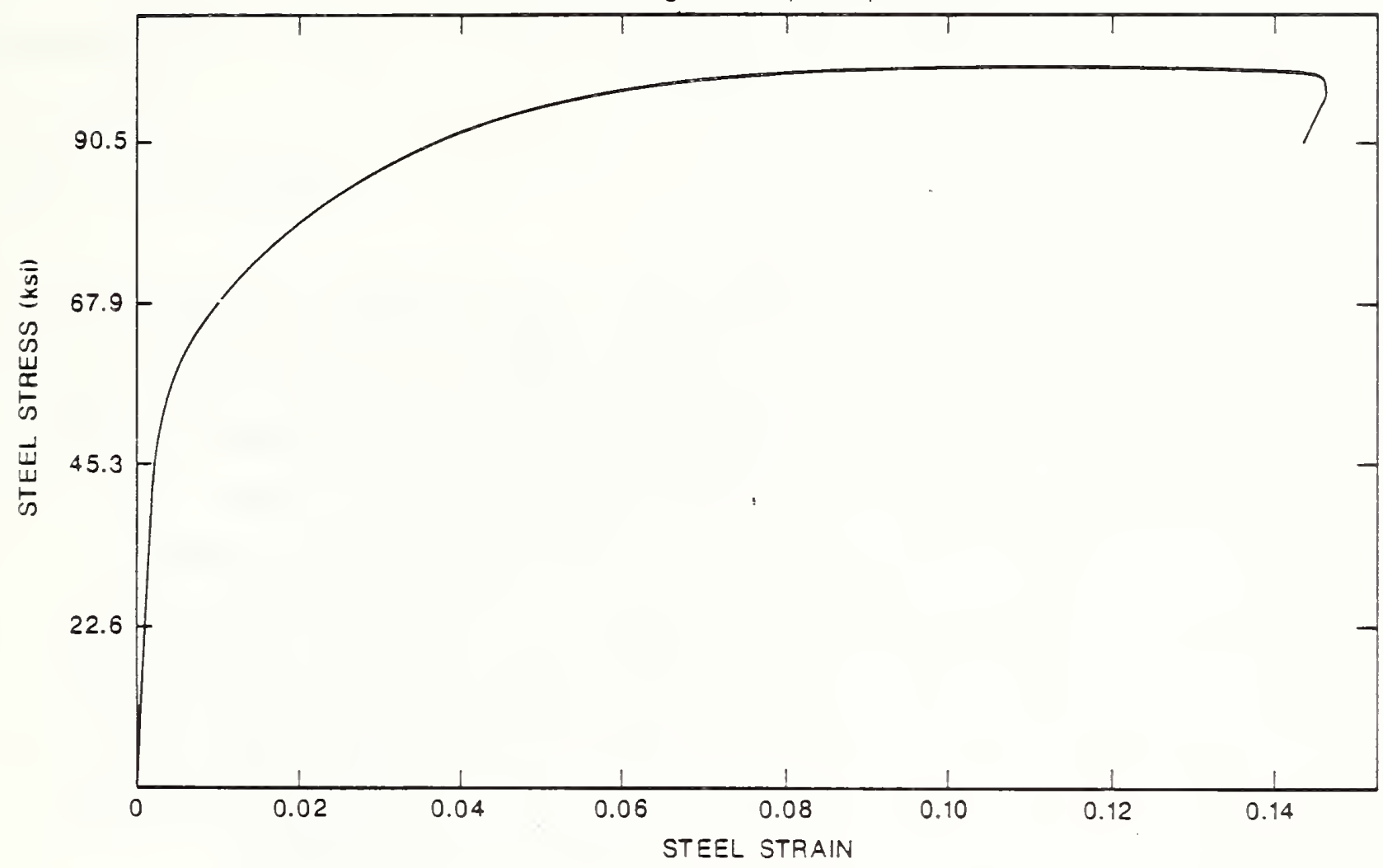

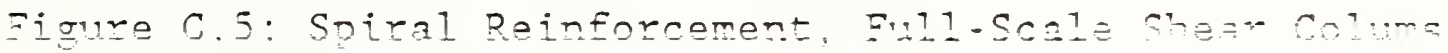

SPIRAL REINFORCEMENT FOR SHEAR MODEL COLUMNS

from straightened spiral specimens)

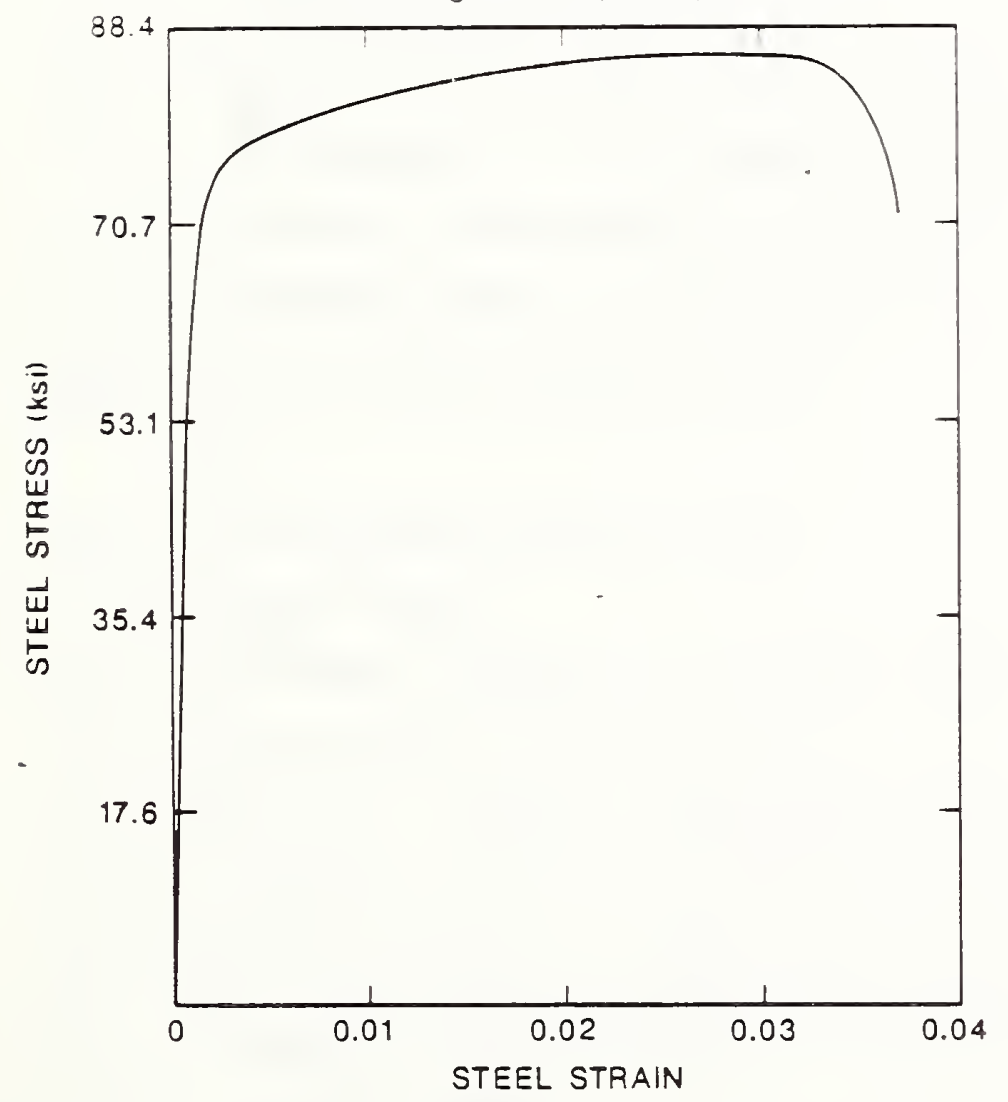

Figure U.o: jusral Reinforcement, Model Shear Columns 


\section{APPENDIX D}

List of Symbols

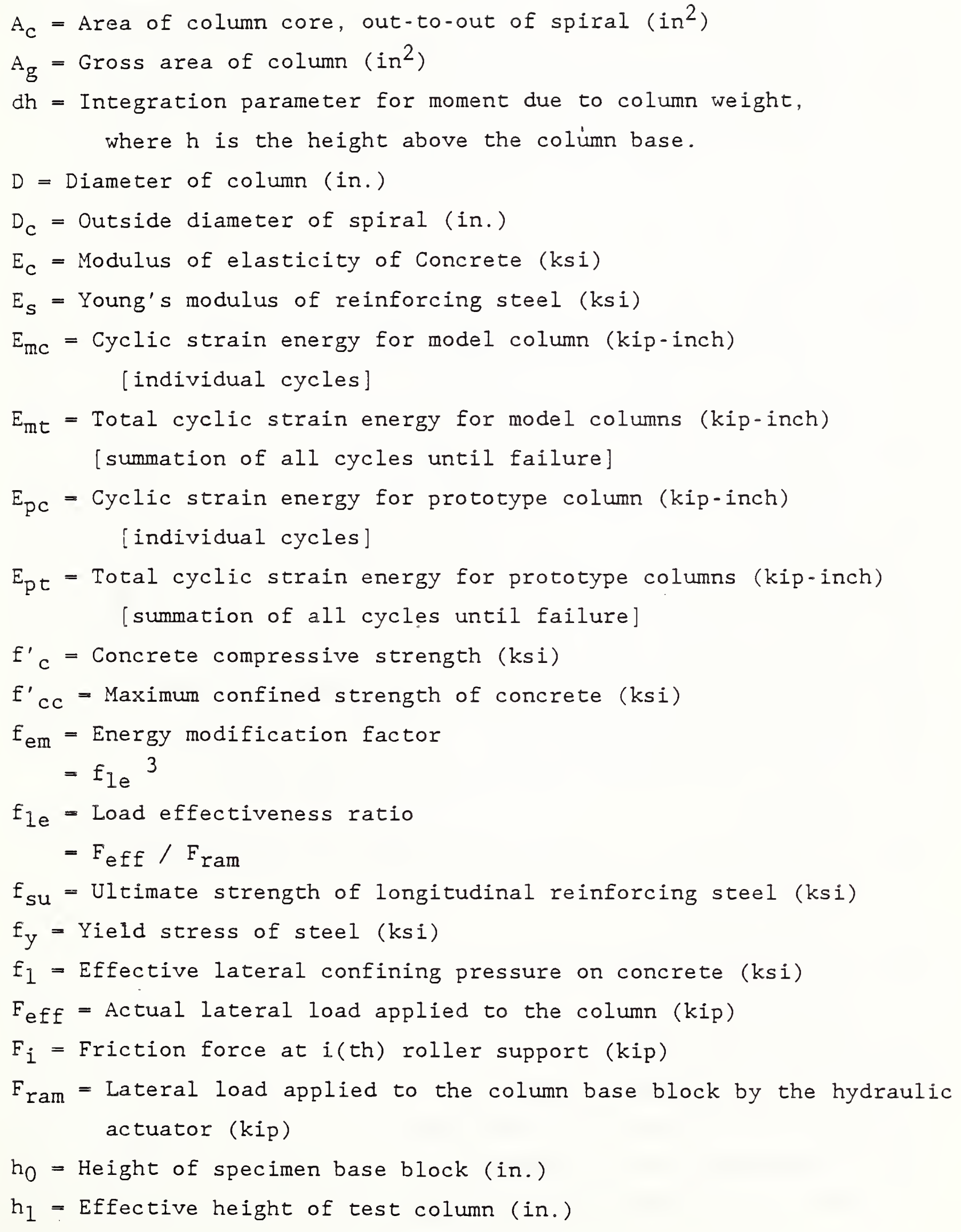




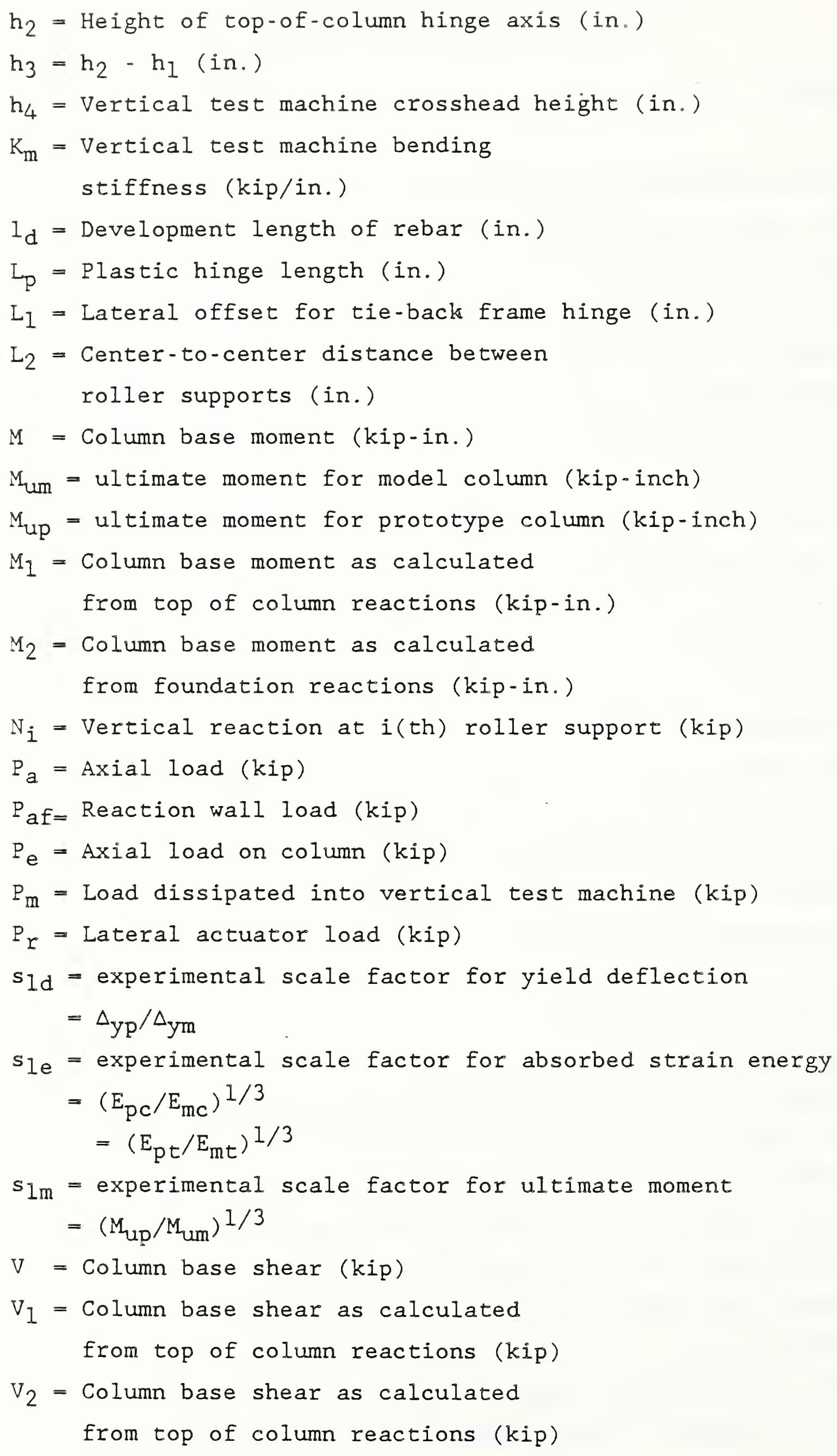


$\mathrm{W}=$ Specimen weight (including base block) (kip)

$\mathrm{W}_{\mathrm{i}}=$ Unit weight of column (kip/in.)

$\alpha=\rho_{\text {provided }} / \rho_{\text {code }}$

$\Delta_{\mathrm{h}}=$ Vertical offset of tie-back hinge

due to top-of-column rotation (in.)

$\Delta(h)=$ Lateral deflection of column @ height "h" (in.)

$\Delta_{r}=$ Lateral deflection at base of column (in.)

$\Delta_{t}=$ Total displacement for computation of P- $\Delta$ moment (in.)

$\Delta_{y}=$ Yield deflection (in.)

$\Delta_{y m}=$ Yield deflection for model column (in.)

$\Delta_{y p}=$ Yield deflection for prototype column (in.)

$\epsilon_{\text {sh }}=$ Steel strain at the onset of strain hardening

$\epsilon_{\text {su }}=$ Maximum steel strain

$\epsilon_{1 i}=$ Tensile strain as measured by clip gage at height $i$

$\epsilon_{2 i}=$ Compressive strain as measured by clip gage at height $i$

$\mu=$ Displacement ductility

$\mu_{i}=$ Coefficient of friction at $i(t h)$ roller support

$\phi=$ Strength reduction factor for confined members

$\phi_{\mathrm{y}}=$ Yield curvature (rad/in.)

$\rho_{\text {code }}=$ Volumetric transverse steel ratio required by NZ-3101 [20]

$\rho_{\text {provided }}=$ Volumetric transverse steel ratio provided for NBS test specimens as guided by standard CALTANS practice

$\rho_{S}=$ Volumetric or transverse steel ratio

$\rho_{t}=$ Reinforcing ratio for longitudinal steel 


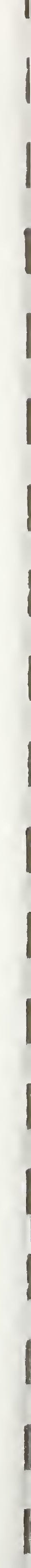




\section{REFERENCES}

1. Cheok, Geraldine S., and Stone, William C., "Behavior of 1/6 - Scale Model Bridge Columns Subjected to Cyclic Inelastic Loading", NBSIR 86-3494, U.S. Department of Commerce, November, 1986.

2. "Recommendations for Future Research", Applied Technology Council Workshop on Earthquake Resistance of Highway Bridges, Jan. 1979. Applied Technology Council, Berkeley, California. 625pp.

3. Lew, H. S., Leyendecker, E. V., and Dikker, R. D.,"Engineering Aspects of the 1971 San Fernando Earthquake, NBS Building Science Series \#40, U.S. Department of Commerce, Dec. 1971.

4. "Standard Specifications for Highway Bridges", as amended by AASTHO interims through 1998 with revisions by CALTRANS, AASHTO, 1983.

5. "Seismic Design Guideline for Highway Bridges", Applied Technology Council, Berkeley, California, October 1981. 200pp.

6. "Exerpts from the Standard Specifications for Highway Bridges Relating to Seismic Design," 13th Edition, 1983 Adopted by the American Association of State Highway and Transportation Officials with Revisions by CALTRANS, Division of Structures. Version October 1985.

7. Ang, Beng Ghee, "Ductility of Reinforced Concrete Bridge Piers Under Seismic Loading," Research Report 81-3, February 1981, Department of Civil Engineering, University of Canterbury, Christchurch, New Zealand

8. ACI Structures Journal Nov. 1968, Feb 1971

9. Montgomery, Neil, "Single Rope Techniques," Available from the National Speleological Society Bookstore, 1 Cave Ave., Hunstville, A1. 1977.

10. Padget, Alan, et.al., "On Rope," Published by the National Speleological Society, 1 Cave Ave., Huntsville, Al. 1987.

11. ACI Committee 340, "Design Handbook," in accordance with the Strength Design Method of ACI 318-77, Vol. 2, SP-17A (78), American Concrete Institute, 1978.

12. Personal Communication with Dr. M.J.N. Priestly, University of Canterbury, 1985.

13. "Recommended Testing Procedure for Assessing the Behavior of Structural Steel Elements under Cyclic Loads," ECCS -Technical Committee 1, Structural Safety and Loadings Technical Working Group 1.3 - Seismic Design Report. First Edition No. 45, 1986. European Convention for Constructional Steelwork. Available from A. Plumier, Institut du Genie Civil, 6 Quai Banning, Universite de Liege, Belgium. 
14. Krawinkler, H. et.al., "Recommendations for Experimental Studies on the Seismic Behavior of Steel Components and Materials," Report No. 61, The John A. Blume Earthquake Engineering Center, Department of Civil Engineering, Stanford University, September 1983.

15. Mander, J.B., "Seismic Design of Bridge Piers," Research Report 84-2. February 1984, Department of Civil Engineering, University of Canterbury, Christchurch, New Zealand.

16. Priestly, M.J.N., and Park, R., "Strength and Ductility of Bridge Substructures," Research Report 84-20, December 1984. Department of Civil Engineering, University of Canterbury, Christchurch, New Zealand

17. Priestly, M.J.N., and Park, R., "Strength and Ductility of Concrete Bridge Columns Under Seismic Loading," ACI Structural Journal, Title No. 84-S8, Vol. 84, No. 1, January-February 1987. American Concrete Institute, Detroit, MI.

18. Personal communication, Mr. James Gates, Chief Engineer, Structures Division, CALTRANS, 1983.

19. Stone, W.C., and Breen, J.E., "Behavior of Post-Tensioned Girder Anchorage Zones," PCI Journal, Jan-Feb, 1984, Vol. 29, No. 1, pp 64-109. Prestressed Concrete Institute, Chicago, III.

20. Baker, A.L., and Amarakone, A.M., "Inelastic Hyperstatic Frames Analysis," Proceedings of the International Symposium on the Flexural Mechanics of Reinforced Concrete, ASCE-ACI, Miami, November 1964, pp 85-142.

21. Corley, W.G., "Rotational Capacity of Reinforced Concrete Beams," Journal of Structural Division, ASCE, Vol. 92, ST5, October 1966 , pp $121-146$.

22. "NZS-3101: 1982 'Code of Practice for the Design of Concrete Structures'", (Two Volumes: Code and Commentary), Standards Association of New Zealand, 1982. 
NBS.114A (REV. 2-8C)

U.S. DEFT. OF COMM

BIBLIOGRAPHIC DATA

SHEET (See instrucions)

1. PUBLICATION OR

REPORT NO.

NBSIR $88-3788$

MAY 1988

4. TITLE AND SUBTITLE

INELASIIC BEHAVIOR OF FULI-SCALE BRIDGE COLUMNS SUBJECTED TO CYCLIC IOADING

5. AUTHOR(S)

WILIIAM C. STONE and GERAIDINE S. CHEOK

6. PERFORMING ORGANIZATION (If joint or other than NBS, see instructions)

7. Contraed Grane No.

NATIONAL BLREAU OF STANDARDS

U.S. DEPARTMENT OF COMMERCE

GAITHERSBURG, MD 20899

9. SPONSORING ORGANIZATION NAME AND COMPLETE ADDRESS (Street, City, Stote, ZIP)

1. National Science Foundation (NSF)

2. Federal Highway Administration (FHTA)

3. California Department of Transportation (CALTRANS)

4. National Bureau of Standards (NBS)

10. SUPPLEMENTARY NOTES

Document describes a comouter program; SF-185, FIPS Software Summary, is attached.

11. ABSTRACT (A 200-word or less foctual summory of most significont information. If document includes a significant

bibliogrodhy or literoture survey, mention it nere)

Circular, spirally reinforced concrete bridge columns were subjected to cyclic

loading (representing seismic loads) in the laboratory. The test articles were

prototype columns designed in accordance with recent (1983) California Department

of Iransportation (CAITRANS) specifications. Two full-scale columns, each

measuring 5 feet $(1.52 \mathrm{~m}$ ) in diameter with aspect ratios (height/width) of 3 and 6 , were subjected to slow reversed cyclic lateral load with constant axial load to simulate the gravity weight of the bridge superstructure. Details are presented concerning the design of the special test apparatus required to conduct the project as

well as recommendations for future inprovements in test orocedures.

Results irom the tests are presented in the form of energy absorption graphs and bar charts, load-displacement hysteresis curves, longitudinal and confining steel strains, and curvature profiles. Comparisons of the ultimate moment capacities, measured displacement ductilities, plastic hinge lengths, cyclic energy absorption capacity and the failure modes of the full-scale specimens are made with those observed from 1/6-scale model tests.

12. KEY WOROS (Six to twelve entries; alphabetical order; capitalize only proper names; and seporate key words by semicolons) Axial Load; Behavior; Bridges; Columns; Concrete; Confinement; Cyclic Load; Ductility; Energy Absorption; Eallure; Fu11-Scale; Lateral Load; Microconcrete; Scale Effects

13. AVAILABILITY

Y Unlimiced

Eor Official Distribution. Do Not Release to NTIS

Z Order From Suderintendent of Documents, U.S. Government Printing Office, Washington, D.C. 20402.

X Order From National Technical Information Service (NTIS), Soringfield, VA. 2216I
14. NO. OF

PRINTED PAGES

262

15. Price

$\$ 24.95$ 
